UNIVERSITAT POLITÉCNICA DE VALÈNCIA

DEPARTAMENTO DE QUÍMICA

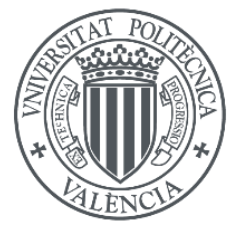

\title{
METAL-ORGANIC FRAMEWORKS AS \\ HETEROGENEOUS PHOTOCATALYSTS FOR THE PRODUCTION OF SOLAR FUELS
}

\author{
DOCTORAL THESIS \\ María Cabrero Antonino
}

Supervisors:

Dr. Sergio Navalón Oltra

Dr. Hermenegildo García Baldoví

Valencia, July 2021 

Dr. SERGIO NAVALÓN OLTRA, Profesor Titular de la Universitat Politècnica de València y Dr. HERMENEGILDO GARCÍA BALDOVÍ, investigador asociado doctor en Química Sostenible

\section{CERTIFICAN:}

Que la presente tesis doctoral, titulada: “METAL-ORGANIC FRAMEWORKS AS HETEROGENEOUS PHOTOCATALYSTS FOR THE PRODUCTION OF SOLAR FUELS", ha sido desarrollada por María Cabrero Antonino, en el marco del Programa de Doctorado de Química, bajo su dirección, en el Departamento de Química de la Universitat Politècnica de València. 

A mis padres, Ramón y Mạ Rosario,

A mi hermano Jose Ramón,

Por todo, por tanto. 

Estos cuatro años en los que he estado desarrollando mi tesis doctoral ha estado repleto tanto de buenos como de menos buenos momentos. Por suerte, en este intenso camino he estado acompañada de gente maravillosa, principalmente mi familia, que ha sabido en cada momento ayudarme y tenderme la mano cuando más lo he necesitado y hacia la que solo tengo palabras de gratitud. Cuando decidí empezar la tesis doctoral, no estaba del todo convencida de que tal decisión me fuese a completar tanto como persona. Por suerte, el hecho de poder ver recompensado todo el esfuerzo y el trabajo depositado en el desarrollo de mi tesis doctoral, me hace estar completamente convencida de que tomé una decisión acertada en el momento que decidí emprender esta aventura. Por todo ello, me gustaría agradecer a cada una de las personas que a su modo me han acompañado en este camino.

A mi director de tesis Sergio Navalón, por haber confiado en mí y por haberme dado la oportunidad de crecer tanto personal como profesionalmente. Gracias por haberme exigido siempre tanto, eso me ha hecho superarme día a día y sacar lo mejor de mí, o al menos haberlo intentado. Hacer la tesis bajo tu supervisión ha sido todo un reto. Gracias por todo lo que me has enseñado. Quiero también agradecer a Herme por haberme ayudado siempre que lo he necesitado y por darme siempre buenos consejos sobre química.

A Mercedes y Belén, por ayudarme y animarme siempre que lo he necesitado.

Finalmente, al Profesor Hermenegildo García, por haberme dado la oportunidad de formar parte de su grupo científico y haberme permitido aprender a su lado acerca del excitante campo de la fotocatálisis. Ha sido una experiencia muy enriquecedora, muchas gracias por cada minuto que has invertido en mí y por tu confianza. 
A mis padres, Ramón y Ma Rosario, por ser las personas más fuertes, valientes y nobles que conozco. Gracias por estar siempre a mi lado, por apoyarme en cualquier decisión y por no fallarme nunca. Si hoy soy lo que soy y estoy donde estoy, no tengo ninguna duda, es gracias a vosotros. Solo puedo agradeceros todo lo que hacéis por mí, os lo debo todo. Ojalá poder devolveros una pequeña parte. Que suerte la mía tener unos padres como vosotros. Os quiero con todo mi corazón!!!

A mi hermano José Ramón, la persona más especial de mi vida. Mi mejor ejemplo a seguir. Una persona maravillosa, constante, valiente, fuerte y sobre todo luchadora. Gracias por enseñarme que la vida nunca te golpea con suficiente fuerza como para no poder levantarte. Gracias por estar siempre a mi lado, por no dejarme caer nunca y por quererme como me quieres. Gracias a Dios y gracias a mis padres por darme un hermano como él. Ojalá y consigas todo lo que te propongas, yo estaré siempre a tu lado para acompañarte. Et vull tete!!!

A mi cuñada Rosa, por ser como eres conmigo, por siempre querer lo mejor para mí y por estar siempre que te he necesitado. Gracias por no haberme fallado nunca. Espero que al igual que mi hermano llegues tan lejos como te mereces, yo siempre estaré a vuestro lado para acompañaros y por supuesto ayudaros en lo que necesitéis. Una de las mejores cosas que me ha regalado la tesis ha sido poder compartir más tiempo con vosotros, que afortunada soy. Et vull molt Roseta!!!

A Fernando, mi compañero de vida. Gracias por haberte cruzado aquel día en mi camino, que suerte la mía. Gracias por tranquilizarme, apoyarme y animarme siempre que lo necesito. Gracias por estar siempre a mi lado, espero que nunca me sueltes de la mano, yo tampoco lo haré. Juntos siempre llegaremos más lejos. Te quiero!!!

A la última y más especial incorporación a la familia, mi sobrino Josep. Gracias a mi hermano y a Rosa por hacerme este regalo tan especial. Supo llegar en el mejor momento, para darnos a todos la felicidad que necesitábamos. Gracias, 
porque sin saberlo, tienes una capacidad infinita de hacerme feliz. Si antes de conocerte ya me tenías enamorada, no me quiero imaginar cuando me digas que soy tu tía preferida.

A todas mis estrellas en el cielo, mis abuelos, mis tíos, ojalá poder abrazaros. No tengo ninguna duda que desde allí arriba me guiais por el camino correcto. Tío Pepe, hoy te echaré especialmente de menos, siempre te gustaba acompañarme en los momentos importantes, estoy segura de que lo harás igualmente.

A mi amiga Ainoa, la persona que la da el verdadero significado a la palabra amistad. Por estar siempre y porque, aunque pase mucho tiempo sin vernos, sabemos que estaremos siempre.

A mis compañeros del departamento, Andrea y Juan Carlos, gracias por hacer que los inicios fueran muy fáciles, por estar siempre dispuestos a ayudarme y por todo lo que me enseñasteis. Gracias por todo lo que hicisteis por mí. A mis compañeras de inicio de tesis, aquí estamos terminando esto juntas, compartir con vosotras esta etapa ha sido un placer. Arianna, por todo lo que hemos compartido, te deseo que consigas llegar tan lejos como desees, seguro que lo consigues. Cristina, tan diferentes, pero a la vez tan iguales, tan única. Gracias por estar siempre que lo he necesitado, por hacer que estos cuatro años hayan sido más fáciles con tu compañía. Estoy segura de que encontraras el camino correcto para continuar con tu futuro, te lo mereces. A Eva, por esa tranquilidad y alegría que siempre transmites que hace que todo sea más fácil. Espero haberte enseñado bien todo lo que sé, me lo has puesto fácil. Compartir contigo todo este tiempo ha sido un placer. Estoy segura de que vas a llegar muy lejos. A las nuevas incorporaciones al laboratorio: Celia, Maria Novoa, aunque hayamos compartido poco tiempo, gracias por vuestra amabilidad y ayuda, os deseo lo mejor. A Alberto, aunque tu paso por el laboratorio fue fugaz, dejaste huella. Estar contigo siempre es alegría. Gracias por cada momento, hay días que nunca se olvidaran, no cambies nunca. A Marina, por cada 
rato que hemos compartido, ha sido un placer conocerte. Y por último, a Paco, aunque poco hemos coincidido, gracias por todo.

A los técnicos del departamento, Enrique, Manolo y todos los que me han ayudado en cualquier cosa que he necesitado, haciendo siempre más fácil el trabajo.

A mis compañeros del laboratorio A4, por todo lo que hemos vivido, que no ha sido poco, por suerte aquí seguimos. A Rubén, la alegría del laboratorio. Gracias por estar siempre, por hacer más fácil el trabajo día a día, por alegrarnos los días y por ser como eres, te deseo lo mejor. A la última incorporación, Andrés, por llegar en el último momento, pero convertirte en uno de los compañeros de tesis que siempre recordare. Gracias por escucharme y darme siempre buenos consejos. Alberto, por todos esos momentos aprendiendo valenciano y comparando nuestros puntos de vista de la química, compartir laboratorio contigo ha sido muy guay. A Abde, por ayudarme sin dudarlo desde el minuto uno, muchísimas gracias. A todos los demás compañeros: Lu, Xiangze, Jiajui, Aisha y Yong, por hacer que perdiese el miedo a hablar en inglés, gracias pese a nuestras diferencias en el idioma, entendernos tan bien. A Rocío y Elena, gracias por todo. Y por último a los compañeros del laboratorio G3: Amparo, Alejandra, Ana, Horatiu, Esther, Josep, Pedro, Esther y Ana Primo. Gracias a todos.

A los técnicos del ITQ: Área, TGA (Maribel y Amparo), IR (Rosa), UV (Ma Jesús), XPS (Dolo), Raman (Adelina), EPR (Alejandro) y Rayos X (Jose Luis), sin una correcta caracterización de un material, es imposible avanzar. Gracias

Y por último, al profesor Christian Serre, a la Doctora Patricia Horcajada y al Doctor Guillermo Mínguez por las fructíferas colaboraciones en las que hemos podido participar.

Por todo ello, Muchas gracias a todos 
Abbreviations and Acronyms 



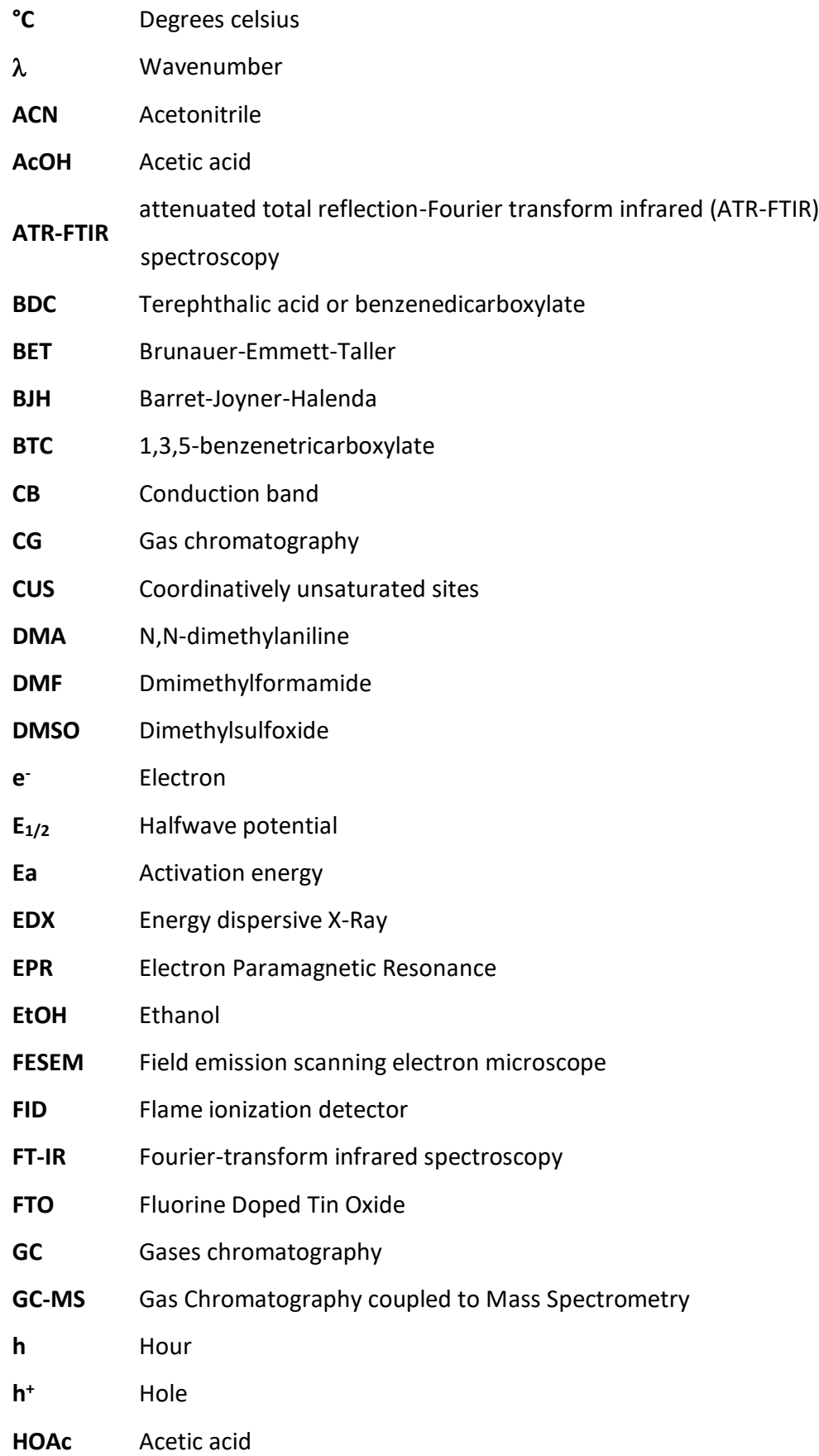




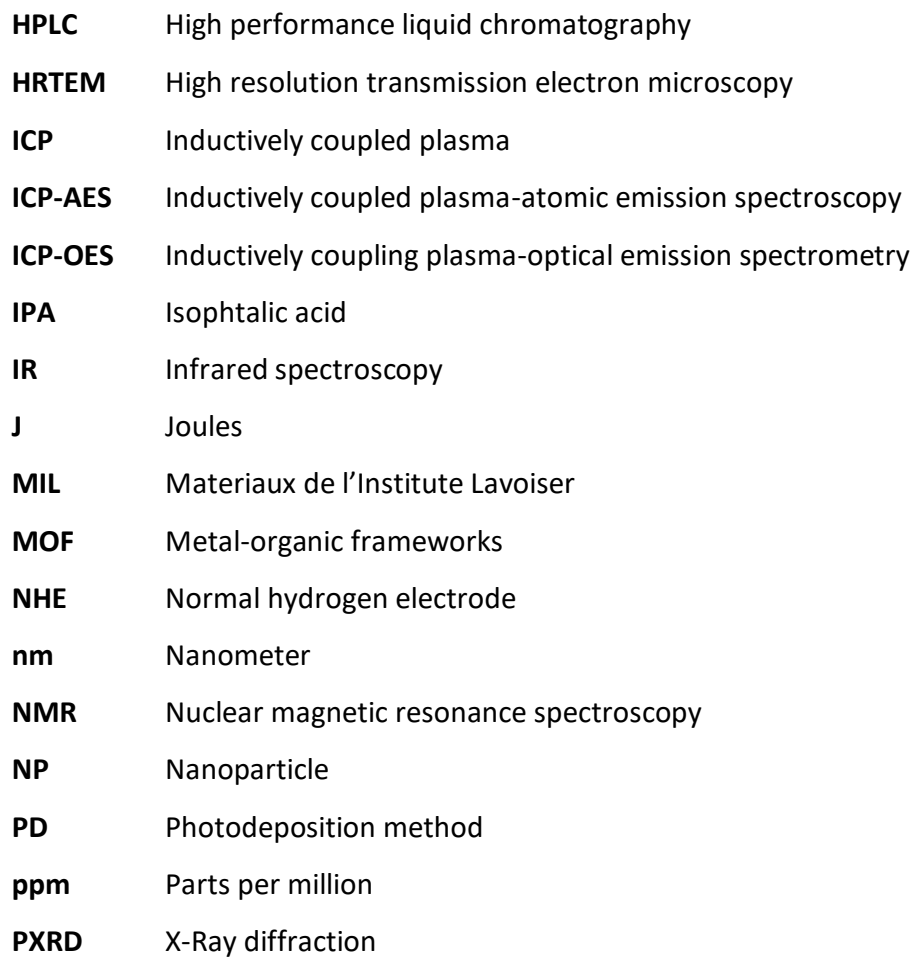

TPD-MS Temperature programmed desorption coupled to a mass-spectometer

u.a. Arbitrary units

UiO University of Oslo

UV Ultraviolet

UV-Vis Ultraviolet-Visible 


$\begin{array}{ll}\text { V } & \text { Volts } \\ \text { W } & \text { Watts } \\ \mathbf{W} / \mathbf{m}^{2} & \text { Watts per square meter } \\ \text { VB } & \text { Valence band } \\ \text { XPS } & \text { X-ray photoelectron spectroscopy } \\ \text { XRD } & \text { Powder X-ray diffraction }\end{array}$



Index 



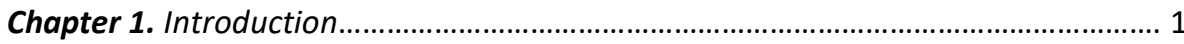

1.1. Solar fuels as sustainable alternative to fossil fuels .................................. 3

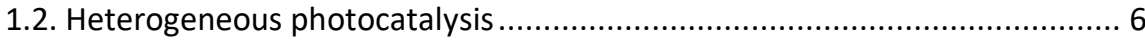

1.3. Metal-organic frameworks ....................................................................... 10

1.4. Metal-organic frameworks as photocatalysts ........................................ 13

1.5. General photocatalytic reaction mechanisms using MOFs....................... 16

1.6. MOF-based photocatalyst for water splitting ...................................... 19

1.7. MOF-based photocatalyst for $\mathrm{CO}_{2}$ reduction ................................... 21

1.8. Photocatalytic MOF stability .............................................................. 23

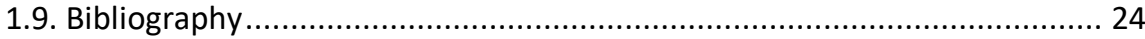

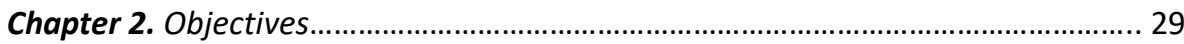

Chapter 3. Influence of co-catalysts on the photocatalytic activity of MIL-125(Ti)- $\mathrm{NH}_{2}$

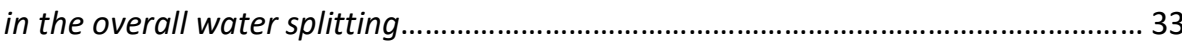

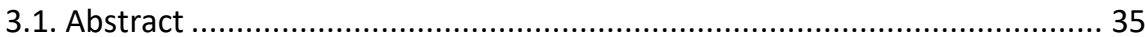

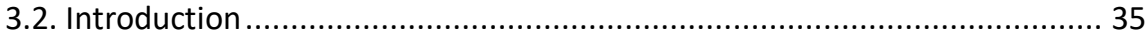

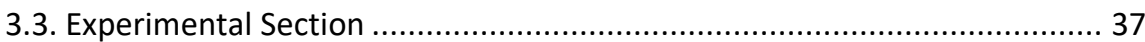

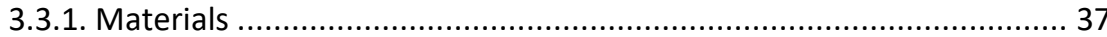

3.3.2. Catalyst Preparation ......................................................................... 37

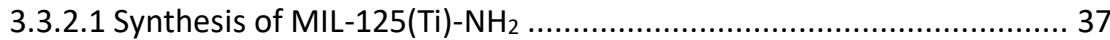

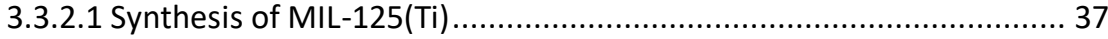

3.3.3.2 Preparation of metal nanoparticles (MNPs, $\mathrm{M}$ : Pt, $\mathrm{CoO}_{\mathrm{x}}$ and $\mathrm{RuO}_{\mathrm{x}}$ ) on

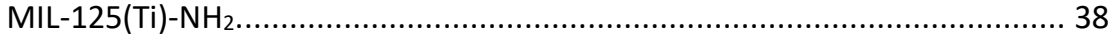

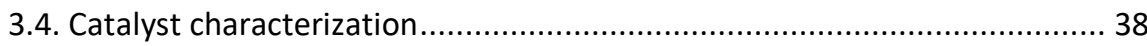

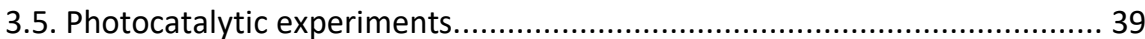

3.5.1. Photocatalytic overall water splitting tests..................................... 39

3.5.2. Monochromator experiments ......................................................... 39

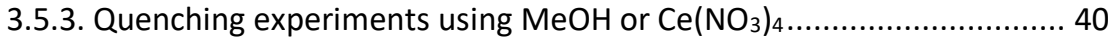

3.5.4. Labelled $\mathrm{H}_{2}{ }^{18} \mathrm{O}$ experiment........................................................ 40

3.5.5. Experiment under natural sunlight irradiation ............................... 40 


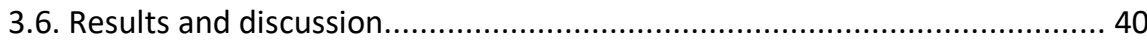

3.6.1. Catalyst preparation and characterization ..................................... 40

3.6.2. Photocatalytic overall water splitting experiments........................... 45

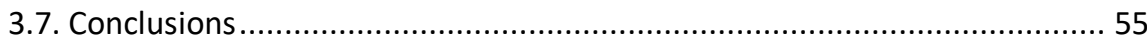

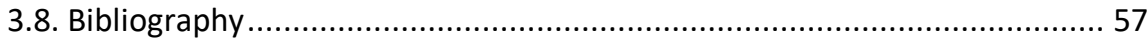

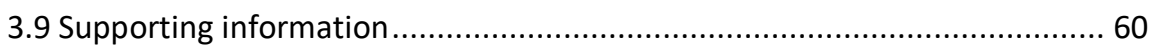

Chapter 4. Plasma-Induced Defects Enhance the Visible Light Photocatalytic Activity of MIL-125(Ti)-NH $\mathrm{H}_{2}$ for Overall Water Splitting......................................................... 81

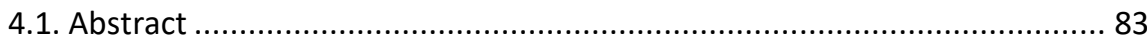

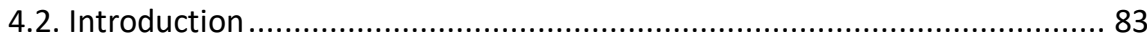

4.3. Results and discussion.................................................................... 85

4.3.1. Photocatalyst preparation and characterization............................... 85

4.4. Photocatalytic activity ............................................................. 91

4.4.1. Photocatalytic overall water splitting ........................................... 91

4.4.2. Photocatalytic water splitting in the presence of methanol. .............. 94

4.4.3. Reaction mechanism / Photoelectrochemical measurements ............ 98

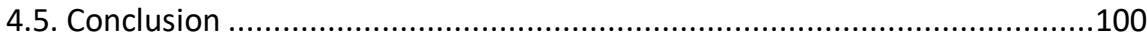

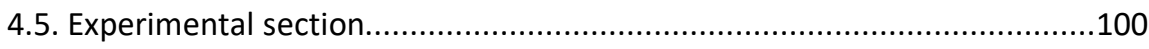

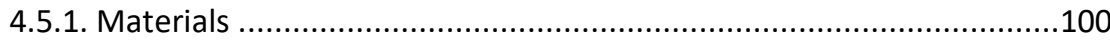

4.5.3. Oxygen plasma treatment...........................................................101

4.5.4. Catalyst characterization........................................................101

4.5.5. Photocatalytic water splitting experiments .....................................102

4.5.6. Methyl viologen $\left(\mathrm{MV}^{2+}\right)$ experiments .........................................102

4.5.6. Photocurrent measurements ...................................................103

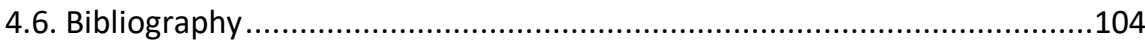

4.7. Supporting information ........................................................................ 106

Chapter 5. Design of cost-efficient and photocatalytically active Zn-based MOFs decorated with $\mathrm{Cu}_{2} \mathrm{O}$ nanoparticles for $\mathrm{CO}_{2}$ methanation .......................................121

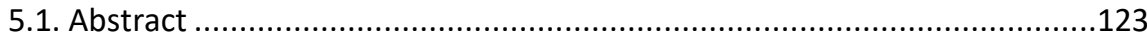




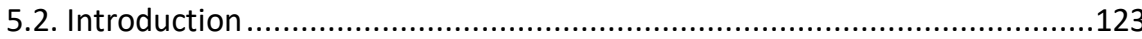

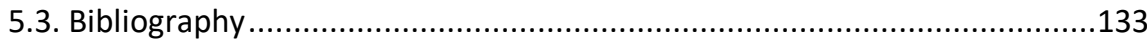

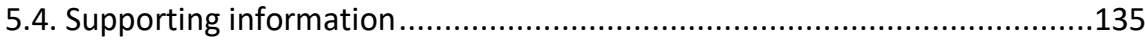

5.4.1. General methods and materials .....................................................135

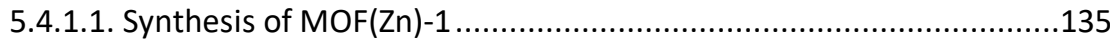

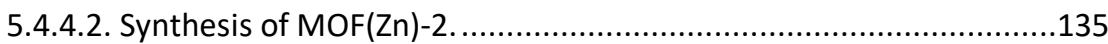

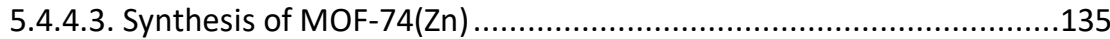

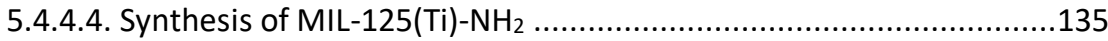

5.4.4.5. Synthesis of $\mathrm{CuO}_{2} @ M O F s$ using the photodeposition method (PD) 136

5.4.2. Structural features of MOF(Zn) ................................................136

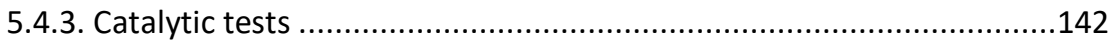

5.4.3.1. Catalyst characterization......................................................142

5.4.3.2. Photocatalytic methanation tests ...........................................142

5.4.5. Determination of valence band energies and optical gaps. ................152

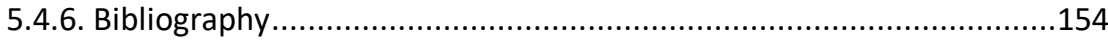

Chapter 6. A Robust Titanium Isophthalate Metal-Organic Framework for Visible Light Photocatalytic CO $\mathrm{CO}_{2}$ Methanation............................................................... 155

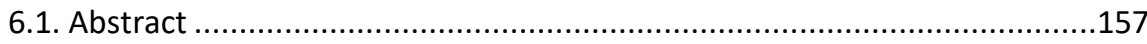

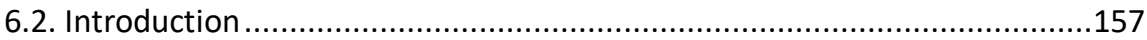

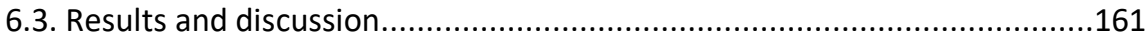

6.3. Experimental procedures .....................................................................182

6.3.1. Synthesis of MIP-208 (small scale) ..............................................182

6.3.2. Synthesis of MIP-208 (scale-up) .................................................183

6.3.3. Typical synthesis of MTV-MIP-208 ............................................183

6.3.4. Photocatalytic methanation tests .............................................183

6.3.5. X-ray crystallographic data......................................................184

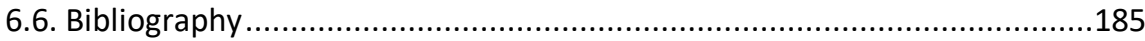

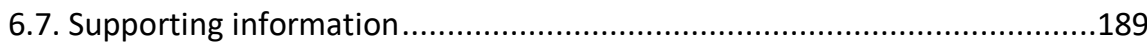




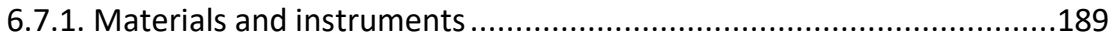

6.7.2. Photoluminescence measurements .............................................190

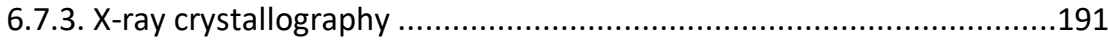

6.7.4. Solid-state NMR data of MIP-208 ..............................................192

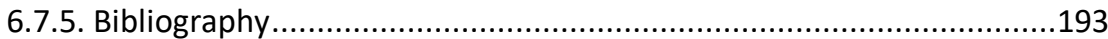

Chapter 7. Toward solar-driven photocatalytic $\mathrm{CO}_{2}$ methanation under continuous flow operation using benchmark MIL-125(Ti)- $\mathrm{NH}_{2}$ supported ruthenium

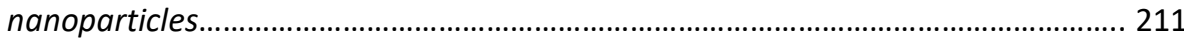

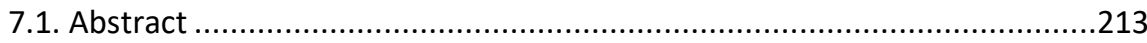

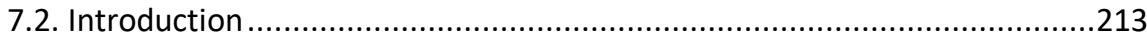

7.3. Experimental section................................................................215

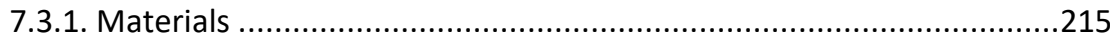

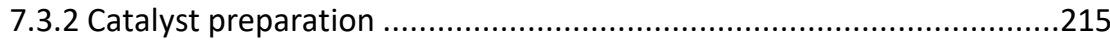

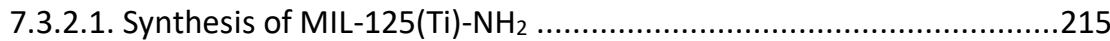

7.3.2.2. Catalyst characterization........................................................216

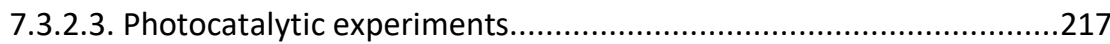

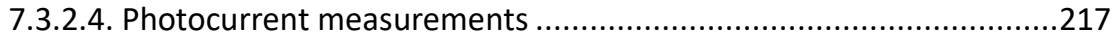

7.3.2.5. Fluorescence experiments ...................................................218

7.3.3 Results and discussion ..................................................................218

7.3.3.1. Photocatalyst preparation....................................................218

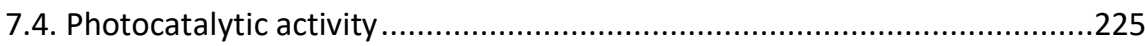

7.4.1. Photocatalytic $\mathrm{CO}_{2}$ methanation under batch conditions .................225

7.4.2. Photocatalyst stability under batch and continuous flow operations .230

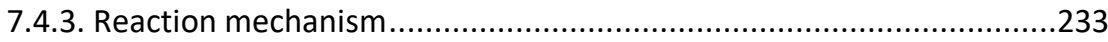

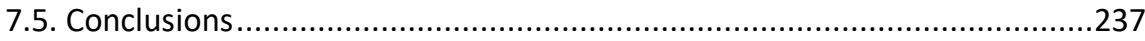

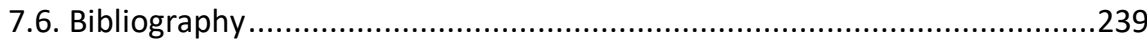

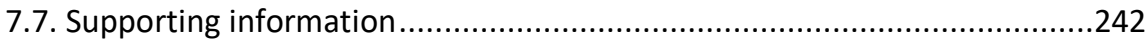

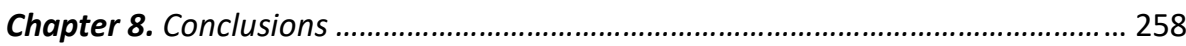

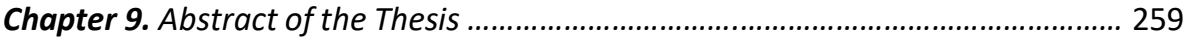




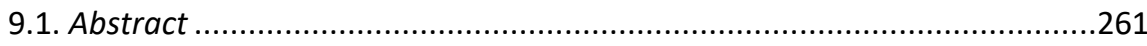

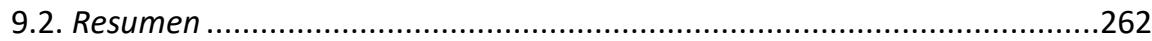

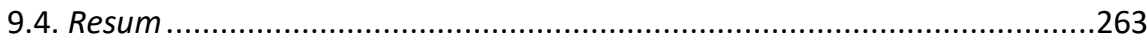

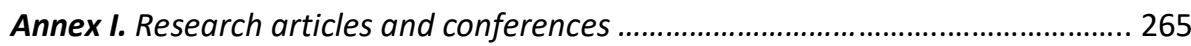

Publications related with the Thesis report ................................................267

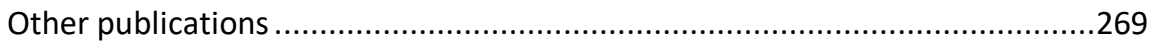

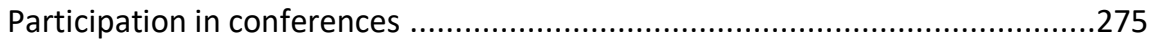



Chapter 1

Introduction 



\subsection{Solar fuels as sustainable alternative to fossil fuels}

Global energy consumption has risen continuously over the years. ${ }^{[1]}$ Currently, more than $80 \%$ of the global primary energy comes from fossil fuels, including petroleum, natural gas and coal. ${ }^{[2]}$ As fossil fuels as the main global energy vector have serious disadvantages, some alternatives are needed. ${ }^{[2]}$ On one hand, fossil fuels are classified as non-renewable energy sources because they are consumed at faster rates than they are produced. On the other, the combustion of fossil fuels results in the emission of $\mathrm{CO}_{2}$ as the main greenhouse gas together with other pollutants including $\mathrm{NO}_{\mathrm{x}}, \mathrm{SO}_{\mathrm{x}}, \mathrm{CO}$, volatile organic compounds and particulate matter. This hampers the use of fossil fuels as primary energy vector from a sustainable point of view due to their limited reserves, but also from their negative impact on human health and the environment. In fact, the persistent growth of the use of fossil fuels as an energy vector has caused the continuous growth of $\mathrm{CO}_{2}$ concentrations in the atmosphere of about 409.85 ppm in 2019. ${ }^{[3]}$ The governments of most industrialized countries have thus signed a commitment to reduce the use of fossil fuels while developing other sustainable, clean and cost-efficient energy vectors. For example, Europe aims to be climate-neutral by 2050, which means reaching net zero $\mathrm{CO}_{2}$ emissions. ${ }^{[4]}$

In this context, solar energy is presented as one of the most interesting approaches to obtain alternative sustainable energy vectors to fossil fuels. ${ }^{[5,6]}$ It is estimated that the amount of solar energy that reaches the earth's surface in one hour is equivalent to the energy now obtained from fossil fuels, nuclear energy and all renewable energy sources combined. Solar intensity is, however, subject to continuous fluctuations and the regions with the highest solar intensity are usually far from those with the highest energy consumption. 


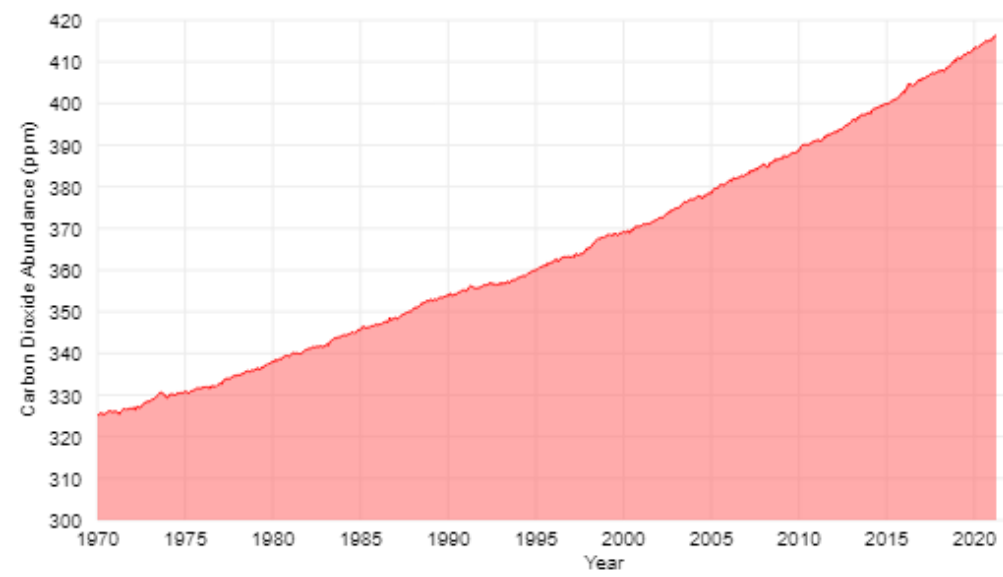

Figure 1. Abundance of $\mathrm{CO}_{2}$ in the atmosphere. Reprinted with permission from ref. ${ }^{[7]}$

The development of technologies to convert solar energy into chemical energy is thus of the highest importance. The use of solar energy to convert sustainable chemical feedstocks such as $\mathrm{H}_{2} \mathrm{O}^{[8]}$ and $\mathrm{CO}_{2}{ }^{[9]}$ into the so-called solar fuels such as $\mathrm{H}_{2}$ or hydrocarbons (i.e. $\mathrm{CH}_{4}, \mathrm{HCOOH}$ ) has emerged as a promising technology to develop viable alternative energy vectors to fossil fuels. 


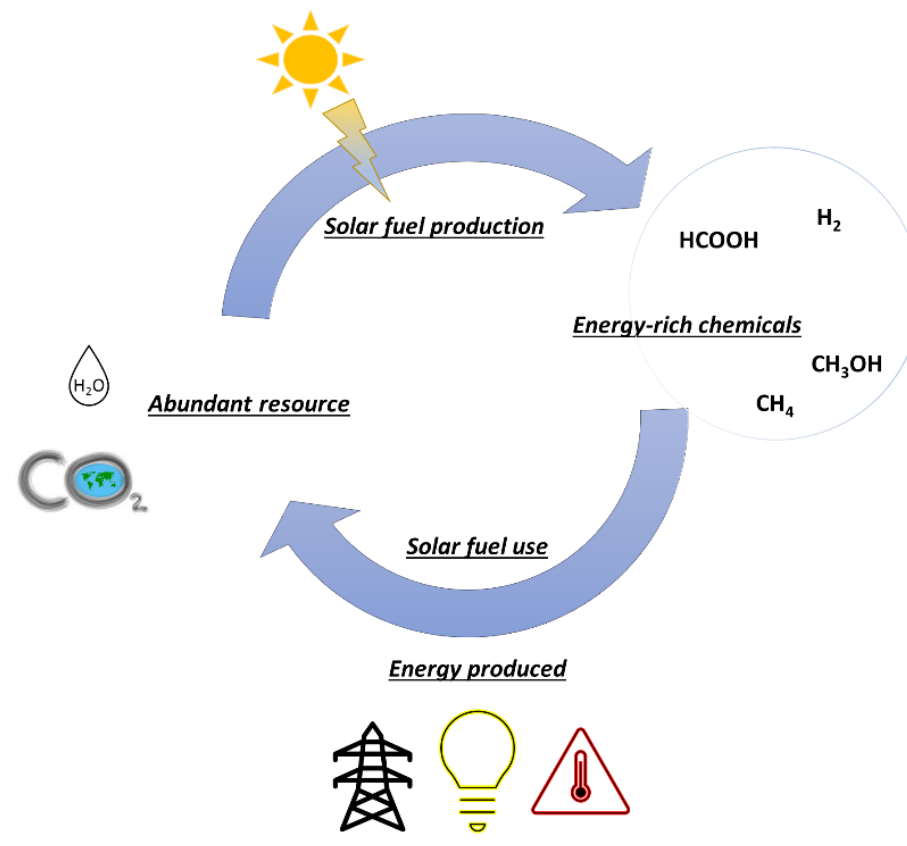

Figure 2. Figure of solar fuels production from $\mathrm{H}_{2} \mathrm{O}$ or $\mathrm{CO}_{2}$.

Hydrogen obtained from $\mathrm{H}_{2} \mathrm{O}$ and solar energy is considered the ideal energy vector to supply clean energy. ${ }^{[10]}$ Currently, however, hydrogen is mainly obtained through a non-sustainable process called steam methane reforming. ${ }^{[11]}$ This process consists in the reaction of methane with $\mathrm{H}_{2} \mathrm{O}$ to produce syngass, a mixture of $\mathrm{H}_{2}$ and $\mathrm{CO}_{2}$. The process is carried out at high temperature mainly using fossil fuels as energy vector. In this context, heterogeneous photocatalysis (section 1.2) assisted by solar light irradiation, where solar energy is converted into chemical energy, is among the most promising approaches to obtain $\mathrm{H}_{2}$ and $\mathrm{O}_{2}$ from $\mathrm{H}_{2} \mathrm{O}$. ${ }^{[12,13]}$ The $\mathrm{H}_{2}$ obtained in this process is considered a clean and sustainable solar fuel and, thus, sometimes referred as green $\mathrm{H}_{2}$. It should be commented, however, that adequate hydrogen storage for transportations still need to be solved. 
Heterogeneous photocatalysis can be also employed for the production of solar fuels from $\mathrm{CO}_{2}$. In this case, $\mathrm{CO}_{2}$ in the presence of a reducing agent can be transformed into $\mathrm{HCOOH}, \mathrm{CH}_{3} \mathrm{OH}$ or $\mathrm{CH}_{4}$ among other possible compounds. ${ }^{[15]} \mathrm{H}_{2} \mathrm{O}$ would be the ideal reducing agent. It should be commented, however, that the photocatalytic water oxidation is a demanding reaction that requires the mediation of four protons and four electrons of water to $\mathrm{O}_{2}$ (section 1.2). ${ }^{[12]}$

Alternatively, green $\mathrm{H}_{2}$ can also be used as a sustainable reducing agent to promote $\mathrm{CO}_{2}$ reduction to solar fuels. ${ }^{[16]}$ In contrast to green $\mathrm{H}_{2}$, the solar fuels derived from $\mathrm{CO}_{2}$ can be handled and processed similarly to fossil fuels. $\mathrm{HCOOH}$ and $\mathrm{CH}_{3} \mathrm{OH}$ can also be used in a fuel cell without chemical combustion to obtain electrical energy. Ideally, the use of solar fuels derived from $\mathrm{CO}_{2}$ would reduce the carbon footprint to zero, since the $\mathrm{CO}_{2}$ generated in the combustion processes could be used again as raw material to obtain solar fuel in a reversible process within the so-called "circular economy".

\subsection{Heterogeneous photocatalysis}

Heterogeneous photocatalysis has traditionally been carried out using inorganic semiconductors. ${ }^{[8,9}$, 12, 17-19] In a pioneering work, Fujishima and Honda demonstrated that it was possible to obtain $\mathrm{H}_{2}$ from $\mathrm{H}_{2} \mathrm{O}$ using $\mathrm{TiO}_{2}$ photoelectrodes. ${ }^{[18]}$ Since then a large amount of research has focused on the use of various inorganic semiconductors as heterogeneous photocatalysts. ${ }^{[8]}$ The following paragraphs will briefly describe the fundamentals of overall photocatalytic overall water splitting and $\mathrm{CO}_{2}$ photoreduction with inorganic semiconductors as photocatalysts.

Scheme 1 shows two general approaches for photocatalytic $\mathrm{H}_{2} \mathrm{O}$ dissociation into $\mathrm{H}_{2}$ and $\mathrm{O}_{2}{ }^{[8]}$ and $\mathrm{CO}_{2}{ }^{[9,14,15]}$ photoreduction in the presence of $\mathrm{H}_{2} \mathrm{O}$ or other reducing agents, thanks to the dual ability of $\mathrm{H}_{2} \mathrm{O}$ to be oxidized and reduced by an inorganic semiconductor such as $\mathrm{TiO}_{2} \cdot{ }^{[19,20]}$ In these photocatalytic processes at least four elementary steps can be differentiated: i) light absorption of appropriate energy by the semiconductor material, ii) a charge separation process 
after photoexcitation of one electron from the valence band to the conduction band of the semiconductor; iii) charge carrier migration towards the surface of the particle; iv) oxidation process in positive holes and reduction process with excited electrons. Two basic requisites are needed to obtain an efficient photocatalytic process: first, the energy of the incident photons has to be equal or greater than the band gap of the semiconductor to generate charge separation, and secondly facilitating charge carrier migration towards the external part of the particle while avoiding electron-pair also determines the efficiency of the process.
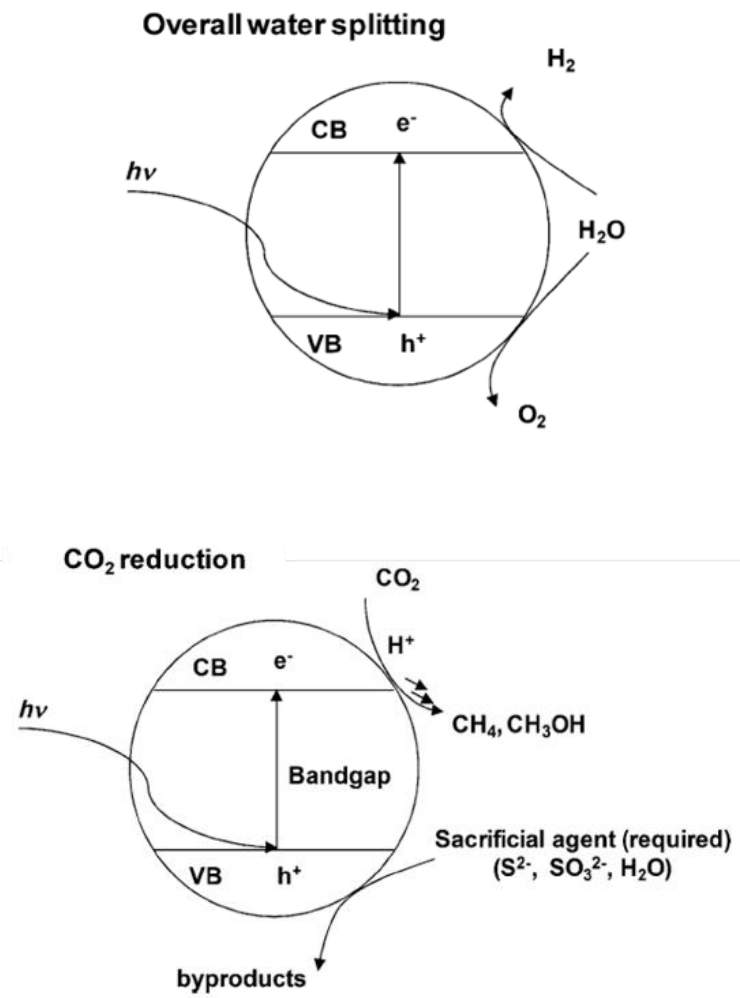

Scheme 1. Elemental stages that occur in the photocatalytic overall water splitting into $\mathrm{H}_{2}$ and $\mathrm{O}_{2}(\mathrm{a})$ and in the $\mathrm{CO}_{2}$ reduction process. Adapted with permission from ref. [15] 
Figure 3 shows the positions of the conduction bands (red line) and valence bands (green line) of some inorganic semiconductors. ${ }^{[21]}$ In any photocatalytic process using semiconductors, the positions of the valence and conduction bands must meet the thermodynamic requirements determined by the reduction potentials that take place. ${ }^{[8,9,21]}$ In the case of the photocatalytic overall water splitting into $\mathrm{H}_{2}$ and $\mathrm{O}_{2}$ at $\mathrm{pH} 7$, the semiconductor photocatalyst must have a band gap of at least $1.23 \mathrm{~V}$, and the valence and conduction band positions between -0.41 and $0.82 \mathrm{~V}$, respectively. Frequently for experimental purposes, a cathodic and anodic overpotential of $0.1 \mathrm{~V}$ and $0.2 \mathrm{~V}$, respectively, is used.

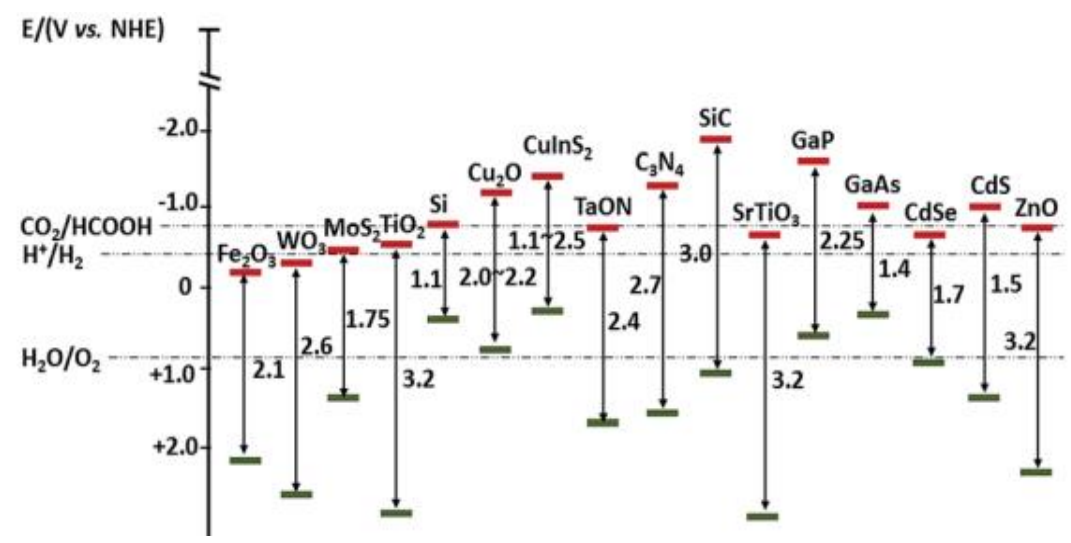

Figure 3. Positions of conduction (red lines) and valence (green lines) bands of some semiconductors ( $\mathrm{V}$ vs NHE at $\mathrm{pH}$ 7). Reprinted with permission from ref. [21]

In the case of the photocatalytic $\mathrm{CO}_{2}$ reduction to $\mathrm{CO}_{2}{ }^{--}$the photocatalysts require a high and negative reduction potential (-1.9 V). ${ }^{[22]}$ In contrast, photocatalytic $\mathrm{CO}_{2}$ reduction is thermodynamically favoured through a multielectronic process assisted by protons giving rise to $\mathrm{CO}, \mathrm{HCOOH}, \mathrm{CH}_{3} \mathrm{OH}$ or $\mathrm{CH}_{4}$ (Figure 2 and Figure 4) among other possible reaction products (Figure 5). ${ }^{[16]}$ 


\begin{tabular}{|c|c|c|}
\hline \multicolumn{2}{|c|}{ Reaction } & $\mathrm{E}_{\text {redox }}^{0}, \mathrm{~V}$ vs. NHE \\
\hline $2 \mathrm{H}^{+}+2 \mathrm{e}^{-}$ & $\longrightarrow \mathrm{H}_{2}$ & -0.41 \\
\hline $\mathrm{H}_{2} \mathrm{O}$ & $\longrightarrow 1 / 2 \mathrm{O}_{2}+2 \mathrm{H}^{+}+2 \mathrm{e}^{-}$ & 0.82 \\
\hline $\mathrm{CO}_{2}+\mathrm{e}^{-}$ & $\longrightarrow \mathrm{CO}_{2}^{*-}$ & -1.90 \\
\hline $\mathrm{CO}_{2}+\mathrm{H}^{+}+2 \mathrm{e}^{-}$ & $\longrightarrow \mathrm{HCO}_{2}^{-}$ & -0.49 \\
\hline $\mathrm{CO}_{2}+2 \mathrm{H}^{+}+2 \mathrm{e}^{-}$ & $\longrightarrow \mathrm{CO}+\mathrm{H}_{2} \mathrm{O}$ & -0.53 \\
\hline $\mathrm{CO}_{2}+4 \mathrm{H}^{+}+4 \mathrm{e}^{-}$ & $\longrightarrow \mathrm{HCHO}+\mathrm{H}_{2} \mathrm{O}$ & -0.48 \\
\hline $\mathrm{CO}_{2}+6 \mathrm{H}^{+}+6 \mathrm{e}^{-}$ & $\longrightarrow \mathrm{CH}_{3} \mathrm{OH}+\mathrm{H}_{2} \mathrm{O}$ & -0.38 \\
\hline $\mathrm{CO}_{2}+8 \mathrm{H}^{+}+8 \mathrm{e}^{-}$ & $\longrightarrow \mathrm{CH}_{4}+2 \mathrm{H}_{2} \mathrm{O}$ & -0.24 \\
\hline
\end{tabular}

Figure 4. Reduction potentials of some reactions that take place in the process of photoreduction of $\mathrm{CO}_{2}$ and generation of $\mathrm{H}_{2}$ using $\mathrm{H}_{2} \mathrm{O}$ at $\mathrm{pH}$ 7. Adapted with permission from refs. ${ }^{[21,22]}$

Improving the photocatalytic efficiency of the processes shown in Scheme 1 using photocatalysts actived by sunlight irradiation is still a scientific challenge. ${ }^{[8,12]}$ It should be remembered that the solar spectrum is approximately $4 \%$ UV-Vis light (290 - $380 \mathrm{~nm}), 46 \%$ visible light (380-780 $\mathrm{nm})$ and $50 \%$ infrared light (780-2500 $n m)$. Unfortunately, the main drawback to $\mathrm{TiO}_{2}$ and many other inorganic semiconductors is their low absorption above $380 \mathrm{~nm}$ and therefore their inefficiency when irradiated by sunlight. The development of methods able to modify inorganic semiconductors like $\mathrm{TiO}_{2}$ in such a way that they can absorb visible light to improve their efficiency when irradiated by sunlight is thus a research area of great interest. The strategies frequently used to modify inorganic photocatalysts such as $\mathrm{TiO}_{2}$ include $[15,19,20,21]$ : i) Doping $\mathrm{TiO}_{2}$ with elements such as nitrogen to reduce the semiconductor band gap and favour light absorption in the visible region; ii) incorporation of organic chromophores (i.e. dyes, porphyrins or phthalocyanines) or metal complexes (i.e. ruthenium trisbipyridine) as visible light harvesters that inject electrons into the conduction band of $\mathrm{TiO}_{2}$ upon photoexcitation; iii) Deposition of metal nanoparticles such as $\mathrm{Au}, \mathrm{Ag}$ or $\mathrm{Cu}$, which exhibit surface plasmon resonance in the visible light region; iv) deposition of inorganic quantum dots such as CdS to extent visible light absorption. There is also a line of research 
focused on the development of photocatalysts able to absorb visible light derived from metal oxides other than titanium (e.g. $\mathrm{BiVO}_{4}, \mathrm{Bi}_{2} \mathrm{WO}_{6}, \operatorname{InTaO} \mathrm{O}_{4}$ ) or metal sulphides $\left(\mathrm{CdS}, \mathrm{Bi}_{2} \mathrm{~S}_{3}\right)$. However, the advances made with the different metallic oxides or sulphides with or without metallic nanoparticles (e.g. Pt), are still far from achieving the required efficiency to make the processes suitable for large scale applications.

In photocatalytic overall water splitting the target is to reach between 5 and $10 \%$ solar-to-hydrogen conversion efficiency. ${ }^{[12]}$ Many materials have been tested as photocatalysts for this reaction, including inorganic metal oxide semiconductors such as $\mathrm{TiO}_{2}$, chalcogenides and even metal-free carbon nitride and graphenes, among others. However, the required goals of solar energy-to-hydrogen conversion efficiency and catalyst stability have not yet been achieved and the materials have proved difficult to tune to improve their activity to values of commercial interest. One of the most efficient inorganic semiconductors developed for this purpose is based on the Al-doped $\mathrm{SrTiO}_{3}$ semiconductor using expensive noble metal co-catalysts, although its STH efficiency is still only around $0.6 \%{ }^{[12]}$

In $\mathrm{CO}_{2}$ photoreduction, some of the most efficient and promising candidates are based on $\mathrm{Cu}_{2} \mathrm{O}$ or $\mathrm{CdS}^{[9]}$ Other less explored materials for this purpose include g- $\mathrm{C}_{3} \mathrm{~N}_{4}$-based materials, while one of the challenges in this field is still the development of active and stable photocatalysts under solar light irradiation.

Some studies have shown the potential of a series of porous crystalline hybrid organic-inorganic materials known as metal-organic frameworks (MOFs) as a promising alternative to traditional photocatalysts for the production of solar fuels from $\mathrm{H}_{2} \mathrm{O}$ and $\mathrm{CO}_{2}$. ${ }^{[24-26]}$

\subsection{Metal-organic frameworks}

MOFs, also known as porous coordination polymers (PCP), are a class of porous and crystalline materials composed of metal ions or metal clusters coordinated with multitopic organic ligands containing electron donor atoms or 
functional groups (Figure 5). ${ }^{[27-32]}$ The MOF metal nodes are frequently based on transition metals, while MOFs containing alkaline, alkaline-earth and lanthanide elements have also been reported. ${ }^{[31,33]}$ Organic ligands are commonly constituted by di-, tri- and even tetra-substituted aromatic moieties. Carboxylates are the most common organic ligands while MOFs based on phosphonates and even with sulfonates have been prepared. ${ }^{[34]}$ In addition to carboxylate-based MOFs, a large number of MOF structures have been prepared using azolates- or bipyridine-based organic ligands. ${ }^{[34,35]}$ Stable MOFs containing organic ligands with different functional groups such as pyridine substituted with carboxylic acids have also been reported. ${ }^{[36]}$

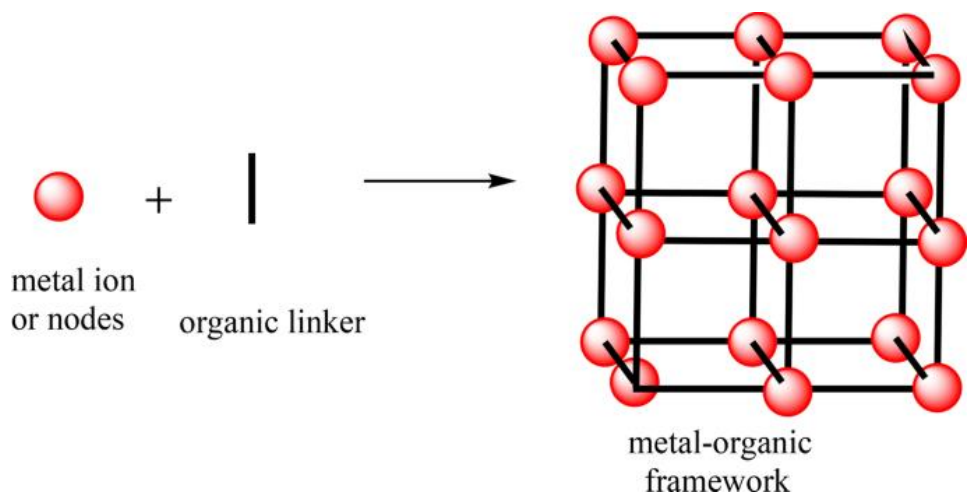

Figure 5. Illustration of MOF's building blocks and resulting porous, crystalline structure. Reprinted with permission from ref. [37]

Most of the MOFs reported until now have a 3D structural topology although 2D and 1D MOFs can be also prepared. ${ }^{[31,38]}$ In some cases MOFs with different structural topologies can be prepared using the same organic ligand ca terephthalic acid and same metal center ca $\mathrm{Zn}^{2+}$ with different coordination mode in each case. ${ }^{[39]}$ Importantly, isoreticular MOFs having a similar network topology while different textural, physico-chemical and electronic properties among others can be prepared. ${ }^{[40]}$ As a general strategy, some isoreticular MOFs can be prepared using similar organic ligand derivatives such as monosubstituted terephthalic acid organic 
ligands with several functional groups (i.e. $\mathrm{NH}_{2}, \mathrm{CH}_{3}, \mathrm{NO}_{2}, \mathrm{SO}_{3} \mathrm{H}$ ) among many other possibilities. ${ }^{[41-44]}$

A
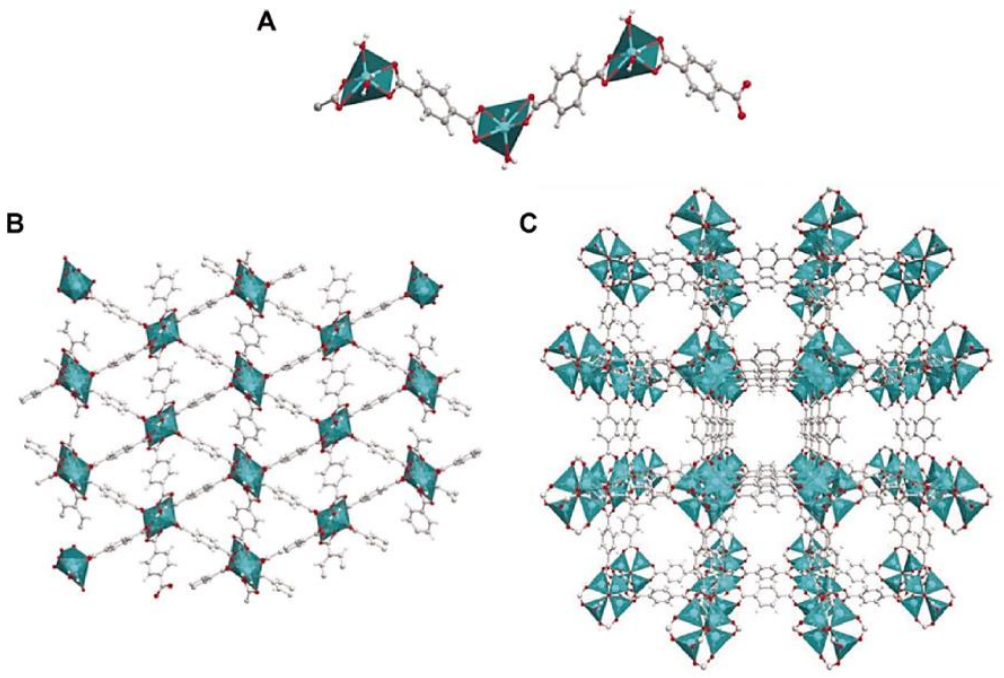

Figure 6. Dimensionalities adopted by crystalline framework structures con-structed from 1,4--BDC and $\mathrm{Zn}^{2+}$ ions. (A) 1-D structure, (B) 2-D structure, and (C) 3-D structure (MOF-5). The $[\mathrm{Zn}(\mathrm{BDC})(\mathrm{H} 2 \mathrm{O}) 2]$ in its 1-D structure con-sists of approximately tetrahedral $\mathrm{Zn}^{2+}$ centers linked by a herringbone pat-tern of 1,4-BDC molecules aligned approximately along the crystallographic/c diagonal. The lamellar structure is kept through offset $\pi-\pi$ stacking and hydrogen bond interactions between adjacent 1-D chains. Reprinted with permission from ref. [39]

MOFs have several properties that make them attractive materials for a large number of applications, ${ }^{[31,34]}$ including high porosity and surface areas ranging from 100 to $10,000 \mathrm{~m}^{2} / \mathrm{g}$, tunable pore sizes from 3 to $100 \AA$ and pore volumes that frequently range between 0.5 and $2 \mathrm{~cm}^{3} / g .{ }^{[45,46]}$ Another important feature is their high density of metal centres 20-30 wt\%, which can act as redox or Lewis centres. In addition to these unique properties MOFs are generally stable at temperatures between $250-400{ }^{\circ} \mathrm{C}$. Chemical stability strongly depends on the MOF structure and will be discussed latter when focussing on their use as photocatalysts for the production of solar fuels, which is the main topic of the present Thesis. 
The first applications of MOFs appeared at the beginning of the 2000s for selective adsorption or separation of fluids in the gas or liquid phase ${ }^{[47]}$ and later began to be used as heterogeneous catalysts $(\sim 2003)^{[41,48-50]}$ or photocatalysts $(\sim 2009) .{ }^{[24,51]}$ Since then many other applications of MOFs for sensing, ${ }^{[52]}$ drug delivery or biomedicine, ${ }^{[53]}$ magnetism, ${ }^{[54]}$ optoelectronics ${ }^{[55]}$ and many other possibilities have been reported.

\subsection{Metal-organic frameworks as photocatalysts}

Regardless of the vast number of MOFs reported in the literature, the number of MOF families with enough stability to be used as heterogeneous photocatalysts in water for the production of solar fuels is still limited. ${ }^{[24,56,57]}$ MOF stability as photocatalysts include thermal, chemical, mechanical and photochemical properties, among others. The following paragraphs will refer to the common features that make these materials potential photocatalysts for the production of solar fuels.

In general, the MOFs that have found photocatalyst applications are made of mono- or polycyclic aromatic hydrocarbons containing substituents able to strongly coordinate with metals. ${ }^{[24]}$ Some of the most common substituents are carboxylates, which interact with metallic atoms through coordination bonds and also by electrostatic interaction anion-cation. Nitrogen atoms present in organic ligands, such as imidazole, are also frequently found in MOFs. ${ }^{[35]}$ Figure 7 shows some common organic ligands employed in the preparation of MOFs as photocatalysts. 
Dicarboxylic organic ligands

Tricarboxylic organic ligands<smiles>[R]c1cc(C(=O)N[N+](=O)[O-])c([R])cc1C(=O)O</smiles><smiles>O=C(O)c1ccc(-c2cc(-c3ccc(C(=O)O)cc3)cc(-c3ccc(C(=O)O)cc3)c2)cc1</smiles>

Tetracarboxylic organic ligands

Imidazoles

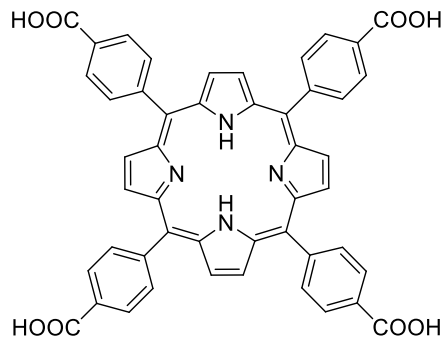<smiles>[R]c1ncc[nH]1</smiles><smiles>c1ccc2[nH]cnc2c1</smiles>

$\mathrm{R}: \mathrm{H}, \mathrm{CH}_{3}$

Figure 7. Representative organic ligands used for the preparation of MOFs as (photo)catalysts.

Several factors determine MOF stability and therefore their potential photocatalyst applications, ${ }^{[56,58-61]}$ one of which is the metal-ligand coordination bond strength. In general, robust MOFs are composed of carboxylate-based ligands coordinated to high-valent metal ions $\left(\mathrm{Al}^{3+}, \mathrm{Cr}^{3+}, \mathrm{Fe}^{3+}, \mathrm{Zr}^{4+}, \mathrm{Ti}^{4+}\right) \cdot{ }^{[34,60]}$ Stable MOFs can also be prepared from nitrogen-rich azoles such as imidazole with low-valent metal ions $\left(\mathrm{Zn}^{2+}, \mathrm{Ni}^{2+}, \mathrm{Co}^{2+}\right) \cdot{ }^{[34,59,60]}$ Another important factor in MOF stability is the organic ligand length. For example, MOFs with the same metal cluster and topology will be more stable when prepared using short organic ligands such as 1,4-benzenedicarboxylic acid rather than the more elongated 4,4'-biphenildicarboxylic acid. Terephthalic acid derivatives with high-valent metal ions and 2-methylimidazole with low valent-metal ions are thus particularly relevant for the preparation of active and relatively stable MOF photocatalysts. ${ }^{[24]}$

Figure 8 shows some MOF families with specific topologies prepared with terephthalic acid and different metal ions that have found applications as 
photocatalysts. ${ }^{[24]}$ Each MOF topology is characterized by a specific connection resulting in characteristic pore sizes and surface areas.

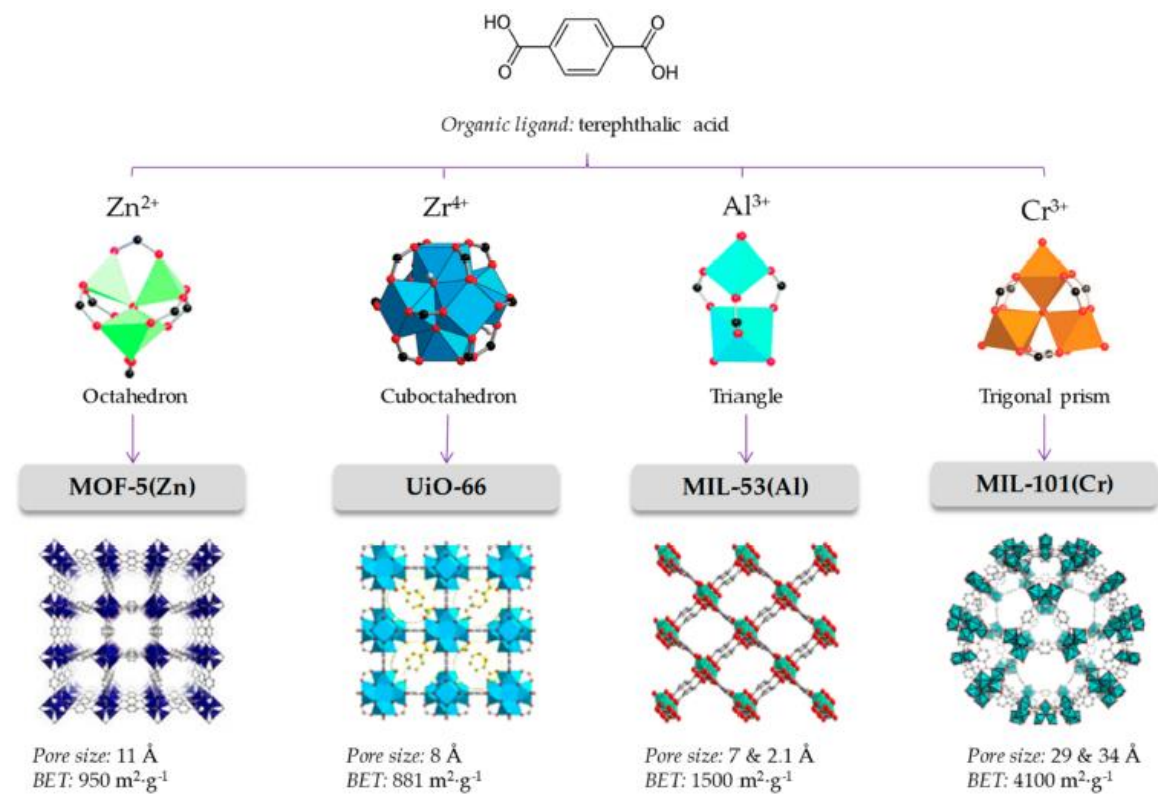

Figure 8. Illustration of several MOF structures prepared from terephthalic acid as organic ligand with different transition metal ions. Reprinted with permission from ref. [62]

In addition to the above, a Ti-MOF called MIL-125(Ti) also prepared also with terephthalic acid has also become a reference MOF photocatalyst due to its relative efficiency and stability. ${ }^{[63]}$ The crystal structure of MIL-125(Ti) consists of eight-membered rings of Ti-oxo clusters tethered by terephthalates having $\mathrm{Ti}_{8} \mathrm{O}_{8}(\mathrm{OH})_{4}-\left(\mathrm{O}_{2} \mathrm{CC}_{6} \mathrm{H}_{5}-\mathrm{CO}_{2}\right)_{6}$ as the ideal formula.

MOFs can be prepared-by-design with a wide flexibility in their composition, structure and tunability, and organic molecules or metal-complexes (i.e. visible-light absorbing photosensitizer) or inorganic (metal nanoparticles as co-catalysts) can be incorporated as guests inside their large internal void spaces. Considerable attention has thus been paid to the possibility of applying MOFs as photocatalysts for hydrogen generation or $\mathrm{CO}_{2}$ photoreduction. ${ }^{[24]}$ 


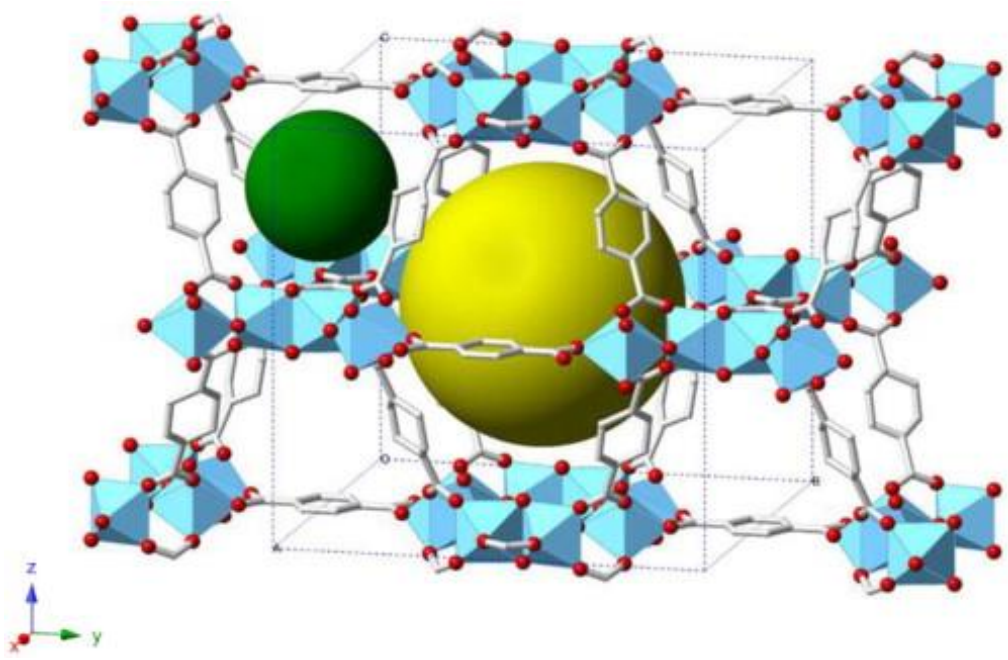

Figure 9. Schematic structure of the MOF MIL-125(Ti). The spaces in the cages are indicated by the yellow and green spheres. Reprinted with permission of ref. [64]

\subsection{General photocatalytic reaction mechanisms using MOFs}

As commented in the Introduction, photocatalysis using inorganic semiconductors require an efficient absorption of photons of certain energy, rapid separation of charges, electrons and holes with adequate redox potentials to the energy levels of the reactions to be promoted, a low level of charge recombination and catalytic centres that efficiently promote the desired processes. ${ }^{[4,19]}$

A general and widely accepted reaction mechanism in MOF photocatalysts is based on the ligand-to-metal-cluster charge-transfer (LCCT) mechanism. ${ }^{[24]}$ In this process MOFs can absorb photons of certain energy through the organic ligands and convert initial excitons into a state of charge separation by the transfer of electrons from the organic ligand to the metal nodes. In many cases, however, MOFs have inefficient charge mobility, so that they should not be strictly considered as semiconductor materials. ${ }^{[57,65]}$ It has thus been proposed that MOFs can be considered as self-assembled molecular entities that can be defined as the crystal equivalents of molecular orbitals, namely the highest occupied crystal orbital (HOCO) 
and lowest unoccupied crystal orbital (LUCO) rather than valence or conduction band, respectively, as in inorganic semiconductors. ${ }^{[65]}$

Some representative examples of photocatalyst MOFs that follow this LCCT mechanism include MOF-5(Zn), UiO-66(Zr) or MIL-125(Ti). ${ }^{[24]}$ In the visible responsible MIL-125(Ti)- $\mathrm{NH}_{2}$, photocatalyst EPR measurements were used to promote the LCCT mechanism. ${ }^{[66]}$ It is interesting to note that the presence of the $\mathrm{NH}_{2}$ group in the terephthalate organic ligand of the MOF favors the absorption of visible light (Figure 11). ${ }^{[67]}$ In addition, the presence of the $\mathrm{NH}_{2}$ group as the electron donating functional group makes the LUCO value of the MOF more positive than the MIL-125(Ti) pattern and thus means the former material is more appropriate for reduction reactions. In fact, this is a general strategy used to tune MOFs optical absorption and electronic properties. ${ }^{[67]}$

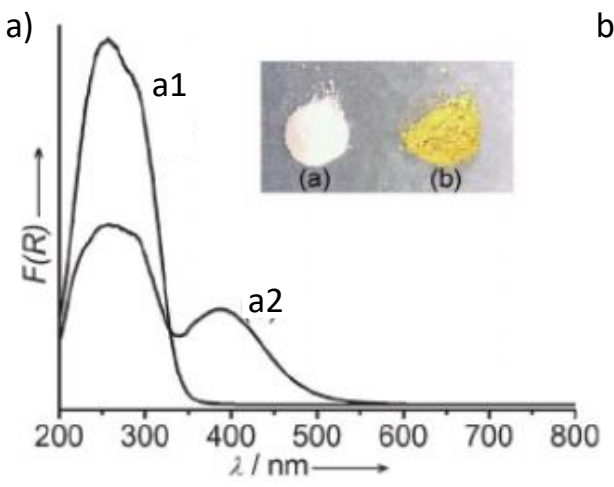

b)

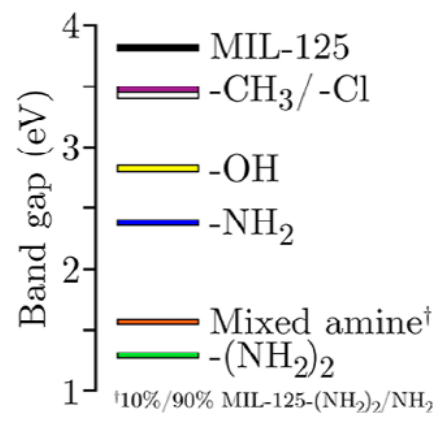

Figure 10. a) UV-Vis spectra of MIL-125(Ti) (a1) and MIL-125(Ti)- $\mathrm{NH}_{2}$ (a2). Reprinted with permission from ref. ${ }^{[66]}$ b) Predicted band gaps of MIL-125(Ti) and its analogues containing functionalized terephthalate organic ligands. Reprinted with permission from ref. [66]

Visible light irradiation of $\mathrm{MIL}-125(\mathrm{Ti})-\mathrm{NH}_{2}$ in the presence of triethanolamine (TEOA) as sacrificial electron donor resulted in the photoinduced electron transfer mechanism from 2-aminoterephthalate ligands to the titanium oxo cluster resulting in the reduction of $\mathrm{Ti}(\mathrm{IV})$ to $\mathrm{Ti}(\mathrm{III}) .{ }^{[66]}$ This process is accompanied by 
a change of MIL-125(Ti)- $\mathrm{NH}_{2}$ colour from yellow to green. These $\mathrm{Ti}(\mathrm{III})$ species have the ability to reduce $\mathrm{CO}_{2}$ into formats and then, the initial yellow coloured MIL-125(Ti)- $\mathrm{NH}_{2}$ is restored.

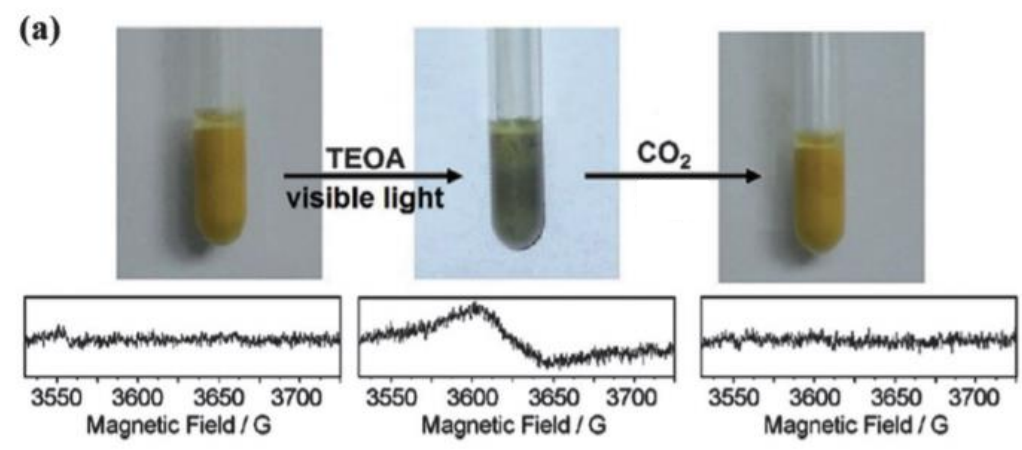

(b)

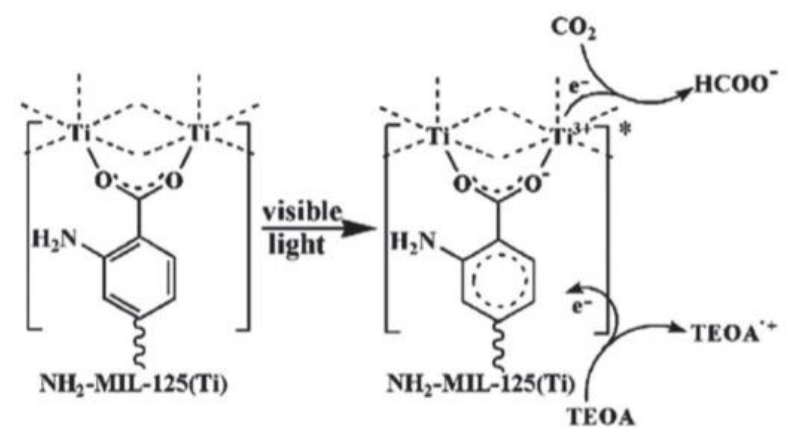

Figure 11. Photos and corresponding EPR spectra of MIL-125(Ti)- $\mathrm{NH}_{2}$ under different conditions: a) fresh MIL-125(Ti)- $\mathrm{NH}_{2}$, b) TEOA, visible light, and $\mathrm{N}_{2}$ and c) after the introduction of $\mathrm{CO}_{2}$ (or $\mathrm{O}_{2}$ ). Proposed mechanism for the photocatalytic $\mathrm{CO}_{2}$ reduction mover MIL-125(Ti)- $\mathrm{NH}_{2}$ under visible light irradiation. Adapted with permission from ref. ${ }^{[66]}$

In the case of iron-containing MOFs such as MIL-101(Fe) or MIL-53(Fe), it has been proposed that the Fe-O clusters can be photoexcited to transfer an electron from $\mathrm{O}^{2-}$ to $\mathrm{Fe}^{3+}$, resulting in the formation of $\mathrm{Fe}^{2+}$ species. ${ }^{[68]}$ In $\mathrm{MIL}-101(\mathrm{Fe})-\mathrm{NH}_{2}$, a dual photoinduced reaction mechanism from the organic ligand to the metal cluster together with Fe-O photoexcitation has also been proposed. ${ }^{[68]}$ 


\subsection{MOF-based photocatalyst for water splitting}

As previously commented, photocatalytic $\mathrm{H}_{2}$ generation from water by solar light energy has attracted interest over the years. ${ }^{[12]}$ In the field of MOFs, García et al reported in 2010 for the first time the use of Pt NPs supported on UiO-66(Zr)- $\mathrm{NH}_{2}$ as photocatalysts for $\mathrm{H}_{2}$ production from $\mathrm{H}_{2} \mathrm{O}$ using $\mathrm{MeOH}$ as sacrificial agents. ${ }^{[69]}$ The photocatalytic system achieved an apparent quantum yield at $370 \mathrm{~nm}$ of $3.5 \%$. Since then a great number of studies have reported the use of MOFs as photocatalysts for $\mathrm{H}_{2}$ generation from water in the presence of sacrificial agents such as methanol or triethanolamine. ${ }^{[13,24,70-76]}$ Metal nanoparticles co-catalysts have also been used as a general strategy to improve the photocatalytic activity of the MOF-based materials. Pt NPs deposited within the MOF cavities are the preferred option for promoting proton reduction to $\mathrm{H}_{2}$ in the presence of sacrificial agents.

In another related approach, MOF defect engineering has appeared as a strategy to tune their photocatalytic activity. ${ }^{[77]}$ For example, Pt NPs supported on UiO-66( $\mathrm{Zr})-\mathrm{NH}_{2}$ with different degrees of defects have shown this strategy can be used to enhance $\mathrm{H}_{2}$ production from water/acetonitrile mixtures in the presence of TEOA as sacrificial agent. ${ }^{[79]} \mathrm{UiO}-66(\mathrm{Zr})-\mathrm{NH}_{2}$ defects were tuned by using several equivalents of acetic acid as modulator during MOF synthesis. The most active sample prepared using 100 equivalents of acetic acid was the sample that most favoured photoinduced charge separation, as revealed by time-resolved transient absorption spectroscopy.

To make photocatalytic $\mathrm{H}_{2}$ generation viable, the photocatalyst should be able to perform the overall water splitting into $\mathrm{H}_{2}$ and $\mathrm{O}_{2 .}{ }^{[12]}$ It should be noted that the use of relatively expensive methanol or TEOA as sacrificial agent hampers the practical application of the process. ${ }^{[24]}$ Photocatalytic overall water splitting is at least one order of magnitude less efficient than hydrogen generation in the presence of sacrificial electron donors, due to higher endoergonicity and much slower rate of oxygen evolution. As previously commented, the water oxidation half-reaction to $\mathrm{O}_{2}$ as hydrogen evolution is more demanding. ${ }^{[12]} \mathrm{H}_{2} \mathrm{O}$ oxidation to $\mathrm{O}_{2}$ firstly requires a 
minimum electrochemical potential of $1.23 \mathrm{~V}$ vs the normal hydrogen electrode (NHE) at pH 0. Secondly, $\mathrm{H}_{2} \mathrm{O}$ oxidation to $\mathrm{O}_{2}$ involves the transfer of four electrons and four protons. In fact, few reports have been published on the possibility of using MOFs for water oxidation to $\mathrm{O}_{2}$ in the presence of sacrificial agents. ${ }^{[79,80]}$ For example, in 2015 Han et al reported the use of $\mathrm{CO}_{3} \mathrm{O}_{4}$ NPs within the cavities of MIL-101(Cr) as an efficient photocatalyst for $\mathrm{H}_{2} \mathrm{O}$ oxidation to $\mathrm{O}_{2}$ in the presence of $\mathrm{Na}_{2} \mathrm{~S}_{2} \mathrm{O}_{8}$ as sacrificial agent and using tris(bipyridine)ruthenium(II) chloride $\left(\mathrm{Ru}\left[(\mathrm{bpy})_{3}\right] \mathrm{Cl}_{2}\right)$ as visible light photosensitizer. ${ }^{\left[{ }^{[1]}\right.}$

In a seminal work in 2017, Liu, Huang and co-workers, reported on MOFs as photocatalysts for overall water splitting. ${ }^{[79]}$ The MOF-based photocatalyst was composed of $\mathrm{Ni}^{2+}$ ions coordinated to the amino group of the 2-aminoterephthalate ligand of MIL-53(Al)- $\mathrm{NH}_{2}$ solid. This system split $\mathrm{H}_{2} \mathrm{O}$ into $\mathrm{H}_{2}\left(66.7 \mu \mathrm{mol} \mathrm{g}^{-1}\right)$ and $\mathrm{O}_{2}$ $\left(33.3 \mu \mathrm{mol} \mathrm{g}^{-1}\right.$ ) under UV-Vis light irradiation (Xe lamp, $150 \mathrm{~W}$ ) for $2.5 \mathrm{~h}$. The same authors also reported on the possibility of using cobalt phosphate (CoPi) and Pt NPs as co-catalysts supported on MIL-125(Ti)- $\mathrm{NH}_{2}$ for overall water splitting into $\mathrm{H}_{2}$ $\left(42.33 \mathrm{~mL} \mathrm{~h}^{-1}\right)$ and $\mathrm{O}_{2}\left(21.33 \mathrm{~mL} \mathrm{~h}^{-1}\right)$ under UV-Vis light irradiation. These studies opened up new avenues for the development of active MOFs as visible light responsive photocatalysts for overall water splitting in the absence of sacrificial electron donors. 


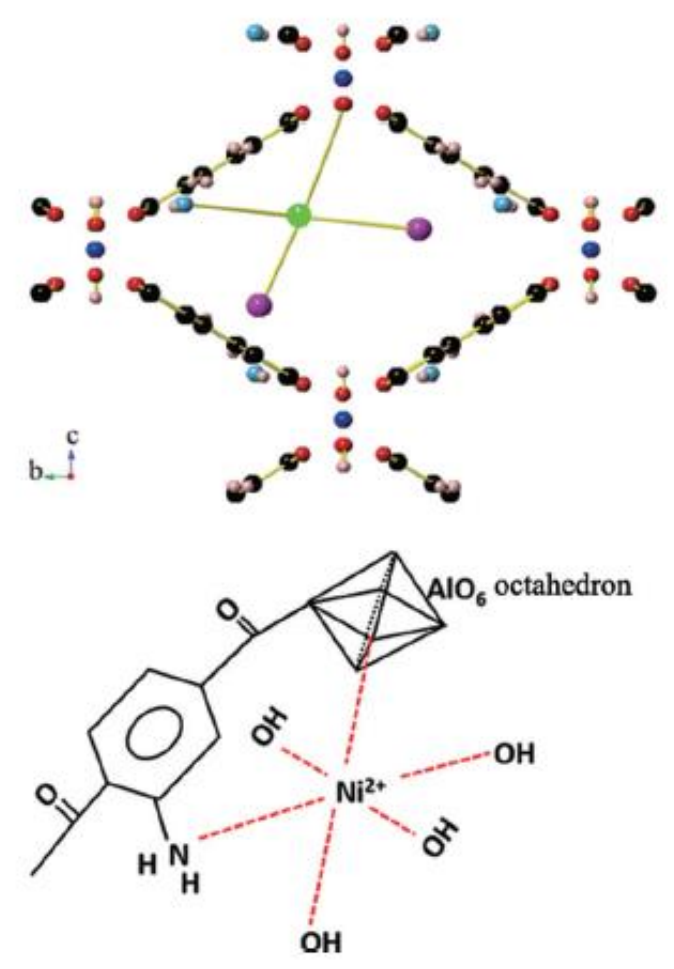

Figure 12. Possible coordination of Ni with Al-ATA MOF; blue: Al, green: Ni, red: O, light blue: $\mathrm{N}$, black: C, purple: $\mathrm{OH}$. Reprinted with permission from ref. [79]

\subsection{MOF-based photocatalyst for $\mathrm{CO}_{2}$ reduction}

The capture and transformation of $\mathrm{CO}_{2}$ into chemical or solar fuels is among the most sustainable options to reduce $\mathrm{CO}_{2}$ environmental impact. ${ }^{[9,14,15,82,83]}$ The main goal in this field is to reduce $\mathrm{CO}_{2}$ photocatalytically with $\mathrm{H}_{2} \mathrm{O}$ under natural sunlight irradiation. ${ }^{[24]}$ This process mimics natural photosynthesis, in which $\mathrm{CO}_{2}$ and $\mathrm{H}_{2} \mathrm{O}$ are transformed into glucose and oxygen, respectively.

In the MOF photocatalyst field, an analysis of the state of the art shows that there are numerous studies describing the reduction of $\mathrm{CO}_{2}$ in solution, mainly to $\mathrm{HCOO}^{-}$and also to $\mathrm{CO}$ using sacrificial agents such as tertiary amines. ${ }^{[24]}$ The list of MOFs includes MIL-125(Ti)-NH2, UiO-66(Zr)-NH2, MIL-101(Fe)-NH2, and 
porphyrin-based MOFs among others. ${ }^{[24]}$ The conditions usually employed consist of the irradiation of MOFs in suspension in organic solvents such as $\mathrm{CH}_{3} \mathrm{CN}$ containing $\mathrm{H}_{2} \mathrm{O}$ in small proportions and trimethylamine or TEOA as electron donor agent. The selection of $\mathrm{CH}_{3} \mathrm{CN}$ as the main solvent is based on the fact that this liquid is capable of dissolving high concentrations of $\mathrm{CO}_{2}$ while it is compatible with MOFs and miscible with $\mathrm{H}_{2} \mathrm{O}$ and is able to dissolve amines. The solubility of $\mathrm{CO}_{2}$ in water at neutral or acidic $\mathrm{pH}$ is very low, while at basic $\mathrm{pH}$, the species present in a solution is the carbonate or bicarbonate ion, which has higher reduction potentials. These solubility problems are avoided by using $\mathrm{CH}_{3} \mathrm{CN}$ as the solvent.

As a representative example, the mixed-metal UiO-66( $\mathrm{Zr} / \mathrm{Ti})-\mathrm{NH}_{2} \mathrm{MOF}$ was used as photocatalyst for $\mathrm{CO}_{2}$ reduction to format in a mixture of water and $\mathrm{CH}_{3} \mathrm{CN}$ as solvents and TEOA as sacrificial electron donor. ${ }^{[83]}$ Based on theoretical calculations and experimental evidence, a photoinduced electron transfer was proposed from the excited 2-aminoterephthalate organic ligand to the mixed-metal cluster, leading to the formation of $\left(\mathrm{Ti}^{3+} / \mathrm{Zr}^{4+}\right)_{6} \mathrm{O}_{4}(\mathrm{OH})_{4}$. The $\mathrm{Ti}^{3+}$ atoms then transferred electrons to the $\mathrm{Zr}^{4+}$, forming the $\mathrm{Zr}^{3+}$ species responsible for $\mathrm{CO}_{2}$ reduction. ${ }^{[84,85]}$

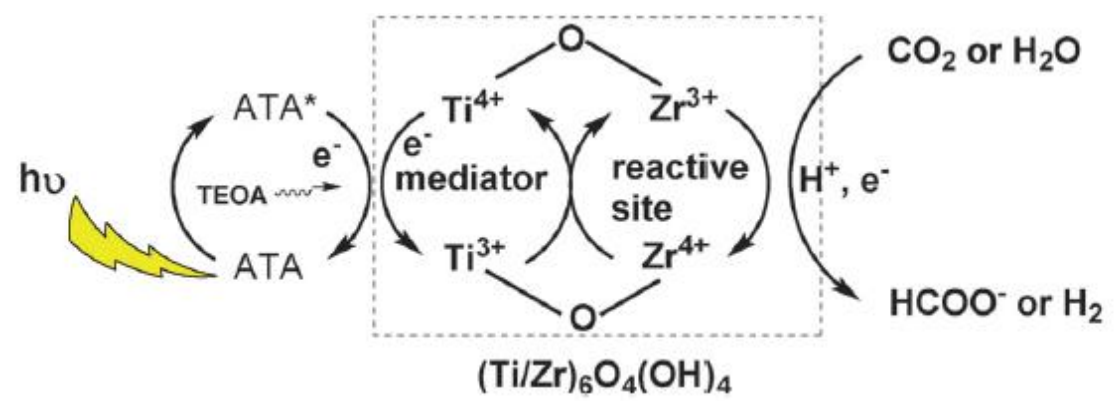

Figure 13. Photocatalytic $\mathrm{CO}_{2}$ reduction using UI66( $\left.\mathrm{Zr} / \mathrm{Ti}\right)-\mathrm{NH}_{2}$ as photocatalyst. Legend: ATA refers to 2-aminoterephthalate. Reprinted with permission from ref. ${ }^{84]}$ 
As when using MOFs in photocatalytic overall water splitting, developing more effective and sustainable routes for $\mathrm{CO}_{2}$ photoreduction to solar fuels still remains a challenge in this field.

\subsection{Photocatalytic MOF stability}

Water stability is particularly important in photocatalysis by MOFs to produce solar fuels. ${ }^{[58,60]}$ However, avoiding the gradual replacement of metal coordinated to organic ligands by water molecules is still a challenge. Some of the common strategies to improve MOF water stability include increasing MOF connectivity by multicarboxylated organic ligands or introducing hydrophobic moieties such as alkyl groups in the organic ligand. Some studies have also shown the possibility of improving MOF water stability by post-synthetic modification strategies, including coating them with hydrophobic polymers.

The photocatalytic stability of a series of MOFs including UiO-66(Zr), UiO-66(Zr)-NO2, MIL-125(Ti)-NH2, MIL-101(Fe), MIL-101(Cr) and Pt/MIL-101(Cr) was evaluated in an argon atmosphere and UV-Vis irradiation at $200{ }^{\circ} \mathrm{C} .{ }^{[86]}$ The results showed that carboxylate-based MOFs suffer partial decarboxylation, reaching values as high as $30 \mathrm{wt} \%$ of the total carboxylic groups present in the pristine material. The characterization of the MOF samples after the photocatalytic test by routine PXRD, TGA or UV-Vis spectroscopy did not reveal any changes in the material, while the porosity and surface area of the solids changed after prolonged irradiation, ZIF-8(Zn) did not produce $\mathrm{CO}_{2}$ or any other gas under the same reaction conditions. This study shows that the photocatalytic activity of MOF-based photocatalysts should be evaluated in the long term to confirm their stability under these reaction conditions. 


\subsection{Bibliography}

[1] P. E. Brockway, S. Sorrell, G. Semieniuk, M. K. Heun, V. Court, Renew. Sustain. Energy Rev. 2021, 141, 110781.

[2] S. Shafiee, E. Topal, Energy Policy 2009, 37, 181-189.

[3] P. Friedlingstein, M. ÓSullivan, M. W. Jones, R. M. Andrew, J. Hauck, A. Olsen, G. P. P. Peters, W. Peters, J. Pongratz, S. Sitch, C. Le Quéré, J. G. Canadell, P. Ciais, R. B. Jackson, S. Alin, L. E. O. C. Aragão, A. Arneth, V. Arora, N. R. R. Bates, M. Becker, A. Benoit-Cattin, H. C. C. Bittig, L. Bopp, S. Bultan, N. Chandra, F. Chevallier, L. P. Chini, W. Evans, L. Florentie, P. M. Forster, T. Gasser, M. Gehlen, D. Gilfillan, T. Gkritzalis, L. Gregor, N. Gruber, I. Harris, K. Hartung, V. Haverd, R. A. Hughton, T. llyina, A. K. Jain, E. Joetzjer, K. Kadono, E. Kato, V. Kitidis, J. I. Korsbakken, P. Landschützer, N. Lefèvre, A. Lenton, S. Lienert, ., Z. Liu, D. Lombardozzi, G. Marland, N. Metzl, D. R. Munro, J. E. M. S. Nabel, S.- I. Nakaoka, Y. Niwa, K. O'Brien, T. Ono, P. I. Palmer, D. Pierrot, B. Poulter, L. Resplandy, E. Robertson, C. Rödenbeck, J. Schwinger, R. Séférian, I. Skjelvan, A. J. P. Smith, A. J. Sutton, T. Tanhua, P. Tans, H. Tian, B. Tilbrook, G. van der Werf, N. Vuichard, A. P. Walker, R. Wanninkhof, A. J. Watson, D. Willis, A. J. Wiltshire, W. Yuan, X. Yue, S. Zaehle, Earth Syst. Sci. Data 2020, 12, 3269-3340.

[4] G. Kakoulaki, I. Kougias, N. Taylor, F. Dolci, J. Moya, A. Jager-Waldau, Energy Convers. Manag. 2021, 228, 113649.

[5] N. S. Lewis, Chem. Rev. 2015, 115 12631-12632.

[6] N. S. Lewis, Science 2016, 351, 1920.

[7] Science \& information for a climate-smart nation < https://climate.gov/newsfeatures/understanding-climate/climate-change-atmospheric-carbon-dioxide> [Inquire: 18 June 2021]

[8] T. Hisatomi, K. Domen, Nat. Catal. 2019, 2, 387-399.

[9] X. Li, J. Yu, M. Jaroniec, X. Chen, Chem. Rev. 2019, 119, 3962-4179.

[10] J. Kim, D. Hansora, P. Sharma, J.-W. Jang, J. S. Lee, Chem. Soc. Rev. 2019, 48, 1908-1971.

[11] J. X. Qian, T. W. Chen, L. R. Enakonda, D. B. Liu, J. M. Basset, L. Zhou, Int. J. Hydrog. Energ. 2020, 45, 15721-15743.

[12] Q. Wang, K. Domen, Chem. Rev. 2020, 120, 919-985.

[13] W. Wang, X. Xu, W. Zhou, Z. Shao, Adv. Sci. 2017, 4, 160037.

[14] A. Dhakshinamoorthy, S. Navalon, A. Corma, H. Garcia, Energy Environ. Sci. 2012, 5, 9217-9233.

[15] S. Navalón, A. Dhakshinamoorthy, M. Álvaro, H. Garcia, ChemSusChem. 2013, 6, 562-577.

[16] J. Albero, Y. Peng, H. García, ACS Catal. 2020, 10, 5734-5749.

[17] Z. Wang, C. Li, K. Domen, Chem. Soc. Rev. 2019, 2109-2125.

[18] A. Fujishima, K. Honda, Nature 1972, 238, 37-38.

[19] A. Fujishima, T. N. Rao, D. A. Tryk, Photochem. Rev. 2000, 1, 1-21.

[20] A. Fujishima, X. Zhang, D. A. Tryk, Surf. Sci. Rep. 2008, 63, 515-582.

[21] J. Zhao, X. Wang, Z. Xu, J. S. C. Loo, J. Mater. Chem. A 2014, 15228-15233.

[22]. V. P. Indrakanti, J. D. Kubickib, H. H. Schobert, Energy Environ. Sci. 2009, 2 745-758. 
[23] A. Dhakshinamoorthy, S. Navalon, A. Corma, H. Garcia, Energy Environ. Sci. 2012, 5, 9217-9233.

[24] A. Dhakshinamoorthy, A. M. Asiri, H. García, Angew. Chem. Int. Ed. 2016, 55, 5414-5445.

[25] A. Dhakshinamoorthy, Z. Li, H. Garcia, Chem. Soc. Rev. 2018, 47, 8134-8172.

[26] S. Wang, X. Wang, 2015, 26, 3097-3112.

[27] H. Li, M. Eddaoudi, M. ÓKeeffe, O.M. Yaghi, Nature 1999, 402, 276-279.

[28] G. Férey, Chem. Soc. Rev. 2018 37, 191-214.

[29] G. Férey, C. Mellot-Draznieks, C. Serre, F. Millange, J. Dutour, S. Surblé, I. Margiolaki, Science 2005, 23, 2040-2042.

[30] S. Kitagawa, R. Kitaura, S.-I. Noro, Angew. Chem. Int. Ed. 2004 43, 2334-2375.

[31] H. Furukawa, K.E. Cordova, M. O'Keeffe, O.M. Yaghi, Science 2013, 341, 1230444.

[32] C. Gropp, S. Canossa, S. Wuttke, F. Gándara, Q. Li, L. Gagliardi, O.M. Yaghi, ACS Cent. Sci. 2020, 6, 1255-1273.

[33] T. Devic, C. Serre, Chem.Soc.Rev. 2014, 43, 6097-6115.

[34] S. Yuan, L. Feng, K. Wang, J. Pang, M. Bosch, C. Lollar, Y. Sun, J. Qin, X. Yang, P. Zhang, Q. Wang, L. Zou, Y. Zhang, L. Zhang, Y. Fang, J. Li, H. Zhou, Adv. Mater. 2018, 30, 1704303.

[35] K.S. Park, Z. Ni, A.P. Côté, J.Y. Choi, R. Huang, F.J. Uribe-Romo, Chae H.K., M. O'Keeffe, O.M. Yaghi, Proc. Natl. Acad. Sci. 2016, 103, 10186-10191.

[36] M.-M. Xu, Q. Chen, L.-H. Xie, J.-R. Li, Coord. Chem. Rev. 2020, 421, 213421.

[37] Singh, S. Mukhopadhyay, I. Hod, Nano Converg. 2021, 8.

[38] S. Furukawa, J. Reboul, S. Diring, K. Sumida, S. Kitagawa, Chem. Soc. Rev. 2014, 43, 5700-5734.

[39] M.O. Rodrigues, M.V. de Paula, K.A. Wanderley, I.B. Vasconcelos, S. Alves Jr., T. A. Soares, Int. J. Quantum Chem. 2012, 112, 3346-3355.

[40] M. Eddaoudi, J. Kim, N. Rosi, D. Vodak, J. Wachter, M. O'Keeffe, O. M. Yaghi, Science 2002, 295, 469-472.

[41] A. Bavykina, N. Kolobov, S. Khan, J. A. Bau, A. Ramirez, J. Gascon, Chem. Rev. 2020, 120, $16,8468-8535$

[42] A. Santiago-Portillo, H.G. Baldoví, M.T.G. Fernandez, S. Navalón, P. Atienzar, B. Ferrer, M. Alvaro, H. Garcia, Z. Li, J. Phys. Chem. C 2017, 121, 7015-7024.

[43] A. Santiago-Portillo, J. F. Blandez, S. Navalón, M. Álvaro, H. García, Catal. Sci. Technol. 2017, 7, 1351-1362.

[44] A. Santiago-Portillo, M. Cabrero-Antonino, M. Álvaro, S. Navalón, H. García, Chem. Eur. J. 2019, 9280-9286.

[45] H. Deng, S. Grunder, K. E. Cordova, C. Valente, H. Furukawa, M. Hmadeh, J. F. Stoddart, Science 2012, 336, 1018-1023.

[46] H. Li, L. Li, R.-B. Lin, W. Zhou, Z. Zhang, S. Xiang, B. Chen, P, EnergyChem. 2019 1,100006.

[47] J.-R. Li, J. Sculley, H.-C. Zhou, Chem. Rev. 2012, 112, 869-932.

[48] J. Gascon, A. Corma, F. Kapteijn, F.X. Llabrés i Xamena, ACS Catal. 2014, 4, 361-378.

[49] S. M . J. Rogge, A. Bavykina, J. Hajek, H. H. Garcia, A. I. A. I. Olivos-Suarez, A. A. Sepúlveda-Escribano, A. A. Vimont, G. G. Clet, P. P. Bazin, F. F. Kapteijn, M. M. Daturi, E. 
V. Ramos-Fernandez, F. X. Llabrés i Xamena, V. Van Speybroeck, J. Gascon, Chem. Soc. Rev. 2017, 46, 3134-3184.

[50] L. M. Aguirre-Díaz, D. Reinares-Fisac, M. Iglesias, E. Gutiérrez-Puebla, F. Gándara, N. Snejko, M. A. Monge, Coord. Chem. Rev. 2017, 335, 1-27.

[51] H. García, S. Navalón. Wiley-VCH Verlag GmbH \& Co. KGaA 2018.

[52] L. E. Kreno, K. Leong, O. K. Farha, M. Allendorf, R. P. Van Duyne, J. T. Hupp, Chem. Rev. 2011, 112, 1105-1125.

[53] P. Horcajada, R. Gref, T. Baati, P.K. Allan, G. Maurin, P. Couvreur, G. Férey, R. E. Morris, C. Serre, Chem. Rev. 2012, 112, 1232-1268.

[54] C. Janiak, Dalton Trans. 2003, 14, 2781-2804.

[55] R. Medishetty, J. K. Zaręba, D. Mayer, M. Samoć, R. A. Fischer, Chem. Soc. Rev. 2017, 46, 4976-5004.

[56] G. Mouchaham, F. S. Cui, F. Nouar, V. Pimenta, J.-S. Chang, C. Serre, Trends Chem. 2020, 2, 990-1003.

[57] M. A. Nasalevich, M. Van Der Veen, F. Kapteijn, J. Gascon, CrystEngComm. 2014, 16, 4919-4926.

[58] M. Ding, X. Cai, H.-L. Jiang, Chem. Sci. 2019, 10, 10209-10230.

[59] N. Li, J. Xu, R. Feng, T.-L. Hu, X.-H. Bu, Chem. Commun. 2016, 52, 8501-8513.

[60] S. Wang, C. Serre, ACS Sustain. Chem. Eng. 2019, 7, 11911-11927.

[61] Q. Yu, H. Dong, X. Zhang, Y.-X. Zhu, J.-H. Wang, F.-M. Zhang, X.-J. Sun, CrystEngComm 2018, 20, 3228-3233.

[62] P. Rocío-Bautista, I. Taima-Mancera, J. Pasán, V. Pino, Separations 2019, 6, 33.

[63] M. Dan-Hardi, C. Serre, T. Frot, L. Rozes, G. Maurin, C. Sanchez, G. Ferey, J. Am. Chem. Soc. 2009, 131, 10857-10859.

[64] S.-N. Kim, J. Kim, H.-Y. Kim, H.-Y. Cho, W.-S. Ahn, Catal. 2013, 204, 85-93.

[65] J. G. Santaclara, A. I. Olivos-Suarez, I. du Fossé, A. Houtepen, J. Hunger, F. Kapteijn, J. Gascon, M. A. van der Veen, Faraday Discuss. 2017, 20, 71-86.

[66] Y. Fu, D. Sun, Y. Chen, R. Huang, Z. Ding, X. Fu, Z. Li, Angew. Chem. Int. Ed. 2012, 124, 3420-3427.

[67] C. H. Hendon, D. Tiana, M. Fontecave, C. Sanchez, L. D'arras, C. Sassoye, L. Rozes, C. Mellot-Draznieks, A. Walsh, J. Am. Chem. Soc. 2013, 135, 10942-10945.

[68] D. Wang, R. Huang, W. Liu, D. Sun, Z. Li, ACS Catal. 2014, 4, 4254-4260.

[69] C. G. Silva, I. Luz, F. X. Llabrés I Xamena, A. Corma, H. García, Chem. Eur. J. 2010, 11133-11138.

[70] H. Luo, Z. Zeng, G. Zeng, C. Zhang, R. Xiao, D. Huang, C. Lai, M. Cheng, W. Wang, W. Xiong, Y. Yang, L. Qin, C. Zhou, H. Wang, Y. Zhou, C. Tian, Chem. Eng. J. 2020, 383, 123196.

[71] K. Meyer, M. Ranocchiari, J. A. van Bokhoven, Energy Environ. Sci. 2015, 8, 1923-1937.

[72] L. Shen, M. Luo, Y. Liu, R. Liang, F. Jing, L. Wu, Appl. Catal. B 2015, 166-167, 453-455.

[73] F. Song, W. Li, Y. Sun, Inorganics 2017, 5, 40.

[74] M. Wen, K. Mori, Y. Kuwahara, T. An, H. Yamashita, Chem. Asian J. 2018, 13, 1767-1779.

[75] W. Xiang, Y. Zhang, H. Lin, C.-J. Liu, Molecules 2017, 22, 2103. 
[76] H. Luo, Z. Zeng, G. Zeng, C. Zhang, R. Xiao, D. Huang, C. Lai, M. Cheng, W. Wang, W. Xiong, Y. Yang, L. Qin, C. Zhou, H. Wang, Y. Zhou, S. Tian, Chem. Eng. J. 2020, 383, 123196.

[77] W. Xiang, Y. Zhang, Y. Chen, C.-J. Liu, X. Tu, J. Mater. Chem. A 2020, 8, 21526-21546.

[78] X. Ma, L. Wang, Q. Zhang, H.-L. Jiang, Angew. Chem. Int. Ed. 2019, 58, 12175-12179.

[79] Y. An, Y. Liu, P. An, J. Dong, B. Xu, Y. Dai, X. Qin, X. Zhang, M.-H. Whangbo, B. Huang, Angew. Chem. Int. Ed. 2017, 56, 3036-3040.

[80] A. Melillo, M. Cabrero-Antonino, S. Navalón, M. Alvaro, B. Ferrer, H. García, Appl. Catal. B 2020, 278, 119345.

[81] J. Han, D. Wang, Y. H. Du, S. Xi, J. Hong, S. Yin, Z. Chen, T. Zhou, R. Xu, J. Mater. Chem. A 2015, 3, 20607-20613.

[82] D. Li, M. Kassymova, X. Cai, S.-Q. Zang, H.-L. Jiang, Coord. Chem. Rev. 2020, 412, 213262.

[83] M. Marszewski, S. Cao, J. Yu, M. Jaroniec, Mater. Horizons 2015, 2, 261-278.

[84] D. Sun, W. Liu, M. Qiu, Y. Zhang, Z. Li, Chem. Commun. 2015, 51, 2056-2059.

[85] J.G. Santaclara, F. Kapteijn, J. Gascon, M.A. van der Veen, CrystEngComm 2017,19, 41184125.

[86] D. Mateo, A. Santiago-Portillo, J. Albero, S. Navalón, M. Alvaro, H. García, Angew. Chem. Int. Ed. 2019, 58, 17843-17848. 

Chapter 2

Objectives 

The aim of this Thesis is the development of MOF-based photocatalysts for the production of solar fuels from $\mathrm{H}_{2} \mathrm{O}$ and $\mathrm{CO}_{2}$.

The specific objectives of each chapter of the Thesis are the following:

To study the influence of $\mathrm{Pt}, \mathrm{RuO}_{\mathrm{x}}$ or $\mathrm{CoO}_{x}$ nanoparticles as co-catalysts on the photocatalytic activity of $\mathrm{MIL}-125(\mathrm{Ti})-\mathrm{NH}_{2}$ for overall water splitting. The photocatalytic activity of the most active sample will be evaluated under both UV-Vis and natural sunlight irradiation. In this case the apparent quantum efficiency of the photocatalytic process will be also evaluated at selected wavelengths.

To study the use of oxygen plasma treatment to introduce structural defects in the MIL-125(Ti)- $\mathrm{NH}_{2}$ solid and evaluate the photocatalytic activity of the resulting samples in overall water splitting. The photocatalysts will be characterized by several techniques, including PXRD, spectroscopic techniques (XPS, FT-IR, UV-Vis), elemental analysis, thermogravimetric measurements together with TEM and SEM measurements. The relationship between the physico-chemical, optical and electronic properties of the samples, the resulting photocatalytic activity, and the reusability and stability of the most active sample will then be evaluated.

To develop cost-efficient and photocatalytically active Zn-based MOFs for $\mathrm{CO}_{2}$ methanation. The influence of small $\mathrm{Cu}_{2} \mathrm{O}$ NPs as co-catalyst deposited on Zn-based MOFs on the resulting catalytic activity will be evaluated.

To develop the new Ti-MOF namely MIP-208(Ti), based on 5-aminoisophthalic acid organic ligand and $\mathrm{Ti}_{8}$ oxocluster, to be used as a photocatalyst for $\mathrm{CO}_{2}$ methanation. To study the influence of $\mathrm{RuO}_{\mathrm{x}}$ nanoparticles as co-catalyst in MIP-208(Ti) on the resulting photocatalytic activity. To evaluate the photocatalytic activity and stability of $\mathrm{RuO}_{\mathrm{x}} @ \mathrm{MIP}-208(\mathrm{Ti})$ on reuse. To obtain insights into the photocatalytic reaction mechanism of $\mathrm{CO}_{2}$ methanation using the RuOx@MIP-208 photocatalyst. 
To develop MOF-based materials based on $\mathrm{RuO}_{x}$ nanoparticles supported on MIL-125(Ti)- $\mathrm{NH}_{2}$ and their use as benchmark photocatalysts towards solar-driven $\mathrm{CO}_{2}$ methanation, for which increased loadings of $\mathrm{RuO}_{\mathrm{x}}$ nanoparticles will be supported on MIL-125(Ti)- $\mathrm{NH}_{2}$. The activity and reusability of the most active sample will be evaluated under both batch and continuous flow operations. The possible reaction mechanism that takes place during photocatalytic $\mathrm{CO}_{2}$ methanation will be studied in the most active sample. 


\section{Chapter 3}

Influence of co-catalysts on the photocatalytic activity of MIL-125(Ti)-NH $\mathrm{N}_{2}$ in the overall water splitting 



\subsection{Abstract}

Titanium containing aminoterephthalate metal organic framework promotes the photocatalytic overall water splitting into $\mathrm{H}_{2}$ and $\mathrm{O}_{2}$ at a rate that depends on the presence of $\mathrm{Pt}, \mathrm{RuO}_{2}$ and $\mathrm{CoO}_{x}$ co-catalyst. The best values of have been obtained for the MIL-125(Ti)-NH $\mathrm{NH}_{2}$ material that contains $\mathrm{Pt}$ and $\mathrm{RuO}_{2}$, reaching a production of 218 and $85 \mu \mathrm{mol} / \mathrm{g}_{\text {photocatalyst }}{ }^{-1}$ at $24 \mathrm{~h}$ for $\mathrm{H}_{2}$ and $\mathrm{O}_{2}$, respectively.

\subsection{Introduction}

In the context of the transition from fossil to renewable fuels, there is much interest in the production of solar fuels by photocatalysis. ${ }^{[1-7]}$ Although $\mathrm{TiO}_{2}$ and other wide bandgap metal Oxides are efficient photocatalysts under UV irradiation, ${ }^{[8-9]}$ the solar spectrum reaching the Earth surface contains mainly visible and near-infrared photons and the response of these materials to these wavelengths is usually negligible. Different strategies have been developed to introduce visible light photoresponse in metal Oxide semiconductors, but there is still a need for exploring different materials. ${ }^{[9-10]}$

Among the photocatalysts alternative to metal Oxides, metal-organic frameworks (MOFs) have attracted much current interest. ${ }^{[13-18]}$ MOFs are crystalline porous materials in where the lattice is constituted by nodes of a transition metal ion or a cluster of a few metal ions that are held in place by rigid bi- or multipodal organic linkers, typically aromatic polycarboxylates. ${ }^{[19-23]}$ MOFs offer as photocatalysts a series of advantages including a wide flexibility in the composition, high surface area and porosity, a large degree of design and the possibility to incorporate guests that can act as co-catalysts. ${ }^{[16,19,24-26]}$ As an example, the presence of amino substituents in the aromatic linker has been used to expand the photoresponse of MOFs into the visible region, ${ }^{[27-29]}$ while the intimate contact between linkers and metal nodes is responsible in many cases for an efficient electron transfer from excited organic linker to the metal nodes. ${ }^{[25]}$ Due to the combination of these favorable features, MOFs have been reported among the most 
efficient visible light photocatalysts for hydrogen generation and photocatalytic $\mathrm{CO}_{2}$ reduction, among other reactions. ${ }^{[16,31-33]}$

The vast majority of the reported examples in the use of MOFs for hydrogen generation upon visible light excitation have employed sacrificial electron donors, there being only a few precedents on the use of MOFs for overall water splitting. ${ }^{[13,}$ 15-16] Since photon absorption generates electrons and holes that have to be consumed at the same rate, the presence of electron donors quenching the holes, decouples the reductive hydrogen generation process from hole consumption. Accordingly, in the presence of good electron donor agents, the highest efficiency for hydrogen generation can be reached. ${ }^{[34-35]}$ However, when considering the real application of hydrogen generation from water, the two processes, hydrogen generation and oxygen evolution from water have to take simultaneously place. Since oxygen evolution from water is four electrons, four protons process, it is thermodynamically and kinetically the limiting step. ${ }^{[8,36-37]}$ There are only a few precedents describing photocatalytic oxygen evolution using MOFs as photocatalyst ${ }^{[38]}$ and photocatalytic overall water splitting promoted by MOFs has been rarely reported, ${ }^{[39-40]}$ in spite of the large number of published articles using these materials for photocatalytic hydrogen generation articles.

In view of the scarcity of reports describing the overall water splitting by MOFs, this area remains still largely unexplored. This situation sharply contrasts with the vast number of studies on the photocatalytic hydrogen generation by MOFs. ${ }^{[13,15,38]}$ Therefore, there is a need to provide additional information regarding the possibility to conduct overall water splitting by MOFs.

The present manuscript reports the influence of various co-catalysts on the overall water splitting using MIL-125(Ti)- $\mathrm{NH}_{2}$ as solar light photocatalyst. It will be shown that the photocatalytic activity largely depends on the presence of co-catalysts, the highest efficiency being reached when two complementary 
co-catalysts to manage the transfer of electrons and holes, are simultaneously present in the material.

\subsection{Experimental section}

\subsubsection{Materials}

All the reagents employed in this work were of analytical or HPLC grade and supplied by Sigma-Aldrich.

\subsubsection{Catalyst preparation}

\subsubsection{Synthesis of MIL-125(Ti)- $\mathrm{NH}_{2}$}

MIL-125(Ti)- $\mathrm{NH}_{2}$ was prepared following previously reported procedures. ${ }^{[41-43]}$ Briefly, 2-aminoterephthalic acid (1.43 g, $\left.7.9 \mathrm{mmol}\right)$ was dissolved in anhydrous $\mathrm{N}, \mathrm{N}$-dimethylformamide (DMF, $20 \mathrm{~mL}$ ), then, anhydrous methanol (5 $\mathrm{mL}$ ) was added to the flask and the system sonicated for $20 \mathrm{~min}$. The reaction mixture was transferred to a Teflon-lined autoclave $(50 \mathrm{~mL})$ before titanium isopropoxide (1.36 g, $4.8 \mathrm{mmol})$ was added. The autoclave was sealed and heated at $110{ }^{\circ} \mathrm{C}$ for 72 h. After cooling the system to room temperature, the resulting precipitate was filtered, washed with DMF at room temperature for $12 \mathrm{~h}$ and then, washed with DMF at $120^{\circ} \mathrm{C}$ for $12 \mathrm{~h}$. This washing procedure was repeated using methanol as solvent. Finally, the solid was recovered by filtration and dried in an oven at $100{ }^{\circ} \mathrm{C}$.

\subsubsection{Synthesis of MIL-125(Ti)}

MIL-125(Ti) was prepared following the procedure described by Se-NaKim. ${ }^{[44]}$ Briefly, titanium isopropoxide $(9 \mathrm{mmol})$ and 1,4-benzene dicarboxylic acid (15 mmol) were added to a mixture of DMF and methanol $(9: 1 ; 50 \mathrm{~mL})$ in a Duran bottle $(150 \mathrm{~mL})$ and the system sonicated for $20 \mathrm{~min}$. Subsequently, the mixture was heated in oven at $150{ }^{\circ} \mathrm{C}$ for $16 \mathrm{~h}$. After cooling to room temperature, the resulting precipitate was filtrated and washed twice with DMF and methanol as in the case described for MIL-125(Ti)- $\mathrm{NH}_{2}$. Finally, the resulting solid was dried at $150{ }^{\circ} \mathrm{C}$ overnight under vacuum. 


\subsubsection{Preparation of metal nanoparticles (MNPs, $\mathrm{M}$ : $\mathrm{Pt}, \mathrm{CoO}_{\mathrm{x}}$ and $\mathrm{RuO}_{\mathrm{x}}$ ) on MIL-125(Ti)-NH2}

MNPs were deposited in the previously formed MIL-125(Ti)- $\mathrm{NH}_{2}$ solid using the photodeposition method. ${ }^{[45]}$ Briefly, MOF $(50 \mathrm{mg})$ was dispersed in the corresponding solvent $(18 \mathrm{~mL})$ using a quartz tube. For the preparation of $\mathrm{Pt}, \mathrm{CoO}_{\mathrm{x}}$ and $\mathrm{RuO}_{\times} \mathrm{NPs}$, a mixture of Milli-Q water $(13 \mathrm{~mL})$ and $\mathrm{MeOH}(5 \mathrm{~mL})$ as sacrificial agent was employed. In the case of Pt-RuOx-MIL-125(Ti)- $\mathrm{NH}_{2}$ water $(18 \mathrm{~mL})$ was employed as solely solvent. After dispersion of the MOF in the appropriate solvent, the metal salt precursor dissolved in water $(2 \mathrm{~mL})$ was added and the system purged with $\mathrm{Ar}$ for $20 \mathrm{~min}$. The mixture was subsequently irradiated with UV-Vis light lamp for $4 \mathrm{~h}$. The solid obtained was filtered, washed with water and dried in oven at $100{ }^{\circ} \mathrm{C}$ overnight. The monometallic cobalt and ruthenium NPs deposited on MIL-125(Ti)- $\mathrm{NH}_{2}$ solid the samples were further oxidized on purpose at $180{ }^{\circ} \mathrm{C}$ for 2 $h$ in an oven under ambient conditions.

\subsection{Catalyst characterization}

Powder X-ray diffractograms (PXRD) were recorded using a Philips XPert diffractometer equipped with a graphite monochromator (40 kV and $45 \mathrm{~mA}$ ) employing $\mathrm{Ni}$ filtered $\mathrm{CuK}_{\alpha}$ radiation. The morphology and composition of the MOF samples were characterized using a scanning electron microscope (SEM, Zeiss instrument, AURIGA Compact) coupled with a EDX detector. Scanning transmission electron microscopy images in dark field (DF-STEM) were recorded on a JEOL JEM2100F instrument operating at $200 \mathrm{~kW}$. MNP size distribution was estimated by measuring more than 300 particles from the sample. Isothermal nitrogen adsorption measurements were carried out using an ASAP 2010 Micromeritics device. X-ray photoelectron spectra (XPS) were collected on a SPECS spectrometer with a MCD-9 detector using a monochromatic Al (K $\alpha=1486.6 \mathrm{eV}) \mathrm{X}$-ray source. Spectra deconvolution was performed after Shirley subtraction of background with the CASA software using the $\mathrm{C} 1 \mathrm{~s}$ peak at $284.4 \mathrm{eV}$ as binding energy reference. Inductively coupled plasma-atomic emission spectroscopy (ICP-AES) analysis was used to 
determine the metal content of the catalyst after dissolving it in concentrated nitric acid. FTIR spectra were recorded on compressed powders using a Bruker spectrophotometer in an attenuated total reflectance (ATR) cell.

\subsection{Photocatalytic experiments}

\subsubsection{Photocatalytic overall water splitting Tests}

The photocatalyst sample was sonicated for $10 \mathrm{~min}$ in the appropriate amount of Milli-Q water (optimized concentration $1 \mathrm{mg}$ of photocatalyst per $\mathrm{mL}$ of water) to obtain a good dispersion of the photocatalyst. The suspension was placed in a quartz reactor and the system was purged for $1 \mathrm{~h}$ under argon to evacuate oxygen from the solution and the atmosphere. The suspension was stirred at room temperature and irradiated with a $150 \mathrm{~W}$ Xenon lamp while maintaining stirring. The gases evolved were analyzed from the head space directly connecting the reactor to an Agilent 490 Micro GC system (Molsieve $5 \AA$ column using Ar as carrier gas) without manual handling. The temperature of the reactor was monitored, and the pressure was analyzed by means of a manometer.

\subsubsection{Monochromator experiments}

The Pt-RuO $2-\mathrm{MIL}-125(\mathrm{Ti})-\mathrm{NH}_{2}(20 \mathrm{mg})$ photocatalyst was suspended in Milli-Q $\mathrm{H}_{2} \mathrm{O}(20 \mathrm{~mL})$, the solution was treated as described in section 2.4.1. The suspension was subsequently excited with a $150 \mathrm{~W}$ Xenon lamp through a CzernyeTurner monochromator (PTI model 101). The incident power density was calculated using a Newport (818-UV-L) calibrated photodiode. The sample was irradiated at the following wavelengths: $350 \mathrm{~nm}\left(2358 \mathrm{~W} / \mathrm{m}^{2}\right), 400 \mathrm{~nm}\left(9906 \mathrm{~W} / \mathrm{m}^{2}\right)$ and $450 \mathrm{~nm}\left(16943 \mathrm{~W} / \mathrm{m}^{2}\right)$. Quantum yields were calculated according to Equation 1 and Equation 2.

$$
\phi=\frac{\text { number photons emitted }}{\text { number photons absorbed }} \times 100=\frac{\text { number molecules } \mathrm{H}_{2} \times 2}{\text { number photons incidents }}
$$

\section{Equation 1}




$$
\begin{aligned}
& \text { Number photons incidents }=\frac{\mathrm{E} \times \lambda \times \text { Radiated Area }}{\mathrm{c} \times \hbar} \\
& \text { Radiated Area }=\frac{\pi \times \mathrm{d}^{2}}{4}
\end{aligned}
$$

\section{Equation 2}

\subsubsection{Quenching experiments using $\mathrm{MeOH}$ or $\mathrm{Ce}\left(\mathrm{NO}_{3}\right)_{4}$}

The photocatalyst was suspended in an aqueous solution $\left(\mathrm{V}_{\text {total }}=20 \mathrm{~mL}\right)$ containing either $\mathrm{MeOH}(20 \%)$ as donor or $\mathrm{Ce}\left(\mathrm{NO}_{3}\right)_{4}(0.01 \mathrm{mM})$ as electron acceptor, and the samples were irradiated in a quartz reactor under the same Xenon light source. $\mathrm{H}_{2}$ and $\mathrm{O}_{2}$ evolution were monitored using a Micro GC.

\subsubsection{Labelled $\mathrm{H}_{2}{ }^{18} \mathrm{O}$ experiment}

This experiment was carried out using an especially designed small quartz reactor $\left(\mathrm{V}_{\max }=2 \mathrm{~mL}\right), \mathrm{Pt}-\mathrm{RuO}_{2}-\mathrm{MIL}-125(\mathrm{Ti})-\mathrm{NH}_{2}(5 \mathrm{mg})$ was introduced in the reactor and labelled $\mathrm{H}_{2}{ }^{18} \mathrm{O}(500 \mu \mathrm{L})$ was subsequently introduced. The system was purged with helium for 5 minutes and the mixture was irradiated using a Xe lamp. Gases were analyzed in a GC-MS (5973N-6890N) Agilent spectrometer equipped with TRB-5MS column (5 \% phenyl, $95 \%$ polymethylsiloxane, $30 \mathrm{~m}, 0.25 \mathrm{~mm} \times 0.25 \mu \mathrm{m}$, Teknokroma).

\subsubsection{Experiment under natural sunlight irradiation}

The reactor was set in the building roof on a sunny spring day (geographic coordinates: $39.478766 /-0.339703$ ) with a highest ambient temperature of $30^{\circ} \mathrm{C}$ and an ambient relative humidity of $85 \%$. The mixture was stirred under the specified conditions and samples were analyzed by a micro gas chromatograph.

\subsection{Results and discussion}

\subsubsection{Catalyst preparation and characterization}

The purpose of the present study is to obtain data of the photocatalytic overall water splitting of $\mathrm{MIL}-125(\mathrm{Ti})-\mathrm{NH}_{2}$ having co-catalysts to promote simultaneous hydrogen and oxygen evolution. For the sake of sample 
characterization, MIL-125(Ti) was also prepared. In agreement with previous reports, ${ }^{[46]}$ Figure 1 a shows that MIL-125(Ti) and MIL-125(Ti)- $\mathrm{NH}_{2}$ are isostructural crystalline solids. In addition, the titanium metal content determined by ICP-OES of a previously acid digested MIL-125(Ti) or MIL-125(Ti)- $\mathrm{NH}_{2}$ sample agrees with the theoretical formula of these MOFs, either $\mathrm{T}_{i 8} \mathrm{O}_{8}(\mathrm{OH})_{4} \mathrm{BDC}_{6}$ or $\mathrm{T}_{\mathrm{i} 8} \mathrm{O}_{8}(\mathrm{OH})_{4}\left(\mathrm{NH}_{2}-\mathrm{BDC}\right)_{6}$, respectively, confirming the high crystallinity of the solids. Thermogravimetric analysis of the MIL-125(Ti)- $\mathrm{NH}_{2}$ sample confirm the thermal stability of the sample up to $300^{\circ} \mathrm{C}$ and allow also to corroborate the experimental amount of titanium of the sample (22.5 wt\%) in good agreement with the theoretical one ( $23 \mathrm{wt} \%$ for the $\mathrm{C}_{48} \mathrm{H}_{34} \mathrm{~N}_{6} \mathrm{O}_{36} \mathrm{Ti}_{8}$ ) (Figure S1). The presence of the amino group in the MIL-125(Ti)- $\mathrm{NH}_{2}$ solid was assessed by observing its characteristic $\mathrm{N}-\mathrm{H}\left(3,300,1,610\right.$ and $\left.760 \mathrm{~cm}^{-1}\right)$ and C-N (1,255 $\left.\mathrm{cm}^{-1}\right)$ FT-IR vibration bands that do not appear in the MIL-125(Ti) sample (Figure S2). XPS of individual atoms (C1s, O1s, Ti2p and/or N1s) present in the MIL-125(Ti)- $\mathrm{NH}_{2}$ material (Figure S3) in agreement with the literature. ${ }^{[43,47-48]}$

As already known, MIL-125(Ti) absorbs light in the UV region, while the presence of $-\mathrm{NH}_{2}$ substituent in $\mathrm{MIL}-125(\mathrm{Ti})-\mathrm{NH}_{2}$ expands its absorption towards the visible by introducing a new electronic transition involving the lone electron pair region of the nitrogen atoms. ${ }^{[27]}$ Figure $1 \mathrm{~b}$ presents the diffuse reflectance UV-Vis spectra of series of MIL-125(Ti) materials under study. As it can be observed in this Figure, MIL-125(Ti) and MIL-125(Ti)-NH $\mathrm{NH}_{2}$ exhibit a more intense band in the UV region with a maximum of $280 \mathrm{~nm}$ that is ascribed to the Ti-O ligand to metal charge transfer transition. In the case of the MIL-125(Ti)- $\mathrm{NH}_{2}$, another absorption band with maximum around $380 \mathrm{~nm}$ is recorded. This band is associated to the electron transfer from the aminoterephthalate ligand to the $\mathrm{Ti}_{8} \mathrm{O}_{8}(\mathrm{OH})_{4}$ cluster. 


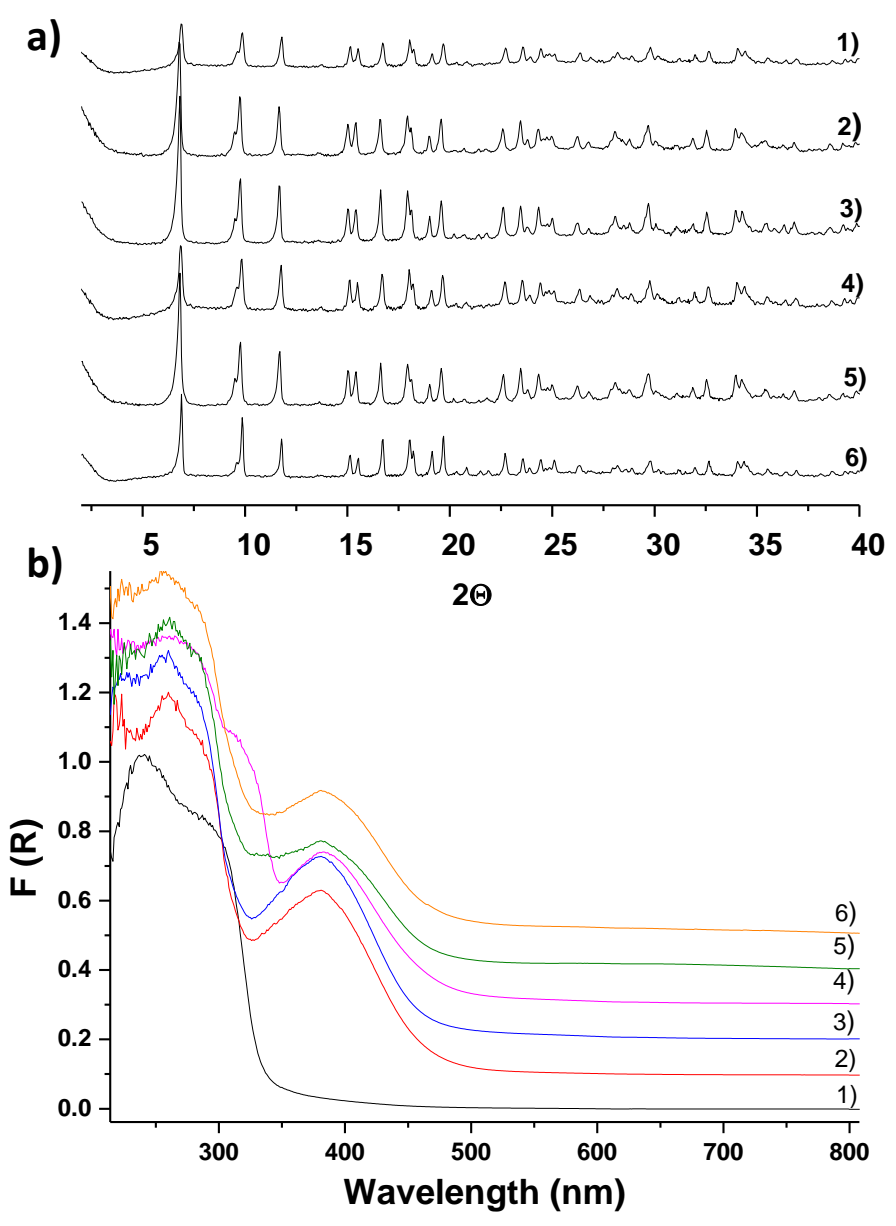

Figure 1. XRD (a) and (b) DR-UV spectra of the MIL-125(Ti)- $\mathrm{NH}_{2}$ series presented in this work. 1) MIL-125(Ti), 2) MIL125(Ti)-NH2, 3) $\mathrm{CoO}_{x}-\mathrm{MIL125}(\mathrm{Ti})-\mathrm{NH}_{2}$, 4) Pt-MIL-125(Ti)-NH $\mathrm{RuO}_{\mathrm{x}}-\mathrm{MIL125}(\mathrm{Ti})-\mathrm{NH}_{2}$, 6) Pt-RuO $\mathrm{x}-\mathrm{MIL125}(\mathrm{Ti})-\mathrm{NH}_{2}$.

The morphology (Figure S4) and the composition of these two materials have been assessed by SEM measurements coupled to EDX measurements (Figures S5-S6). The porosity of the materials was assessed by performing isothermal $\mathrm{N}_{2}$ adsorption measurements. Regardless space needed for accommodation of the 
amino group in the MIL-125(Ti)- $\mathrm{NH}_{2}$ material a high BET surface area and pore volume of $1,200 \mathrm{~m}^{2} \mathrm{~g}^{-1}$ and $0.55 \mathrm{~g} \mathrm{~cm}^{-3}$, respectively, were obtained.

Co-catalysts were introduced on the material to determine the influence of the nature of these guests on the efficiency of the overall water splitting. MNP deposition on MIL-125(Ti)- $\mathrm{NH}_{2}$ solid was performed by irradiating the material with UV-Vis light to generate electron-hole pairs in the absence $\mathrm{Pt}-\mathrm{RuO}_{2}$ or in the presence of $\mathrm{MeOH}$ as sacrificial agent $\left(\mathrm{RuO}_{2}\right.$ and $\left.\mathrm{CoO}_{x}\right)$. Figure $1 \mathrm{a}$ shows that the crystal structure of the MIL-125(Ti)- $\mathrm{NH}_{2}$ remains unaltered upon photodeposition of the co-catalysts. The absence of diffraction peaks characteristic of the metal or metal Oxide NPs indicates the good dispersion and/or small supported MNPs. This fact has been confirmed by means of TEM measurements (Figure 2).

Table 1 summarizes the metal content, metal or metal Oxide particle size distribution and standard deviation of the prepared catalyst. In general, the average particle size of the photodeposited co-catalyst NPs on MIL-125(Ti)- $\mathrm{NH}_{2}$ is lower than $3 \mathrm{~nm}$, being compatible with the internal location of these NPs. The composition of these small MNPs has been confirmed by performing selected area EDX analyses of individual MNPs on the as-prepared materials (Figure S7). SEM-EDX measurements revealed the good dispersion of the different elements (Figures S8-S11). XPS allows to detected all the expected elements $(\mathrm{C}, \mathrm{O}, \mathrm{N}, \mathrm{Ti})$ of the different samples as well as to confirm the predominant reduction form of $\mathrm{Pt}(0)$ NPs and oxidized $\mathrm{CoO}_{x} \mathrm{NPs}$ (Figures S12-S15). Ruthenium nanoparticles, however, overlaps with C1s binding energy although considering that after the photodeposition the sample is treated at $180^{\circ} \mathrm{C}$ for $2 \mathrm{~h}$ in an oven under ambient conditions it is likely assume that are partially oxidized in the form of $\mathrm{RuO}_{\mathrm{x}}$ (Figure S14). As it will be commented below, somewhat different co-catalyst loadings were achieved by photodeposition. However, this method of co-catalyst formation was preferred, since this method ensures the formation of the co-catalyst NPs at those locations of the crystal were electrons (Pt) 
or holes $\left(\mathrm{CoO}_{x}\right.$ and $\left.\mathrm{RuO}_{\mathrm{x}}\right)$ are preferentially located. ${ }^{[31]}$ The loading of these co-catalysts are given in Table 1.
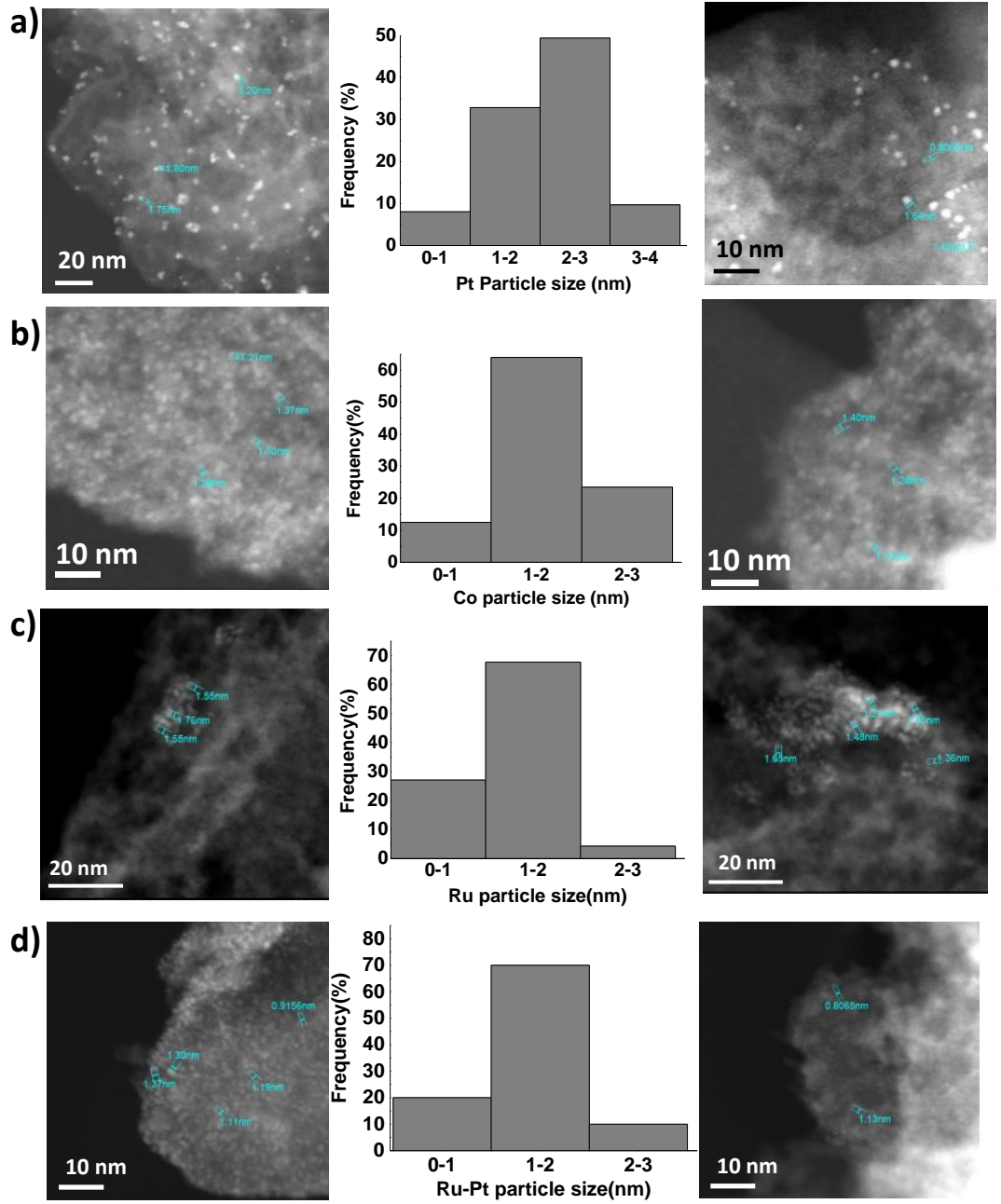

Figure 2. DF-STEM images and histograms of metal particle size distribution of Pt-MIL-125(Ti)-NH $\mathrm{NH}_{2} \quad$ (a), $\quad \mathrm{CoO}_{x}-\mathrm{MIL}-125(\mathrm{Ti})-\mathrm{NH}_{2} \quad$ (b), $\mathrm{RuO}_{\mathrm{x}}-\mathrm{MIL}-125(\mathrm{Ti})-\mathrm{NH}_{2} \quad$ (c) and Pt-RuO $-\mathrm{MIL}-125(\mathrm{Ti})-\mathrm{NH}_{2}$ (d). 
Table 1. List of MIL-125(Ti)- $\mathrm{NH}_{2}$ photocatalysts employed in this study for the overall water splitting. ${ }^{a, b}$

\begin{tabular}{|c|c|c|c|}
\hline Photocatalyst & $\begin{array}{c}\text { Metal } \\
\text { Content } \\
(w t \%)^{c}\end{array}$ & $\begin{array}{l}\text { Average particle size } \\
(\mathrm{nm}) \text { and standard } \\
\text { deviation }(\mathrm{nm}) \text { of fresh } \\
\text { samples }\end{array}$ & $\begin{array}{c}\text { Average particle size } \\
(\mathrm{nm}) \text { and standard } \\
\text { deviation }(\mathrm{nm}) \text { of used } \\
\text { samples }\end{array}$ \\
\hline Pt-MIL-125(Ti)-NH & 0.20 & $2.1 \pm 0.50$ & $2.3 \pm 0.51$ \\
\hline $\mathrm{CoO}_{x}-\mathrm{MIL}-125(\mathrm{Ti})-\mathrm{NH}_{2}$ & 0.95 & $1.6 \pm 0.45$ & $1.8 \pm 0.49$ \\
\hline $\mathrm{RuO}_{\mathrm{x}}-\mathrm{MIL}-125(\mathrm{Ti})-\mathrm{NH}_{2}$ & 0.23 & $1.3 \pm 0.51$ & $1.3 \pm 0.52$ \\
\hline $\begin{array}{c}\text { Pt-RuO }{ }_{x}-\mathrm{MIL}-125(\mathrm{Ti})- \\
\mathrm{NH}_{2}\end{array}$ & $\begin{array}{l}0.12(\mathrm{Pt})- \\
0.24(\mathrm{Ru})\end{array}$ & $1.4 \pm 0.44$ & $1.5 \pm 0.53$ \\
\hline
\end{tabular}

a) Isothermal nitrogen adsorption measurements allowed to estimate a BET surface area and pore volume of $1.200 \mathrm{~m}^{2} \mathrm{~g}^{-1}$ and $0.55 \mathrm{~g} \mathrm{~cm}^{-3}$, respectively; b) The same batch of the MIL-125(Ti)- $\mathrm{NH}_{2}$ has been employed to prepare this sample; c) Determined by ICP-AES after acid digestion of the solid samples.

\subsubsection{Photocatalytic overall water splitting experiments}

Considering the known influence of the amino substitution on the terephthalate ring on the visible light absorption, MIL-125(Ti)- $\mathrm{NH}_{2}$ was selected as photocatalyst to determine its performance to promote the overall water splitting under simulated sunlight irradiation as a function of the nature of co-catalyst. Previous calculations have proposed that the highest occupied crystal orbital (HOCO) in MIL-125(Ti)- $\mathrm{NH}_{2}$ is located at the organic linker and the lowest unoccupied crystal orbital (LUCO) at the Ti 3d-orbitals. ${ }^{[49]}$ Accordingly, it is expected that upon photon absorption, an efficient electron transfer from the terephthalate ligand to the $\mathrm{Ti}^{4+}$ cation can occur, as it has also been proposed based on transient absorption spectroscopy. ${ }^{[50]}$ In agreement with these proposals, EPR measurements have shown that photoexcitation of MIL-125(Ti)- $\mathrm{NH}_{2}$ results in the formation of $\mathrm{Ti}^{3+}$ species. ${ }^{[51]}$ Moreover, the energy values of the valence and conduction bands in 
MIL-125(Ti)- $\mathrm{NH}_{2}$ (see Table 2) would, in principle, allow this material in the charge separated state to perform the overall water splitting. ${ }^{[39,52]}$ Thus, the bottom level of the conduction band is more negative than the reduction potential of the $\mathrm{H}^{+} / \mathrm{H}_{2}$ couple ( $\mathrm{E}^{0}$ red $\mathrm{OV}$ vs $\mathrm{NHE}$ ), and the top level of the valence band more positive than the Oxidation potential of the $\mathrm{O}_{2} / \mathrm{H}_{2} \mathrm{O}$ redox pair ( $+1.23 \mathrm{~V}$ vs $\left.\mathrm{NHE}\right)$. In accordance with previous reports, ${ }^{[39,52]}$ the estimated band gap of the MIL-125(Ti)- $\mathrm{NH}_{2}$ material is around $2.45 \mathrm{eV}$, therefore, it also meets the requirement of having a band gap higher than the necessary $2.3 \mathrm{eV}$ to permit the reaction. Table 2 summarizes the thermodynamic data.

Table 2. HOCO and LUCO energy values and bandgap energy for MOFs related to the MIL-125 series. ${ }^{34,47}$.

\begin{tabular}{cccc}
\hline Material & HOCO $[\mathrm{eV}]$ & LUCO $[\mathrm{eV}]$ & Band Gap [eV] \\
\hline MIL-125(Ti) & 2.40 & -1.40 & 3.80 \\
& & & \\
MIL-125(Ti)-NH & 2.40 & -0.05 & 2.45 \\
\hline
\end{tabular}

As already mentioned, most of the literature precedents are focused on the evolution of one of the half-reactions, particularly hydrogen. ${ }^{[16,17,53]}$ Thus despite their known sensitivity to $\mathrm{pH}, \mathrm{MOFs}$ have proven its capability to generate hydrogen or oxygen in the presence of sacrificial electron donors and electron acceptors. ${ }^{[54]}$ There are only two examples regarding the overall water splitting utilizing MOFs as photocatalyst in the literature, both by Huang, Liu and colleagues, reporting the use of an aluminum based MOF derived from 2-aminoterephthalic acid (AI-NH $\mathrm{NH}_{2} \mathrm{BDC}$ MOF) ${ }^{[40]}$ and also MIL-125(Ti) doped with CoPi (Pi phosphate) and Pt. ${ }^{[39]}$ To the best of our knowledge there are no examples regarding the use of MIL-125Ti)- $\mathrm{NH}_{2}$ for the overall water splitting. 
Apart from different LUCO and bandgap energy values, the main advantage of MIL-125- $\mathrm{NH}_{2}$ against MIL-125 is the extended absorption in the visible region what is extremely important in solar photocatalysis. For their use in the overall water splitting, MIL-125- $\mathrm{NH}_{2}$ was functionalized by photodeposition ${ }^{[45]}$ with co-catalysts, namely Pt, $\mathrm{CoO}_{x}, \mathrm{RuO}_{x}$ and a bimetallic Pt-RuO material. $^{[31]}$ The roles of co-catalysts are to improve the efficiency of charge separation and to act as active sites for oxygen and hydrogen evolution. ${ }^{[39]}$ Numerous studies have shown that Pt NPs are the preferred active sites for $\mathrm{H}_{2}$ evolution, ${ }^{[31]}$ while $\mathrm{O}_{2}$ evolution reaction is commonly catalyzed by $\mathrm{RuO}_{2}{ }^{[55]}$ or oxidized cobalt NPs. ${ }^{[55-56]}$

In a preliminary experiment, the photocatalytic overall reaction was performed over as-synthesized MIL-125- $\mathrm{NH}_{2}$ to evaluate the performance of the semiconductor without any co-catalyst in the system. It was observed that $\mathrm{H}_{2}$ and $\mathrm{O}_{2}$ gases were generated in a quasi-stoichiometric ratio resulting in 48 and 27 $\mu \mathrm{mol} \cdot \mathrm{g}^{-1}$ photocatalyst of $\mathrm{H}_{2}$ and $\mathrm{O}_{2}$, respectively, in $21 \mathrm{~h}$ (Figure 3a). Control experiments in the dark showed no $\mathrm{H}_{2}$ and $\mathrm{O}_{2}$ evolution (data not shown). The concentration of the heterogeneous photocatalyst was optimized keeping constant irradiation conditions (Figure $3 b$ ). As it can be seen there, lower catalyst concentrations (10 or $5 \mathrm{mg}$ photocatalyst: $20 \mathrm{~mL}$ of water) resulted in higher $\mathrm{H}_{2}$ or $\mathrm{O}_{2}$ production per weight of MOF spent in the reaction. However, these small amounts of MIL-125(Ti)- $\mathrm{NH}_{2}$ result in lower oxygen evolution that would be affected by larger experimental errors and, therefore, were not chosen. 


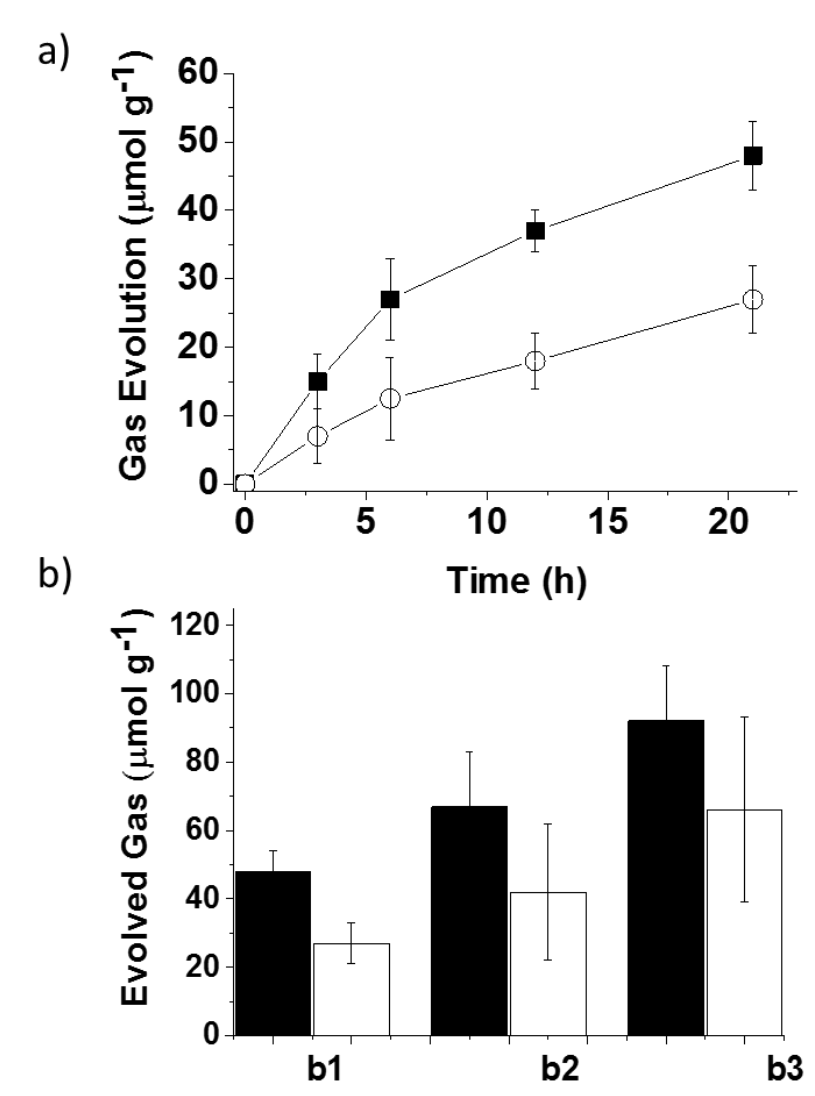

Figure 3. a) Photocatalytic $\mathrm{H}_{2}$ and $\mathrm{O}_{2}$ evolution reaction over $\mathrm{MIL}-125(\mathrm{Ti})-\mathrm{NH}_{2}$. b) Photocatalytic gas evolution MIL-125(Ti)- $\mathrm{NH}_{2}$ using different photocatalyst concentrations: Catalyst concentration of $20 \mathrm{mg} / 20 \mathrm{~mL}(\mathrm{a}, \mathrm{b} 1), 10 \mathrm{mg} / 20 \mathrm{~mL}$ (b2), $5 \mathrm{mg} / 20 \mathrm{~mL}$ (b3). Legend: $\mathrm{H}_{2}$ (black symbols) and $\mathrm{O}_{2}$ (white symbols) Reaction conditions: light source: UV-Vis Xe lamp (150 $\left.\mathrm{mW} \times \mathrm{cm}^{-2}\right), \mathrm{H}_{2} \mathrm{O}(20 \mathrm{~mL})$, photoreactor volume $(51 \mathrm{~mL})$, temperature $\left(35^{\circ} \mathrm{C}\right)$.

To study the effect of co-catalyst deposition on the photocatalytic water splitting, cobalt Oxide NPs were photodeposited onto pristine MIL-125(Ti)-NH2. As it can be observed in Figure 4a, this $\mathrm{CoO}_{x}-\mathrm{MIL}-125(\mathrm{Ti})-\mathrm{NH}_{2}$ photocatalyst is also able to promote overall water splitting with a maximum $\mathrm{H}_{2}$ and $\mathrm{O}_{2}$ production of 147 and 61 $\mu$ mol. ghotocatalyst $^{-1}$, respectively, in $21 \mathrm{~h}$. Thus, loading $\mathrm{CoO}_{x} \mathrm{NPs}$ in less than $1 \%$ in MIL-125(Ti)- $\mathrm{NH}_{2}$ increases by three-fold the gases evolved compared to the pristine 
MIL-125(Ti)- $\mathrm{NH}_{2}$. This improvement in the activity of the photocatalyst reflects the positive effect of cobalt oxide as co-catalyst to lower the activation energy.
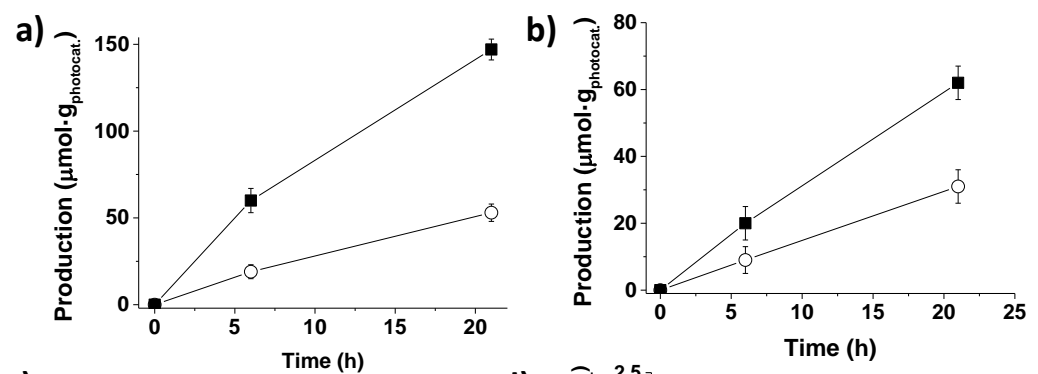

c)

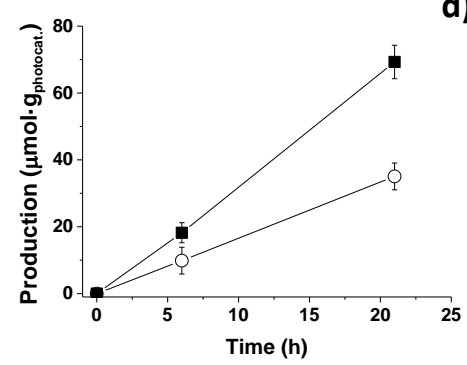

d)

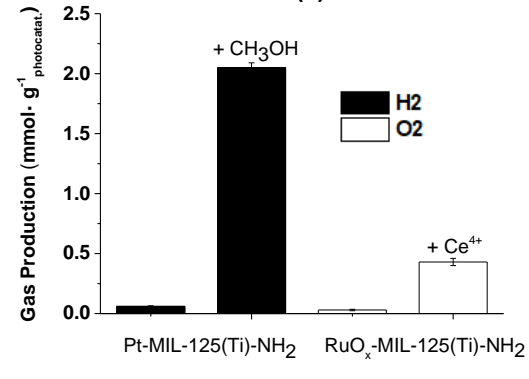

Figure 4. Photocatalytic $\mathrm{H}_{2}$ and $\mathrm{O}_{2}$ evolution per gram of $\mathrm{CoO}_{x}-\mathrm{MIL}-125(\mathrm{Ti})-\mathrm{NH}_{2}$ (a), Pt-MIL--125(Ti)- $\mathrm{NH}_{2}$ (b) and RuO $-\mathrm{MIL}-125$ (Ti)- $\mathrm{NH}_{2}$ (c). Comparison of the photocatalytic $\mathrm{H}_{2}$ production for Pt-MIL-125(Ti)- $\mathrm{NH}_{2}$ (black bars) and $\mathrm{O}_{2}$ production for $\mathrm{RuO}_{\mathrm{x}}-\mathrm{MIL}-125(\mathrm{Ti})-\mathrm{NH}_{2}$ (white bars) in the absence or in the presence of indicated sacrificial agents. Reaction conditions: Photocatalyst (20 mg /20 mL Milli Q- $\mathrm{H}_{2} \mathrm{O}$ ), UV-Vis Xe lamp (150 mW $\times \mathrm{cm}^{-2}$ ), temperature $35^{\circ} \mathrm{C}$.

Besides cobalt oxide, the influence of the presence of Pt NPs on the overall water splitting was also investigated. Pt-MIL-125(Ti)- $\mathrm{NH}_{2}$ was characterized and tested for the overall water splitting under the optimal conditions commented above. The average Pt NP particle size was $2.2 \mathrm{~nm}$ that is compatible with the internal location of the NPs prepared by photodeposition. Figure $4 \mathrm{~b}$ depicts the gas evolution and the time profiles for the photocatalytic overall water splitting over Pt-MIL-125(Ti)- $\mathrm{NH}_{2}$. There was also improvement in the values with respect to the blank MIL-125(Ti)- $\mathrm{NH}_{2}$ obtaining in this case up to $62 \mu \mathrm{mol} \mathrm{g}^{-1}$ of $\mathrm{H}_{2}$ and the stoichiometrically generated $\mathrm{O}_{2}\left(31 \mu \mathrm{mol} \mathrm{g}^{-1}\right)$. The enhancement of the reaction is 
smaller than the one measured for cobalt oxide as co-catalyst. When comparing the performance of both $\mathrm{CoO}_{x}$ and Pt NPs as co-catalysts, it should, however, be reminded that the loading of cobalt oxide and Pt NPs in weight percentage is not exactly coincident and it is likely that other co-catalyst loadings could have given different enhancements of the photocatalytic activity. The most conclusive point was that both co-catalysts enhance the photocatalytic activity for overall water splitting respect to the pristine MIL-125(Ti)- $\mathrm{NH}_{2}$ material.

A third co-catalyst tested for the overall water splitting was ruthenium oxide, also a typical co-catalyst for Oxygen evolution. ${ }^{[55]}$ An enhancement in the photocatalyst activity for overall water splitting similar to that measured for Pt NPs was observed upon photodeposition of $\mathrm{RuO}_{2} . \mathrm{H}_{2}$ and $\mathrm{O}_{2}$ generation values were 70 and $35 \mu \mathrm{mol}$, respectively (Figure 4c) when Ru-MIL-125( $\left.\mathrm{NH}_{2}\right)$ was used as photocatalyst. When making the comparison, it should be commented again, the impossibility to prepare by photodeposition samples with exactly the same atomic loading of different metals or metal oxides per weight of MIL-125(Ti)- $\mathrm{NH}_{2}$.

To evaluate the reduction and Oxidation half-reactions independently, the photocatalytic gas evolution measurements were carried out in the presence of methanol as electron donor in case of Pt-MIL-125(Ti)- $\mathrm{NH}_{2}$ and cerium ammonium nitrate as electron acceptor for $\mathrm{RuO}_{x}-\mathrm{MIL}-125(\mathrm{Ti})-\mathrm{NH}_{2}$. The results, depicted in Figure $4 \mathrm{~d}$, clearly demonstrated that the efficiency of $\mathrm{H}_{2}$ and $\mathrm{O}_{2}$ evolution increases considerably in the presence of the appropriate sacrificial agent. These results are in good agreement with the literature that shows that $\mathrm{H}_{2}{ }^{[16]}$ or $\mathrm{O}_{2}{ }^{[57]}$ evolution in aqueous suspensions reaches the maximum values when sacrificial agents are present in the medium quenching efficiently holes and electrons, respectively. In this way, a remarkable increase of the produced gases is achieved in the presence of complementary sacrificial agents, reaching values of $2 \mathrm{mmol} \mathrm{H}_{2} \cdot \mathrm{g}_{\text {photocatalyst }}{ }^{-1}$ when $\mathrm{MeOH}$ is added to the Pt-MIL-125(Ti)- $\mathrm{NH}_{2}$ photocatalyzed reaction, and about 
$0.5 \mathrm{mmol}$ of $\mathrm{O}_{2} \cdot$ gphotocatalyst $^{-1}$ when $\mathrm{Ce}\left(\mathrm{NO}_{3}\right)_{4}$ is present in the reaction photocatalyzed by $\mathrm{RuO}_{2}-\mathrm{MIL}-125(\mathrm{Ti})-\mathrm{NH}_{2}$.

To check whether the photocatalytic activity for overall water splitting improves in the presence of two complementary photocatalysts, a MIL-125(Ti)- $\mathrm{NH}_{2}$ containing both Pt and $\mathrm{RuO}_{\times}$NPs was prepared. The results presented in Figure 5a and show that the water splitting activity of the MIL-125(Ti)- $\mathrm{NH}_{2}$ containing both $\mathrm{Pt}$ and $\mathrm{RuO}_{x}$ co-catalyst is the highest of the series (Figure 5b) reaching values of $\mathrm{H}_{2}$ and $\mathrm{O}_{2}$ production of 218 and $85 \mu \mathrm{mol} \cdot \mathrm{g}_{\text {photocatalyst }}{ }^{-1}$, respectively at a reaction temperature of $35{ }^{\circ} \mathrm{C}$. An analogous experiment working at $10{ }^{\circ} \mathrm{C}$ results in a $\mathrm{H}_{2}$ and $\mathrm{O}_{2}$ production of 88 and $38 \mu \mathrm{mol} \cdot$ gphotocatalyst $^{-1}$, respectively (Figure S16). The lower than stoichiometric $\mathrm{O}_{2}$ production observed in the measurement could indicate alternative ways of hole consumption and/or the reaction of some percentage of nascent $\mathrm{O}_{2}$ with $\mathrm{Ru}$ co-catalyst, other MOF components or electrons.
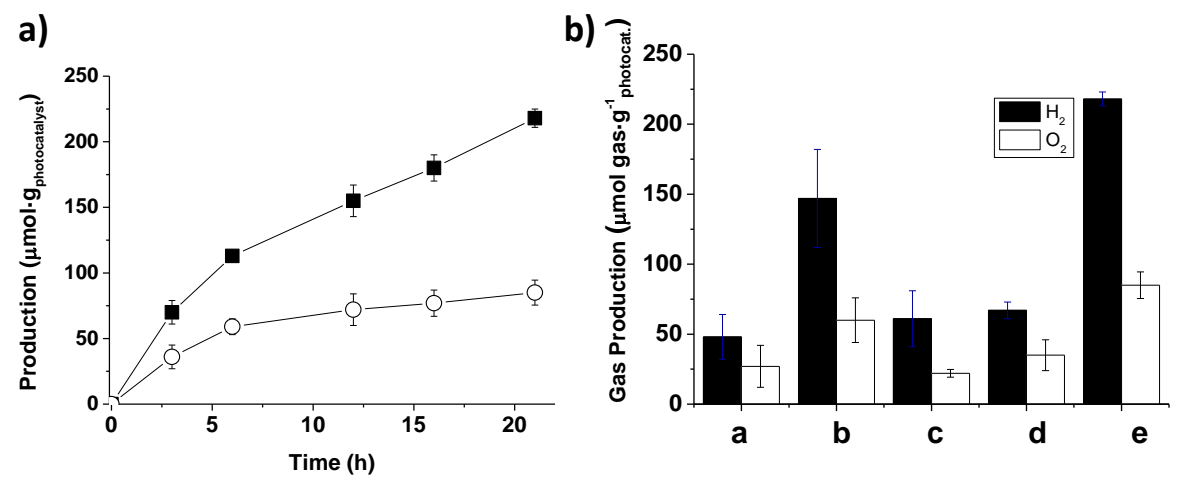

Figure 5. a) Overall water splitting using Pt-RuO $-\mathrm{MIL}-125(\mathrm{Ti})-\mathrm{NH}_{2}$ as photocatalyst. b) Values of $\mathrm{H}_{2}$ and $\mathrm{O}_{2}$ production for the photocatalytic overall water splitting using MIL-125(Ti)- $\mathrm{NH}_{2}$ (a), $\mathrm{CoO}_{x}-\mathrm{MIL}-125(\mathrm{Ti})-\mathrm{NH}_{2}$ (b), Pt-MIL-125(Ti)- $\mathrm{NH}_{2} \quad$ (c), $\mathrm{RuO}_{x}-\mathrm{MIL}-125(\mathrm{Ti})-\mathrm{NH}_{2} \quad$ (d) and Pt-RuO $-\mathrm{MIL}-125(\mathrm{Ti})-\mathrm{NH}_{2}$ (e) at $21 \mathrm{~h}$ reaction time. Reaction conditions: Photocatalyst $(20 \mathrm{mg}$ $/ 20 \mathrm{~mL}$ Milli Q- $\left.\mathrm{H}_{2} \mathrm{O}\right)$, UV-Vis Xe lamp $\left(150 \mathrm{~mW} \times \mathrm{cm}^{-2}\right)$, temperature $35^{\circ} \mathrm{C}$.

As it has been already remarked, the MIL-125(Ti)- $\mathrm{NH}_{2}$ photocatalysts do not contain the same co-catalyst loading (Table 1). Thus, although the initial particle size 
was similar for all the samples, due to the intrinsic conditions of the photodeposition method, loading was somewhat different. Therefore, it could be that the photocatalytic efficiency varied somewhat as a function of the co-catalyst loading.

To take into account the co-catalyst loading as a possible parameter, the experimental gas evolution rates were divided by the mass of the co-catalyst, rather than by the mass of MIL-125(Ti)- $\mathrm{NH}_{2}$. The results are presented in Figure 6 . As it can be seen in this Figure, plotting the data in this way shows that $\mathrm{Pt}$ is $\mathrm{RuO}_{\mathrm{x}}$ a somewhat better co-catalyst per mass unit than $\mathrm{CoO}_{x}$, although the activity when a single co-catalyst is present varies in a relatively small range. In addition, this plot also shows the benefits of having two complementary co-catalysts for the overall water splitting, since the activity of Pt-RuO $-\mathrm{MIL}-125(\mathrm{Ti})-\mathrm{NH}_{2}$ increases by a higher factor of about three with respect to the improvement when a single co-catalyst is present.

The stability of the used catalyst after $22 \mathrm{~h}$ irradiation were evaluated by their characterization by PXRD and TEM measurements. Importantly, it should be commented that all the tested photocatalysts for the overall water splitting retains their initial crystallinity as revealed by XRD measurements (Figures S17-S21). TEM measurements reveal that the average particle size of the supported NPs on the MIL-125(Ti)- $\mathrm{NH}_{2}$ after $22 \mathrm{~h}$ irradiation during the photocatalytic experiment (Figure S22) only slightly increases ( $<0.2 \mathrm{~nm}$ in average) respect to the fresh samples, possibly due to the operation of the Ostwald ripening mechanism during the photocatalytic reaction. XPS of the most active sample Pt-RuOx-MIL-125(Ti)-NH after one use further confirms the stability of this photocatalyst under the present reaction conditions (Figure S23). 


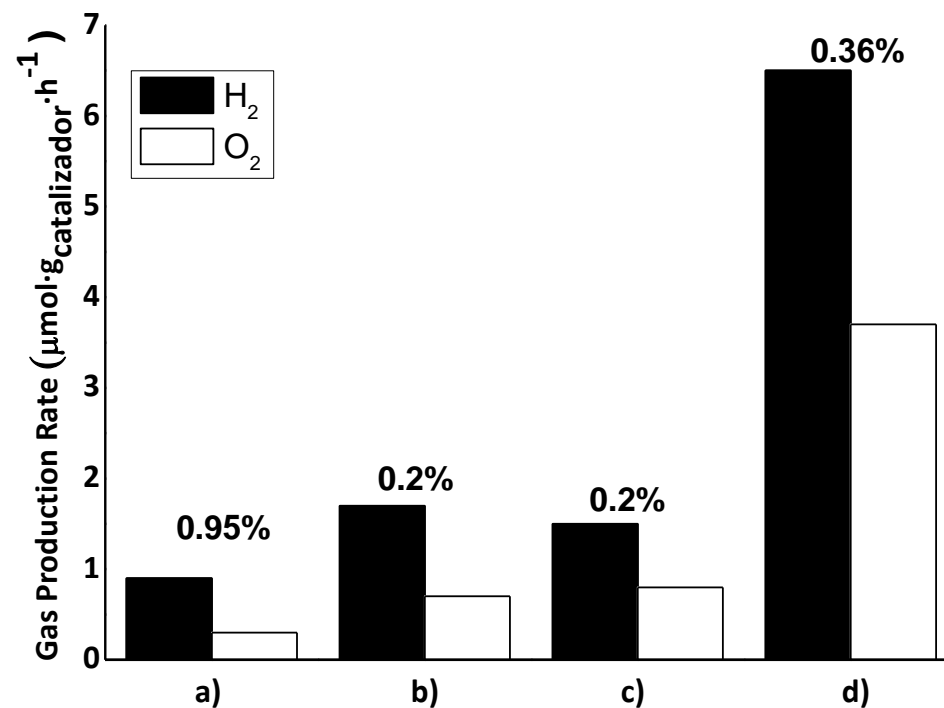

Figure 6. $\mathrm{H}_{2}$ and $\mathrm{O}_{2}$ maximum production rates. Production rate in $\mu$ mol per gram of deposited metal co-catalyst per hour. Legend: $\mathrm{CoO}_{x}-\mathrm{MIL}-125(\mathrm{Ti})-\mathrm{NH}_{2}$ (a), Pt-MIL-125(Ti)- $\mathrm{NH}_{2}$ (b), $\mathrm{RuO}_{\mathrm{x}}-\mathrm{MIL}-125(\mathrm{Ti})-\mathrm{NH}_{2}$ (c) and Pt-RuO $\mathrm{O}^{-} \mathrm{MIL}-125(\mathrm{Ti})-\mathrm{NH}_{2}$ (d). The number represents the metal weight percent supported in the MOF. Reaction conditions: Photocatalysts $(20 \mathrm{mg} / 20 \mathrm{~mL}$ Milli $\left.\mathrm{Q}-\mathrm{H}_{2} \mathrm{O}\right), \mathrm{UV}-\mathrm{Vis} \mathrm{Xe}$ lamp $\left(150 \mathrm{~mW} \times \mathrm{cm}^{-2}\right)$, temperature $35^{\circ} \mathrm{C}$, reaction time: $6 \mathrm{~h}$.

One of the challenges in photocatalysis for the overall water splitting is develop efficient materials under visible light irradiation. Importantly, the most active $\mathrm{Pt}-\mathrm{RuO}_{\mathrm{x}}-\mathrm{MIL}-125(\mathrm{Ti})-\mathrm{NH}_{2}$ photocatalyst prepared in this work is able to use the natural Sunlight irradiation to promote the overall water splitting. Results show that under natural sunlight irradiation Pt-RuO $-\mathrm{MIL}-125(\mathrm{Ti})-\mathrm{NH}_{2}$ was able to achieve the overall water splitting with a maximum production of $27 \mu \mathrm{mol} \cdot \mathrm{g}^{-1}$ of $\mathrm{H}_{2}$ and 14 $\mu \mathrm{mol} \cdot \mathrm{g}^{-1}$ of $\mathrm{O}_{2}$ (Figure 7a). This is one of the first examples in which a MOF material has demostrated their ability to perform the quasi-stoichiometric overall water splitting under real conditions. 

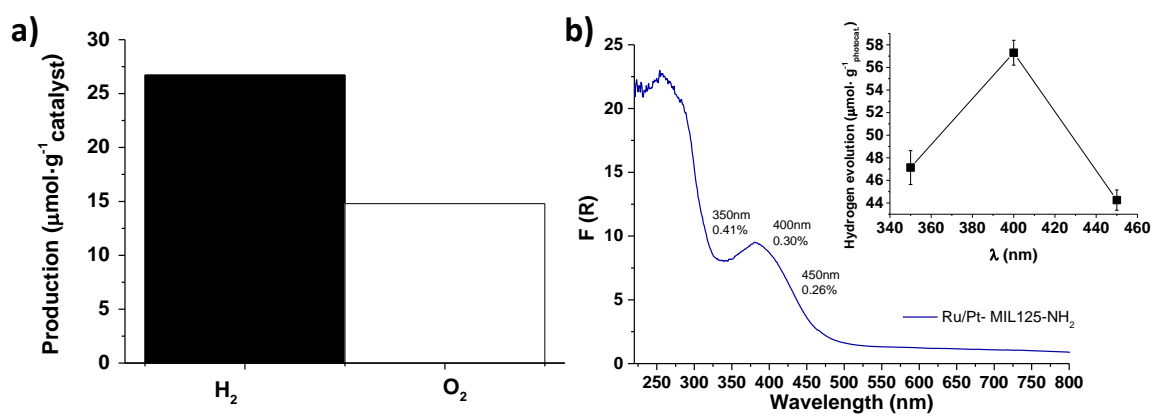

Figure 7. a) Photocatalytic overall water splitting under natural Sunlight irradiation using Pt-RuO ${ }_{x}-\mathrm{MIL}-125$ (Ti)- $\mathrm{NH}_{2}$. Reaction conditions: Photocatalyst $\left(20 \mathrm{mg} / 20 \mathrm{~mL}\right.$ Milli Q- $\mathrm{H}_{2} \mathrm{O}$ ), sunlight (100 $\left.\mathrm{mW} \times \mathrm{cm}^{-2}\right)$, ambient temperature $30{ }^{\circ} \mathrm{C}$, reaction time: $\left.10 \mathrm{~h} . \mathrm{b}\right) \mathrm{H}_{2}$ production using a monochromator at the selected wavelengths and comparison in the UV-Vis spectra. Reaction conditions: Photocatalyst ( $20 \mathrm{mg} / 20 \mathrm{~mL}$ Milli Q- $\mathrm{H}_{2} \mathrm{O}$ ), sample was irradiated using a $150 \mathrm{~W}$ Xenon lamp equipped with a CzernveTurner monochromator, temperature $\left(35^{\circ} \mathrm{C}\right)$, reaction time: $21 \mathrm{~h}$.

Using the most efficient $\mathrm{Pt}-\mathrm{RuO}_{2}-\mathrm{MIL}-125(\mathrm{Ti})-\mathrm{NH}_{2}$ photocatalyst the quantum efficiency at selected wavelengths was determined by using monochromatic light. As it can be seen in Figure 7b, the photocatalytic activity data follows the absorption spectrum of the material, being the efficiency at $400 \mathrm{~nm}$ higher than at $350 \mathrm{~nm}$ or $450 \mathrm{~nm}$. The maximum quantum efficiency for overall water splitting is remarkable and ranks Pt-RuO $-\mathrm{MIL}-125(\mathrm{Ti})-\mathrm{NH}_{2}$ among the most efficient photocatalysts reported so far. It should be noted that as commented in the introduction, most of the previous reports on hydrogen generation from aqueous media contain sacrificial electron donor ${ }^{[18]}$ or pollutants playing this role. ${ }^{[58]}$

As observed in the results commented earlier, the fact that $\mathrm{H}_{2}$ and $\mathrm{O}_{2}$ are stoichiometrically produced, suggests that gases evolution arises from water splitting reaction. To further investigate this fact, an experiment was designed where isotopically labeled $\mathrm{H}_{2}{ }^{18} \mathrm{O}$ was utilized (97 atom $\%{ }^{18} \mathrm{O}$ normalized with respect to hydrogen) instead of regular water. The evolution of the isotopically labelled $\mathrm{O}_{2}(36$ $\mathrm{m} / \mathrm{z}$ ) was followed by gas chromatography mass spectrometry (GC/MS), as well as 
the possible molecule fragmentation usually observed in this technique. In this case the reaction was purged with helium to avoid the presence of argon since the latter exhibits the ${ }^{36} \mathrm{Ar}$ stable isotope occurring with a natural abundance of $0.337 \%$. Table 3 summarizes the $m / z$ ratio abundance obtained for the different masses. The peak corresponding to $36 \mathrm{~m} / \mathrm{z}$ shows a threefold increase after 24 hours of light radiation (up to $0.32 \%$ ) (Figure S24). Another remarkable change is the approximately twenty-fold enhancement in the signal corresponding to the $18 \mathrm{~m} / \mathrm{z}$ with respect to sample taken before reaction owing to the oxygen molecule $\left({ }^{18} \mathrm{O}-{ }^{18} \mathrm{O}\right)$ fragmentation during the analysis, values from $0.45 \%$ before irradiation to $8.5 \%$ after $24 \mathrm{~h}$. All the evidence commented above lead to the conclusion that the overall water splitting reaction is photocatalyzed by the metal organic framework and that the oxygen generated in the reaction comes from the water added in the reaction.

Table 3. \% Abundance for the different $\mathrm{m} / \mathrm{z}$ ratio elements found by mass spectrometry during the course of the reaction (normalized to the peak of 32).

\begin{tabular}{cccccc}
\hline $\begin{array}{c}\mathrm{m} / \mathrm{z} \text { ratio } \\
\text { [\% abundance }]\end{array}$ & $\mathbf{3 6}$ & 34 & 20 & $\mathbf{1 8}$ & 16 \\
\hline $0 \mathrm{~h}$ & $\mathbf{0 . 1 1}$ & 0.6 & 2.1 & $\mathbf{0 . 4 5}$ & 5.5 \\
$24 \mathrm{~h}$ & $\mathbf{0 . 3 2}$ & 0.38 & 1.5 & $\mathbf{8 . 5}$ & 5.9 \\
\hline
\end{tabular}

\subsection{Conclusions}

In the present work it has been found that MIL-125(Ti)- $\mathrm{NH}_{2}$ as photocatalyst can promote overall water splitting evolving $\mathrm{H}_{2}$ and $\mathrm{O}_{2}$ in the expected stoichiometric amounts. The activity of this material is strongly dependent on the presence and nature of co-catalysts. Although photodeposition method has the advantage that locates the co-catalyst NPs at the places in the crystal where electrons are holes are present, the exact loading amount of co-catalyst cannot be controlled. When corrected for the co-catalyst mass, it has been determined that the activity 
enhancement follows the order: $\mathrm{Pt} \approx \mathrm{RuO}_{2}>\mathrm{CoO}_{x}$. The presence of complementary co-catalysts increases even further the activity that has reached a maximum hydrogen production of $218 \mu \mathrm{mol} \cdot \mathrm{g}^{-1}$, with a maximum quantum efficiency at 400 $n m$ of $0.30 \%$. 


\subsection{Bibliography}

[1] D. Gust, T. A. Moore, A. L. Moore, Acc. Chem. Res. 2009, 42, 1890-1898.

[2] G. Centi, S. Perathoner, ChemSusChem 2010, 3, 195-208.

[3] H. B. Gray, Nat. Chem. 2009, 1, 7.

[4] K. Li, B. Peng, T. Peng, ACS Catal. 2016, 6, 7485-7527.

[5] P. V. Kamat, J. Bisquert, J. Phys. Chem. C 2013, 117, 14873-14875.

[6] J. Li, N. Wu, Catal. Sci. Technol. 2015, 5, 1360-1384.

[7] S. Protti, A. Albini, N. Serpone, Phys. Chem. Chem. Phys 2014, 16, 19790-19827.

[8] M. Ni, M. K. Leung, D. Y. Leung, K. Sumathy, Renew. Sust. Energ. Rev. 2007, 11, 401-425.

[9] A. Fujishima, T. N. Rao, D. A. Tryk, J. Photoch. Photobio. C: Photochem. Rev. 2000, 1, $1-21$.

[10] S. Malato, J. Blanco, A. Vidal, C. Richter, Appl. Catal. B 2002, 37, 1-15.

[11] H. He, J. Cao, M. Guo, H. Lin, J. Zhang, Y. Chen, S. Chen, Appl. Catal. B 2019, 2, 246-256

[12] C. Zhu, M. Zhu, Y. Sun, Y. Zhou, H. Huang, Y. Lifshitz, S.-T. Lee, J. Zhong, Y. Liu, Z. Kang Z., Appl. Catal. B 2018, 237, 166-174.

[13] Y. Li, H. Xu, S. Ouyang, J. Ye, Phys. Chem. Chem. Phys 2016, 18,7563-7572.

[14] T. Zhang, W. Lin, Chem. Soc. Rev. 2014, 43, 5982-5993.

[15] J.-L. Wang, C. Wang, W. Lin, ACS Catal. 2012, 2, 2630-2640.

[16] A. Dhakshinamoorthy, A. M. Asiri, H. Garcia, Angew. Chem. Int. Ed. 2016, 55, 5414-5445.

[17] A. Dhakshinamoorthy, Z. Li, H. Garcia, Chem. Soc. Rev. 2018, 47, 8134-8172.

[18] M. Wen, K. Mori, Y. Kuwahara, T. An, H. Yamashita, Chem. Asian J. 2018, 13, 1767-1779.

[19] J. L. Rowsell, O. M. Yaghi, Microporous Mesoporous Mater. 2004, 73, 3-14.

[20] J. R. Long, O. M. Yaghi, Chem. Soc. Rev. 2009, 38, 1213-1214.

[21] L J. Lee, O. K. Farha, J. Roberts, K. A. Scheidt, S. T. Nguyen, J. T. Hupp, Chem. Soc. Rev. 2009, 38, 1450-1459.

[22] R. Matsuda, R. Kitaura, S. Kitagawa, Y. Kubota, R. V. Belosludov, T. C. Kobayashi, H. Sakamoto, T. Chiba, M. Takata, Y. Kawazoe, Nature 2005, 436, 238.

[23] A. K. Cheetham, G. Férey, T. Loiseau, Angew. Chem. Int. Ed. 1999, 38, 3268-3292.

[24] H. Li, M. Eddaoudi, M. O'Keeffe, O. M. Yaghi, Nature 1999, 402, 276.

[25] Y. Liu, Z. Liu, D. Huang, M. Cheng, G. Zeng, C. Lai, C. Zhang, C. Zhou, W. Wang, D. Jiang, H. Wang, B. Shao, Coord. Chem. Rev. 2019, 388, 63-78.

[26] J. Qiu, X. Zhang, Y. Feng, X. Zhang, H. Wang, J. Yao, Appl. Catal. B 2018, 231, 317-342.

[27] C. Gomes Silva, I. Luz, F. X. Llabrés i Xamena, A. Corma, H. García, Chem. Eur. J. 2010, 16, 11133-11138.

[28] Y. Horiuchi, T. Toyao, M. Saito, K. Mochizuki, M. Iwata, H. Higashimura, M. Anpo, M. Matsuoka, Phys. Chem. C 2012, 116, 20848-20853.

[29] C. H. Hendon, D. Tiana, M. Fontecave, C. Sanchez, L. D'arras, C. Sassoye, L. Rozes, C. Mellot-Draznieks, A. Walsh, J. Am. Chem. Soc. 2013, 135, 10942-10945.

[30] M. Alvaro, E. Carbonell, B. Ferrer, F. X. Llabres i Xamena, H. Garcia, Chem. Eur. J. 2007, 13, 5106-5112.

[31] J. D. Xiao, Q. Shang, Y. Xiong, Q. Zhang, Y. Luo, S. H. Yu, H. L. Jiang, Angew. Chem. Int. Ed. 2016, 55, 9389-9393. 
[32] Y. Fu, D. Sun, Y. Chen, R. Huang, Z. Ding, X. Fu, Z. Li, Angew. Chem. Int. Ed. 2012, 51, 3364-3367.

[33] D. Sun, Y. Fu, W. Liu, L. Ye, D. Wang, L. Yang, X. Fu, Z. Li, Chem. Eur. J. 2013, 19, 14279-14285.

[34] X. Chen, S. Shen, L. Guo, S. S. Mao, Chem. Rev. 2010, 110, 6503-6570.

[35] C. Gomes Silva, R. Juárez, T. Marino, R. Molinari, H. García, J. Am. Chem. Soc. 2010, 133, 595-602.

[36] K. Maeda, A. Xiong, T. Yoshinaga, T. Ikeda, N. Sakamoto, T. Hisatomi, M. Takashima, D. Lu, M. Kanehara, T. Setoyama, Angew. Chem. Int. Ed. 2010, 49, 4096- 4099.

[37] C. G. Silva, Y. Bouizi, V. Fornés, H. García, J. Am. Chem. Soc. 2009, 131, 13833-13839.

[38] K. Meyer, M. Ranocchiari, J. A. van Bokhoven, Energy Environ. Sci. 2015, 8, 1923-1937.

[39] Y. An, B. Xu, Y. Liu, Z. Wang, P. Wang, Y. Dai, X. Qin, X. Zhang, B. Huang, ChemistryOpen 2017, 6, 701-705.

[40] Y. An, Y. Liu, P. An, J. Dong, B. Xu, Y. Dai, X. Qin, X. Zhang, M. H. Whangbo, B. Huang, Angew. Chem. Int. Ed. 2017, 56, 3036-3040.

[41] M. A. Nasalevich, C. H. Hendon, J. G. Santaclara, K. Svane, B. van der Linden, S. L. Veber, M. V. Fedin, A. J. Houtepen, M. A. van der Veen, A. Walsh, J. Gascon, Sci. Rep. 2016, 6, 23676.

[42] M. A. Moreira, J. C. Santos, A. F. P. Ferreira, J. M. Loureiro, F. Ragon, P. Horcajada, P. G. Yot, C. Serre, A. E. Rodrigues, Microporous Mesoporous Mater. 2012, 158, 229-234.

[43] S. Daliran, A. Santiago-Portillo, S. Navalón, A. R. Oveisi, M. Álvaro, R. Ghorbani-Vaghei, D. Azarifar, H. García, J. Colloid Interface Sci. 2018, 532, 700-710.

[44] M. Dan-Hardi, C. Serre, T. Frot, L. Rozes, G. Maurin, C. Sanchez, G. Férey, J. Am. Chem. Soc. 2009, 131, 10857-10859.

[45] K. Wenderich, G. Mul, Chem. Rev. 2016, 116, 14587-14619.

[46] S. Vaesen, V. Guillerm, Q. Yang, A. D. Wiersum, B. Marszalek, B. Gil, A. Vimont, M. Daturi, T. Devic, P. L. Llewellyn, C. Serre, G. Maurin, G. De Weireld, Chem. Commun. 2013, 49, 10082-10084.

[47] H. Wang, X. Yan, Y. Wu, G. Zeng, X. Chen, L. Leng, Z. Wu, L. Jiang, H. Li, J. Hazard. Mater. 2015, 286, 187-194.

[48] L. Zhang, P. Cui, H. Yang, J. Chen, F. Xiao, Y. Guo, Y. Liu, W. Zhang, F. Huo, B. Liu, Adv. Sci. 2016, 3, 1500243.

[49] M. A. Nasalevich, C. H. Hendon, J. G. Santaclara, K. Svane, B. Van Der Linden, S. L. Veber, M. V. Fedin, A. J. Houtepen, M. A. Van Der Veen, F. Kapteijn, Sci. Rep. 2016, 6, 23676.

[50] M. de Miguel, F. Ragon, T. Devic, C. Serre, P. Horcajada, H. García, ChemPhysChem 2012, 13, 3651-3654.

[51] M. A. Nasalevich, R. Becker, E. V. Ramos-Fernandez, S. Castellanos, S. L. Veber, M. V. Fedin, F. Kapteijn, J. N. H. Reek, J. I. van der Vlugt, J. Gascon, Energy Environ. Sci. Technol. 2015, 8, 364-375.

[52] C. H. Hendon, D. Tiana, M. Fontecave, C. Sanchez, L. D'arras, C. Sassoye, L. Rozes, C. Mellot-Draznieks, A. Walsh, J. Am. Chem. Soc. 2013, 135, 10942-10945.

[53] B. Zhu, R. Zou, Q. Xu, Adv. Energy. Mater. 2018, 8, 1801193. 
[54] S. Kampouri, T. N. Nguyen, C. P. Ireland, B. Valizadeh, F. M. Ebrahim, G. Capano, D. Ongari, A. Mace, N. Guijarro, K. Sivula, A. Sienkiewicz, L. Forro, B. Smit, K. C. Stylianou, J. Mater. Chem. A 2018, 6, 2476-2481.

[55] J. Yang, D. Wang, H. Han, C. Li, Acc. Chem. Res. 2013, 46, 1900-1909.

[56] J. Han, D. Wang, Y. Du, S. Xi, J. Hong, S. Yin, Z. Chen, T. Zhou, R. Xu, J. Mater. Chem. A 2015, 3, 20607-20613.

[57] G.R. Bamwenda, T. Uesigi, Y. Abe, K. Sayama, H. Arakawa, Appl. Catal. A Gen. 2001, 205, 117-128.

[58] M. Wen, G. Li, H. Liu, J. Chen, T. An, H. Yamashita, Environ. Sci. Nano 2019, 6, 1006-1025. 


\subsection{Supporting information}

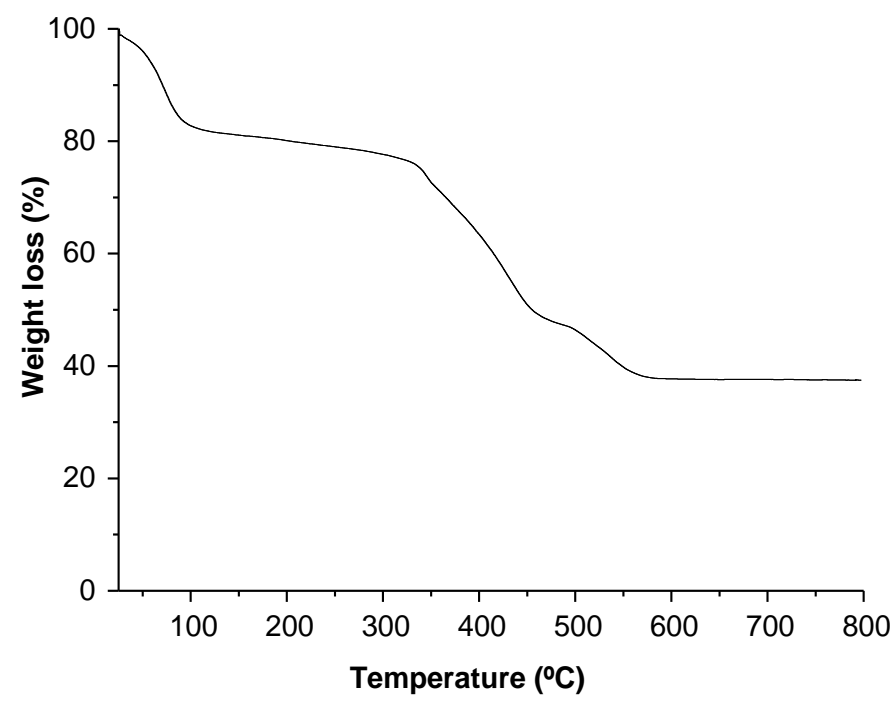

Figure S1. Thermogravimetric analysis of the MIL-125(Ti)- $\mathrm{NH}_{2}$ sample.

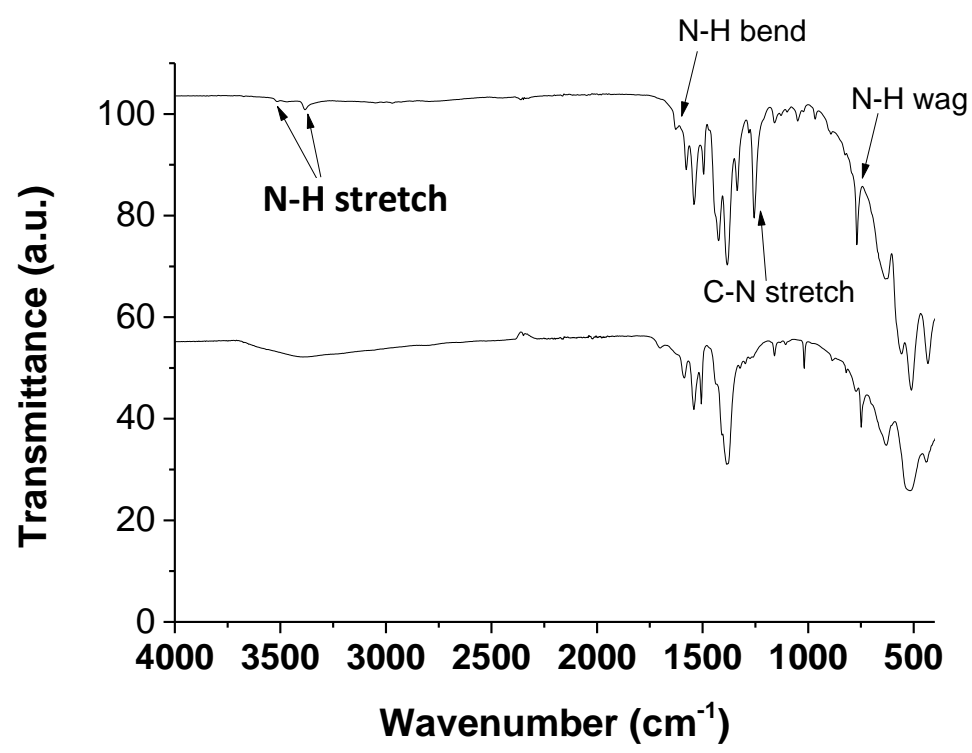

Figure S2. FT-IR spectra of MIL-125(Ti)- $\mathrm{NH}_{2}$ and MIL-125(Ti). The characteristic vibrations due to the presence of the amino group in the terephthalic organic ligand are indicated. 


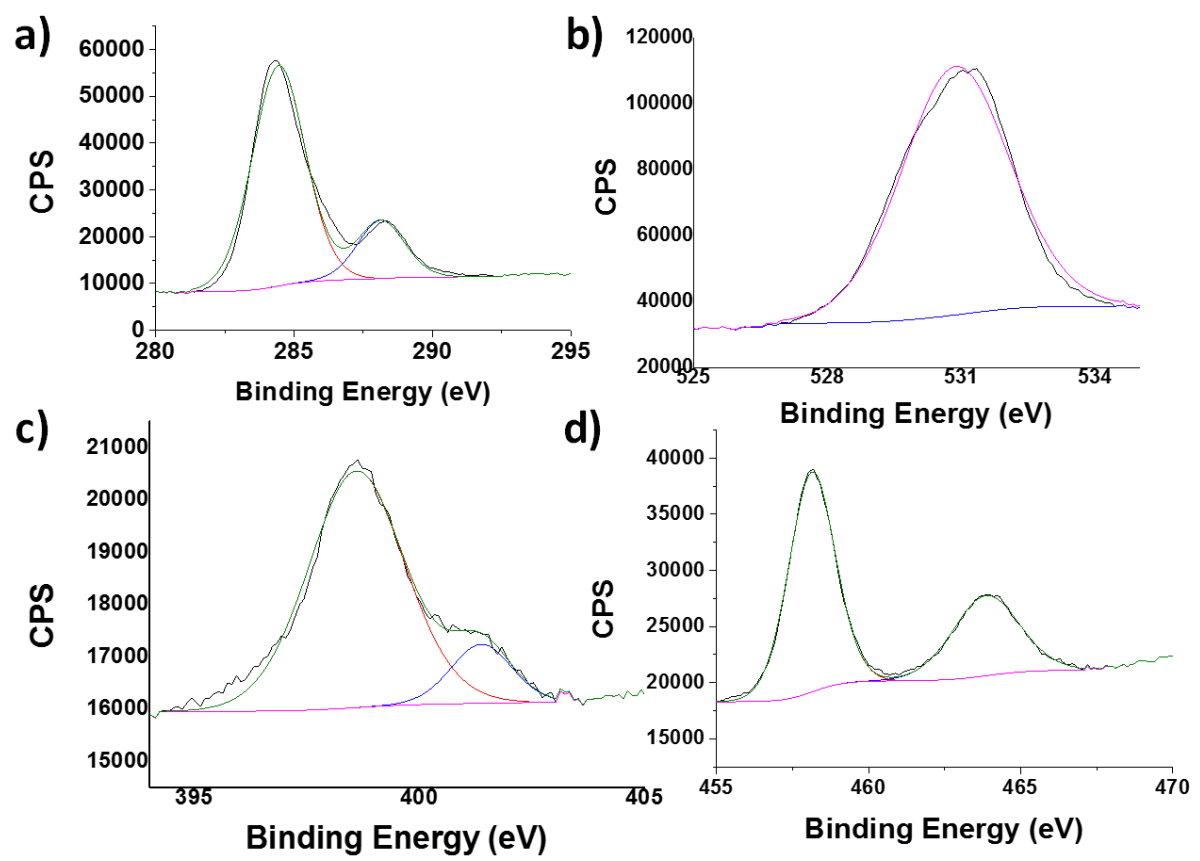

Figure S3. XPS spectra of MIL-125(Ti)-NH $\mathrm{NH}_{2}$ sample. Legend: C1s (a), O1s (b), N1s (c), Ti2p (d)

a)

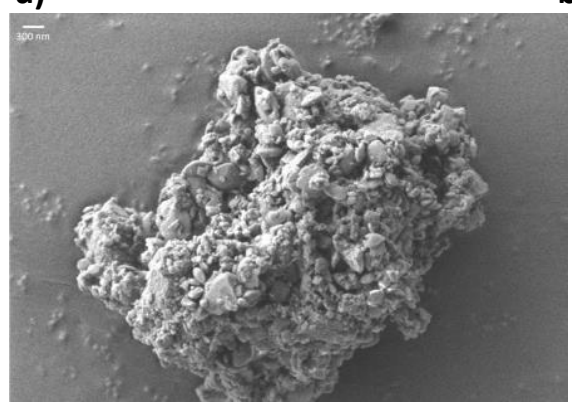

b)

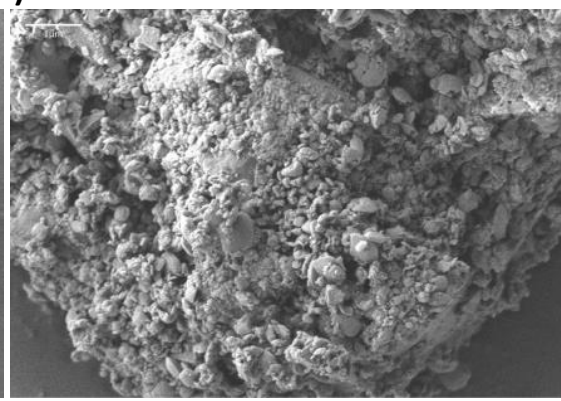

Figure S4. SEM images of MIL-125(Ti)- $\mathrm{NH}_{2}$ (a) and MIL-125(Ti) (b). 

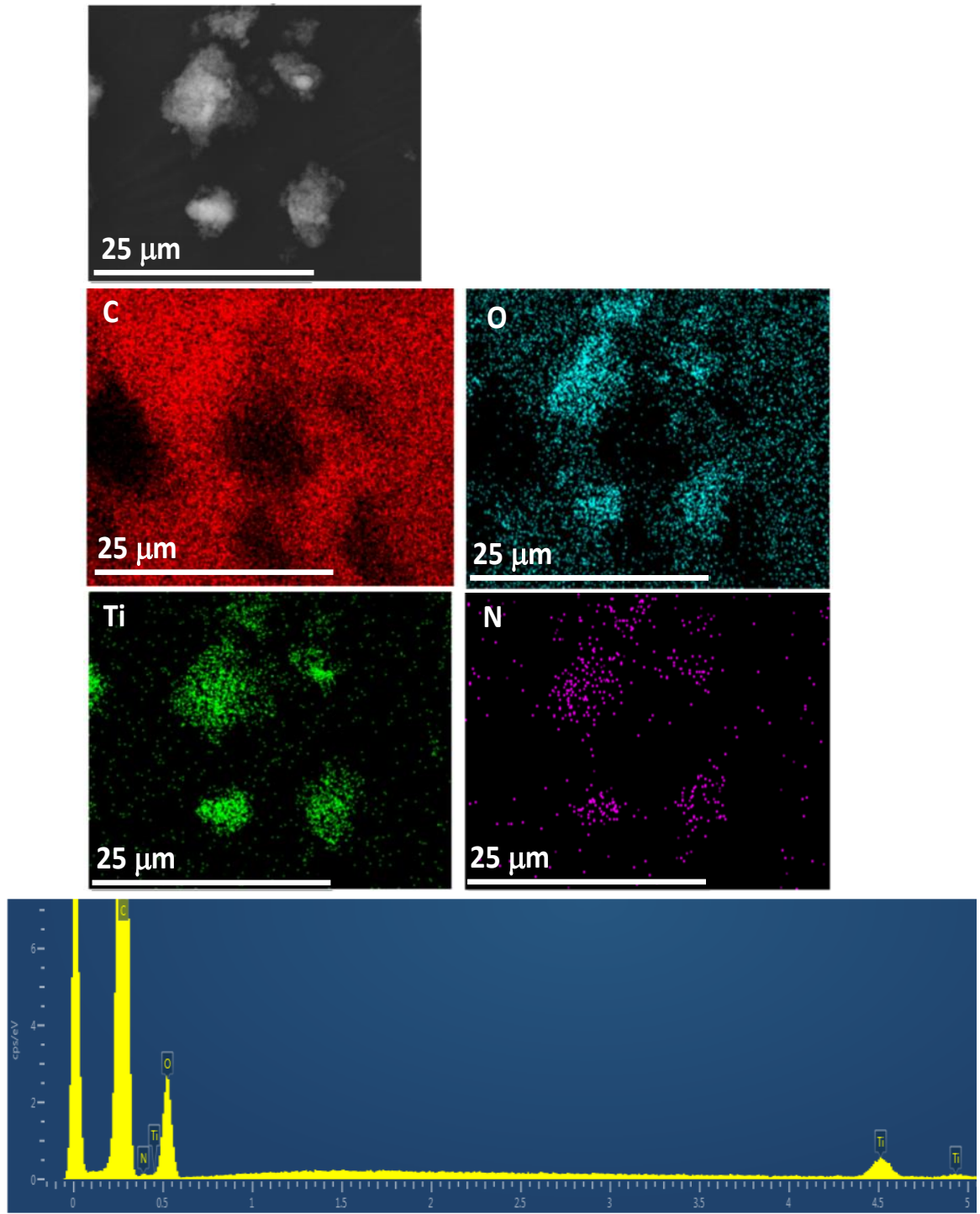

Figure S5. SEM image, EDX mapping analysis of the elements present in the MIL-125(Ti)- $\mathrm{NH}_{2}$ sample and EDX spectrum. 

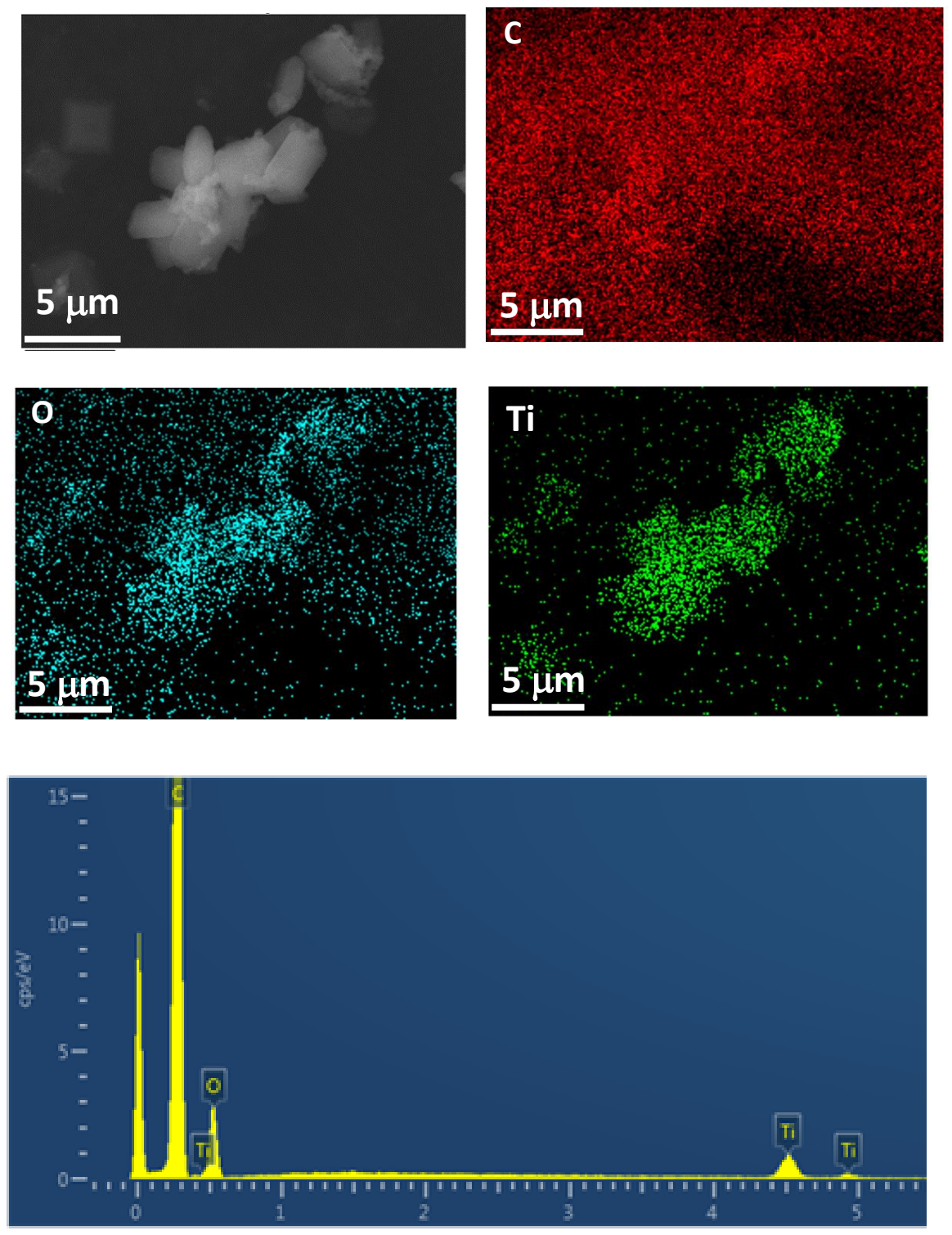

Figure S6. SEM image, EDX mapping analysis of the elements present in the MIL-125(Ti) sample and EDX spectrum. 
a)
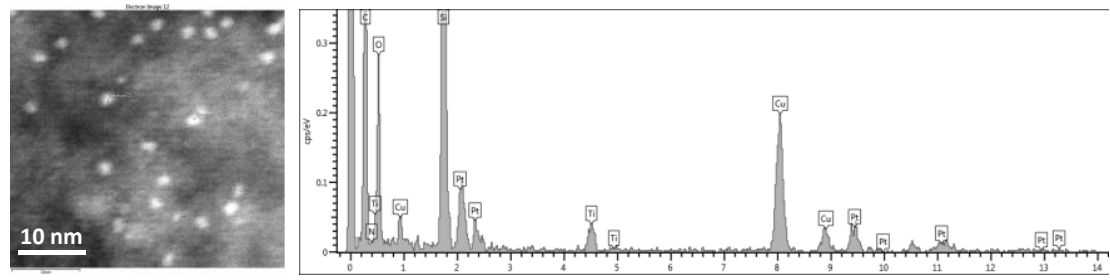

b)

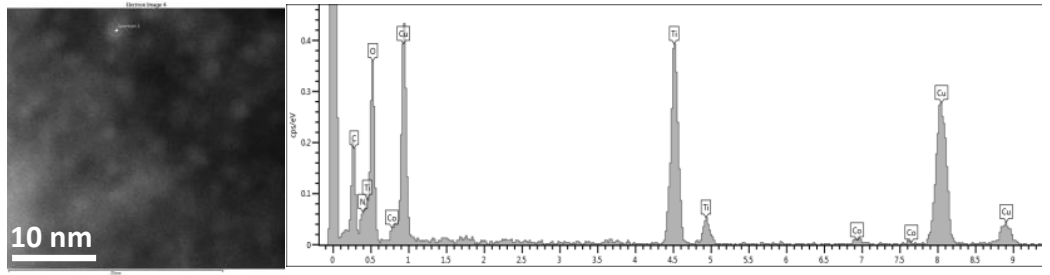

c)
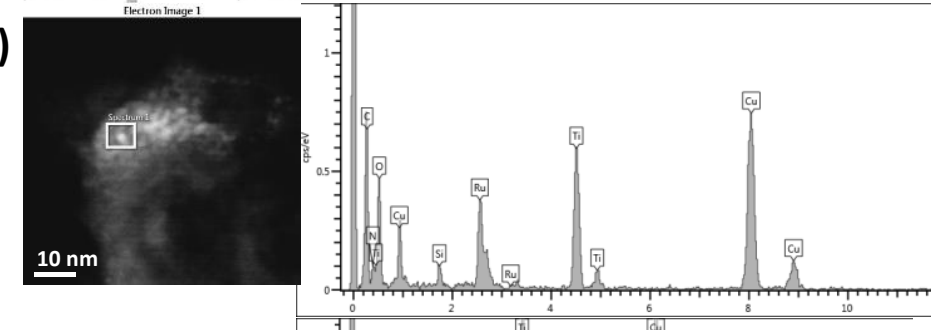

d)

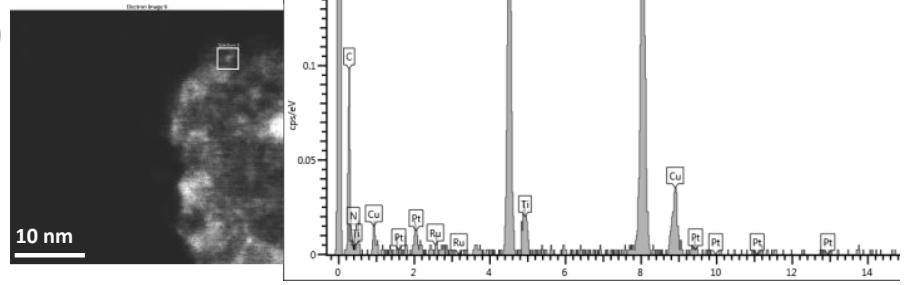

e)
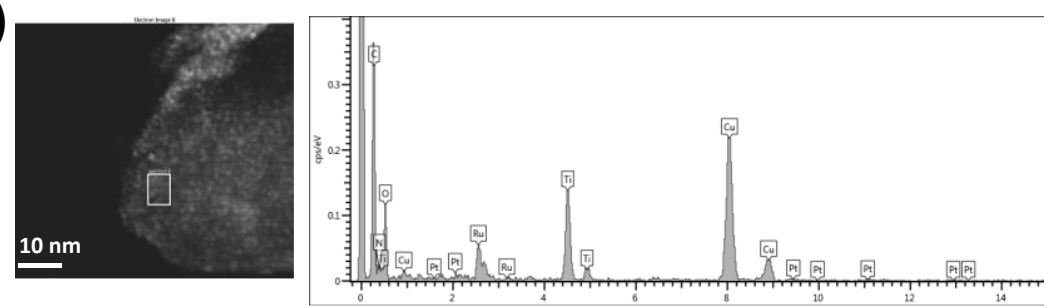

Figure S7. DF-STEM images and EDX analysis of selected areas of the fresh Pt-MIL-125(Ti)-NH (a), $\mathrm{CoO}_{x}-\mathrm{MIL}-125(\mathrm{Ti})-\mathrm{NH}_{2}$ (b), $\mathrm{RuO}_{x}-\mathrm{MIL}-125(\mathrm{Ti})-\mathrm{NH}_{2}$ (c) and Pt-RuO ${ }_{x}-\mathrm{MIL}-125(\mathrm{Ti})-\mathrm{NH}_{2}$ (d, e) photocatalysts. 

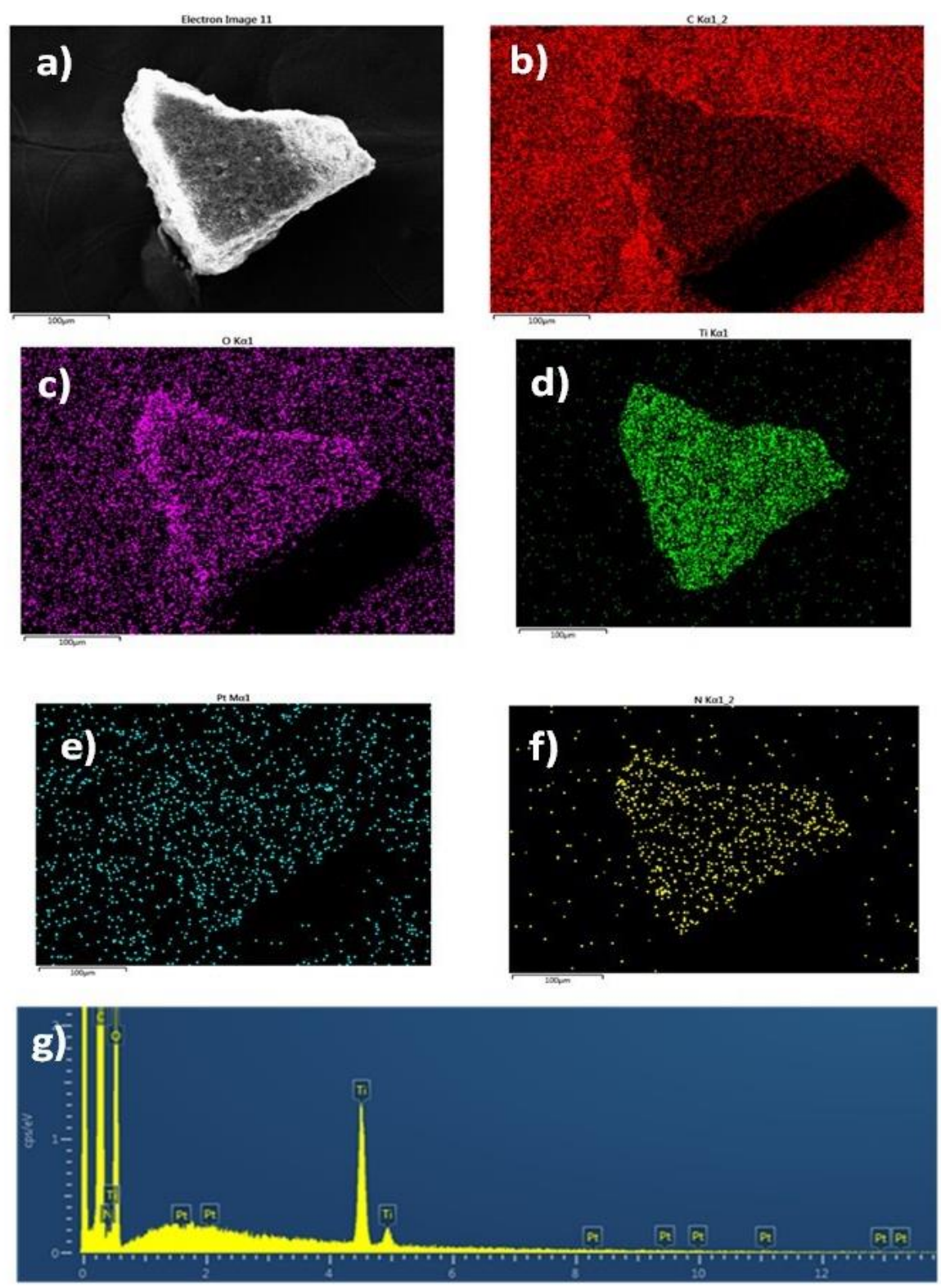

Figure S8. SEM image (a), EDX mapping analysis (b-f) and EDX spectrum (g) of a representative area of the Pt-MIL-125(Ti)-NH $\mathrm{NH}_{2}$ sample. 

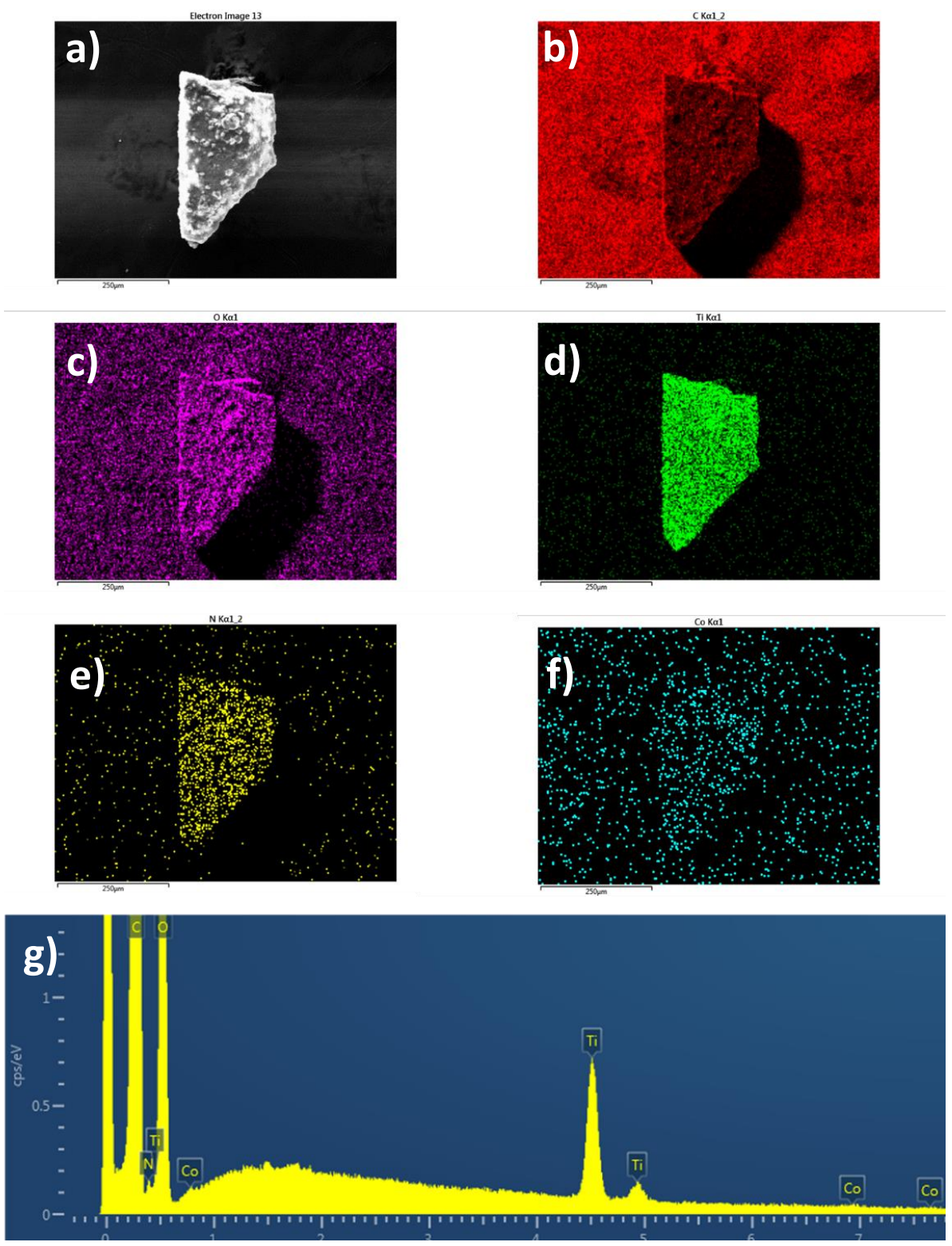

Figure S9. SEM image (a), EDX mapping analysis (b-f) and EDX spectrum (g) of a representative area of the $\mathrm{CoO}_{x}-\mathrm{MIL}-125$ (Ti)- $\mathrm{NH}_{2}$ sample. 

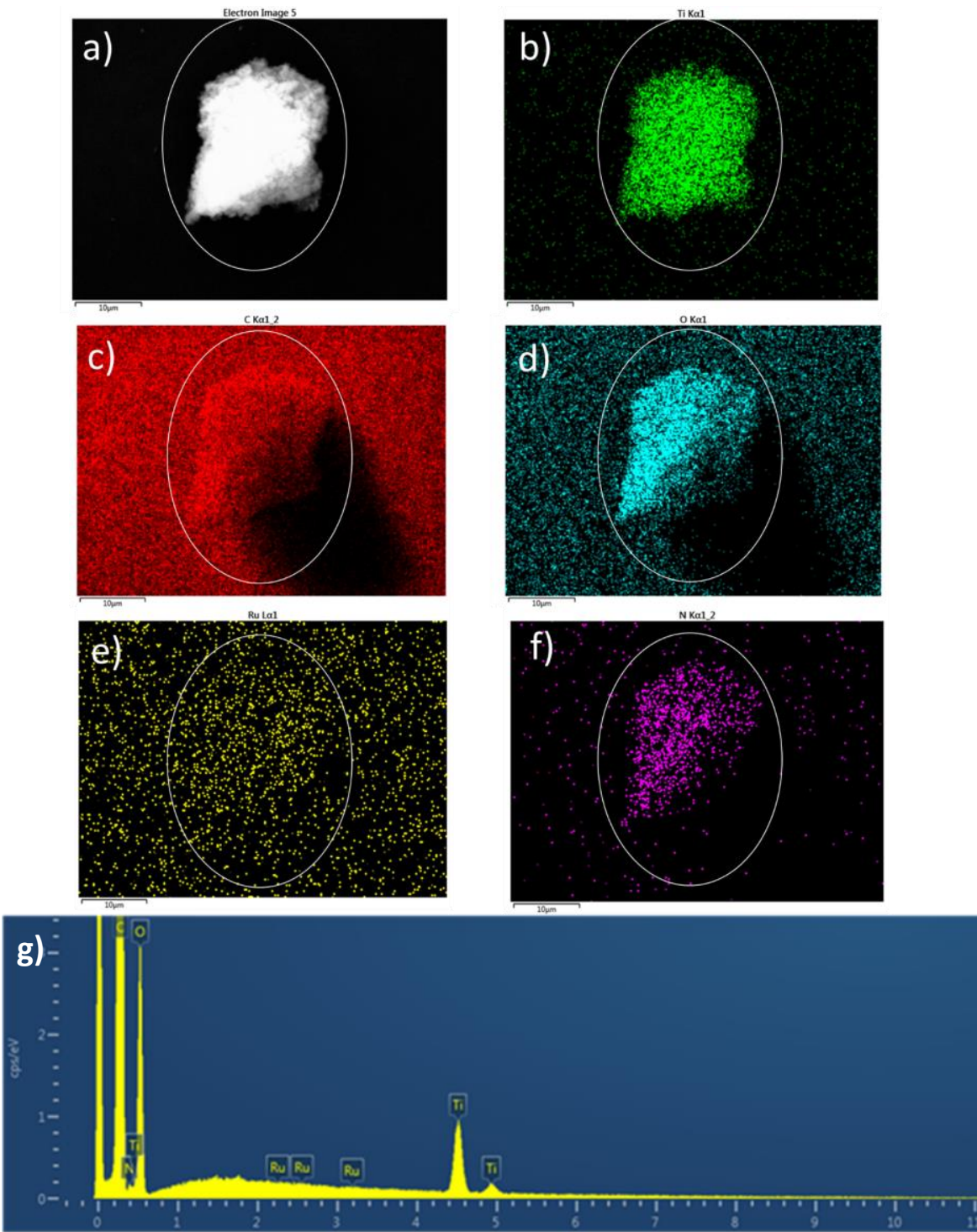

Figure S10. SEM image (a), EDX mapping analysis (b-f) and EDX spectrum (g) of a representative area of the $\mathrm{RuO}_{x}-\mathrm{MIL}-125(\mathrm{Ti})-\mathrm{NH}_{2}$ sample. 


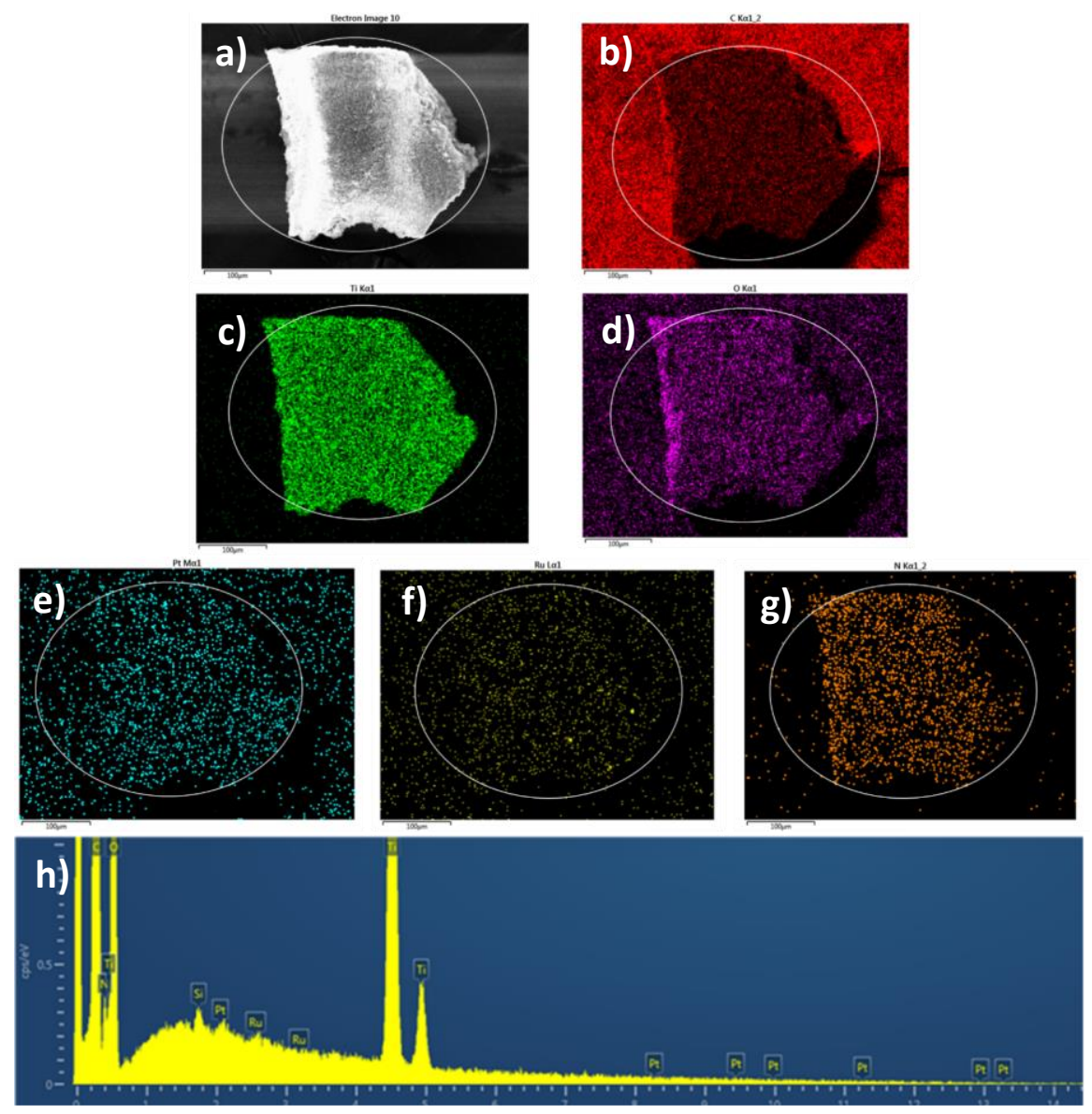

Figure S11. SEM image (a), EDX mapping (b-g) analysis and EDX spectrum (h) of a representative area of the $\mathrm{Pt}-\mathrm{RuO}_{\mathrm{x}}-\mathrm{MIL}-125(\mathrm{Ti})-\mathrm{NH}_{2}$ sample. 

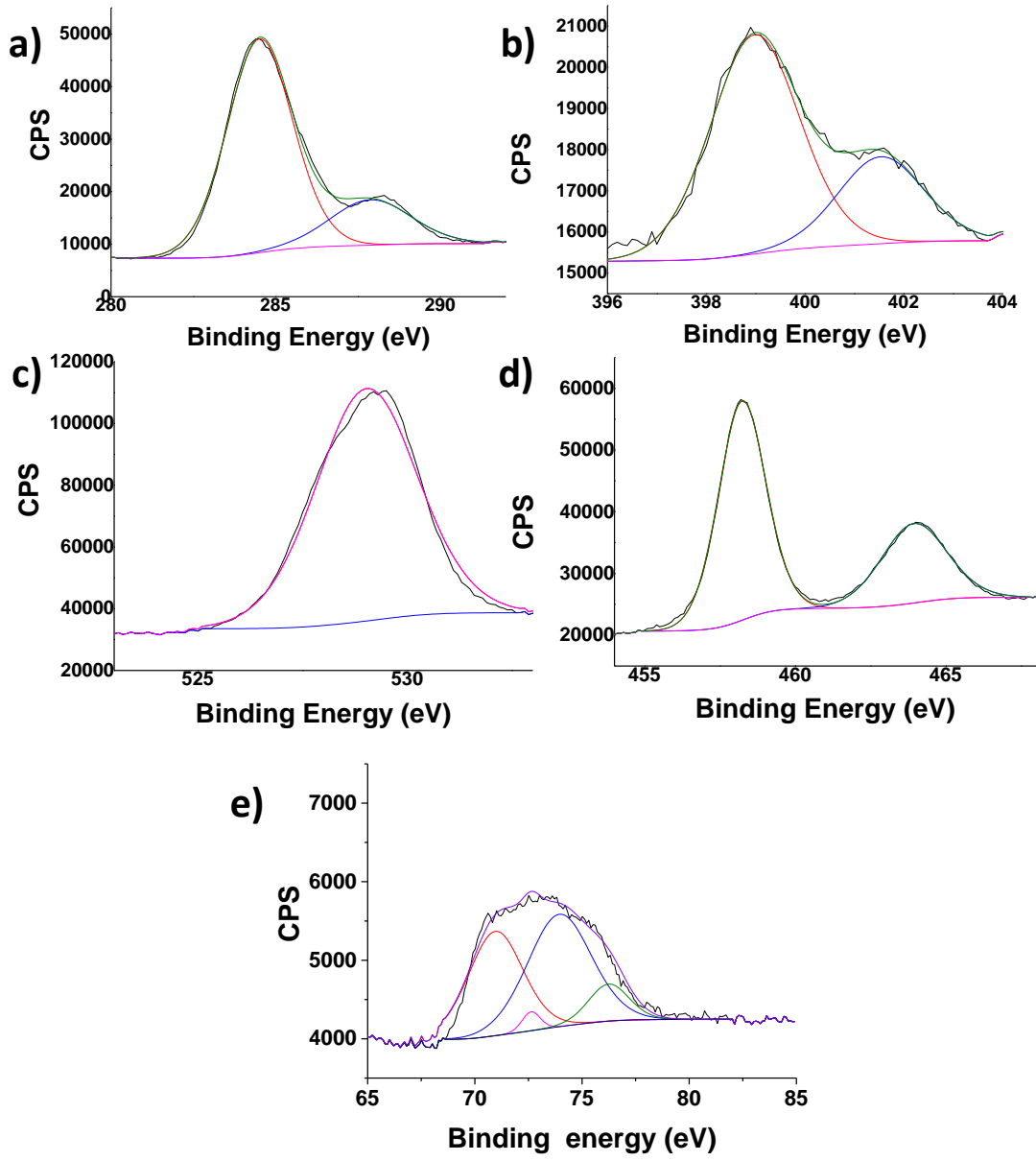

Figure S12. High resolution XPS peaks recorded for the Pt-MIL-125(Ti)-NH $\mathrm{NH}_{2}$ sample and the best deconvolution of the C1s (a), O1s (b), N1s (c), Ti2p (d) and Pt4f (e) peaks. 


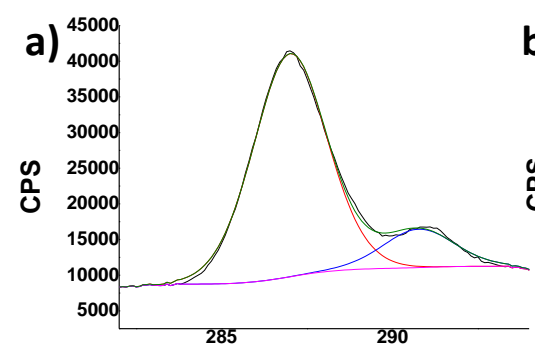

Binding Energy (eV)
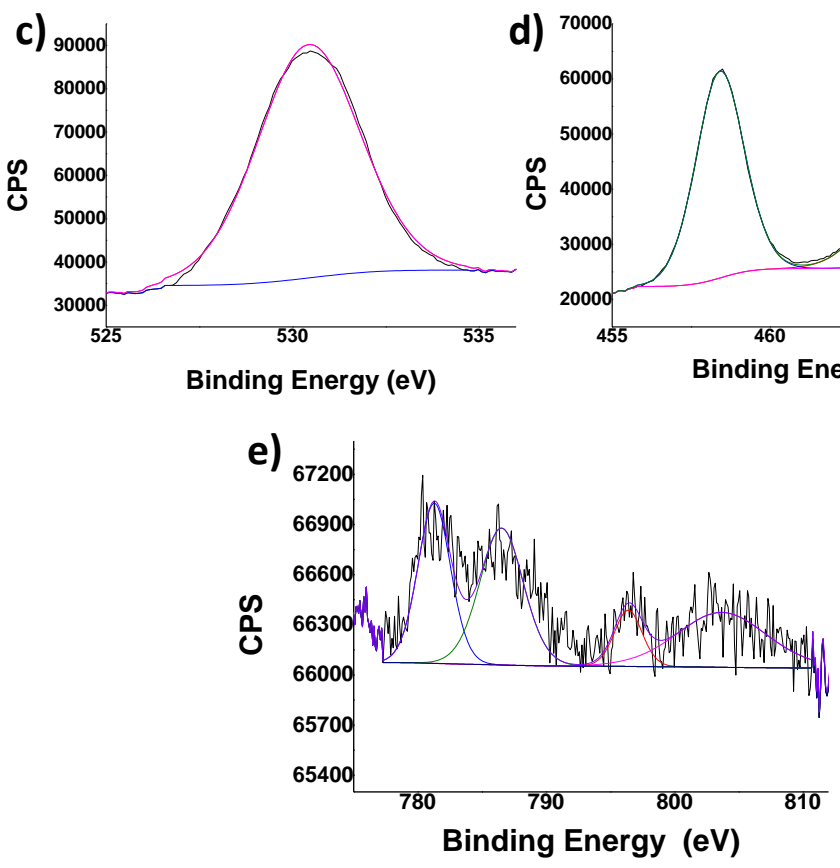

Figure S13. High resolution XPS peaks recorded for the $\mathrm{CoO}_{x}-\mathrm{MIL}-125(\mathrm{Ti})-\mathrm{NH}_{2}$ sample and the best deconvolution of the C1s (a), O1s (b), N1s (c), Ti2p (d) and Co2p (e) peaks. 

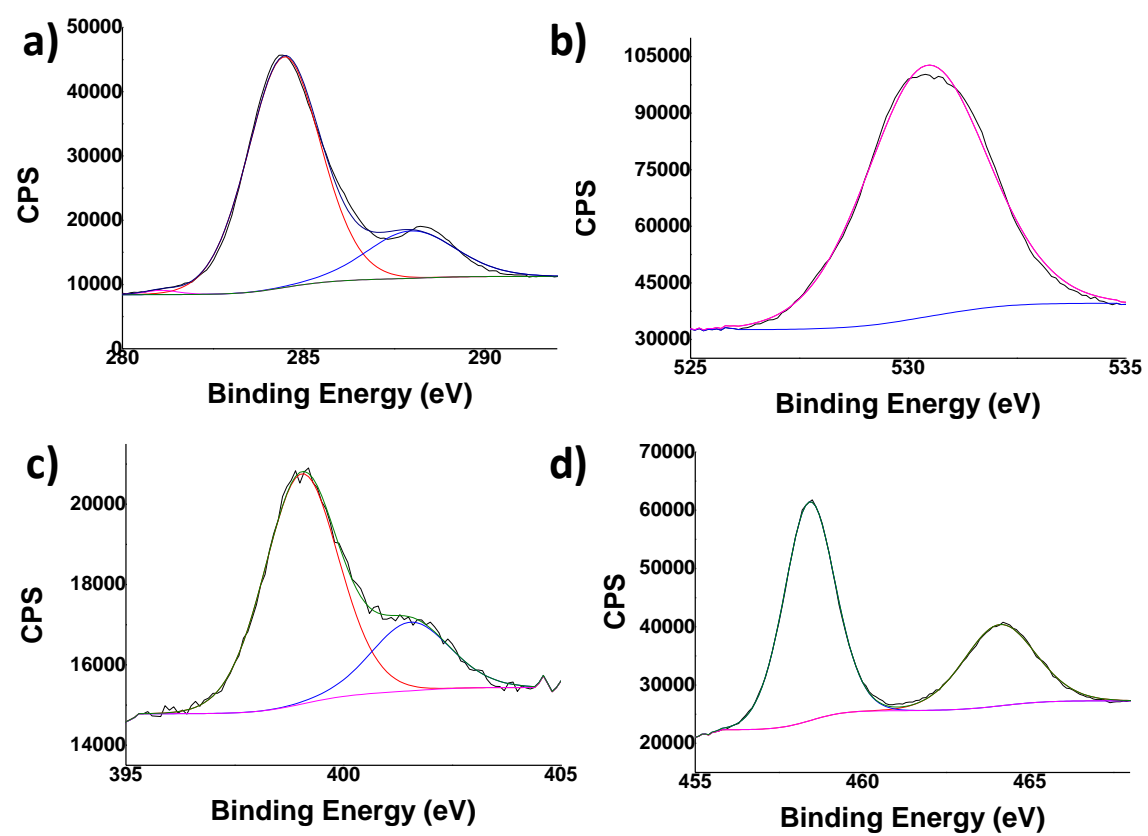

Figure S14. High resolution XPS peaks recorded for the $\mathrm{RuO}_{\mathrm{x}}-\mathrm{MIL}-125(\mathrm{Ti})-\mathrm{NH}_{2}$ sample and the best deconvolution of the C1s (a), O1s (b), N1s (c) and Ti2p (d). Note that Ru3d signal overlaps with that of $\mathrm{C} 1 \mathrm{~h}$ but the small content does not allow to distinguish it in panel a). 

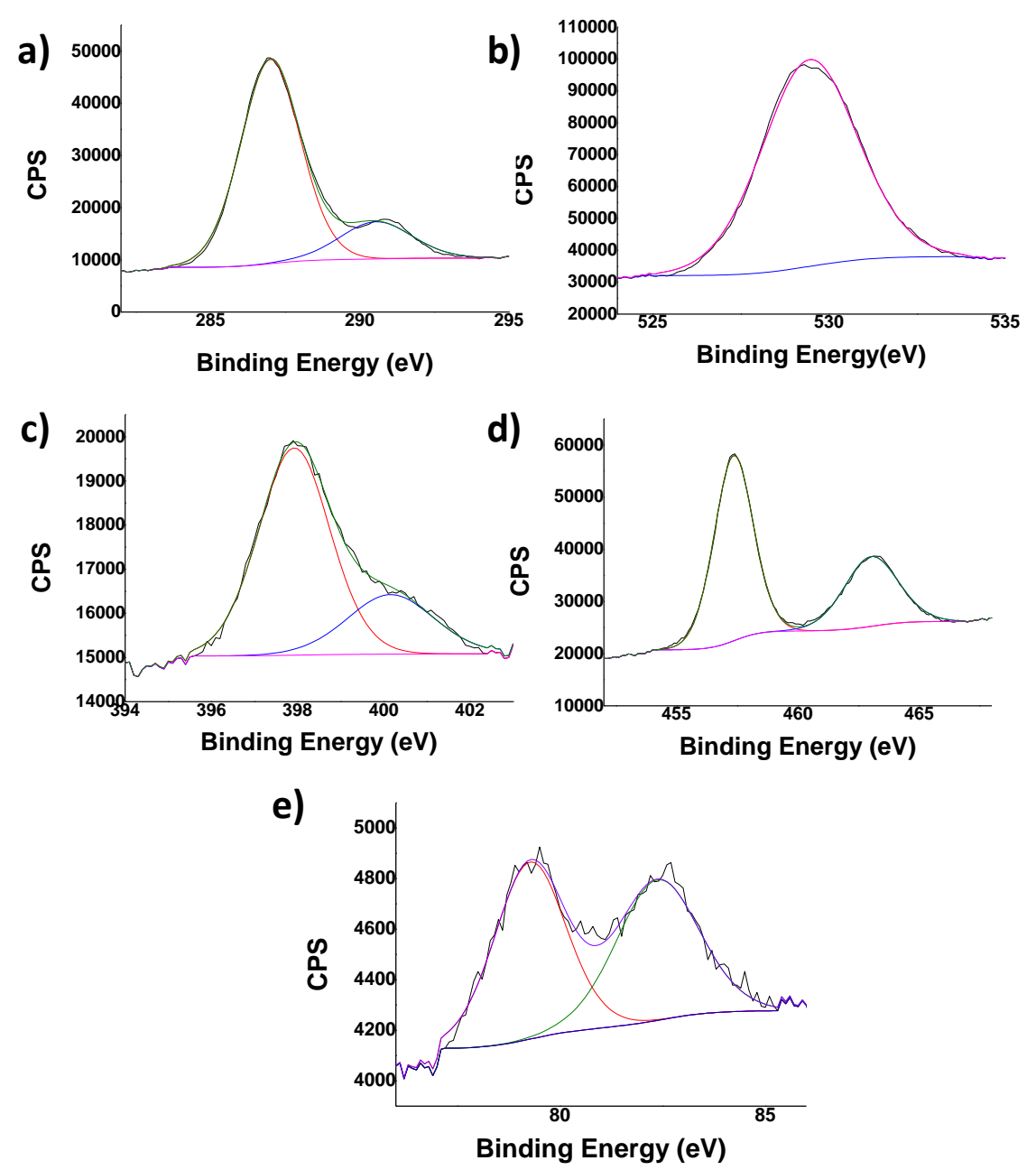

Figure S15. High resolution XPS peaks recorded for the Pt-RuO ${ }_{x}-\mathrm{MIL}-125(\mathrm{Ti})-\mathrm{NH}_{2}$ sample and the best deconvolution of the C1s (a), O1s (b), N1s (c), Ti2p (d) and Pt4f (e). Note that Ru 3d signal overlaps with that of $\mathrm{C} 1 \mathrm{~s}$ but the small content does not allow to distinguish it in panel a). 


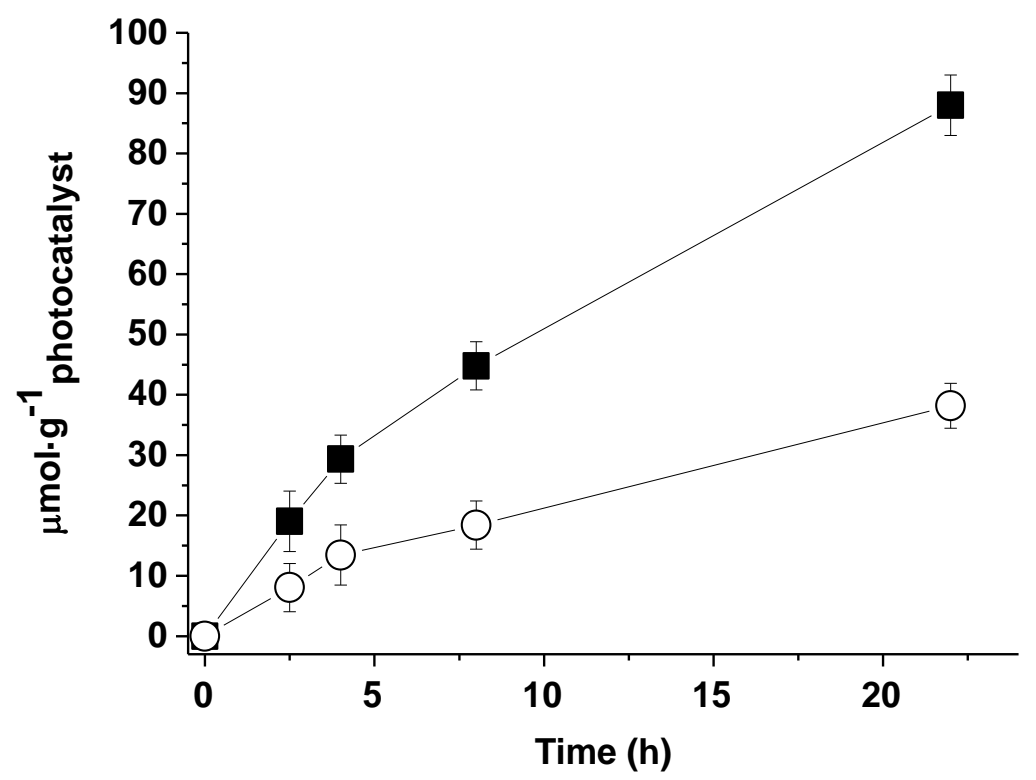

Figure S16. Overall water splitting using Pt-RuO $-\mathrm{MIL}-125(\mathrm{Ti})-\mathrm{NH}_{2}$ as photocatalyst working at $10{ }^{\circ} \mathrm{C}$. Reaction conditions: Photocatalyst $\left(20 \mathrm{mg} / 20 \mathrm{~mL}\right.$ Milli Q $\left.-\mathrm{H}_{2} \mathrm{O}\right)$, UV-Vis Xe lamp $\left(150 \mathrm{~mW} \times \mathrm{cm}^{-2}\right)$, reaction temperature $10^{\circ} \mathrm{C}$. 


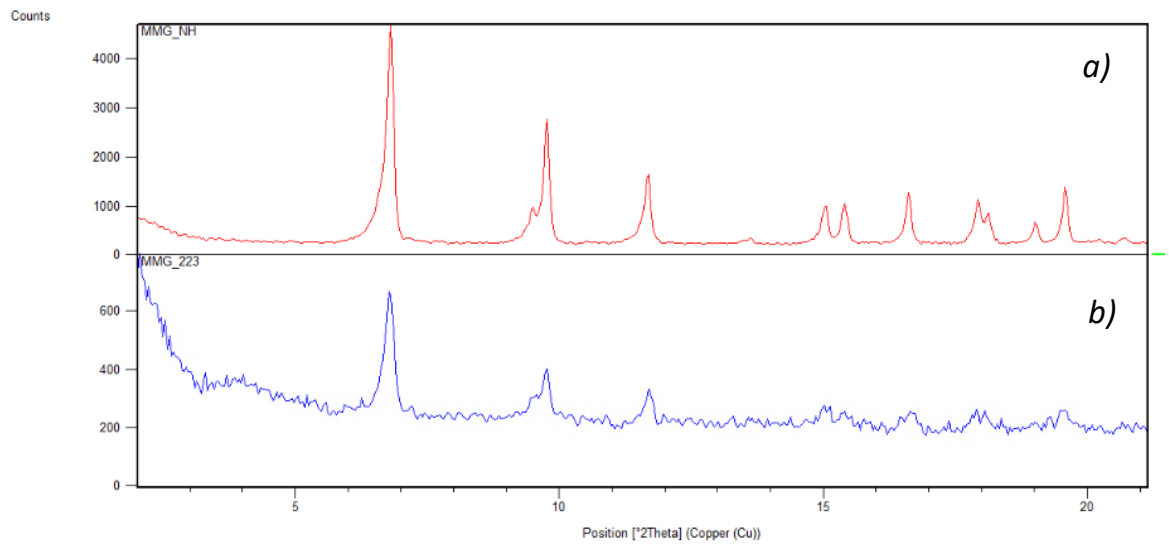

Figure S17. XRD of MIL-125(Ti)- $\mathrm{NH}_{2}$ photocatalyst before (a) and after (b) an overall water splitting experiment.

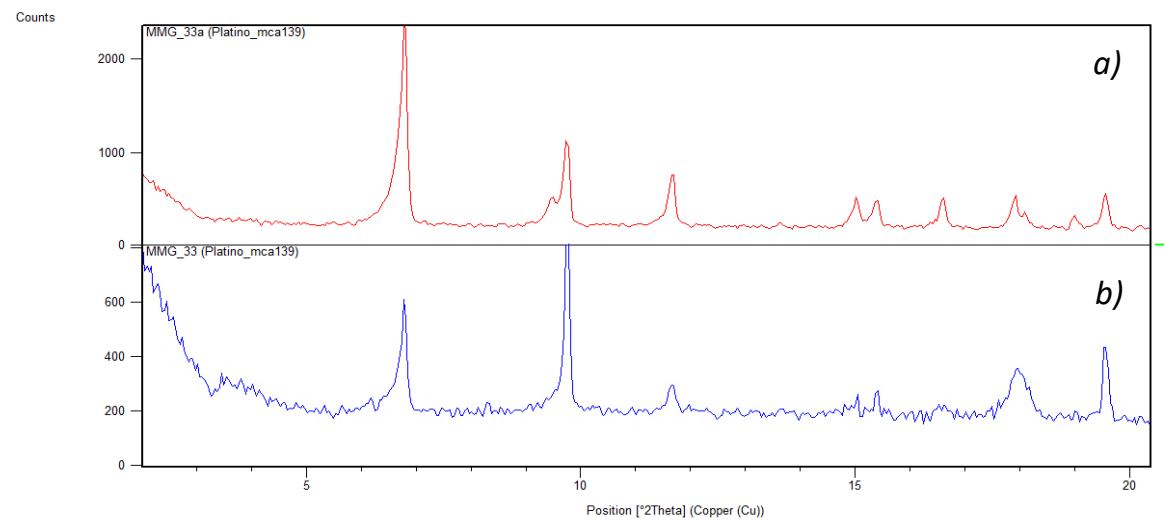

Figure S18. XRD of Pt-MIL-125(Ti)-NH $\mathrm{NH}_{2}$ photocatalyst before (a) and after (b) an overall water splitting experiment. 


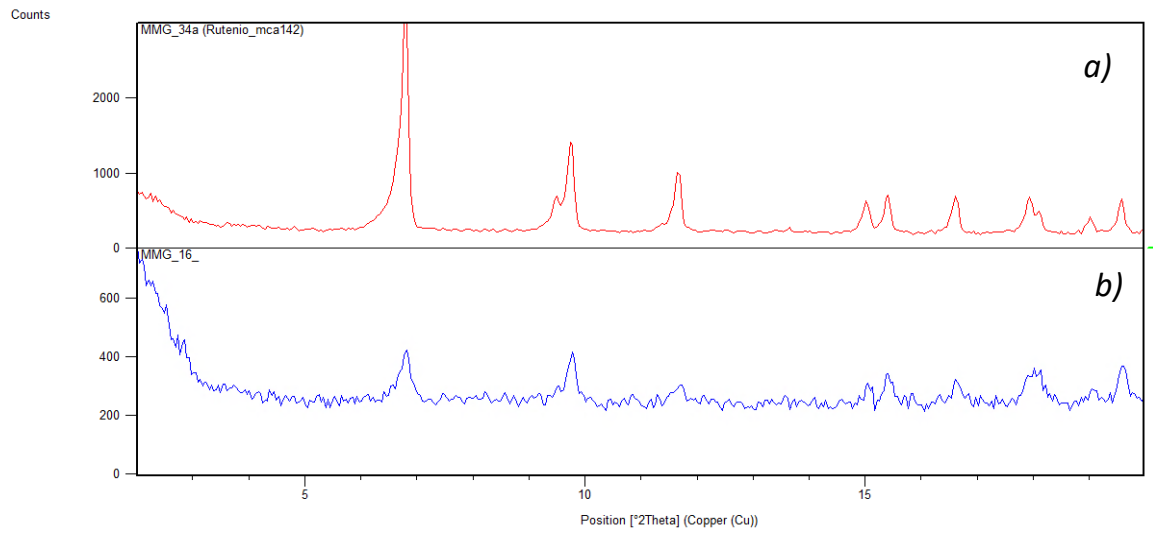

Figure S19. XRD of $\mathrm{RuO}_{\mathrm{x}}-\mathrm{MIL}-125(\mathrm{Ti})-\mathrm{NH}_{2}$ photocatalyst before (a) and after (b) an overall water splitting experiment.

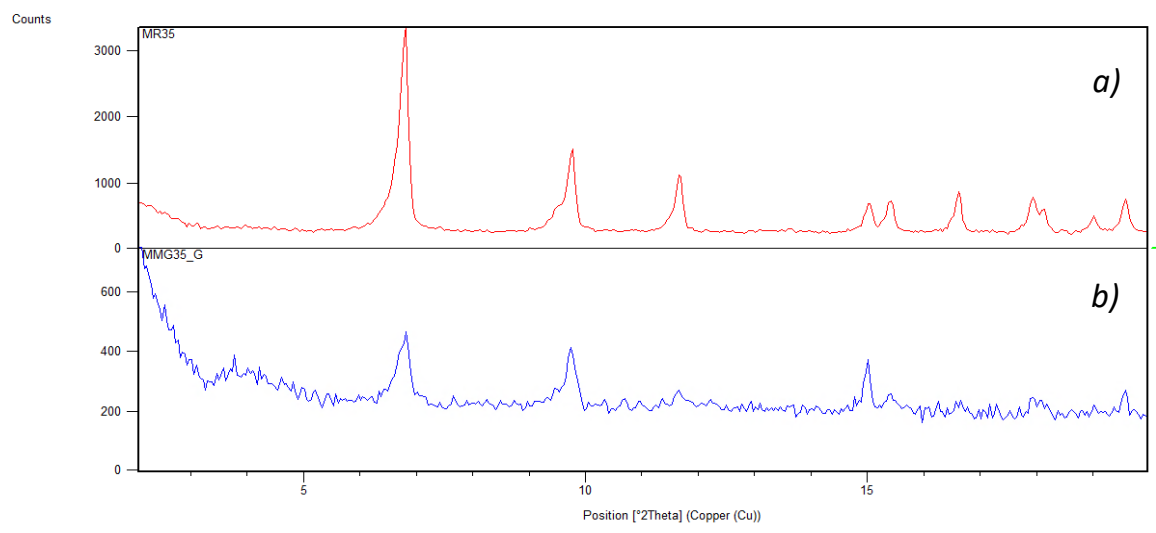

Figure S20. XRD of $\mathrm{CoO}_{x}-\mathrm{MIL}-125(\mathrm{Ti})-\mathrm{NH}_{2}$ photocatalyst before (a) and after (b) an overall water splitting experiment. 


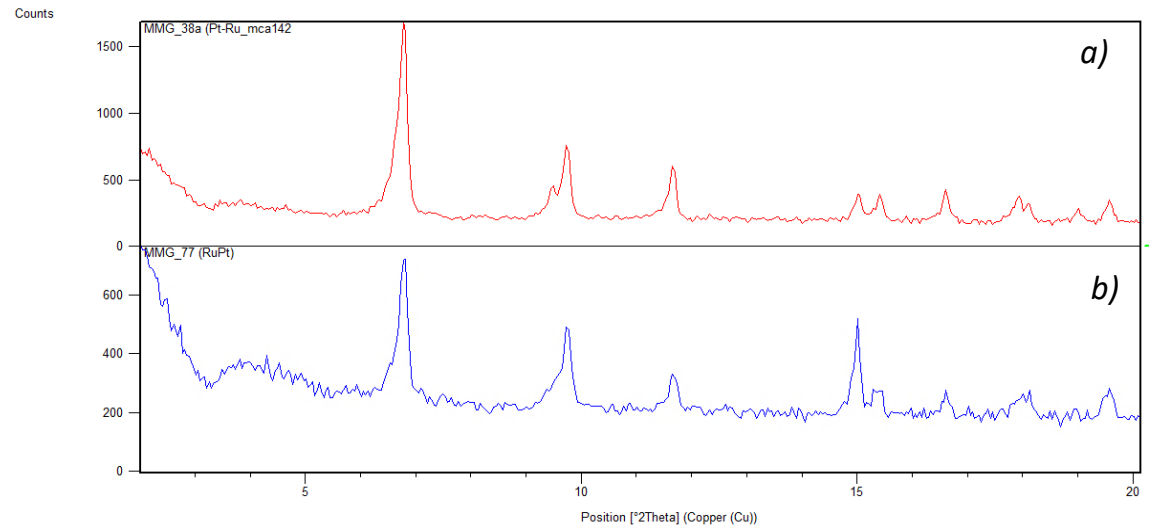

Figure S21. XRD of Pt-RuO $-\mathrm{MIL}-125(\mathrm{Ti})-\mathrm{NH}_{2}$ photocatalyst before (a) and after (b) an overall water splitting experiment. 
a)
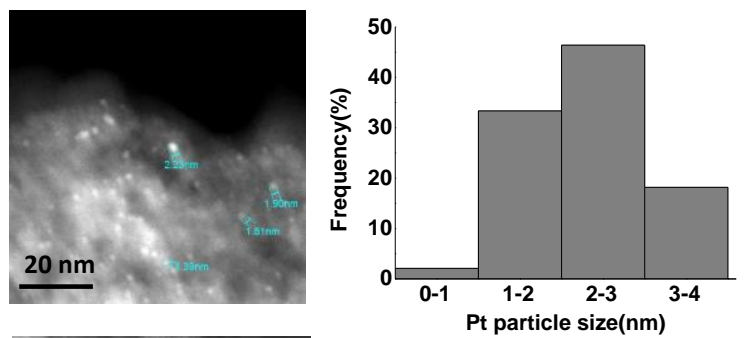

b)

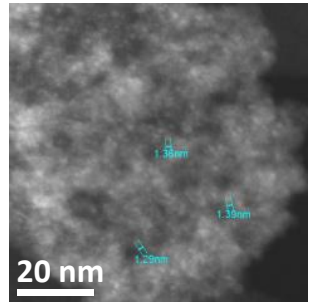

c)

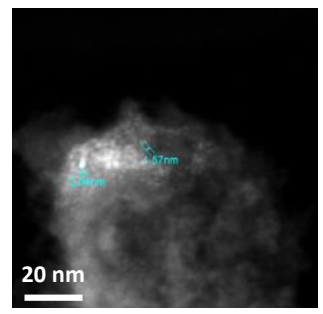

d)

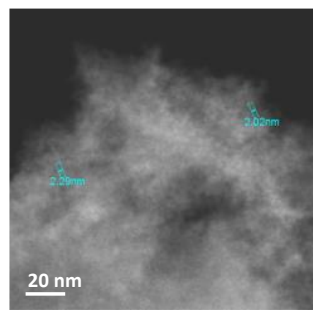

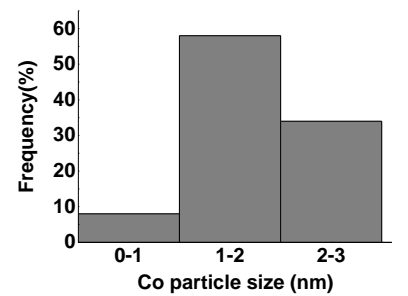
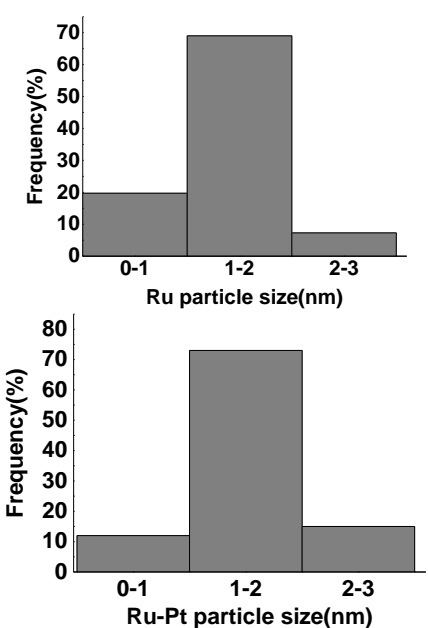
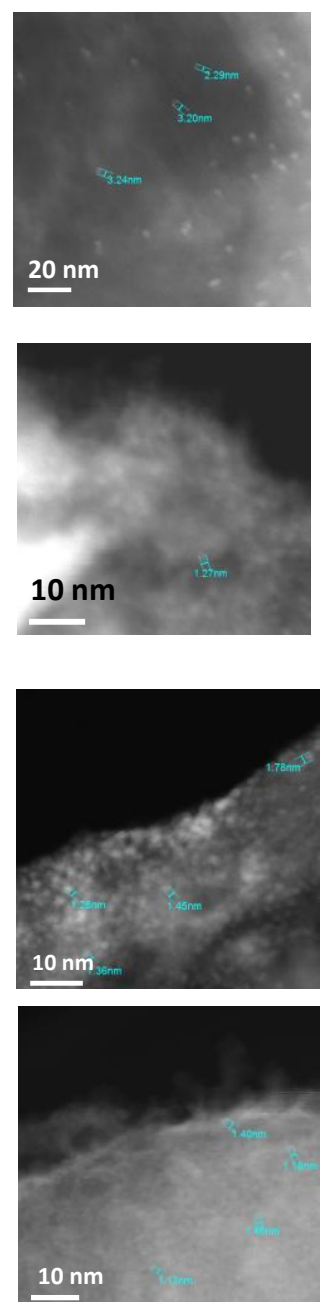

Figure S22. DF-STEM images and histograms of metal particle size distribution of Pt-MIL-125(Ti)-NH $\quad$ (a), $\quad \mathrm{CoO}_{x}-\mathrm{MIL}-125(\mathrm{Ti})-\mathrm{NH}_{2} \quad$ (b), $\mathrm{RuO}_{\mathrm{x}}-\mathrm{MIL}-125(\mathrm{Ti})-\mathrm{NH}_{2} \quad$ (c) and Pt-RuO ${ }_{x}-\mathrm{MIL}-125(\mathrm{Ti})-\mathrm{NH}_{2}$ (d) after $22 \mathrm{~h}$ irradiation for the overall water splitting. 

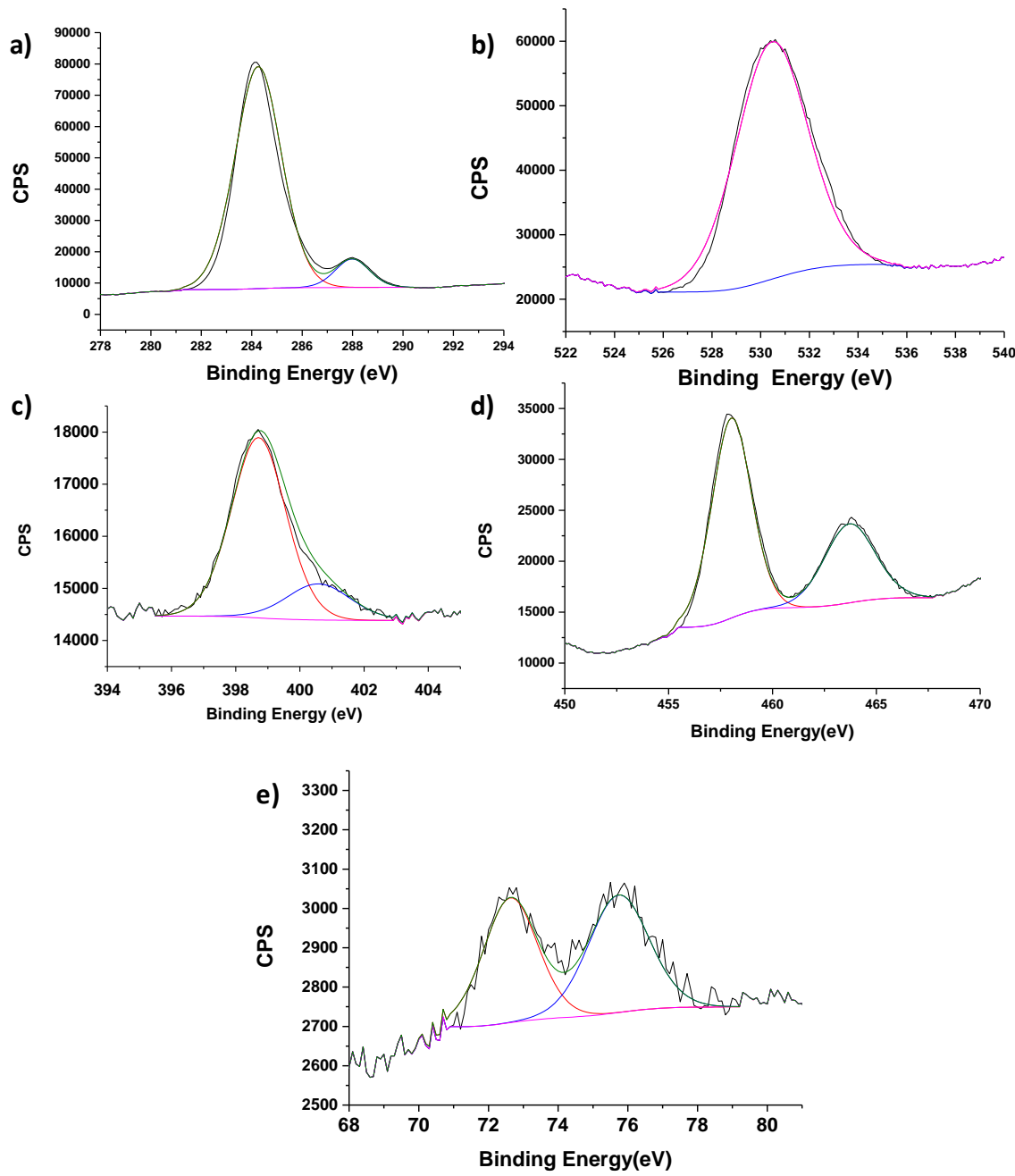

Figure S23. High resolution XPS peaks recorded for the used $\mathrm{RuO}_{\mathrm{x}}-\mathrm{MIL}-125$ (Ti)- $\mathrm{NH}_{2}$ sample and the best deconvolution of the C1s (a), O1s (b), N1s (c) and Ti2p (d). Note that Ru 3d signal overlaps with that of $\mathrm{C} 1 \mathrm{~h}$ but the small content does not allow to distinguish it in panel a). 

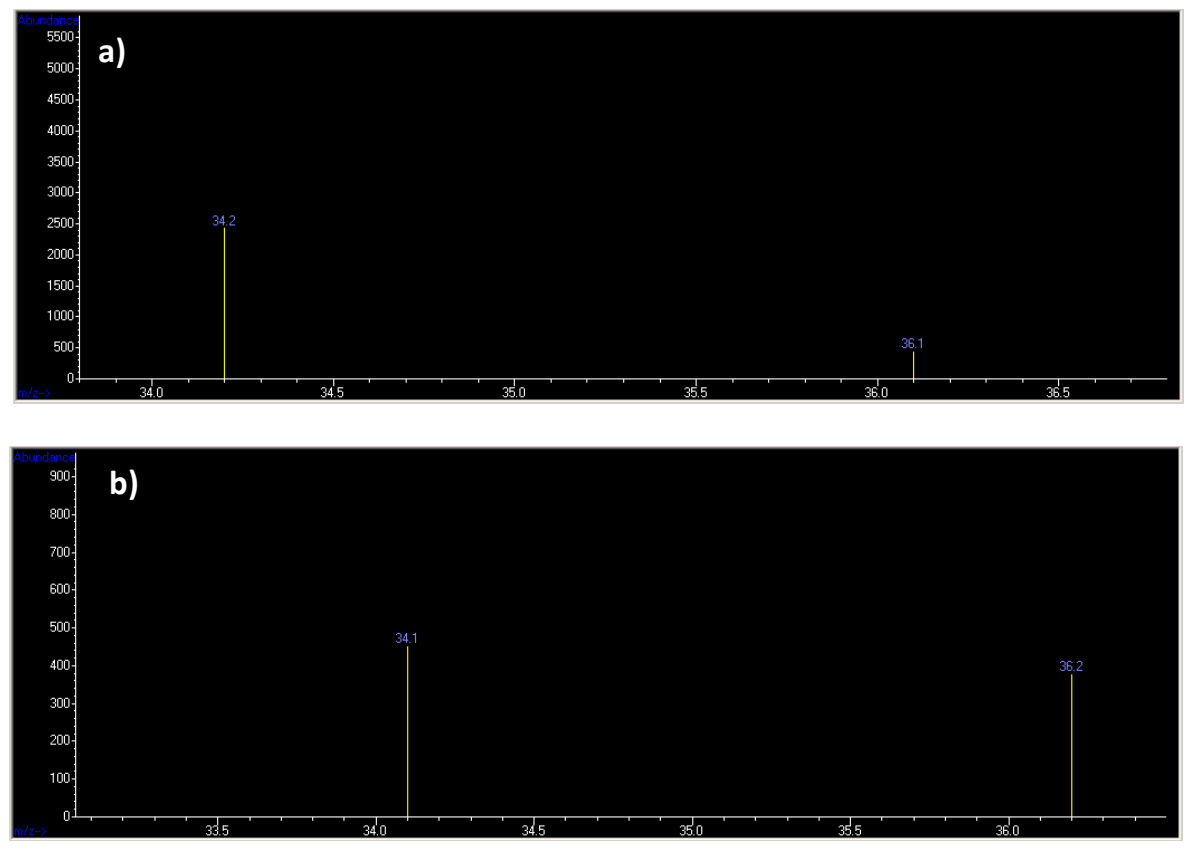

Figure S24. Comparison of the mass spectra recorded: a) before light irradiation, and b) after 1 day. Pt-RuO $2-\mathrm{MIL}-125$ (Ti)- $\mathrm{NH}_{2}$ (5 mg of photocatalyst in $500 \mu \mathrm{L}$ of $\mathrm{H}_{2}{ }^{18} \mathrm{O}$ ), UV-Vis Xe lamp as used as light source, gases were analyzed in a GC-MS, temperature $35^{\circ} \mathrm{C}$ (see experimental section 2.4.4.) 



\section{Chapter 4}

Plasma-induced defects enhance the visible-light photocatalytic activity of MIL-125(Ti)-NH $\mathrm{H}_{2}$ for overall water splitting 



\subsection{Abstract}

Defect engineering in metal-organic frameworks is commonly performed by using thermal or chemical treatments. Herein, it is reported that oxygen plasma treatment generates structural defects on MIL-125(Ti)- $\mathrm{NH}_{2}$ leading to an increase of its photocatalytic activity. Characterization data indicates that plasma-treated materials retain most of their initial crystallinity, while exhibiting somewhat lower surface area and pore volume. XPS and FT-IR spectroscopy reveal that oxygen plasma induces MIL-125(Ti)- $\mathrm{NH}_{2}$ partial terephthalate decarboxylation and an increase of the $\mathrm{Ti}-\mathrm{OH}$ population. Thermogravimetric analyses confirm the generation of structural defects by oxygen plasma and allowed an estimation of the resulting experimental formula of the treated MIL-125(Ti)- $\mathrm{NH}_{2}$ solids. SEM analyses show that the oxygen plasma treatment of MIL-125(Ti)- $\mathrm{NH}_{2}$ gradually decreases its particle size. Importantly, diffuse reflectance UV-Vis spectroscopy and valence band measurements demonstrate that oxygen-plasma treatment alters MIL-125(Ti)- $\mathrm{NH}_{2}$ band gap and, more significantly, the alignment of highest occupy and lowest unoccupied crystal orbitals. An optimal oxygen plasma treatment to achieve the highest efficiency in water splitting with or without methanol as sacrificial electron donor under UV-Vis or simulated sunlight was determined. The optimized plasmatreated MIL-125(Ti)- $\mathrm{NH}_{2}$ photocatalyst acts as truly heterogeneous photocatalysts and retains most of its initial photoactivity and crystallinity upon reuse.

\subsection{Introduction}

Metal organic frameworks (MOFs) are being increasingly used as photocatalysts for hydrogen generation and $\mathrm{CO}_{2}$ reduction. ${ }^{[1]}$ Following the lead of $\mathrm{TiO}_{2}$, ${ }^{[2]}$ Ti-containing MOFs, and particularly MIL-125(Ti) are among the preferred materials, since they combine structural robustness with high photocatalytic activity. ${ }^{[3]}$ Recently, our group has reported the photocatalytic activity of MIL-125(Ti)-NH $\mathrm{NH}_{2}$ to promote overall water splitting under both UV-Vis or visible light irradiation. ${ }^{[4]}$ The visible light response of the photocatalyst is introduced to the 
presence of the amino group on the terephthalate ligand. The highest occupied crystal orbital (HOCO, $2.40 \mathrm{eV}$ ) is located at the 2-aminoterephthalate while lowest unoccupied crystal orbital (LUCO, $-0.05 \mathrm{eV}$ ) at the Ti $3 \mathrm{~d}$ orbitals. ${ }^{[5]}$ Therefore, $^{-}$ MIL-125(Ti)- $\mathrm{NH}_{2}$ accomplish the thermodynamically requirements for $\mathrm{H}_{2} \mathrm{O}$ oxidation to $\mathrm{O}_{2}\left(1.23 \mathrm{eV}\right.$ vs NHE) and $\mathrm{H}_{2} \mathrm{O}$ reduction to $\mathrm{H}_{2}(0 \mathrm{eV}$ vs NHE) and allow to perform the overall water splitting under visible light irradiation. ${ }^{[6]}$ Transient absorption spectroscopy and EPR measurements have provided evidence that upon photoexcitation with the appropriate wavelength, electron transfer from the organic ligand to the Ti(IV) metal nodes leading to the formation of a positive hole on the organic linker and a Ti(III) species takes place. ${ }^{[7]}$

There is a continuous need in increasing the efficiency of the photocatalytic systems to reach the long-standing goal of industrial application. In this context, van der Voort and others have shown that defect engineering as a methodology to increase the photocatalytic activity. ${ }^{[8]}$ Plasma treatment is a general technique to modify catalysts, generating defects in their structure. ${ }^{[9]}$ For instance plasma treatment of graphenes increases their catalytic activity. ${ }^{[10]}$ In one precedent of plasma treatment in MOFs, a low-temperature $\mathrm{NH}_{3}$-plasma treatment was applied to decompose a Ni-based MOF into Ni nanocrystals encapsulated in a thin overlayer of $\mathrm{N}$-doped carbon and further applied for $\mathrm{H}_{2}$ evolution during water electrolysis in alkaline solution. ${ }^{[11]} \mathrm{A}$ milder treatment would be advisable to find the compromise between defect generation while maintaining MOF crystal structure ${ }^{[1 \mathrm{a}]}$.

The present study reports the low-power, oxygen plasma treatment of well-known MIL-125(Ti)- $\mathrm{NH}_{2}$ photocatalyst, showing that just a few minutes treatment increases its photocatalytic efficiency for overall water splitting by a factor of 2. Characterization data indicates that plasma treatment causes terephthalate decarboxylation and these defects shifts to more negative potentials the LUCO energy, resulting in a stable and reusable optimized photocatalyst. 


\subsection{Results and discussion}

\subsubsection{Photocatalyst preparation and characterization}

As commented, the aim of this work is to study the influence of the defect-induced oxygen plasma treatment on pristine MIL-125(Ti)- $\mathrm{NH}_{2}$ on the photocatalytic activity for the water splitting. After several trials, an optimized oxygen plasma treatment at $10 \mathrm{~W}$ power was able to generate defects on MIL-125(Ti)- $\mathrm{NH}_{2}$ in relatively short times (min). Figure 1 shows that the oxygen-plasma treated MIL-125(Ti)- $\mathrm{NH}_{2}$ solids retains their crystallinity after the plasma treatment at 5, 10 and $15 \mathrm{~min}$.

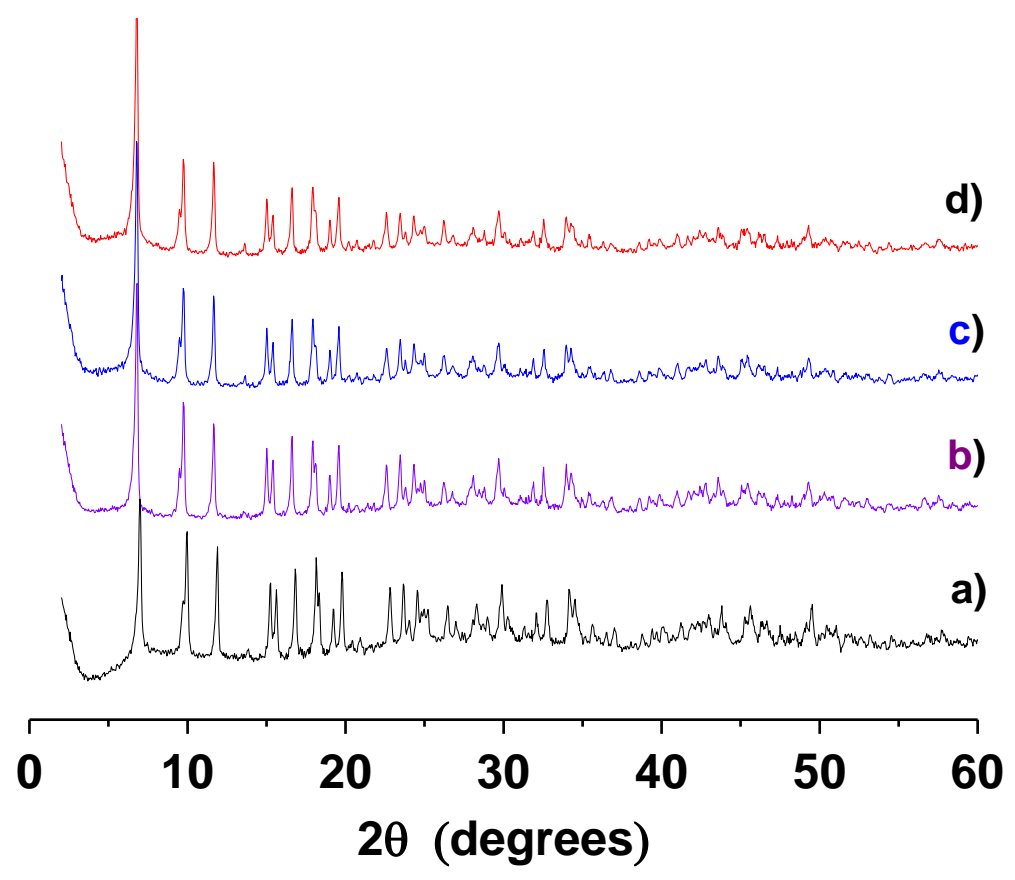

Figure 1. XRD of MIL-125(Ti)-NH (a), MIL-125(Ti)- $\mathrm{NH}_{2}-5 m$ (b), MIL-125(Ti)-NH $-10 m$ (c), MIL-125(Ti)- $\mathrm{NH}_{2}-15 \mathrm{~m}$ (d).

The density of defects induced by the oxygen plasma treatment was conveniently quantified by thermogravimetric analyses (TGA) of the plasma-treated 
MIL-125(Ti)-NH $\mathrm{NH}_{2}$ samples (Figure S1). The MIL-125(Ti)-NH $\mathrm{NH}_{2}$ treated for 5 and $10 \mathrm{~min}$ with oxygen-plasma exhibits a decrease of the organic content with a concomitant increase of Ti content respect to the pristine MIL-125(Ti)- $\mathrm{NH}_{2}$ material. In contrast, the MIL-125(Ti)- $\mathrm{NH}_{2}$ sample treated with oxygen plasma for 15 min shows a $\mathrm{Ti}$ content lower than pristine MIL-125(Ti)- $\mathrm{NH}_{2}$. TGA data was employed to estimate the experimental MIL-125(Ti)- $\mathrm{NH}_{2}$ formulae (Table 1) of the different samples under study and their deviation respect to the ideal one $\left(\mathrm{Ti}_{8} \mathrm{O}_{8}\right)(\mathrm{OH})_{4}\left(\mathrm{C}_{6} \mathrm{H}_{3} \mathrm{C}_{2} \mathrm{O}_{4} \mathrm{NH}_{2}\right)_{6}$. ${ }^{[12]}$

Isothermal $\mathrm{N}_{2}$ adsorption measurements of plasma-treated MIL-125(Ti)- $\mathrm{NH}_{2}$ solids shows that plasma treatment decreases somehow the BET and pore volume values respect to the pristine MIL-125(Ti)- $\mathrm{NH}_{2}$ material (Table 1 and Figure S2). In good agreement with these results, isothermal Ar adsorption measurements also confirmed the decrease of surface area and pore volume of the photocatalytically most active MIL-125(Ti)-NH $-10 \mathrm{~m}\left(1022 \mathrm{~m}^{2} \mathrm{~g}^{-1}\right.$ and $\left.0.59 \mathrm{~cm}^{3} \mathrm{~g}^{-1}\right)$ sample respect to pristine MIL-125(Ti)- $\mathrm{NH}_{2}\left(1071 \mathrm{~m}^{2} \mathrm{~g}^{-1}\right.$ and $0.62 \mathrm{~cm}^{3} \mathrm{~g}^{-1}$ ) (Figures S3-S4). SEM measurements also show the occurrence of morphological changes, especially the decrease of MIL-125(Ti)- $\mathrm{NH}_{2}$ average particle size as the plasma treatment time increases (Table 1 and Figures S5-S6). These morphological changes in the plasma treated MIL-125(Ti)- $\mathrm{NH}_{2}$ samples respect to pristine MIL-125(Ti)- $\mathrm{NH}_{2}$ are also evidenced by transmission electron microscopy (TEM) measurements (Figure S7).

In order to get some insight on the effect of the oxygen plasma treatment on structure of MIL-125(Ti)- $\mathrm{NH}_{2}$ solid, XPS and FT-IR analyses of the different samples under study were performed. Figures S8-S11 collect the corresponding XP spectra with the best fitting to each individual component present. The XPS C 1s peak of pristine MIL-125(Ti)-NH2 shows two bands centred at 284.4 and $289 \mathrm{eV}$, corresponding to the aromatic carbons and the carboxylate groups of the 2-amino terephthalate organic ligand, respectively. In addition, O 1s XPS shows a broad signal that can be deconvoluted into two individual bands at 534 and $529 \mathrm{eV}$ characteristic of the titanol groups ( $\mathrm{Ti}-\mathrm{OH})$ present in the metal nodes and the carboxylate oxygen 
atoms, respectively. N 1s XPS show a main band at $399 \mathrm{eV}$ corresponding to the amino group, accompanied by a smaller signal at $402 \mathrm{eV}$ attributable to the partially protonated amino group. The Ti 2 p XPS is constituted by two bands centred at 458 and $465 \mathrm{eV}$, characteristic of $\mathrm{Ti} 2 \mathrm{p}_{3 / 2}$ and $\mathrm{Ti} 2 \mathrm{p}_{1 / 2}$ of the $\mathrm{Ti}^{4+}$ ions at the metal node of the MOF.

Table 1. List of MIL-125(Ti)-NH $\mathrm{NH}_{2}$ samples studied in this work including their experimental formula, (a) BET and pore volume(b) and average particle size(c).

\begin{tabular}{|c|c|c|c|}
\hline Sample & Experimental formula & $\begin{array}{l}\text { BET / pore } \\
\text { volume }\end{array}$ & $\begin{array}{l}\text { MOF average particle } \\
\text { size and standard } \\
\text { deviation }(\mathrm{nm})\end{array}$ \\
\hline $\begin{array}{c}\text { MIL-125(Ti)- } \\
\mathrm{NH}_{2}\end{array}$ & $\left(\mathrm{Ti}_{7.9} \mathrm{O}_{11.9}\right)(\mathrm{OH})_{3.4}\left(\mathrm{C}_{6} \mathrm{H}_{3} \mathrm{C}_{2} \mathrm{O}_{4} \mathrm{NH}_{2}\right)_{4.6}$ & $\begin{array}{c}1137 / \\
0.60\end{array}$ & $470 \pm 219$ \\
\hline $\begin{array}{l}\text { MIL-125(Ti)- } \\
\mathrm{NH}_{2} 5 \text { min }\end{array}$ & $\left(\mathrm{Ti}_{8.5} \mathrm{O}_{19.1}\right)(\mathrm{OH})_{1.3}\left(\mathrm{C}_{6} \mathrm{H}_{3} \mathrm{C}_{2} \mathrm{O}_{4} \mathrm{NH}_{2}\right)_{4.2}$ & $\begin{array}{c}1083 / \\
0.59\end{array}$ & $408 \pm 205$ \\
\hline $\begin{array}{l}\text { MIL-125(Ti)- } \\
\mathrm{NH}_{2} 10 \mathrm{~min}\end{array}$ & $\left(\mathrm{Ti}_{10.1} \mathrm{O}_{18.4}\right)(\mathrm{OH})_{1.5}\left(\mathrm{C}_{6} \mathrm{H}_{3} \mathrm{C}_{2} \mathrm{O}_{4} \mathrm{NH}_{2}\right)_{3.7}$ & $\begin{array}{c}1054 / \\
0.58\end{array}$ & $282 \pm 86$ \\
\hline $\begin{array}{l}\text { MIL-125(Ti)- } \\
\mathrm{NH}_{2} 15 \mathrm{~min}\end{array}$ & $\left(\mathrm{Ti}_{10.1} \mathrm{O}_{8.3}\right)(\mathrm{OH})_{1.5}\left(\mathrm{C}_{6} \mathrm{H}_{3} \mathrm{C}_{2} \mathrm{O}_{4} \mathrm{NH}_{2}\right)_{5.1}$ & $\begin{array}{c}1045 / \\
0.57\end{array}$ & $242 \pm 108$ \\
\hline
\end{tabular}

[a] Based on TGA data from Figure S1

[b] Based on isothermal $\mathrm{N}_{2}$ adsorption

[c] Based on SEM measurements from Figure S3

Comparison of the XPS spectra of the pristine and oxygen-plasma treated MIL-125(Ti)- $\mathrm{NH}_{2}$ samples reveal a decrease of the relative intensities of the $\mathrm{C} 1 \mathrm{~s}$ band at $289 \mathrm{eV}$ and $\mathrm{O}$ 1s band at $539 \mathrm{eV}$ indicating that the oxygen plasma-treatment induces partial decarboxylation (Figure 2). In agreement with these observations, the XPS $O$ 1s peak of the oxygen plasma-treated samples exhibits a relative higher 
proportion of $\mathrm{Ti}-\mathrm{OH}$ groups respect to carboxylate $\mathrm{O}$ atoms that agrees with the occurrence of decarboxylation.

a)

c)
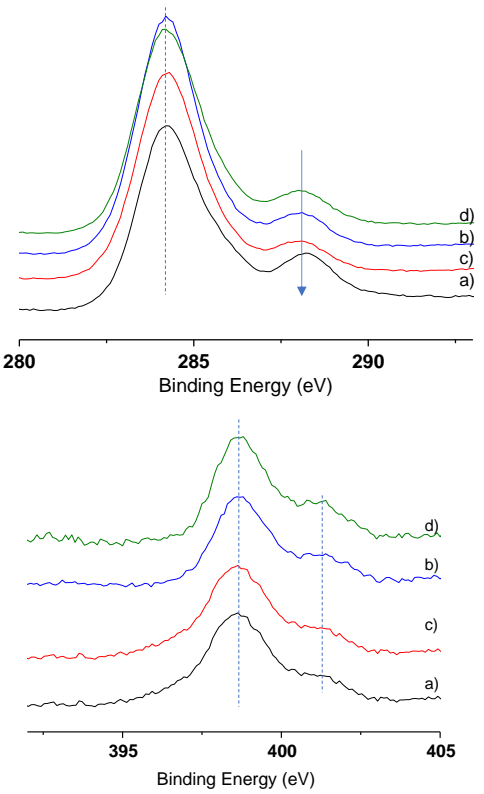

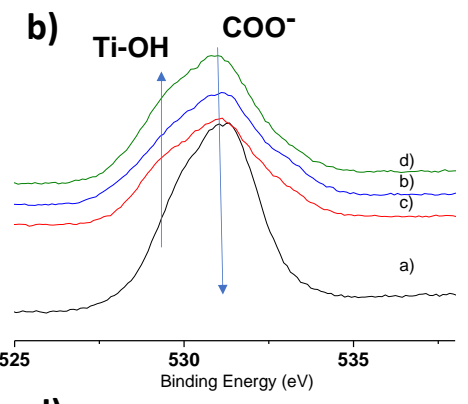

d)

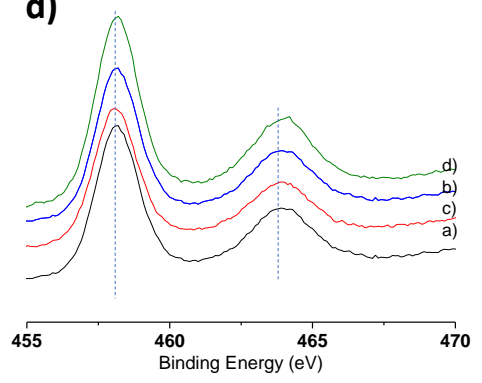

Figure 2. High-resolution XPS peaks of C1s (a), O1s (b), N1s (c) and Ti2p (d) elements for MIL-125(Ti)-NH 2 (a), MIL-125(Ti)-NH -5 m (b), MIL-125(Ti)-NH $-10 m$ (c), MIL-125(Ti)-NH $\mathrm{NH}_{2}-15 \mathrm{~m}$ (d).

Comparison of FT-IR spectra of the MIL-125(Ti)- $\mathrm{NH}_{2}$ series clearly shows that the oxygen plasma treatment generates an intense band at $3,420 \mathrm{~cm}^{-1}$ attributable of the $-\mathrm{OH}$ vibration of the titanol groups formed in the decarboxylation process. FT-IR spectroscopy shows that the remaining carboxylate groups do not undergo any shift during the plasma treatment. 


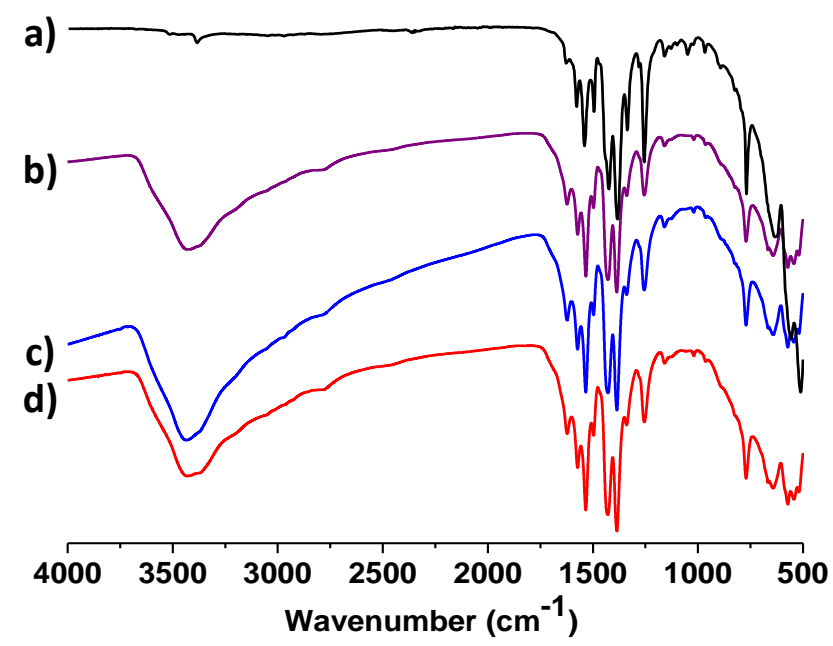

Figure 3. FT-IR of MIL-125(Ti)- $\mathrm{NH}_{2}$ (a), MIL-125(Ti)- $\mathrm{NH}_{2}-5 m$ (b), MIL-125(Ti)- $\mathrm{NH}_{2}-10 \mathrm{~m}$ (c), MIL-125(Ti)- $\mathrm{NH}_{2}-15 \mathrm{~m}$ (d).

Overall, the characterization data indicates that the main effect of oxygen plasma treatment of MIL-125(Ti)- $\mathrm{NH}_{2}$ is the partial decarboxylation of terephthalate ligand, maintaining the crystal structure of the treated solid and with some decrease in the porosity. Figure 4 shows a simplified illustration of the ideal MIL-125(Ti)- $\mathrm{NH}_{2}$ sample and defective MIL-125(Ti)- $\mathrm{NH}_{2}$ materials resulting by plasma treatment. 

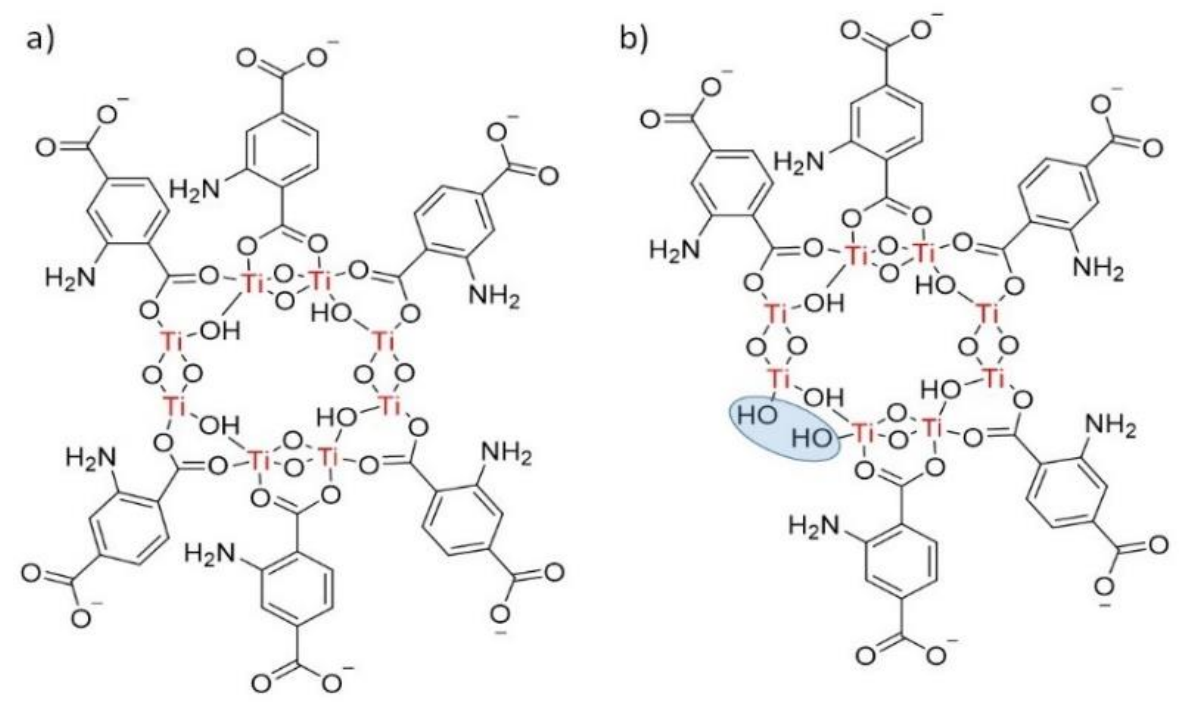

Figure 4. Simplified illustration of ideal (a) and oxygen plasma treated (b) MIL-125(Ti)-NH materials.

From the photocatalytic point of view, it is relevant to determine if the generation of defects is reflected in variation on the energy levels of the highest occupied and lowest unoccupied crystal orbitals (HOCO and LUCO, respectively). These possible variations were addressed by analysing diffuse reflectance UV-Vis spectra (Figure S8) and valence band energy determined by XPS (Figure S12-13). In general, diffuse reflectance UV-Vis spectra show one band centred at $280 \mathrm{~nm}$ due to the $\mathrm{Ti}-\mathrm{O}$ ligand-to-metal charge transfer together with a band at $390 \mathrm{~nm}$ related to the charge transfer from the 2-aminoterephthalate organic ligand to the oxotitanium metal node. The Tauc plot was used to calculate the band gap for the series of solids, observing small differences in all samples, oxygen plasma treatment slight increasing its value. XPS was employed to estimate the valence band edge of the different materials. ${ }^{[13]}$ Table 2 collects the band gap, HOCO and LUCO energy values estimated for the different MIL-125(Ti)- $\mathrm{NH}_{2}$ solids under study. Regardless the 
similar band gap values of the different samples, significant differences between HOCO and LUCO energies were determined. As it will be commented later the energy band alignment strongly influences the resulting photocatalytic activity for the water splitting.

Table 2. Influence of the oxygen plasma treatment on the electronic alignment of the MIL-125(Ti)- $\mathrm{NH}_{2}$ solids.

\begin{tabular}{|c|c|c|c|}
\hline Sample & Estimated band gap (eV) & $\mathrm{HOCO}(\mathrm{eV})$ & LUCO $(\mathrm{eV})$ \\
\hline MIL-125(Ti)-NH & 2.64 & 2.34 & -0.30 \\
\hline MIL-125(Ti)- $\mathrm{NH}_{2} 5 \mathrm{~min}$ & 2.81 & 2.18 & -0.62 \\
\hline MIL-125(Ti)-NH $10 \mathrm{~min}$ & 2.71 & 2.40 & -0.31 \\
\hline MIL-125(Ti)-NH 15 min & 2.76 & 1.85 & -0.91 \\
\hline
\end{tabular}

\subsection{Photocatalytic activity}

\subsubsection{Photocatalytic overall water splitting}

Since it has been proposed that structural defects can influence positively the photocatalytic activity, ${ }^{[8]}$ and considering the relevance of robust MIL-125(Ti)- $\mathrm{NH}_{2}$ as visible light photocatalyst, ${ }^{[4,5 b, 12,14]}$ it was of interest to experimentally address the possible influence of plasma treatment on the photocatalytic activity for overall water splitting. Aimed at this purpose, a systematic study of the photocatalytic activity of the series of MIL-125(Ti)- $\mathrm{NH}_{2}$ samples in overall water splitting under the same conditions was undertaken. Figure 5 a shows that the oxygen plasma treatment gradually increases the efficiency of the overall water splitting for MIL-125(Ti)- $\mathrm{NH}_{2}$ under UV-Vis irradiation with an optimum for $10 \mathrm{~min}$ of treatment. Attempts to prolong the oxygen plasma treatment beyond $15 \mathrm{~min}$ on MIL-125(Ti)- $\mathrm{NH}_{2}$ resulted in a decrease of photoactivity. It is remarkable that the optimized MIL-125(Ti)- $\mathrm{NH}_{2}-10 \mathrm{~m}$ sample exhibits double photocatalytic activity than 
pristine MIL-125(Ti)-NH2. It should be noted that the photoactivity of MIL-125(Ti)-NH2-10m is even higher than an analogous MIL-125(Ti)- $\mathrm{NH}_{2}$ sample incorporating $\mathrm{RuO}_{x}$ nanoparticles as co-catalyst $\left(69 \mu \mathrm{mol} \mathrm{g}^{-1}\right.$ in $22 \mathrm{~h}$ ) under analogous reaction conditions. ${ }^{[4]}$ Worth noting is that the present results reconfirm the ability of MIL-125(Ti)- $\mathrm{NH}_{2}$ to promote $\mathrm{O}_{2}$ generation from $\mathrm{H}_{2} \mathrm{O}$. This point was further proved in an experiment using labelled $\mathrm{H}_{2}{ }^{18} \mathrm{O}$, whereby the formation of ${ }^{18} \mathrm{O}_{2}(\mathrm{~m} / \mathrm{z}$ 36 a.u.) was monitored by mass spectrometry as the only $\mathrm{O}_{2}$ species (Figure $\mathrm{S} 14$ ).

The same trend of photocatalytic activity was observed under visible light irradiation ( $\lambda>450 \mathrm{~nm}$ ) (Figure $5 \mathrm{~b}$ ) for the overall water splitting with the sample MIL-125(Ti)- $\mathrm{NH}_{2}-10 \mathrm{~m}$ being the most active. These experiments under visible light irradiation indicate that a large percentage of the observed photoactivity derives from the visible zone of the radiation spectrum. Importantly, the most active oxygen plasma treated MIL-125(Ti)- $\mathrm{NH}_{2}$ sample exhibits good photocatalytic activity (Figure $5 c$ ) and reusability (Figure $5 \mathrm{~d}$ ) under simulated sunlight irradiation, maintaining its crystallinity as revealed by XRD (Figure S15). The heterogeneity of the reaction was confirmed that observing that once $\mathrm{H}_{2}$ and $\mathrm{O}_{2}$ gases are evolving from water, if the solid is removed by filtration and the system allowed react further under the same photocatalytic reaction conditions, no additional gas evolution occurs (Figure S16). 
a)

c)

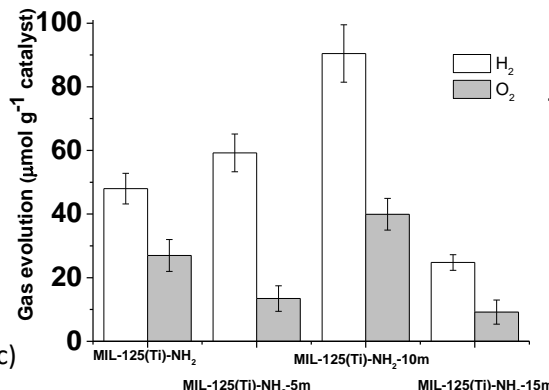

b)

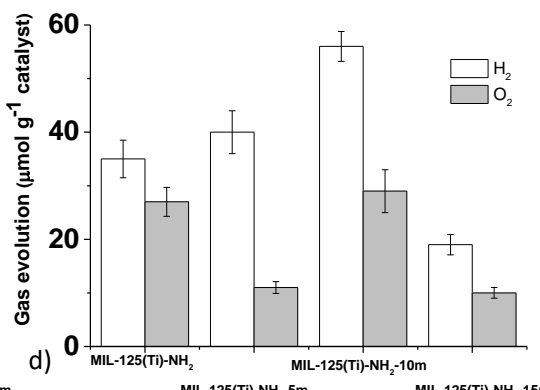

d)

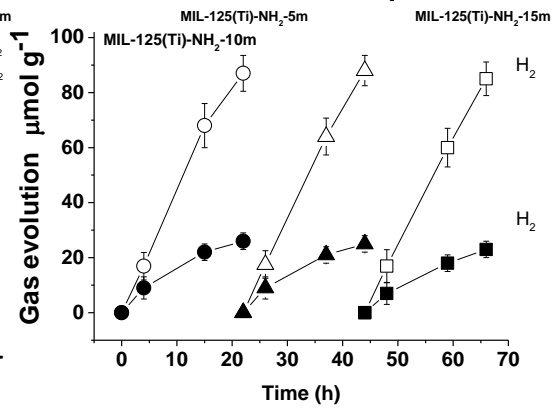

Figure 5. Overall water splitting using MIL-125(Ti)- $\mathrm{NH}_{2}$ materials as photocatalysts under UV-Vis (a), visible $(\lambda>450)$ and simulated sunlight irradiation for three consecutive cycles (c, d). General reaction conditions: photocatalyst $(20 \mathrm{mg}), \mathrm{H}_{2} \mathrm{O}(20 \mathrm{~mL}), 35^{\circ} \mathrm{C}$, irradiation source (Xe lamp $150 \mathrm{~W}$ equipped or not with $450 \mathrm{~nm}$ filter or solar simulator of 1 sun) reaction time $22 \mathrm{~h}$.

The increase of photoactivity upon oxygen plasma treatment of MIL-125(Ti)- $\mathrm{NH}_{2}-5 \mathrm{~m}$ and MIL-125(Ti)- $\mathrm{NH}_{2}-10 \mathrm{~m}$ can be explained considering that the samples with slightly higher band gap values exhibit a more positive HOMO and negative LUCO values respect to the pristine MIL-125(Ti)- $\mathrm{NH}_{2}$ solid (Table 2 and Figure 6). Furthermore, the smaller average particle size of the MIL-125(Ti)- $\mathrm{NH}_{2}$ samples treated at 5 and $10 \mathrm{~min}$ should also be beneficial for light harvesting respect to the bigger crystals of pristine MIL-125(Ti)- $\mathrm{NH}_{2}$. In contrast, the MIL-125(Ti)- $\mathrm{NH}_{2}-15 \mathrm{~m}$ sample with the longer treatment affecting more pronouncedly the structure shows the lowest photocatalytic activity of all the samples in the series. This observation can be explained considering that MIL-125(Ti)- $\mathrm{NH}_{2}-15 \mathrm{~m}$ sample exhibits the less oxidizing HOCO and, thus, the 
thermodynamically and kinetically most difficult half-reaction $\mathrm{H}_{2} \mathrm{O}$ oxidation to $\mathrm{O}_{2}$ is less favoured.

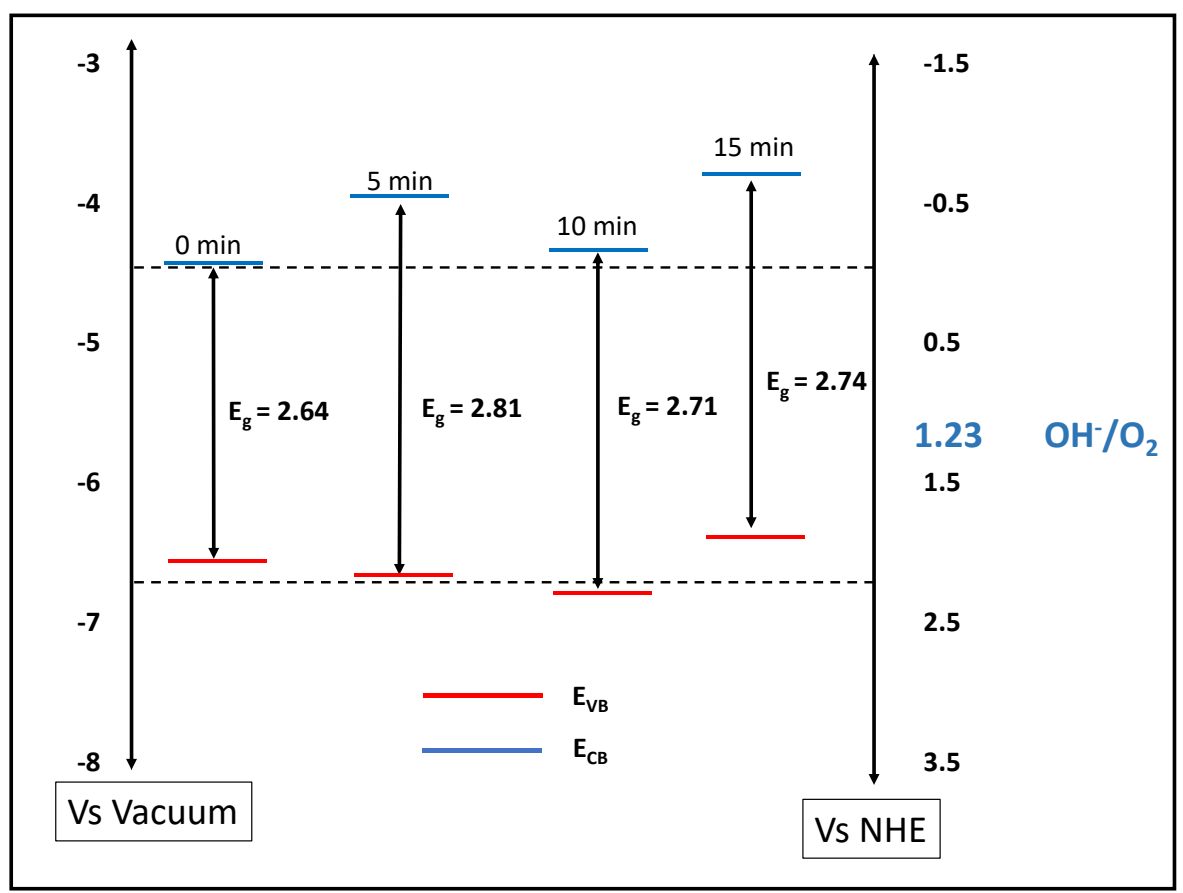

Figure 6. Energy levels of the MIL-125(Ti)- $\mathrm{NH}_{2}$ samples without ( $0 \mathrm{~min}$ ) or with oxygen plasma treatment ( $5 \mathrm{~min}, 10 \mathrm{~min}$ and $15 \mathrm{~min}$ ) under vacuum of NHE as reference.

\subsubsection{Photocatalytic water splitting in the presence of methanol.}

A series of experiments of photocatalytic hydrogen generation in the presence of methanol as electron donor was also carried out comparing the efficiency of pristine and oxygen plasma-treated MIL-125(Ti)- $\mathrm{NH}_{2}$ samples. In this case, all the oxygen-plasma treated samples exhibited higher $\mathrm{H}_{2}$ production than the pristine MIL-125(Ti)-NH2 sample under UV-Vis irradiation (Figure 7a). This observation can be understood according to Figure 6 considering that all the oxygen plasma treated MIL-125(Ti)-NH2 samples exhibit lower LUCO values than pristine MIL-125(Ti)- $\mathrm{NH}_{2}$. The highest $\mathrm{H}_{2}$ generation activity for MIL-125(Ti)- $\mathrm{NH}_{2}-10 \mathrm{~m}$ with 
less negative LUCO and higher particle size respect to MIL-125(Ti)- $\mathrm{NH}_{2}-15 \mathrm{~m}$ can be explained considering the higher ability of MIL-125(Ti)- $\mathrm{NH}_{2}-10 \mathrm{~m}$ to promote methanol oxidation than MIL-125(Ti)- $\mathrm{NH}_{2}-15 \mathrm{~m}$ and, thus, higher $\mathrm{H}_{2}$ evolution.

a)

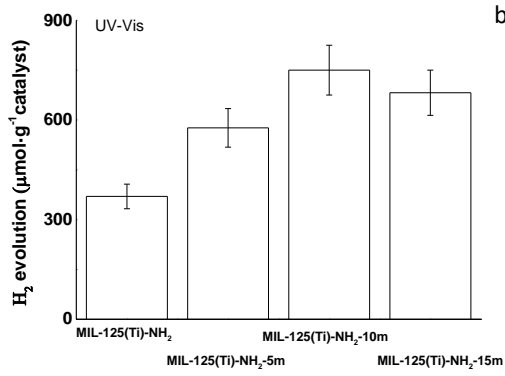

c)

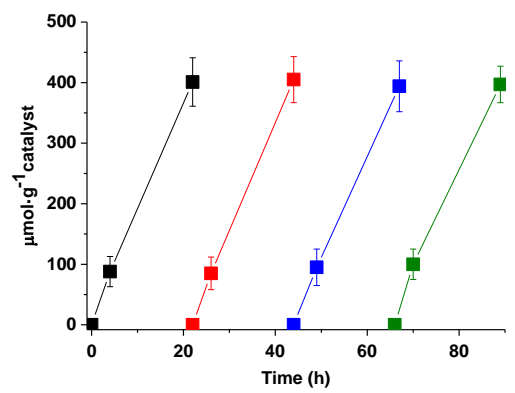

b) 900 MIL-125(Ti)- $\mathrm{NH}_{2}-10 \mathrm{~m}$
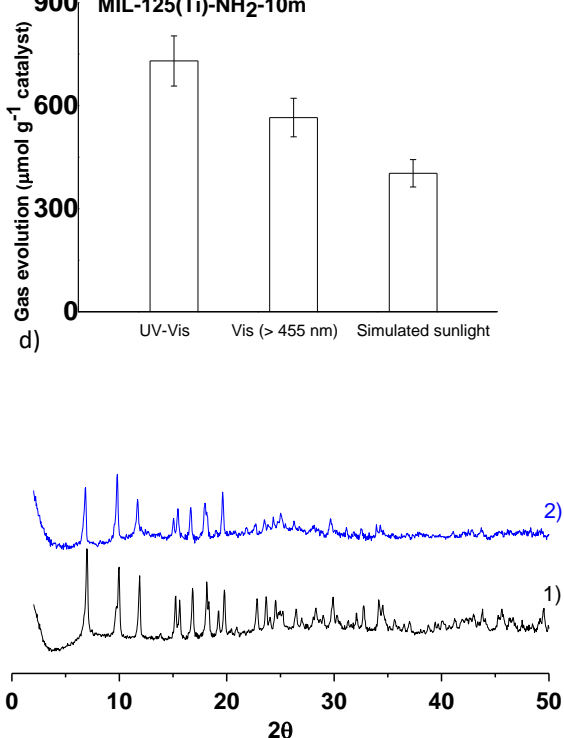

Figure 7. Photocatalytic hydrogen generation in the presence of methanol using several MIL-125(Ti)- $\mathrm{NH}_{2}$ materials under UV-Vis irradiation (a), Visible light $(\lambda>450 \mathrm{~nm})$ (b) and simulated sunlight irradiation (c) for several reuses (c). Panel d) shows the XRD of the fresh (1) and three times used (2) MIL-125(Ti)- $\mathrm{NH}_{2}-10 \mathrm{~m}$ photocatalyst. General reaction conditions: photocatalyst ( $20 \mathrm{mg}), \mathrm{H}_{2} \mathrm{O}(20 \mathrm{~mL}$ ), irradiation source (Xe lamp $150 \mathrm{~W}$ equipped or not with $450 \mathrm{~nm}$ filter), $35^{\circ} \mathrm{C}$, reaction time $22 \mathrm{~h}$.

Importantly, the higher photocatalytic activity of the optimized oxygen-plasma treated MIL-125(Ti)- $\mathrm{NH}_{2}-10 \mathrm{~m}$ for $\mathrm{H}_{2}$ generation in the presence of methanol also occurs under visible $(\lambda>455 \mathrm{~nm})$ and simulated sunlight irradiation (Figure 7b). Furthermore, the MIL-125(Ti)- $\mathrm{NH}_{2}-10 \mathrm{~m}$ maintains its photoactivity under simulated sunlight irradiation after several reuses (Figure 7c) and retains its crystallinity as revealed by XRD (Figure 7d). To further support the higher activity of oxygen-plasma treated MIL-125(Ti)- $\mathrm{NH}_{2}$ samples to promote reduction reactions 
respect to pristine $\mathrm{MIL}-125(\mathrm{Ti})-\mathrm{NH}_{2}$, methyl viologen $\left(\mathrm{MV}^{2+}, \mathrm{E}^{0}=-0.44 \mathrm{~V}, \mathrm{pH}\right.$ independent) was used as probe molecule. $\mathrm{MV}^{2+}$ is commonly used in photochemistry as electron acceptor rendering a visually observable blue coloured radical cation stable under inert atmosphere. ${ }^{[15]}$

In the present case, it was observed that all the MIL-125(Ti)- $\mathrm{NH}_{2}$ samples tested in this work promote $\mathrm{MV}^{2+}$ reduction to the coloured $\mathrm{MV}^{+\cdot}$ radical cation. Figure $8 \mathrm{a}$ illustrates the one electron reduction of $\mathrm{MV}^{2+}$ to $\mathrm{MV}^{+\cdot}$ using MIL-125(Ti)-- $\mathrm{NH}_{2}-10 \mathrm{~m}$. Interestingly, the photocatalytic activity of oxygen-plasma treated MIL-125(Ti)- $\mathrm{NH}_{2}$ samples follows for the photocatalytic $\mathrm{MV}^{2+}$ reduction the same trend respect to pristine MIL-125(Ti)- $\mathrm{NH}_{2}$ than that previously observed in the photocatalytic water splitting or hydrogen generation (Figure 8b). Thus, it seems that the more negative LUCO reduction potential values of plasma-treated MIL-125(Ti)- $\mathrm{NH}_{2}$ samples increases their ability to promote reduction reactions respect to pristine MIL-125(Ti)-NH2. 
a)
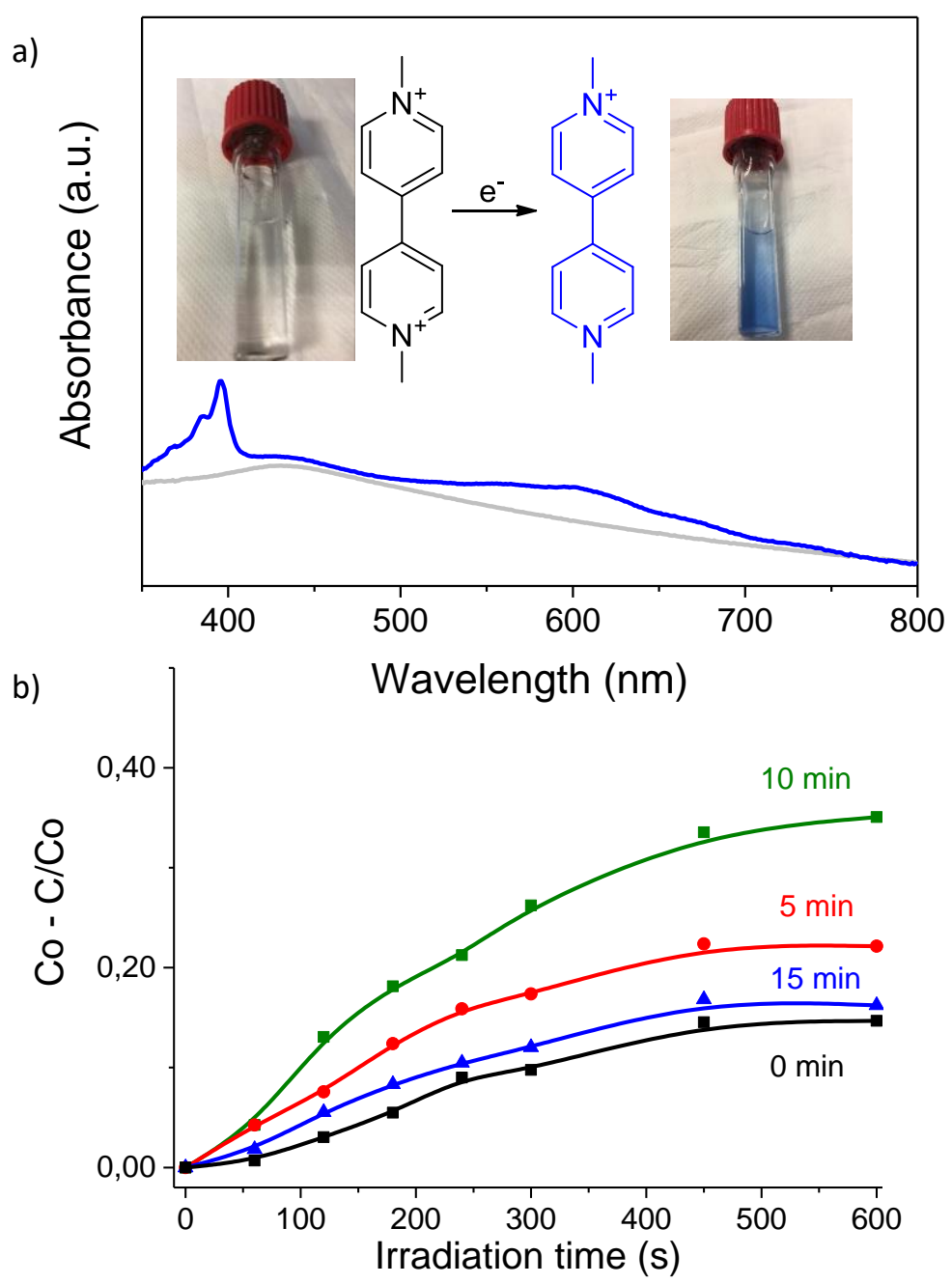

Figure 8. a) UV-vis spectra and photographs of Ar-purged acetonitrile suspension of MIL-125(Ti)- $\mathrm{NH}_{2}-10 \mathrm{~m}$ containing $\mathrm{MV}^{2+}$ in ethanol before (grey line) and after (blue line) irradiation with a Xe lamp. The blue colour indicates to the presence of $\mathrm{MV}^{++}$formed by one electron reduction of $\mathrm{MV}^{2+}$. b) Temporal evolution of the concentration of $\mathrm{MV}^{\bullet+}$ upon irradiation. 


\subsubsection{Reaction mechanism / Photoelectrochemical measurements}

The previous results indicate the higher photocatalytic activity of MIL-125(Ti)- $\mathrm{NH}_{2}-10 \mathrm{~m}$ for the overall water splitting, $\mathrm{H}_{2}$ evolution and $\mathrm{MV}^{2+}$ reduction. These results fit with the calculated changes in the HOMO and LUCO band energy alignment caused by plasma treatment. In addition, the MIL-125(Ti)- $\mathrm{NH}_{2}-10 \mathrm{~m}$ sample has smaller average particle size than the pristine MIL-125(Ti)- $\mathrm{NH}_{2}$ solid, favouring diffusion and light harvesting.

In order to further insights on the optimal photocatalytic activity of oxygen-plasma treated MIL-125(Ti)- $\mathrm{NH}_{2}-10 \mathrm{~m}$ sample respect to the pristine MIL-125(Ti)-NH2 solid, the photocurrent response of MIL-125(Ti)- $\mathrm{NH}_{2}-10 \mathrm{~m}$ on FTO electrodes was measured. ${ }^{[16]}$ Figure 9 shows that the photocurrent intensity increases as the polarization voltage increases. Interestingly, the onset potential for MIL-125(Ti)- $\mathrm{NH}_{2}-10 \mathrm{~m}$ is somewhat smaller by $0.1 \mathrm{~V}$ respect to pristine MIL-125(Ti)- $\mathrm{NH}_{2}$ material (see insets of Figure 9). This observation agrees with the shift in the HOCO-LUCO band energy values measured by XPS and absorption spectroscopy upon plasma treatment. Furthermore, a higher photocurrent increase was observed upon addition of methanol when using MIL-125(Ti)- $\mathrm{NH}_{2}-10 \mathrm{~m}$ respect to pristine MIL-125(Ti)- $\mathrm{NH}_{2}$. This observation agrees with the higher photocatalytic $\mathrm{H}_{2}$ production measured for MIL-125(Ti)-NH $-10 \mathrm{~m}$ respect to MIL-125(Ti)- $\mathrm{NH}_{2}$ in the presence of methanol as sacrificial electron donor. 


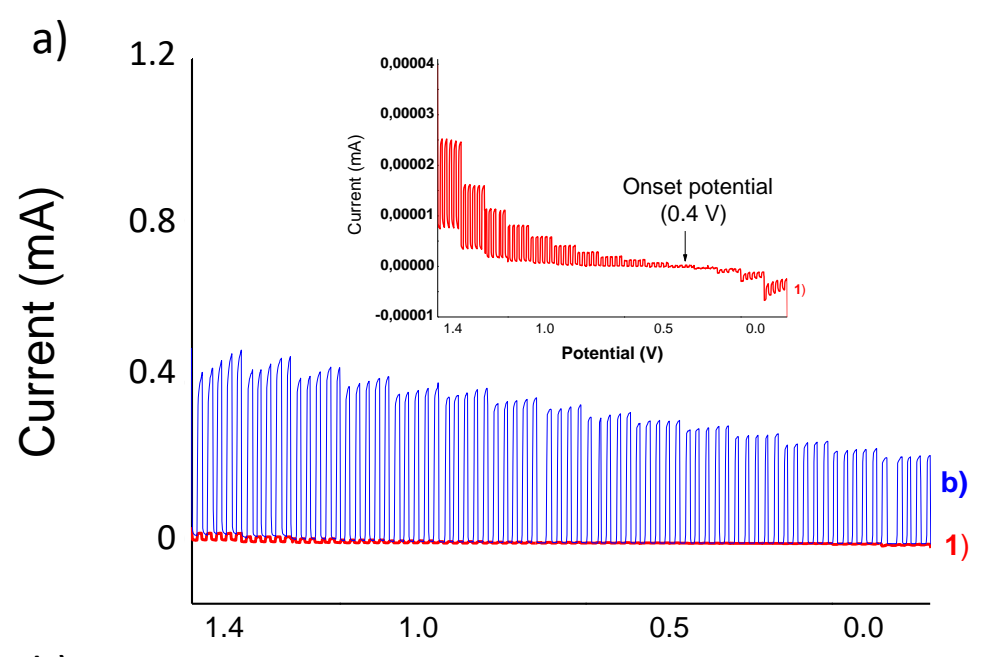

b)

Potential (V)

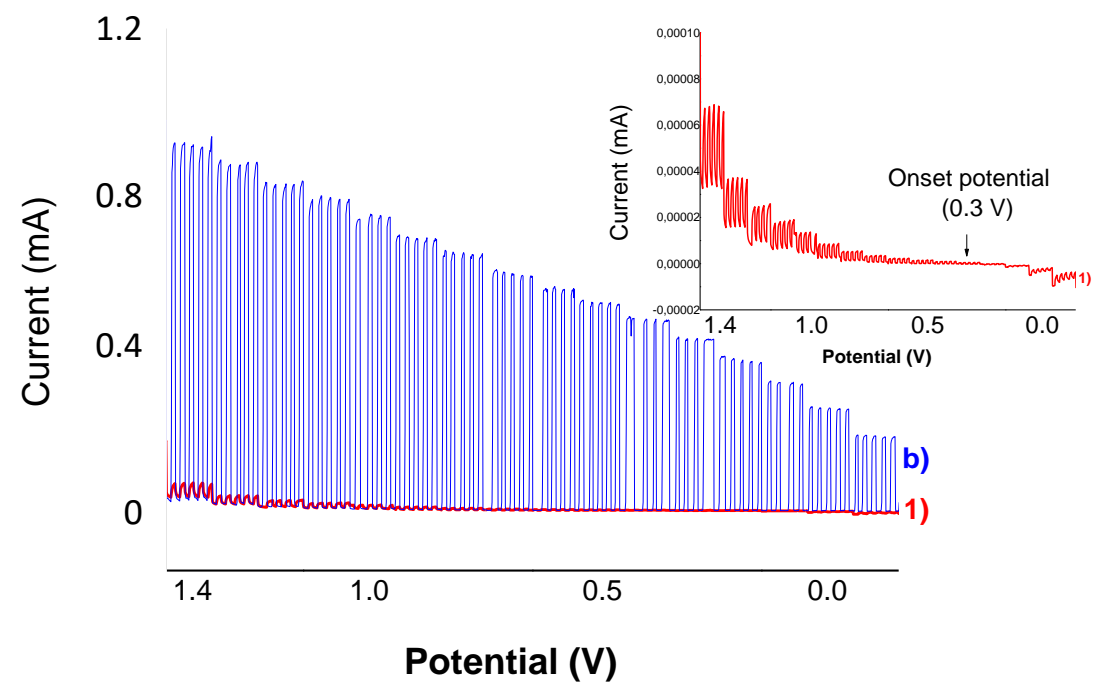

Figure 9. Photocurrent intensity versus polarization potential measured for the pristine MIL-125(Ti)-NH 2 FTO (a) or MIL-125(Ti)-10m/FTO (b) electrode in a deoxygenated TBAPF 6 $(0.1 \mathrm{M})$ acetonitrile solution in the absence $(1$, red line) or in the presence $(b$, blue line) of methanol upon $150 \mathrm{~W}$ Xe lamp illumination. The insets show a magnification of the photoresponse in the absence of methanol, with indication of the onset potential. 


\subsection{Conclusion}

The present study shows that oxygen plasma treatment on the benchmark MIL-125(Ti)- $\mathrm{NH}_{2}$ material generates structural defects that induces electronic changes resulting in the formation of an optimized solid with enhanced photocatalytic activity. Characterization data by PXRD and isothermal $\mathrm{N}_{2}$ adsorption reveal that plasma treated $\mathrm{MIL}-125(\mathrm{Ti})-\mathrm{NH}_{2}$ solids retain crystallinity in a large extent, diminishing somewhat BET and pore volume. XPS, FT-IR and thermogravimetric analyses have shown that plasma treatment on MIL-125(Ti)- $\mathrm{NH}_{2}$ induces partial decarboxylation and concomitant Ti-OH formation. Diffuse reflectance UV-Vis spectroscopy and valence band determination shows the alteration of the band energy values. Importantly, optimized MIL-125(Ti)- $\mathrm{NH}_{2}-10 \mathrm{~m}$ solid exhibits superior photocatalytic activity for overall water splitting and hydrogen evolution in the presence of methanol as sacrificial agent respect to the pristine MIL-125(Ti)-NH2. In summary, this work provides evidence of the influence of structural defects on the photocatalytic activity proposed in theoretical studies and shows a strategy to further increase the photocatalytic activity of MOFs through defect engineering by plasma treatment.

\subsection{Experimental section}

\subsubsection{Materials}

All the chemicals and reagents used in this work were of analytical or HPLC grade and supplied by Merck.

\subsubsection{Synthesis of MIL-125(Ti)- $\mathrm{NH}_{2}$}

MIL-125(Ti)- $\mathrm{NH}_{2}$ was prepared by a solvothermal method as previously reported. ${ }^{[16]}$ Briefly, 2-aminoterephthalic acid (1.43 g, $\left.7.9 \mathrm{mmol}\right)$ was dissolved in anhydrous $\mathrm{N}, \mathrm{N}$-dimethylformamide (DMF, $20 \mathrm{~mL}$ ) and, then, anhydrous methanol $(5 \mathrm{~mL})$ was added to the flask. The system was sonicated for $20 \mathrm{~min}$ and then, transferred to a Teflon-lined autoclave $(50 \mathrm{~mL})$. Subsequently, titanium isopropoxide $(1.36 \mathrm{~g}, 4.8 \mathrm{mmol})$ was added and the autoclave was sealed and heated up to $110^{\circ} \mathrm{C}$ 
for $72 \mathrm{~h}$. The system was cooled down to room temperature and the resulting precipitate was recovered by filtration, washed with DMF at room temperature for $12 \mathrm{~h}$ under stirring and, then, washed with DMF at $120^{\circ} \mathrm{C}$ for $12 \mathrm{~h}$. The same washing procedure was repeated using methanol as solvent. Finally, the solid was recovered by filtration and dried in an oven at $100^{\circ} \mathrm{C}$.

\subsubsection{Oxygen plasma treatment}

Oxygen plasma treatment of MIL-125(Ti)- $\mathrm{NH}_{2}$ was carried out using a commercially available, low-pressure plasma FEMTO (Diener) instrument. Briefly, a certain amount of sample (100 mg) weighed on a crucible was introduced in the plasma chamber. The chamber was firstly degassed under vacuum for $30 \mathrm{~min}$ and then, an $\mathrm{O}_{2}$ flow was introduced achieving after 5 min a stable and constant pressure of 4 mbar. An optimized potential of $10 \mathrm{~W}$ was found to be appropriate to generate structural defects on the MIL-125(Ti)- $\mathrm{NH}_{2}$ material in relatively short times $(5,10$ and $15 \mathrm{~min})$. Finally, the plasma chamber was submitted to vacuum for $5 \mathrm{~min}$ and then, refilled with Ar until atmospheric pressure was reached.

\subsubsection{Catalyst characterization}

Powder X-ray diffractograms (PXRD) of plasma-treated MIL-125(Ti)- $\mathrm{NH}_{2}$ samples were recorded in a Philips XPert diffractometer ( $40 \mathrm{kV}$ and $45 \mathrm{~mA}$ ) using $\mathrm{Ni}$ filtered $\mathrm{Cu} \mathrm{K} \alpha$ radiation. Diffuse reflectance UV-visible spectra of the solids were recorded in a Cary 5000 Varian spectrophotometer with an integrating sphere where the sample as compressed powder was placed in a sample holder. X-ray photoelectron spectra (XPS) were recorded using a SPECS spectrometer equipped with a MCD-9 detector using a monochromatic Al (K $\alpha=1486.6 \mathrm{eV}) \mathrm{X}$-ray source. Spectra deconvolution was performed after Shirley subtraction of background with the CASA software using the C 1 s peak at $284.4 \mathrm{eV}$ as binding energy reference. Fourier-transform infrared (FTIR) spectra were recorded on compressed powders using a Bruker spectrophotometer in an attenuated total reflectance (ATR) cell. The morphology of the MOF samples was characterized using a scanning electron 
microscope (SEM, Zeiss instrument, AURIGA Compact). MOF particle size distribution was estimated for each sample by measuring more than 300 particles. Isothermal $\mathrm{N}_{2}$ adsorption measurements of the MIL-125(Ti) solids were carried out using an ASAP 2010 Micromeritics station.

\subsubsection{Photocatalytic water splitting experiments}

All the experiments were carried out at least in triplicate. The presented data points correspond to the average of the independent measurements and the error bar corresponds to the standard deviation. The photocatalytic water splitting experiments were carried out in the absence or in the presence of methanol as sacrificial electron donor. Briefly, $20 \mathrm{mg}$ of catalyst was dispersed in $20 \mathrm{~mL}$ of distilled $\mathrm{H}_{2} \mathrm{O}$ or a mixture of $\mathrm{H}_{2} \mathrm{O}(18 \mathrm{~mL})$ and methanol $(2 \mathrm{~mL})$ using a quart reactor $(51 \mathrm{~mL})$ and the system sonicated for 20 min to obtain a good solid dispersion. Then, the system was purged with Ar for $1 \mathrm{~h}$. The suspension under stirring was irradiated with a Xe lamp (150 W). In some cases, a cut-off filter $(\lambda>450 \mathrm{~nm})$ was employed to ensure visible light irradiation. In other experiments irradiations were carried out under simulated sunlight irradiation (OrielTM, 1 sun power).

The evolved gases from the different experiments were analysed by withdrawing from the head space several aliquots at different reaction times. Then, the reaction aliquots were injected into an Agilent 490 Micro GC system (Molsieve 5 Å column using Ar as carrier gas). The temperature of the reactor was monitored and the pressure was analysed by means of a manometer.

\subsubsection{Methyl viologen $\left(\mathrm{MV}^{2+}\right)$ experiments}

Photoinduced electron transfer measurements were carried out using MOF dispersions $(0.2 \mathrm{mg} / \mathrm{mL})$ in water/methanol mixtures (9:1 vol: vol) containing acetonitrile solution of $\mathrm{MV}^{2+}(0.15 \mathrm{mM})$. The MOF dispersions containing $\mathrm{MV}^{2+}$ were sonicated, placed in quartz cuvette capped with septa and bubbling Ar for 5 min prior irradiation. The cuvettes containing the MOF dispersions under Ar atmosphere were irradiated with a Hg-Xe lamp (150 W) for different times and measuring the UV-Vis 
absorbance with a Cary 50 Conc UV-Vis spectrophotometer. The photoinduced electron transfer measurements were followed by the increase of the absorption band centered near $400 \mathrm{~nm}$ and corresponding to the $\mathrm{MV}^{++}$radical cation.

\subsubsection{Photocurrent measurements}

Photocurrent measurements were carried out in a standard three-electrode electrochemical cell using a transparent fluoride-doped tin oxide (FTO)-coated glass substrate coated with a thin layer of the corresponding MIL-125(Ti)- $\mathrm{NH}_{2}$ sample (FTO-MIL-125(Ti)-NH2). The FTO-MIL-125(Ti)- $\mathrm{NH}_{2}$ films were employed as working electrode, a platinum wire as the counter electrode and a standard calomel electrode (SCE) as the reference electrode. Prior to the measurement, the oxygen present in the cell was removed by bubbling an Ar stream through the electrolyte. The photocurrent was measured under dark and under illumination upon polarizing the working electrode at potentials from 1.4 to $-0.2 \mathrm{~V}$. Irradiation was performed using an optical fiber connected to a $150 \mathrm{~W}$ Xe lamp. 


\subsection{Bibliography}

[1] a) A. Dhakshinamoorthy, A. M. Asiri, H. García, Angew. Chem. Int. Ed. 2016, 55, 5414-5445; b) A. Dhakshinamoorthy, Z. Li, H. García, Chem. Soc. Rev. 2018, 47, 8134-8172; c) T. Zhang, W. Lin, Chem. Soc. Rev. 2014, 43, 5982-5993; d) W. Wang, X. Xu, W. Zhou, Z. Shao, Adv. Sci. 2017, 4, 160037; e) J.-L. Wang, C. Wang, W. Lin, ACS Catal. 2012, 2, 2630-2640; f) M. Wen, K. Mori, Y. Kuwahara,T. An, H. Yamashita, Chem. Asian J. 2018, 13, 1767-1779; g) M. Ding, R. W. Flaig, H.-L. Jiang, O. M. Yaghi, Chem. Soc. Rev. 2019, 48, 2783-2828; h) D. Li, M. Kassymova, X. Cai, S.-Q. Zang, H.-L. Jiang, Coord. Chem. Rev. 2020, 412, 213262; i) T. Zhang, Y. Jin, Y. Shi, M. Li, J. Li, C. Duan, Coord. Chem. Rev. 2019, 380, 201-229; j) H. Luo, Z. Zeng, G. Zeng, C. Zhang, R. Xiao, D. Huang, C. Lai, M. Cheng, W. Wang, W. Xiong, Y. Yang, L. Qin, C. Zhou, H. Wang, Y. Zhou, C. Tian, Chem. Eng. J. 2019, 383, 123196.

[2] a) J. Schneider, M. Matsuoka, M. Takeuchi, J. Zhang, Y. Horiuchi, M. Anpo, D. W. Bahnemann, Chem. Rev. 2014, 114, 9919-9986; b) A. Fujishima, T. N. Rao, D. A. Tryk, J. Photochem. Photobiol. C 2000, 1, 1-21; c) A. Fujishima, X. Zhang, D. A. Tryk, Surf. Sci. Rep. 2008, 63, 515-582.

[3] a) J. Zhu, P.-Z. Li, W. Guo, Y. Zhao, R. Zou, Coord. Chem. Rev. 2018, 359, 80-101; b) X Chen, X. Peng, L. Jiang, X. Yuan, H. Yub, H. Wang, J. Zhang, Q. Xia, Chem. Eng. J. 2020, 395, 125080.

[4] S. Remiro-Buenamañana, M. Cabrero-Antonino, M. Martínez-Guanter, M. Alvaro, S. Navalón, H. García, Appl. Catal. B 2019, 254, 677-684.

[5] a) Y. An, B. Xu, Y. Liu, Z. Wang, P. Wang, Y. Dai, X. Qin, X. Zhang, B. Huang, ChemistryOpen 2017, 6, 701-705; b) C. H. Hendon, D. Tiana, M. Fontecave, C. Sanchez, L. D’arras, C. Sassoye, L. Rozes, C. Mellot-Draznieks, A. Walsh, J. Am. Chem. Soc. 2013, 135, 10942-10945.

[6] T. Hisatomi, K. Domen, Nat. Catal. 2019, 2, 387-399.

[7] M. A. Nasalevich, C. H. Hendon, J. G. Santaclara, K. Svane, B. van der Linden, S. L. Veber, M. Fedin, A. J. Houtepen, M. A. van der Veen, F. Kapteijn, A. Walsh, J. Gascon, Sci. Rep. 2016, 6, 23676.

[8] a) X. Ma, L. Wang, Q. Zhang, H.-L. Jiang, Angew. Chem. Int. Ed. 2019, 58, 12175-12179; b) A. De Vos, K. Hendrickx, P. Van Der Voort, V. Van Speybroeck, K. Lejaeghere, Chem. Mater. 2017, 29, 3006-3019; c) M. Taddei, G. M. Schukraft, M. E. A. Warwick, D. Tiana, M. J. McPherson, D. J. Jones, C. Petit, J. Mater. Chem. A 2019, 7, 23781-23786; d) K. L. Svane, J. K. Bristow, J. D. Gale, A. Walsh, J. Mater. Chem. A 2018, 6, 8507-8513; e) K. Hendrickx, D. E. P. Vanpoucke, K. Leus, K. Lejaeghere, A. V. Van Yperen-De Deyne, V. Van Speybroeck, P. Van Der Voort, K. Hemelsoet, Inorg. Chem. 2015, 54, 10701-10710.

[9] a) Z. Wang, Y. Zhang, E. C. Neyts, X. Cao, X. Zhang, B. W.-L. Jang, C.-J. Liu, ACS Catal. 2018, 8, 2093-2110; b) Z. Jiang, L. Ge, L. Zhuang, M. Li, Z. Wang, Z. Zhu, ACS Appl. Mater. Interfaces 2019, 11, 44300-44307; c) C. W. Xiang, J. Ren, S. Chen, C. Shen, Y. Chen, M. Zhang, C.-J. Liu, Appl. Energy 2020, 277, 115560.

[10] A. Primo, A. Franconetti, M. Magureanu, N. B. Mandache, C. Bucur, C. Rizescu, B. Cojocaru, V. I. Parvulescu, H. Garcia, Green Chem. 2018, 20, 2611-2623. 
[11] Y. Guo, X. Gao, C. Zhang, Y. Wu, X. Chang, T. Wang, X. Zheng, A. Du, B. Wang, J. Zheng, K. K. Ostrikovc, X. Li, J. Mater. Chem. A 2019, 7, 8129-8135.

[12] M. Dan-Hardi, C. Serre, T. Frot, L. Rozes, G. Maurin, C. Sanchez, G. Ferey, J. Am. Chem. Soc. 2009, 131, 10857-10859.

[13] Y. Peng, A. Rendón-Patiño, A. Franconetti, J. Albero, A. Primo, H. García, ACS Appl. Energy Mater. 2020, 3, 6623-6632.

[14] A. Melillo, M. Cabrero-Antonino, S. Navalón, M.Álvaro, B. Ferrer, H. García, Appl. Catal. B 2020, 278, 119345.

[15] a) T. W. Ebbesen, G. Ferraudi, J. Phys. Chem. 1983, 87, 3717-3721; b) H. Garcia, S. Navalon, Wiley- $\mathrm{VCH} 2018$.

[16] A. A. Babaryk, O. R. C. Almengor, M. Cabrero-Antonino, S. Navalón, H. García, P. Horcajada, Inorg. Chem. 2020, 59, 3406-3416. 


\subsection{Supporting information}

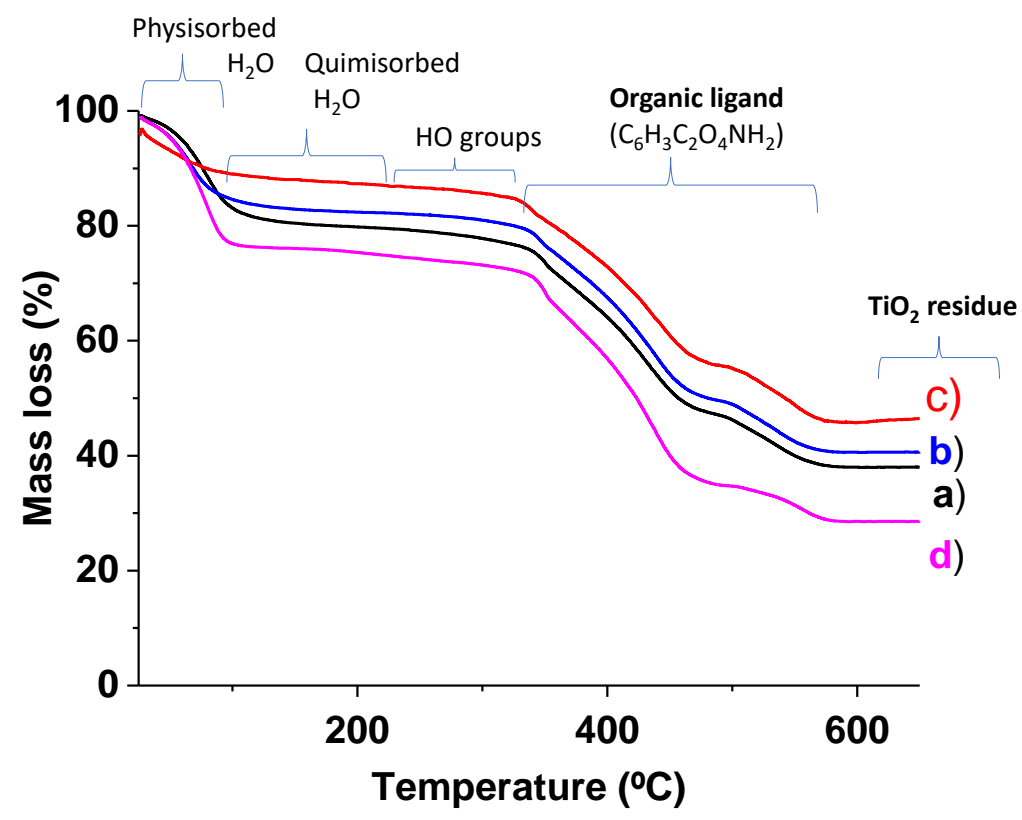

Figure S1. Thermogravimetric analyses for MIL-125(Ti)- $\mathrm{NH}_{2}$ (a), MIL-125(Ti)- $\mathrm{NH}_{2}-5 \mathrm{~m}$ (b), MIL-125(Ti)- $\mathrm{NH}_{2}-10 \mathrm{~m}$ (c), MIL-125(Ti)- $\mathrm{NH}_{2}-15 \mathrm{~m}$ (d). 
a)

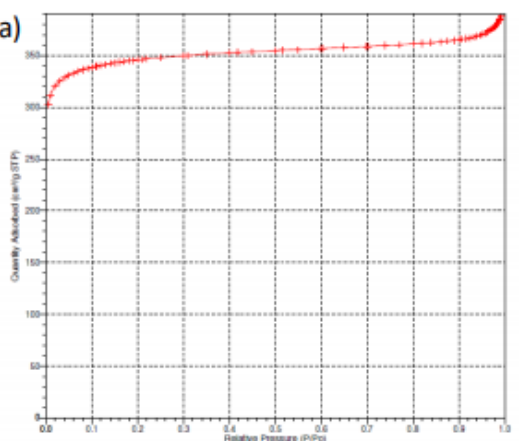

c)

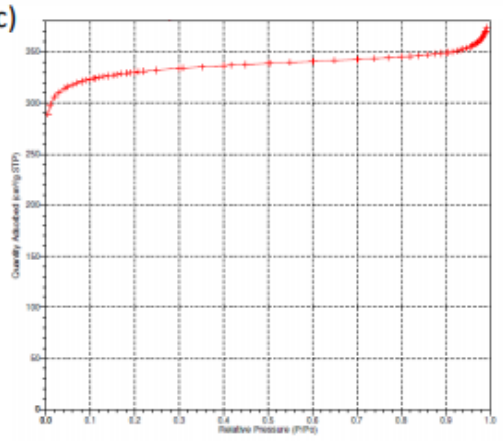

b)

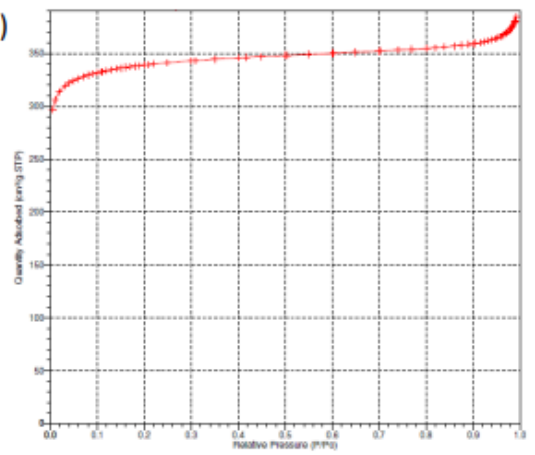

d)

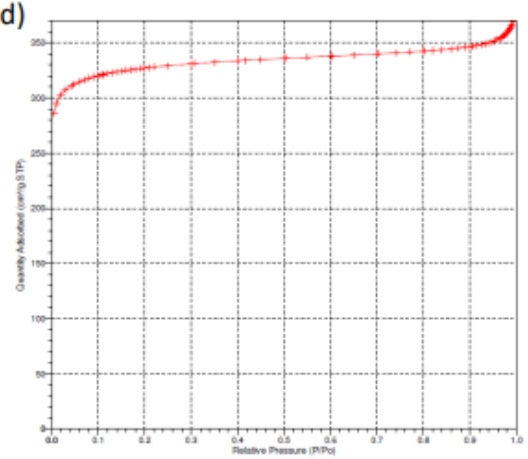

Figure S2. Isothermal $\mathrm{N}_{2}$ adsorption measurements for pristine $\mathrm{MIL}-125(\mathrm{Ti})-\mathrm{NH}_{2}$ (a), MIL-125(Ti)-NH $-5 m$ (b), MIL-125(Ti)- $\mathrm{NH}_{2}-10 \mathrm{~m}$ (c) and MIL-125(Ti)-NH $-15 \mathrm{~m}$ (d). 
a)

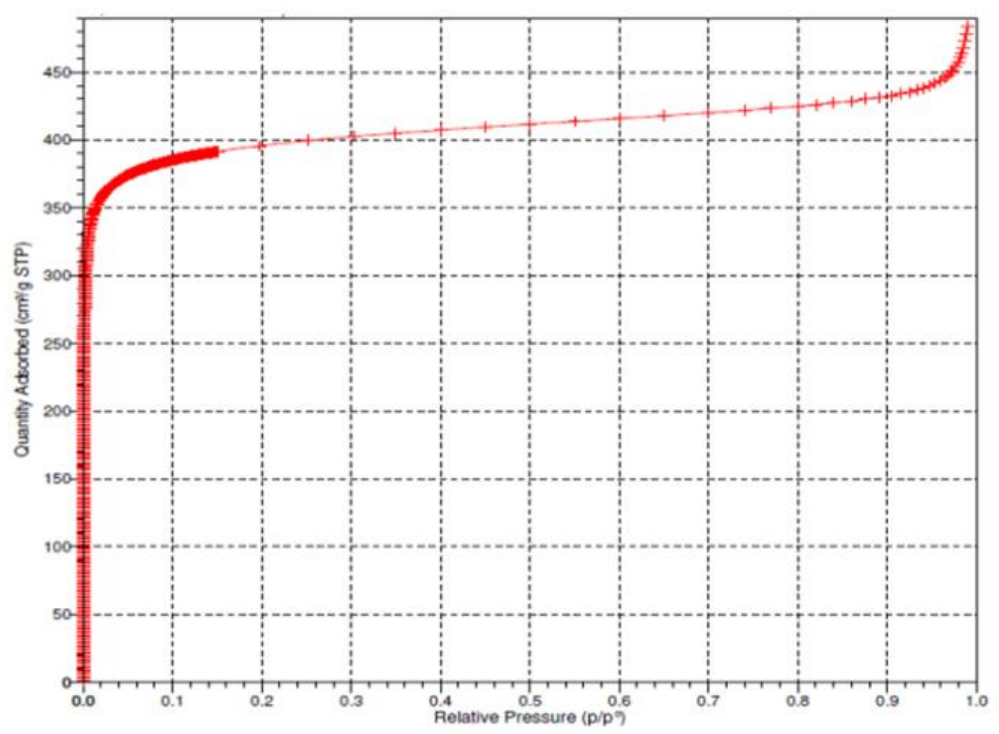

b)

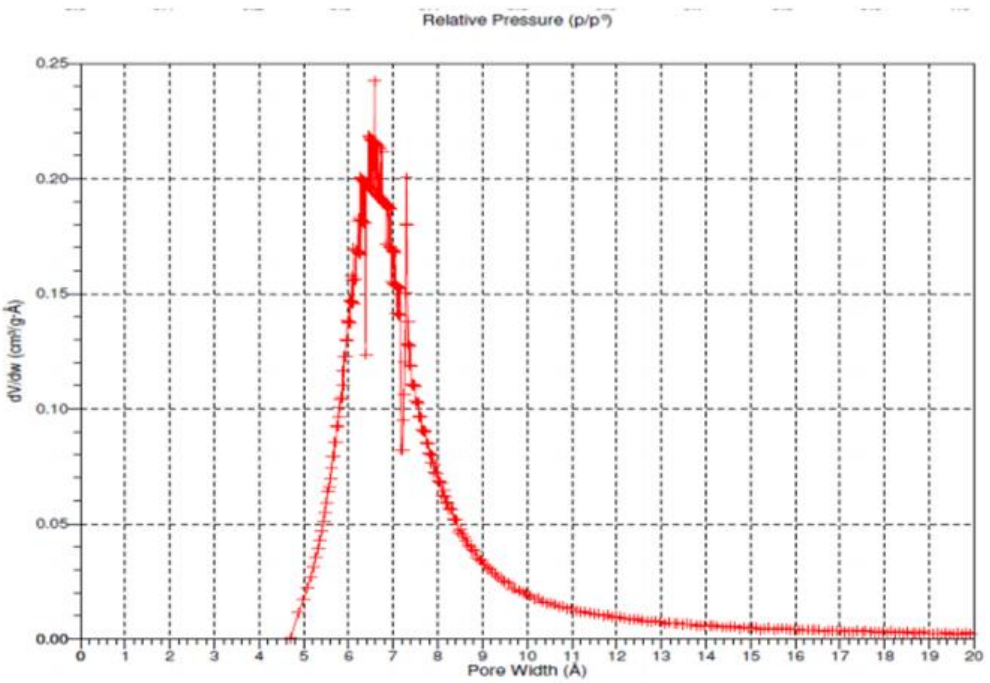

Figure S3. a) Isothermal Ar adsorption at $87 \mathrm{~K}$ and b) Horvath-Kawazoe differential pore volume plot for pristine MIL-125(Ti)- $\mathrm{NH}_{2}$ sample. 


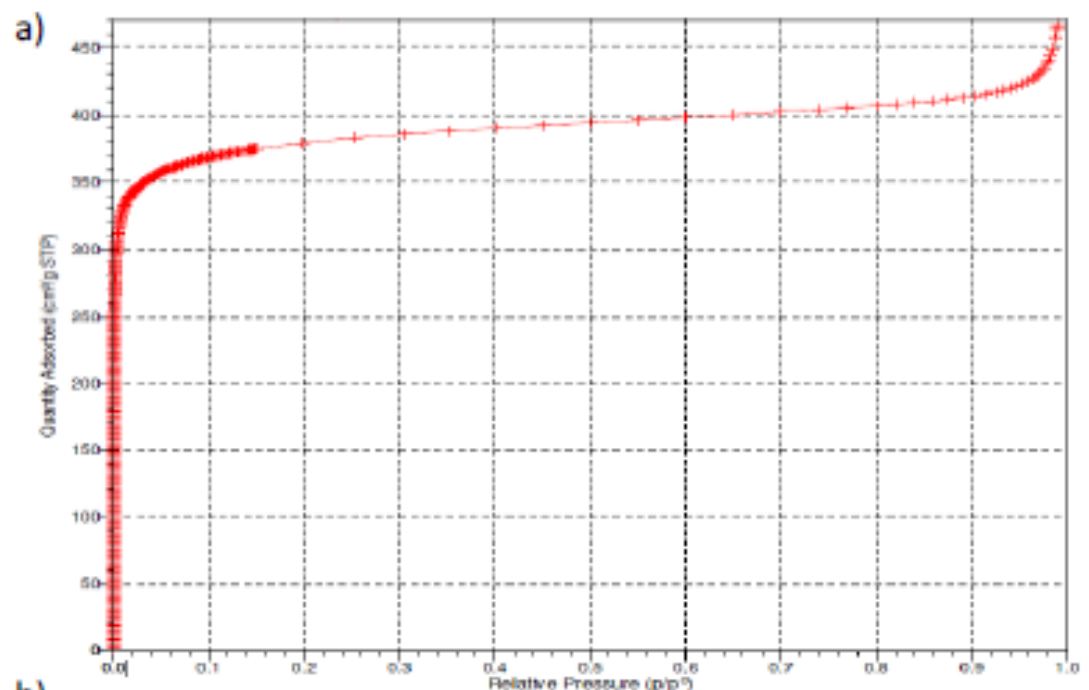

b)

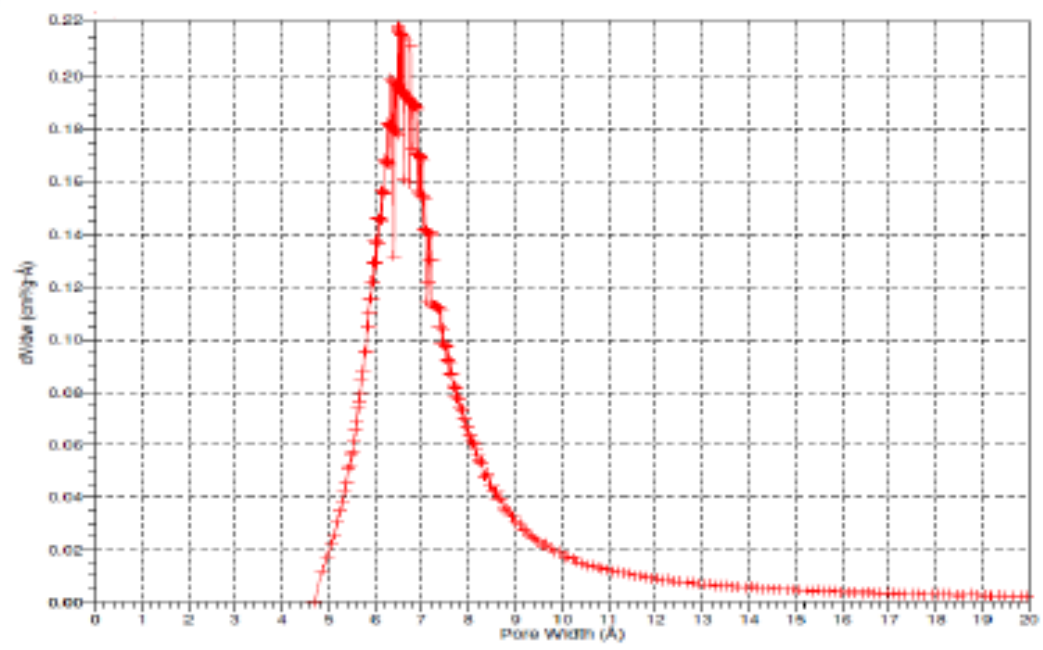

Figure S4. a) Isothermal Ar adsorption at $87 \mathrm{~K}$ and b) Horvath-Kawazoe differential pore volume plot for pristine MIL-125(Ti)- $\mathrm{NH}_{2}-10 \mathrm{~m}$ sample. 
a)

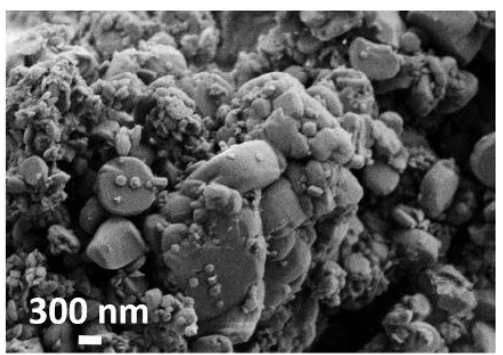

c)

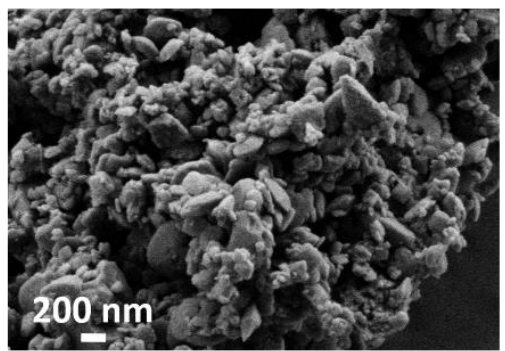

b)

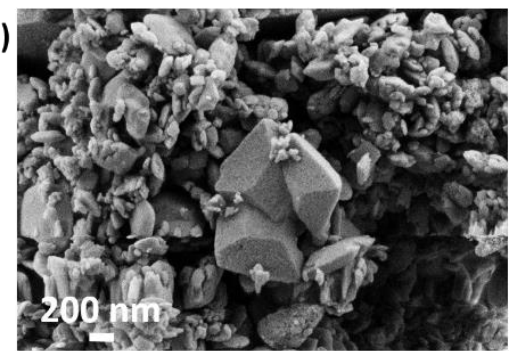

d)

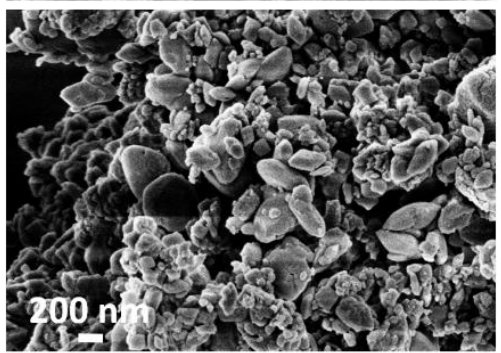

Figure S5. Representative SEM images of pristine MIL-125(Ti)- $\mathrm{NH}_{2}$ (a), MIL-125(Ti)- $\mathrm{NH}_{2}-5 \mathrm{~m}$ (b), MIL-125(Ti)- $\mathrm{NH}_{2}-10 \mathrm{~m}$ (c), MIL-125(Ti)- $\mathrm{NH}_{2}-15 \mathrm{~m}$ (d).

a)

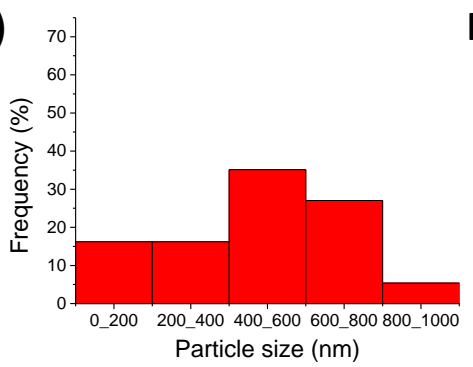

c)

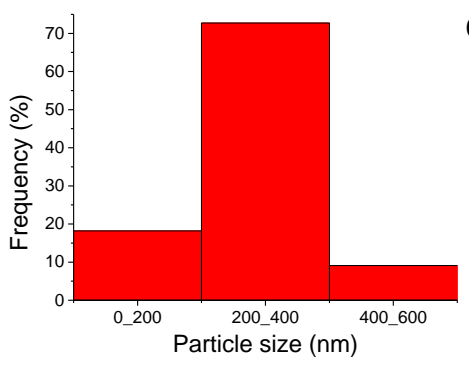

b)

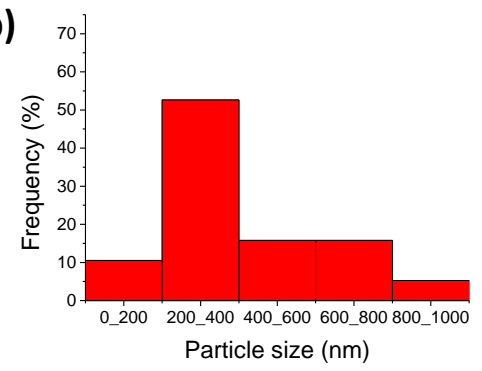

d)

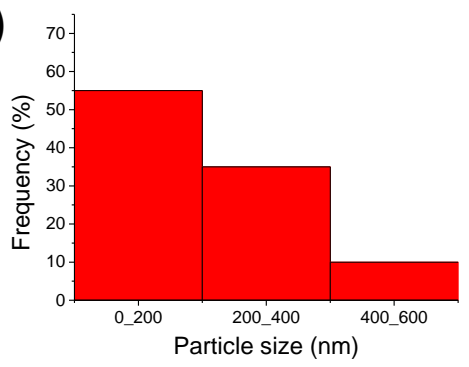

Figure S6. Particle size distribution for MIL-125(Ti)- $\mathrm{NH}_{2}$ (a), MIL-125(Ti)- $\mathrm{NH}_{2}-5 \mathrm{~m}$ (b), MIL-125(Ti)- $\mathrm{NH}_{2}-10 \mathrm{~m}$ (c), MIL-125(Ti)- $\mathrm{NH}_{2}-15 \mathrm{~m}$ (d). Data based on SEM measurements of more than 300 particles of each MOF sample. 
a)

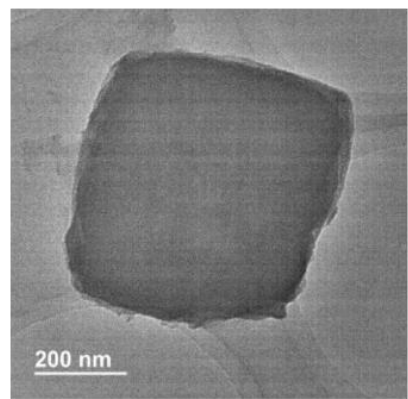

c)

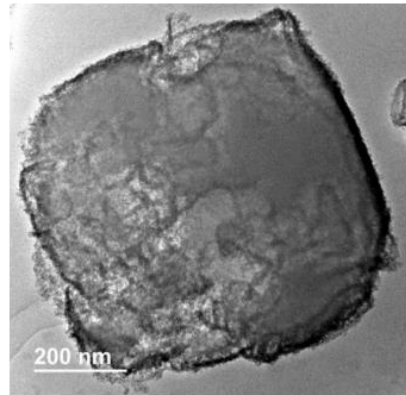

e)

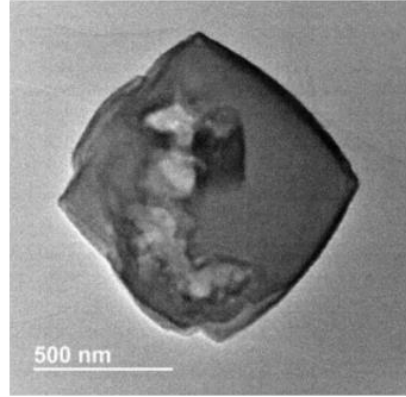

g)

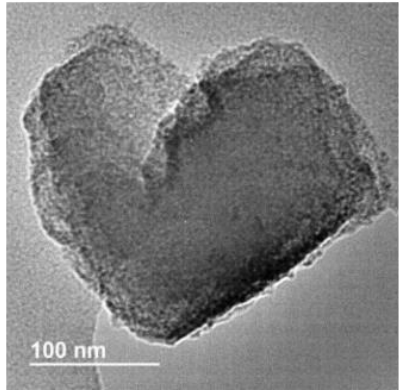

b)

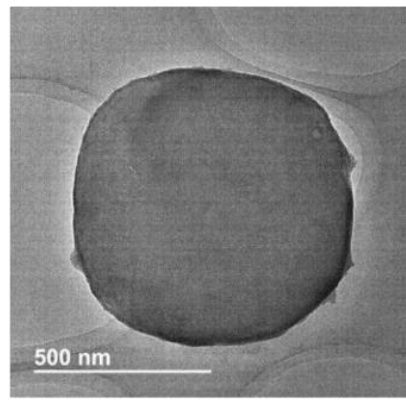

d)

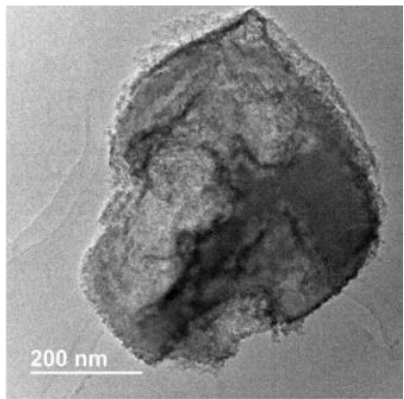

f)

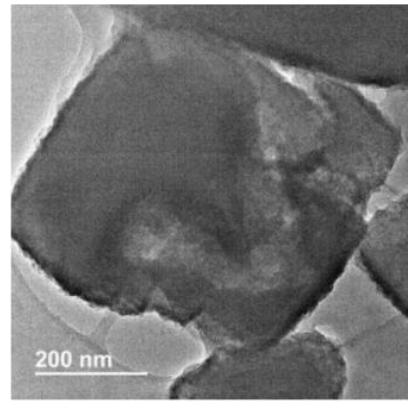

h)

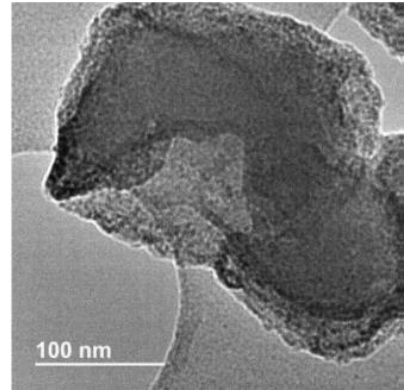

Figure S7. Representative TEM images of pristine MIL-125(Ti)- $\mathrm{NH}_{2}$ (a-b), MIL-125(Ti)- $\mathrm{NH}_{2}-5 \mathrm{~m}$ (cd), MIL-125(Ti)-NH $\mathrm{NH}_{2}-10 \mathrm{~m}$ (e-f), MIL-125(Ti)-NH $\mathrm{N}_{2}-15 \mathrm{~m}$ (g-h). 
a)

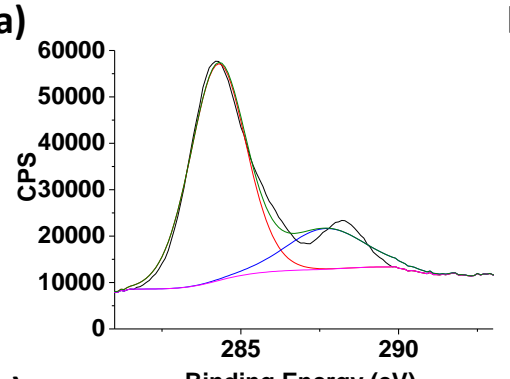

c)

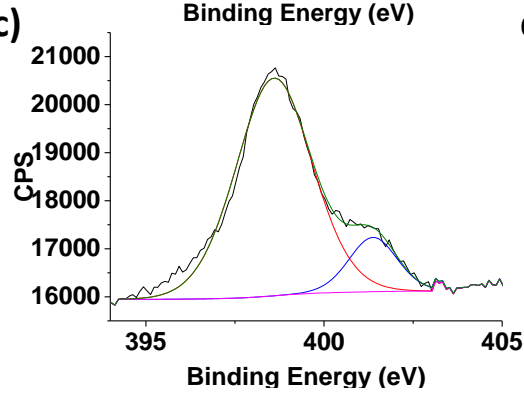

b)

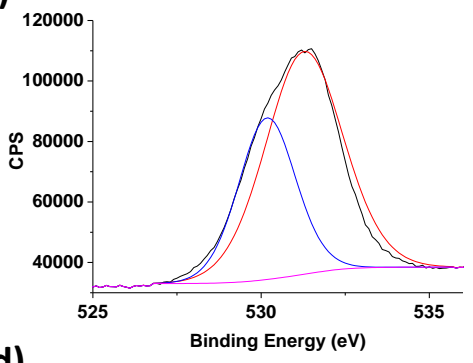

d)

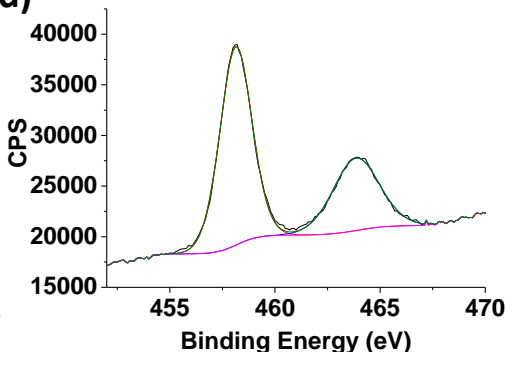

Figure S8. High resolution XPS peaks and the best deconvolution for the C1s (a), O1s (b) N1s (c) and Ti2p (d) signals recorded for the MIL-125(Ti)- $\mathrm{NH}_{2}$ sample.

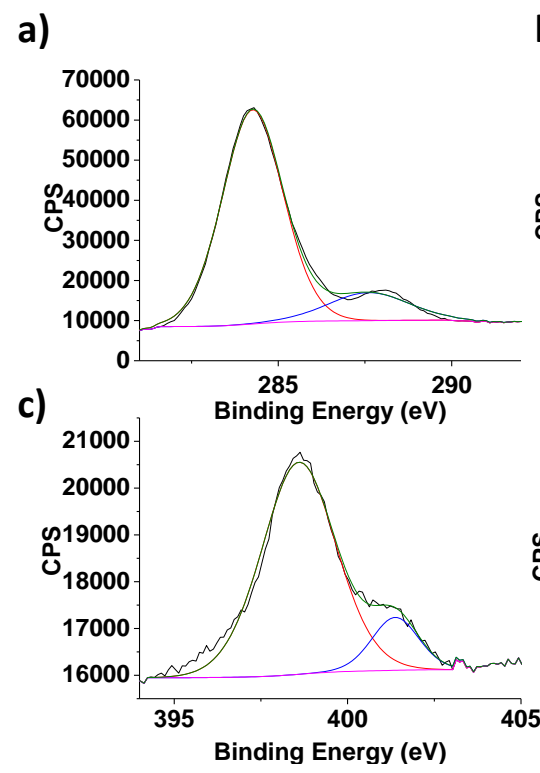

\section{b)}
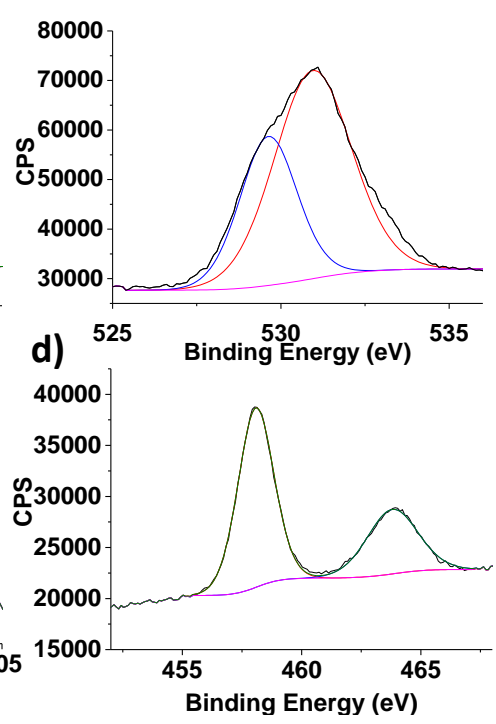

Figure S9. High resolution XPS peaks and the best deconvolution for the C1s (a), O1s (b) N1s (c) and Ti2p (d) signals recorded for the MIL-125(Ti)-NH $\mathrm{NH}_{2}-5 \mathrm{~m}$ sample. 

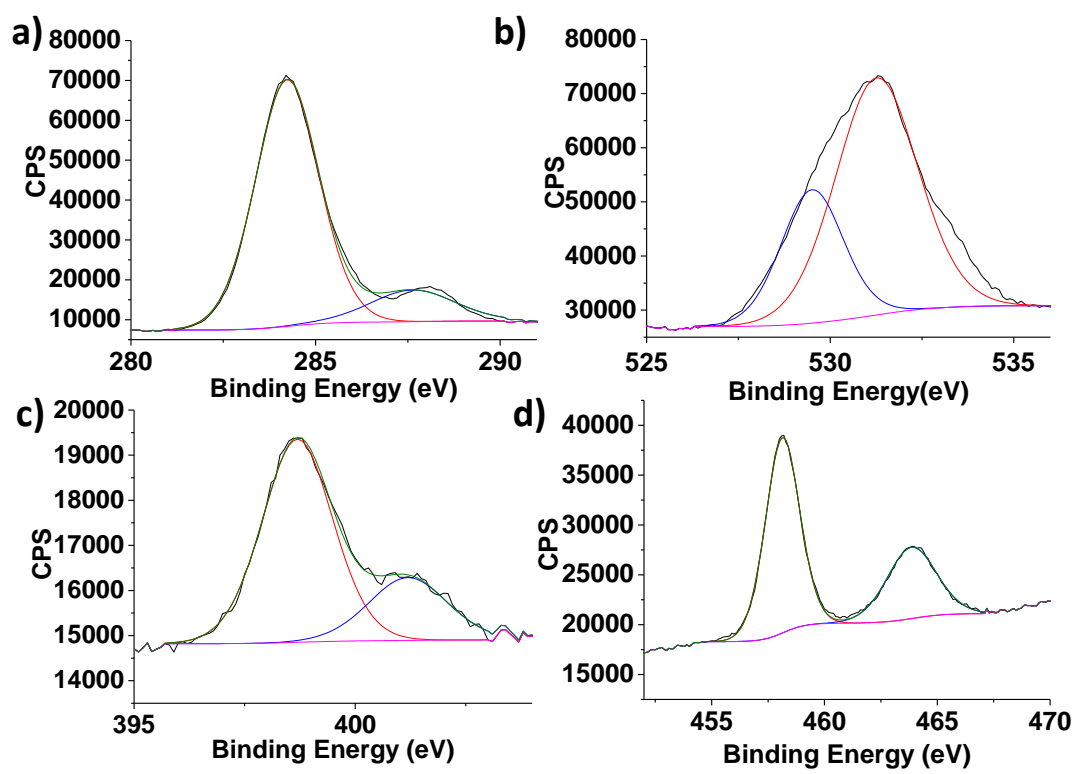

Figure S10. High resolution XPS peaks and the best deconvolution for the C1s (a), O1s (b) N1s (c) and Ti2p (d) signals recorded for the MIL-125(Ti)- $\mathrm{NH}_{2}-10 \mathrm{~m}$ sample.
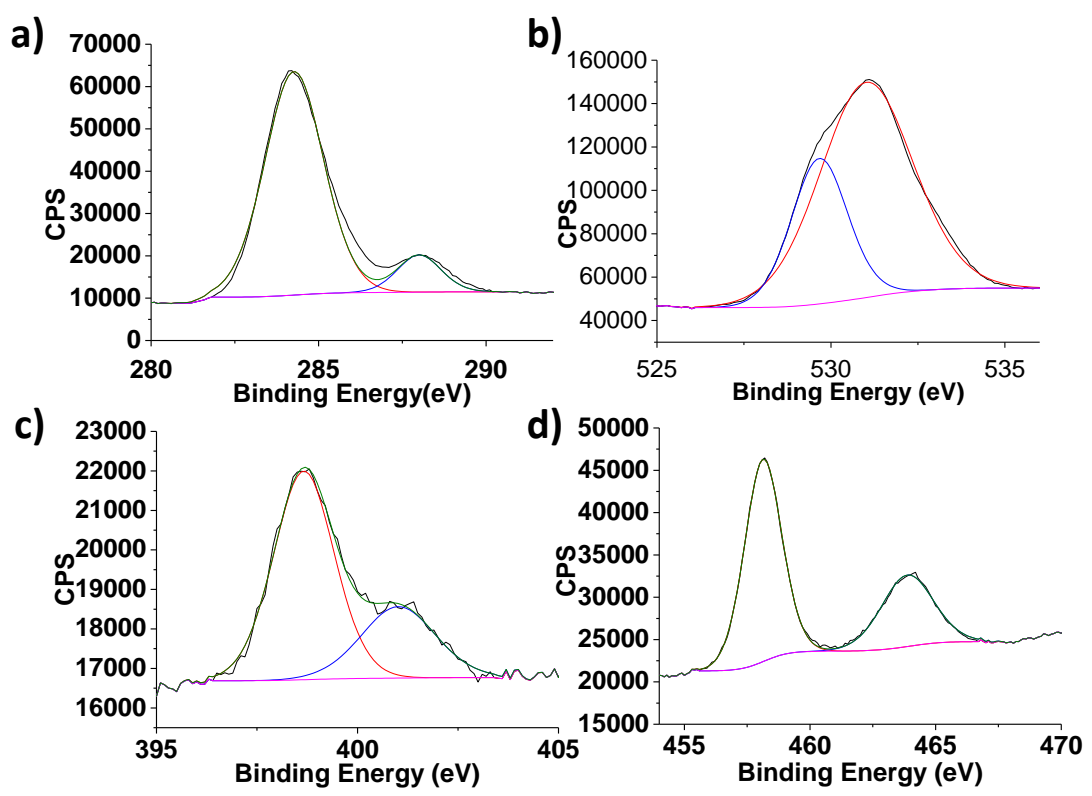

Figure S11. High resolution XPS peaks and the best deconvolution for the C1s (a), O1s (b) N1s (c) and Ti2p (d) signals recorded for the MIL-125(Ti)- $\mathrm{NH}_{2}-15 \mathrm{~m}$ sample. 
a)

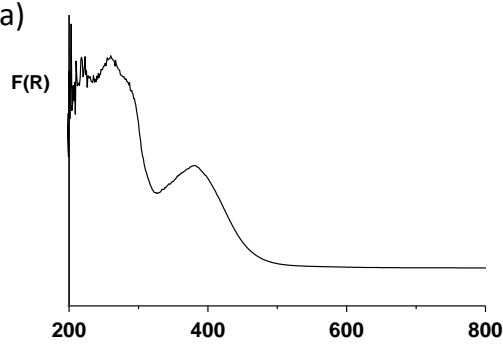

c)

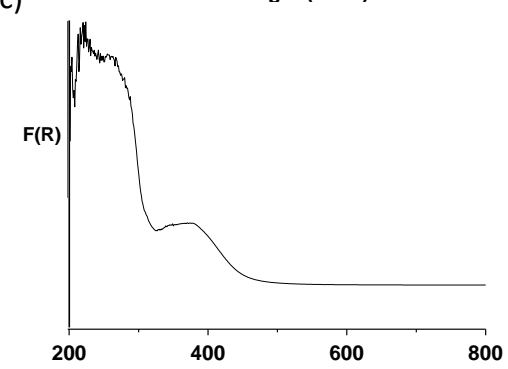

e)

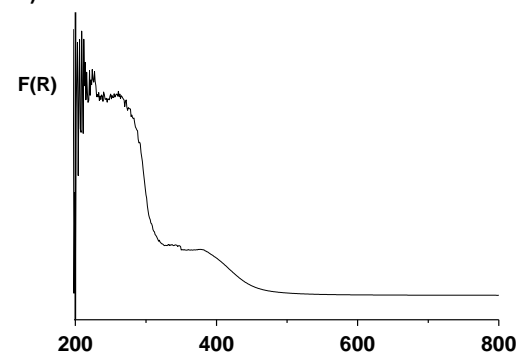

g)

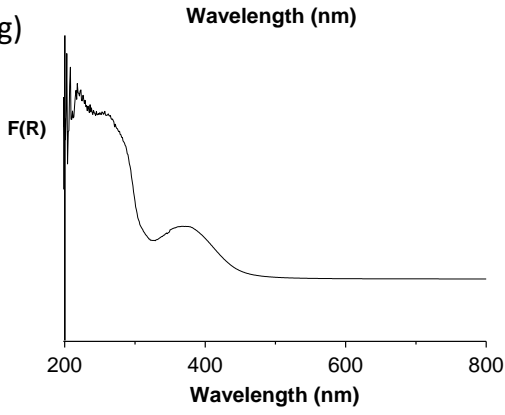

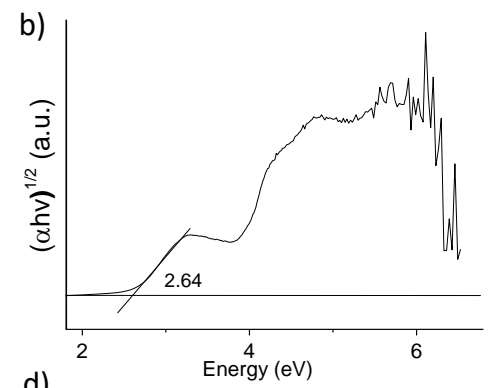

d)
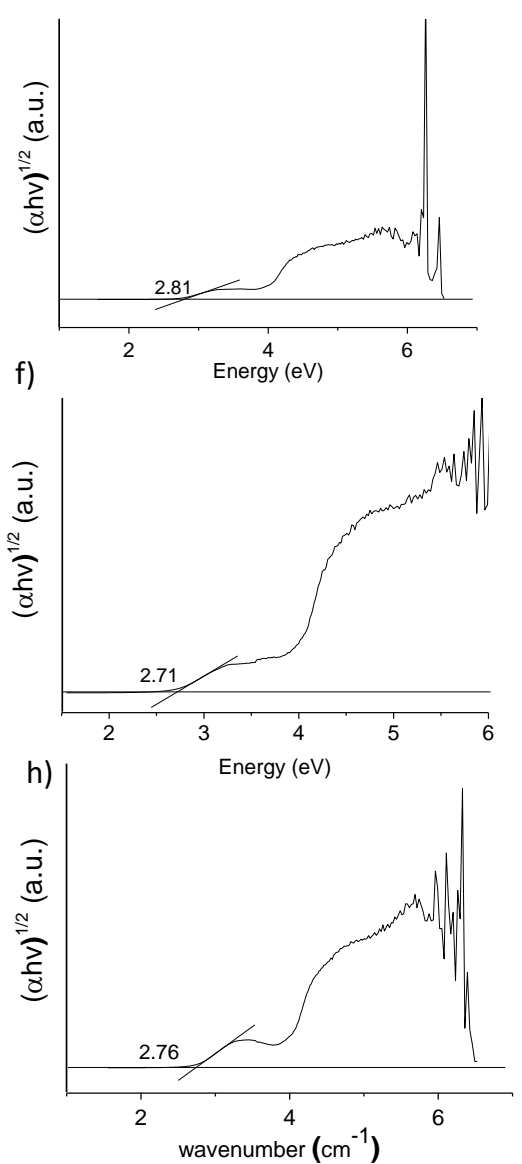

Figure S12. Diffuse reflectance UV-Vis $(a, c$, e and $g$ ) and Tauc plot $(b, d, f$ and $h)$ for MIL-125(Ti)-NH $\mathrm{NH}_{2}$ (a, b), MIL-125(Ti)-NH $-5 \mathrm{~m} \quad$ (c, d), MIL-125(Ti)-NH $-10 m$ (e, f), MIL-125(Ti)-NH $-15 m(g, h)$. 
a)

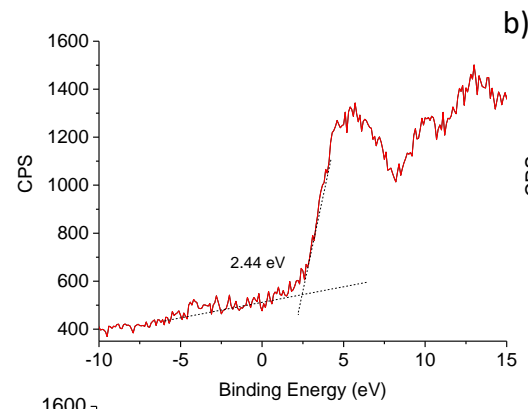

c)

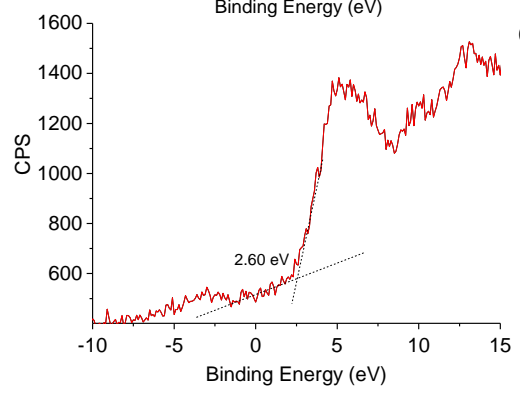

b)
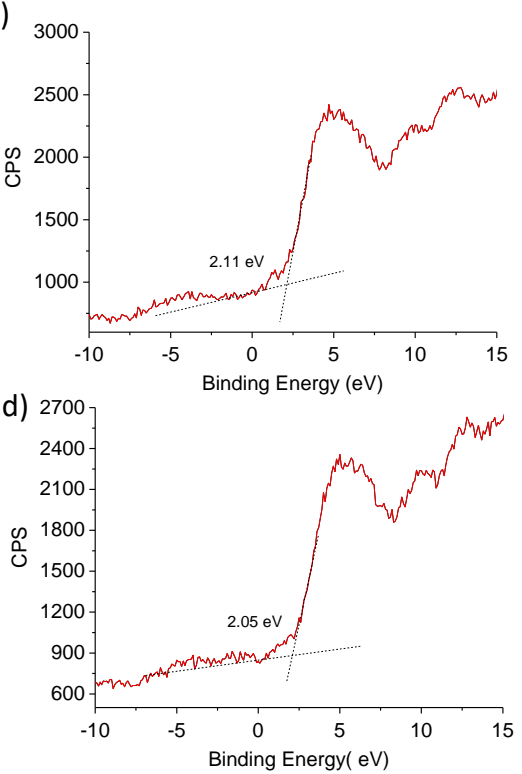

Figure S13. Region of XPS intensity onset from where the valence band potential values were

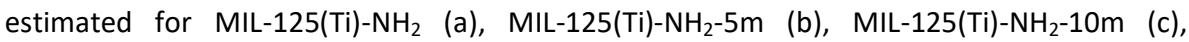
MIL-125(Ti)- $\mathrm{NH}_{2}-15 \mathrm{~m}$ (d).

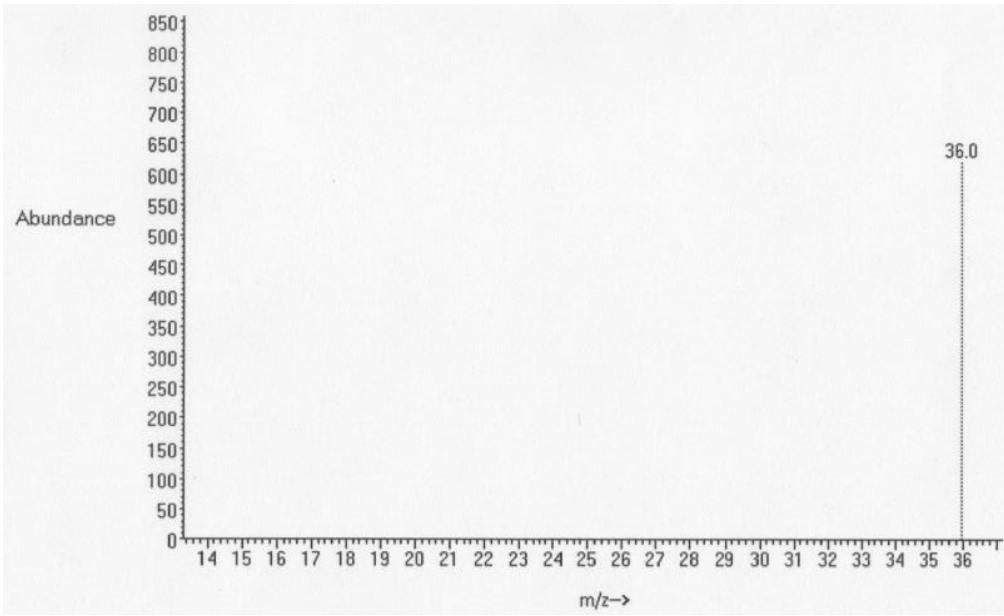

Figure S14. Mass spectrum of the head space gas for the overall splitting of labelled $\mathrm{H}_{2}{ }^{18} \mathrm{O}$ using MIL-125(Ti)- $\mathrm{NH}_{2}-10 \mathrm{~m}$ as photocatalyst under simulated sunlight irradiation. Reaction conditions: photocatalyst $(20 \mathrm{mg}), \mathrm{H}_{2} \mathrm{O}(20 \mathrm{~mL})$, Xe lamp $(150 \mathrm{~W}), 35^{\circ} \mathrm{C}$, reaction time $22 \mathrm{~h}$. 

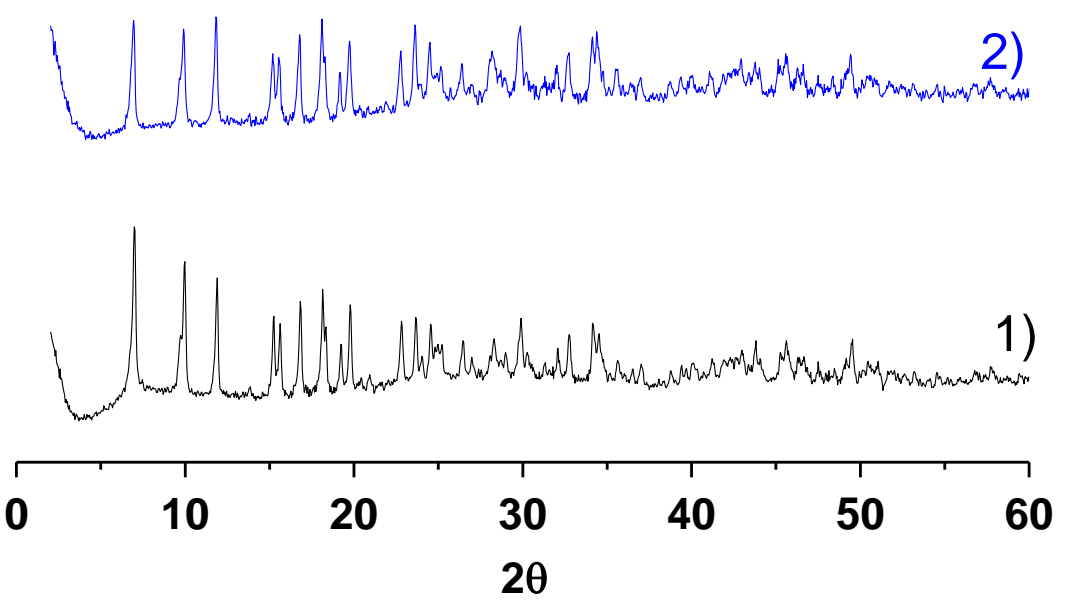

Figure S15. XRD of fresh (1) and used (2) MIL-125(Ti)- $\mathrm{NH}_{2}$ after the overall water splitting under simulated sunlight irradiation. Reaction conditions: photocatalyst $(20 \mathrm{mg}), \mathrm{H}_{2} \mathrm{O}(20 \mathrm{~mL})$, $35^{\circ} \mathrm{C}$, reaction time $22 \mathrm{~h}$.

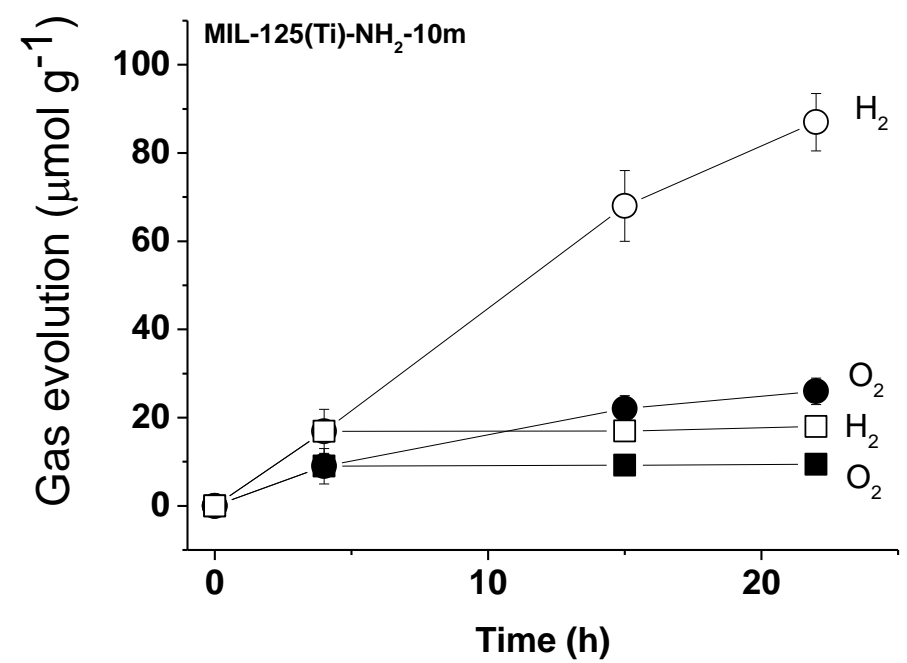

Figure S16. Photocatalytic overall water splitting in the presence of MIL-125(Ti)- $\mathrm{NH}_{2}$ as photocatalyst (circle symbols) and after the removal of the catalyst at about $4 \mathrm{~h}$ of the reaction (close symbols) under simulated sunlight irradiation. Reaction conditions: photocatalyst (20 $\mathrm{mg})$, solar simulator (1 sun), $\mathrm{H}_{2} \mathrm{O}(20 \mathrm{~mL}), 35^{\circ} \mathrm{C}$, reaction time $22 \mathrm{~h}$. 
Table S1 collects the percentage of $\mathrm{Ti}$, organic matter and the different $\mathrm{O}$ atom types present in the ideal formula as well as the MIL-125(Ti)- $\mathrm{NH}_{2}$ samples under study estimated by TGA. The amount of oxygen present in the metal node for the pristine and plasma treated MIL-125(Ti)- $\mathrm{NH}_{2}$ samples is estimated in Table $\mathrm{S} 2$.

Table S1. Percentage of different MIL-125(Ti)- $\mathrm{NH}_{2}$ components present in the ideal and MOF samples under study.

\begin{tabular}{|c|c|c|c|c|c|}
\hline Sample & $\mathrm{Ti}(\%)$ & $\begin{array}{l}\text { O cluster } \\
(\%)\end{array}$ & $\begin{array}{l}\mathrm{OH} \\
(\%)\end{array}$ & $\begin{array}{l}\text { Organic } \\
\text { content }\end{array}$ & $\begin{array}{c}\text { Organic } \\
\mathrm{O}(\%)\end{array}$ \\
\hline $\begin{array}{c}\left(\mathrm{Ti}_{8} \mathrm{O}_{8}\right)(\mathrm{OH})_{4}\left(\mathrm{C}_{6} \mathrm{H}_{3} \mathrm{C}_{2} \mathrm{O}_{4} \mathrm{NH}_{2}\right)_{6} \\
\text { ideal }\end{array}$ & 23.2 & 7.7 & 4.1 & 65 & 23.2 \\
\hline MIL-125(Ti)- $\mathrm{NH}_{2}$ pristine & $22.95^{a}$ & - & $3.52^{\mathrm{a}}$ & $50.3^{a}$ & $18^{d}$ \\
\hline MIL-125(Ti)-NH $\mathrm{N}_{2}-5 \mathrm{~m}$ & 24.60 & - & 1.34 & 45.8 & 16.4 \\
\hline MIL-125(Ti)-NH $-10 m$ & 29.2 & - & 1.6 & 40.3 & 14.4 \\
\hline MIL-125(Ti)-NH $2-15 m$ & 29.2 & - & 1.6 & 55.0 & 19.7 \\
\hline
\end{tabular}

a From TGA data considering the residue at $600{ }^{\circ} \mathrm{C}$ to be $\mathrm{TiO}_{2}$

b From TGA data considering the weight loss between 220 and $320^{\circ} \mathrm{C}$

c From TGA data considering the weight loss between 320 and $600{ }^{\circ} \mathrm{C}$

d Percentage of organic oxygen

The amount of oxygen present in the titanium cluster, ideally $\mathrm{Ti}_{8} \mathrm{O}_{8}$, was estimated from elemental analysis of the different samples under study was carried out. 
Table S2. Percentage of different atoms present in the ideal and MIL-125(Ti)- $\mathrm{NH}_{2}$ samples under study.

\begin{tabular}{|c|c|c|c|c|c|c|c|}
\hline Sample & $C(\%)$ & $H(\%)$ & $N(\%)$ & $\begin{array}{c}\text { O in the metal } \\
\text { cluster }\end{array}$ & $\begin{array}{c}\mathrm{O} \text { in } \mathrm{OH} \\
(\%)\end{array}$ & $\begin{array}{c}\text { Organic O } \\
(\%)\end{array}$ & $\mathrm{Ti}(\%)$ \\
\hline $\begin{array}{c}\left(\mathrm{Ti}_{8} \mathrm{O}_{8}\right)(\mathrm{OH})_{4} \\
\left(\mathrm{C}_{6} \mathrm{H}_{3} \mathrm{C}_{2} \mathrm{O}_{4} \mathrm{NH}_{2}\right)_{6} \text { ideal }\end{array}$ & 34.8 & 2.1 & 5.1 & 7.7 & 3.9 & 23.2 & 23.2 \\
\hline $\begin{array}{l}\text { MIL-125(Ti)-NH } \\
\text { pristine }\end{array}$ & 35.6 & 2.3 & 6.3 & 11.5 & 3.3 & 18 & 23 \\
\hline MIL-125(Ti)- $\mathrm{NH}_{2}-5 \mathrm{~m}$ & 31.1 & 2.7 & 5.5 & 18.5 & 1.3 & 16.4 & 24.6 \\
\hline $\begin{array}{c}\text { MIL-125(Ti)- } \mathrm{NH}_{2-} \\
10 \mathrm{~m}\end{array}$ & 29.0 & 2.7 & 5.4 & 17.8 & 1.5 & 14.4 & 29.2 \\
\hline $\begin{array}{c}\text { MIL-125(Ti)- } \mathrm{NH}_{2}- \\
15 \mathrm{~m}\end{array}$ & 32.9 & 2.4 & 6.3 & 8.1 & 1.5 & 19.7 & 29.2 \\
\hline
\end{tabular}

a Percentage estimated by difference: 100 - (combined percentages of $\mathrm{C}, \mathrm{H}, \mathrm{N}, \mathrm{O}$ in $\mathrm{OH}, \mathrm{O}$ in the organic ligand and $\mathrm{Ti}$ )

Table S3. Moles of different atoms present in the ideal and MIL-125(Ti)- $\mathrm{NH}_{2}$ samples under study.

\begin{tabular}{|c|c|c|c|c|c|c|c|c|}
\hline Sample & $\begin{array}{c}C \\
(\%)\end{array}$ & $\begin{array}{c}\mathrm{H} \\
(\%)\end{array}$ & $\mathrm{N}(\%)$ & $\begin{array}{l}\text { O in the } \\
\text { metal } \\
\text { cluster }\end{array}$ & $\begin{array}{l}\mathrm{O} \text { in } \\
\mathrm{OH} \\
(\%)\end{array}$ & $\begin{array}{l}\text { Org. } \\
\mathrm{O}(\%)\end{array}$ & $\begin{array}{c}\mathrm{Ti} \\
(\%)\end{array}$ & $\begin{array}{l}\text { Org } \\
(\%)\end{array}$ \\
\hline \multicolumn{9}{|l|}{$\left(\mathrm{Ti}_{8} \mathrm{O}_{8}\right)(\mathrm{OH})_{4}$} \\
\hline$\left(\mathrm{C}_{6} \mathrm{H}_{3} \mathrm{C}_{2} \mathrm{O}_{4}\right.$ & 48 & 34 & 6 & 8 & 4 & 24 & 8 & 6 \\
\hline $\left.\mathrm{NH}_{2}\right)_{6}$ ideal & & & & & & & & \\
\hline $\begin{array}{l}\text { MIL-125(Ti)- } \\
\mathrm{NH}_{2} \text { pristine }\end{array}$ & 49.1 & 38.8 & 7.4 & 11.9 & 3.4 & 18.6 & 7.9 & 4.6 \\
\hline $\begin{array}{l}\text { MIL-125(Ti)- } \\
\mathrm{NH}_{2}-5 \mathrm{~m}\end{array}$ & 42.9 & 44.8 & 6.4 & 19.1 & 1.3 & 16.9 & 8.5 & 4.2 \\
\hline $\begin{array}{l}\text { MIL-125(Ti)- } \\
\mathrm{NH}_{2}-10 \mathrm{~m}\end{array}$ & 40.0 & 45.2 & 6.4 & 18.4 & 1.5 & 14.9 & 10.1 & 3.7 \\
\hline $\begin{array}{l}\text { MIL-125(Ti)- } \\
\mathrm{NH}_{2}-15 \mathrm{~m}\end{array}$ & 45.4 & 39.6 & 7.5 & 8.3 & 1.5 & 20.3 & 10.1 & 5.1 \\
\hline
\end{tabular}


Chapter 4. Plasma-Induced defects enhance the visible-light photocatalytic activity of MIL-125(Ti)-NH for $_{\text {overall water }}$ splitting

Table S4. List of atomic $\mathrm{C} / \mathrm{Ti}$ and $\mathrm{O} / \mathrm{Ti}$ ratios obtained by elemental analyses.

\begin{tabular}{|c|c|c|}
\hline Sample & $\mathrm{C} / \mathrm{Ti}$ & $\mathrm{O} / \mathrm{Ti}$ \\
\hline$\left(\mathrm{Ti}_{8} \mathrm{O}_{8}\right)(\mathrm{OH})_{4}\left(\mathrm{C}_{6} \mathrm{H}_{3} \mathrm{C}_{2} \mathrm{O}_{4} \mathrm{NH}_{2}\right)_{6}$ ideal & 6 & 4.5 \\
\hline MIL-125(Ti)- $\mathrm{NH}_{2}$ pristine & 6.19 & 4.3 \\
\hline MIL-125(Ti)- $\mathrm{NH}_{2}-5 \mathrm{~m}$ & 5.0 & 4.4 \\
\hline MIL-125(Ti)-NH $-10 m$ & 4.0 & 3.45 \\
\hline MIL-125(Ti)-NH $-15 m$ & 4.5 & 3.0 \\
\hline
\end{tabular}





\section{Chapter 5}

Design of cost-efficient and photocatalytically active Zn-based MOFs decorated with $\mathrm{Cu}_{2} \mathrm{O}$ nanoparticles for $\mathrm{CO}_{2}$ methanation. 



\subsection{Abstract}

Here we show for the first time a MOF that is photocatalytically active for light-assisted $\mathrm{CO}_{2}$ methanation under mild conditions $\left(215^{\circ} \mathrm{C}\right)$ without the inclusion of metallic nanoparticles or any sacrificial agent. The presence of $\mathrm{Cu}_{2} \mathrm{O}$ nanoparticles causes a $50 \%$ increase in the photocatalytic activity. This result paves the way for developing efficient and cost-effective materials for $\mathrm{CO}_{2}$ elimination.

\subsection{Introduction}

The development of technologies that allow the efficient fixation and transformation of $\mathrm{CO}_{2}$ into valuable chemicals such as $\mathrm{CH}_{3} \mathrm{OH}$, or fuels such as $\mathrm{CH}_{4}$ will lead to a decrease in the atmospheric emissions of the main greenhouse gas responsible for global warming. ${ }^{[1]}$ One of the traditional routes for this purpose is the Sabatier reaction, which consists of $\mathrm{CO}_{2}$ reduction to $\mathrm{CH}_{4}$ using molecular $\mathrm{H}_{2}$. This reaction occurs at high temperatures, Typically, above $550{ }^{\circ} \mathrm{C}$, and requires the presence of a heterogeneous catalyst. In general, high efficiencies can be achieved employing noble metal nanoparticles (NPs) or clusters as active centers supported in high surface area materials. ${ }^{[1,2]}$ Some cost effective metals such as $\mathrm{Cu}$, Co or $\mathrm{Ni}$ can be employed as active centres for $\mathrm{CO}_{2}$ methanation, Although metal NP sintering commonly occurs at high temperatures $\left(\sim 300^{\circ} \mathrm{C}\right)$ causing catalyst deactivation. ${ }^{[2,3]}$ More recently, the photocatalytic version of the Sabatier reaction has become a possible alternative, allowing a decrease in the reaction temperature with a minimum impact on the resulting catalytic activity and partially avoiding catalyst deactivation by metal NP aggregation. ${ }^{[4]}$

During the last 30 years, metal-organic frameworks (MOFs), materials constituted by organic ligands coordinated to metal ions or clusters defining a porous and crystalline network, ${ }^{[5]}$ have been employed for $\mathrm{CO}_{2}$ fixation and/or valorisation. ${ }^{[6]}$ In addition, MOFs have shown to be excellent catalysts for different reactions, ${ }^{[7]}$ and are even currently used as photocatalysts, ${ }^{[8]}$ for visible light $\mathrm{CO}_{2}$ reduction by triethanolamine, ${ }^{[9]}$ or for promoting $\mathrm{C}-\mathrm{C}$ bond formation. ${ }^{[10]}$ In most 
cases, they exhibit an intrinsic photoresponse which can be combined with the presence of metal NPs in the pores in order to promote charge separation favouring electron transfer to the substrate. ${ }^{[1]}$ However, the use of MOFs to promote the Sabatier reaction is almost unexplored, ${ }^{[12,13]}$ possibly due to the severe conditions of this reaction that are not compatible with the stability of many MOFs.

In this work, we report photoassisted $\mathrm{CO}_{2}$ methanation by a MOF of formula $\left[\mathrm{Zn}_{3}(\text { btca })_{2}(\mathrm{OH})_{2}\right]\left(\mathrm{H}_{2}\right.$ btca $=1$ 2,3-benzotriazole-5-carboxylic acid). ${ }^{[14]}$ This MOF, denoted as $\operatorname{MOF}(Z n)-1$, is based on infinite rod-shape secondary building units (SBUs) formed by two independent 6-coordinated Zn(") centres bridged by hydroxyl groups and by carboxylate and triazolate groups from the ligand (Figure 1a). This flexible MOF contains 1D pores whose size depends on the degree of solvation (see the ESI, Figure S1 and S2).

The $\mathrm{CO}_{2}$ sorption capacity of $\operatorname{MOF}(\mathrm{Zn})-1$ has been previously described with different values depending on the activation temperature: Xiao et al. ${ }^{[14]}$ reported a BET surface area of $700 \mathrm{~m}^{2} \mathrm{~g}^{-1}$ calculated from $\mathrm{CO}_{2}$ sorption at 1 bar and $195 \mathrm{~K}$ when activating the material at $4401 \mathrm{C}$, whereas Yue et al. ${ }^{[15]}$ reported a BET value of 300 $\mathrm{m}^{2} \mathrm{~g}^{-1}$, under the same conditions, when the material was activated at $150{ }^{\circ} \mathrm{C}$. In order to further understand these contradictory results, we have performed a detailed structural analysis on the different degrees of breathing depending on the temperature of activation. We concluded that increasing the temperature causes a continuous breathing with a decrease in the volume cell similar to other reported MOFs (see Figure S1, ESI). ${ }^{[16]}$ However, upon further heating (above $400{ }^{\circ} \mathrm{C}$ ), the MOF exhibits an irreversible phase transition with an unexpected pore opening and modification of the SBU and metal coordination environment, which is accompanied by some loss of crystallinity (see Figure S2 and S3, ESI). The activated sample at 400 ${ }^{\circ} \mathrm{C}$ is referred to as $\operatorname{MOF}(\mathrm{Zn})-2$. 

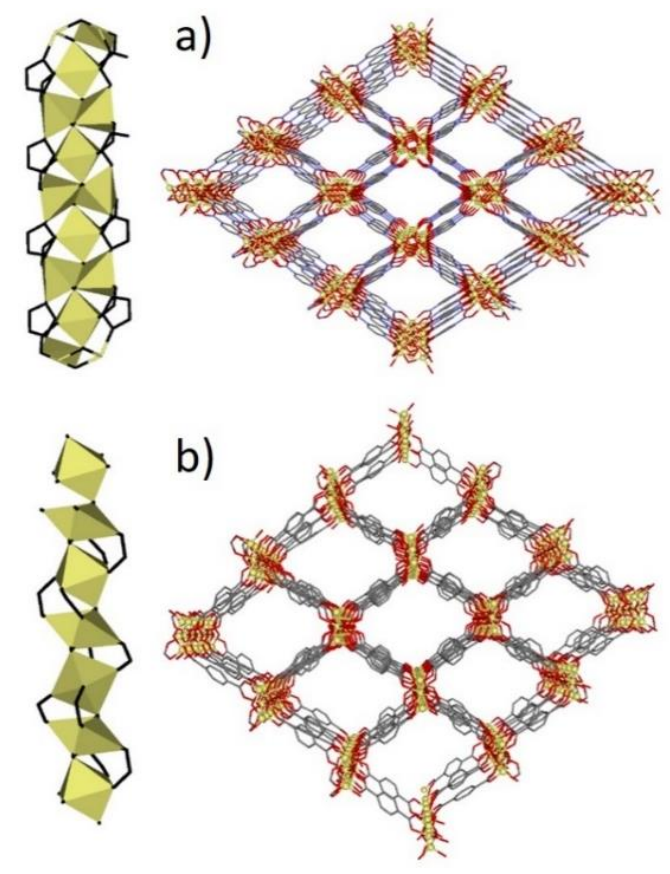

Figure 1. Representation of crystal structures along the c-axes of (a) $\operatorname{MOF}(\mathrm{Zn})-1$ and (b) MOF-74(Zn). The rod-like SBU is shown for each MOF, together with a schematic representation of the ligand.

$\operatorname{MOF}(Z n)-1$ combines the presence of the active counterparts of the benchmark reference material for $\mathrm{CO}_{2}$ methanation $(\mathrm{ZnO})$, together with a $\mathrm{N}$-electron rich heteroatom network of a porous structure with a specific pore size for $\mathrm{CO}_{2}$ interaction. Thus, we have explored the activity of this material for photoassisted $\mathrm{CO}_{2}$ methanation by molecular hydrogen and compared it with MOF(Zn)-2 and two reference materials, MOF-74(Zn), ${ }^{[17]}$ and MIL-125(Ti)-NH ${ }_{2}{ }^{[18]}$ MOF-74(Zn) is very similar to $\operatorname{MOF}(Z n)-1$ from a structural point of view, as both MOFs are formed by rod-like SBUs of the same metal (ZnII), albeit in the case of MOF-74(Zn) with no nitrogenated ligands (Figure 1b). MIL-125(Ti)-NH2 exhibits a structure based on octameric $\mathrm{Ti}_{8} \mathrm{O}_{4}(\mathrm{OH})_{4}$ oxoclusters and 2-amino-terephthalate dianions and has been shown to be an efficient photocatalyst. ${ }^{[19]}$ 
$\operatorname{MOF}(\mathrm{Zn})-1$ exhibits intrinsic activity for selective photocatalytic $\mathrm{CO}_{2}$ methanation under a stoichiometric amount of hydrogen at $215^{\circ} \mathrm{C}$ under UV-vis irradiation (Figure 2). The only product observed is methane, with an initial $\mathrm{CH}_{4}$ production of $4 \mu \mathrm{mol} \mathrm{g} \mathrm{cat}^{-1} \mathrm{~h}^{-1}$, and $30 \mu \mathrm{mol} \mathrm{g}_{\text {catalyst }}{ }^{-1}$ after 24 hours. Although this activity value is not large, this is the first time that a bare MOF, i.e. without the addition of any nanoparticle or any sacrificial agent, exhibits photocatalytic activity for the Sabatier reaction. The temporal profile of $\mathrm{CO}_{2}$ generation exhibits two regimes with two different reaction rates, which has been previously attributed to the effect of $\mathrm{H} 2 \mathrm{O}$ formed in the reaction simultaneously with $\mathrm{CH}_{4}$ deactivating the catalyst. ${ }^{[4 c]}$ Blank control experiments in the presence of the $\operatorname{MOF}(\mathrm{Zn})-1$ catalyst and $\mathrm{H}_{2}$ as a reducing agent, but in the absence of $\mathrm{CO}_{2}$, do not show the formation of methane. Similarly, performing the photocatalytic reaction at room temperature, or upon irradiation of visible light only, does not produce any methane. The other blank control in the absence of UV-vis light irradiation results in a methane production lower than $0.1 \mu \mathrm{mol}$ gatalyst $^{-1}$ after $24 \mathrm{~h}$.

Importantly, the catalytic activity of MOF-74(Zn) or MIL-125(Ti)- $\mathrm{NH}_{2}$ is negligible under the same reaction conditions (see Figure 2). This lack of photocatalytic activity can be a consequence of the low harnessing ability of these MOFs in comparison to $\operatorname{MOF}(\mathrm{Zn})-1$, as their $\mathrm{CO}_{2}$ adsorption capacity is higher. Interestingly, $\operatorname{MOF}(\mathrm{Zn})-2$, which has a wider pore aperture than $\operatorname{MOF}(\mathrm{Zn})-1$, is less active (initial production of $2.88 \mu \mathrm{mol}$ gcatalyst $^{-1} \mathrm{~h}^{-1}$ and $15 \mu \mathrm{mol}$ gcatatalyst $^{-1}$ after 24 hours) for photocatalytic $\mathrm{CO}_{2}$ methanation than $\operatorname{MOF}(\mathrm{Zn})-1$, which can be explained by the modification of the SBU and the loss in crystallinity of the bulk material upon temperature treatment, as shown by X-ray powder diffraction (see Figure S2, ESI). 


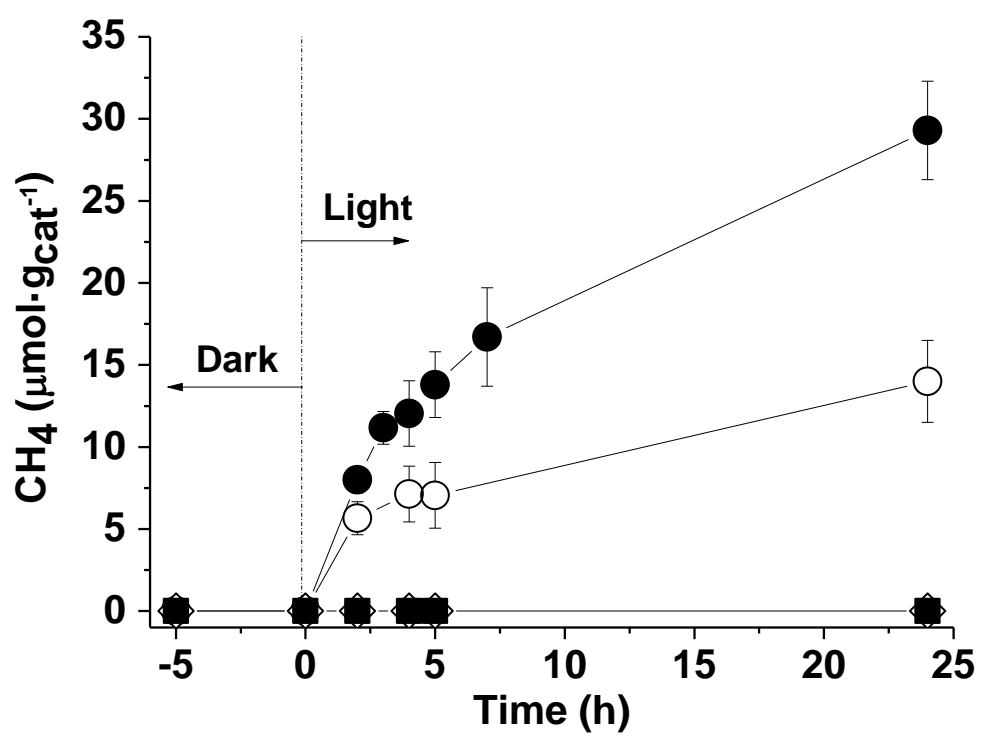

Figure 2. $\mathrm{CH}_{4}$ production obtained at $215^{\circ} \mathrm{C}$ upon $2236 \mathrm{~W} \mathrm{~m}^{-2}$ irradiation using a $150 \mathrm{~W}$ Xe lamp. $\mathrm{P}_{\mathrm{H} 2}=1.05$ bar, $\mathrm{P}_{\mathrm{CO} 2}=0.25$ bar. $\operatorname{MOF}(\mathrm{Zn})-1(\bullet), \operatorname{MOF}(\mathrm{Zn})-2(\mathrm{O}), \operatorname{MOF}-74(\mathrm{Zn})(\mathbf{a})$ and $\mathrm{MIL}-125(\mathrm{Ti})-\mathrm{NH}_{2}(0)$.

In order to enhance the catalytic activity of $\operatorname{MOF}(Z n)-1$, we have evaluated the influence of metal NPs encapsulation in the pores of the MOF. Recently, $\mathrm{Ni}$ encapsulated into the cavities of MIL-101(Cr) have resulted in a stable catalyst for $\mathrm{CO}_{2}$ methanation. ${ }^{[12]}$ However, $\mathrm{Cu}$ NPs supported on $\mathrm{ZnO}$ finely dispersed in a high surface area $\mathrm{Al}_{2} \mathrm{O}_{3}$ support is a reference industrial material for $\mathrm{CO}_{2}$ hydrogenation, ${ }^{[20]}$ and it has been previously shown that $\mathrm{Cu}_{2} \mathrm{O}$ is an active semiconductor for photocatalytic $\mathrm{CO}_{2}$ methanation. ${ }^{[4 \mathrm{~b}]}$ Based on these precedents, we have prepared $\mathrm{Cu}_{2} \mathrm{O}$ NPs deposited into MOF(Zn)-1 by using the photodeposition method. For comparison, $\mathrm{Cu}_{2} \mathrm{O}$ NPs were also deposited into $\mathrm{MOF}(\mathrm{Zn})-2, \mathrm{MOF}-74(\mathrm{Zn})$ and MIL-125(Ti)- $\mathrm{NH}_{2}$ solids.

Specifically, upon UV-vis irradiation of a MOF suspension in an aqueous $\mathrm{Cu}^{2+}$ solution using methanol as a sacrificial electron donor, $\mathrm{Cu}_{2} \mathrm{O}$ NPs of a few $\mathrm{nm}$ could 
be prepared. ICP-OES analyses confirm a 1 wt\% copper loading on the various MOFs. Powder X-ray diffraction (PXRD) measurements of the copper-supported MOFs confirm the stability of the materials during the photodeposition while no peaks attributable to the diffraction of any copper species could be observed. This failure to detect $\mathrm{Cu}$ diffraction peaks can be attributed to the good dispersion of small copper NPs in the MOFs and/or low copper content of the catalysts (1 wt\%). In agreement with this hypothesis, TEM analysis reveals that the narrowest copper particle size distribution is achieved using the $\operatorname{MOF}(Z n)-1$ support (1.61 $\pm 0.46 \mathrm{~nm})$, followed by MIL-125(Ti)-NH2 $(4.29 \pm 0.95 \mathrm{~nm}), \operatorname{MOF}(\mathrm{Zn})-2(5.35 \pm 2.36 \mathrm{~nm})$ and MOF-74(Zn) (6.07 $\pm 1.52 \mathrm{~nm})$ (Figure S4 and S6, ESI). The small copper particle size achieved in the $\mathrm{Cu}_{2} \mathrm{O} @ \operatorname{MOF}(\mathrm{Zn})-1$ is compatible with the internal location inside the pores. SEM measurements show that the morphologies of $\operatorname{MOF}(\mathrm{Zn})-1$ or $\operatorname{MOF}(\mathrm{Zn})-2$ are not modified after copper deposition (Figure S7, ESIt) and copper NPs are well-dispersed in the MOFs (Figure S8 and S9, ESI+).

XPS spectra of $\mathrm{Cu}_{2} \mathrm{O} @ \mathrm{MOF}(\mathrm{Zn})-1$ and $\mathrm{Cu}_{2} \mathrm{O} @ \mathrm{MOF}(\mathrm{Zn})-2$ reveal the presence of the different elements (C, O, N, Zn and $\mathrm{Cu}$ ) in the samples (Figure S9-S11, ESI). Regarding the high resolution XPS spectrum of the Cu2p peak (Figure S9d, ESI), the presence of $\mathrm{Cu} 2 \mathrm{p}_{3 / 2}$ and $\mathrm{Cu} 2 \mathrm{p}_{1 / 2}$ and their deconvolution allow the detection of reduced copper species $\left(\mathrm{Cu}^{0}\right.$ and/or $\left.\mathrm{Cu}^{+}\right)$together with $\mathrm{Cu}^{2+}$. It should be noted, however, that under the photocatalytic reaction conditions at $215^{\circ} \mathrm{C}$ under $\mathrm{H}_{2}$ flow, the $\mathrm{Cu}^{2+}$ would probably be reduced to $\mathrm{Cu}^{+},{ }^{[21]}$ while the reduction of $\mathrm{Cu}_{2} \mathrm{O}$ to metallic copper starts to take place at temperatures above $300{ }^{\circ} \mathrm{C}$.

The copper-containing MOF samples were evaluated as photocatalysts under the same conditions as pristine MOFs lacking $\mathrm{Cu}_{2} \mathrm{O}$ nanoparticles (vide supra). The temporal evolution of $\mathrm{CH}_{4}$ formation is presented in Figure 3, which shows, as expected, an enhanced activity upon $\mathrm{Cu}_{2} \mathrm{O}$ incorporation. As in the case of $\operatorname{MOF}(\mathrm{Zn})-1$, the photocatalytic activity of $\mathrm{Cu}_{2} \mathrm{O} @ \mathrm{MOF}(\mathrm{Zn})-1$ is derived exclusively from the UV region. The deposition of copper NPs in MOF-74(Zn) and 
MIL-125(Ti)- $\mathrm{NH}_{2}$ results in the formation of solids capable of promoting the $\mathrm{CO}_{2}$ photoreduction by $\mathrm{H}_{2}$ to $\mathrm{CH}_{4}$, although it can clearly be observed that the best performing MOF photocatalyst is $\mathrm{Cu}_{2} \mathrm{O} @ \operatorname{MOF}(\mathrm{Zn})-1$ (initial $\mathrm{CH}_{4}$ production of 10 $\mu \mathrm{mol} \mathrm{g}_{\text {catalyst }}{ }^{-1} \mathrm{~h}^{-1}$ and $45 \mu \mathrm{mol} \mathrm{g}_{\text {cat }}{ }^{-1}$ after 24 hours), which increased around $50 \%$ its photocatalytic activity compared with the pristine MOF lacking $\mathrm{Cu}_{2} \mathrm{O}$ particles. The estimated TOF of $\mathrm{Cu}_{2} \mathrm{O} @ \mathrm{MOF}(\mathrm{Zn})-1$, measured at $2 \mathrm{~h}$ after subtracting the activity of $\operatorname{MOF}(\mathrm{Zn})-1$, is as high as about $50 \times 10^{-3} \mathrm{~s}^{-1}$ at $215^{\circ} \mathrm{C}$, which is much better than that reported for Ni@MIL-101(Cr) $\left(1.63 \times 10^{-3} \mathrm{~s}^{-1}\right.$ at $\left.300{ }^{\circ} \mathrm{C}\right) .{ }^{[12]}$

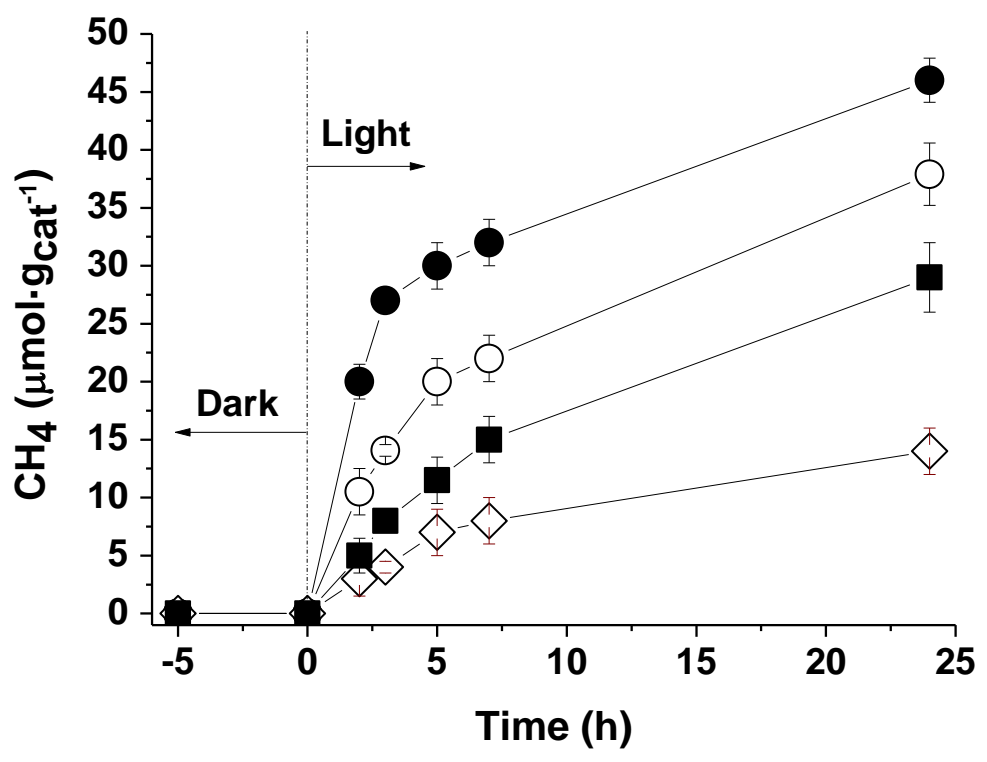

Figure 3. $\mathrm{CH}_{4}$ production using $\mathrm{Cu}_{2} \mathrm{O} @ \mathrm{MOFs}$ working $215^{\circ} \mathrm{C}$ upon $2236 \mathrm{~W} \mathrm{~m}^{-2}$ irradiation using a $150 \mathrm{~W}$ Xe lamp. $\mathrm{P}_{\mathrm{H} 2}=1.05$ bar, $\mathrm{P}_{\mathrm{CO} 2}=0.25$ bar. Legend $\mathrm{Cu}_{2} \mathrm{O} @ \mathrm{MOF}(\mathrm{Zn})-1(\bullet)$, $\mathrm{Cu}_{2} \mathrm{O} @ M O F(\mathrm{Zn})-2(0), \mathrm{Cu}_{2} \mathrm{O} @ M O F-74(\mathrm{Zn})(\mathbf{m})$, and $\mathrm{Cu}_{2} \mathrm{O} @ \mathrm{MIL}-125(\mathrm{Ti})-\mathrm{NH}_{2}(0)$.

To confirm the origin of methane, an additional experiment using ${ }^{13} \mathrm{C}^{18} \mathrm{O}_{2}$ as a reagent was performed and the photoproduct was analysed by GC-MS (Figure S15, ESI), observing the formation of ${ }^{13} \mathrm{CH}_{4}(\mathrm{~m} / \mathrm{z} 17)$ and $\mathrm{H}_{2}{ }^{18} \mathrm{O}(\mathrm{m} / \mathrm{z} 20)$, accompanied by 
$\mathrm{H}_{2}{ }^{16} \mathrm{O}$ (m/z 18), thus corroborating the simultaneous formation of $\mathrm{CH}_{4}$ and $\mathrm{H}_{2} \mathrm{O}$. The PXRD patterns of the used samples show that the MOF materials employed in this study retain their initial crystallinity under the present reaction conditions (Figure S12, ESI). For the most active sample, $\mathrm{Cu}_{2} \mathrm{O} @ \mathrm{MOF}(\mathrm{Zn})-1, \mathrm{TEM}$ measurements of the used sample (Figure S13, ESI) show that the average copper particle size distribution and standard deviation remain constant $(1.7 \pm 0.9 \mathrm{~nm})$ with respect to the fresh sample $(1.6 \pm 0.5 \mathrm{~nm})$, and ICP-OES analysis of the used sample reveals that the copper content is practically the same as the fresh sample. In fact, although $\mathrm{Cu}_{2} \mathrm{O}$ exhibits intrinsic photocatalytic activity in the absence of the support, the main limitation of this semiconductor is the stability under photocatalytic conditions, ${ }^{\text {[22] }}$ which is enhanced upon incorporation into the pores of $\operatorname{MOF}(\mathrm{Zn})-1$, as previously demonstrated. ${ }^{[23]}$

The higher activity of $\mathrm{Cu}_{2} \mathrm{O} @ \mathrm{MOF}(\mathrm{Zn})-1$ is attributed to the intrinsic photoactivity of the material. This is revealed by self activity of the support and, more importantly, further combination with small $\mathrm{Cu}_{2} \mathrm{O}$ NPs behaving both as a semiconductor and a co-catalyst close to the $\mathrm{Zn}-\mathrm{O}$ reduction centres. In addition, we have examined if the presence of incorporated $\mathrm{Cu}_{2} \mathrm{O}$ NPs increases the charge separation efficiency. The lack of significant changes in the photoluminescence of $\operatorname{MOF}(\mathrm{Zn})-1$ in the absence and in the presence of occluded $\mathrm{Cu}_{2} \mathrm{O}$ NPs suggests that there is no charge transfer between the two components, indicating that the charge recombination in $\operatorname{MOF}(\mathrm{Zn})-1$ is not altered by the presence of $\mathrm{Cu}_{2} \mathrm{O}$. The difference in photoactivity between $\operatorname{MOF}(\mathrm{Zn})-1$ and $\operatorname{MOF}-74(\mathrm{Zn})$ is further explained by the energies of the conduction and the valence bands, which have been experimentally determined by the combination of electrochemistry (Figure S16, ESI) and optical spectroscopy (Figure S17, ESI). As can be seen in Figure 4, the valence band energies are similar in both materials, but the optical band gaps (calculated from the absorption spectra) are remarkably different resulting in a different energy for the conduction bands $(0.06 \mathrm{eV}$ vs. $-0.975 \mathrm{eV}$ for MOF(Zn)-1 and MOF-74(Zn) respectively). In fact, in the case of MOF-74(Zn), the conduction band energy is not 
enough to promote the photochemical reduction of $\mathrm{CO}_{2}(-0.24 \mathrm{eV}) \cdot{ }^{\left[{ }^{[2]}\right.}$ However, this process is thermodynamically possible in the case of $\operatorname{MOF}(\mathrm{Zn})-1$, explaining why this material has intrinsic photocatalytic activity.

In summary, the photocatalytic activity for the light-assisted $\mathrm{CO}_{2}$ methanation has been shown for the first time using a bare MOF, a Zn-based MOF denoted as $\operatorname{MOF}(\mathrm{Zn})-1$. The low temperature photocatalytic activity $\left(215^{\circ} \mathrm{C}\right)$ allows the use of MOFs in this important reaction, which is typically limited due to degradation caused by the extreme conditions $\left(\mathrm{T}>500{ }^{\circ} \mathrm{C}\right)$.

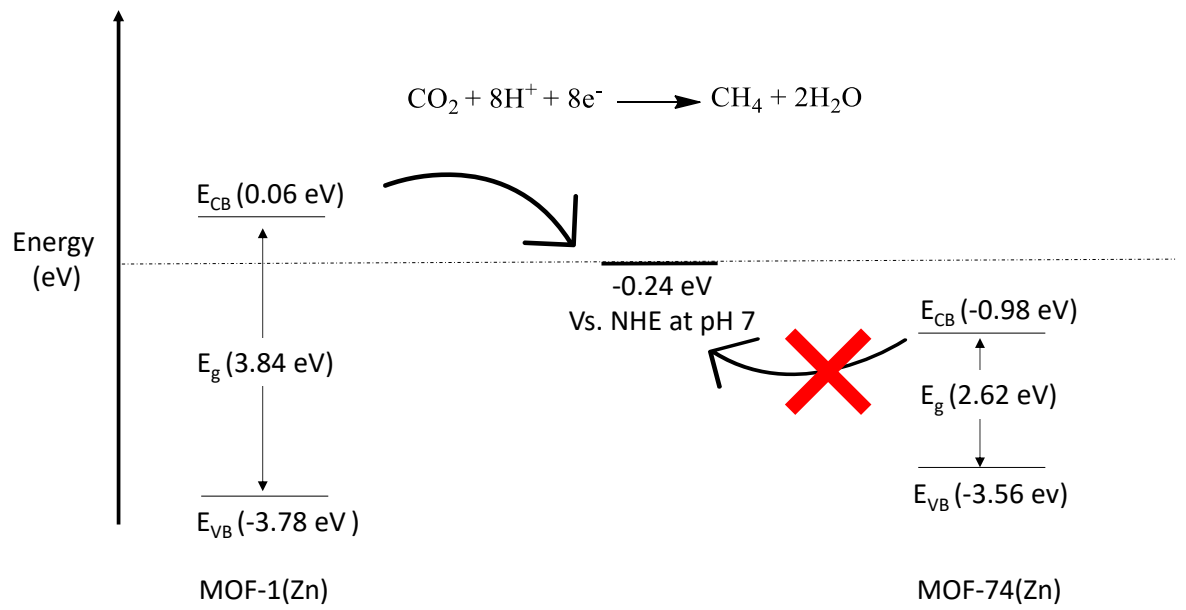

Figure 4. Energetic diagram for $\operatorname{MOF}(\mathrm{Zn})-1$ and $\operatorname{MOF}-74(\mathrm{Zn})$. The band gap (Eg) has been calculated from the Tauc plot; the energy of the valence band $\left(\mathrm{E}_{\mathrm{VB}}\right)$ has been calculated from the oxidation potential; and the energy of the conduction band $\left(E_{C B}\right)$ has been calculated from the following equation:

$$
\mathrm{E}_{\mathrm{CB}}=\mathrm{E}_{\mathrm{g}}+\mathrm{E}_{\mathrm{VB}}
$$

(see Figure S16 and S17 for details, ESI).

Furthermore, its activity has additionally been increased upon incorporation of small $\mathrm{Cu}_{2} \mathrm{O}$ nanoparticles, with a TOF value of $50 \times 10^{-3} \mathrm{~s}^{-1}$ at $215^{\circ} \mathrm{C}$, the highest ever reported for a MOF. This result is the combination of a high intrusive photocatalytic activity of the framework with the small $\mathrm{Cu}_{2} \mathrm{O}$ nanoparticles as 
Chapter 5. Design of cost-efficient and photocatalytically active $\mathrm{Zn}$-based MOFs decorated with $\mathrm{Cu}_{2} \mathrm{O}$ nanoparticles for $\mathrm{CO}_{2}$ methanation

co-catalysts. This work highlights the potential of specific MOF design to develop efficient and cost-effective materials to overcome the drawbacks derived from the increasing presence of the undesirable $\mathrm{CO}_{2}$ greenhouse gas. 


\subsection{Bibliography}

[1] (a) X. Li, J. Yu, M. Jaroniec, X. Chen, Chem. Rev. 2019, 119, 3962; (b) T. Sakakura, J.-C. Choi, H. Yasuda, Chem. Rev. 2007, 107, 2365.

[2] M. Younas, L. L. Kong, M. J. K. Bashir, H. Nadeem, A. Shehzad, S. Sethupathi, Energy Fuel 2016, 30, 8815.

[3] S. Rönsch, J. Schneider, S. Matthischke, M. Schlüter, M. Götz, J. Lefebvre, P. Prabhakaran, S. Bajohr, Fuel 2016, 166, 276.

[4] (a) T. Yui, A. Kan, C. Saitoh, K. Koike, T. Ibusuki, O. Ishitani, ACS Appl. Mater. Interfaces 2011, 3, 2594; (b) D. Mateo, J. Albero, H. García, Energy Environ. Sci. 2017, 10, 2392; (c) D. Mateo, D. De Masi, J. Albero, L.-M. Lacroix, P.-F. Fazzini, B. Chaudret, H. García, Chem. Eur. J. 2018, 24, 18436; (d) D. Mateo, J. Albero, H. García, Appl. Catal. B 2018, 224, 563.

[5] (a) H.-C. Zhou, J. R. Long, O. M. Yaghi, Chem. Rev. 2012, 112, 673; (b) G. Maurin, C. Serre, A. Cooper, G. Férey, Chem. Soc. Rev. 2017, 46, 3104.

[6] C. A. Trickett, A. Helal, B. A. Al-Maythalony, Z. H. Yamani, K. E. Cordova, O. M. Yaghi, Nat. Rev. Mater. 2017, 2, 17045.

[7] (a) S. M. J. Rogge, A. Bavykina, J. Hajek, H. Garcia, A. I. Olivos-Suarez, A. Sepúlveda-Escribano, A. Vimont, G. Clet, P. Bazin, F. Kapteijn, M. Daturi, E. V. Ramos-Fernandez, F. X. Llabrés i Xamena, V. Van Speybroeck, J. Gascon, Chem. Soc. Rev. 2017, 46, 3134; (b) M. Souto, A. Santiago-Portillo, M. Palomino, I. J. Vitórica-Yrezábal, C. Vieira, J. C. Waerenborgh, S. Valencia, S. Navalón, H. García, G. Mínguez Espallargas, Chem. Sci. 2018, 9, 2413.

[8] (a) Y. Li, H. Xu, S. Ouyang, J. Ye, Phys. Chem. Chem. Phys., 2016, 8, 7563; (b) A. Dhakshinamoorthy, Z. Li, H. García, Chem. Soc. Rev., 2018, 47, 8134; (c) R. Li, W. Zhang, K. Zhou, Adv. Mater. 2018, 30, 1705512; (d) Y. Han, H. Xu, Y. Su, Z. Xu, K. Wang, W. Wang, J. Catal. 2019, 370, 70.

[9] (a) D. Sun, Y. Gao, J. Fu, X. Zeng, Z. Chen, Z. Li, Chem. Commun. 2015, 51, 2645; (b) Y. Lee, S. Kim, J. K. Kang, S. M. Cohen, Chem. Commun. 2015, 51, 5735.

[10] D. Shi, C. He, W. Sun, Z. Ming, C. Meng , C. Duan, Chem. Commun. 2016, 52, 4714.

[11] (a) A. Dhakshinamoorthy, A. M. Asiri, H. García, Angew. Chem. Int. Ed. 2016, 55, 5414;

(b) T. Zhang, Y. Jin, Y. Shi, M. Li, J. Li, C. Duan, Coord. Chem. Rev. 2019, 380, 201; (c) R. Li, W. Zhang, K. Zhou, Adv. Mater. 2018, 30, 1705512.

[12] W. Zhen, F. Gao, B. Tian, P. Ding, Y. Deng, Z. Li, H. Gao, G. Lu, J. Catal. 2017, 348, 200.

[13] (a) M. Mon, M.-A. Rivero-Crespo, J. Ferrando-Soria, A. Vidal-Moya, M. Boronat, A. Leyva-Pérez, A. Corma, J.-C. Hernández-Garrido, M. López-Haro, J.-J. Calvino, G. Ragazzon, A. Credi, D. Armentano, E. Pardo, Angew. Chem. Int. Ed. 2018, 57, 6186; (b) Z. W. Zhao, X. Zhou, Y.-N. Liu, C.-C. Shen, C.-Z. Yuan, Y. F. Jiang, S.-J. Zhao, L.-B. Ma, T.-Y. Cheang, Z.-W. Xu, Catal. Sci. Technol. 2018, 8, 3160; (c) W. Zhen, B. Li, G. Lu, J. Ma, Chem. Commun. 2015, 51, 1728; (d) R. Lippi, S. C. Howard, H. Barron, C. D. Easton, I. C. Madsen, L. J. Waddington, C. Vogt, M. R. Hill, C. J. Sumby, C. J. Doonan, D. F. Kennedy, J. Mater. Chem. A. 2017, 5, 12990.

[14] J. Xiao, Y. Wu, M. Li, B.-Y. Liu, X.-C. Huang,D. Li, Chem. Eur. J. 2013, 19, 1891. 
[15] Y. Yue, J.-A. Rabone, H. Liu, S.-M. Mahurin, M.-R. Li, H. Wang, Z. Lu, B. Chen, J. Wang, Y. Fang, S. Dai, J. Phys. Chem. C 2015, 119, 9442.

[16] (a) G. Férey, C. Mellot-Draznieks, C. Serre, F. Millange, J. Dutour, S. Surblé, I. Margiolaki, Science 2005, 309, 2040; (b) E. J. Carrington, C. A. McAnally, A. J. Fletcher, S. P. Thompson, M. Warren, L. Brammer, Nat. Chem. 2017, 9, 882; (c) M. Souto, J. Romero, J. Calbo, I. J. Vitórica-Yrezábal, J. L. Zafra, J. Casado, E. Ortí, A. Walsh, G. Mínguez Espallargas, J. Am. Chem. Soc. 2018, 140, 10562.

[17] Rosi, J. Kim, M. Eddaoudi, B. Chen, M. O'Keeffe, O. M. Yaghi, J. Am. Chem. Soc. 2005, 127, 1504.

[18] (a) M. Dan-Hardi, C. Serrem, T. Frot, L. Rozes, G. Maurin, C. Sánchez, G. Fèrey, J. Am. Chem. Soc. 2009, 131, 10857; (b) S. Vaesen, V. Guillerm, Q. Yang, A. D. Wiersum, B. Marszalek, B. Gil, A. Vimont, M. Daturi, T. Devic, P. L. Llewellyn, C. Serre, G, Maurin, G. De Weireld, Chem. Commun. 2013, 49, 10082.

[19] (a) Y. Yoshida, Y. Izumi, J. Catal. 2015, 332, 1; (b) K. Meyer, S. Bashir, J. Llorca, H. Idriss, M. Ranocchiari, J. A. van Bokhoven, Chem. Eur. J. 2016, 22, 13894; (c) M. B. Chambers, J. Am. Chem. Soc. 2017, 139, 8222; (d) S. Kampouri, T. N. Nguyen, M. Spodaryk, R. G. Palgrave, A. Züttel, B. Smit, K. C. Stylianou, Adv. Funct. Mater. 2018, 28, 1806368.

[20] W. Wang, S. Wang, X. Ma, J. Gong, Chem. Soc. Rev. 2011, 40, 3703.

[21] J. Y. Kim, J. A. Rodriguez, J. C. Hanson, A. I. Frenkel, P. L. Lee, J. Am. Chem. Soc. 2003, $125,10684$.

[22] A. D. Handoko, J. Tiang, Int. J. Hydrog. Energy 2013, 38, 13017.

[23] (a) M. Meilikhov, K. Yusenko, D. Esken, S. Turner, G. Van Tendelo, R. A. Fischer, Eur. J. Inorg. Chem. 2010, 3701; (b) A. Santiago-Portillo, M. Cabrero-Antonino, M. Álvaro, S. Navalón, H. García, Chem. Eur. J. 2019, 25, 9280.

[24] S. N. Habisreutinger, L. Schmidt-Mende, J. K. Stolarczyk, Angew. Chem. Int. Ed. 2013, 52, 7372 . 


\subsection{Supporting information}

\subsubsection{General methods and materials}

Materials and reagents. All the reagents and solvents employed in this study were of analytical reagent or HPLC grade and were supplied by Sigma-Aldrich.

\subsubsection{Synthesis of $\operatorname{MOF}(\mathrm{Zn})-1$}

$3 \mathrm{H}$-benzotriazole-5-carboxylate (10 $\mathrm{mg}, 0.06 \mathrm{mmol}$ ) was dissolved in $0.5 \mathrm{~mL}$ of DMF before adding $0.5 \mathrm{~mL}$ of distilled water. Separately $16.51 \mathrm{mg}(0.09 \mathrm{mmol})$ of $\mathrm{Zn}\left(\mathrm{CH}_{3} \mathrm{COO}\right)_{2}$ was dissolved in $0.5 \mathrm{~mL}$ of distilled water before adding $0.5 \mathrm{~mL}$ of DMF. Both solutions were mixed and the resulting solution was placed in a closed glass vessel and introduced in an oven at 95 ${ }^{\circ} \mathrm{C}$ for $12 \mathrm{~h}$, after which yellow/brown single crystals were isolated, which were washed with water/methanol. Yield: $55 \%$ based on metal. Heating at different temperatures produce different degrees of breathing as revealed by single-crystal diffraction (see below).

\subsubsection{Synthesis of $\operatorname{MOF}(\mathrm{Zn})-2$.}

$\operatorname{MOF}(\mathrm{Zn})-2$ is obtained upon heating at $400^{\circ} \mathrm{C}$ for $2 \mathrm{~h}$ crystals of $\operatorname{MOF}(\mathrm{Zn})-1$.

\subsubsection{Synthesis of MOF-74(Zn)}

Synthesis of MOF-74(Zn) was adapted from a previously reported procedure. ${ }^{[\mathrm{S} 1]} \mathrm{A}$ mixture of 2,5-hydroxy-1,4-benzenedicarboxylic acid ( $\left.\mathrm{H}_{2} \mathrm{DHBDC}\right)(2.4 \mathrm{~g}, 12.1 \mathrm{mmol})$ and zinc nitrate tetrahydrate, $\mathrm{Zn}\left(\mathrm{NO}_{3}\right)_{2}{ }_{4}{ }_{4}\left(\mathrm{H}_{2} \mathrm{O}\right)(179 \mathrm{mg}, 60.5 \mathrm{mmol})$ were dissolved in DMF (240 mL) and water $(120 \mathrm{~mL})$, dissolved and heated to $105^{\circ} \mathrm{C}$ for 20 hours and then cooled to room temperature. Yellow needle crystals were obtained in yield 51 \% (based on $\mathrm{H}_{2} \mathrm{DHBDC}$ ) that were washed with DMF and methanol, and dried in air.

\subsubsection{Synthesis of MIL-125(Ti)- $\mathrm{NH}_{2}$}

MIL-125(Ti)- $\mathrm{NH}_{2}$ was prepared following previously reported procedures. ${ }^{[\mathrm{S2}]}$ 2-Aminoterephtalic acid $(1.43 \mathrm{~g}, 7.9 \mathrm{mmol})$ was dissolved in $20 \mathrm{~mL}$ of anhydrous $\mathrm{N}$,Ndimethylformamide (DMF). Anhydrous methanol ( $5 \mathrm{~mL}$ ) was then added to the reaction mixture and the system sonicated for $20 \mathrm{~min}$. The reaction mixture was transferred to a Teflon-lined autoclave $(50 \mathrm{~mL})$ and titanium isopropoxide $(1.36 \mathrm{~g}, 4.8 \mathrm{mmol})$ was subsequently added. The autoclave was sealed and heated at $110^{\circ} \mathrm{C}$ for $72 \mathrm{~h}$. After cooling the Teflon to room temperature, the resulting precipitate was filtered, washed with DMF at room temperature for $12 \mathrm{~h}$ and, then, washed with DMF at $120^{\circ} \mathrm{C}$ for $12 \mathrm{~h}$. This washing procedure 
was repeated using methanol as solvent. Finally, the solid was recovered by filtration and dried in the oven at $100^{\circ} \mathrm{C}$.

\subsubsection{Synthesis of $\mathrm{CuO}_{2} @ M O F s$ using the photodeposition method (PD)}

Copper NPs were deposited in the previously synthesized MOFs (MOF(Zn)-1, MOF(Zn)-2, MOF-74(Zn) and MIL-125(Ti)-NH2) using the PD method.. ${ }^{[\mathrm{S} 3]}$ Each MOF was dispersed by sonication in a mixture of water $(13 \mathrm{~mL})$ and methanol $(5 \mathrm{~mL})$. Then, $\mathrm{Cu}\left(\mathrm{NO}_{3}\right)_{2} \cdot 3 \mathrm{H}_{2} \mathrm{O}$ was dissolved in water $(2 \mathrm{~mL})$ and it was added to the MOF solution at initial $1 \mathrm{wt} \%$. The solution was purged with argon for $20 \mathrm{~min}$. Finally, the mixture was irradiated using an UV Visible light Xe lamp ( $150 \mathrm{~W}$ ) for $4 \mathrm{~h}$. The resulting solid was filtered, washed with water and dried in the oven at $100^{\circ} \mathrm{C}$ for $24 \mathrm{~h}$.

\subsubsection{Structural features of $\operatorname{MOF}(Z n)$}

Upon heating the as-synthetised material $(\operatorname{MOF}(\mathrm{Zn}))$, the solvent molecules (DMF and $\mathrm{H}_{2} \mathrm{O}$ ) are removed from the channels causing a reversible continuous shrinkage of the structure. ${ }^{[54,55]}$ Three different MOFs with a different degree of breathing have been isolated after $2 \mathrm{~h}$ heating at $100{ }^{\circ} \mathrm{C}, 200{ }^{\circ} \mathrm{C}$, and $350{ }^{\circ} \mathrm{C}$, denoted MOF(Zn)-100, MOF(Zn)-200 (corresponding to $\operatorname{MOF}(\mathrm{Zn})-1$ ), and $\operatorname{MOF}(\mathrm{Zn})-350$. Interestingly, upon further heating at $400^{\circ} \mathrm{C}$, the crystal structure expands and a much more open structure is obtained (MOF(Zn)-2).

The X-ray intensity data were collected on a Bruker D8 Venture diffractometer (MOF(Zn), MOF(Zn)-RT, MOF(Zn)-100, MOF(Zn)-350 and MOF(Zn)-1) and on a Rigaku Oxford Diffraction Supernova diffractometer ( $\operatorname{MOF}(\mathrm{Zn})-1$ and $\operatorname{MOF}(\mathrm{Zn})-2)$, using Mo-Ka radiation. The data for $\operatorname{MOF}(Z n), \operatorname{MOF}(Z n)-R T, \operatorname{MOF}(Z n)-100$, and $\operatorname{MOF}(Z n)-350$ were integrated with SAINT ${ }^{[56]}$ and corrected for absorption effects with SADABS ${ }^{[57]}$. The data for MOF(Zn)-1 and $\operatorname{MOF}(\mathrm{Zn})-2$ were processed with CrysAlisPro ${ }^{[88]}$, and absorption corrections based on multiple-scanned reflections were carried out with SCALE3 ABSPACK in CrysAlisPro. All crystal structures were solved with SHELXT ${ }^{[59]}$ and refined with SHELXL ${ }^{[S 9]}$. The OLEX2 software was used as a graphical interface S10. Anisotropic atomic displacement parameters were introduced for all non-hydrogen atoms. Hydrogen atoms were placed at geometrically calculated positions and refined with the appropriate riding model, with Uiso(H) $=1.2$ Ueq $(C$, O) (1.5 for methyl groups).

Even though crystal data was collected up to 0.77 Angstroms resolution, crystals still diffracted quite weakly at high angle due to their rather low quality (with exception to 
Chapter 5. Design of cost-efficient and photocatalytically active $\mathrm{Zn}$-based MOFs decorated with $\mathrm{Cu}_{2} \mathrm{O}$ nanoparticles for $\mathrm{CO}_{2}$ methanation

$\operatorname{MOF}(\mathrm{Zn})-\mathrm{RT}$ and $\operatorname{MOF}(\mathrm{Zn})-1)$ and data were cut off according to intensity statistics, using restraints and constraints during refinement. In $\operatorname{MOF}(\mathrm{Zn})$, it was not possible to clearly see electron-density peaks in difference maps which would correspond with acceptable locations for the $\mathrm{H}$ atoms bonded to $\mathrm{O} 1 \mathrm{~W}$. Therefore, the refinement was completed with no allowance for these $\mathrm{H}$ atoms in the model. The contributions of these missing atoms (formulae, formula weight, etc.) have been included in the CIF.

In MOF(Zn)-RT, a DMF solvent molecule was found disordered over two alternative positions (0.52:0.48 ratio), and was refined with rigid groups, partially equal anisotropic displacement parameters and restraints on geometry and displacement parameters. In this heavy-atom structure it was not possible to clearly see electron-density peaks in difference maps which would correspond with acceptable locations for the $\mathrm{H}$ atoms of the disordered DMF molecule. Therefore, the refinement was completed with no allowance for these $\mathrm{H}$ atoms in the model. The contributions of these missingatoms (formulae, formula weight, etc.) have been included in the CIF.

During the refinement of $\operatorname{MOF}(Z n)-100$, a number of ISOR restraints had to be used to obtain reasonable displacement parameters for all non-hydrogen atoms. Their $\mathrm{U}_{\mathrm{ij}}$ values were therefore restrained to be approximately spherical. Severely disordered DMF in $\operatorname{MOF}(\mathrm{Zn})-100$ could not be modelled reasonably, and were therefore removed from the diffraction data (using the OLEX2 Mask tool) but considered for calculation of empirical formula, formula weight, density, linear absorption coefficient and $F(000)$. A solvent mask was calculated and 322.0 electrons were found in a volume of $642.0 \AA^{3}$ in one void. This is consistent with the presence of 2 DMF molecules per formula unit which account for 320.0 electrons.

A number of ISOR restraints had to be used to obtain reasonable displacement parameters for all nonhydrogen atoms in $\operatorname{MOF}(\mathrm{Zn})-350$. Their Uij values were therefore restrained to be approximately spherical. In this heavy-atom structure it was not possible to clearly see electron-density peaks in difference maps which would correspond with acceptable locations for the $\mathrm{H}$ atoms bonded to $\mathrm{O} 1 \mathrm{~W}, \mathrm{O} 2 \mathrm{~W}$ and $\mathrm{O} 3$. Therefore, the refinement was completed with no allowance for these $\mathrm{H}$ atoms in the model. The contributions of these missing atoms (formulae, formula weight, etc.) have been included in the CIF. 
Chapter 5. Design of cost-efficient and photocatalytically active $\mathrm{Zn}$-based MOFs decorated with $\mathrm{Cu}_{2} \mathrm{O}$ nanoparticles for $\mathrm{CO}_{2}$ methanation

In MOF(Zn)-1, SADI, FLAT, RIGU and EADP commands were used to obtain reasonable geometry and anisotropic displacement parameters for the DMF solvent molecule. This molecule is disordered across a twofold rotation axis; bonds to symmetry equivalents were suppressed using PART-1 command. In this heavy-atom structure it was not possible to clearly see electron-density peaks in difference maps which would correspond with acceptable locations for the $\mathrm{H}$ atoms of the disordered DMF molecule. Therefore, the refinement was completed with no allowance for these $\mathrm{H}$ atoms in the model. The contributions of these missing atoms (formulae, formula weight, etc.) have been included in the CIF.

Whole molecule disorder of the btca ligand was modelled in MOF(Zn)-2 via AFIX, DFIX, FLAT, EADP, and RIGU commands. The ratio between the two components was refined freely and converged at 0.48:0.52. A DFIX command was used to restrain the geometry of the $\mu 2$-bridging format ligand in order to exhibit a O-CH-O moiety between symmetry related $\mathrm{Zn} 2$ atoms (symmetry operation: $-x,+y, 5 / 2-z$ ). Figure 1.d. shows a labelled ORTEP plot showing the $\mu_{2}$-bridging formato ligand linking two symmetry-related half-occupancy $Z n 2$ atoms. Crystal data and refinement details are listed in Table S1. 
Chapter 5. Design of cost-efficient and photocatalytically active $\mathrm{Zn}$-based MOFs decorated with $\mathrm{Cu}_{2} \mathrm{O}$ nanoparticles for $\mathrm{CO}_{2}$ methanation

Table S1. Selected crystallographic data for all compounds.

\begin{tabular}{|c|c|c|c|c|c|c|}
\hline Compound & \multicolumn{5}{|c|}{$\operatorname{MOF}(Z n)-1$} & \multirow{2}{*}{$\begin{array}{c}\mathrm{MOF} \\
(\mathrm{Zn})-2 \\
2 \mathrm{~h} \text { at } \\
400^{\circ} \mathrm{C}\end{array}$} \\
\hline $\begin{array}{l}\text { Activation } \\
\text { temperature }\end{array}$ & $\begin{array}{c}\text { As } \\
\text { synthesise } \\
\text { d }\end{array}$ & $24 \mathrm{~h}$ at $\mathrm{RT}$ & $\begin{array}{l}2 \mathrm{~h} \text { at } \\
100^{\circ} \mathrm{C}\end{array}$ & $\begin{array}{l}2 \mathrm{~h} \text { at } \\
200^{\circ} \mathrm{C}\end{array}$ & $\begin{array}{l}2 \mathrm{~h} \text { at } \\
350^{\circ} \mathrm{C}\end{array}$ & \\
\hline Space group & $\mathrm{C} 2 / \mathrm{C}$ & $\mathrm{C} 2 / \mathrm{C}$ & $\mathrm{C} 2 / \mathrm{C}$ & $\mathrm{C} 2 / \mathrm{C}$ & $\mathrm{C} 2 / \mathrm{C}$ & $\mathrm{C} 2 / \mathrm{C}$ \\
\hline Chemical formula & $\begin{array}{c}\mathrm{C}_{20} \mathrm{H}_{24} \mathrm{~N}_{8} \mathrm{O}_{9} \\
\mathrm{Zn}_{3}\end{array}$ & $\begin{array}{c}\mathrm{C}_{20} \mathrm{H}_{22} \mathrm{~N}_{8} \mathrm{O}_{8} \\
\mathrm{Zn}_{3}\end{array}$ & $\begin{array}{c}\mathrm{C}_{20} \mathrm{H}_{22} \mathrm{~N}_{8} \mathrm{O}_{8} \\
\mathrm{Zn}_{3}\end{array}$ & $\begin{array}{c}\mathrm{C}_{17} \mathrm{H}_{15} \mathrm{~N}_{7} \mathrm{O}_{7} \\
\mathrm{Zn}_{3}\end{array}$ & $\begin{array}{c}\mathrm{C}_{14} \mathrm{H}_{16} \mathrm{~N}_{6} \mathrm{O}_{10} \\
\mathrm{Zn}_{3}\end{array}$ & $\begin{array}{c}\mathrm{C}_{15} \mathrm{H}_{7} \mathrm{~N}_{6} \mathrm{O}_{7} \\
\mathrm{Zn}_{4}\end{array}$ \\
\hline $\begin{array}{l}\text { Formula Mass } \\
(\mathrm{g} / \mathrm{mol})\end{array}$ & 716.58 & 698.56 & 698.56 & 625.47 & 624.55 & 644.75 \\
\hline a $(\AA ̊)$ & $\begin{array}{c}17.7182 \\
(14)\end{array}$ & $\begin{array}{c}18.037 \\
(2)\end{array}$ & $18.94(3)$ & $\begin{array}{c}19.2623 \\
(14)\end{array}$ & $19.544(2)$ & $16.643(2)$ \\
\hline$b(\AA)$ & $\begin{array}{c}13.0967 \\
(12)\end{array}$ & $\begin{array}{c}12.5871 \\
(13)\end{array}$ & $\begin{array}{c}10.098 \\
(16)\end{array}$ & $9.9839(6)$ & $\begin{array}{c}9.0665 \\
(12)\end{array}$ & $14.593(2)$ \\
\hline$c(\AA)$ & $\begin{array}{c}11.0610 \\
(10)\end{array}$ & $\begin{array}{c}11.0828 \\
(13)\end{array}$ & $10.957(17)$ & $11.0852(7)$ & $\begin{array}{c}11.0933 \\
(13)\end{array}$ & $10.964(2)$ \\
\hline$\theta(*)$ & $94,014(4)$ & $93,046(5)$ & $90,71(4)$ & $90,246(8)$ & $90,176(4)$ & $\begin{array}{c}90,296 \\
(16) \\
\end{array}$ \\
\hline$V\left(\AA^{3}\right)$ & $2560,4(4)$ & $2512.6(5)$ & $2095(6)$ & $2131,8(2)$ & $1965,7(4)$ & $2662,8(7)$ \\
\hline Z & 4 & 4 & 4 & 4 & 4 & 4 \\
\hline $\mathrm{T}$ & $150 \mathrm{~K}$ & $120 \mathrm{~K}$ & $120 \mathrm{~K}$ & $120 \mathrm{~K}$ & $120 \mathrm{~K}$ & $120 \mathrm{~K}$ \\
\hline$p\left(\mathrm{~g} \cdot \mathrm{cm}^{-3}\right)$ & 1,859 & 1,847 & 2,215 & 1,949 & 2,11 & 1,608 \\
\hline $2 \theta$ range $(*)$ & $\begin{array}{l}2.305- \\
22.960\end{array}$ & $\begin{array}{l}2.658- \\
25.197 \\
\end{array}$ & $\begin{array}{l}2.286- \\
19.167 \\
\end{array}$ & $\begin{array}{l}3.676- \\
25.052 \\
\end{array}$ & $\begin{array}{l}2.476- \\
25.051 \\
\end{array}$ & $\begin{array}{l}3,354- \\
17,216 \\
\end{array}$ \\
\hline $\begin{array}{c}\text { Data/Restraints/Para } \\
\text { meters }\end{array}$ & $\begin{array}{c}1765 / 0 / \\
195 \\
\end{array}$ & $\begin{array}{c}2238 / 144 \\
/ 226 \\
\end{array}$ & $\begin{array}{c}848 / 90 / \\
132 \\
\end{array}$ & $\begin{array}{c}1877 / 27 / \\
173 \\
\end{array}$ & $\begin{array}{c}1588 / 90 / \\
150 \\
\end{array}$ & $\begin{array}{c}805 / 263 / \\
156 \\
\end{array}$ \\
\hline № reflections & 15414 & 7245 & 7160 & 16741 & 5727 & 6607 \\
\hline $\begin{array}{c}\text { Independt reflections } \\
{[1>2 \sigma(I)]}\end{array}$ & 1765 & 2238 & 848 & 1877 & 1588 & 805 \\
\hline GoF & 1.106 & 1.072 & 1.664 & 1.126 & 1.06 & 1.165 \\
\hline \multirow{2}{*}{ R Factor $[1>2 s(I)]$} & $\begin{array}{c}\mathrm{R} 1= \\
0.0402\end{array}$ & $\begin{array}{c}\mathrm{R} 1= \\
0.0494\end{array}$ & $\begin{array}{c}\mathrm{R} 1= \\
0.1798\end{array}$ & $\begin{array}{c}\mathrm{R} 1= \\
0.0296\end{array}$ & $\mathrm{R} 1=0.0625$ & $\begin{array}{c}\mathrm{R} 1= \\
0.1035\end{array}$ \\
\hline & $\begin{array}{c}\text { wR2 } \\
=0.0828\end{array}$ & $\begin{array}{c}\text { wR2 } \\
=0.0831\end{array}$ & $\begin{array}{c}\text { wR2 } \\
=0.4035\end{array}$ & $\begin{array}{c}\text { wR2 } \\
=0.0666\end{array}$ & $\begin{aligned} & w R 2 \\
= & 0.1336\end{aligned}$ & $\begin{array}{c}\text { wR2 } \\
=0.2575\end{array}$ \\
\hline \multirow{2}{*}{ R Factor (all data) } & $\begin{array}{c}R 1= \\
0.0587\end{array}$ & $\begin{array}{c}R 1= \\
0.0860\end{array}$ & $\begin{array}{c}R 1= \\
0.2122\end{array}$ & $\begin{array}{c}R 1= \\
0.0349\end{array}$ & $\mathrm{R} 1=0.1151$ & $\begin{array}{c}R 1= \\
0.1239\end{array}$ \\
\hline & $\begin{array}{c}\text { wR2 } \\
=0.0891\end{array}$ & $\begin{array}{c}\text { wR2 } \\
=0.0918\end{array}$ & $\begin{array}{c}\text { wR2 } \\
=0.4232\end{array}$ & $\begin{array}{c}\text { wR2 } \\
=0.0689\end{array}$ & $\begin{array}{c}\text { wR2 } \\
=0.1578\end{array}$ & $\begin{array}{c}\text { wR2 } \\
=0.2778\end{array}$ \\
\hline CCDC Code & 1916085 & 1916086 & 1916087 & 1916083 & 1916082 & 1916084 \\
\hline
\end{tabular}


a)
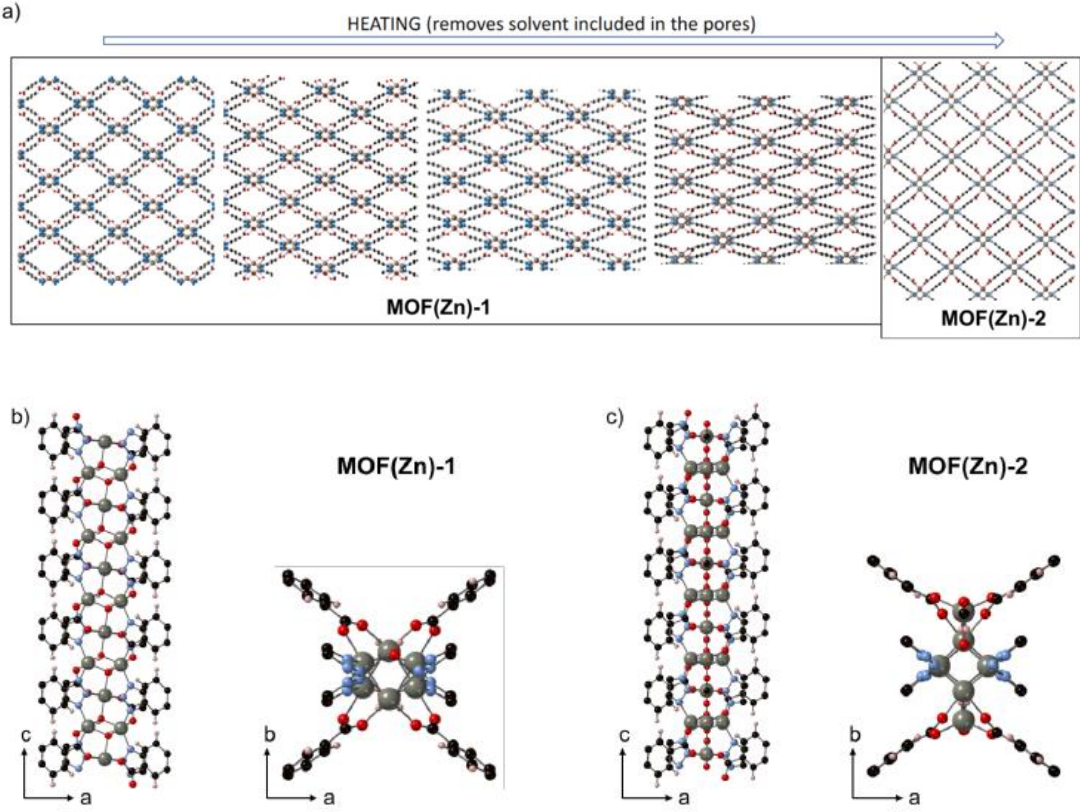

$\operatorname{MOF}(\mathrm{Zn})-2$
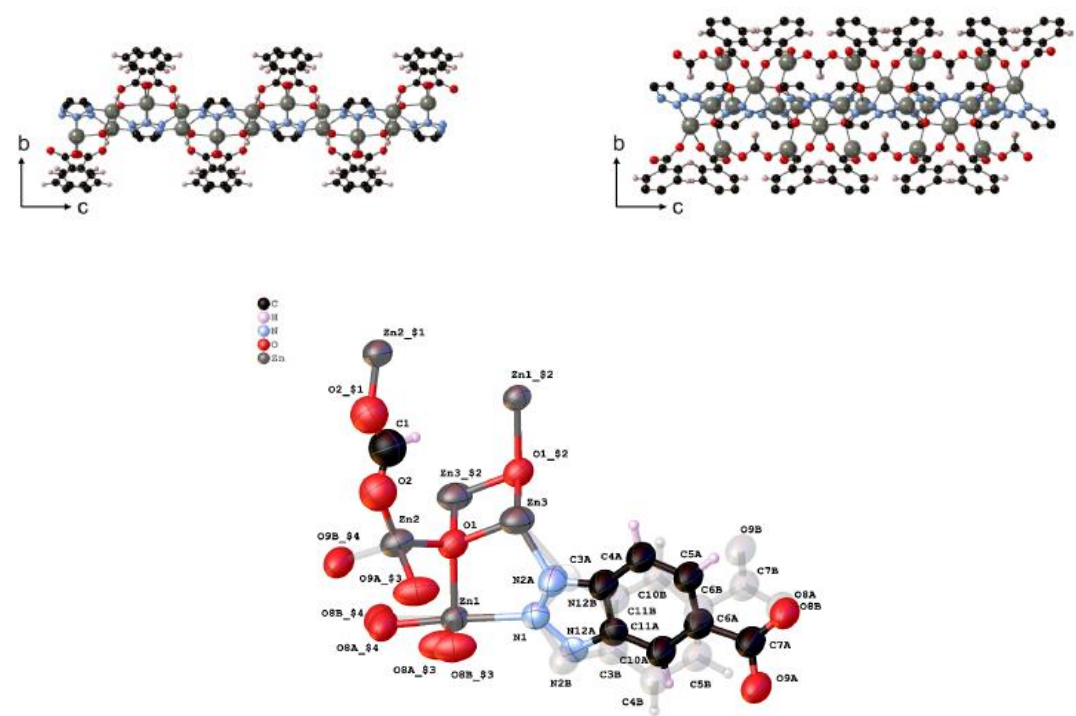

Figure S1. (a) Representation of the different crystal structures obtained during the breathing process upon increasing the temperature. (b) Different views of the structure of MOF(Zn)-1. (c) Different views of the structure of $\operatorname{MOF}(Z n)-2$. (d) A labelled ORTEP plot at $50 \%$ probability level of the asymmetric unit of $\operatorname{MOF}(Z n)-2$ showing the $\mu_{2}$-bridging formato ligand linking two symmetry-related half occupancy $\mathrm{Zn} 2$ atoms and the disordered btca ligand (symmetry operations: \$1: $-x,+y, 5 / 2-z ;$; : $-x,-y, 2-z ; \$ 3:-1 / 2-x, 1 / 2+y, 3 / 2-z ; \$ 4: 1 / 2+x, 1 / 2+y,+z)$. 


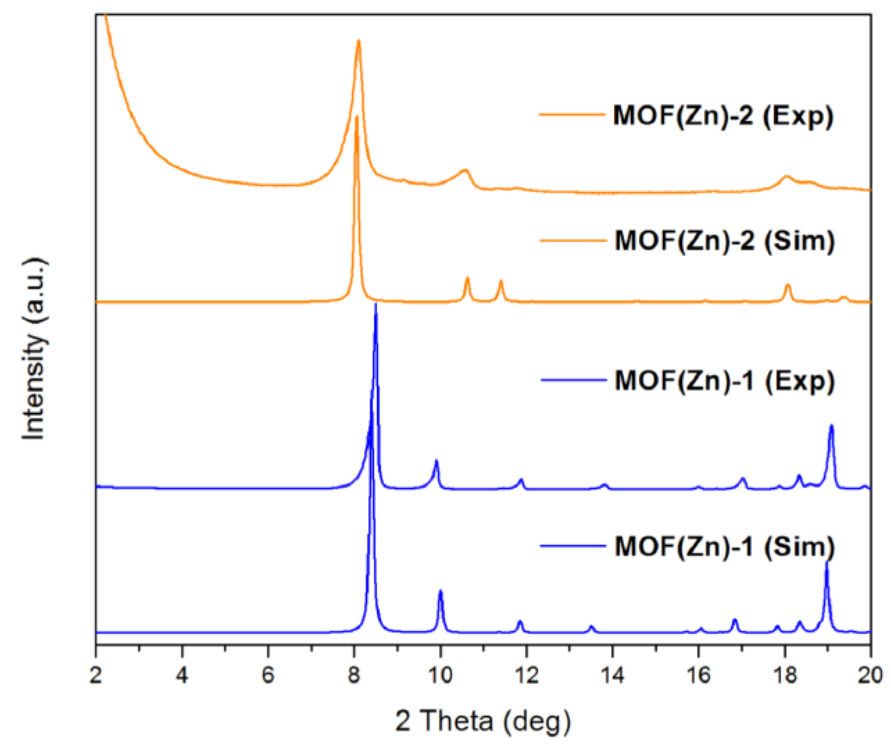

Figure S2. Experimental and simulated PXRD spectra of the MOF activated at $200^{\circ} \mathrm{C}$ (MOF(Zn)-1) and at $400^{\circ} \mathrm{C}(\mathrm{MOF}(\mathrm{Zn})-2)$.

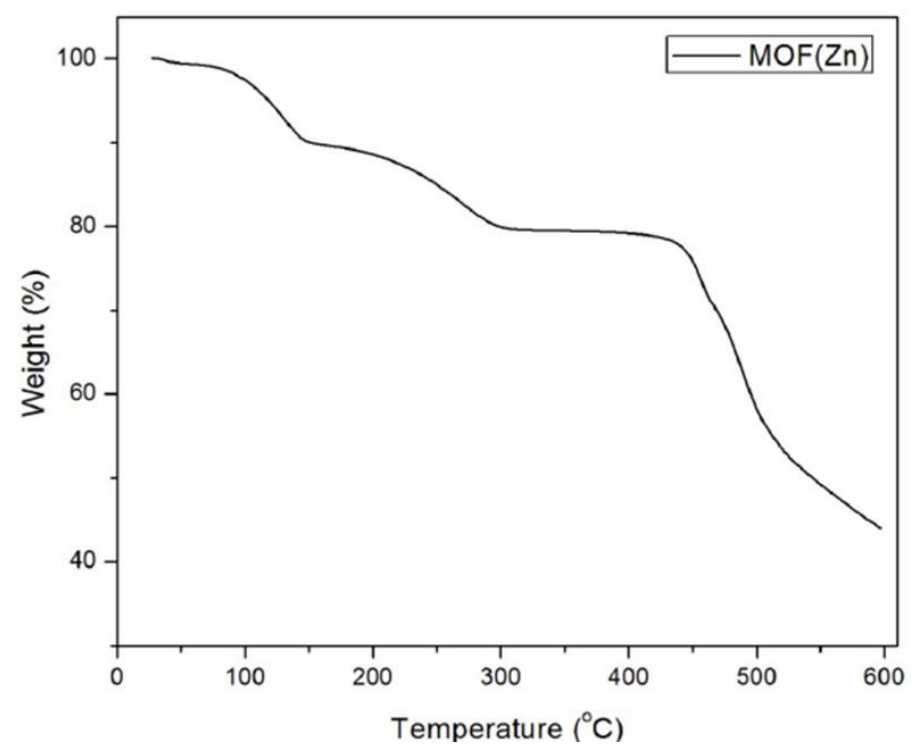

Figure S3. Thermogravimetric analysis (TGA) profile of $\operatorname{MOF}(\mathrm{Zn})$ at a heating rate of $5^{\circ} \mathrm{C} / \mathrm{min}$ under a constant stream of $\mathrm{N}_{2}$. 


\subsubsection{Catalytic tests}

\subsubsection{Catalyst characterization.}

High resolution transmission electron microscopy images (HR-TEM) and scanning TEM images in dark field mode (DF-STEM) were recorded on a JEOL JEM2100F instrument operating at $200 \mathrm{~kW}$. An Oxford detector coupled to the STEM instrument was employed to measure the composition of selected MOF areas. The metal particle size distribution and standard deviation were estimated by counting about 300 nanoparticles. The morphology and composition of the MOF samples were further characterized using a scanning electron microscope (SEM, Zeiss instrument, AURIGA Compact) coupled with a EDX detector. Isothermal nitrogen adsorption experiments were carried out using an ASAP 2010 Micromeritics device. X-ray photoelectron (XP) spectra were collected on a SPECS spectrometer with a MCD-9 detector using a monochromatic $\mathrm{Al}(\mathrm{K} \alpha=1486.6 \mathrm{eV}) \mathrm{X}$-ray source. Spectra deconvolution was performed with the CASA software using the C 1 s peak at $284.4 \mathrm{eV}$ as binding energy reference. Inductively coupled plasma atomic emission spectroscopy (ICP-AES) has been used to confirm the metal content of the catalyst previously digested in concentrated nitric acid. The content of $\mathrm{Cu}_{2} \mathrm{O}$ metal loaded was determined by IPC-AES before (0.92 \%wt $\mathrm{Cu})$ and after $(0.89 \% w t \mathrm{Cu})$ use.

\subsubsection{Photocatalytic methanation tests}

For the photoassisted methanation, a quartz photoreactor equipped with a heating mantle to control the desired temperature during the experiment was utilized. The photocatalyst $(15 \mathrm{mg})$ as powder was placed as a bed inside the reactor, the system was purged and charged with $\mathrm{H}_{2}$, and then $\mathrm{CO}_{2}$ was added until a ratio 4 to 1 was achieved. The photoreactor was heated up to $215^{\circ} \mathrm{C}$, once the temperature was stable, the photocatalyst was irradiated under UV-Vis light using a Xe lamp (150 W) as light source. The reaction was monitored by taking periodically gas samples from the reactor that were injected into an Agilent 490 MicroGC equipped with two channels and thermal conductivity detectors. One channel allows analyzing $\mathrm{H}_{2}, \mathrm{O}_{2}, \mathrm{~N}_{2}$ and $\mathrm{CO}$ with a MolSieve $5 \AA$ column while the other channel shows $\mathrm{CO}_{2}, \mathrm{CH}_{4}$ and short chain hydrocarbons using a Pore Plot $\mathrm{Q}$ column. Gases were quantified calibrating the instrument analyzing of gas mixtures. The limit of detection of the micro-GC of the reaction that is estimated to be below $0.1 \mu \mathrm{g} \cdot$ catalyst $^{-1} \cdot \mathrm{h}^{-1}$. 


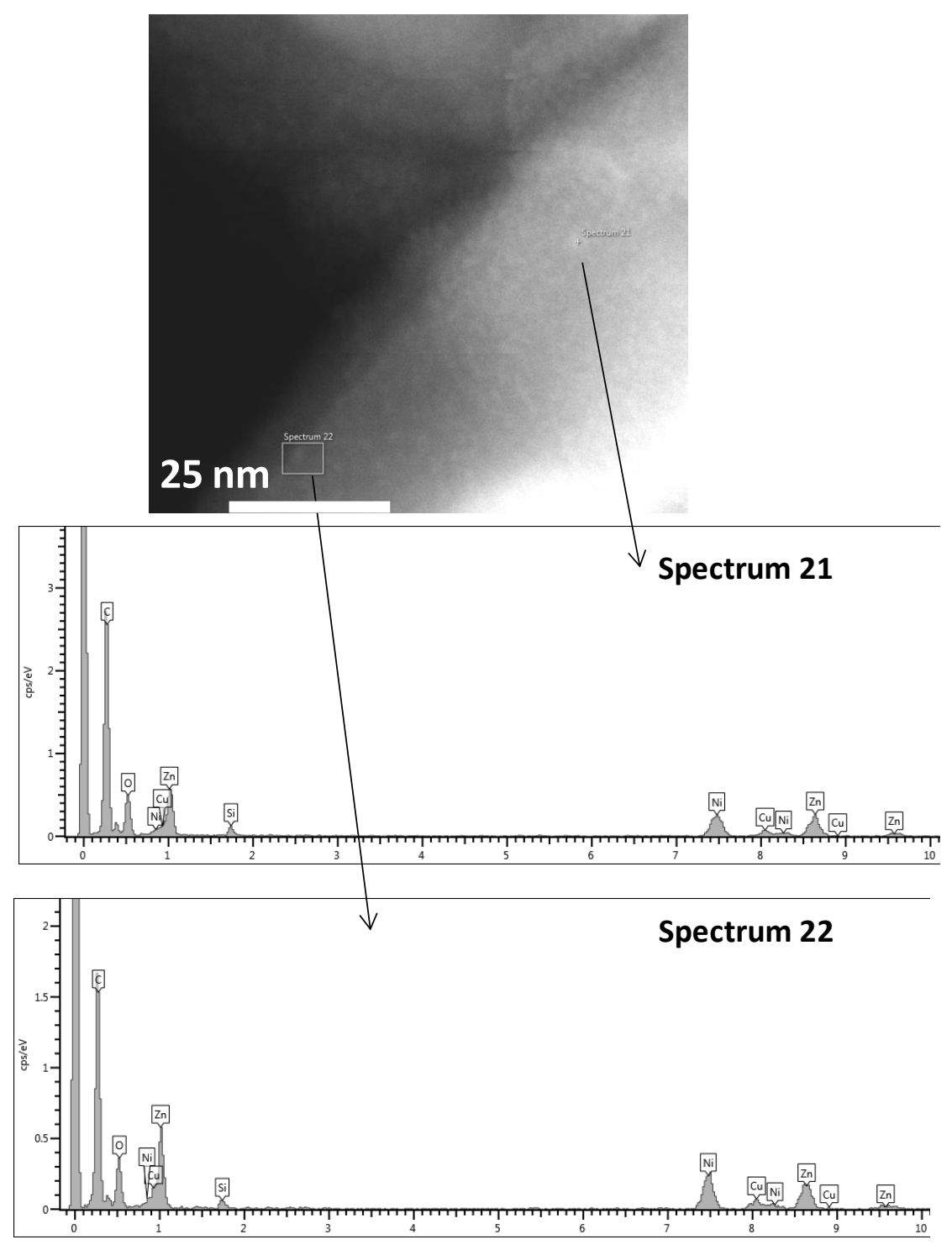

Figure S4. (a) Representative DF-STEM image of $\mathrm{Cu}_{2} \mathrm{O} @ \mathrm{MOF}(\mathrm{Zn})-1$. (b) EDS analysis of two copper nanoparticles (spectrum A and B). 

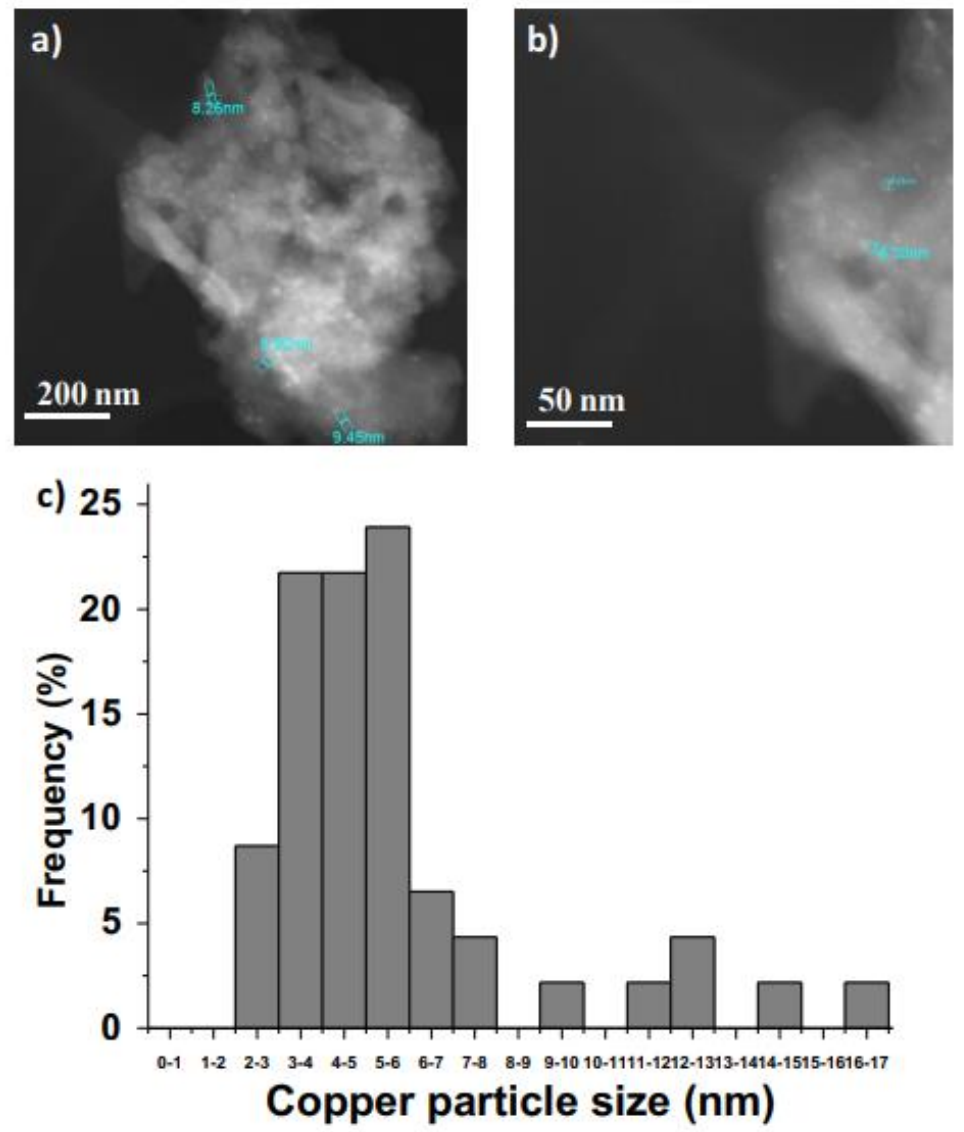

Figure S5. (a,b) DF-STEM images of $\mathrm{Cu}_{2} \mathrm{O} @ M O F(Z n)-2$. (c) Copper particle size distribution. 

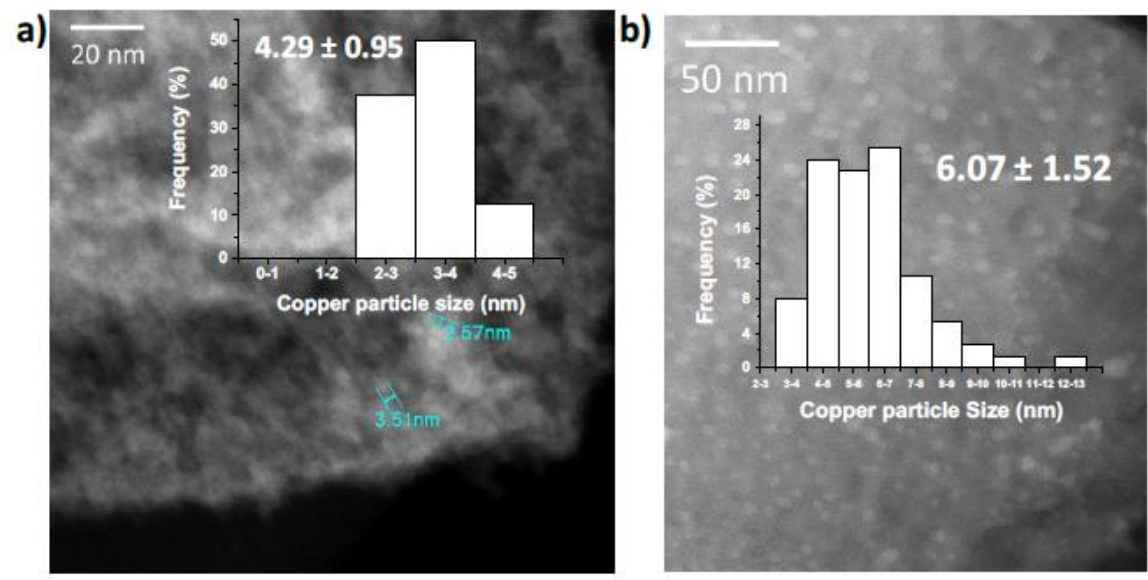

Figure S6. DF-STEM images of (a) $\mathrm{Cu}_{2} \mathrm{O} @ \mathrm{MIL}-125$ (Ti)- $\mathrm{NH}_{2}$ and (b,c) $\mathrm{Cu}_{2} \mathrm{O} @ \mathrm{MOF}-74(\mathrm{Zn})$. The insets show the copper particle size distribution, the average copper particle size and standard deviation obtained after counting more than 300 particles.
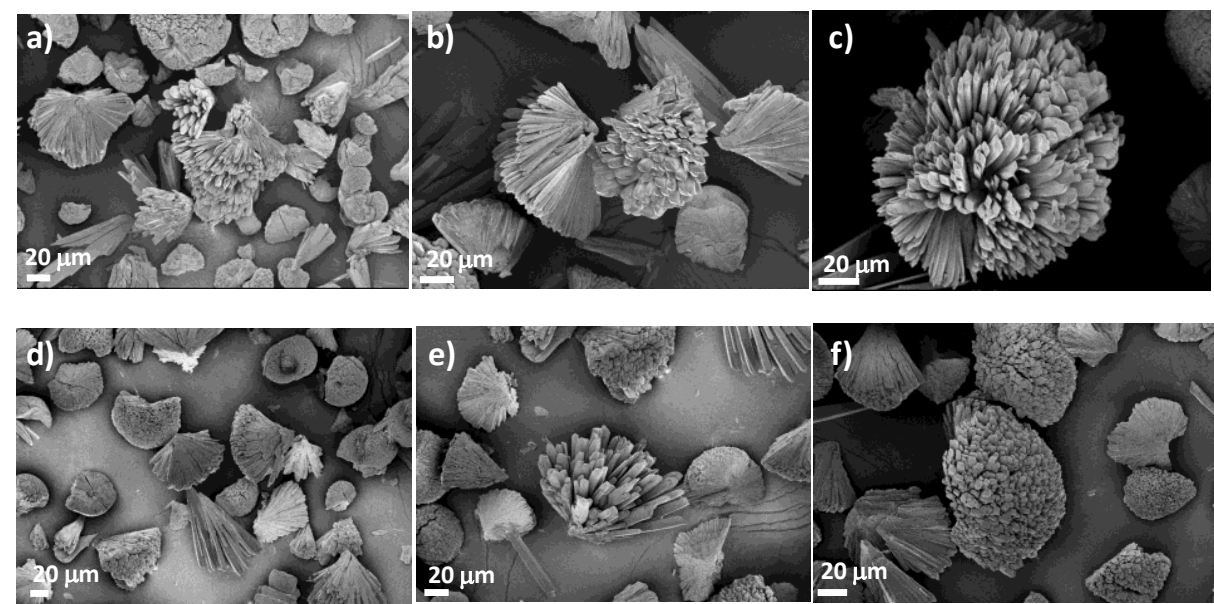

Figure S7. SEM images of $(a, b, c) \mathrm{Cu}_{2} \mathrm{O} @ \operatorname{MOF}(\mathrm{Zn})-1$ and $(d, e, f) \mathrm{Cu}_{2} \mathrm{O} @ \mathrm{MOF}(\mathrm{Zn})-2$, revealing the morphology of the crystals. 

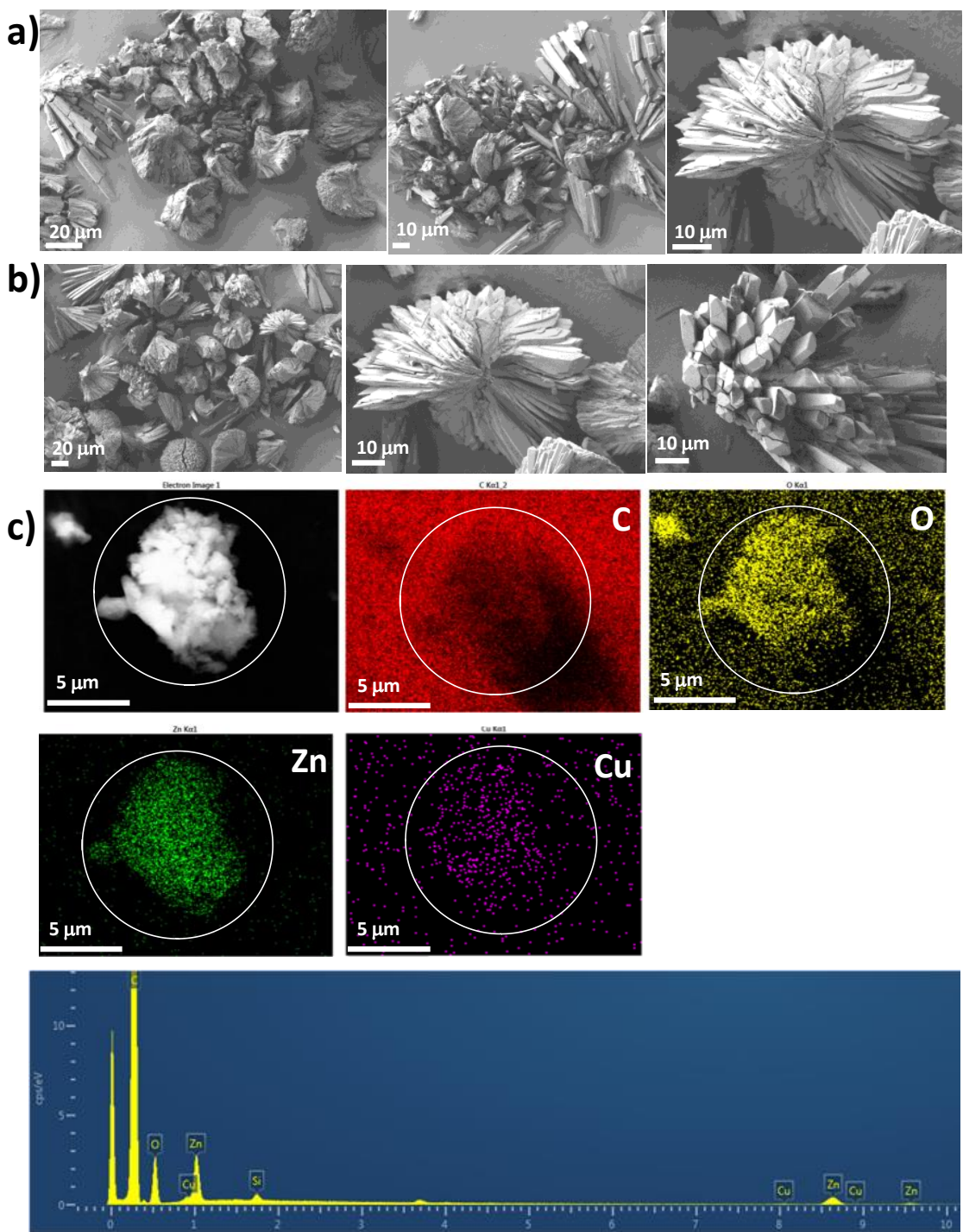

Figure S8. SEM images of (a) $\mathrm{Cu}_{2} \mathrm{O} @ \mathrm{MOF}(\mathrm{Zn})-1$ and (b) $\mathrm{Cu}_{2} \mathrm{O} @ \mathrm{MOF}(\mathrm{Zn})-2$. (c) Elemental analysis mapping of a selected area of $\mathrm{Cu}_{2} \mathrm{O} @ \mathrm{MOF}(\mathrm{Zn})-1$. 

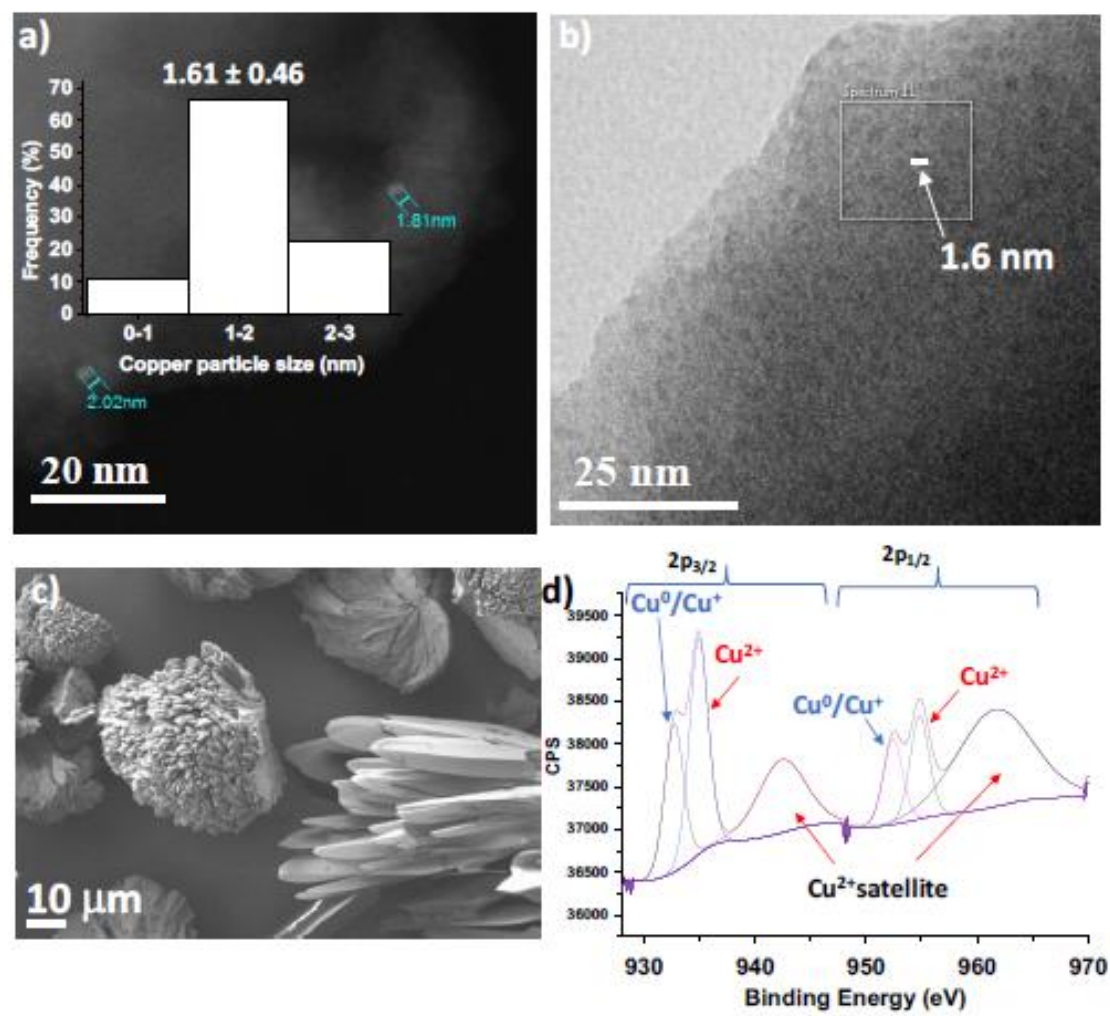

Figure 59. (a) DF-STEM and (b) BF-STEM images of fresh $\mathrm{Cu}_{2} \mathrm{O} @ M O F(Z n)-1$ photocatalyst; the inset corresponds to the copper particle size distribution obtained by counting about 300 particles. (c) SEM image of fresh SEM image and (d) XPS Cu2p spectrum of $\mathrm{Cu}_{2} \mathrm{O} @ M O F(\mathrm{Zn})-1$ showing the best deconvolution to individual components. 


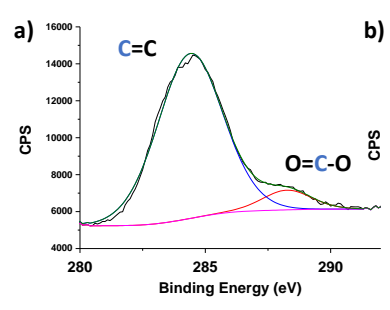

d)

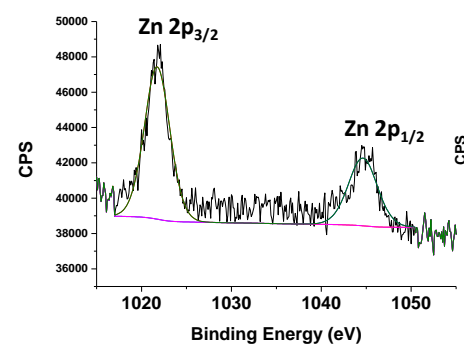

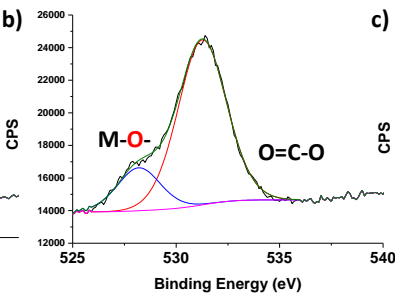

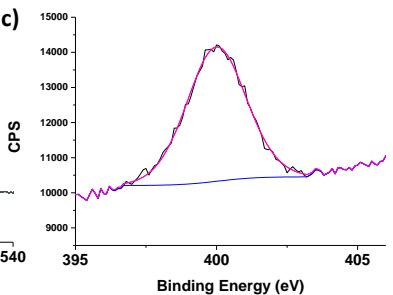

e)

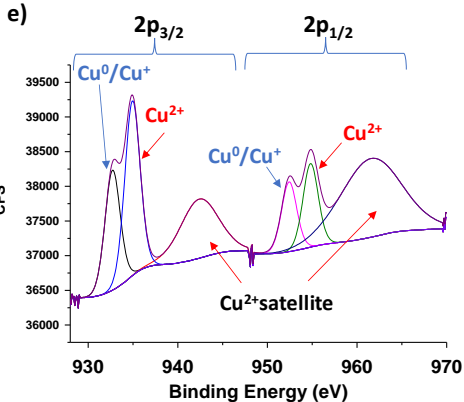

Figure S10. XPS spectra of $\mathrm{Cu}_{2} \mathrm{O} @ M O F(Z n)-1$. (a) C1s XPS, (b) O1s XPS, (c) N1s XPS, (d) Cu2p XPS, (e) Zn2p XPS.

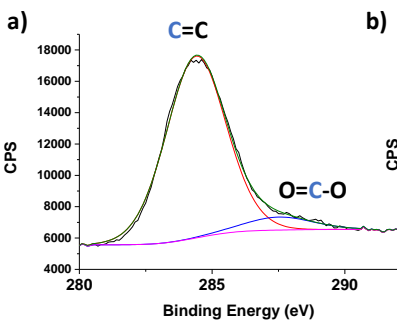

d)

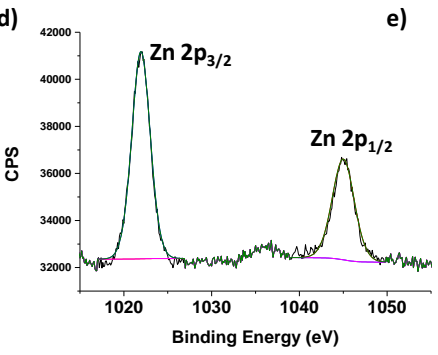

b)

e)
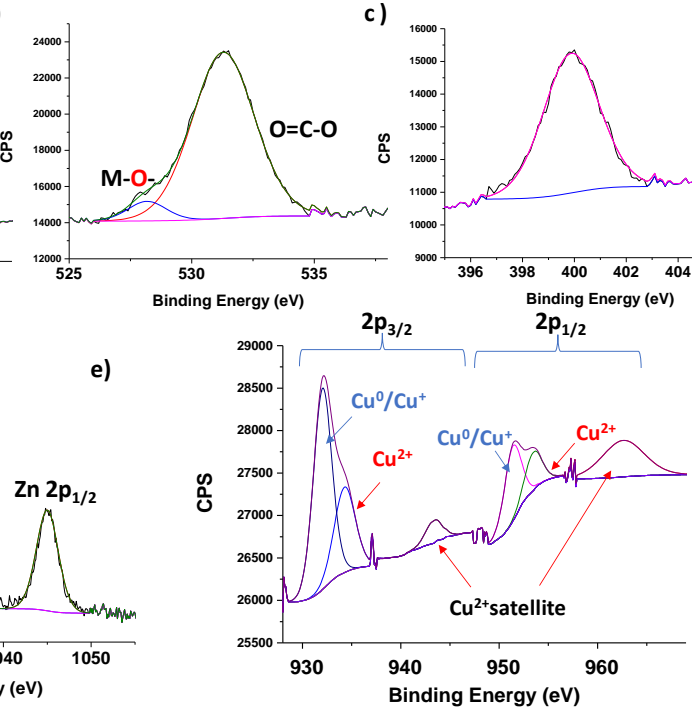

Figure S11. XPS spectra of $\mathrm{Cu}_{2} \mathrm{O} @ M O F(Z n)-2$. (a) C1s XPS, (b) O1s XPS, (c) N1s XPS, (d) Cu2p $X P S,(e)$ Zn2p XPS. 


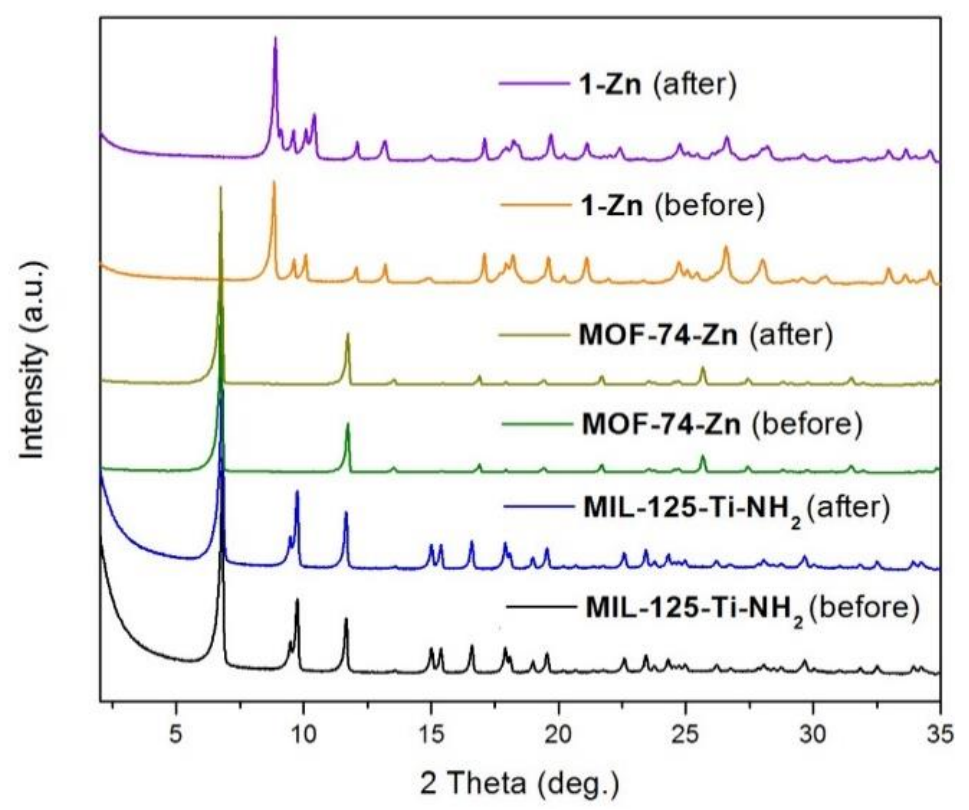

Figure S12. Powder X-ray diffraction patterns of the different copper-supported MOF based catalysts (MOF(Zn)-1, MOF-74(Zn) and MIL-125(Ti)-NH2) before and after the photocatalytic tests.

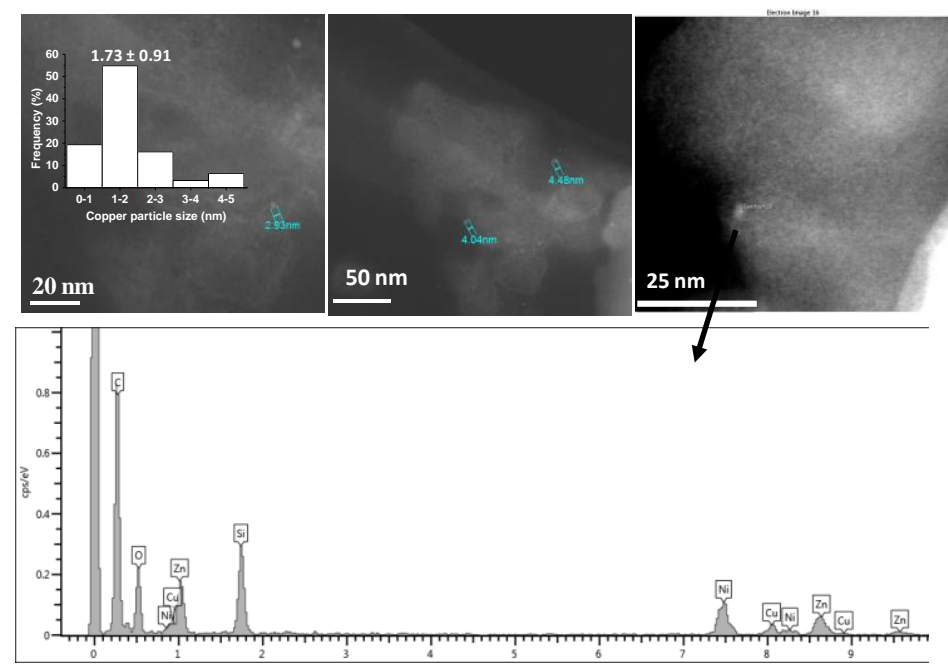

Figure S13. DF-SEM images and EDX spectrum of selected area of $\mathrm{Cu}_{2} \mathrm{O} @ \mathrm{MOF}(\mathrm{Zn})-1$ sample after photocatalytic methanation of $\mathrm{CO}_{2}$. 


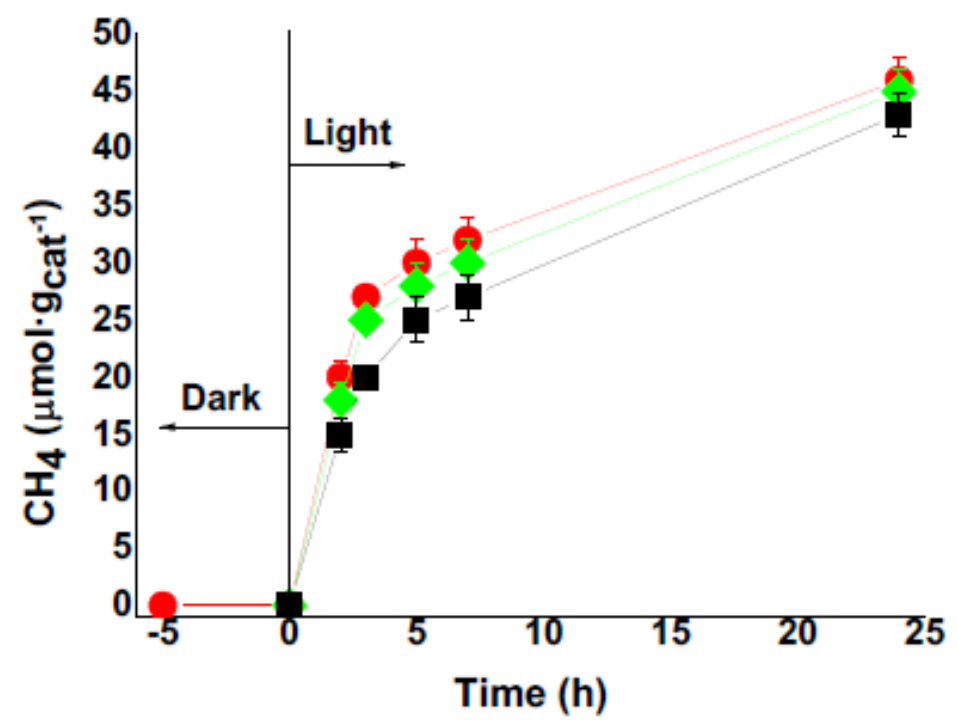

Figure S14. Reusability of $\mathrm{Cu}_{2} \mathrm{O} @ \mathrm{MOF}(\mathrm{Zn})-1$ for the $\mathrm{CH} 4$ production at $215^{\circ} \mathrm{C}$ upon $2236 \mathrm{~W}$ $\mathrm{m}^{-2}$ irradiation using a $150 \mathrm{~W}$ Xe lamp. $\mathrm{PH}_{2}=1.05$ bar, $\mathrm{PCO}_{2}=0.25$ bar. Legend First use $\mathrm{Cu}_{2} \mathrm{O} @ \operatorname{MOF}(\mathrm{Zn})-1 \quad(\bullet)$, Second use $\mathrm{Cu}_{2} \mathrm{O} @ \mathrm{MOF}(\mathrm{Zn})-1 \quad(\diamond)$ and third use of $\mathrm{Cu}_{2} \mathrm{O} @ \mathrm{MOF}(\mathrm{Zn})-1(\mathbf{\square})$. 
Chapter 5. Design of cost-efficient and photocatalytically active $\mathrm{Zn}$-based MOFs decorated with $\mathrm{Cu}_{2} \mathrm{O}$ nanoparticles for $\mathrm{CO}_{2}$ methanation
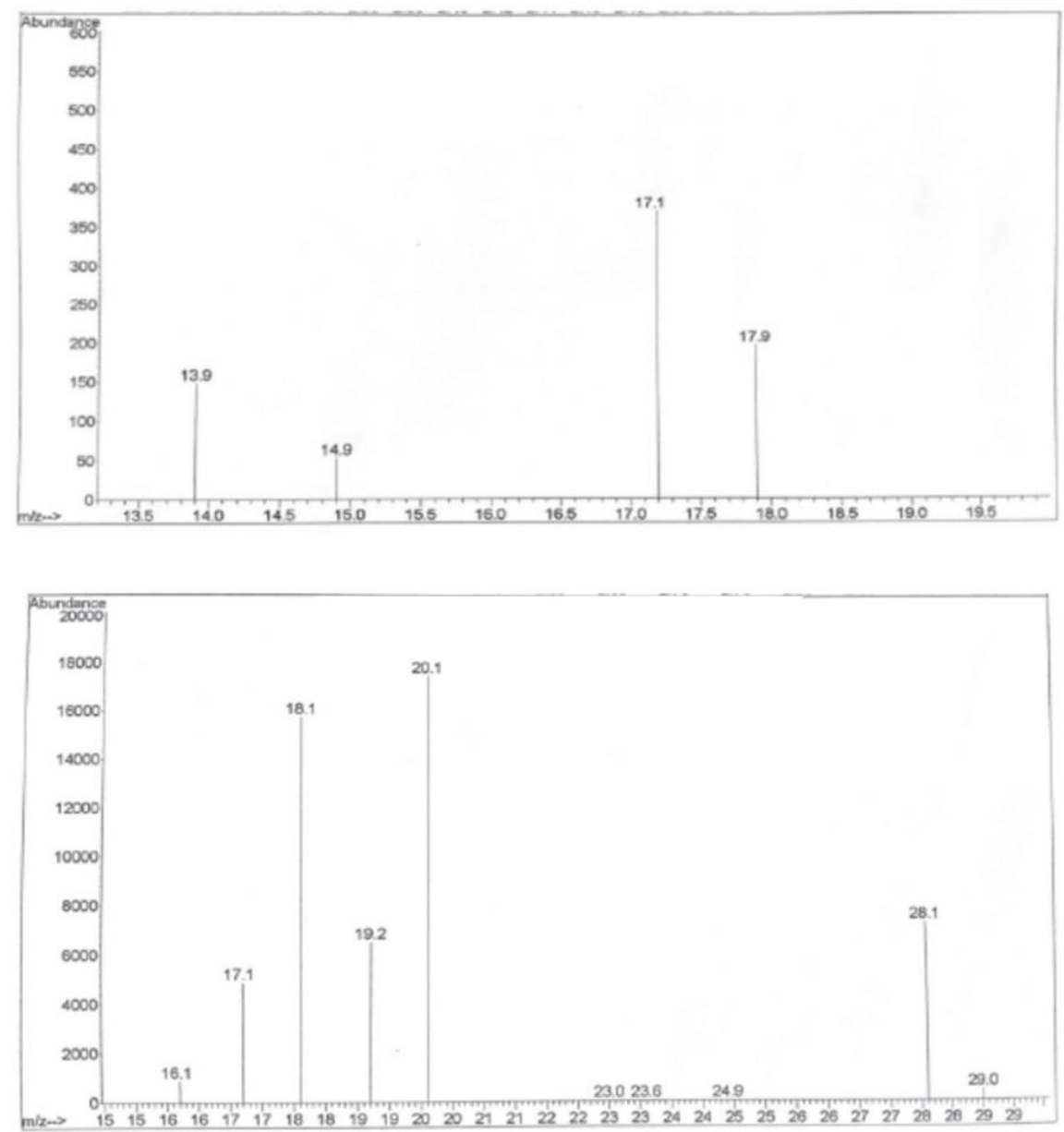

Figure S15. Mass spectra of the reaction products after the photocatalytic reaction using $\mathrm{Cu}_{2} \mathrm{O} @ \mathrm{MOF}(\mathrm{Zn})-1$ for 22 hours at $215^{\circ} \mathrm{C}$ using ${ }^{13} \mathrm{C}^{18} \mathrm{O}_{2}$. 


\subsubsection{Determination of valence band energies and optical gaps.}

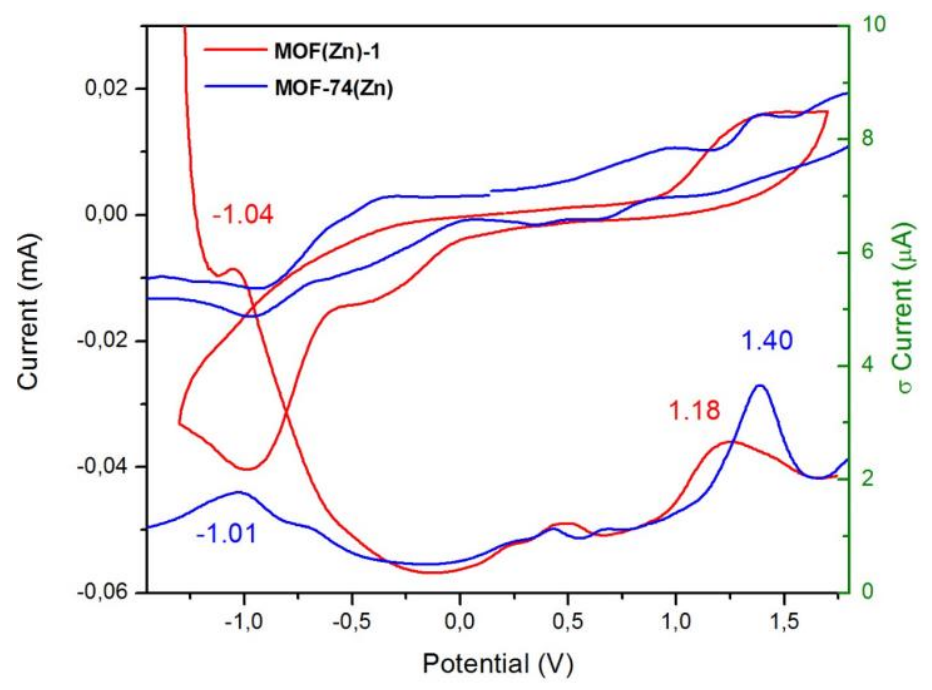

Figure S16. Solid-state Cyclic Voltammetry (CV) and Differential Pulse Voltammetry (DPV) of MOF(Zn)-1 and MOF-74(Zn) using TBAPF $6.1 \mathrm{M}$ in $\mathrm{CH}_{3} \mathrm{CN}$ as electrolyte and $0.05 \mathrm{~V} / \mathrm{s}$ scan rate. Platinum wire was used as counter electrode and silver wire as pseudoreference electrode. Ferrocene was added as internal standard. All potentials are reported versus $\mathrm{Ag} / \mathrm{AgCl}$. 


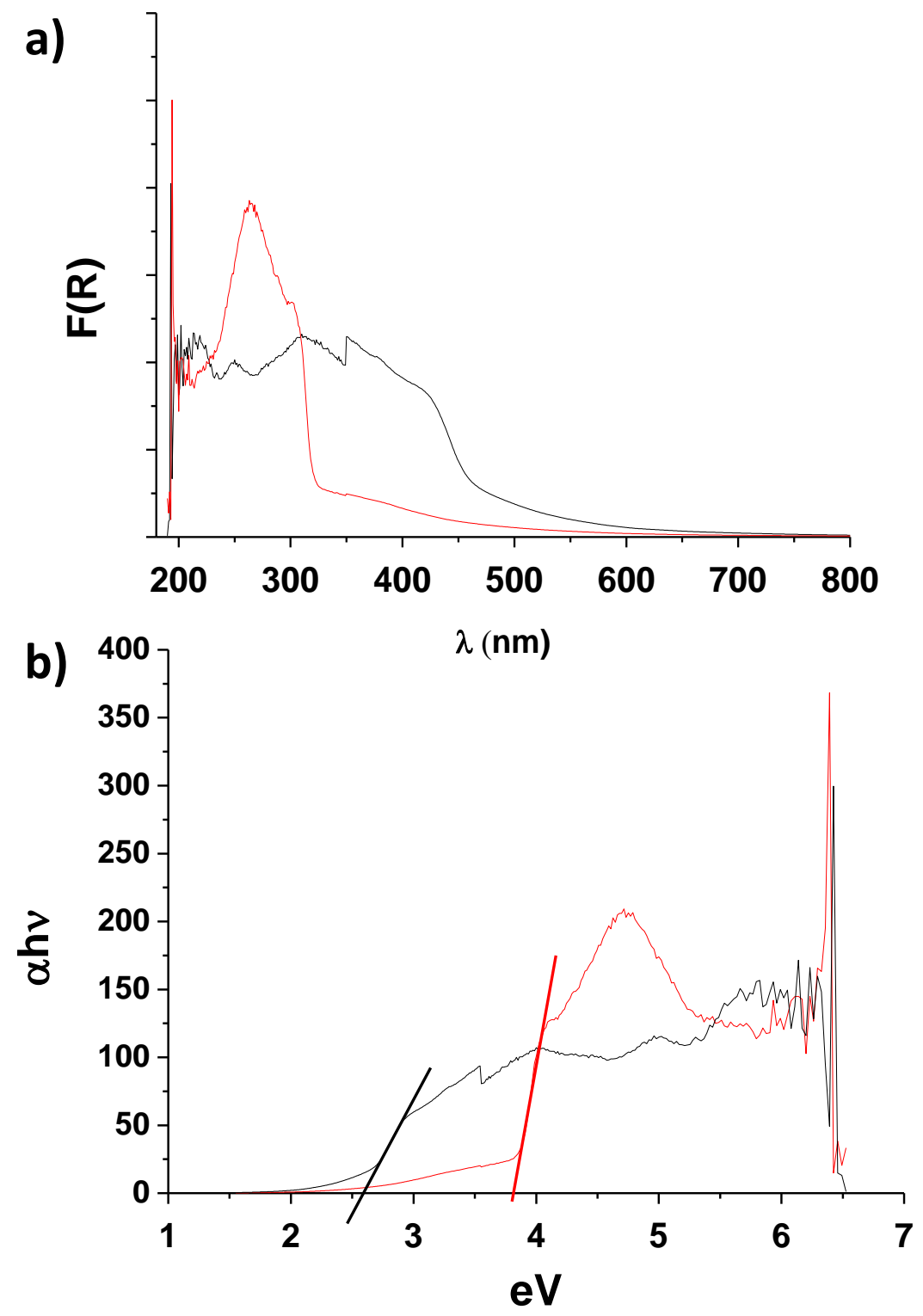

Figure S17. (a) UV-Vis diffuse reflectance and (b) Tauc plot for MOF(Zn)-1 (red line) and MOF--74(Zn) (black line). 


\subsubsection{Bibliography}

[S1] N. Rosi, J. Kim, M. Eddaoudi, B. Chen, M. O’Keeffe, O. M. Yaghi, J. Am. Chem. Soc. 2005, 127, 1504.

[S2] M. A. Nasalevich, R. Becker, E. V. Ramos-Fernandez, S. Castellanos, S. L. Veber, M. V. Fedin, F. Kapteijn, J. N. H. Reek, J. I. van der Vlugt, J. Gascon, Energy Environ. Sci. 2015, $8,364$.

[S3] S. Remiro-Buenamanana, M. Cabrero-Antonino, M. Martinez-Guanter, M. Alvaro, S. Navalon, H. Garcia, Appl. Catal. B Environ. 2019, 254, 677-684.

[S4] J. Xiao, Y. Wu, M. Li, B.-Y. Liu, X.-C. Huang, D. Li, Chem. Eur. J. 2013, 19, 1891.

[S5] Y. Yue, J. A. Rabone, H. Liu, S. M. Mahurin, M. Li, H. Wangll, Z. Lu, B. Chen, J. Wang, Y. Fang, S. Dai, J. Phys. Chem. C 2015, 119, 9442.

[S6] SAINT v8.37A, Bruker AXS Inc., Madison, Wisconsin, USA, 2015.

[S7] L. Krause, R. Herbst-Irmer, G.M. Sheldrick, D. Stalke. J. Appl. Cryst. 2005, 48, 3.

[S8] CrysAlisPro 1.171.38.46. Rigaku Oxford Diffraction, 2015.

[S9] G.M. Sheldrick, Acta Cryst. 2015, A71, 3.

[S10] O. V. Dolomanov, L. J. Bourhis, R. J. Gildea, J. A. K. Howard, H. Puschmann, J. Appl. Crystallogr. 2009, 42, 339. 


\section{Chapter 6}

A Robust Titanium Isophthalate Metal-Organic Framework for Visible-Light Photocatalytic $\mathrm{CO}_{2}$ Methanation 



\subsection{Abstract}

Isophthalic acid (IPA) has been considered to build metal-organic frameworks (MOFs), owing to its facile availability, unique connection angle-mode, and a wide range of functional groups attached. Constructing titanium-IPA frameworks that possess photoresponse properties is an alluring characteristic with respect to the challenge of synthesizing new titanium-based MOFs (Ti-MOFs). Here, we report the first Ti-IPA MOF (MIP-208) that efficiently combines the use of preformed $\mathrm{Ti}_{8}$ oxoclusters and in situ acetylation of the $5-\mathrm{NH}_{2}$-IPA linker. The mixed solid-solution linkers strategy was successfully applied, resulting in a series of multivariate MIP-208 structures with tunable chemical environments and sizable porosity. MIP-208 shows the best result among the pure MOF catalysts for the photocatalytic methanation of carbon dioxide. To improve the photocatalytic performance, ruthenium oxide nanoparticles were photo-deposited on MIP-208, forming a highly active and selective composite catalyst, MIP-208@RuO features a notable visible-light response coupled with excellent stability and recycling ability.

\subsection{Introduction}

Metal-organic frameworks (MOFs) or porous coordination polymers (PCPs) have been recognized as one of the most intensively investigated heterogeneous catalysts for liquid phase reactions, due to their porous tunable structure, high surface area, and acidic/basic sites or metal nodes with versatile and spatially controlled distributions. ${ }^{[1-3]}$ Organic ligands play an essential role in the formation of the MOF structure and the introduction of its corresponding property. ${ }^{[4,5]}$ As organic synthesis has evolved significantly over the last few decades, an almost unlimited number of organic compounds have been applied to MOF fabrication via the linker-engineering strategy, resulting in a vast combination of structures and functions. ${ }^{[6-9]}$ However, the time and effort requiring organic synthesis for linker preparation undoubtedly limits the reproduction and application of costly MOF 
candidates. $^{[10,11]}$ In this regard, commercially available organic linkers from industry are of great interest due to their ready availability on a large scale and low cost. ${ }^{[12,13]}$

Benzene-dicarboxylic acid isomers are representative compounds that fulfill the demand currently produced on a billion-kilogram scale per annum. The three isomers, namely ortho-phthalic acid (phthalic acid), meta-phthalic acid (isophthalic acid, IPA) and para-phthalic acid (terephthalic acid), are all important feedstocks for the preparation of a large number of industrial products. ${ }^{[14,15]}$ In their use of constructing MOFs, phthalic acid alone tends to form materials of low dimensionality, mainly due to the deficient separation and steric hindrance between the adjacent carboxylate groups. ${ }^{[16,17]}$ On the contrary, terephthalic acid is one of the most popular carboxylate linkers since the very beginning of MOF science. ${ }^{[18]}$ Its ideal configuration with a suitable molecular length, perfect separation of the coordination sites and varied connection modes, make this linker adaptable to MOF structures with any dimension, and built with almost every sort of metal element. ${ }^{[19-21]}$

In the case of IPA, the unique angle $\left(120^{\circ}\right)$ and the medium distance between the two carboxylate groups enable a large degree of manipulation in the synthesis of MOFs compared with the other two isomers. Numerous metal-IPA frameworks have been identified with nodes ranging from the alkaline earth metals, ${ }^{[22]}$ to divalent and trivalent transition metals, ${ }^{[23-26]}$ as well as rare earth ${ }^{[27-29]}$ or main group elements, ${ }^{[30-32]}$ and even mixed metal systems, ${ }^{[33-35]}$ in which the meta-side of the coordinated carboxylate groups on the benzene ring frequently faces the structure void. IPA offers thus an obvious and facile opportunity of tuning the chemical environment of the MOF pore via the introduction of functional groups on the meta-side. Correspondingly, distinct organic functions on the 5- and 4-position of the benzene ring have been reported, showing great interest and potential in fine-tuning the structure-property correlation. ${ }^{[36-39]}$ 
It is noteworthy that isophthalic acid is suitable for MOF assembly with every transition metal subgroup except for the Group 4 elements in the periodic table, and to the best of our knowledge, there has been no report of IPA based-MOF examples built with titanium (Ti), zirconium $(\mathrm{Zr})$, hafnium $(\mathrm{Hf})$ or rutherfordium (Rf)- On the other hand, Ti and $\mathrm{Zr}$, the most common Group 4 metals, have attracted much attention from the MOF research community during the past years, due to their high natural abundance, low toxicity, strong interactions with oxygen sites and thus significantly enhanced stabilities once in the MOF structures. ${ }^{[40,41]}$

More recently, the potential of MOFs has expanded into other areas of catalysis, particularly in photocatalysis. ${ }^{[42]}$ The strong interaction between the positively charged metal nodes and negatively charged antenna linkers in rigid configurations makes MOFs suitable for the promotion of photoinduced charge separation. ${ }^{[42]}$ Hence, an electron transfer from the organic linker in its excited state to the metal node upon light absorption appears to be a general photochemical step, especially in the case of a favorable overlap between the lowest occupied crystal orbit (LOCO) with the atomic orbitals of the metal cations. ${ }^{[43]}$ For this reason, MOFs are among the most promising category of porous photocatalysts, particularly for the production of solar fuels.

Taking into account the prevalent role of MOFs and derivative materials in photocatalysis, Ti-MOFs have attracted considerable attention due to the known activities of $\mathrm{TiO}_{2}$ and Ti-oxo clusters to undergo photoinduced charge separation. ${ }^{[44]}$ In general, Ti-MOFs are not only promising candidates as photo-responsive materials, ${ }^{[45]}$ but also show great potential in gas separation, ${ }^{[46,47]}$ proton conduction $^{[48]}$ and clinical applications. ${ }^{[49]}$ Nevertheless, direct synthesis of Ti-MOFs still remains an important challenge, ${ }^{[50]}$ despite the gradually increasing numbers of reported Ti-MOF structures over the past decade, which have been attained mostly through serendipity. It is expected that an infinite number of interconnected $\mathrm{Ti}-\mathrm{O}$ 
units would facilitate photoinduced charge separation and charge mobility, in comparison with MOFs based on discrete inorganic units with a low number of Ti-O bonds. One and two dimensional (1D and 2D) arrays of Ti-O units should thus in principle improve the semiconducting properties of the Ti-MOFs. ${ }^{[51]}$ In this context, the photoactive Ti-MOFs that have been prepared so far are those with 1D chains or nanowires of $\mathrm{Ti}-\mathrm{O}$ building units, whose photo-responsive behavior have been proven to be closer to those compounds constructed of discrete Ti-O clusters than that of bulk $\mathrm{TiO}_{2}{ }^{\left[{ }^{52]}\right.}$ As shown in Figure 1, there are only three kinds of $1 \mathrm{D} \mathrm{Ti-O}$ inorganic building units reported to date, namely the TiO chains in MIL-91, ${ }^{[53]}$ the $\mathrm{Ti}_{6} \mathrm{O}_{9}$ nanowires in MIP-177-HT, ${ }^{[52]}$ ZSTU-1, 2 and $3,{ }^{[54]}$ and the TiO chain in DGIST-1. ${ }^{[55]}$ Therefore, as these MOFs are all constructed from sophisticated ligands, it would be of great interest to synthesize IPA type linker-based Ti-MOFs with infinite Ti-O building units. It would not only expand the scope of Ti-MOFs structural and chemical diversity, but also may lead to improved photocatalytic performances.

Herein, we report an ultramicroporous Ti-MOF, denoted as MIP-208 (MIP stands for the Materials of the Institute of porous materials from Paris), the first MOF composed of Group 4 metal and IPA type linker. In the crystal structure of MIP-208, helical chains of cis-connected corner-sharing $\mathrm{TiO}_{6}$ polyhedra are held in place by the in situ generated 5-acetamidoisophthalate (5-Aa-IPA) linker molecules, giving rise to a 3D framework with $1 D$ channe-like accessible voids running along the $c$-axis. Benefiting from their shared structural configuration and coordination adaptability, mixed linkers of 5-Aa-IPA and other IPA derivatives with diverse functional groups on the meta-position of the carboxylate groups could be further introduced in the framework following a solid-solution strategy, resulting in a series of multivariate MIP-208 structures. Furthermore, the dual presence of the amide group and the 1D TiO chain unit in the porous structure of MIP-208, associated with an excellent thermal and hydrothermal stability, has allowed the development of a photocatalyst 
for the methanation of carbon dioxide $\left(\mathrm{CO}_{2}\right)$ based on $\mathrm{RuO}_{\mathrm{x}}$ nanoparticles (NPs) under visible light, reaching a productivity of $0.8 \mathrm{mmol}_{\text {catalyst }}{ }^{-1}$ at $200{ }^{\circ} \mathrm{C}$ in $22 \mathrm{~h}$.
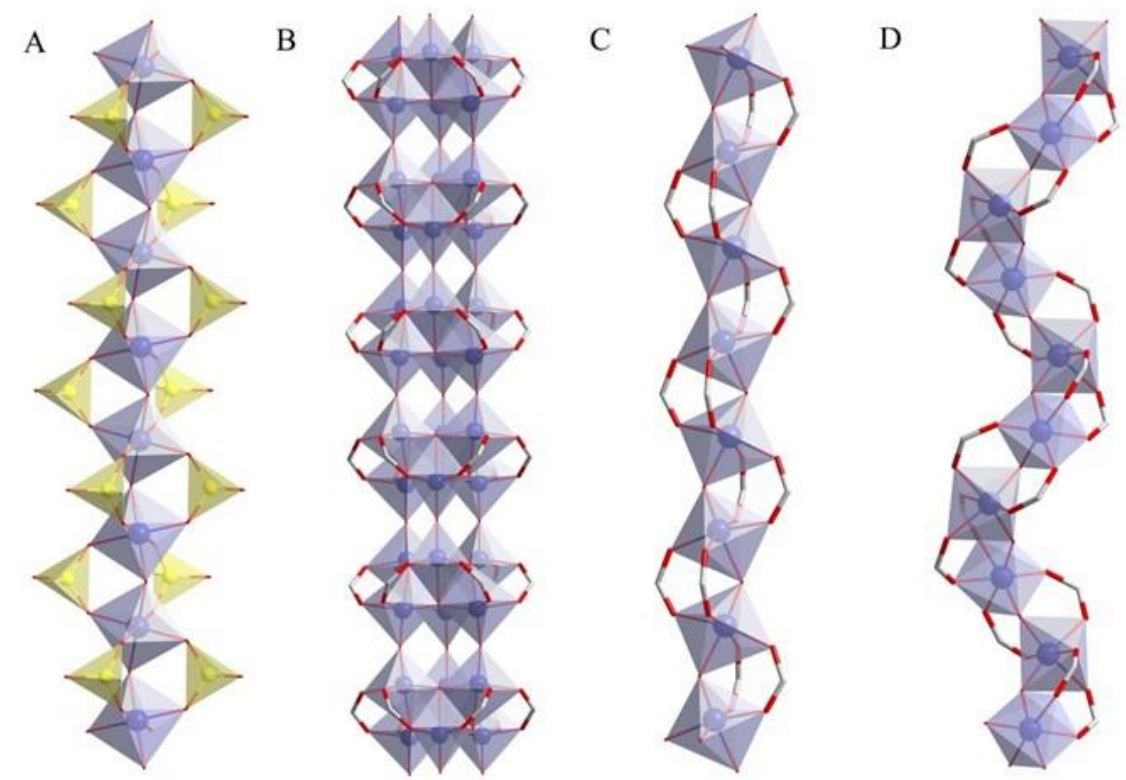

Figure 1. Comparison of 1D Ti-O inorganic building units reported.
(A) Linear TiO chain in MIL-91
(B) Linear $\mathrm{Ti}_{6} \mathrm{O}_{9}$ nanowire in MIP-177-HT, ZSTU-1, 2 and 3
(C) Linear TiO chain in DGIST-1 and ACM-1
(D) Helical TiO chain in MIP-208 reported here

\subsection{Results and discussion}

Twenty-four different Ti-MOFs prepared from direct-synthesis have been reported to date. The Ti sources used to produce these MOFs can be classified into two kinds: simple Ti complexes and polynuclear TiO clusters. Compared with simple Ti complexes, such as $\mathrm{TiCl}_{3}, \mathrm{TiCl}_{4}$, and $\mathrm{Ti}(\mathrm{iPrO})_{4}$, Ti-oxoclusters are known to slow down the reaction rate and avoid the undesirable hydrolytic formation of $\mathrm{TiO}_{2}$, owing to the gradual rearrangements of $\mathrm{Ti}-\mathrm{O}$ connections of the oxocluster precursor for 
most cases. Thus, Ti-oxoclusters usually lead to highly crystalline Ti-MOF materials composed of large single crystals. ${ }^{[55-57]}$ In this regard, a $\mathrm{Ti}_{8} \mathrm{O}_{8}$ cluster with formate and acetate terminals ( $\left.\mathrm{Ti}_{8} \mathrm{AF}\right)$ was selected here as a reactant, due to its facile preparation, easy handling, suitable stability and reactivity. ${ }^{[58]}$ Regarding solvent for the reaction, it is well-recognized that the conventional ones, such as dimethylformamide (DMF) and diethylformamide (DEF), should be replaced by greener solvents to decrease the toxicity to humans and the environment. Based on our previous success of preparing Group 4 metal MOFs, formic acid, acetic acid and acetic anhydride, which have been shown to efficiently slow down the reaction leading to highly crystalline products, were selected as solvents. 5- $\mathrm{NH}_{2}$-IPA was selected as the linker due to the documented benefit of the amino group presence in increasing the $\mathrm{CO}_{2}$ adsorption and enhancing the visible light photoresponse. ${ }^{[59 ; 60]}$

Initial reaction attempts indicated that the three acidic solvents can interfere with decomposition of the $\mathrm{Ti}_{8} \mathrm{AF}$ precursor, while offering a good solubility for the $5-\mathrm{NH}_{2}$-IPA linker. However, all attempts did not generate any crystalline solid. Various additives known to either facilitate the linker exchange or promote the rearrangement of Ti-O connections were tested, such as water, methanol, ethanol, acetone, and DMF. A highly crystalline product of a dark yellow or light brown color was formed only when methanol was used in the mixture of acetic acid and acetic anhydride. Acetic acid was found to be not necessary for the product formation, but to accelerate the reaction rate. An in situ amidation took place between the amino group of 5- $\mathrm{NH}_{2}$-IPA and acetic anhydride, generating the 5-acetamide-IPA (5-Aa-IPA) as the final framework building linker (Figure S1). Solid state NMR data collected on the as-synthesized MIP-208 sample demonstrated the complete conversion of 5- $\mathrm{NH}_{2}$-IPA to 5-Aa-IPA, which serves as the linker to build the MOF structure (Figures S2-S4). 
It is likely that the in situ acetylation step is critical to yield the crystalline material, which possibly slows down the reaction rate significantly. A control experiment using the preformed 5-Aa-IPA as linker under the same reaction conditions did not lead to MIP-208, but to an amorphous solid. Therefore, this solvothermal synthesis is likely to benefit synergistically from the rearrangement of the $\mathrm{Ti}_{8} \mathrm{AF}$ cluster and in situ linker formation, which is a rare case for MOF preparation reported so far. However, it could provide a valuable and even rational strategy for the synthesis of new Ti-MOFs through a control of the reaction rate from both inorganic and organic precursor conversions.

MIP-208 was obtained as micro-sized single crystals, ruling out its structure determination from laboratory diffraction. Thus single-crystal X-ray diffraction data of MIP-208 were collected with microfocused X-rays on the synchrotron beamline PPOXIMA 2A (Synchrotron SOLEIL, France) ${ }^{[61]}$ to determine its crystal structure. The coordination environment of the $\mathrm{Ti}^{4+}$ ion and the overall framework connection could be solved precisely, even though the position of the acetamide group could not be accurately located due to its disorder. Assisted by the solid-state NMR characterization, an empirical formula of $\mathrm{Ti}\left(\mu_{2}-\mathrm{O}\right)(5-\mathrm{Aa}-\mathrm{IPA})$ could be dertermined for MIP-208. Rietveld refinement carried out on the high resolution powder X-ray diffraction data (PXRD) of MIP-208 confirms the aforementioned structural model (Figure S5). It crystallizes in tetragonal $14_{1} /$ amd space group (No. 141) with the unit-cell constants $a=b=21.8190 \AA$ and $c=10.9380 \AA$. . As shown in Figure $2 \mathrm{~A}$, each $\mathrm{Ti}^{4+}$ ion is in an octahedral coordination geometry with four carboxylate oxygen atoms and two $\mu_{2}-\mathrm{O}$ oxo groups. The adjacent $\mathrm{TiO}_{6}$ polyhedra adopt a cis-connected corner-sharing mode to connect each other, giving rise to a $1 \mathrm{D}$ infinite chain of secondary building units (SBUs) running along the $c$-axis. Unlike the linear 1D Ti-O SBUs in MIL-91, ${ }^{[53]}$ DGIST-1 ${ }^{[55]}$ and MIP-177-HT, ${ }^{[52]}$ the helical TiO chain in MIP-208 is the first example of this type of SBU observed in Ti-MOFs, to our knowledge (Figure 1). An $\mathrm{Al}(\mathrm{OH})$ chain with a similar configuration was discovered previously in the 
CAU-10 MOF series (CAU stands for Christian-Albrechts-University), ${ }^{[62]}$ with $\mu_{2}-\mathrm{OH}$ group as the shared corner.
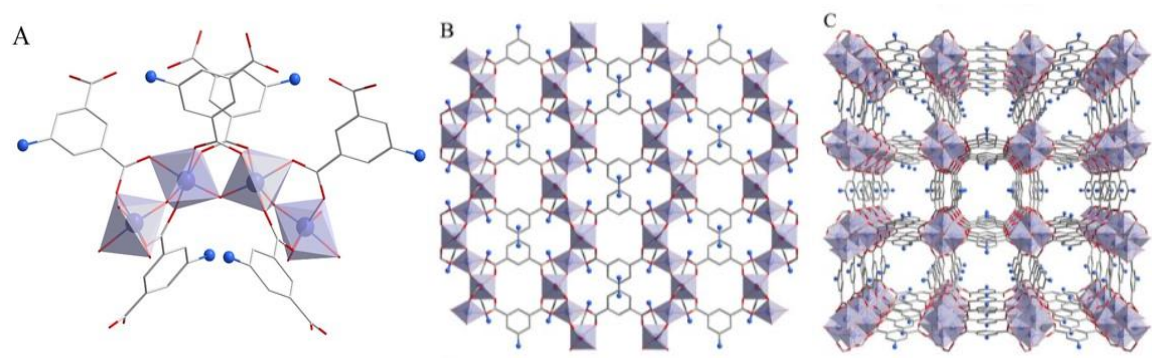

Figure 2. Crystal structure of MIP-208.

(A) Coordination environment of the $\mathrm{Ti}^{4+}$ ions and arrangement of 5-Aa-IPA linkers around them

(B) Structure viewed along the $b$-axis

(C) Structure viewed along the $c$-axis, showing 1D channels ( $\mathrm{Ti}$ in purple, $\mathrm{C}$ in gray, $\mathrm{O}$ in red, and the blue ball represents the acetamide group, all hydrogen atoms are omitted for clarity)

Notably, the replacement of the bridging $\mathrm{OH}$ in trivalent metal-based MOFs by an oxo group in similar MOFs built with tetravalent metals could lead to a dramatic difference in terms of structural flexibility and related properties, as documented in MIL-47 and MIL-53 compounds (MIL stands for Materials from Institute Lavoisier). ${ }^{[63 ; 64]}$ In particular, the presence of $\mathrm{OH}$ or oxo groups in $\mathrm{Ti}-\mathrm{O}$ materials has been demonstrated to be critical to their performance in photocatalysis, ${ }^{[65-67]}$ which highlights the importance of TiO chains in MIP-208 structure over its analogues with the lower valence metal ions.

The neighboring TiO chains are interconnected via pairs of 5-Aa-IPA linkers in an 'up and down' mode to avoid as much as possible any steric hindrance (Figure $2 B)$, resulting in a 3D framework with double-walled $1 D$ channels running along the $c$-axis (Figure 2C). One can expect its micropores to be accessible for guest molecules as reported before for $\mathrm{CAU}-10$ compounds constructed from IPA bearing the bulkiest 
functional groups, ${ }^{[62,68]}$ due to the large size and thus considerable steric hindrance of the acetamide groups facing the pores. As reported before for CAU-10-OMe and CAU-10-Br, MIP-208 did not show any accessibility for nitrogen at $77 \mathrm{~K}$, but a noticeable porosity for $\mathrm{CO}_{2}$ (Figure S4).

A large number of functionalized IPAs are commercially available chemicals offered at low prices. The high compatibility of IPA derivatives regarding their behavior in coordination chemistry has been documented, ${ }^{[37]}$ thus offering the possibility to tune the chemical environment of the pore in the MIP-208 structure via a solid-solution mixed linker strategy. The solid-solution synthesis strategy is a powerful alternative way to introduce multiple functional groups together in MOF structures, especially when the direct synthesis of the isostructural MOF with the single linker bearing specific functional group as a reactant is challenging. ${ }^{[69-71]}$ This strategy suits perfectly the case of MIP-208, since all attempts to directly synthesize the corresponding MIP-208 analogues using other functionalized IPAs instead of 5- $\mathrm{NH}_{2}$-IPA have failed up to now, resulting in either amorphous solids or crystalline phases of different structures.

Therefore, mixed linkers were considered via one-pot reactions to prepare a series of multivariate MIP-208s (MTV-MIP-208, Figure 3A). Several representative IPA-type dicarboxylic acids, including IPA, 5-NO 2 -IPA, 5-Me-IPA, 5-Br-IPA, 5-tBu-IPA, 3,5-pyrazole-dicarboxylic acid (PDA) and camphoric acid, were selected as the substitution linkers, aiming to replace the 5-Aa-IPA spacer in the MIP-208 framework. All the tested linkers except for 5- $\mathrm{NO}_{2}-\mathrm{IPA}$ and camphoric acid could reach certain substitution ratios, ranging from $11 \mathrm{~mol} \%$ to $50 \mathrm{~mol} \%$ (Figure S8), as deduced from the NMR data. However, the reason for the unsuccessful inclusion of 5- $\mathrm{NO}_{2}-\mathrm{IPA}$ and camphoric acid is not yet clear and still under investigation.

As shown in Figure 3B, the inclusion of the second linker did not generate noticeable changes in the overall structural long-range order, as evidenced by their 
highly similar PXRD patterns. However, the porosities of the resulting materials were altered, as deduced from the $\mathrm{CO}_{2}$ adsorption isotherms collected at $273 \mathrm{~K}$ (Figure 3C). For instance, the sample with 50 mol \% IPA substitution ratio led to a significant enhancement of $\mathrm{CO}_{2}$ uptake (50\% at both 0.1 and 1 bar) compared with the pure MIP-208, likely because of the smaller $\mathrm{H}$ atoms providing less steric hindrance over the larger acetamide group.

A similar observation was noticed for the 5-Me-IPAmixedsample (33 mol\%) in the case of the5-Br-IPA derivative (38 mol\%), a slight decrease of uptake in comparison with the parent compound was observed, possibly attributable to the much heavier atomic weight of the $\mathrm{Br}$ atom, despite its lower steric hindrance. When the slightly bulkier tBu group, but of similar molecular weight, was introduced to replace the acetamide group, the sample showed a limited drop in pore volume mainly due to the small linker substitution ratio (17 mol\%). It is worth noting that even PDA, which has a five-membered heterocyclic aromatic moiety, could be included in the MIP-208 framework, though the substitution ratio was low (11 mol\%), probably due to the small change in the angle of the two carboxylate groups and the presence of basic $\mathrm{N}$-site on the heterocyclic ring. Therefore, the solid-solution synthesis strategy here is an efficient way to expand and modify the chemical variety of the MIP-208 structural cavity, leading to a series of MTV-MIP-208 materials. The stability of any MOF is a practical concern in its applications. For instance, photocatalytic methanation requires a combination of thermal, hydrolytic and UV irradiation stability of the MOF catalyst, since the catalysis is normally carried out at temperatures close to $200{ }^{\circ} \mathrm{C}$, under UV irradiation and in the presence of stoichiometric water generated as the side product. Therefore, the stability of MIP-208 was tested before applying it to the photocatalytic methanation. The results from both temperature-dependent PXRD measurements and thermogravimetric analysis (TGA) support the high stability of MIP-208 (Figure S9). Its ordered crystal structure is stable up to $325^{\circ} \mathrm{C}$ in air, which is comparable to MIP-177-HT, and clearly 
surpasses MIL-91 and DGIST-1 (unstable above $200^{\circ} \mathrm{C}$ ). Furthermore, the activated MIP-208 sample hardly adsorbs water (less than 5 wt\%) when exposed to air for a long time, considerably much less than the Al-CAU-10 series do. This enhanced hydrophobicity of MIP-208 is thus associated to the bridging oxo group effect, in comparison with the $\mathrm{OH}$ in $\mathrm{CAU}-10$, as well as the limited hydrophilic character of acetamide.

Soaking MIP-208 in liquid water at room temperature for three days and heating it in boiling water for $8 \mathrm{~h}$, separately, tested its hydrolytic stability. The PXRD patterns of the tested samples are identical to those of the as-synthesized ones (Figure 4A), supporting the robustness of the crystalline long-range order. The $\mathrm{CO}_{2}$ adsorption data (Figure 4B) confirm the high hydrolytic stability of MIP-208, with minor differences between the sample before and after water treatments. In addition, the hydrolytic stability of MIP-208 in aqueous solution with various $\mathrm{pH}$ values were also investigated, which supports the excellent resistance of MIP-208 towards those chemical treatments (Figure S10). It is worth noting that MIP-208 is among the most hydrothermally stable Ti-MOFs (comparable to that of the Ti-bisphosphonate MIL-91) and outperforms all Ti-carboxylate MOFs reported thus far.

As MIP-208 possesses 1D TiO chain building block, a good photoresponsive activity is expected. Photocatalytic conversion of $\mathrm{CO}_{2}$ to methane was thus selected as the model reaction since this reaction could generate value-added product from $\mathrm{CO}_{2}$ emissions. Promising progress has been achieved lately in using MOF-based heterogeneous catalysts for $\mathrm{CO}_{2}$ conversion to methane. ${ }^{[72]}$ For instance, MOFs supported nickel and platinum nanoparticles (NPs) could promote the thermal methanation under harsh conditions, such as high pressures and temperatures. Photocatalytic methanation by MOF-based catalysts has, however, been hampered for a long time by poor selectivity until the recent success reported of a HKUST-1@ $\mathrm{TiO}_{2}$ core-shell composite applied under UV irradiation, albeit its rather 
low efficiency. ${ }^{[73]}$ Lately, the first example of a pure photoactive MOF displaying catalytic methanation has been reported, which involves $\mathrm{ZnO}$ inorganic bricks in a nitrogen-rich framework exhibiting a $\mathrm{CH}_{4}$ generation productivity of $30 \mu \mathrm{mol} \cdot \mathrm{g}_{\text {catalyst }}{ }^{-1}$ after $24 \mathrm{~h}$ at $215^{\circ} \mathrm{C}$ under UV light irradiation. A notable enhancement of activity was attained via supporting $\mathrm{Cu}_{2} \mathrm{O}$ NPs on the $\mathrm{Zn}-\mathrm{MOF}$ to form a composite catalyst, which led to $\mathrm{a} \mathrm{CH}_{4}$ production of $45 \mu \mathrm{mol} \cdot \mathrm{g}_{\text {catalyst }}{ }^{-1}$ under the same conditions. ${ }^{[74]}$ These breakthroughs are undoubtedly encouraging, although the photocatalytic activity of MOF materials remains very low. Therefore, developing efficient and selective MOF-based photocatalysts for methanation is of great interest, but still remains a challenge.
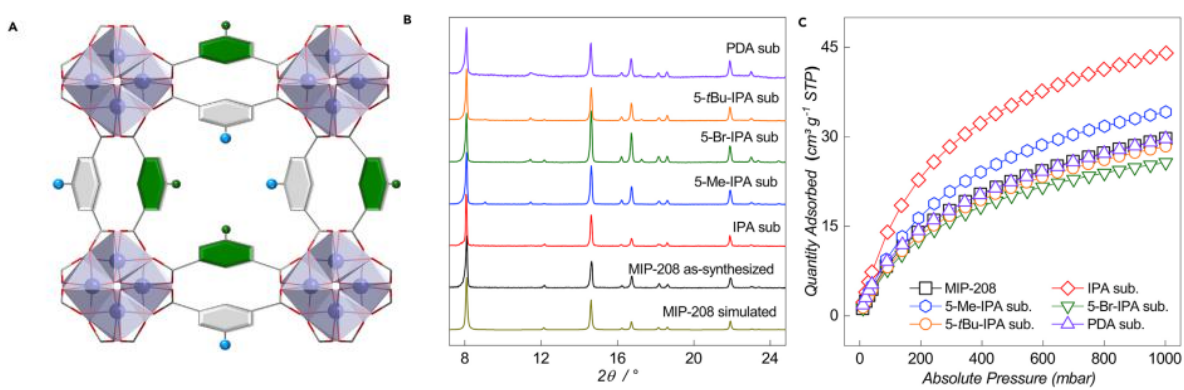

Figure 3. Illustration and characterizations of MTV-MIP-208 materials.

(A) Illustration of MTV-MIP-208 structure with multiple functional groups (the blue ball represents the acetamide group, the green ball represents the other functional groups. Hydrogen atoms are omitted for clarity)

(B) PXRD patterns of the parent and MTV-MIP-208s $\left(\lambda_{\mathrm{Cu}} \approx 1.5406 \AA\right)$

(C) $\mathrm{CO}_{2}$ adsorption isotherms collected at $273 \mathrm{~K}$ for parent and MTV-MIP-208 solid 

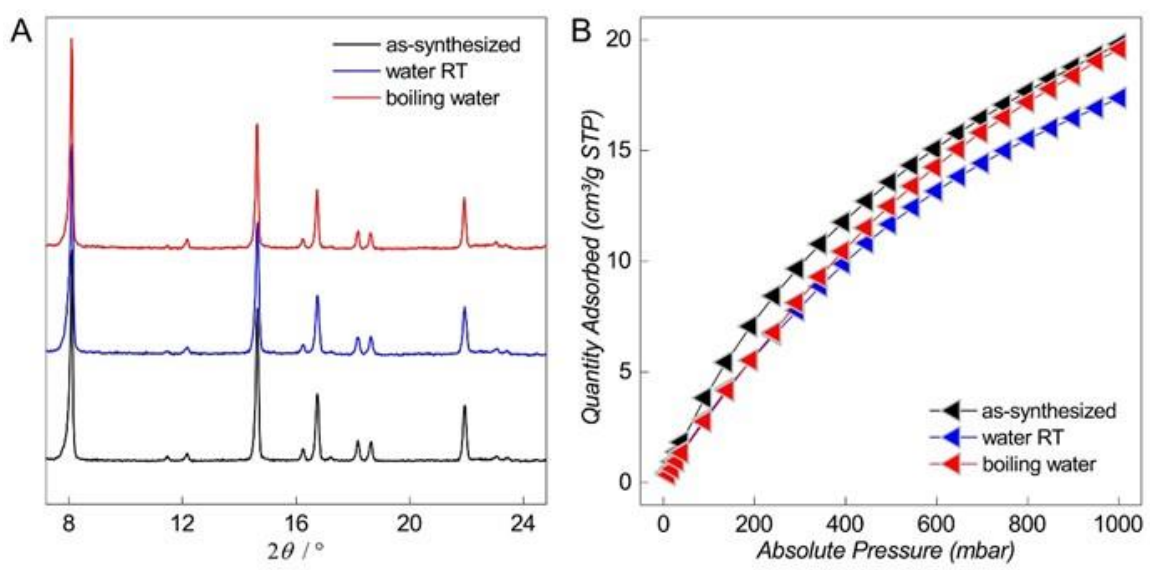

Figure 4. Results of water stability test.

(A) PXRD patterns for the MIP-208 samples before and after water treatments

(B) $\mathrm{CO}_{2}$ adsorption isotherms collected at $298 \mathrm{~K}$ for the MIP-208 samples before and after water treatments

Pure MIP-208 samples were first tested for photocatalytic methanation. Preliminary control experiments under similar conditions as those used in the photocatalytic reaction, but in the dark, showed that MIP-208 did not promote thermally $\mathrm{CO}_{2}$ reduction to $\mathrm{CH}_{4}$. In contrast, a $\mathrm{CH}_{4}$ production of about $40 \mu \mathrm{mol}$ g catalyst $^{-1}$ could be achieved using MIP-208 as the catalyst in the mixture of $\mathrm{CO}_{2}(0.25$ bar) and hydrogen (1.05 bar) under UV-Vis irradiation (Xenon lamp, $1350 \mathrm{~W} \times \mathrm{m}^{-2}$ ) at $200^{\circ} \mathrm{C}$ after 22 hours (Figure S11). This result highlights the positive influence of the 1D TiO chain SBU in MIP-208 regarding its photo-response, since the benchmark compound $\mathrm{NH}_{2}-\mathrm{MIL}-125$, which is built with discrete $\mathrm{Ti}_{8}$ clusters, exhibits negligible photocatalytic activity under similar reaction conditions. ${ }^{[7]}$ Furthermore, in comparison with the state-of-the-art MOF photocatalysts for methanation, ${ }^{[74]}$ an enhancement of $33 \%$ in efficiency was noticed for MIP-208, suggesting that 
MIP-208, to our knowledge, could be the most efficient pure MOF photocatalyst for methanation to date.

In order to further improve the $\mathrm{CH}_{4}$ formation rate, incorporation of metal NPs onto MIP-208 was considered to form a composite catalyst, since it is well-documented that photocatalytic methanation generally requires the presence of a metal or metal oxide with hydrogenation activity, such as nickel, copper, rhodium, palladium, or ruthenium. ${ }^{[75]}$ We initially selected $\mathrm{RuO}_{x}$ NPs as the composite component, owing to the fact that Ru species generally show the highest activity in the methantion of $\mathrm{CO}_{2}$ under milder conditions, despite their limited selectivity compared with other active elements. ${ }^{[76,77]}$ In addition, the oxide form, instead of elemental metal NPs, features an elevated stability to facilitate easy handling during catalysis process. The MIP-208@RuOx composite was obtained following the post-synthetic photo-deposition of $\mathrm{RuO}_{x} \mathrm{NPs}$ on MIP-208 by the photocatalytic reduction of water-soluble $\mathrm{KRuO}_{4}$ using methanol as the sacrificial electron donor (Figure S12). The success of $\mathrm{RuO}_{x}$ photodeposition by photocatalytic perruthenate reduction further demonstrates the photoactivity of MIP-208, as it has been proven that an evidence supporting the occurrence of photoinduced charge separation upon irradiation of a solid is the observation of photodeposition onto the material of metal NPs from aqueous solutions. ${ }^{[78]}$

After deposition, determination of the Ru content and average particle size in the composite was carried out. Energy-dispersive X-ray spectroscopy (EDX) analysis of MIP-208@RuOx showed a Ru content of 0.76 wt\%. Field emission scanning electron microscopy (FESEM) images of MIP-208@RuO displayed a similar crystallite morphology as that of the pristine MOF, without obvious free $\mathrm{RuO}_{\mathrm{x}}$ particles (Figure S13). Dark-field scanning transmission electron microscopy (DF-STEM) measurements revealed the presence of small RuO NPs $(1.4 \pm 0.14 \mathrm{~nm})$. 
The homogeneous distribution of RuO NPs all over MIP-208 was further confirmed by DF-STEM coupled to an EDX detector (Figure S14).

Preservation of the crystalline structure of MIP-208 after $\mathrm{RuO}_{x}$ photodeposition was confirmed by PXRD data (Figure S15). The lack of additional peaks in the composite pattern compared with that of the pure MIP-208 could be attributed to the low Ru loading and the evenly distributed small particle size, as determined by TEM images.

The MIP-208@RuOx solid was also characterized by X-ray photoelectron spectroscopy (XPS, Figure S16). The C1s spectrum shows the presence of aromatic carbons $(284.4 \mathrm{eV})$. In addition, a band centred at $285.9 \mathrm{eV}$ attributable to the $\mathrm{C}-\mathrm{N}$ bond of the amide groups is observed, together with another centred at $289 \mathrm{eV}$ that can be assigned to the carbonyl of both the amide and the carboxylate groups. The amide group is clearly observed in the N1s band centred at about $399 \mathrm{eV}$ as well. The broad $01 \mathrm{~s}$ band is mainly due to the presence of oxygen atoms in the carboxylate and amide groups, together with the Ti-O and Ru-O bonds. Ti $2 p$ spectrum can be assigned to the presence of $\mathrm{Ti}^{4+}$ ions. Ruthenium is recognized by the bands appearing at about 280.7 and $282.4 \mathrm{eV}$ that can be assigned to the $\mathrm{Ru} 3 \mathrm{~d}_{5 / 2}$ of $\mathrm{RuO}_{2}$ and hydrated $\mathrm{RuO}_{2}$, respectively. ${ }^{[79,80]}$ The expected $\mathrm{Ru} 3 \mathrm{~d}_{3 / 2}$ band appearing at higher binding energies ( $4.1 \mathrm{eV}$ ) (Figure S16) is, however, difficult to observe, since it overlaps with the C-N contribution of the acetamido groups. ${ }^{[78 ; 80]}$ XPS analysis also can provide an estimation of the valence band maximum of the MIP-208@RuOx solid by measuring the lowest energy electron band of the material referred to the work function of the instrument. As shown in Figure S17, a valence band potential of -1.51 $\mathrm{eV}$ was estimated. This value together with the $2.92 \mathrm{eV}$ bandgap measured from the Tauc plot of the diffuse reflectance UV-Vis spectrum, gives a value for the LUCO of $-2.874 \mathrm{eV}$. 
The photocatalytic performance of the MIP-208@RuOx composite in the methanation of $\mathrm{CO}_{2}$ was then evaluated under the same reaction conditions as that used for testing the pristine MOF. Control experiments using MIP-208@RuO in the dark under the same reaction condition showed negligible $\mathrm{CH}_{4}$ production. As expected, a selective $\mathrm{CO}_{2}$ conversion into $\mathrm{CH}_{4}\left(800 \mu \mathrm{mol} \mathrm{g}_{\text {catalyst }}{ }^{-1}\right)$ as the only product was observed (Figure 5A). Specifically, the amounts of $\mathrm{CO}$ and $\mathrm{C}_{2} \mathrm{H}_{6}$ were under the detection limit of our micro-GC. This $\mathrm{CH}_{4}$ production value is 20 times higher compared with that obtained using the pure MIP-208 sample. Regarding product selectivity, photocatalytic $\mathrm{CO}_{2}$ hydrogenation renders generally methane or $\mathrm{CO}$ as the main products, accompanied by minor amounts of $C_{2}$ and $C_{3}{ }^{[81]}$. Selectivity to methane or $\mathrm{CO}$ depends mainly on the strength of $\mathrm{CO}$ adsorption and the hydrogenating activity of the photocatalysts. In general, if $\mathrm{CO}$ remains strongly adsorbed on the photocatalyst, further hydrogenation takes place and the final product is methane. It is proposed that MIP-208 favors $\mathrm{CO}$ adsorption near the $\mathrm{RuO}_{\mathrm{x}}$ active sites and thus leads to high methane selectivity.
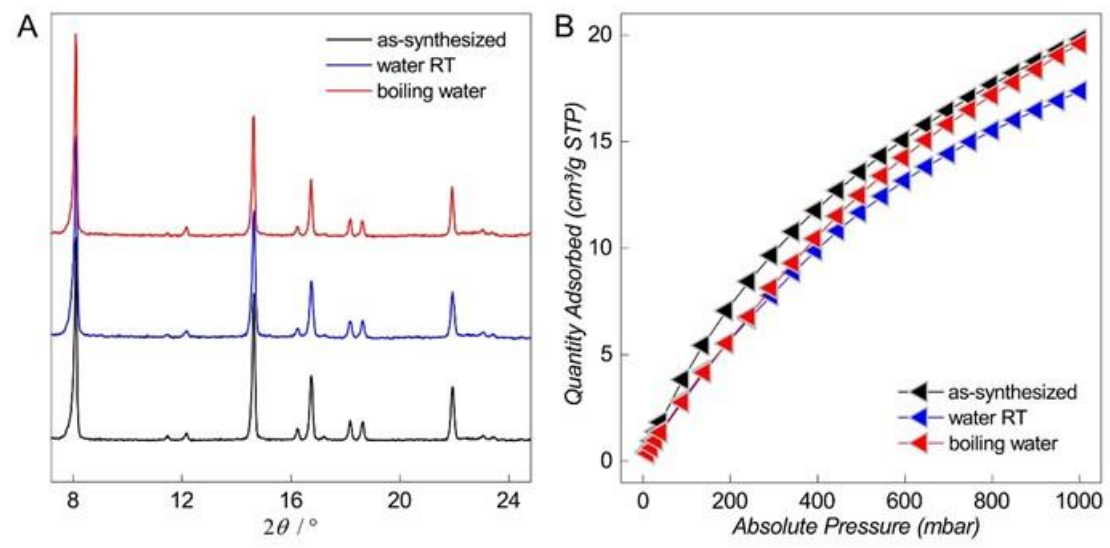

Figure 4. Results of water stability tests.

(A) PXRD patterns for the MIP-208 samples before and after water treatment

(B) $\mathrm{CO}_{2}$ adsorption isotherms collected at $298 \mathrm{~K}$ for the MIP-208 samples before and after water treatments 
Pure MIP-208 samples were first tested for photocatalytic methanation. Preliminary control experiments under similar conditions as those used in the photocatalytic reaction, but in the dark, showed that MIP-208 did not promote thermally $\mathrm{CO}_{2}$ reduction to $\mathrm{CH}_{4}$. In contrast, a $\mathrm{CH}_{4}$ production of about 40 $\mu \mathrm{mol} \cdot \mathrm{g}_{\text {catalyst }}{ }^{-1}$ could be achieved using MIP-208 as the catalyst in the mixture of $\mathrm{CO}_{2}$ (0.25 bar) and hydrogen (1.05 bar) under UV-Vis irradiation (Xenon lamp, 1350 $\mathrm{W} \times \mathrm{m}^{-2}$ ) at $200{ }^{\circ} \mathrm{C}$ after 22 hours (Figure S11). This result highlights the positive influence of the 1D TiO chain SBU in MIP-208 regarding its photo-response, since the benchmark compound $\mathrm{NH}_{2}-\mathrm{MIL}-125$, which is built with discrete Ti 8 clusters, exhibits negligible photocatalytic activity under similar reaction conditions. ${ }^{[74]}$ Furthermore, in comparison with the state-of-the-art MOF photocatalysts for methanation, ${ }^{[74]}$ an enhancement of $33 \%$ in efficiency was noticed for MIP-208, suggesting that MIP-208, to our knowledge, could be the most efficient pure MOF photocatalyst for methanation to date.

In order to further improve the $\mathrm{CH}_{4}$ formation rate, incorporation of metal NPs onto MIP-208 was considered to form a composite catalyst, since it is well-documented that photocatalytic methanation generally requires the presence of a metal or metal oxide with hydrogenation activity, such as nickel, copper, rhodium, palladium, or ruthenium. ${ }^{[75]}$ We initially selected $\mathrm{RuO}_{x} \mathrm{NPs}$ as the composite component, owing to the fact that Ru species generally show the highest activity in the methantion of $\mathrm{CO}_{2}$ under milder conditions, despite their limited selectivity compared with other active elements. ${ }^{[76,77]}$ In addition, the oxide form, instead of elemental metal NPs, features an elevated stability to facilitate easy handling during catalysis process. The MIP-208@RuOx composite was obtained following the post-synthetic photo-deposition of $\mathrm{RuO}_{x} \mathrm{NPs}$ on MIP-208 by the photocatalytic reduction of water-soluble $\mathrm{KRuO}_{4}$ using methanol as the sacrificial electron donor (Figure S12). The success of $\mathrm{RuO}_{x}$ photodeposition by photocatalytic perruthenate reduction further demonstrates the photoactivity of MIP-208, as it has 
been proven that an evidence supporting the occurrence of photoinduced charge separation upon irradiation of a solid is the observation of photodeposition onto the material of metal NPs from aqueous solutions. ${ }^{[78]}$

After deposition, determination of the Ru content and average particle size in the composite was carried out. Energy-dispersive X-ray spectroscopy (EDX) analysis of MIP-208@RuOx showed a Ru content of 0.76 wt\%. Field emission scanning electron microscopy (FESEM) images of MIP-208@RuO displayed a similar crystallite morphology as that of the pristine MOF, without obvious free $\mathrm{RuO}_{x}$ particles (Figure S13). Dark-field scanning transmission electron microscopy (DF-STEM) measurements revealed the presence of small RuO $\mathrm{NPs}(1.4 \pm 0.14 \mathrm{~nm})$. The homogeneous distribution of RuO NPs all over MIP-208 was further confirmed by DF-STEM coupled to an EDX detector (Figure S14).

Preservation of the crystalline structure of MIP-208 after $\mathrm{RuO}_{\mathrm{x}}$ photodeposition was confirmed by PXRD data (Figure S15). The lack of additional peaks in the composite pattern compared with that of the pure MIP-208 could be attributed to the low Ru loading and the evenly distributed small particle size, as determined by TEM images.

The MIP-208@RuOx solid was also characterized by X-ray photoelectron spectroscopy (XPS, Figure S16). The C1s spectrum shows the presence of aromatic carbons (284.4 eV). In addition, a band centred at $285.9 \mathrm{eV}$ attributable to the $\mathrm{C}-\mathrm{N}$ bond of the amide groups is observed, together with another centred at $289 \mathrm{eV}$ that can be assigned to the carbonyl of both the amide and the carboxylate groups. The amide group is clearly observed in the N1s band centred at about $399 \mathrm{eV}$ as well. The broad 01s band is mainly due to the presence of oxygen atoms in the carboxylate and amide groups, together with the Ti-O and Ru-O bonds. Ti $2 p$ spectrum can be assigned to the presence of $\mathrm{Ti}^{4+}$ ions. Ruthenium is recognized by the bands appearing at about 280.7 and $282.4 \mathrm{eV}$ that can be assigned to the $\mathrm{Ru} 3 \mathrm{~d}_{5 / 2}$ of $\mathrm{RuO}_{2}$ 
and hydrated $\mathrm{RuO}_{2}$, respectively. ${ }^{[79,80]}$ The expected $\mathrm{Ru} 3 \mathrm{~d}_{3 / 2}$ band appearing at higher binding energies ( $4.1 \mathrm{eV}$ ) (Figure S16) is, however, difficult to observe, since it overlaps with the C-N contribution of the acetamido groups. ${ }^{[78,80]}$ XPS analysis also can provide an estimation of the valence band maximum of the MIP-208@RuOx solid by measuring the lowest energy electron band of the material referred to the work function of the instrument. As shown in Figure S17, a valence band potential of -1.51 $\mathrm{eV}$ was estimated. This value together with the $2.92 \mathrm{eV}$ bandgap measured from the Tauc plot of the diffuse reflectance UV-Vis spectrum, gives a value for the LUCO of $-2.874 \mathrm{eV}$.

The photocatalytic performance of the MIP-208@RuOx composite in the methanation of $\mathrm{CO}_{2}$ was then evaluated under the same reaction conditions as that used for testing the pristine MOF. Control experiments using MIP-208@RuO in the dark under the same reaction condition showed negligible $\mathrm{CH}_{4}$ production. As expected, a selective $\mathrm{CO}_{2}$ conversion into $\mathrm{CH}_{4}\left(800 \mu \mathrm{mol} \mathrm{g}_{\text {catalyst }}{ }^{-1}\right)$ as the only product was observed (Figure 5A). Specifically, the amounts of $\mathrm{CO}$ and $\mathrm{C}_{2} \mathrm{H}_{6}$ were under the detection limit of our micro-GC. This $\mathrm{CH}_{4}$ production value is 20 times higher compared with that obtained using the pure MIP-208 sample. Regarding product selectivity, photocatalytic $\mathrm{CO}_{2}$ hydrogenation renders generally methane or $\mathrm{CO}$ as the main products, accompanied by minor amounts of $C 2$ and $C 3^{[81]}$. Selectivity to methane or CO depends mainly on the strength of $\mathrm{CO}$ adsorption and the hydrogenating activity of the photocatalysts. In general, if $\mathrm{CO}$ remains strongly adsorbed on the photocatalyst, further hydrogenation takes place and the final product is methane. It is proposed that MIP-208 favors $\mathrm{CO}$ adsorption near the $\mathrm{RuO}_{x}$ active sites and thus leads to high methane selectivity. 

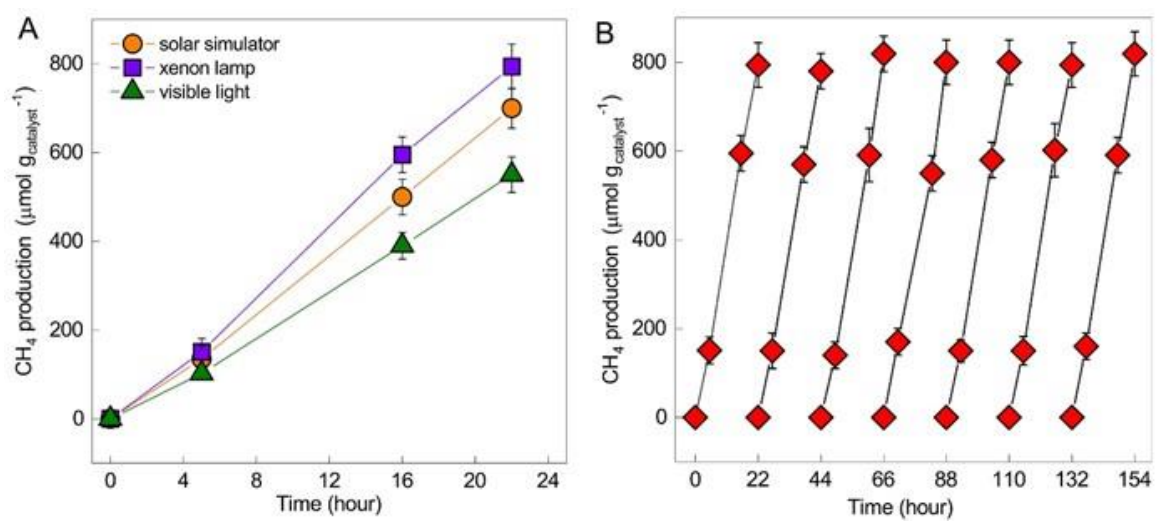

Figure 5. Photocatalytic performance of MIP-208@RuO ${ }_{x}$ in $\mathrm{CO}_{2}$ methanation.

(A) Temporal evolution of $\mathrm{CH}_{4}$ during the photocatalytic $\mathrm{CO}_{2}$ reduction with MIP-208@RuO as the catalyst using a solar simulator, a xenon lamp with full range lights and visible light (Xe lamp with $\lambda>455 \mathrm{~nm}$ filter)

(B) Reusability of MIP-208@RuO in the photocatalytic methanation of $\mathrm{CO}_{2}$ (seven-times cycling) using a xenon lamp as irradiation source. Reaction conditions: catalyst (15 mg), $\mathrm{H}_{2}$ (1.05 bar), $\mathrm{CO}_{2}(0.25$ bar $)$, temperature $\left(200^{\circ} \mathrm{C}\right)$, irradiation source a xenon lamp $\left(1350 \mathrm{~W} \times \mathrm{m}^{-2}\right)$ or solar simulator $\left(1000 \mathrm{~W} \times \mathrm{m}^{-2}\right)$

Similar time-conversion plots, with a slightly lower $\mathrm{CH}_{4}$ formation rate, were also measured using simulated sunlight irradiation (1 Sun) (Figure 5A). The difference between the $\mathrm{CH}_{4}$ production using a xenon lamp or simulated sunlight can be attributed to the lower power of the simulated sunlight $\left(1000 \mathrm{~W} \times \mathrm{m}^{-2}\right)$ compared to the xenon lamp $\left(1350 \mathrm{~W} \times \mathrm{m}^{-2}\right)$. Furthermore, photomethanation of $\mathrm{CO}_{2}$ using MIP-208@RuOx as catalyst was also performed upon visible light irradiation by filtering the output beam of the Xe lamp $(\lambda>455 \mathrm{~nm})$. A similar temporal $\mathrm{CH}_{4}$ formation profile was recorded, with a $\mathrm{CH}_{4}$ production at final time for visible light about $78 \%$ respect to the use of the full UV-Vis light emission provided by the Xe lamp (Figure $5 \mathrm{~A}$ ). This similarity in the temporal $\mathrm{CO}_{2}$ conversion indicates that a major percentage of the MIP-208@RuOx photoresponse must derive from the visible region. Both experiments under simulated sunlight illumination and visible light 
irradiation indicate that a considerable proportion of the MIP-208- $\mathrm{RuO}_{\mathrm{x}}$ photoresponse derives from the visible region. This photoresponse indicates that $\mathrm{RuO}_{\mathrm{x}}$ is acting as light harvester in addition as active site, since MIP-208 in the absence of $\mathrm{RuO}_{\mathrm{x}}$ exhibits much less photomethanation rate and should not be responsive under visible light.

The recycling stability of the MIP-208@RuOx composite as a photocatalyst was determined by performing a series of consecutive recycling runs following the temporal evolution of $\mathrm{CO}_{2}$ conversion and $\mathrm{CH}_{4}$ formation. These stability tests are important considering the conditions of photocatalytic methanation, particularly the presence of $\mathrm{H}_{2} \mathrm{O}$ and the reaction temperature of $200{ }^{\circ} \mathrm{C}$. The results presented in Figure $5 \mathrm{~B}$ show coincident plots for the temporal $\mathrm{CH}_{4}$ evolution upon seven consecutive runs, supporting the stability of the material under the conditions of the photocatalytic reaction. It is noteworthy that this highly selective and constant methanation activity promoted by $\mathrm{RuO}_{x}$ has hardly been achieved before, as $\mathrm{CO}$ has been proven to be the side product in this reaction, which led to a considerable deactivation of the catalyst. ${ }^{[7]}$ Additionally, irradiation of the MIP-208@RuOx composite in argon atmosphere using the xenon lamp or solar simulator at $200{ }^{\circ} \mathrm{C}$ revealed the evolution of a tiny amount of $\mathrm{CO}_{2}$, corresponding to the decomposition of a small fraction of the IPA linkers present in the material $\left(<0.05 \mu \mathrm{mol} \mathrm{CO}_{2} / \mu \mathrm{mol}\right.$

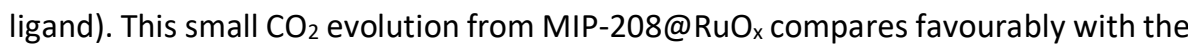
stability of the most robust MOFs reported as photocatalysts under similar irradiation conditions. ${ }^{[82]}$

The crystallinity of the MIP-208@RuOx sample after seven catalytic cycles was well-maintained, as no notable change in the PXRD pattern was observed (Figure S18). Furthermore, the solid-state ${ }^{13} \mathrm{C}-\mathrm{NMR}$ spectra of the fresh and seven-times reused MIP-208@RuO were coincident (Figure S19). DF-TEM images of the catalyst after recycling were also similar to those of the fresh sample, without any evidence 
of $\mathrm{RuO}_{\mathrm{x}}$ particle growth or agglomeration (Figure S20). Thus, both photocatalytic activity and characterization of the seven-times used MIP-208@RuOx sample indicate the stability of the material under irradiation conditions.

To determine the origin of $\mathrm{CH}_{4}$, an experiment using ${ }^{13} \mathrm{C}$-labelled $\mathrm{CO}_{2}$ was carried out, monitoring the isotopic composition of $\mathrm{CH}_{4}$ evolved by mass spectrometry. The results presented in Figure S21 show the peaks corresponding to ${ }^{13} \mathrm{CH}_{4}$ appearing at 17 Dalton. It is important to note that injection of a sample before irradiation does not show in the chromatogram any peak at the retention time of ${ }^{13} \mathrm{CH}_{4}$.

To shed light about the main operating mechanism of the photocatalytic methanation, $\mathrm{H}_{2}$ was replaced by dimethylaniline as the sacrificial electron donor. Two possible operating mechanisms have been reported for the photocatalytic methanation of $\mathrm{CO}_{2}$, either the so-called photothermal pathway or the photoinduced charge separation pathway. ${ }^{[78]}$ In the photothermal mechanism, light energy is converted into local heat on the metal NPs and the temperature increases on the NP surface promotes the thermal conversion of $\mathrm{CO}_{2}$ and $\mathrm{H}_{2}$ into the product. [78] This local temperature increase is undetectable by measurements of the macroscopic system due to the low proportion of $\mathrm{RuO}_{\mathrm{x}}$. In the photocatalytic mechanism, light absorption leads to a charge separation with the generation of electrons in the conduction band and holes in the valence band that causes $\mathrm{CO}_{2}$ reduction and $\mathrm{H}_{2}$ oxidation, respectively. In the photoinduced charge separation state, the use of an electron donor better than $\mathrm{H}_{2}$ should equally result in $\mathrm{CO}_{2}$ conversion to methane, with an even higher reaction rate than using $\mathrm{H}_{2}$ as reagent. On the contrary, this electron donor should not be adequate for the photothermal reaction. In the present study, dimethylaniline $(0.76 \mathrm{~V}$ vs $\mathrm{Ag} / \mathrm{AgCl})$ was selected as electron donor. ${ }^{[83]}$ The results show that $\mathrm{CH}_{4}$ is formed in the presence of dimethylaniline $(40 \mu \mathrm{L})$ even at a higher rate than in the presence of $\mathrm{H}_{2}$ as a reagent, 
reaching a $\mathrm{CH}_{4}$ production rate in $5 \mathrm{~h}$ of $250 \mu \mathrm{mol}_{\text {catalyst }}{ }^{-1}$ compared to $180 \mu \mathrm{mol}$ g catalyst $^{-1}$ when using $\mathrm{H}_{2}$ as a reagent. Interestingly, a similar experiment using anisole as electron donor with higher oxidation potential (1.93 $\mathrm{V}$ vs $\mathrm{Ag} / \mathrm{AgCl}$ ) than dimethylaniline $(0.90 \mathrm{~V}$ vs $\mathrm{Ag} / \mathrm{AgCl})$ resulted in a lower $\mathrm{CH}_{4}$ production $(25 \mu \mathrm{mol}$ g catalyst $\left.^{-1}\right)$. This observation is in agreement with previous report using $\mathrm{Cu}_{2} \mathrm{O}$ supported on graphene as photocatalyst and observing that the methane production rates decreases as the oxidation potential of the sacrificial electron donor increases ${ }^{[84,85]}$. Furthermore, if photomethanation is attempted under the same conditions, but in the presence of nitrobenzene $(40 \mu \mathrm{L},-0.36 \mathrm{~V} \text { vs. } \mathrm{Ag} / \mathrm{AgCl})^{[86]}$ as electron quencher competing with $\mathrm{CO}_{2}$, then, no formation of $\mathrm{CH}_{4}$ is observed. This dependence of $\mathrm{CH}_{4}$ formation on the presence and redox potential of electron donor and acceptor quenchers is fully consistent with the prevalent operation of a photocatalytic mechanism involving photoinduced $\mathrm{e}^{-} / \mathrm{h}^{+}$separation and $\mathrm{CH}_{4}$ formation by consecutive eight $\mathrm{e}^{-}$(plus $8 \mathrm{H}^{+}$) reduction of $\mathrm{CO}_{2}$.

The occurrence of the photoinduced charge separation and the reaction of this photoinduced charge separated state with electron donors was additionally confirmed by photocurrent measurements. A thin film of MIP-208@RuOx was further deposited on a transparent FTO electrode. Starting from a polarization potential of $1.6 \mathrm{~V}$, the MIP-208@RuO electrode was submitted to a decreasing bias potential in a single electrochemical cell using tetrapropylammonium tetrafluoroborate in acetonitrile as electrolyte. The current density clearly increased at each voltage upon illumination of the photoanode with the output of a Xe lamp (Figure S22). Furthermore, the presence of methanol as an electron donor increases significantly the photocurrent, indicating that this reagent is acting as a sacrificial electron donor, becoming oxidized and donating electrons to the MIP-208@RuOx in its excited state. 
Besides the photocatalytic mechanism of $\mathrm{CO}_{2}$ reduction to $\mathrm{CH}_{4}$, there are reports in the literature showing that $\mathrm{CO}_{2}$ reduction can take place alternatively through a photothermal pathway ${ }^{[75,87]}$. In this mechanism, photon energy is dissipated in the active site that undergoes a local heating at nanometer scale sufficient to overcome the activation barrier for a thermocatalytic pathway. The local temperature of these nanometric hot spots cannot be determined macroscopically, particularly considering the low proportion of these hot spots in the composition of the photocatalyst and the thermal conductivity of the medium. One common methodology to assess the occurrence of local heating is the use of quantum dots (QDs) monitoring the emission intensity decrease as local thermometer. ${ }^{[84]}$ This method is based on the decrease of the emission intensity of quantum dots as the temperature experienced by nanoparticle increases in a certain temperature range.

In a preliminary calibration study, it was determined that the photoluminescence lifetime emission of CdSe-ZnS QDs decreases as the temperature increases (Figure S23). This observation is a consequence of the emission intensity decrease of core-shell CdSe-ZnS nanoparticles as the temperature increases in the range from 25 to $200^{\circ} \mathrm{C}$ (Figure S24). Thus, core-shell CdSe-ZnS nanoparticles can be used as local, nanometric thermometer to get some information about local temperature changes during irradiation that could distinguish between photocatalytic or photothermal reaction mechanism when using MIP-208@RuO in photomethanation. After calibration, the CdSe-ZnS nanoparticles were dispersed on the MIP-208@RuOx sample. Comparison of the emission intensity of CdSe-ZnS adsorbed on MIP-208@RuOx depending on whether the solid is in the dark or illuminated with the Xe lamp conclusively shows that, even if the macroscopic temperature is supposed to be constant, CdSe-ZnS QDs experience a local heating under Xe irradiation, required for a photothermal mechanism (Figure S25). However, it has to be commented that although the experiments with CdSe-ZnS as local temperature probes conclusively show the temperature increase at the nanometric 
scale and not observed macroscopically, the previously commented quenching experiments and particularly the fact that a good electron acceptor completely stops methane formation indicates that the mechanism is fully photocatalytic derived from charge-separation, but accompanied with temperature increase at the nanoparticles that does not cause product formation. Otherwise, nitrobenzene, quenching electrons but not impeding heating, would have not completely stop $\mathrm{CH}_{4}$ formation.

The influence of the temperature was addressed by performing photomethanation by MIP-208@RuOx at different temperatures in the range from 100 to $200{ }^{\circ} \mathrm{C}$ (Figure S26). It was observed that $\mathrm{CH}_{4}$ formation starts at $100{ }^{\circ} \mathrm{C}$ but undergoes a significant formation rate increase at temperatures higher than $150{ }^{\circ} \mathrm{C}$. Control experiments in the dark indicate that $\mathrm{CH}_{4}$ formation is one order of magnitude less or lower than upon irradiation. This behavior indicates that the photocatalytic process has an activation energy.

To understand the origin of the thermal activation of the photocatalytic reaction, the possible role of $\mathrm{H}_{2} \mathrm{O}$ as a poison was considered. $\mathrm{H}_{2} \mathrm{O}$ is a reaction product that can be strongly adsorbed on the active sites competing favorably with $\mathrm{CO}_{2}$ adsorption and stopping the reaction. In this case, one of the roles of heating would be $\mathrm{H}_{2} \mathrm{O}$ desorption from the active sites. Aimed at providing some support to this proposal, a control experiment was performed adding $\mathrm{H}_{2} \mathrm{O}(60 \mu \mathrm{L})$ at the initial reaction stage of the photocatalytic methanation. A significant decrease in the initial methanation rate by one order of magnitude from 40 to about $4 \mu \mathrm{mol} \mathrm{g}_{\text {catalyst }}{ }^{-1} \mathrm{~h}^{-1}$ was measured (Figure S26). This negative role of $\mathrm{H}_{2} \mathrm{O}$ should also take place in the reactor as photomethanation starts and temperatures above $100{ }^{\circ} \mathrm{C}$ would allow its desorption.

In summary, benefiting from a synergetic adjustment including both the preformed $\mathrm{Ti}_{8} \mathrm{AF}$ cluster rearrangement and the in situ linker formation, which slows down the reaction, MIP-208, the first Ti-IPA MOF, was synthesized with high 
crystallinity and tunable scale. Its crystal structure, which is isostructural to CAU-10, constitutes cis-connected corner-sharing $\mathrm{TiO}_{6}$ polyhedra that extend along the $c$-axis resulting in a 1D helical chain inorganic building unit. Multivariate MIP-208 structures with tunable chemical environments and sizable porosities could be achieved by adopting the solid-solution mixed-linker synthesis strategy. This material has been proven to be the best photocatalyst for the methanation of $\mathrm{CO}_{2}$ in terms of activity and selectivity among all the pure MOFs, owing to its excellent stability and photoresponse. Further improvement of catalytic activity was achieved by the photodeposition of $\mathrm{RuO}_{\mathrm{x}}$. The resulting MIP-208@RuOx composite exhibits, under identical conditions, an enhancement of efficiency of a factor of about 20 in comparison with that of the pure MOF. The composite catalyst displays a high stability and reusability. These results illustrate the continuous interest in the synthesis of novel Ti-MOFs that could lead to improved generations of photocatalysts, suitable for the production of solar fuels and the photoinduced methanation of $\mathrm{CO}_{2}$.

\subsection{Experimental procedures}

\subsubsection{Synthesis of MIP-208 (small scale)}

To a $23 \mathrm{~mL}$ Teflon reactor, $\mathrm{Ti}_{8} \mathrm{AF}$ cluster solid $(220 \mathrm{mg}$ ) was added followed by adding acetic anhydride $(5 \mathrm{~mL})$ and acetic acid $(5 \mathrm{~mL})$. The mixture was stirred at room temperature for 20 minutes before 5- $\mathrm{NH}_{2}$-IPA (362 mg, $2 \mathrm{mmol}$ ) was added once. After stirring for 10 minutes, $\mathrm{MeOH}(0.5 \mathrm{~mL})$ was added and the overall mixture was stirred at room temperature for another 10 minutes. Afterwards, the reaction was heated in an oven at $180^{\circ} \mathrm{C}$ for 48 hours. When the reaction was cooled to room temperature, the dark yellow/light brown product was collected by filtration, washed with acetone then air dried. Yield: $330 \mathrm{mg}$ (average of five parallel reactions). 


\subsubsection{Synthesis of MIP-208 (scale-up)}

To a $125 \mathrm{~mL}$ Teflon reactor, Ti, AF cluster solid (3.5 g) was added followed by adding acetic anhydride $(25 \mathrm{~mL})$ and acetic acid $(25 \mathrm{~mL})$. The mixture was stirred at room temperature for 20 minutes before 5- $\mathrm{NH}_{2}-\mathrm{IPA}(3.62 \mathrm{~g}, 20 \mathrm{mmol})$ was added once. After stirring for 10 minutes, $\mathrm{MeOH}(3.5 \mathrm{~mL})$ was added and the overall mixture was stirred at room temperature for another 10 minutes. Afterwards, the reaction was heated in an oven at $180^{\circ} \mathrm{C}$ for 48 hours. When the reaction was cooled to room temperature, the dark yellow/light brown product was collected by filtration, washed with acetone than air dried. Yield: $4.3 \mathrm{~g}$ (average of five parallel reactions).

\subsubsection{Typical synthesis of MTV-MIP-208}

To a $23 \mathrm{~mL}$ Teflon reactor, Ti 8 AF cluster solid (220 mg) was added followed by adding acetic anhydride $(5 \mathrm{~mL})$ and acetic acid $(5 \mathrm{~mL})$. The mixture was stirred at room temperature for 20 minutes before a linker mixture of 5- $\mathrm{NH}_{2}-\mathrm{IPA}(1 \mathrm{mmol})$ and the secondary IPA ligand ( $1 \mathrm{mmol}$ ) was added. After stirring for 10 minutes, $\mathrm{MeOH}$ $(0.5 \mathrm{~mL})$ was added and the overall mixture was stirred at room temperature for another 10 minutes. Afterwards, the reaction was heated in an oven at $180{ }^{\circ} \mathrm{C}$ for 48 hours. When the reaction was cooled to room temperature, the dark yellow/light brown product was collected by filtration, washed with acetone then air dried.

\subsubsection{Photocatalytic methanation tests}

The photocatalytic methanation of $\mathrm{CO}_{2}$ experiments were carried out using a quartz photoreactor $(51 \mathrm{~mL})$ equipped with a heating mantle to control the desired temperature. In a typical experiment the powdered photocatalyst $(15 \mathrm{mg}$ ) is placed as a bed in the reactor, and then the system purged first with $\mathrm{H}_{2}$ and later with $\mathrm{CO}_{2}$ until a ratio of 4 to 1 is obtained. Subsequently, the photoreactor is heated at 200 ${ }^{\circ} \mathrm{C}$, and then the photocatalyst is irradiated using a Xe lamp (150 W) or a solar simulator. At the desired reaction time, an aliquot was sampled from the photoreactor and analyzed in an Agilent 490 MicroGC equipped with two channels 
and thermal conductivity detectors. One channel equipped with a MolSieve $5 \AA$ column allows analysis of $\mathrm{H}_{2}, \mathrm{O}_{2}, \mathrm{~N}_{2}$ and $\mathrm{CO}$, while the other channel equipped with a Pore Plot $\mathrm{Q}$ column allows determining $\mathrm{CO}_{2}, \mathrm{CH}_{4}$ and short chain hydrocarbons. Quantification was performed using calibration plots employing commercially available gas mixtures.

\subsubsection{X-ray crystallographic data}

The single crystal X-ray crystallographic data for MIP-208 were collected on the PROXIMA 2A beamline at Synchrotron SOLEIL and have been deposited at the Cambridge Crystallographic Data Centre (CCDC), under deposition number CCDC 1989406. High-resolution PXRD data of MIP-208 for Rietveld refinement were collected on the STOE STADI PESSENTIAL X-ray diffractometer equipped with a Mythen II detector in the Debye-Scherrer mode with pure $\mathrm{Cu} \mathrm{K} \alpha 1$ radiation $(\lambda=1.5406 \mathrm{~A})$ (capillary: $0.2 \mathrm{~mm}$, angle range: $5-120^{\circ}$, step size: $0.015^{\circ}$, total counting time: $16.5 \mathrm{~h}$, room temperature), and have been deposited at CCDC under the deposition number CCDC 2011709. These data can be obtained free of charge from the CCDC database via www.ccdc.cam.ac.uk. All other relevant data supporting the findings of this study are available from the corresponding authors on request. 


\subsection{Bibliography}

[1] A. Dhakshinamoorthy, Z. Li, H. Garcia, Chem. Soc. Rev. 2018, 47, 8134-8172.

[2] L. Chen, Q. Xu, Matter 2019 1, 57-89.

[3] H. García, S. Navalón, Wiley-VCH Verlag GmbH \& Co. KGaA, 2018.

[4] H. Yeung, W. Li, P. J. Saines, T. K. Koster, C. P. Grey, A. K. Cheetham, Angew. Chem. Int. Ed. 2013, 52, 5544-5547.

[5] W. Lu, Z. Wei, Z.-Y. Gu, T.-F. Liu, J. Park, J. Park, J. Tian, M. Zhang, Q. Zhang, T. Gentle, M. Boscha, H.-C. Zhou, Chem. Soc. Rev. 2014, 43, 5561-5593.

[6] A. V. Desai, S. Sharma, S. Let, S. K. Ghosh, Coord. Chem. Rev. 2019, 395, 146-192.

[7] H. Zhang, R. Zou, Y. Zhao, Coord. Chem. Rev. 2015, 292, 74-90.

[8] Y. He, B. Li, M. O'Keeffe, B. Chen, Chem. Soc. Rev. 2014, 43, 5618-5656.

[9] H. Wang, Q.-L. Zhu, R. Zou, Q. Xu, Chem 2017, 2, 52-80.

[10] R. J. Kuppler, D. J. Timmons, Q.-R. Fang, J.-R. Li, T. A. Makal, M. D. Young, Coord. Chem. Rev. 2019, 253, 3042-3066.

[11] A. U. Czaja, N. Trukhan, U. Muller, Chem. Soc. Rev. 2014, 38, 1284-1293.

[12] P. Silva, S. M. Vilela, J. P.Tome, F. A. Almeida Paz, Chem. Soc. Rev. 2015, 44, 6774-6803.

[13] J. Ren, X. Dyosiba, N. M. Musyoka, H. W. Langmi, M. Mathe, S. Liao, Coord. Chem. Rev. 2017, 352, 187-219.

[14] P. M. Lorz, F. K. Towae, W. Enke, R. Jäckh, N. Bhargava, W. Hillesheim, In Ullmann's Encyclopedia of Industrial Chemistry 2007.

[15] R. J. Sheehan, In Ullmann's Encyclopedia of Industrial Chemistry 2011.

[16] M. Ohtani, K. Takase, P. Wang, K. Higashi, K. Ueno, N. Yasuda, K. Sugimoto, M. Furutaa, K. Kobiro, CrystEngComm 2016, 18, 1866-1870.

[17] H. Reinsch, D. De Vos, N. Stock, Anorg. Allg. Chem. 2013, 639, 2785-2789.

[18] H. Li, C. E. Davis, T. L. Groy, D. G. Kelley, O. M. Yaghi, J. Am. Chem. Soc. 1998, 120, 2186-2187.

[19] D. Banerjee, J. B. Parise, Cryst. Growth Des. 2011, 11, 4704-4720.

[20] C. Pagis, M. Ferbinteanu, G. Rothenberg, S. Tanase, ACS Catal. 2016, 6, 6063-6072.

[21] L. M. Aguirre-Díaz, D. Reinares-Fisac, M. Iglesias, E. Gutiérrez-Puebla, F. Gándara, N. Snejko, M. Ángeles Monge, Coord. Chem. Rev. 2017, 335, 1-27.

[22] M. P. Kang, D. B. Luo, Y. R. Deng, R. X. Li, Z. E. Lin, Inorg. Chem. Commun. 2014, 47, 52-55.

[23] S. A. Bourne, J. J. Lu, A. Mondal, B. Moulton, M. J. Zaworotko, Angew. Chem. Int. Ed. 2001, 40, 2111-2113.

[24] D. T. Vodak, M. E. Braun, J. Kim, M. Eddaoudi, O. M. Yaghi, Chem. Commun. 2001, 2534-2535.

[25] K. Barthelet, D. Riou, G. Ferey, Chem. Commun. 2002, 1492-1493.

[26] O. T. Qazvini, R. Babarao, Z. L. Shi, Y. B. Zhang, S. G. Telfer, J. Am. Chem. Soc. 2019, 141, 5014-5020.

[27] J.-Y. Kim, A. J. Norquist, D. O'Hare, Dalton Trans. 2013, 2813-2814. 
[28] G. Wang, T. Song, Y. Fan, J. Xu, M. Wang, H. Zhang, L. Wang, L. Huang, L. Wang, Inorg. Chem. Commun. 2010, 13, 502-505.

[29] I. Mihalcea, N. Henry, N. Clavier, N. Dacheux, T. Loiseau, Inorg. Chem. 2011, 50, 6243-6249.

[30] M. Vougo-Zanda, X. Wang, A. J. Jacobson, Inorg. Chem. 2007, 46, 8819-8824.

[31] F. Bu, S. J. Xiao, CrystEngComm 2010, 12, 3385-3387.

[32] T. Panda, T. Kundu, R. Banerjee, Chem. Commun. 2013, 49, 6197-6199.

[33] P. K. Chen, Y. X. Che, J. M. Zheng, S. R. Batten, Chem. Mat. 2007, 19, 2162-2167.

[34] L. Zhang, Y. Y. Qin, Z. J. Li, Q. P. Lin, J. K. Cheng, J. Zhang, Y-G. Yao, Inorg. Chem. 2008, 47, 8286-8293.

[35] J. P. Zhang, S. K. Ghosh, J. B. Lin, S. Kitagawa, Inorg. Chem. 2009, 48, 7970-7976.

[36] L. J. McCormick, S. A. Morris, A. M. Z. Slawin, S. J. Teat, R. E. Morris, Cryst. Growth Des. 2016, 16, 5771-5780.

[37] J. Chen, C.-P. Li, M. Du, CrystEngComm 2011, 13, 1885-1893.

[38] M. Du, Z.-H. Zhang, Y.-P. You, X.-J. Zhao CrystEngComm 2008, 10, 306-321.

[39] L. Chen, J.-W. Ye, H.-P. Wang, M. Pan, S.-Y. Yin, Z.-W. Wei, Nat. Commun. 2007, 8, 15985.

[40] S. Yuan, J.-S. Qin, C. T. Lollar, H.-C. Zhou, ACS Cent. Sci. 2016, 4, 440-450.

[41] A. J. Rieth, A. M. Wright, M. Dinca, Nat. Rev. Mater. 2019, 4, 708-725.

[42] A. Dhakshinamoorthy, A. M. Asiri, H. Garcia, Angew. Chem. Int. Ed. 2016, 55, 5414-5445.

[43] M. Alvaro, E. Carbonell, B. Ferrer, F. X. Llabres i Xamena, H.Garcia, Chemistry 2007, 13, 5106-5112.

[44] M. A. Nasalevich, M. G. Goesten, T. J. Savenije, F. Kapteijn, J. Gascon, Chem. Commun. 2013, 49, 10575-10577.

[45] J. J. Zhu, P. Z. Li, W. H. Guo, Y. L. Zhao, R. Q. Zou, Coord. Chem. Rev. 2018, 359, 80-101.

[46] V. Benoit, R. S. Pillai, A. Orsi, P. Normand, H. Jobic, F. Nouar, P. Billemont, E. Bloch, S. Bourrelly, T. Devic, P. A. Wright, G. de Weireld, C. Serre, G. Maurin, P. L. Llewellyn, J. Mater. Chem. A 2016, 4, 1383-1389.

[47] Y. Sun, Y. Liu, J. Caro, X. Guo, C. Song, Y. Liu, Angew. Chem. Int. Ed. 2018, 57, 16088-16093.

[48] M. Wahiduzzaman, S. J. Wang, J. Schnee, A. Vimont, V. Ortiz, P. G. Yot, M. Daturi, J. Sun Lee, J.-S. Chang, C. Serre, G. Maurin, S. Devautour-Vinot, ACS Sustain. Chem. Eng. 2019, 7, 5776-5783.

[49] R. V. Pinto, S. Wang, S. R. Tavares, J. Pires, F. Antunes, A. Vimont, M. Daturi, C. Serre, M. L. Pinto, Angew. Chem. Int. Ed. 2020, 59, 5135-5143.

[50] H. Assi, G. Mouchaham, N. Steunou, T. Devic, C. Serre, Chem. Soc. Rev. 2017, 46, 3431-3452.

[51] T. Tachikawa, S. Tojo, M. Fujitsuka, T. Sekino, T. Majima, J. Phys. Chem. B 2016, 110, 14055-14059. 
[52] S. Wang, T. Kitao, N. Guillou, M. Wahiduzzaman, C. Martineau-Corcos, F. Nouar, A. Tissot, L. Binet, N. Ramsahye, S. Devautour-Vinot, S. Kitagawa, S. Seki, Y. Tsutsui, V. Briois, N. Steunou, G. Maurin, T. Uemura, C. Serre, Nat. Commun. 2018, 9, 1660.

[53] C. Serre, J. A. Groves, P. Lightfoot, A. M. Z. Slawin, P. A. Wright, N. Stock, Bein, T. M. Haouas,F. Taulelle, G. Ferey, Chem. Mat. 2006, 18, 1451-1457.

[54] C. Li, H. Xu, J. Gao, W. Du, L. Shangguan, X. Zhang, R.-B. Lin, H. Wu, W. Zhou, X. Liu, J. Yaoa, B. Chen, J. Mater. Chem. A 2019, 7, 11928-11933.

[55] Y. Keum, S. Park, Y.-P. Chen, J. Park, Angew. Chem. Int. Ed. 2018, 57, 14852-14856.

[56] S. Yuan, T.-F. Liu, D. Feng, J. Tian, K. Wang, J. Qin, Q. Zhang, Y.-P. Chen, M. Bosch, L. Zou, S. J. Teat, S. J. Dalgarnoc, H.-C. Zhou, Chem Sci. 2015, 6, 3926-3930.

[57] N. M. Padial, J. Castells-Gil, N. Almora-Barrios, M. Romero-Angel, I. da Silva, M. Barawi, A. García-Sánchez, V. A. de la Peña O’Shea, C. Martí-Gastaldo, J. Am. Chem. Soc. 2019, 141, 13124-13133.

[58] S. Wang, H. Reinsch, N. Heymans, X. Wahiduzzaman, C. Martineau-Corcos, G. De Weireld, G. Maurin, C. Serre, Matter 2020, 2, 440-450.

[59] C. H. Hendon, D. Tiana, M. Fontecave, C. Sanchez, L. D'Arras, C. Sassoye, L. Rozes, C. Mellot-Draznieks, A. Walsh, J. Am. Chem. Soc. 2013, 135, 10942-10945.

[60] Y. Fu, D. Sun, Y. Chen, R. Huang, Z. Ding, X. Fu, Z. Lu, Angew. Chem. Int. Ed. 2012, 51, 3364-3367.

[61] D. Duran, S. L. Couster, K. Desjardins, A. Delmotte, G. Fox, R. Meijers, T Moreno, M. Savko, W. Shepard, J. Phys. Conf. Ser. 2013, 425, 012005.

[62] H. Reinsch, M. A. van der Veen, B. Gil, B. Marszalek, T. Verbiest, D. de Vos, N. Stock, Chem. Mat. 2013, 25, 17-26.

[63] G. Férey, C. Serre, Chem. Soc. Rev. 2009, 38, 1380-1399.

[64] G. Férey, New J. Chem. 2016, 40, 3950-3967.

[65] T. Leshuk, R. Parviz, P. Everett, H. Krishnakumar, R. A. Varin, F. Gu, ACS Appl. Mater. Interfaces 2013, 5, 1892-1895.

[66] X. Chen, L. Liu, F. Huang, Chem. Soc. Rev. 2015, 44, 1861-1885.

[67] L. Liu, X. Chen, Chem. Rev. 2014, 114, 9890-9918.

[68] H. Reinsch, S. Waitschat, N. Stock, Dalton Trans. 2013, 42, 4840-4847.

[69] H. Deng, C. J. Doonan, H. Furukawa, R. B. Ferreira, J. Towne, C. B. Knobler, B. Wang, O. M Yaghi, Science 2010, 327, 846-850.

[70] M. L. Foo, R. Matsuda, S. Kitagawa, Chem. Mater. 2014, 26, 310-322.

[71] A. Helal, Z. H. Yamani, K. E Cordova, O. M. Yaghi, Natl. Sci. Rev. 2017, 4, 296-298.

[72] M. Ding, R. W. Flaig, H. L. Jiang, O. M. Yaghi, Chem. Soc. Rev. 2019, 48, 2783-2828.

[73] R. Li, J. Hu, M. Deng, H. Wang, X. Wang, Y. Hu, H.-L. Jiang, J. Jiang, Q. Zhang, Y.Xie, Y. Xiong, Adv. Mater. 2014, 26, 4783-4788.

[74] M. Cabrero-Antonino, S. Remiro-Buenamañana, M. Souto, A. A. Garcia-Valdivia, D. Choquesillo-Lazarte, S. Navalon, D. hoquesillo-Lazarte, A. Rodriguez-Dieguez, G. M. Espallargas, H. Garcia, Chem. Commun. 2019, 55, 10932-10935. 
[75] U. Ulmer, T. Dingle, P. N. Duchesne, R. H. Morris, A. Tavasoli, T. Wood, G. A. Ozin, Nat. Commun. 2019, 10, 3169.

[76] M. Younas, L. L. Kong, M. J. K. Bashir, H. Nadeem, A. Shehzad, S. Sethupathi, Energ. Fuel 2016, 30, 8815-8831.

[77] D. Mateo, J. Albero, H. García, Joule 2019, 3, 1949-1962.

[78] K. Wenderich, G. Mul, Chem Rev. 2016, 116, 14587-14619.

[79] T. P. L. Giang, T. N. M. Tran, X. T. Le, Adv. Nat. Sci. Nanosci. Nanotechnol. 2012, 3, 015008.

[80] D. J. Morgan, Surf. Interface Anal. 2019, 47, 1072-1079.

[81] J. Albero, Y. Peng, H. Garcia, ACS Catal. 2020, 10, 5734-5749.

[82] D. Mateo, A. Santiago-Portillo, J. Albero, S. Navalon, M. Alvaro, H. Garcia, Angew. Chem. Int. Ed. 2019, 58, 17843-17848.

[83] D. Mateo, J. Albero, H. García, Appl Catal. B 2018, 224, 563-571.

[84] D. Mateo, J. Albero, H. Garcia, Energy Environ. Sci. 2017, 10, 2392-2400.

[85] D. Mateo, A. M. Asiri, J. Albero, H. Garcia, Photochem. Photobiol Sci. 2018, 17, 829-834.

[86] R. Karthik, M. Govindasamy, S. M. Chen, V. Mani, R. Umamaheswari, T. S. T. Balamurugan, Int. J. Electrochem. Sci. 2016, 11, 6164-6172.

[87] X. Li, J. Yu, M. Jaroniec, X. Chen, Chem. Rev. 2019, 119, 3962-4179. 


\subsection{Supporting information}

\subsubsection{Materials and instruments}

All chemicals were purchased from commercial suppliers and used as received without further purification. Tis AF cluster precursor was synthesized according to the reported procedure. ${ }^{[1]}$ Powder X-ray Diffraction (PXRD) data were recorded on a high-throughput Bruker D8 Advance diffractometer working on transmission mode and equipped with a focusing Göbel mirror producing CuKa radiation $(\lambda=1.5418 \AA$ ) and a LynxEye detector. Temperature dependent PXRD data were recorded with sample closely packed in quartz capillary on a PANalytical EMPYREAN diffractometer with $\mathrm{CuK}_{\alpha}$ radiation $(\lambda=1.5418 \AA$ ) and equipped with a HTK-1200N (Anton Parr) high-temperature chamber and a GaliPIX3D detector. PXRD patterns were collected every $25^{\circ} \mathrm{C}$ from room temperature to $450{ }^{\circ} \mathrm{C}$, with onehour scan for each temperature. Carbon dioxide adsorption at $273 \mathrm{~K}$ were carried out on a Micromeritics Triflex instrument. SEM images were recorded with FEI Magellan 400 scanning electron microscope. The morphology of the MIP-208@RuOx samples was characterized using a scanning electron microscope (SEM, Zeiss instrument, AURIGA Compact). The $\mathrm{RuO}_{\mathrm{x}}$ particle size distribution and its location on the MIP-208@RuOx composite were determined from scanning transmission electron microscopy images in dark field (DF-STEM) collected using a JEOL JEM2100F instrument operating at $200 \mathrm{~kW}$ coupled to an energy-dispersive X-ray (EDX) detector. $\mathrm{RuO}_{\mathrm{x}}$ size distribution was estimated by measuring more than 300 particles from the sample. X-ray photoelectron spectra (XPS) of samples were collected on a SPECS spectrometer with a MCD-9 detector using a monochromatic $\mathrm{Al}$ (K $\alpha=1486.6$ eV) X-ray source. Spectra deconvolution was performed with the CASA software using the $\mathrm{C} 1 \mathrm{~s}$ peak at $284.4 \mathrm{eV}$ as binding energy reference. The ruthenium metal content was determined by inductively coupled plasma atomic emission spectroscopy (ICP-AES) analysis after digesting the solid sample in concentrated nitric acid. Photocurrent experiments were performed using a standard 
three-electrode electrochemical cell using a fluoride-doped tin oxide (FTO)-coated glass substrate with MIP-208@RuOx as working electrode, a platinum wire as the counter electrode and a standard calomel electrode (SCE) as the reference electrode. Oxygen was removed from the cell by bubbling an Ar stream through the electrolyte. Irradiation was performed using an optical fiber connected to a $150 \mathrm{~W}$ Xe lamp. The photocurrent was measured under dark and upon illumination polarizing the working electrode at potentials from 1.6 to $-0.2 \mathrm{~V}$. TGA data were collected on Mettler Toledo TGA/DSC 2, STAR System apparatus with a heating rate of $5^{\circ} \mathrm{C} / \mathrm{min}$ under the oxygen flow. Solid-state NMR spectra were recorded with an Advance Bruker 500 NMR spectrometer.

\subsubsection{Photoluminescence measurements}

Photoluminescence measurements were carried out by using commercial CdSe-ZnS core-shell quantum dots (QDs, Meso-N40-P62-07142015, Mesolight). Previous studies have reported the increased quantum yield and photoluminescence of CdSe-ZnS coreshell with respect to CdSe QDs2. The photoluminescence lifetime of CdSe-ZnS coreshell QDs supported on a quartz glass plate was measured using a time-resolved luminescence system (optical building blocks corporation EasyLifeTM) using a laser filter at $407 \mathrm{~nm}$ and supported filter of $610 \mathrm{~nm}$. Briefly, an acetonitrile solution of CdSe-ZnZ QDs was dropwise on a quart glass plate and then, the system dried at $50{ }^{\circ} \mathrm{C}$ using a laboratory hot plate. Afterwards, the photoluminescence lifetime of the supported CdSe-ZnS QDs previously heated at the corresponding temperature was measured. A JASCO FP8500 spectrofluorimeter equipment was used to measure the photoluminescence spectrum of $\mathrm{CdSe} / \mathrm{ZnS}$ core-shell QDs or MIP-208@RuOx CdSe/ZnS upon excitation at $620 \mathrm{~nm}$. For this purpose, CdSe/ZnS dissolved in $\mathrm{CH}_{3} \mathrm{CN}$ were dropwise on a quartz support and the solvent evaporated in a heating plate. Then, the QDs supported on quartz were heated on a hot plate at the corresponding temperature before and after irradiation the sample with a Xe lamp. Similar measurements were carried out using CdSe/ZnS QDs supported on 
MIP-208@RuOx. Briefly, the MIP-208@RuOx samples was supported on a quartz using the doctor blade technique using a MIP-208@RuOx suspension in terpineol and acetone. Then, the CdSe/ZnS QDs were added dropwise into the MIP-208@RuOx supported on quartz.

\subsubsection{X-ray crystallography}

The single crystal data of MIP-208 were collected on Proxima-2A microfocused beamline at the SOLEIL Synchrotron $\left(\lambda=0.68879 \AA{ }^{\prime}\right)$ at $100 \mathrm{~K}$. The data were integrated and reduced using XDS software. The structure was then solved using SHELXT and refined with SHELXL software. High-resolution PXRD data for Rietveld refinement were collected on the STOE STADI PESSENTIAL X-ray diffractometer equipped with a Mythen II detector in the Debye-Scherrer mode with pure Cu K $\alpha 1$ radiation ( $\lambda=1.5406 \mathrm{~A}$ ) (capillary: $0.2 \mathrm{~mm}$, angle range: $5-120^{\circ}$, step size: $0.015^{\circ}$, total counting time: $16.5 \mathrm{~h}$, room temperature).

Table S1. Single crystal structure data of MIP-208.

\begin{tabular}{cc}
\hline Crystal System & \multicolumn{2}{c}{ Tetragonal } \\
\hline Space group & I 41/a m d (No. 141) \\
A=b/A & $21.819(3)$ \\
c / $\AA$ & $10.938(2)$ \\
Volume / ${ }^{3}$ & $5207.2(18)$ \\
Cell Formula units Z & 16 \\
D / g cm ${ }^{-3}$ & 1.454 \\
F(000) & 2304 \\
Goodness of fit & 1.045 \\
R1 & 0.1783 \\
wR2 & 0.4082 \\
\hline
\end{tabular}




\subsubsection{Solid-state NMR data of MIP-208}

The ${ }^{1} \mathrm{H}$ MAS and ${ }^{1} \mathrm{H} \rightarrow{ }^{15} \mathrm{~N}$ and ${ }^{1} \mathrm{H} \rightarrow{ }^{13} \mathrm{C}$ CPMAS NMR spectra of 5- $\mathrm{NH}_{2}$-IPA and MIP-208 were recorded on a Bruker Advance NEO 500 MHz NMR spectrometer (11.7 T), which correspond to Larmor frequencies of 500.3, 125.8 and $50.7 \mathrm{MHz}$ for ${ }^{1} \mathrm{H},{ }^{13} \mathrm{C}$ and ${ }^{15} \mathrm{~N}$, respectively. The samples were packed in $4 \mathrm{~mm}$ zirconia rotors and spun at $12.5 \mathrm{kHz}$ MAS frequency. The ${ }^{1} \mathrm{H}$ and ${ }^{13} \mathrm{C}$ chemical shifts are referenced to the proton and carbon signals of TMS. The ${ }^{15} \mathrm{~N}$ chemical shifts are referenced to $\mathrm{CH}_{3} \mathrm{NO}_{2}$ using the ${ }^{15} \mathrm{~N}$ NMR signal of glycine at $-347.2 \mathrm{ppm}$ as secondary reference. ${ }^{[3]}$ For the ${ }^{1} \mathrm{H} \rightarrow{ }^{15} \mathrm{~N}$ and ${ }^{1} \mathrm{H} \rightarrow{ }^{13} \mathrm{C}$ CPMAS NMR experiments, the initial ${ }^{1} \mathrm{H} \pi / 2$ pulse was set to $3.0 \mu \mathrm{s} .{ }^{13} \mathrm{C}$ and ${ }^{15} \mathrm{~N}$ radiofrequency (RF) pulses of $50 \mathrm{kHz}$ were applied during the contact period, while a ramped-amplitude pulse was applied on ${ }^{1} \mathrm{H}$, for which $\mathrm{RF}$ was adjusted to match the $\mathrm{n}=+1$ Hartman Hahn condition. The contact time was 8.0 and 3.5 ms for ${ }^{1} \mathrm{H} \rightarrow{ }^{15} \mathrm{~N}$ and ${ }^{1} \mathrm{H} \rightarrow{ }^{13} \mathrm{C}$ CPMAS, respectively. The recycle delay was $5 \mathrm{~s}$. $152^{[64]}$ for 5- $\mathrm{NH}_{2}$-IPA and 3348 (1024) for MIP-208 transients were accumulated to obtain the ${ }^{15} \mathrm{~N}\left({ }^{13} \mathrm{C}\right)$ NMR spectra. The ${ }^{1} \mathrm{H}$ MAS NMR spectrum was recorded with a Hahn-echo experiment, using $3.0 \mu \mathrm{s} \pi / 2$ pulse and an interpulse delay synchronized with one rotor period. The 2D ${ }^{1} \mathrm{H}-{ }^{1} \mathrm{H}$ MAS NMR spectrum was recorded using the back-to-back (BABA) sequence. ${ }^{[4]}$ The recoupling time was set to $160 \mu \mathrm{s} 80 \mathrm{t}_{1}$ slices with 32 transients each were co-added. The spectra were analyzed using the DMFit software. ${ }^{[5]}$ 


\section{In situ acetylation of 5- $\mathrm{NH}_{2}-$ IPA}

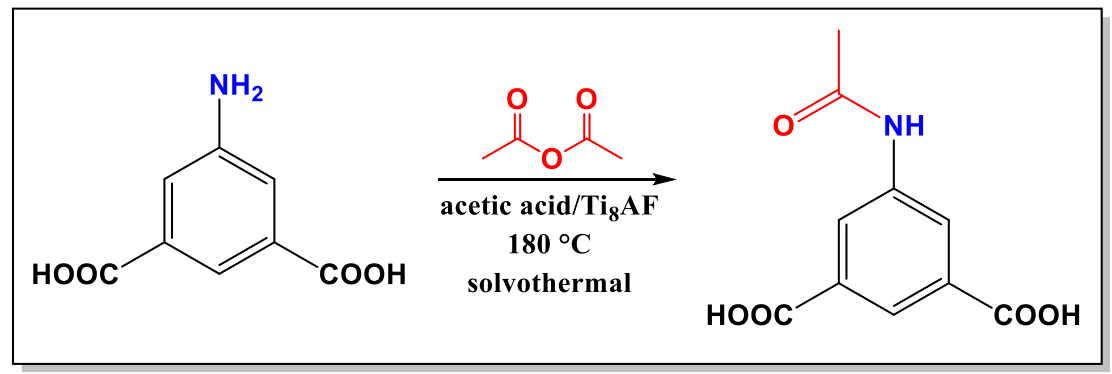

Scheme S1. In situ acetylation of 5- $\mathrm{NH}_{2}$-IPA by acetic anhydride under solvothermal conditions leading to the 5-Acetamide-IPA.

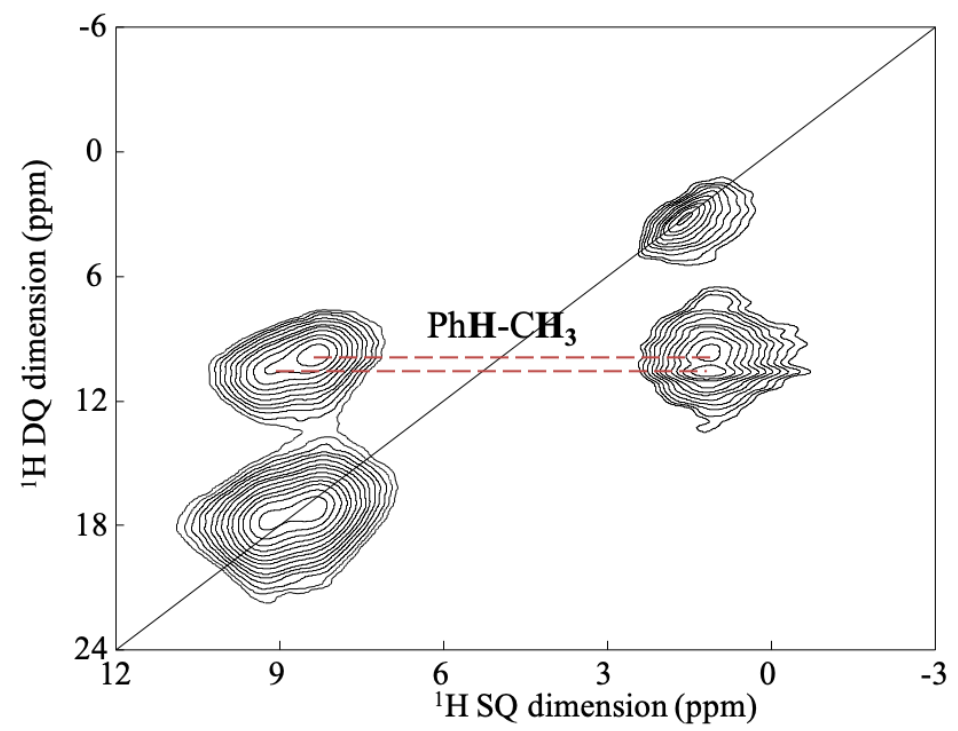

Figure S2. ${ }^{1} \mathrm{H}-{ }^{1} \mathrm{H}$ 2D MAS NMR correlation spectrum of MIP-208. The red dahs lines show the cross-correlation peaks between the $\mathrm{CH}_{3}$ resonance of the amide function and the protons from the aromatic groups, which indicates close spatial proximity (a few $\AA$ ). 


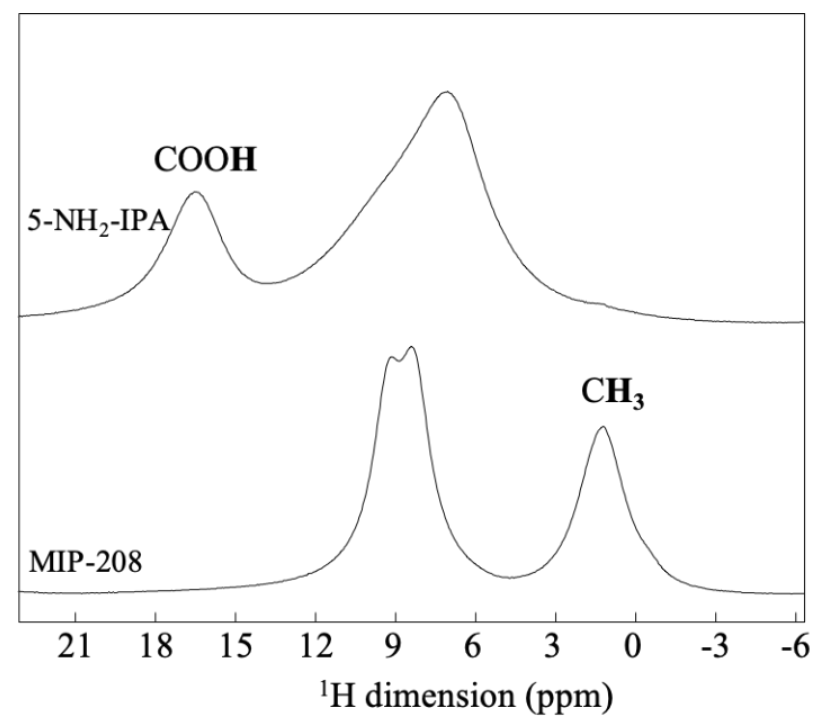

Figure S3. ${ }^{1} \mathrm{H}$ MAS NMR spectra of 5- $\mathrm{NH}_{2}$-IPA and MIP-208, showing the deprotonation of the carboxylic groups in MIP-208.

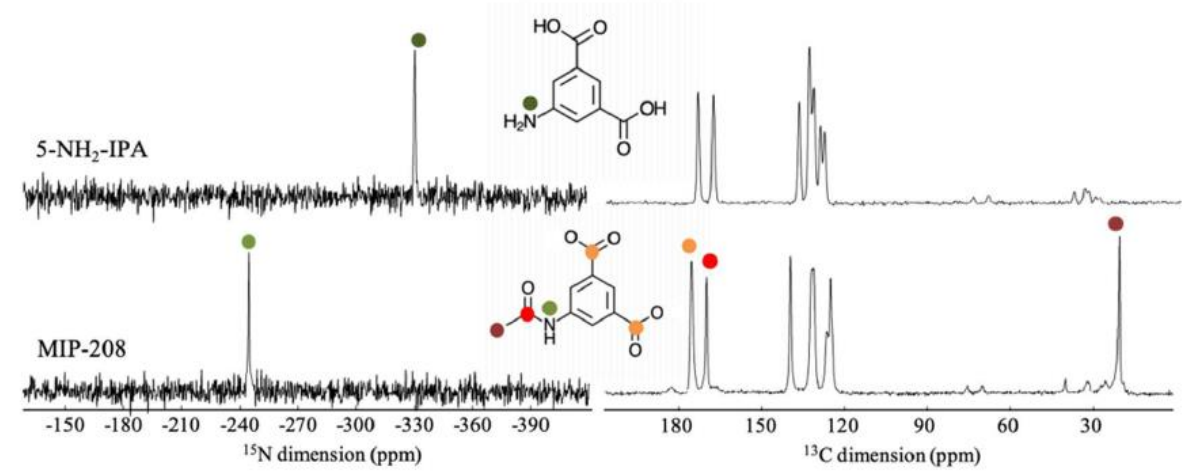

Figure S4. ${ }^{15} \mathrm{~N}$ and ${ }^{13} \mathrm{C}$ NMR spectra of 5- $\mathrm{NH}_{2}-$ IPA and MIP-208, which show the full conversion of the amine function to amide. 


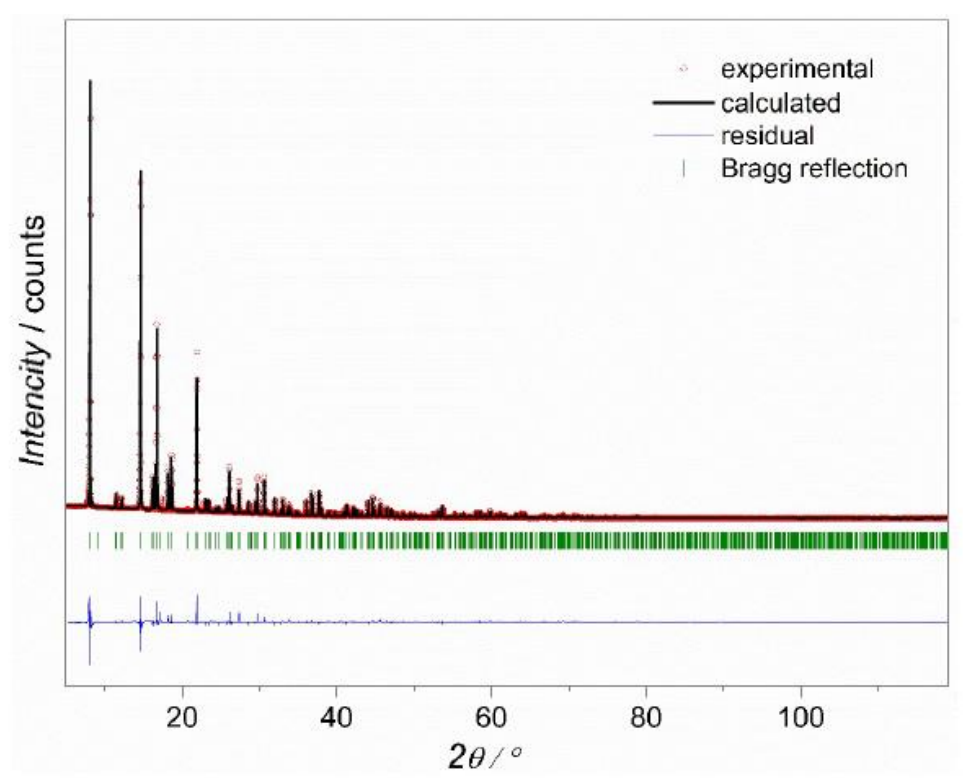

Figure S5. The refinement of MIP-208 crystal structure using the Rietveld method (CuK 1 radiation; space group I41/amd; $a=21.84148(17) \AA$, $c=10.93204(17) \AA ̊ R I=7.97 \%, R p=5.58 \%$, Rwp $=8.83 \%$ ).

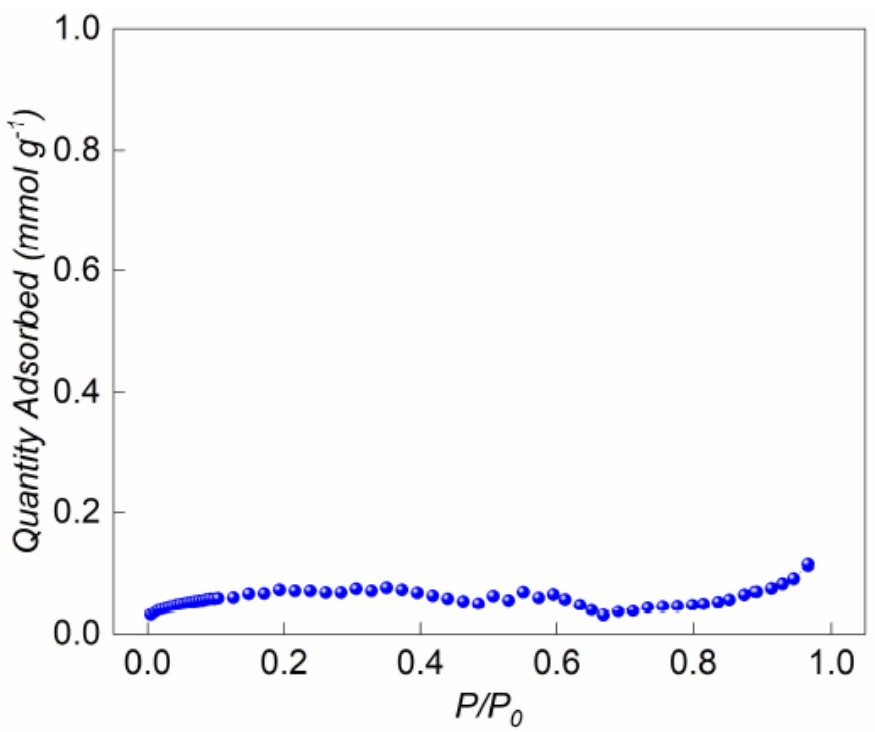


Figure S6. Nitrogen adsorption isotherm of MIP-208 collected at 77K.

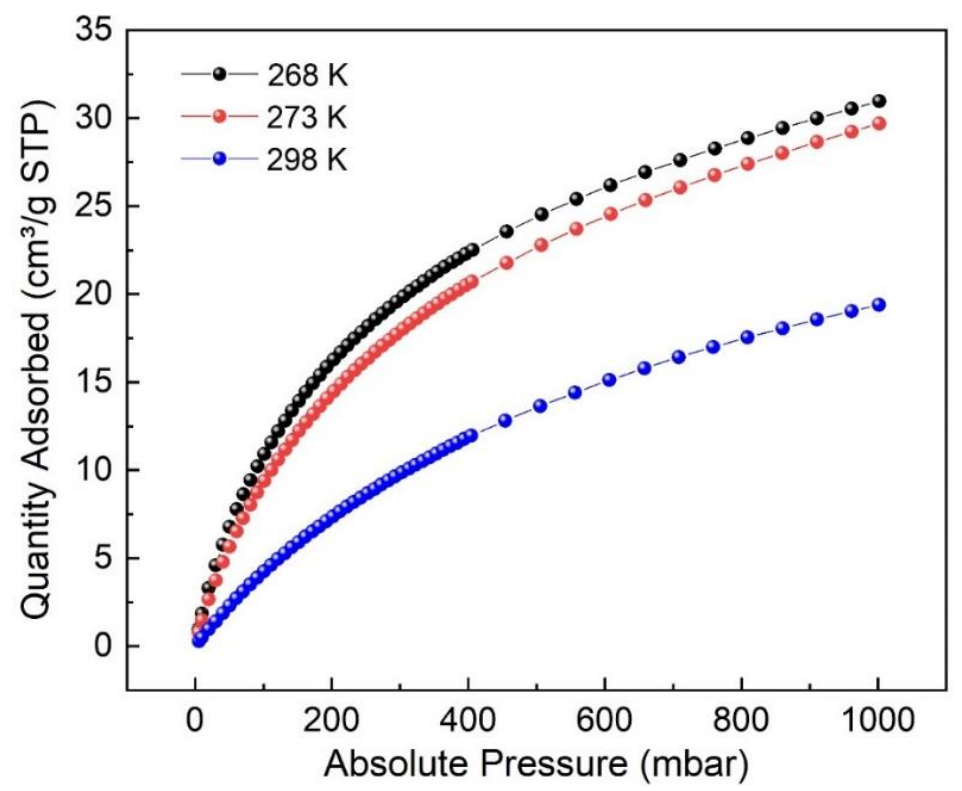

Figure S7. $\mathrm{CO}_{2}$ adsorption isotherms of MIP-208 collected at different temperatures. 

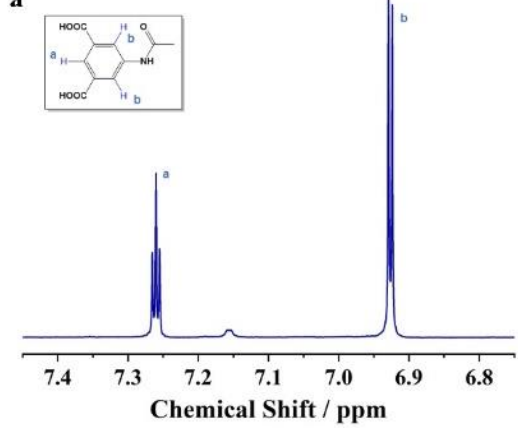

c
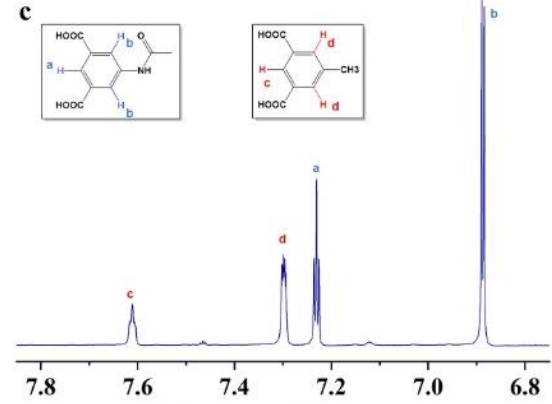

Chemical Shift / ppm

e
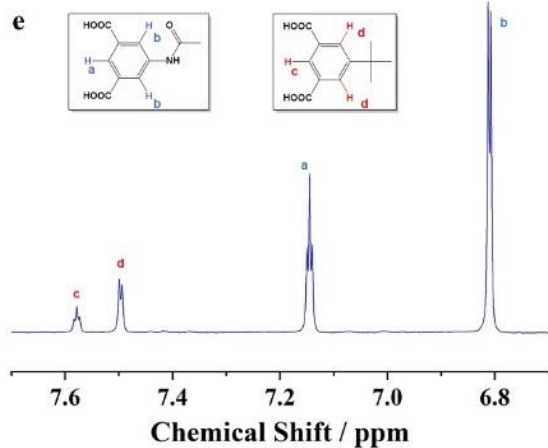

b
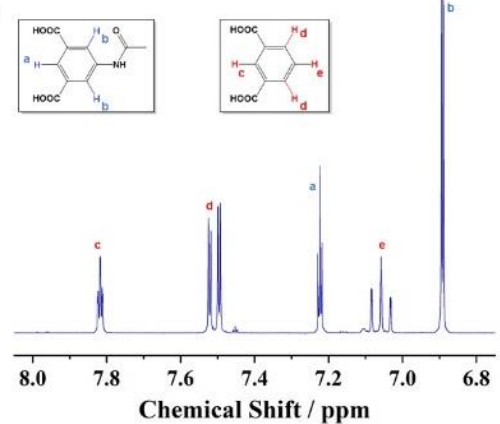

d
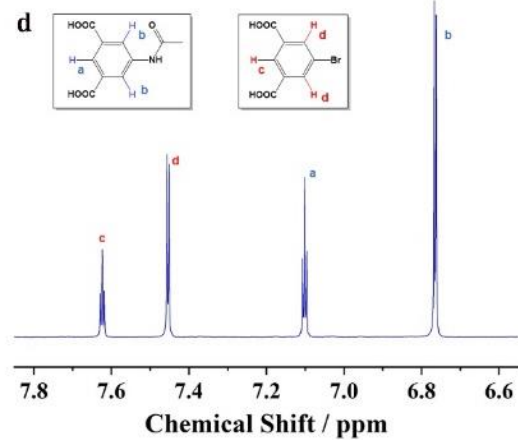

f
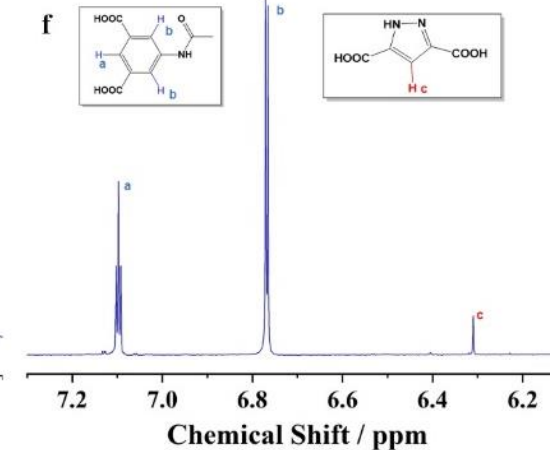

Figure S8. $1 \mathrm{H}$ NMR spectra of MTV-MIP-208s after digestion in $\mathrm{NaOH} / \mathrm{D}_{2} \mathrm{O}$ solvent. 

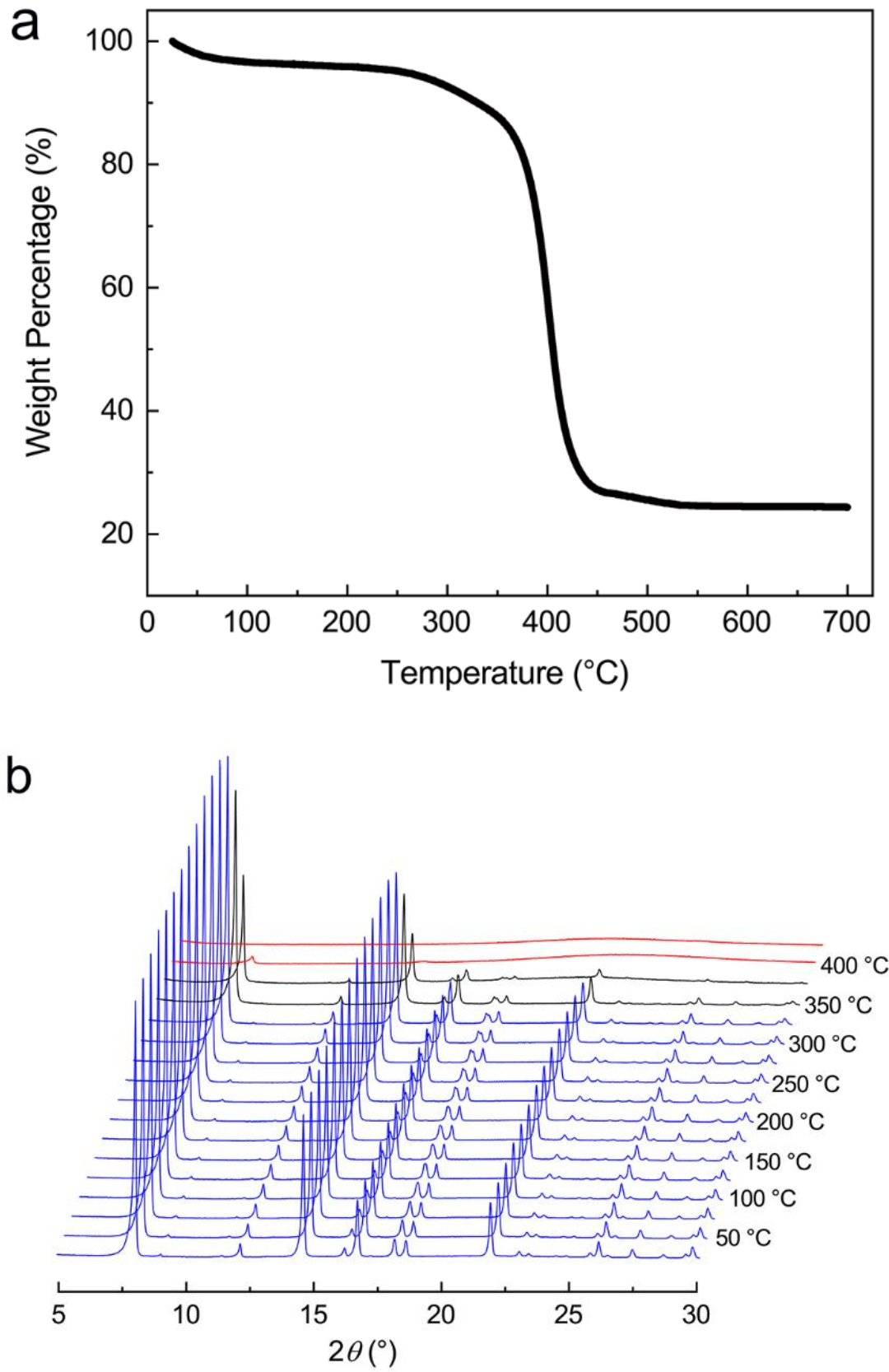

Figure S9. (a) TGA curve and (b) temperature-dependent PXRD patterns of MIP-208. 
a

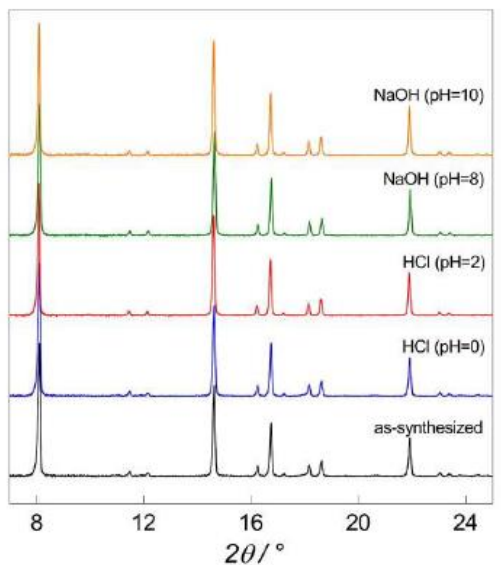

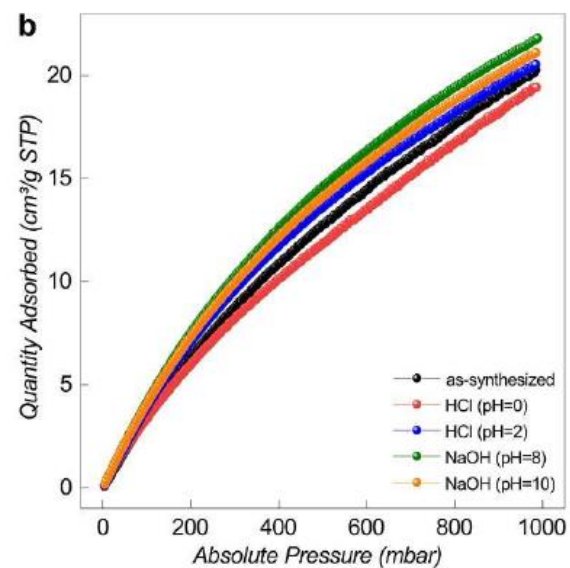

Figure S10. (a) PXRD patterns and (b) $\mathrm{CO}_{2}$ adsorption isotherms of MIP-208 samples before and after treatment in aqueous solution with different $\mathrm{pH}$ values.

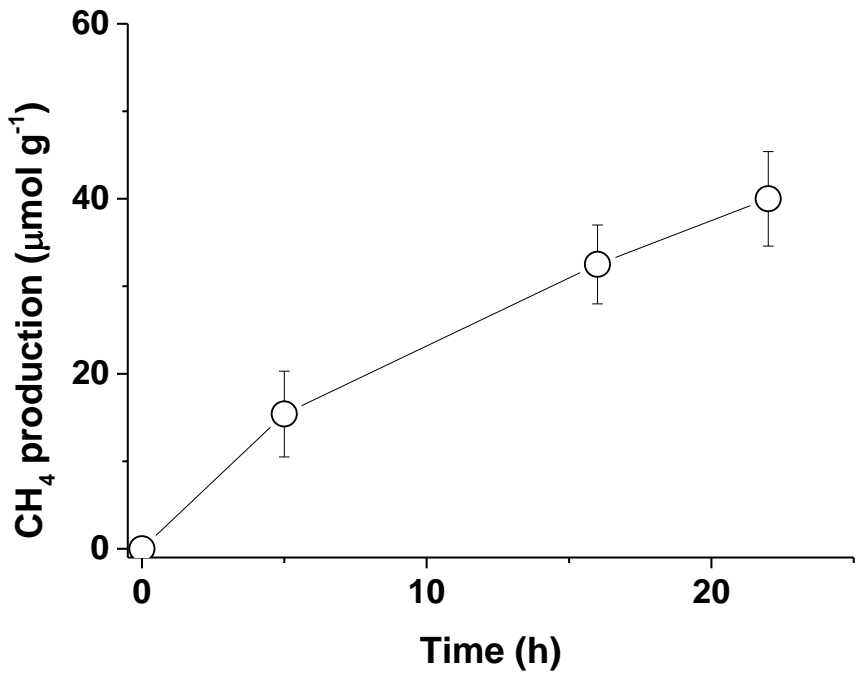

Figure S11. Temporal evolution of $\mathrm{CH}_{4}$ during the photocatalytic $\mathrm{CO}_{2}$ reduction with pure MIP-208 as the catalyst using a Xenon lamp. Reaction conditions: catalyst (15 mg), $\mathrm{H}_{2}$ (1.05 bar), $\mathrm{CO}_{2}\left(0.25\right.$ bar), temperature $\left(200^{\circ} \mathrm{C}\right)$, irradiation source a Xenon lamp $\left(1350 \mathrm{~W} \times \mathrm{m}^{-2}\right)$. 

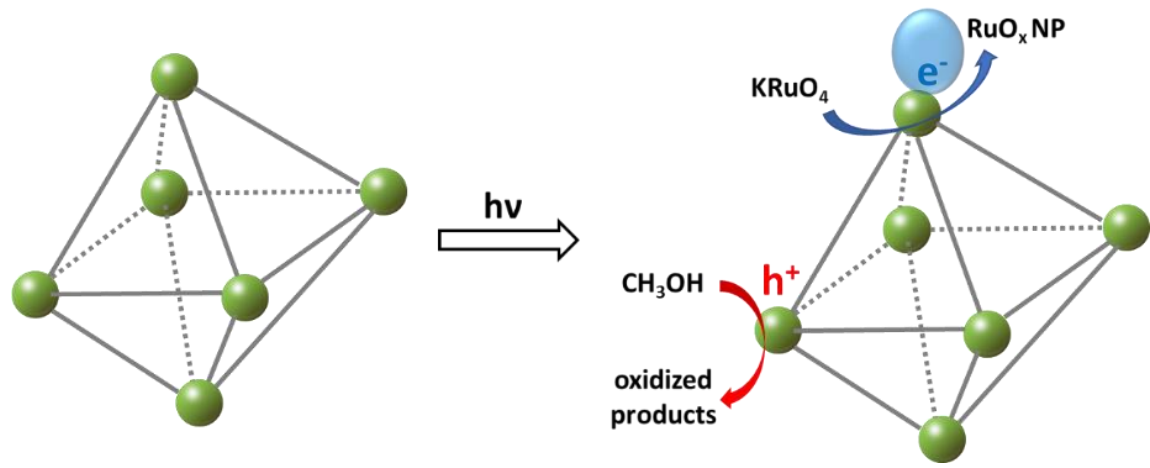

Scheme S12. Simplified illustration of photodeposition of $\mathrm{RuO}_{\mathrm{x}} \mathrm{NPs}$ on MIP-208.
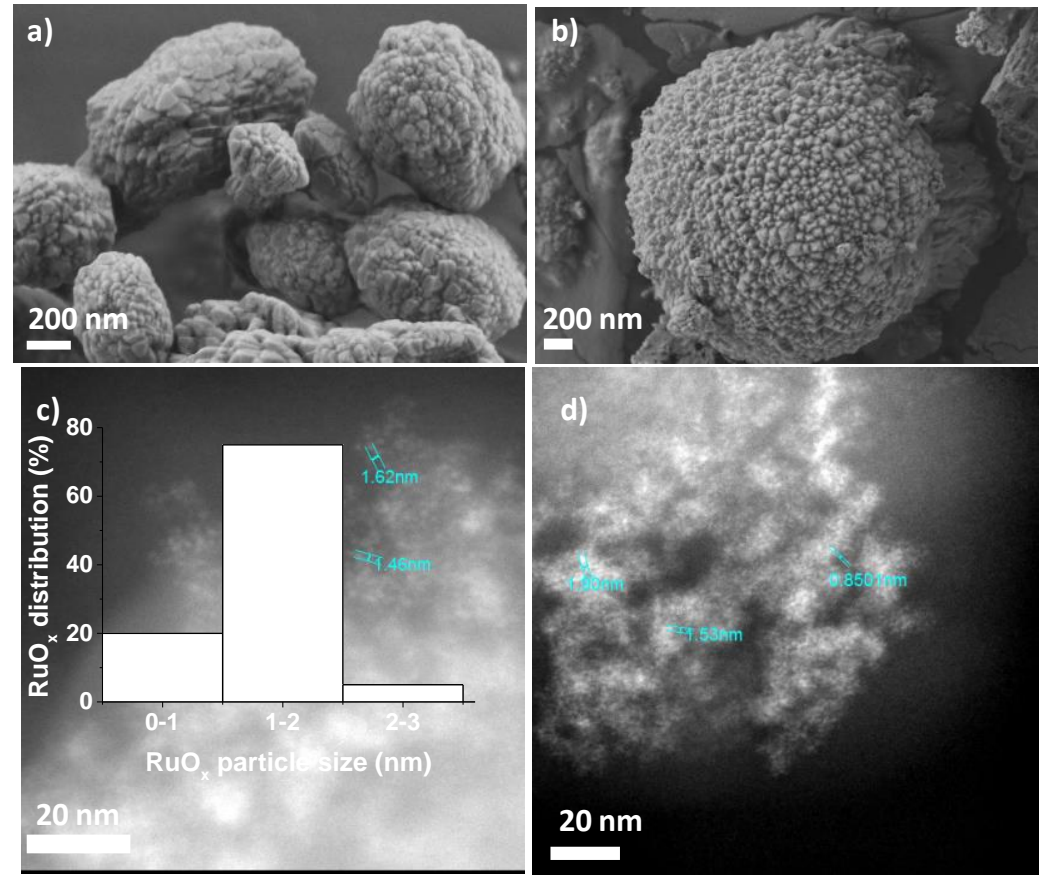

Figure S13. FESEM images of (a) MIP-208 and (b) MIP-208@RuO ${ }_{x}$ DF-SEM images (c and d) of RuO $@$ @MIP-208 and RuO particle size distribution (inset in frame c). 
a)

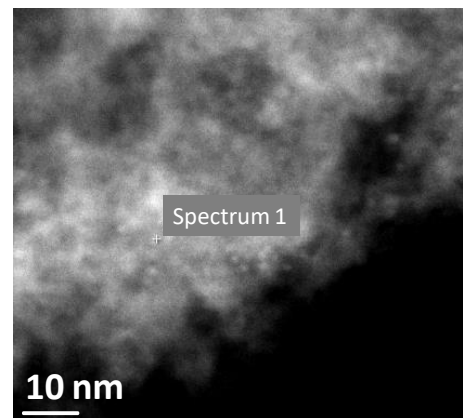

b)

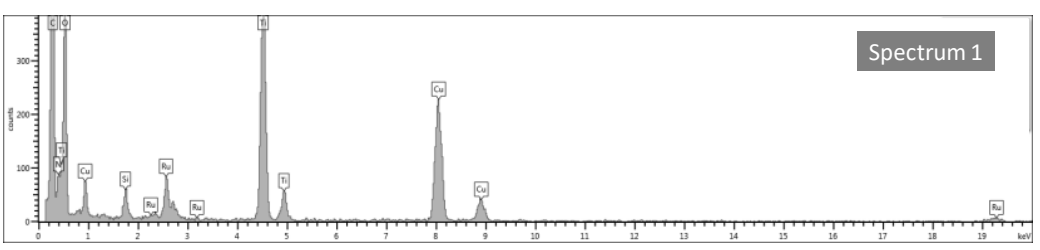

Figure S14. STEM image (a) and EDX spectrum of selected area showing the presence of ruthenium NPs. The copper element detected by EDX is due to the composition of the TEM grid used as sample holder.

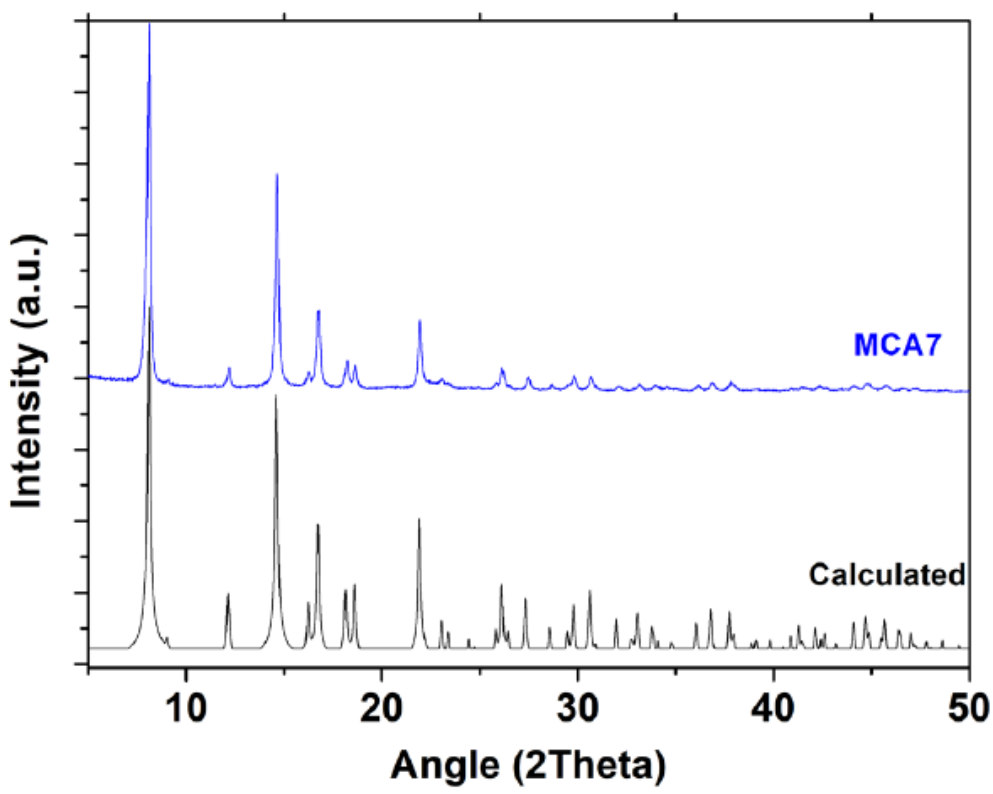

Figure S15. PXRD comparison of MIP-208@RuO and MIP-208. 

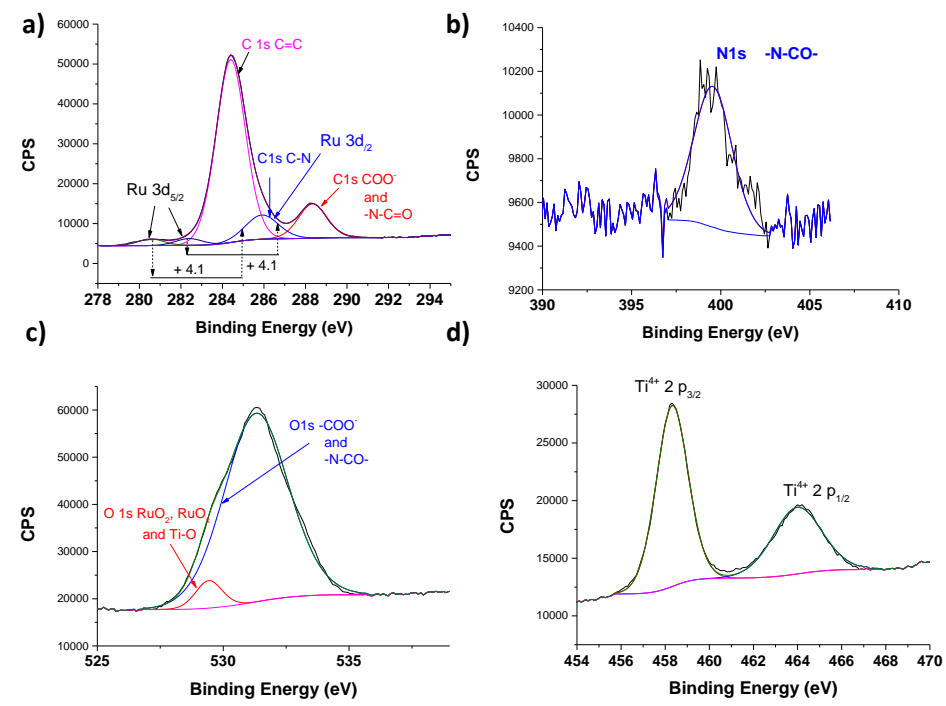

Figure S16. XPS peaks of C1s, N1s, O1s and Ti2p peaks in MIP-208@RuO

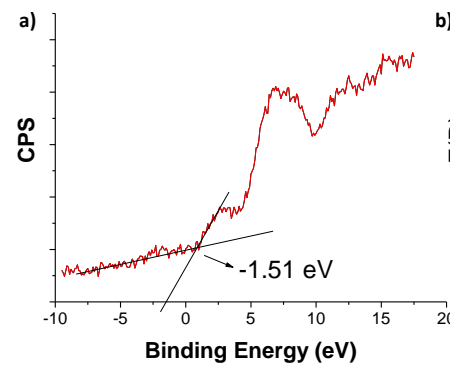

c)

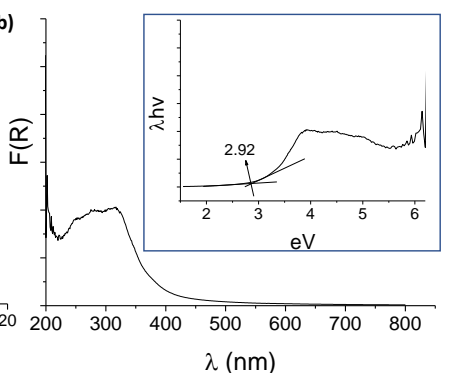

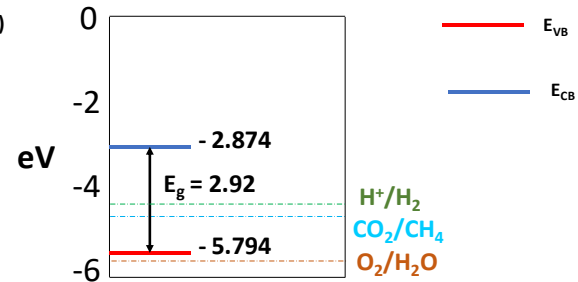

Figure S17. (a) XPS valence band estimation for MIP-208@RuO $(b)$ UV-Vis diffuse reflectance plot of MIP-208@RuOx. The inset shows the Tauc plot for MIP-208@RuO (c) Bandgap and band edge positions of MIP-208@RuO together with some redox potentials of interest under vacuum level. 


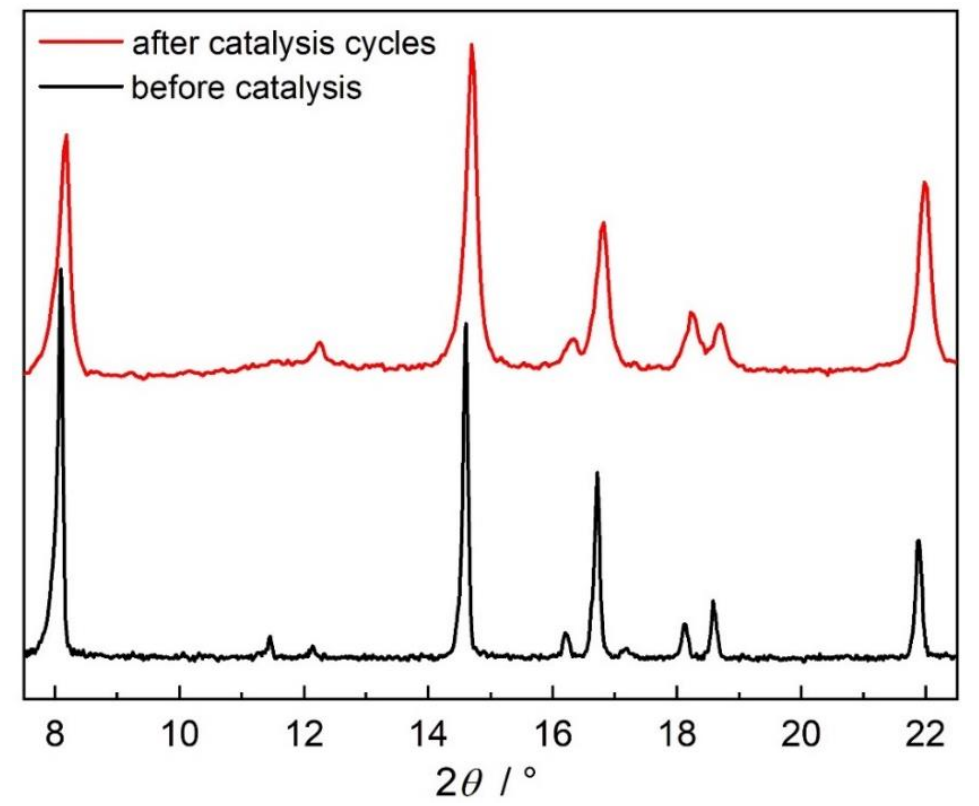

Figure S18. PXRD comparison of MIP-208@RuO samples before and after seven times cycling.

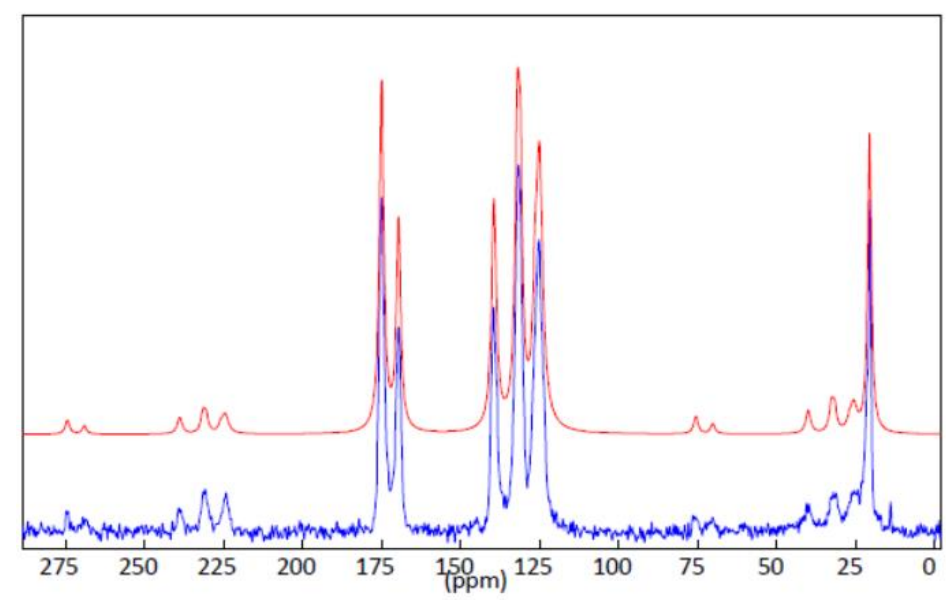

Figure S19. ${ }^{13} \mathrm{C}-\mathrm{NMR}$ of the MIP-208@RuO $\mathrm{x}$ sample after seven times uses (blue line) and the deconvoluted (red line). Reaction conditions: catalyst (15 mg), $\mathrm{H}_{2}$ (1.05 bar), $\mathrm{CO}_{2}$ (0.25 bar), temperature $\left(200^{\circ} \mathrm{C}\right)$, irradiation source a Xenon lamp $\left(1350 \mathrm{~W} \times \mathrm{m}^{-2}\right)$. 


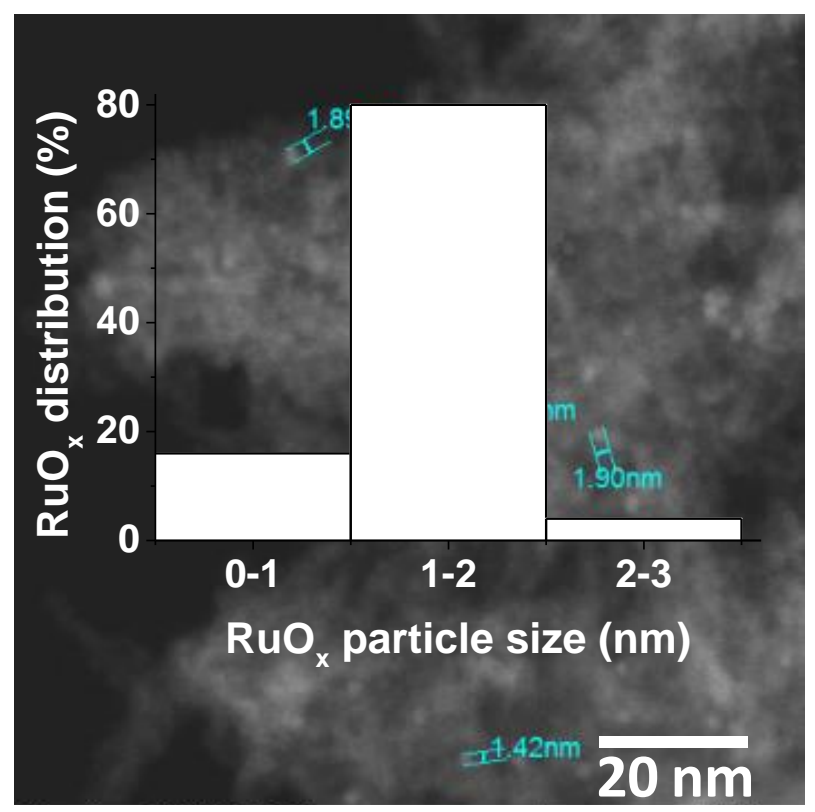

Figure S20. DF-SEM image and $\mathrm{RuO}_{\mathrm{x}}$ particle size distribution of the seven times used MIP-208@RuO photocatalyst.

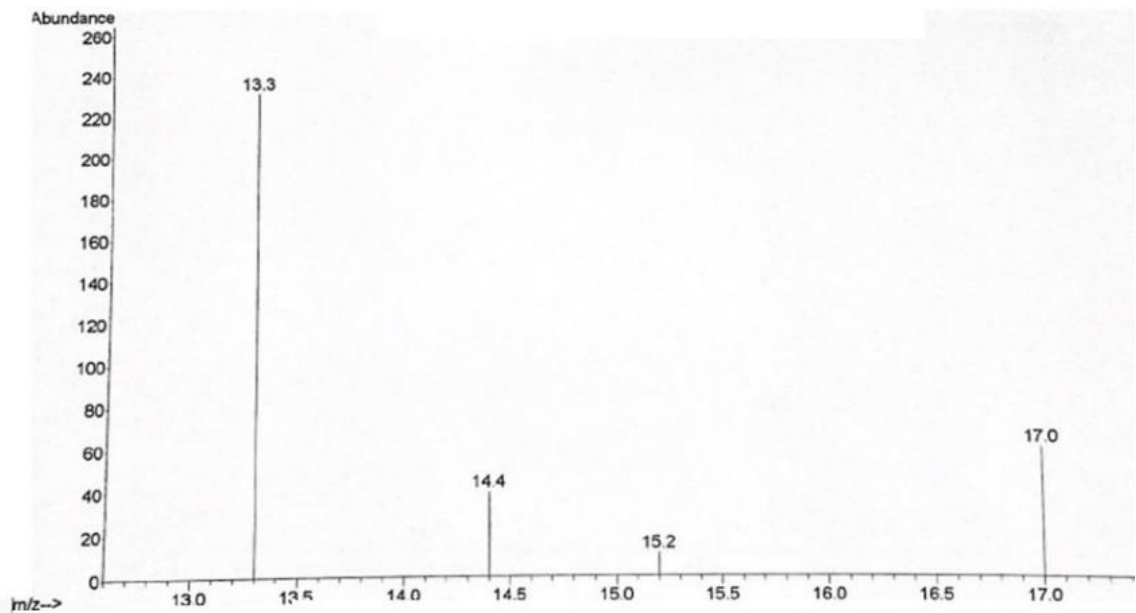

Figure S21. Mass spectrum of the peak corresponding to ${ }^{13} \mathrm{CH}_{4}$ generated during the photoreduction of ${ }^{13} \mathrm{CO}_{2}$ using MIP-208@RuO material. 


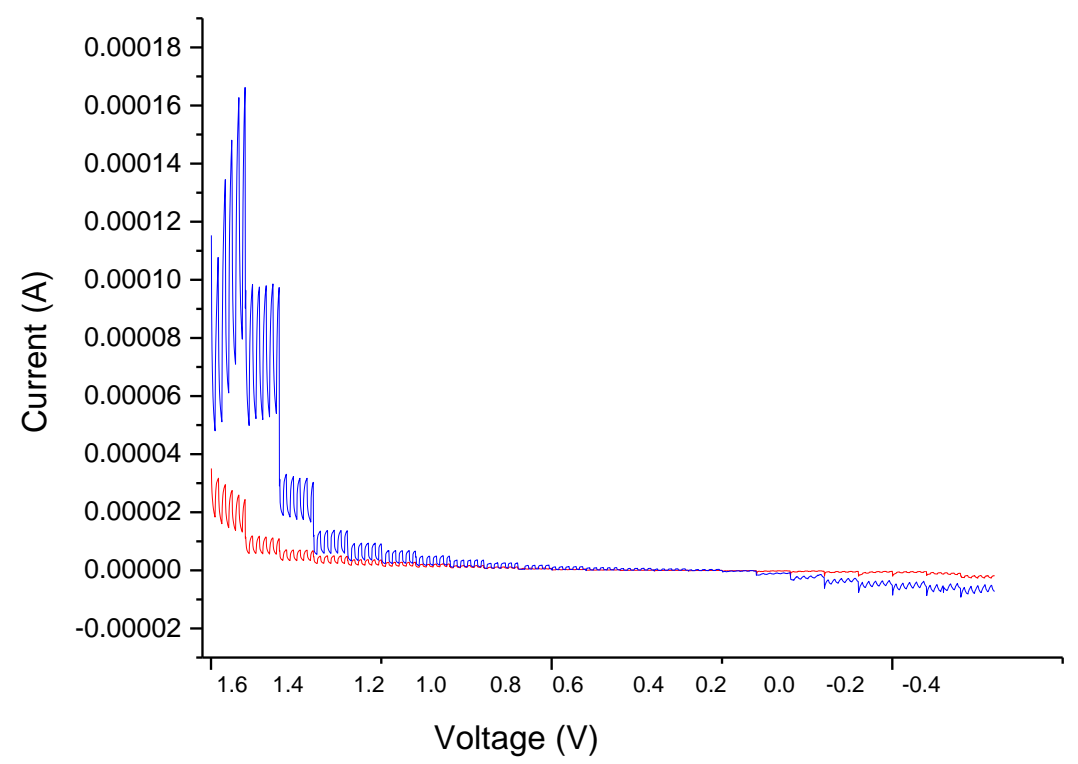

Figure S22. Photocurrent intensity versus polarization potential measured for MIP-208@RuO supported on FTO electrode. Measurement conditions: Deaerated acetonitrile solution of 0.1 $\mathrm{MTPAPF}_{6}$ in the absence (red line) or in the presence (red line) of $\mathrm{MeOH}$ as sacrificial electron donor, irradiation with the beam output of a $150 \mathrm{~W}$ Xe lamp.
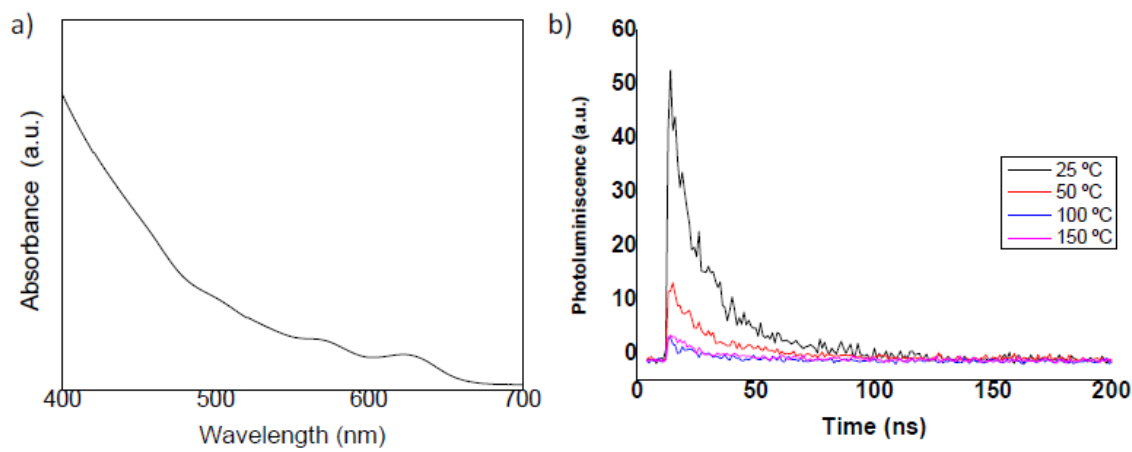

Figure S23. a) UV-Vis spectra of CdSe-ZnS QDs and (b) photoluminescence lifetime of CdSe-ZnS as a function of the cell temperature upon laser irradiation filter at $407 \mathrm{~nm}$ and filter at 610 $\mathrm{nm}$. 


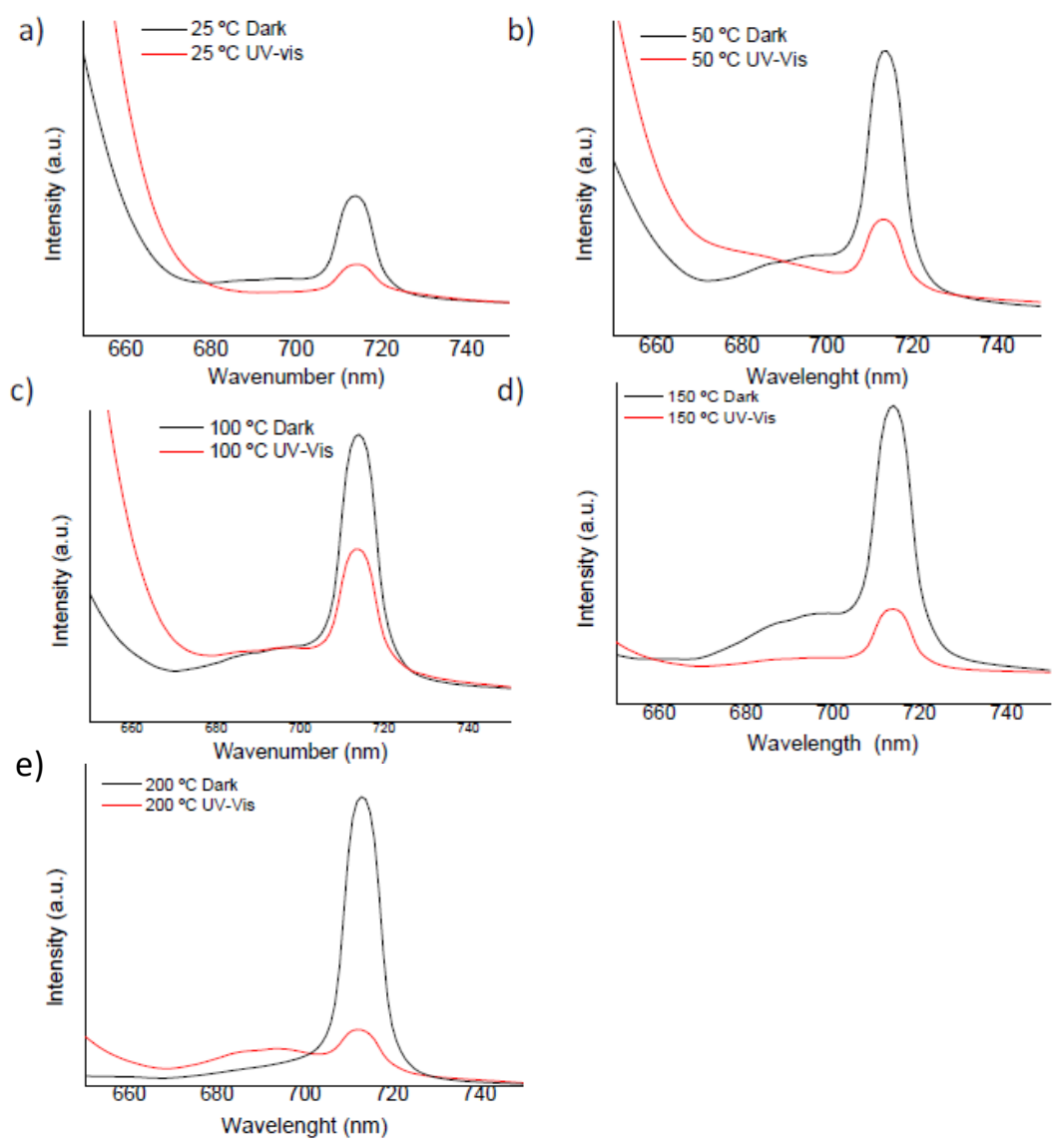

Figure S24. Photoluminescence of CdSe-ZnS QDs under dark and UV-Vis irradiation at different temperatures. The emission of the same sample was measured in the dark and immediately after upon illumination with the Xe lamp beam. 


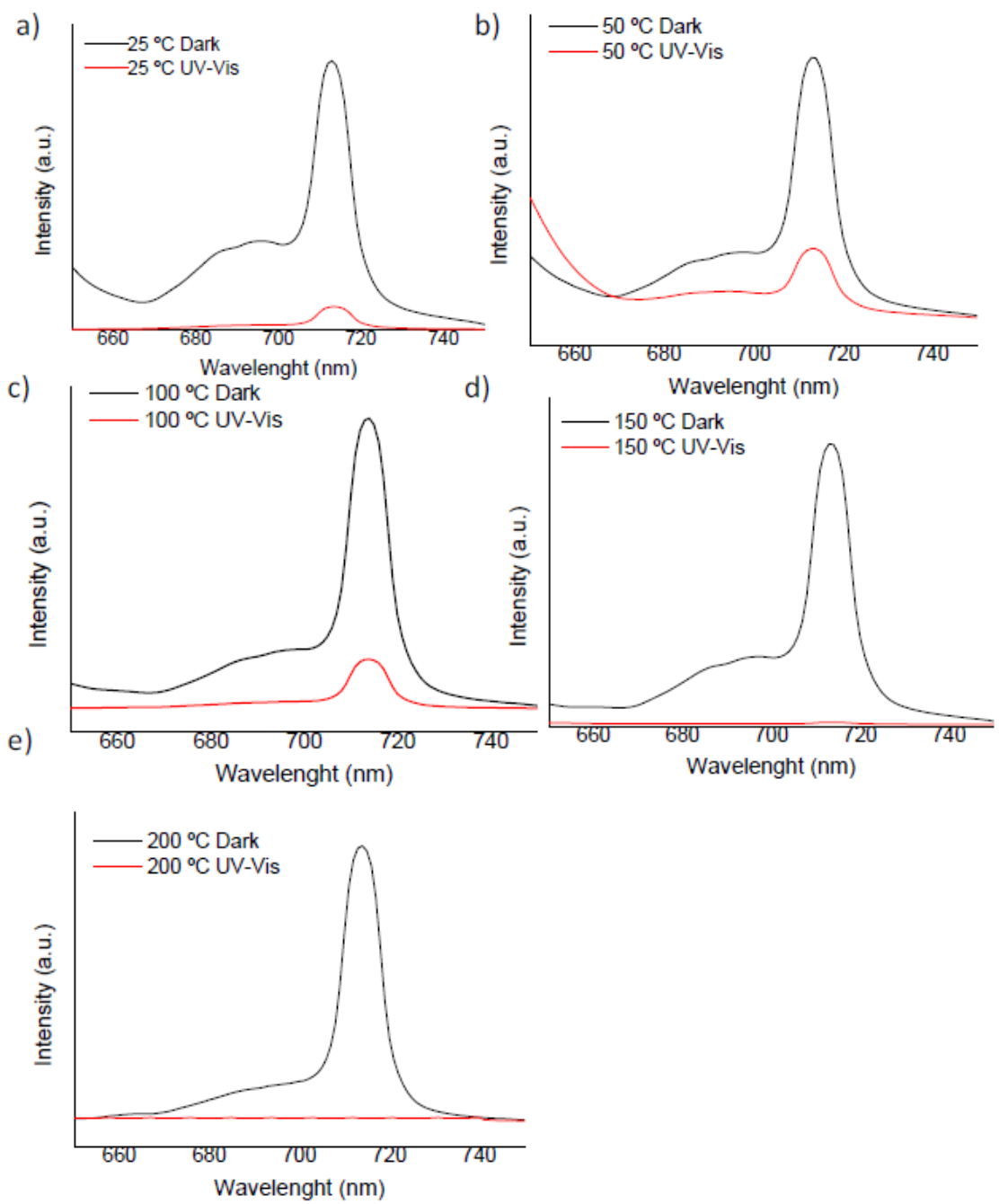

Figure S25. Photoluminescence spectra of MIP-208@RuO $\mathrm{x}^{-}(\mathrm{CdSe}-\mathrm{ZnS})$ under dark and UV-Vis irradiation at different temperatures. The emission of the same sample is measured in the dark and immediately after upon illumination with the Xe lamp. 


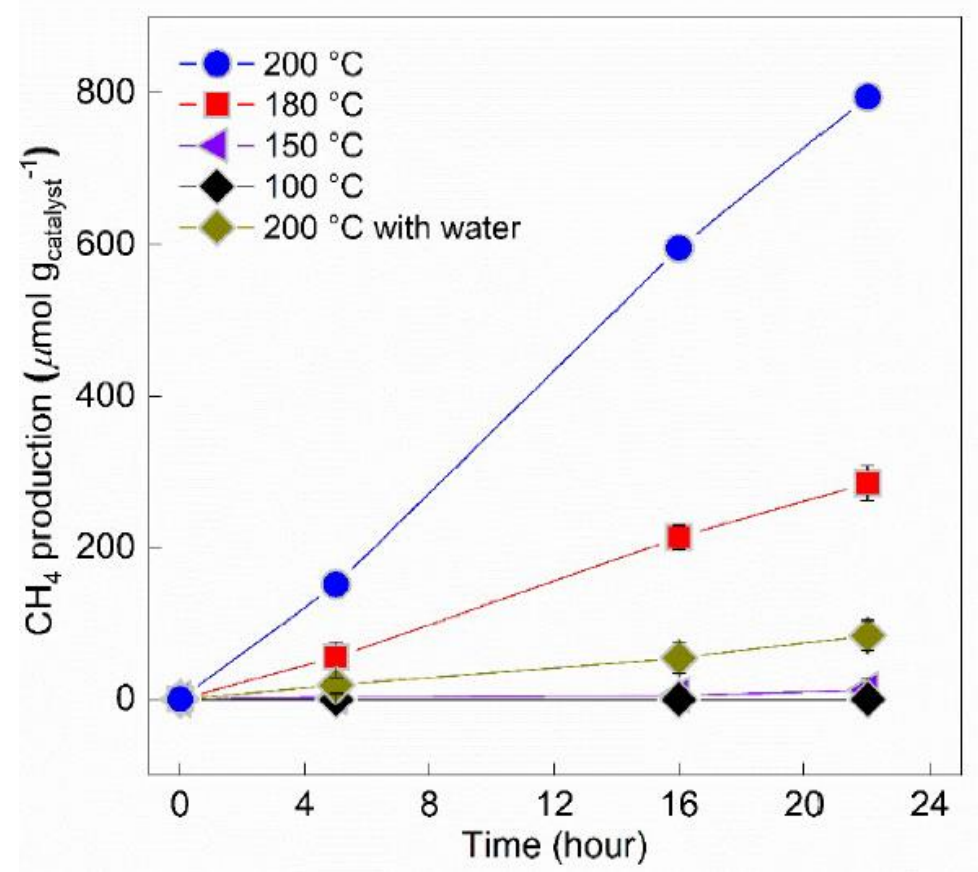

Figure S26. Temporal evolution of $\mathrm{CH}_{4}$ during the photocatalytic $\mathrm{CO}_{2}$ reduction with MIP-208@RuO ${ }_{x}$ as the catalyst using a Xenon lamp at different temperatures. Reaction conditions: catalyst $(15 \mathrm{mg}), \mathrm{H}_{2}(1.05 \mathrm{bar}), \mathrm{CO}_{2}(0.25 \mathrm{bar})$, temperature $\left(200{ }^{\circ} \mathrm{C}\right)$, irradiation source a xenon lamp $\left(1350 \mathrm{~W} \times \mathrm{m}^{-2}\right)$ or solar simulator $\left(1000 \mathrm{~W} \times \mathrm{m}^{-2}\right)$. 


\subsubsection{Bibliography}

[1] S. Wang, H. Reinsch, N. Heymans, M. Wahiduzzaman, C. Martineau-Corcos, G. De Weireld, G. Maurin, C. Serre, Matter 2020, 2 , 440-450.

[2] P. Bertani, J. Raya, B. Bechinger, Solid State Nucl. Magn. Reson. 2014, 61-62, 15-18.

[3] M. Feike, D. E. Demco, R. Graf, J. Gottwald, S. Hafner, H. W. Spiess, Series A. 1996, 122, 214-221.

[4] D. Massiot, F. Fayon, M. Capron, I. King, S. Le Calvé, B. Alonso, J.-O Durand, B. Bujoli, Z. Gan, G. Hoatson, Magn. Reson. Chem. 2002, 40, 70-76. 



\section{Chapter 7}

Toward solar-driven photocatalytic $\mathrm{CO}_{2}$ methanation under continuous flow operation using benchmark MIL-125(Ti)-NH $\mathrm{N}_{2}$ supported ruthenium nanoparticles 



\subsection{Abstract}

The development of solar fuels from $\mathrm{CO}_{2}$ is currently attracting increasing interest. Herein we describe the development of a benchmark metal-organic framework (MOF) photocatalyst based on MIL-125(Ti)- $\mathrm{NH}_{2}$ supported ruthenium nanoparticles for solar-driven selective photocatalytic $\mathrm{CO}_{2}$ methanation under both batch and continuous flow operations. The optimized $\mathrm{RuO}_{x}(10 \mathrm{wt} \% ; 1.48 \mathrm{~nm} \pm 0.53$ $\mathrm{nm}) @ \mathrm{MIL}-125(\mathrm{Ti})-\mathrm{NH}_{2}$ photocatalyst is exceptionally active $\left(18.5 \mathrm{mmol} \mathrm{g}^{-1}\right.$ at $22 \mathrm{~h}$ ) and reusable $\left(7\right.$ cycles for $154 \mathrm{~h}$ ) in the $\mathrm{CO}_{2}$ methanation at $200{ }^{\circ} \mathrm{C}$ under batch conditions and simulated sunlight irradiation. The photocatalyst can also be employed as for continuous-flow $\mathrm{CO}_{2}$ methanation under visible light irradiation $(\lambda>450 \mathrm{~nm})$ at $200{ }^{\circ} \mathrm{C}$. Evidence in support of the operation of a combined photocatalytic mechanism based on $\mathrm{e}^{-} / \mathrm{h}^{+}$separation and photothermal pathway in which the energy of photons produces local heating has been obtained for the photocatalytic $\mathrm{CO}_{2}$ methanation. We are confident that this study will contribute to the development of highly active MOF-based photocatalysts for solar-driven $\mathrm{CO}_{2}$ methanation under continuous flow operations with industrial interest.

\subsection{Introduction}

Fossil fuels now supply about $80 \%$ of the energy demand worldwide, ${ }^{[1]}$ which means millions of Tons of $\mathrm{CO}_{2}$ together with $\mathrm{NO}_{\mathrm{x}}, \mathrm{SO}_{\mathrm{x}}$ and particulate matter are sent into the atmosphere. ${ }^{[2,3]} \mathrm{CO}_{2}$ is one of the most important greenhouse gases, responsible for global warming and climate change. ${ }^{[3]}$ The increased demand for energy and the consumption of fossil fuels has led to a continuous increase in $\mathrm{CO}_{2}$ emissions, with a global atmospheric concentrations of about 409.85 ppm in 2019.4 Several national and international authorities have thus been promoting new policies aimed at reducing $\mathrm{CO}_{2}$ emissions. ${ }^{[3,5]}$ for example the European Union aims to become climate-neutral by $2050 .{ }^{[2]}$ Solar energy is now envisioned as one of the promising alternative primary energy vectors to the use of fossil fuels. 
Since the seminal work of Honda and Fujishima, who used $\mathrm{TiO}_{2}$ as the photoanode for the production of $\mathrm{H}_{2},{ }^{[6]}$ heterogeneous photocatalysis by metal oxide semiconductors has become a promising technology for the production of solar fuels. Photocatalytic overall water ${ }^{[7]}$ splitting and $\mathrm{CO}_{2}$ photoreduction ${ }^{[8]}$ processes have been recognized as the most suitable for the transformation of solar energy into chemical energy, which would at least partially palliate the negative effects of fossil fuels. In spite of the great advances in this field, the limited tunability of these materials somehow hampers achieving high efficiencies in solar light irradiation. The development of a relatively new class of crystalline and porous materials termed as metal-organic frameworks (MOFs) ${ }^{[9-11]}$ greatly expanded the field of heterogeneous photocatalysis. ${ }^{[12,13]}$ Particularly by using Ti-MOF as photocatalysts to produce solar fuels, due to their excellent electronic and optical properties, good stability, low toxicity and the abundance of their counterparts. ${ }^{[14-16]}$ The Ti-MOF referred to as MIL-125(Ti)- $\mathrm{NH}_{2}\left[\left(\mathrm{Ti}_{8} \mathrm{O}_{8}\right)(\mathrm{OH})_{4}\left(\mathrm{C}_{6} \mathrm{H}_{3} \mathrm{C}_{2} \mathrm{O}_{4} \mathrm{NH}_{2}\right)_{6}\right]$, composed of the 2-aminoterephthalate organic ligand coordinated to the titanium-oxo cluster, has become one of the benchmark MOF photocatalysts, ${ }^{[17]}$ in which the amino group in the terephthalate organic ligand is responsible for absorbing visible light. MIL$125(\mathrm{Ti})-\mathrm{NH}_{2}$ exhibits an absorption onset at about $450 \mathrm{~nm}$ resulting in an optical band gap of about $2.64^{[18]}-2.8 \mathrm{eV} .^{[17]}$ The highest occupied crystal orbital (HOCO) is located at the organic linker, whereas the lowest unoccupied crystal orbital (LUCO) is on the titanium oxo cluster. Theoretical and experimental evidence have confirmed HOCO and LUCO overlapping in MIL-125(Ti)- $\mathrm{NH}_{2}$, so that irradiating MIL-125(Ti)- $\mathrm{NH}_{2}$ with appropriate energy leads to a negative ligand-to-metal charge transfer (LMCT) process. $^{[19]}$ In situ electron paramagnetic resonance (EPR) spectroscopy measurements have revealed the formation of photoreduced $\mathrm{Ti}^{3+}$ species on irradiating MIL-125(Ti)- $\mathrm{NH}_{2}$ with UV-Vis light. ${ }^{[19,20]}$ A common strategy to improve MOFs (photo)catalytic activity such as MIL-125(Ti)-NH2 is to deposit NPs as co-catalysts within their framework. ${ }^{[21,22]}$ Ruthenium-based nanoparticles are among the most active co-catalysts for $\mathrm{CO}_{2}$ (photo)methanation. ${ }^{[23]}$ 
With these precedents in mind, in this work we show the possibility of developing highly active and reusable solar-driven photocatalysts based on the benchmark MIL-125(Ti)- $\mathrm{NH}_{2}$ solid supported $\mathrm{RuO}_{x} \mathrm{NPs}$ for selective $\mathrm{CO}_{2}$ methanation. The results obtained show that the optimized $\mathrm{RuO}_{x}(10 \mathrm{wt} \%) @ \mathrm{MIL}-125(\mathrm{Ti})-\mathrm{NH}_{2}$ material has the highest reported photocatalytic activity for this process, using MOFs as photocatalysts. For the first time we found that a MOF-based photocatalyst can be used for selective $\mathrm{CO}_{2}$ methanation under continuous flow operation and visible light irradiation. The authors consider that this work will make a significant contribution to the development of MOF-based photocatalysts with outstanding catalytic activity for the production of solar fuels from $\mathrm{CO}_{2}$.

\subsection{Experimental section}

\subsubsection{Materials}

All the reagents employed in this work were of analytical or HPLC grade and supplied by Merck.

\subsubsection{Catalyst preparation}

\subsubsection{Synthesis of MIL-125(Ti)- $\mathrm{NH}_{2}$}

MIL-125(Ti)- $\mathrm{NH}_{2}$ was prepared following previously reported procedures. ${ }^{[19,24]}$ 2-aminoterephthalic acid $(1.43 \mathrm{~g}, 7.9 \mathrm{mmol})$ was dissolved in anhydrous $\mathrm{N}, \mathrm{N}$-dimethylformamide (DMF, $20 \mathrm{~mL}$ ), then, anhydrous methanol $(5 \mathrm{~mL})$ was added to the flask and the system sonicated for $20 \mathrm{~min}$. This reaction mixture was transferred to a Teflon-lined autoclave $(50 \mathrm{~mL})$, then titanium isopropoxide $(1.36 \mathrm{~g}, 4.8 \mathrm{mmol})$ was added and the autoclave was sealed and heated up to $110^{\circ} \mathrm{C}$ for $72 \mathrm{~h}$. Subsquently, once the system was cooled down to room temperature, the resulting precipitate was filtered, washed with DMF at room temperature for $12 \mathrm{~h}$ and, then, washed with DMF at $120^{\circ} \mathrm{C}$ for $12 \mathrm{~h}$. This washing procedure was repeated using methanol as solvent. Then, the recovered solid was washed in a soxhlet for 24 
h using methanol as solvent. Finally, the solid was recovered by filtration and dried in an oven at $100{ }^{\circ} \mathrm{C}$.

\subsubsection{Catalyst characterization}

Powder X-ray diffractograms (PXRD) were recorded using a Philips XPert diffractometer equipped with a graphite monochromator (40 kV and $45 \mathrm{~mA}$ ) employing $\mathrm{Ni}$ filtered $\mathrm{CuK}_{\alpha}$ radiation. The morphology and composition of the MOF samples were characterized using a scanning electron microscope (SEM, Zeiss instrument, AURIGA Compact) coupled with an energy-dispersive X-ray (EDX) detector. Scanning transmission electron microscopy images in dark field (DF-STEM) were recorded on a JEOL JEM2100F instrument operating at $200 \mathrm{~kW}$. MNP size distribution was estimated by measuring more than 300 particles from the sample. Isothermal nitrogen adsorption measurements were carried out using an ASAP 2010 Micromeritics device. X-ray photoelectron spectra (XPS) were collected on a SPECS spectrometer with a MCD-9 detector using a monochromatic $\mathrm{Al}\left(\mathrm{K}_{\alpha}=1486.6 \mathrm{eV}\right) \mathrm{X}$-ray source. Spectra deconvolution was performed after Shirley subtraction of background with the CASA software using the $\mathrm{C} 1$ s peak at $284.4 \mathrm{eV}$ as binding energy reference. FTIR spectra of the samples were recorded on compressed powders using a Bruker spectrophotometer in an attenuated total reflectance (ATR) cell.

Low temperature $\mathrm{CO}$ adsorption on $\mathrm{RuO}_{x}(10 \mathrm{wt} \%) / \mathrm{MIL}-125(\mathrm{Ti})-\mathrm{NH}_{2}$ were investigated by FT-IR spectroscopy by using a Nexus 8700 FTIR spectrophotometer. The IR cell of the instrument allows in situ treatments at controlled temperature and is connected to a high vacuum system with gas dosing facility. Briefly, the sample was pressed into self-supported wafers and treated in vacuum $\left(10^{-6} \mathrm{mbar}\right)$ at $150{ }^{\circ} \mathrm{C}$ for $4 \mathrm{~h}$. Then, the wafers were cooled down to $-155^{\circ} \mathrm{C}$ under dynamic vacuum followed by $\mathrm{CO}$ dosing at increasing pressure (0.4-6 mbar). After each $\mathrm{CO}$ dosage the FTIR spectrum was recorded. 


\subsubsection{Photocatalytic experiments}

The photocatalytic $\mathrm{CO}_{2}$ methanation under batch conditions were carried out using a quartz photoreactor $(51 \mathrm{~mL})$ equipped with a heating mantle to control the temperature. Briefly, the powdered photocatalyst (15 mg) was introduced in the photoreactor, and then the system was purged with $\mathrm{H}_{2}$ during 20 minutes and later $\mathrm{CO}_{2}$ was introduced in the photoreactor until achieving a $\mathrm{H}_{2}: \mathrm{CO}_{2}$ molar ratio of $4: 1$ and a final pressure of 1.25 bar. Subsequently, the photoreactor was heated at $200^{\circ} \mathrm{C}$, and then the photocatalyst was irradiated using a Xe lamp (150 W) equipped with an AM $1.5 \mathrm{G}$ type filter. The photocatalytic $\mathrm{CO}_{2}$ methanation under continuous flow operation was carried out using a cylindrical quartz column (length $26 \mathrm{~cm}$, diameter $1.2 \mathrm{~cm}$ ) were the catalyst pellets $(50 \mathrm{mg}$; catalyst pellet size $0.2 \mu \mathrm{m}$ ) is placed in the middle of the column (Figure S1). The system is equipped with a heating mantle to control the temperature $\left(150\right.$ or $200{ }^{\circ} \mathrm{C}$ ). The photocatalyst is irradiated with visible light (150 W Xe lamp equipped with a filter of cut-off $\lambda>$ wavelength 455 $\mathrm{nm}$ ) using a guide light optical fibber. A mass flow controller was employed to feed the mixture of gases $\left(\mathrm{H}_{2} 80 \%\right.$ and $\left.\mathrm{CO}_{2} 20 \%\right)$ at $20 \mathrm{~mL} / \mathrm{min}$. At the desired reaction time, an aliquot was sampled from the batch or continuous flow photoreactor and analyzed in an Agilent 490 MicroGC equipped with two channels and thermal conductivity detectors. One channel equipped with a MolSieve $5 \AA$ column allowed the analysis of $\mathrm{H}_{2}, \mathrm{O}_{2}, \mathrm{~N}_{2}$, and $\mathrm{CO}$, whereas the other channel equipped with a Pore Plot $\mathrm{Q}$ column allowed the determination of $\mathrm{CO}_{2}, \mathrm{CH}_{4}$, and short-chain hydrocarbons. Quantification was performed using calibration plots employing commercially available gas mixtures.

\subsubsection{Photocurrent measurements}

Photocurrent measurements were carried out in a standard three-electrode electrochemical cell using a transparent fluoride-doped tin oxide (FTO)-coated glass substrate on which a thin layer of the corresponding Ru@MIL-125(Ti)- $\mathrm{NH}_{2}$ sample was deposited (FTO-Ru@MIL-125(Ti)-NH2). The FTO-Ru@MIL-125(Ti)- $\mathrm{NH}_{2}$ films were employed as working electrode, a platinum wire as the counter electrode and a 
standard calomel electrode (SCE) as the reference electrode. The oxygen present in the cell was removed purging the electrolyte with Ar for $20 \mathrm{~min}$. The photocurrent was measured under dark and under illumination (Xe lamp equipped with a upon polarizing the working electrode at potentials from 1.4 to $0.2 \mathrm{~V}$. Irradiation was performed using an optical fibber connected to a 150W Xe lamp equipped with an AM 1.5G type filter

\subsubsection{Fluorescence experiments}

Fluorescence spectroscopy was carried out with JASCO FP-8500 spectrofluorometer. Measurements took place after adjusting absorption of the samples to 0.35 a.u. at $340 \mathrm{~nm}$ (the excitation wavelength) in acetonitrile after purging the quartz cuvette with argon to remove oxygen from suspension. Relative quantum efficiency was calculated dividing fluorescence curve area of ruthenium-supported MIL-125(Ti)- $\mathrm{NH}_{2}$ by MIL-125(Ti)- $\mathrm{NH}_{2}$.

\subsubsection{Results and discussion}

In this study we aimed to develop a highly active photocatalyst for solar-driven $\mathrm{CO}_{2}$ methanation based on the benchmark MIL-125(Ti)- $\mathrm{NH}_{2}$ solid supported ruthenium NPs. For this, a series of MIL-125(Ti)- $\mathrm{NH}_{2}$ with increasing loadings of $\mathrm{RuO}_{x} \mathrm{NPs}$ were prepared and characterized. The photocatalytic activity of the MOF-based photocatalysts was then tested for $\mathrm{CO}_{2}$ methanation under batch and continuous flow operations under simulated sunlight and visible light irradiation, respectively. The stability and reusability of the most active photocatalyst were assessed under both batch and continuous flow operations. Additional photocatalytic experiments and spectroscopic measurements were performed to gain an insight into the photocatalytic methanation mechanism with the most active sample.

\subsubsection{Photocatalyst preparation}

In the first step the benchmark MIL-125(Ti)- $\mathrm{NH}_{2}$ was prepared according previous reports, ${ }^{[22]}$ after which a series of ruthenium NP co-catalysts at different 
loadings supported MIL-125(Ti)- $\mathrm{NH}_{2}$ were prepared by the photodeposition method. The XRD patterns of MIL-125(Ti)- $\mathrm{NH}_{2}$ solid with or without ruthenium NPs matched well with its simulated diffraction pattern, while the PXRD of MIL-125(Ti)- $\mathrm{NH}_{2}$ supported ruthenium NPs also presented a diffraction peak characteristic of the $\mathrm{RuO}_{2}(110)$ facet (Figure 1).

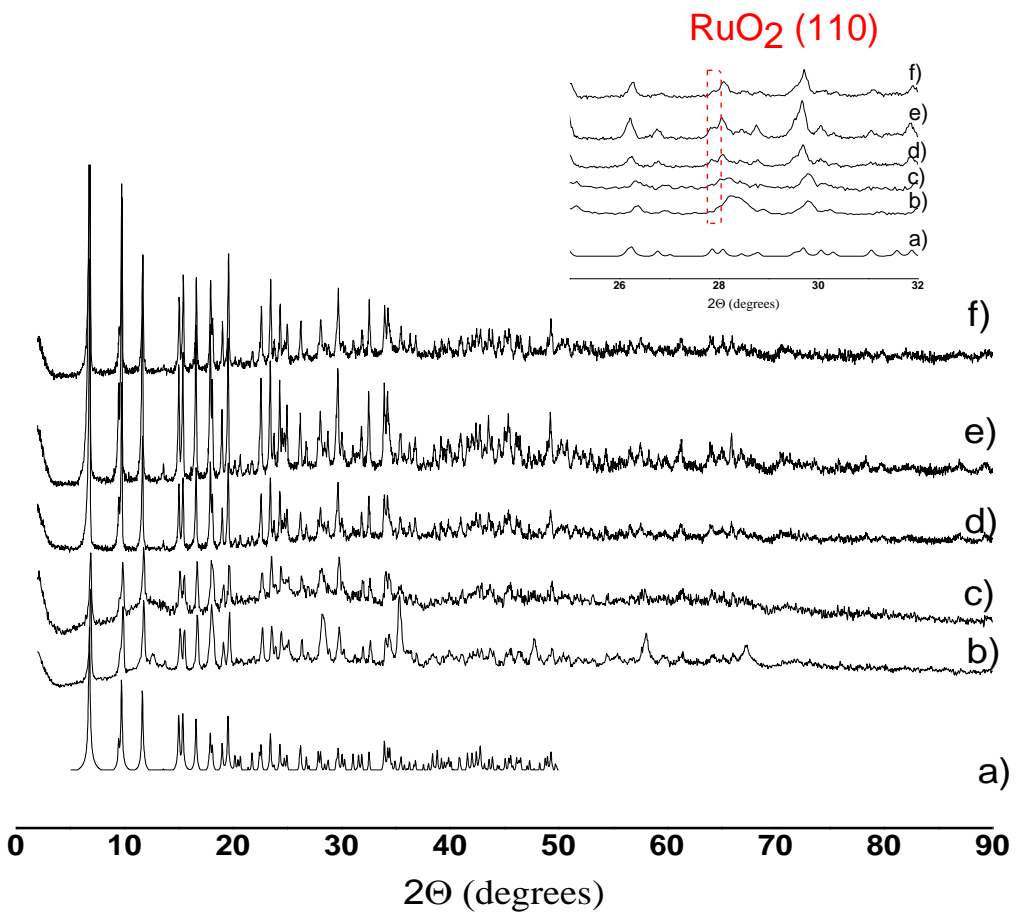

Figure 1. PXRD of simulated MIL-125(Ti)- $\mathrm{NH}_{2}$ (a), pristine MIL-125(Ti)- $\mathrm{NH}_{2}$ (b), $\mathrm{RuO}_{\mathrm{x}}(1 \mathrm{wt} \%) \mathrm{MIL}-125(\mathrm{Ti})-\mathrm{NH}_{2} \quad$ (c), $\mathrm{RuO}_{\mathrm{x}}(2 \quad \mathrm{wt} \%) \mathrm{MIL}-125(\mathrm{Ti})-\mathrm{NH}_{2} \quad$ (d), $\mathrm{RuO}_{\mathrm{x}}(5$ wt\%)MIL-125(Ti)-NH $(\mathrm{e}), \mathrm{RuO}_{x}(10 \mathrm{wt} \%) \mathrm{MIL}-125(\mathrm{Ti})-\mathrm{NH}_{2}$ (f). The inset shows a zoom-in of the characteristic $\mathrm{RuO}_{2}(110)$ facet.

HRSEM images of pristine MIL-125(Ti)- $\mathrm{NH}_{2}$ sample revealed its characteristic circular plate-like morphology was maintained after loading the $\mathrm{RuO}_{x}$ NPs in the MOF (Figure 2a,b and S2). EDX analyses of the samples confirmed that the initial amounts of ruthenium (from 1 to $10 \mathrm{wt} \%$ ) were photodeposited within the 
Chapter 7. Toward solar-driven photocatalytic $\mathrm{CO}_{2}$ methanation under continuous flow operation using benchmark MIL-125(Ti)- $\mathrm{NH}_{2}$ supported ruthenium nanoparticles

MIL-125(Ti)- $\mathrm{NH}_{2}$ solids. Attempts to further increase the ruthenium loading by using an initial amount of 20 wt\% produced a sample with a content of 11.5 wt\% as revealed by EDX, so that we focused on the MIL-125(Ti)- $\mathrm{NH}_{2}$ samples with ruthenium loadings from 1 to $10 \mathrm{wt} \%$. The EDX elemental map of the series of the samples revealed good dispersion of ruthenium in the MIL-125(Ti)- $\mathrm{NH}_{2}$ support (Figure $2 \mathrm{c}$ and S3-S7).

a)
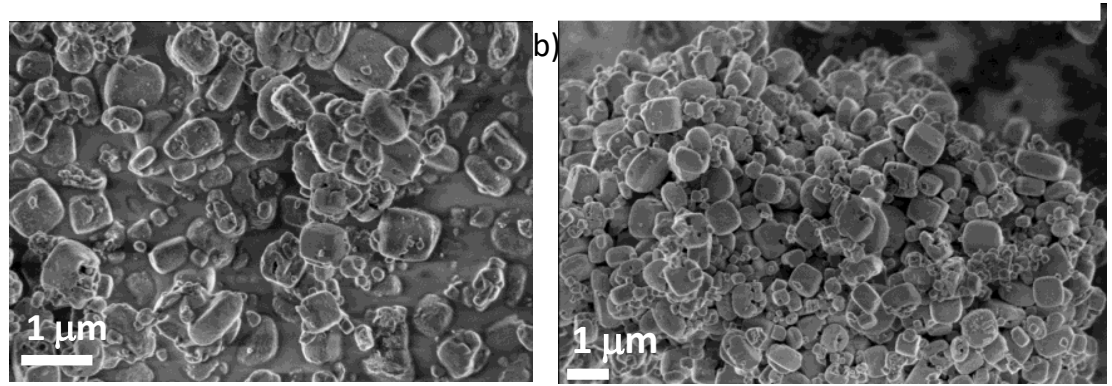

c)
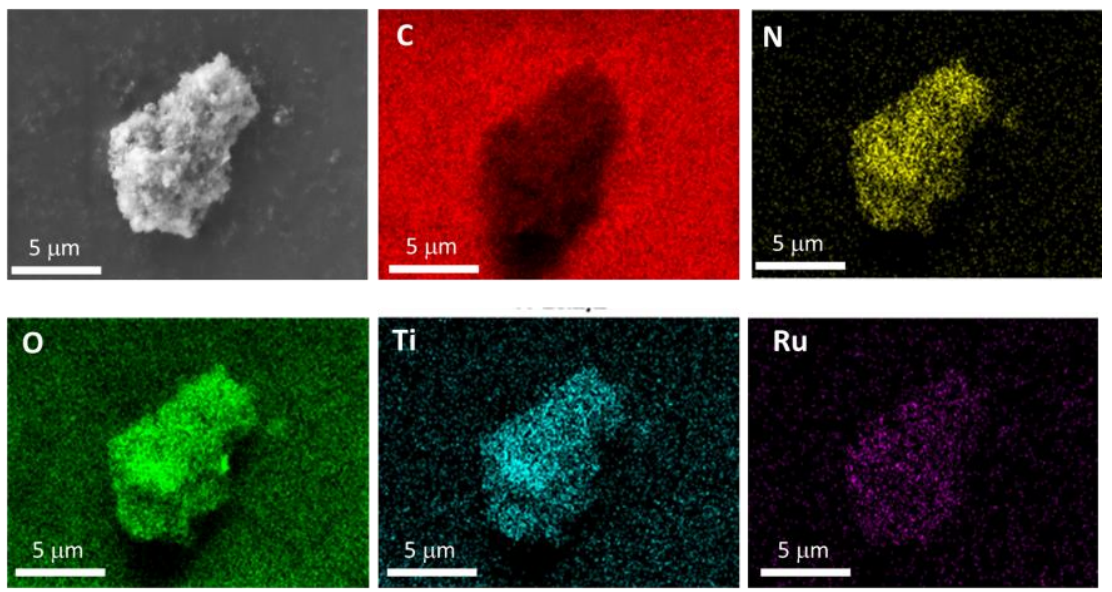

Figure

2.

a) HRSEM

image of

MIL-125(Ti)- $\mathrm{NH}_{2}$

(a) and $\mathrm{RuO}_{x}(10 w t \%) @ M I L-125(\mathrm{Ti})-\mathrm{NH}_{2}$ $\mathrm{RuO}_{x}(10 w \mathrm{t} \%) @ M I L-125(\mathrm{Ti})-\mathrm{NH}_{2}$.

(b). c) SEM image and EDX mapping of

Interestingly, DF-STEM measurements of the $\mathrm{RuO}_{x}$ loaded MIL-125(Ti)- $\mathrm{NH}_{2}$ samples estimated a similar small ruthenium particle size distribution in all the samples (Figure 3). In these cases, the EDX detector coupled to DF-STEM was used 
Chapter 7. Toward solar-driven photocatalytic $\mathrm{CO}_{2}$ methanation under continuous flow operation using benchmark MIL-125(Ti)- $\mathrm{NH}_{2}$ supported ruthenium nanoparticles

to confirm the presence of ruthenium in the NPs dispersed on the MIL-125(Ti)- $\mathrm{NH}_{2}$ support (Figures S8 to S11).
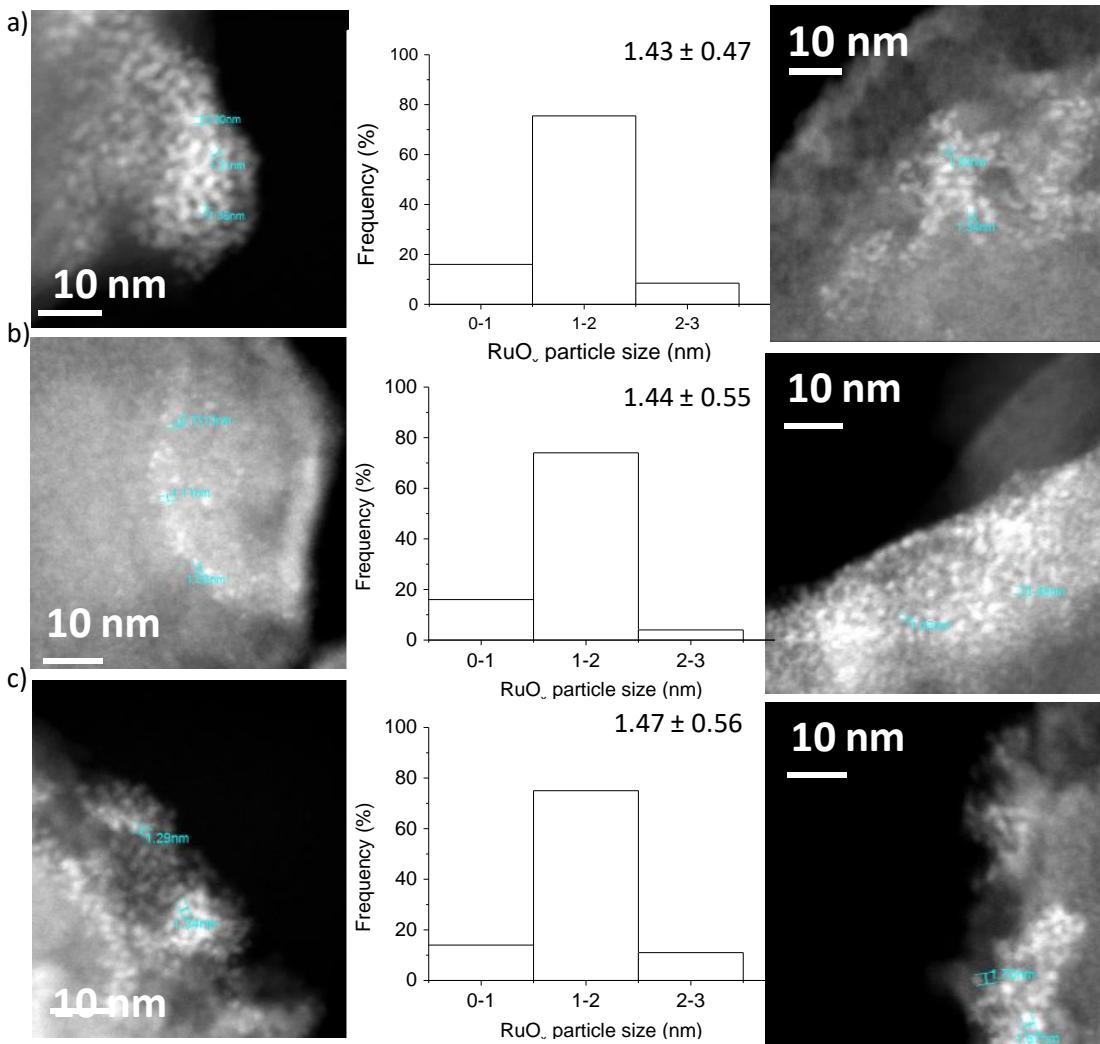

$10 \mathrm{~nm}$
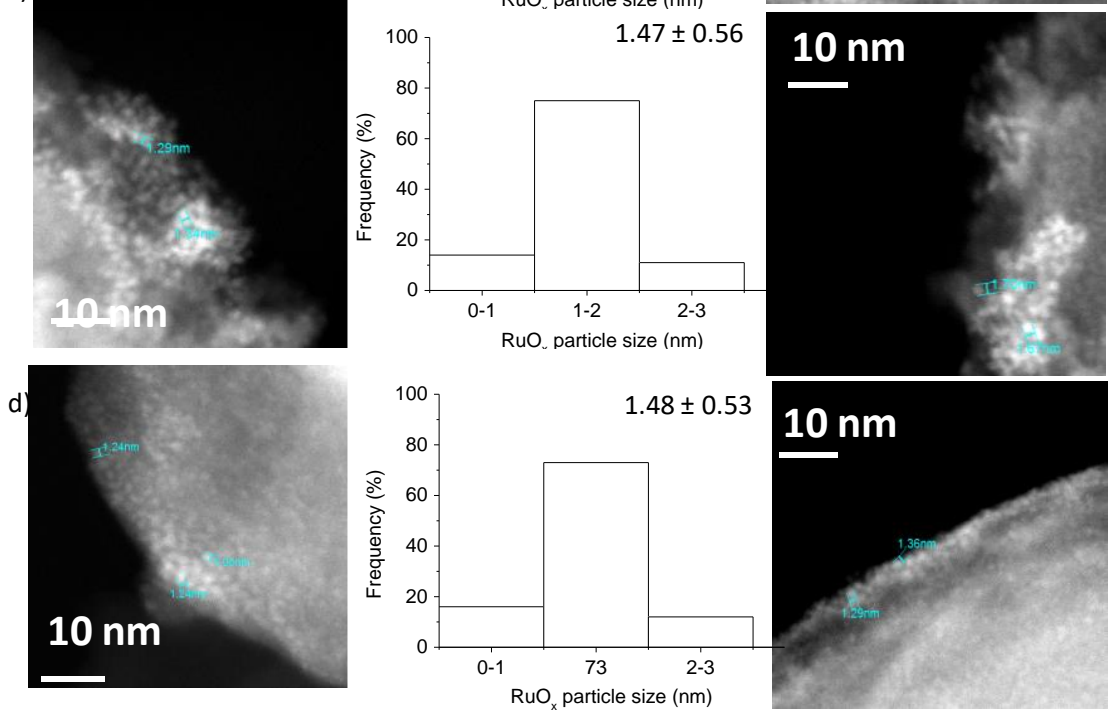

Figure 3. Representative DF-STEM images and ruthenium particle size distribution for $\mathrm{RuO}_{\mathrm{x}}(1 \mathrm{wt} \%) @ \mathrm{MIL}-125(\mathrm{Ti})-\mathrm{NH}_{2}$ (a), $\mathrm{RuO}_{\mathrm{x}}(2 \mathrm{wt} \%) @ \mathrm{MIL}-125(\mathrm{Ti})-\mathrm{NH}_{2}$

(b), $\mathrm{RuO}_{x}(5 \mathrm{wt} \%) @ \mathrm{MIL}-125(\mathrm{Ti})-\mathrm{NH}_{2}$ (c), RuO $\mathrm{R}_{\mathrm{x}}(10 \mathrm{wt} \%) @ \mathrm{MIL}-125(\mathrm{Ti})-\mathrm{NH}_{2}$ (d). Average ruthenium particle size and standard deviation values are also indicated. 
The porosity of the samples was evaluated by isothermal nitrogen adsorption experiments (Figure S12). The pristine MIL-125(Ti)- $\mathrm{NH}_{2}$ had a BET surface area and pore volume of $1214 \mathrm{~m}^{2} / \mathrm{g}$ and $0.57 \mathrm{~cm}^{3} / \mathrm{g}$, in good agreement with previous reports. ${ }^{[18]}$ As expected, $\mathrm{RuO}_{\mathrm{x}}$ deposition within the MOF network at increasing loadings gradually reduced both BET and pore volume. It should be noted that the $\mathrm{RuO}_{\mathrm{x}} / \mathrm{MIL}-125(\mathrm{Ti})-\mathrm{NH}_{2}$ samples with $\mathrm{RuO}_{\mathrm{x}}$ loadings of $1\left(1041 \mathrm{~m}^{2} / \mathrm{g} ; 0.47 \mathrm{~cm}^{3} / \mathrm{g}\right), 2$ $\left(1021 \mathrm{~m}^{2} / \mathrm{g} ; 0.47 \mathrm{~cm}^{3} / \mathrm{g}\right), 5\left(1000 \mathrm{~m}^{2} / \mathrm{g} ; 0.46 \mathrm{~cm}^{3} / \mathrm{g}\right)$, and even those at $10\left(770 \mathrm{~m}^{2} / \mathrm{g}\right.$; $0.33 \mathrm{~cm}^{3} / \mathrm{g}$ ) wt\% loading still had relatively high porosity.

The optical absorption properties of the MIL-125(Ti)- $\mathrm{NH}_{2}$ samples under study with or without ruthenium NPs were inspected by UV-Vis diffuse reflectance spectroscopy (Figure 4a). The UV-Vis MIL-125(Ti)- $\mathrm{NH}_{2}$ spectrum was characterized by one band centred at $280 \mathrm{~nm}$ associated with the $\mathrm{O}$ to Ti ligand-to-metal charge transfer, together with a band centred at $380 \mathrm{~nm}$ attributable to the charge transfer from the 2-aminoterephthalate ligand to the $\mathrm{Ti}_{8} \mathrm{O}_{8}(\mathrm{OH})_{4}$ cluster. ${ }^{[25]}$ The band gap of pristine MIL-125(Ti)- $\mathrm{NH}_{2}$ estimated from the Tauc plot was $2.74 \mathrm{eV}$, in good agreement with previous reports. ${ }^{[17,18]}$ The deposition of $\mathrm{RuO}_{\mathrm{x}} \mathrm{NPs}$ within the MIL-125(Ti)- $\mathrm{NH}_{2}$ material increased the absorption band beyond $800 \mathrm{~nm}$ with respect to pristine $\mathrm{MIL}-125(\mathrm{Ti})-\mathrm{NH}_{2}$ solid due to the $\mathrm{RuO}_{x}$ plasmon band (Figure 4b). ${ }^{[26]}$ 

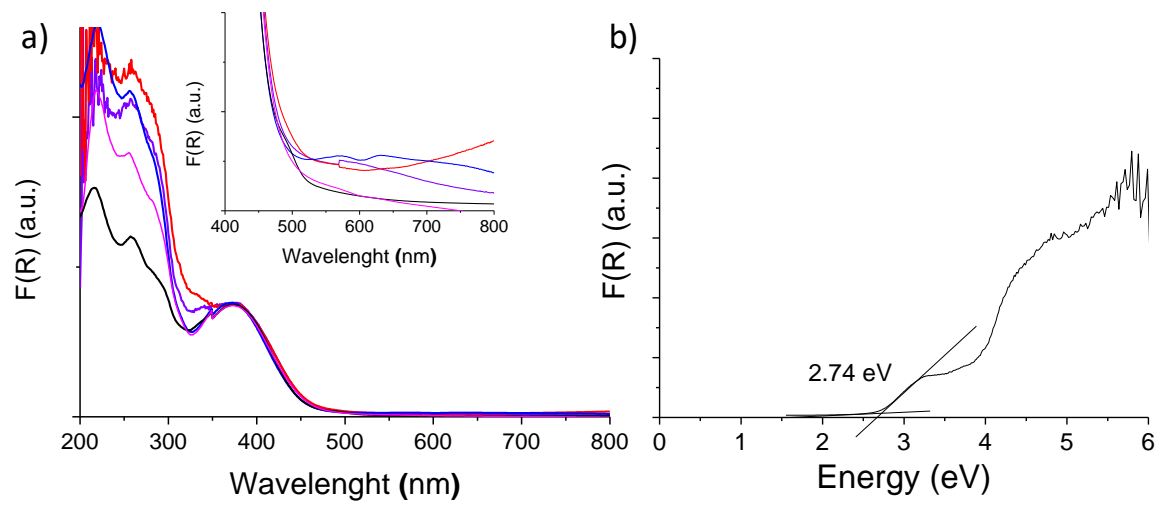

Figure 4. a) Diffuse reflectance UV-Vis spectra of $\mathrm{MIL}-125(\mathrm{Ti})-\mathrm{NH}_{2}$ (black line), $\mathrm{RuO}_{x}(1 \mathrm{wt} \%) \mathrm{MIL}--125(\mathrm{Ti})-\mathrm{NH}_{2}$ (pink line), $\mathrm{RuO}_{x}(2 \mathrm{wt} \%) \mathrm{MIL}-125(\mathrm{Ti})-\mathrm{NH}_{2}$ (purple line), $\mathrm{RuO}_{x}(5 \mathrm{wt} \%) \mathrm{MIL}-125(\mathrm{Ti})-\mathrm{NH}_{2}$ (blue line), RuOx(10 wt\%)MIL-125(Ti)- $\mathrm{NH}_{2}$ (red line). The inset shows a zoom-in of the region between 400 and $800 \mathrm{~nm}$. b) Tauc plot of pristine MIL-125(Ti)- $\mathrm{NH}_{2}$ sample.

XPS was also employed for the characterization of the most active sample of the series during photocatalytic $\mathrm{CO}_{2}$ reduction, which was RuOx@(10wt\%)@MIL--125(Ti)-NH2 (Figure 5). C1s XPS confirmed the presence of aromatic carbons $(284.4 \mathrm{eV})$ together with the characteristic signals of carbon atoms bonded to the amino group ( $\mathrm{C}-\mathrm{N}, 285.9 \mathrm{eV}$ ) and in the carboxylate functional groups $(289 \mathrm{eV}){ }^{[18]}$ The broad O1s XPS band was centred at about $532 \mathrm{eV}$ due to the presence of oxygen atoms in the carboxylate groups together with the Ti-O and Ru$\mathrm{O}$ bonds $(<531 \mathrm{eV})$. The $\mathrm{Ti}^{2 \mathrm{p}}$ XPS spectrum is characteristic of the presence of $\mathrm{Ti}^{4+}$ ions present in the Ti-oxo cluster in the MOF. The $R u 3 d_{3 / 2}$ XPS signal partially overlapped the C1s. The band centred at about $281.7 \mathrm{eV}$ can be attributed to the presence of $\mathrm{RuO}_{2}$ and hydrated ruthenium species. ${ }^{[27,28]}$ The other expected $\mathrm{Ru} 3 \mathrm{~d}_{3 / 2}$ shifted $4.17 \mathrm{eV}$, however it overlapped the $\mathrm{C}-\mathrm{N}$ band. ${ }^{[28,29]}$ Previous reports have shown that the N1s XPS of MIL-125(Ti)-NH2 is composed of a main band centred at about $399 \mathrm{eV}$ and another smaller band at $401 \mathrm{eV}$ due to the presence of free and partially protonated amino groups, respectively. ${ }^{[18]}$ The N1s XPS of 
RuOx@(10wt\%)@MIL-125(Ti)-NH2 sample showed similar XPS bands to the MOF pattern but shifted about $2 \mathrm{eV}$ to higher binding energies. This observation can be attributed to a strong interaction between the $\mathrm{RuO}_{x} \mathrm{NPs}$ and the amino groups present in the MOF network. This strong interaction between $\mathrm{RuO}_{\mathrm{x}} \mathrm{NPs}$ and the amino groups present in the MOF can be at least partially responsible for the small $\mathrm{RuO}_{\mathrm{x}}$ particle size distribution obtained in all the samples, even at loadings as high as $10 \mathrm{wt} \%$. It should be noted that in the field of supported NPs the particle size distribution of the NPs is generally seen to increase with the metal loading in a heterogeneous support, due to the coverage of anchoring sites in the support. ${ }^{[30,31]}$ Other examples have also shown that the presence of amino groups in MOFs organic ligands favour the deposition of small MNPs and avoid metal NP agglomeration during catalytic processes. ${ }^{[32]}$
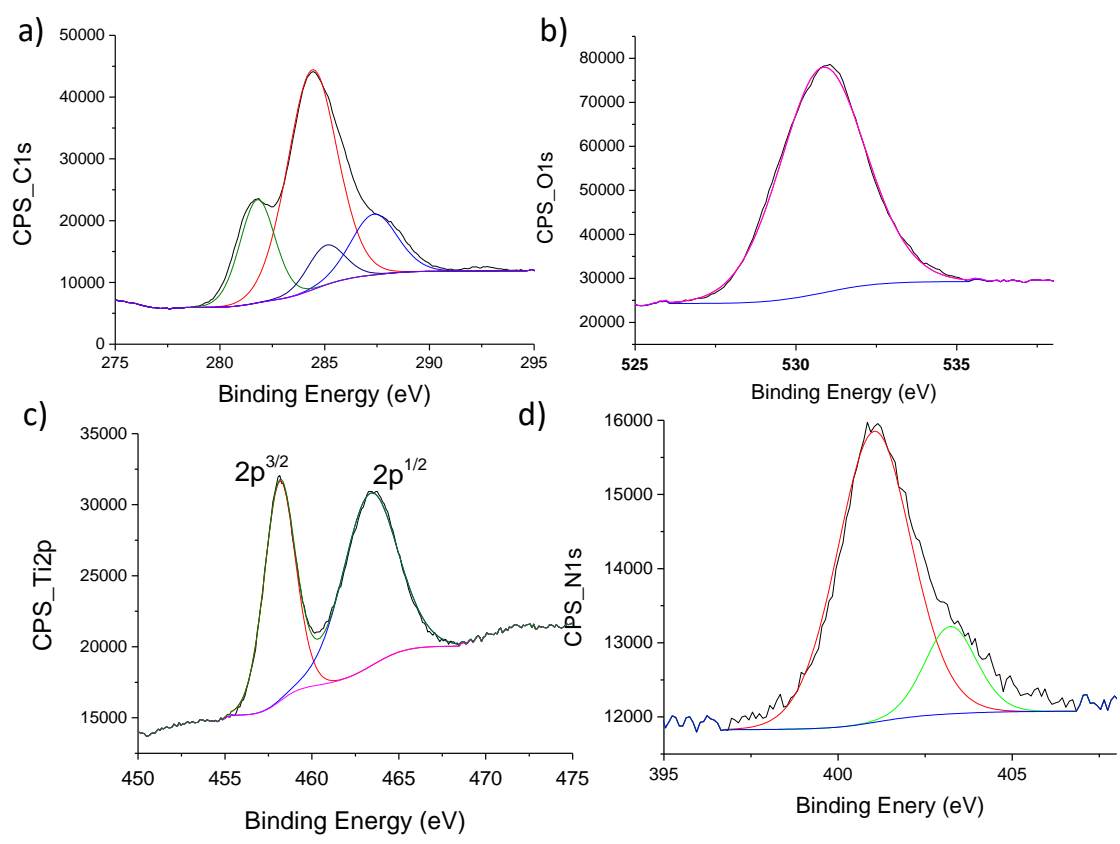

Figure 5. XPS C1s+Ru3d (a), O1s (b), Ti2p (c) and N1s (d) of the RuO ${ }_{x}(10$ wt\%)@MIL-125(Ti)-NH solid. 


\subsection{Photocatalytic activity}

\subsubsection{Photocatalytic $\mathrm{CO}_{2}$ methanation under batch conditions}

The photocatalytic activity of MIL-125(Ti)- $\mathrm{NH}_{2}$ supported $\mathrm{RuO}_{x} \mathrm{NPs}$ at different metal loadings was initially evaluated for $\mathrm{CO}_{2}$ methanation at $200{ }^{\circ} \mathrm{C}$ under simulated sunlight irradiation. Control experiments showed that the reaction did not occur in the absence of a photocatalyst under the reaction conditions studied. The use of MIL-125(Ti)- $\mathrm{NH}_{2}$ as photocatalyst under simulated sunlight resulted in low $\mathrm{CO}_{2}$ methanation ( $\left.15 \mu \mathrm{mol} \mathrm{g}{ }^{-1}\right)$. RuO $\times$ NPs supported on MIL-125(Ti)- $\mathrm{NH}_{2}$ promoted photocatalytic $\mathrm{CO}_{2}$ methanation under simulated sunlight irradiation (Figure 5a). Using the same amount of photocatalyst, there was a positive linear relationship between increasing $\mathrm{RuO}_{x}$ content in $\mathrm{MIL}-125(\mathrm{Ti})-\mathrm{NH}_{2}$ and $\mathrm{CH}_{4}$ production in terms of $\mu \mathrm{mol} \mathrm{g}{ }^{-1}$ catalyst (Figure 5b). The RuOx(10 wt\%)@MIL125(Ti)- $\mathrm{NH}_{2}$ photocatalyst with the highest ruthenium content had the highest photocatalytic activity. In contrast, when photogenerated methane production was given in relation to the ruthenium content ( $\mu \mathrm{mol} \mathrm{CH} \mathrm{g}^{-1}$ _ruthenium), the $\mathrm{RuO}_{\mathrm{x}}\left(1 \mathrm{wt} \%\right.$ )@MIL125(Ti)- $\mathrm{NH}_{2}$ sample having the lowest ruthenium amount was the most active (Figure $6 \mathrm{~b}$ inset).

These activity data indicate that although the activity increase with the $\mathrm{RuO}_{\mathrm{x}}$ loading, the intrinsic activity of each Ru atom decreases. This is generally attributed to a decrease in the dispersion (percentage of Ru atoms exposed on the surface) as loading increases. Metal dispersion undergoes the largest changes when the nanoparticle dimension is of a few nanometers of lesser. Therefore, not surprisingly the other three samples with ruthenium loadings from 2 to $10 \mathrm{wt} \%$ showed a similar photocatalytic methane production, referred to as $\mu \mathrm{mol} \mathrm{CH}_{4} \mathrm{~g}^{-1}$ ruthenium. Regardless of these activity data, since the main purpose of the present study was to develop a solar-driven photocatalyst based on MIL-125(Ti)- $\mathrm{NH}_{2}$ loaded with ruthenium NPs for photocatalytic $\mathrm{CO}_{2}$ methanation under continuous flow operations with the highest possible $\mathrm{CO}_{2}$ conversion, sample $\mathrm{RuO}_{\times}(10$ wt\%)@MIL125(Ti)-NH2 was selected for further studies. Attempts were 
made to use $\mathrm{RuO}_{x}(1 \mathrm{wt} \%) / \mathrm{MIL}-125(\mathrm{Ti})-\mathrm{NH}_{2}$ as photocatalyst in continuous flow, however no methane was produced in these reaction conditions.

This can be attributed to the relatively low photoactivity of the sample in terms of methane production per gram of catalyst. $\mathrm{RuO}_{x}(10 \mathrm{wt} \%) / \mathrm{MIL}-125(\mathrm{Ti})-\mathrm{NH}_{2}$ was therefore selected as the optimized photocatalyst for both batch and flow operations. A control experiment using the RuO ${ }_{x}\left(10\right.$ wt\%)@MIL125(Ti)- $\mathrm{NH}_{2}$ solid catalyst in the presence of $\mathrm{H}_{2}$ at $200{ }^{\circ} \mathrm{C}$ gave a methane production $\left(1.1 \mathrm{mmol} \mathrm{g}{ }^{-1}\right.$ at $22 \mathrm{~h}$ ) of about $10 \%$ of the same experiment under simulated sunlight irradiation. The fact that the catalyst showed some activity in the dark was not unexpected, since, as commented above, ruthenium-based NPs are some of the most active species in $\mathrm{CO}_{2}$ hydrogenation. ${ }^{[23]}$
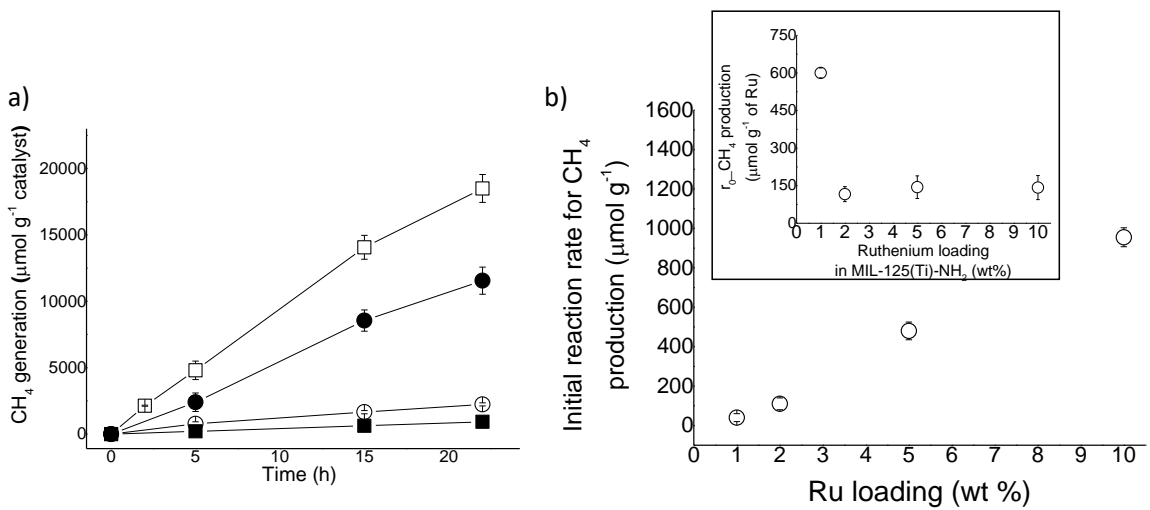

Figure 6. a) Photocatalytic $\mathrm{CH}_{4}$ production using different loadings of $\mathrm{RuO}_{x} \mathrm{NPs}$ supported on MIL-125(Ti)- $\mathrm{NH}_{2}$ under simulated sunlight irradiation. Legend: $1(\square), 2(\bullet), 5(0)$ and 10 (匹) wt\%. b) Influence of simulated sunlight irradiation on $\mathrm{CO}_{2}$ photoreduction to $\mathrm{CH}_{4}$ using $\mathrm{RuO}_{\mathrm{x}}\left(10\right.$ wt\%)@MIL-125(Ti)-NH $\mathrm{NH}_{2}$. Reaction conditions: Photocatalyst (15 mg), $\mathrm{P}_{\mathrm{H} 2}=1.05$ bar, $\mathrm{P}_{\mathrm{CO} 2}=0.25$ bar, reaction temperature $\left(200^{\circ} \mathrm{C}\right.$ ), simulated sunlight irradiation (Xe lamp of 150 W equipped with an AM $1.5 \mathrm{G}$ type filter).

One of the significant features of $\mathrm{RuO}_{\mathrm{x}}(10 \mathrm{wt} \%) @ \mathrm{MIL}-125(\mathrm{Ti})-\mathrm{NH}_{2}$ as photocatalyst is its high selectivity towards reducing $\mathrm{CO}_{2}$ to $\mathrm{CH}_{4}$ (Figure 7). Other possible reaction products such as $\mathrm{CO}$ of higher chain hydrocarbons have not been 
observed under the present reaction conditions. Some studies have pointed out that selective $\mathrm{CO}_{2}$ hydrogenation to $\mathrm{CH}_{4}$ or $\mathrm{CO}$ can be explained by the adsorption strength of $\mathrm{CO}$ as reaction intermediate close to the hydrogenation active centres of the photocatalyst. ${ }^{[33]}$ Strong adsorption of $\mathrm{CO}$ to the active centres further reduces this intermediate to $\mathrm{CO}$, while $\mathrm{CO}$ is the main reaction product when this molecule has a low affinity for binding to the active centres. A series of in situ FT-IR measurements were performed using $\mathrm{CO}$ as probe molecule to evaluate possible reasons for the high selectivity of $\mathrm{RuO}_{x}(10 \mathrm{wt} \%) @ \mathrm{MIL}-125(\mathrm{Ti})-\mathrm{NH}_{2}$ as photocatalyst for methane. Figure 7 shows the in situ CO adsorption on solid MIL-125(Ti)-NH2. The band appearing at about $2138 \mathrm{~cm}^{-1}$ can be assigned to physisorbed $\mathrm{CO}$ within the MOF that disappears upon evacuation. ${ }^{[34,35]}$ This observation was not unexpected, due to the absence of coordinatively unsaturated $\mathrm{Ti}^{4+}$ ions in the MIL-125(Ti)- $\mathrm{NH}_{2}$ material. Using $\mathrm{RuO}_{\times}(10 \mathrm{wt} \%) @ \mathrm{MIL}-125(\mathrm{Ti})-\mathrm{NH}_{2}$ material also exhibits a broad band centred at $1972 \mathrm{~cm}^{-1}$ together with a shoulder at $2058 \mathrm{~cm}^{-1}$ characteristic of quimisorbed $\mathrm{CO}$ into $\mathrm{RuO}_{\mathrm{x}}{ }^{\left[{ }^{36]}\right.}$ Due to $\mathrm{CO}$ quimisorption into $\mathrm{RuO}_{\mathrm{x}}$ evacuation under vacuum does not significantly reduce intensity. These results are in agreement with the ability of $\mathrm{RuO}_{\mathrm{x}}(10 \mathrm{wt} \%) @ \mathrm{MIL}-125(\mathrm{Ti})-\mathrm{NH}_{2}$ as photocatalyst for selective $\mathrm{CO}_{2}$ methanation.
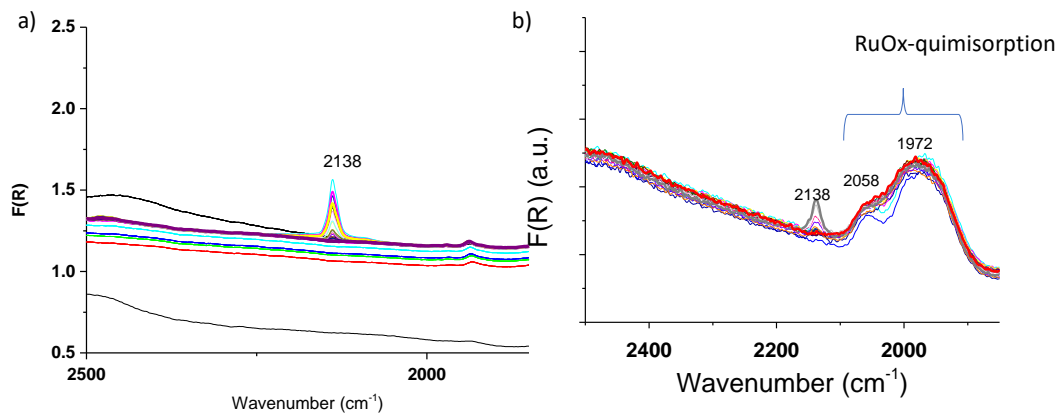

Figure 7. FT-IR spectra of $\mathrm{CO}$ adsorbed in MIL-125(Ti)- $\mathrm{NH}_{2}$ (a) or $\mathrm{RuO}_{\mathrm{x}}(10 \mathrm{wt} \%) @ \mathrm{MIL}-125(\mathrm{Ti})-\mathrm{NH}_{2}$ (b) at $-155^{\circ} \mathrm{C}$. 
To confirm that $\mathrm{RuO}_{\mathrm{x}}(10$ wt\%)@MIL-125(Ti)-NH2 could photocatalytically convert $\mathrm{CO}_{2}$ to $\mathrm{CH}_{4}$ (Eq.1), some experiments were performed using isotopically labelled ${ }^{13} \mathrm{C}^{18} \mathrm{O}_{2}$ during the photocatalytic reaction. Analysis of the gas phase by mass spectrometry after $22 \mathrm{~h}$ of photocatalytic reaction revealed the formation of ${ }^{13} \mathrm{CH}_{4}$ (m/z 17) together with $\mathrm{H}_{2}{ }^{18} \mathrm{O}(\mathrm{m} / \mathrm{z} 20)$ (Figure S13). The simultaneous presence of ${ }^{13} \mathrm{CH}_{4}$ and $\mathrm{H}_{2}{ }^{18} \mathrm{O}$ was attributed to the system's low separation efficiency for these two compounds. It should be noted that ${ }^{13} \mathrm{CH}_{4}$ and $\mathrm{H}_{2}{ }^{18} \mathrm{O}$ were not present in the gas phase of the reaction system at time 0 before irradiation.

$$
\mathrm{CO}_{2}+4 \mathrm{H}_{2} \rightarrow \mathrm{CH}_{4}+2 \mathrm{H}_{2} \mathrm{O}
$$

\section{Equation 1}

Photocatalytic $\mathrm{CO}_{2}$ methanation using solid RuO $\left(10\right.$ wt\%)@MIL125(Ti)- $\mathrm{NH}_{2}$ can even happen at relatively low temperatures $\left(125^{\circ} \mathrm{C} ; 150 \mu \mathrm{mol} \mathrm{g}-1\right.$ at $22 \mathrm{~h}$ ) (Figure 8). To put this value in context, some of us previously reported $\mathrm{Cu}_{2} \mathrm{O}$ (1 wt\%) supported on a $\mathrm{Zn}$-based MOF for $\mathrm{CO}_{2}$ methanation under UV-Vis irradiation, with a production of $45 \mu \mathrm{mol} \mathrm{g}{ }^{-1}$ at $215{ }^{\circ} \mathrm{C}$ under UV-Vis irradiation after $24 \mathrm{~h}^{37}$ In other example, $\mathrm{RuO}_{x}$ NPs (1 wt\%) supported on a Ti-MOF namely MIP-208 was used as photocatalyst for $\mathrm{CO}_{2}$ methanation at $200{ }^{\circ} \mathrm{C}$ under simulated sunlight irradiation resulting in a production of about $700 \mu \mathrm{mol} \mathrm{g}{ }^{-1}$ after $22 \mathrm{~h}$ reaction. ${ }^{[22]}$ In fact, the activity of $\mathrm{RuO}_{x}(1 \mathrm{wt} \%) @ M I L 125(\mathrm{Ti})-\mathrm{NH}_{2} \quad\left(924 \mu \mathrm{mol} \mathrm{g}^{-1}\right)$ compares favorably respect to this $\mathrm{RuO}_{\mathrm{x}}(1 \mathrm{wt} \%) @ \mathrm{MIP}-208$ under similar reaction conditions. It is important to note that the Sabatier reaction for $\mathrm{CO}_{2}$ hydrogenation to $\mathrm{CH}_{4}$ catalyzed by transition metal-based catalysts typically occurs at high temperatures $\left(300-400{ }^{\circ} \mathrm{C}\right)$, so that the possibility of developing solar-driven heterogeneous photocatalytic systems for $\mathrm{CO}_{2}$ methanation at relatively low reaction temperatures is important as regards both technology and economy. Also, photocatalytic activity using the most active $\mathrm{RuO}_{\mathrm{x}}(10 \mathrm{wt} \%) @ \mathrm{MIL125}(\mathrm{Ti})-\mathrm{NH}_{2}$ sample under constant simulated sunlight irradiation increased exponentially with temperature, according to the Arrhenius 
equation. The apparent activation energy for $\mathrm{CO}_{2}$ methanation by $\mathrm{RuO}_{\mathrm{x}}(10 \mathrm{wt} \%) @ \mathrm{MIL125}(\mathrm{Ti})-\mathrm{NH}_{2}$ was estimated to be $68.8 \mathrm{~kJ} \mathrm{~mol}^{-1}$.

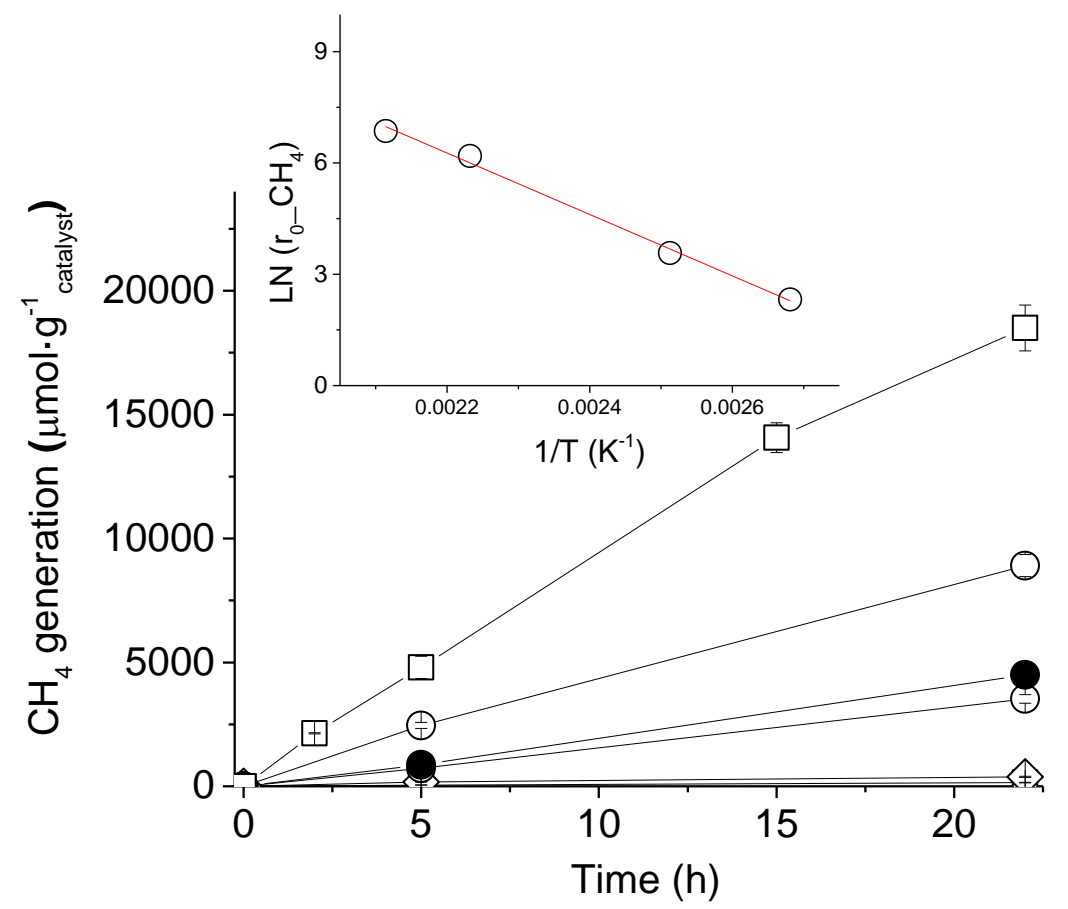

Figure 8. a) Photocatalytic $\mathrm{CO}_{2}$ methanation using $\mathrm{RuO}_{\mathrm{x}}(1 \mathrm{wt} \%) @ \mathrm{MIL}-125(\mathrm{Ti})-\mathrm{NH}_{2}$ as a function of the reaction temperature. Legend: $200{ }^{\circ} \mathrm{C}(\square), 175^{\circ} \mathrm{C}(\square), 165^{\circ} \mathrm{C}(0), 125^{\circ} \mathrm{C}(\Delta)$; $200{ }^{\circ} \mathrm{C}$ in the presence of $\mathrm{H}_{2} \mathrm{O}(60 \mu \mathrm{L})$. The inset shows the Arrhenius plot of $\mathrm{CH}_{4}$ generation as a function of the reaction temperature. Reaction conditions: Photocatalyst (15 mg), $\mathrm{P}_{\mathrm{H} 2}=1.05$ bar, $\mathrm{P}_{\mathrm{CO} 2}=0.25$ bar, simulated sunlight irradiation (Xe lamp of $150 \mathrm{~W}$ equipped with an AM 1.5G type filter), reaction temperature as indicated.

MIL125(Ti)- $\mathrm{NH}_{2}$ as photocatalyst for $\mathrm{CO}_{2}$ methanation some control experiments were carried out. $\mathrm{H}_{2} \mathrm{O}$ was formed during photocatalytic $\mathrm{CO}_{2}$ hydrogenation reaction (Eq. 1) and could be adsorbed on the MOF and interact with the active sites in the photocatalyst. In order to validate this hypothesis, a control photocatalytic reaction was carried out using solid RuOx(10 wt\%)@MIL-125(Ti)-NH2 
at $200{ }^{\circ} \mathrm{C}$ under simulated sunlight irradiation in the presence of water. As the photocatalytic activity of RuOx(10wt\%)@MIL-125(Ti)-NH 2 (18.5 mmol g-1 after 22 h) is reduced ( $4.5 \mathrm{mmol} \mathrm{g}^{-1}$ after $22 \mathrm{~h}$ ) in the presence of water (60 $\mu \mathrm{L}$; Figure 8), it can be supposed that the photocatalytic activity of $\mathrm{RuO}_{\mathrm{x}}(1 \mathrm{wt} \%) @ \mathrm{MIL}-125(\mathrm{Ti})-\mathrm{NH}_{2}$ at reaction temperatures higher than $175^{\circ} \mathrm{C}$ should favour water desorption from the active centres of the photocatalysts and thus enhanced activity.

\subsubsection{Photocatalyst stability under batch and continuous flow operations}

Photocatalytic stability and reusability are basic requisites for the development of industrial processes. MOFs' main limitations include thermal, chemical and photochemical stability for use as photocatalysts and deserve especial attention. ${ }^{[14,17,38]}$ The photocatalytic activity and stability of $\mathrm{RuO}_{\mathrm{x}}(10 \mathrm{wt} \%) @ \mathrm{MIL}-125(\mathrm{Ti})-\mathrm{NH}_{2}$ were first evaluated under batch reaction conditions with simulated sunlight irradiation at $200{ }^{\circ} \mathrm{C}$. Figure 9 a shows that it retained its photocatalytic activity for $154 \mathrm{~h}$ during $\mathrm{CO}_{2}$ methanation in seven consecutive reuses. PXRD shows that the MOFs crystallinity was also retained during the reuse experiments (Figure 9b) and also that the initial $\mathrm{RuO}_{2} \mathrm{NPs}$ supported on the $\mathrm{RuO}_{x}(10 \mathrm{wt} \%) @ \mathrm{MIL}-125(\mathrm{Ti})-\mathrm{NH}_{2}$ photocatalyst were mostly transformed into $\mathrm{Ru}(0)$ NPs after the first use (Figure 9b). In a series of control experiments it was found that the one-time used $\mathrm{RuO}_{x}(10 \mathrm{wt} \%) @ \mathrm{MIL}-125(\mathrm{Ti})-\mathrm{NH}_{2}$ solid catalyst showed higher activity (3.5 mol g-1 after $22 \mathrm{~h}$ ) than the fresh RuOx(10 wt\%)@MIL-125(Ti)-NH2 material $\left(1.1 \mathrm{mmol} \mathrm{g}^{-1}\right.$ at $\left.22 \mathrm{~h}\right)$ to promote $\mathrm{CO}_{2}$ hydrogenation at $200{ }^{\circ} \mathrm{C}$ under dark reaction conditions. This observation attributed to the higher activity of reduced ruthenium species to promote the hydrogenation compared to the initial $\mathrm{RuO}_{\mathrm{x}} \mathrm{NPs}$ present in ambient-equilibrated materials. 


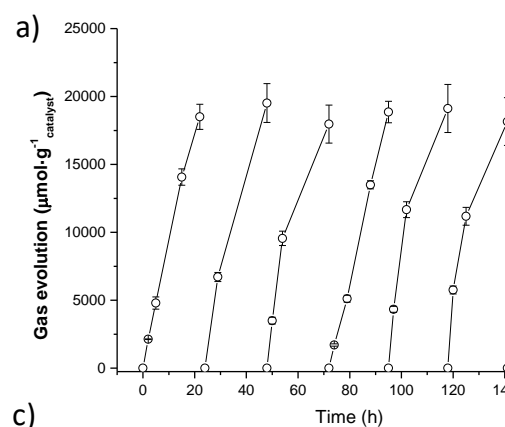

b)

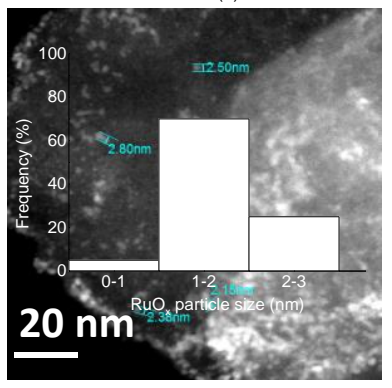

d)
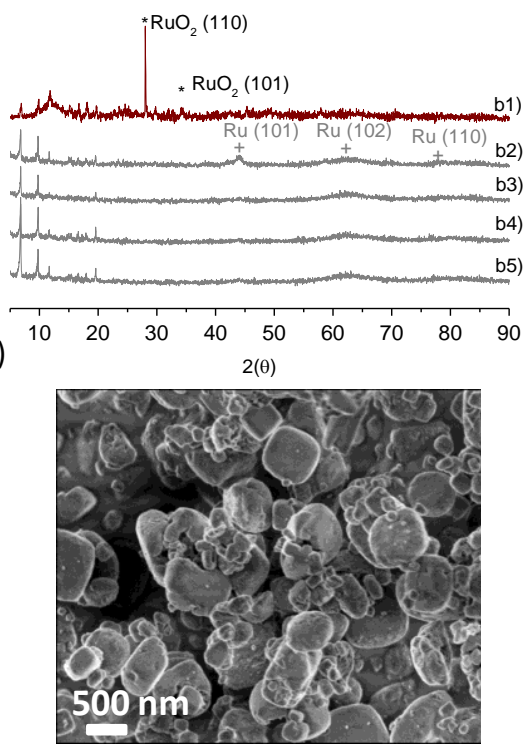

Figure 9. a) $\mathrm{RuO}_{x}(10 w t \%) @ M I L-125(\mathrm{Ti})-\mathrm{NH}_{2}$ reusability during $\mathrm{CO}_{2}$ methanation under batch operation. Reaction conditions: Photocatalyst $(15 \mathrm{mg}), \mathrm{P}_{\mathrm{H} 2}=1.05$ bar, $\mathrm{P}_{\mathrm{CO} 2}=0.25$ bar, reaction temperature $\left(200^{\circ} \mathrm{C}\right.$ ), simulated sunlight irradiation (Xe lamp of $150 \mathrm{~W}$ equipped with a filter cut-off of $\lambda>455 \mathrm{~nm}$ ). b) PXRD of the fresh- (a), one-time (b), four-times (c), six-times (d) and seven-times (e) used photocatalyst. c) DF-TEM image and $\mathrm{RuO}_{\mathrm{x}}$ particle size distribution of the photocatalyst after being used seven times. d) SEM image of the seven-times used photocatalyst.

TEM measurements of the $\mathrm{RuO}_{x}(10 \mathrm{wt} \%) @ \mathrm{MIL}-125(\mathrm{Ti})-\mathrm{NH}_{2}$ photocatalyst after seven cycles showed that the ruthenium particle size distribution had been maintained (Figure 9c and S14). The previously commented strong interaction observed by XPS between ruthenium NPs and the $\mathrm{NH}_{2}$ groups present in the $\mathrm{RuO}_{x}(10 w \mathrm{w} \%) @ \mathrm{MIL}-125(\mathrm{Ti})-\mathrm{NH}_{2}$ could at least be responsible for the negligible Ru NPs aggregation during the photocatalytic tests at $200{ }^{\circ} \mathrm{C}$, even after $154 \mathrm{~h}$. SEM measurements also confirmed that the sample retained its morphology after reuse (Figure 9d). RuOx(10 wt\%)@MIL-125(Ti)-NH2 had good overall stability after reuse. It should be noted, however, that some authors had previously reported that 
carboxylate-based MOFs suffer partial decarboxylation under long-term (weeks) UVVis irradiation at $200{ }^{\circ} \mathrm{C} .{ }^{[38]}$ In this work, a control experiment with $\mathrm{RuO}_{\mathrm{x}}(10 \mathrm{wt} \%) @ \mathrm{MIL}-125(\mathrm{Ti})-\mathrm{NH}_{2}$ in an argon atmosphere and simulated visible light irradiation for $22 \mathrm{~h}$ showed a partial decarboxylation of about $2.1 \mathrm{~mol} \%$ of the initial MOF.

As commented in the introduction, the industrial generation of solar fuels requires the development of continuous flow processes. Due to the high photocatalytic activity and good stability of RuOx(10 wt\%)@MIL-125(Ti)- $\mathrm{NH}_{2}$ under batch conditions we decided to perform photocatalytic methanation in a continuous flow operation under visible light irradiation $(\lambda>455 \mathrm{~nm})$. Figure 10a shows that the $\mathrm{RuO}_{\mathrm{x}}(10 \mathrm{wt} \%) @ \mathrm{MIL}-125(\mathrm{Ti})-\mathrm{NH}_{2}$ photocatalyst can operate under continuous flow at 150 or $200{ }^{\circ} \mathrm{C}$ under visible light irradiation with only 3 seconds of contact time. The crystallinity of the $\mathrm{RuO}_{\mathrm{x}}(10 \mathrm{wt} \%) @ \mathrm{MIL}-125(\mathrm{Ti})-\mathrm{NH}_{2}$ photocatalyst used was maintained after $40 \mathrm{~h}$ of operation, as revealed by PXRD measurements (Figure 10b). As in batch conditions, the oxidation state of supported $\mathrm{RuO}_{x} \mathrm{NPs}$ in the fresh MIL-125(Ti)- $\mathrm{NH}_{2}$ photocatalyst changes to $\mathrm{Ru}(0)$, while TEM (Figure 10c and S15) and SEM (Figure 10d) measurements show that the ruthenium particle size distribution and morphology of the $\mathrm{RuO}_{x}\left(10\right.$ wt\%)@MIL-125(Ti)- $\mathrm{NH}_{2}$ sample used under continuous flow operation were maintained, respectively. 
a)

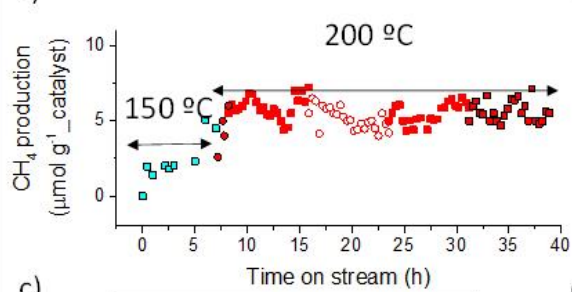

c)

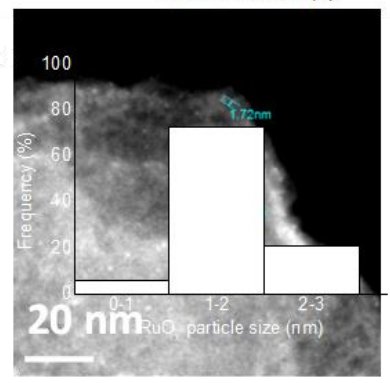

b)

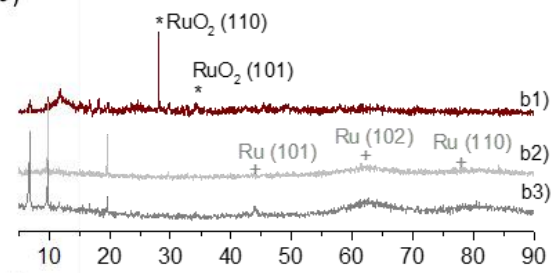

d)

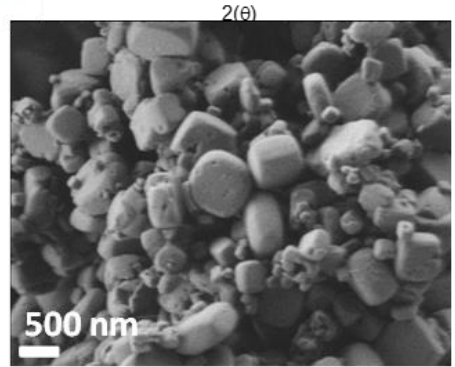

Figure 10. Photocatalytic $\mathrm{CO}_{2}$ methanation by $\mathrm{RuO}_{\mathrm{x}}(10 \mathrm{wt} \%) @ \mathrm{MIL}-125(\mathrm{Ti})-\mathrm{NH}_{2}$ under continuous flow operation. Reaction conditions: Photocatalyst $(50 \mathrm{mg}, 0.2 \mu \mathrm{m}$, total flow $(20 \mathrm{~mL} / \mathrm{min})$, mixture of gases $\left(\mathrm{H}_{2} 80 \%\right.$ and $\mathrm{CO}_{2} 20 \%$ ), reaction temperature $200{ }^{\circ} \mathrm{C}$, contact time ( $3 \mathrm{~s}$ ). b) PXRD of the fresh (b1), $20 \mathrm{~h}$ (b2) and $40 \mathrm{~h}$ (b3) used photocatalyst c) DF-TEM image and $\mathrm{RuO}_{\mathrm{x}}$ particle size distribution of the seven-times used photocatalyst. d) SEM image of the seven-times used photocatalyst.

\subsubsection{Reaction mechanism}

Several experiments were carried out to study the $\mathrm{RuO}_{x}(10$ wt\%)@MIL-125(Ti)-NH2 reaction mechanism for selective photocatalytic $\mathrm{CO}_{2}$ methanation . Its generally accepted reaction mechanism using MIL-125(Ti)- $\mathrm{NH}_{2}$ in photoexcitation with appropriate energy results in an LMCT process. RuO $\mathrm{O}_{x}$ NPs as co-catalyst supported on MIL-125(Ti)- $\mathrm{NH}_{2}$ could favour this LMCT by improving charge separation efficiency. To confirm this hypothesis, the charge transfer energy between MIIL-125(Ti)- $\mathrm{NH}_{2}$ and ruthenium NPs was studied by means of fluorescence spectroscopy. ${ }^{[39]}$ As it has been shown during photocatalytic $\mathrm{CO}_{2}$ methanation by $\mathrm{RuO}_{x}(10 \mathrm{wt} \%) @ \mathrm{MIL}-125(\mathrm{Ti})-\mathrm{NH}_{2}, \mathrm{RuO}_{x} \mathrm{NPs}$ are reduced to metallic Ru NPs as evidenced by PXRD (Figure 9b). Fluorescence measurements were thus carried out using initially the $\mathrm{RuO}_{x}\left(10\right.$ wt\%)@MIL-125(Ti)- $\mathrm{NH}_{2}$ sample after one photocatalytic 
use in which $\mathrm{RuO}_{\mathrm{x}}$ was mostly reduced to metallic Ru by an excitation wavelength of $340 \mathrm{~nm}$, which corresponds to the absorption of the 2-aminoterephthalate present in MIL-125(Ti)-NH2. Figure 11 a clearly shows that the metallic $\mathrm{Ru}$ in the MIL-125(Ti)- $\mathrm{NH}_{2}$ network quenches $41 \%$ fluorescence with respect to pristine MIL-125(Ti)- $\mathrm{NH}_{2}$. For the sake of comparison the same photoluminescence experiments were carried out using the as-prepared $\mathrm{RuO}_{x}(10 \mathrm{wt} \%) @ \mathrm{MIL}-125(\mathrm{Ti})-\mathrm{NH}_{2}$. The RuO in the MOF again quenched fluorescence with respect to pristine MOF (Figure 10a). This data was interpreted considering that the presence of both metallic $\mathrm{Ru}$ and/or $\mathrm{RuO}_{\mathrm{x}}$ in the MIL-125(Ti)- $\mathrm{NH}_{2}$ solid favours the separation of charge carriers during photocatalysis, but the quenching value of metallic $\mathrm{Ru}$ is higher than that of $\mathrm{RuO}_{\mathrm{x}}$.
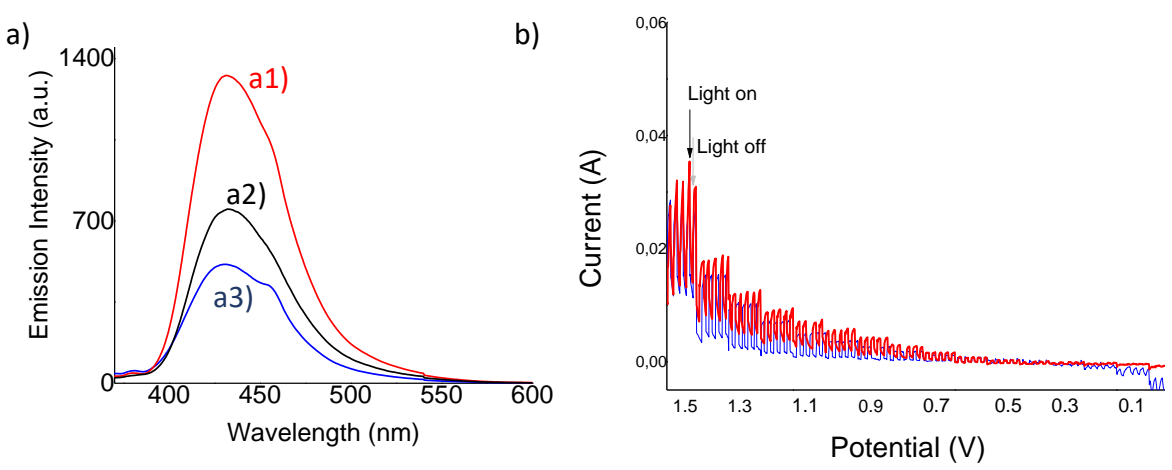

Figure 11. a) Fluorescence emission upon photoexcitation at $340 \mathrm{~nm}$ using deaerated acetonitrile suspensions of MIL-125(Ti)- $\mathrm{NH}_{2}$ (a), RuO $\mathrm{x}_{\mathrm{x}}\left(10\right.$ wt\%)@MIL-125(Ti)- $\mathrm{NH}_{2}$ (a2) or one-time used $\mathrm{RuO}_{x}(10 \mathrm{wt} \%) @ \mathrm{MIL}-125(\mathrm{Ti})-\mathrm{NH}_{2}$ (a3) in the photocatalytic $\mathrm{CO}_{2}$ methanation at $200{ }^{\circ} \mathrm{C}$ under simulated sunlight irradiation. b) Photocurrent intensity vs. polarization potential measured for the $\mathrm{RuO}_{\mathrm{x}}(10 \mathrm{wt} \%) @ \mathrm{MIL}-125(\mathrm{Ti})-\mathrm{NH}_{2} /$ FTO electrode in a deaerated $\mathrm{CH}_{3} \mathrm{CN}$ solution of TPAPF $(0.1 \mathrm{M})$ in the absence of any additive (blue line) or in the presence of $\mathrm{MeOH}$ (red line) upon simulated sunlight irradiation ( $150 \mathrm{~W}$ Xe lamp equipped with a AM $1.5 \mathrm{G}$ filter).

Another common strategy to verify the occurrence of photoinduced charge separation in a material is to measure its photocurrent response. ${ }^{[22,39]}$ For this, a thin film of $\mathrm{RuO}_{\mathrm{x}}(10 \mathrm{wt} \%) @ \mathrm{MIL}-125(\mathrm{Ti})-\mathrm{NH}_{2}$ solid was initially deposited onto FTO as 
transparent conductive electrode, the dark current and photocurrent response of the system were compared at increasing positive voltages. The results are shown in Figure $11 b$. As can be seen, illumination of the electrode at each polarization voltage increased the measured current, which agrees with the methanol sacrificial electron donor increasing the photocurrent.

A photothermal mechanism would also be feasible when using $\mathrm{RuO}_{\mathrm{x}}(10 \mathrm{wt} \%) @ \mathrm{MIL}-125(\mathrm{Ti})-\mathrm{NH}_{2}{ }^{[40]}$ In photothermal $\mathrm{CO}_{2}$ methanation, the light energy is transformed into local heat in the ruthenium NPs favouring thermal conversion of $\mathrm{CO}_{2}$ and $\mathrm{H}_{2}$ into $\mathrm{CH}_{4}$. Further measurements were carried out to study the possible reaction mechanism during photocatalytic $\mathrm{CO}_{2}$ methanation. ${ }^{[38]}$ It should be noted that we used RuOx@MIL-125(Ti)- $\mathrm{NH}_{2}$ materials prepared by photodeposition, which consists of irradiation of MIL-125(Ti)- $\mathrm{NH}_{2}$ in the presence of water soluble $\mathrm{KRuO}_{4}$ using methanol as sacrificial electron donor. As previously described, the characterization data of the different photocatalysts demonstrated the presence of small RuO $\mathrm{R}_{x}$ NPs within the MIL-125(Ti)- $\mathrm{NH}_{2}$ solid, which indirectly proves that the LMCT process occurred in the MIL-125(Ti)- $\mathrm{NH}_{2}$ solid on UV-vis irradiation. The photogenerated electrons and holes were responsible for the reduction of $\mathrm{KRuO}_{4}$ to $\mathrm{RuO}_{x}$ and the oxidation of methanol as sacrificial electron donor, respectively.

Electron quenchers can be used in a similar way during photocatalytic $\mathrm{CO}_{2}$ methanation to underline the process possible reaction mechanism. ${ }^{[22]}$ In this study nitrobenzene $(-0.36 \mathrm{~V}$ versus $\mathrm{Ag}-\mathrm{AgCl})$ was the electron quencher competing with $\mathrm{CO}_{2}$ during the photocatalytic reaction with $\mathrm{H}_{2}$ in the presence of $\mathrm{RuO}_{x}(10 \mathrm{wt} \%) @ \mathrm{MIL}-125(\mathrm{Ti})-\mathrm{NH}_{2}$. The results obtained indicate that the presence of nitrobenzene $(80 \mu \mathrm{L})$ during the photocatalytic reaction at $200{ }^{\circ} \mathrm{C}$ under simulated sunlight irradiation almost inhibited the formation of methane $\left(202 \mu \mathrm{mol} \mathrm{g}{ }^{-1}\right.$ at 22 h). In a similar way, the photocatalytic $\mathrm{CO}_{2}$ reduction was carried out in the absence of $\mathrm{H}_{2}$ but in the presence of dimethylaniline $(40 \mu \mathrm{L})$ as sacrificial electron donor and 
observing the formation of $\mathrm{CH}_{4}\left(1 \mathrm{mmol} \mathrm{g}^{-1}\right.$ at $22 \mathrm{~h}$ under simulated sunlight irradiation). These experiments showed that a photoinduced LMCT mechanism occurred during photocatalytic $\mathrm{CO}_{2}$ methanation by $\mathrm{RuO}_{x}(10 w t \%) @ M I L-125(\mathrm{Ti})-\mathrm{NH}_{2}$.

It should be remembered that a couple of control experiments under optimized photocatalytic reaction conditions in the dark using fresh or one-time used $\mathrm{RuO}_{\mathrm{x}}(10 \mathrm{wt} \%) @ \mathrm{MIL}-125(\mathrm{Ti})-\mathrm{NH}_{2}$ resulted in a methane production of about 10 and $19 \%$, respectively, of the total amount of methane found when the process was carried out under simulated sunlight irradiation. In order to gain some insights about the possible photothermal mechanism the influence of the light intensity on the photocatalytic $\mathrm{CO}_{2}$ methanation was also investigated. ${ }^{[0,41]}$ As it can be seen in Figure 12 the photocatalytic $\mathrm{CH}_{4}$ production increases linearly up to light intensity of $343 \mathrm{~mW} / \mathrm{cm}^{2}$, while higher light intensities results in a quadratic growth of $\mathrm{CH}_{4}$ production. The quadratic relationship between catalytic activity and light intensity would indicate the operation of an additional photo-assisted $\mathrm{CH}_{4}$ production pathway for higher light fluxes NPs. ${ }^{[40,42]}$

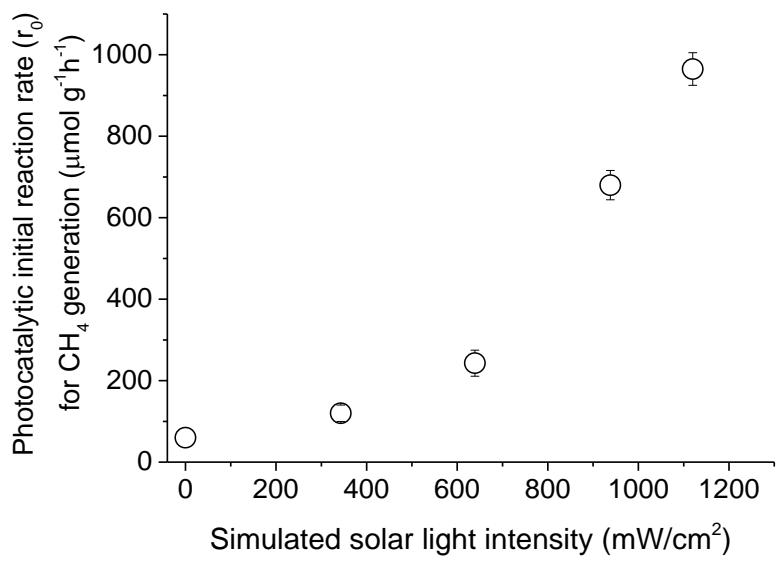

Figure 12. Photocatalytic initial reaction rate $\left(r_{0}\right)$ for methane generation as a function of the simulated solar light intensity. Reaction conditions: Photocatalyst $(15 \mathrm{mg}), \mathrm{P}_{\mathrm{H} 2}=1.05$ bar, $\mathrm{P}_{\mathrm{cO} 2}$ $=0.25$ bar, reaction temperature $\left(200{ }^{\circ} \mathrm{C}\right)$, simulated sunlight irradiation (Xe lamp of $150 \mathrm{~W}$ equipped with a filter cut-off of $\lambda>455 \mathrm{~nm}$ ). 
Overall, these experiments can be interpreted as showing that the main reaction pathway for photocatalytic $\mathrm{CO}_{2}$ methanation by $\mathrm{RuO}_{\mathrm{x}}(10$ wt\%)@MIL125(Ti)- $\mathrm{NH}_{2}$ takes place via the LMCT mechanism, in which ruthenium NPs favour the charge separation efficiency and thus the observed activity. In addition, ruthenium NPs also favours the photothermal mechanism in some extent, particularly at higher light intensity.

\subsection{Conclusions}

The present study has shown the possibility of using the MIL-125(Ti)- $\mathrm{NH}_{2}$ benchmark MOF supported $\mathrm{RuO}_{x}$ nanoparticles as photocatalyst for solar-driven $\mathrm{CO}_{2}$ methanation. The samples prepared with the highest amount of RuO NPs (10 wt\%; $1.48 \pm 0.53 \mathrm{~nm}$ ) supported on MIL-125(Ti)- $\mathrm{NH}_{2}$ obtained the highest photocatalytic activity in terms of mmols $\mathrm{CH}_{4} \mathrm{~g}^{-1}$ catalyst for selective $\mathrm{CO}_{2}$ methanation under simulated sunlight irradiation at $200{ }^{\circ} \mathrm{C}$. The photocatalytic $\mathrm{CH}_{4}$ production as a function of temperature followed the Arrhenius plot equation and allowed us to estimate an apparent activation energy for this process of $68.8 \mathrm{~kJ} \mathrm{~mol}^{-1}$. It should be noted that the $\mathrm{RuO}_{x}(10 \mathrm{wt} \%) / \mathrm{MIL}-125(\mathrm{Ti})-\mathrm{NH}_{2}$ photocatalyst can be reused at least 7 times $(154 \mathrm{~h})$ at $200{ }^{\circ} \mathrm{C}$ under simulated sunlight irradiation without a significant loss of activity while maintaining its crystallinity and morphology, as revealed by PXRD and SEM measurements, respectively, while some partial MOF decarboxylation occurs. This photocatalyst is also active and stable during photocatalytic $\mathrm{CO}_{2}$ methanation at 150 or $200{ }^{\circ} \mathrm{C}$ under visible light irradiation $(\lambda>$ $455 \mathrm{~nm}$ ). Fluorescence spectroscopy and photocurrent measurements together with selective quenching experiments indicate that photocatalytic $\mathrm{CO}_{2}$ methanation by $\mathrm{RuO}_{x}(10 w \mathrm{w} \%) @ \mathrm{MIL}-125(\mathrm{Ti})-\mathrm{NH}_{2}$ at $200{ }^{\circ} \mathrm{C}$ under simulated sunlight irradiation occurs largely via LMCT, in which the ruthenium NPs raise the charge separation efficiency. The observation of a nonlinear relationship between the photocatalytic $\mathrm{CO}_{2}$ methanation and light intensity also indicates that a photothermal pathway takes place. 
Chapter 7. Toward solar-driven photocatalytic $\mathrm{CO}_{2}$ methanation under continuous flow operation using benchmark MIL-125(Ti)- $\mathrm{NH}_{2}$ supported ruthenium nanoparticles

This work exemplifies for the first time the possibility of using MOF-based materials as photocatalysts towards the solar-driven selective $\mathrm{CO}_{2}$ methanation under a continuous flow operation. 


\subsection{Bibliography}

[1] W. Wang, M. O. Tadé, Z. Shao, Chem. Soc. Rev. 2015, 44, 5371-5408.

[2] S. Paraschiv, L. S. Paraschiv, Energy Rep. 2020, 6, 237-242.

[3] R. Shahnazi, Z. D. Shabani, Renew. Sustain. Energy 2021, 169, 293-307.

[4] P. Friedlingstein, M. O'Sullivan, M. W. Jones, R. M. Andrew, J. Hauck, A. Olsen, G. P. P. Peters, W. Peters, J. Pongratz, S. Sitch, C. Le Quéré, J.G. Canadell, P. Ciais, R. B. Jackson, S. Alin, L. E. O. C. Aragão, A. Arneth, V. Arora, N.R. R. Bates, M. Becker, A. Benoit-Cattin, H.C. C. Bittig, L. Bopp, S. Bultan, N. Chandra, F. Chevallier, L.P. Chini, W. Evans, L. Florentie, P. M. Forster, T. Gasser, M. Gehlen, D. Gilfillan, T. Gkritzalis, L. Gregor, N. Gruber, I. Harris, K. Hartung, V. Haverd, R.A. Hughton, T. Ilyina, A. K. Jain, E. Joetzjer, K. Kadono, E. Kato, V. Kitidis, J.I . Korsbakken, P. Landschützer, N. Lefèvre, A. Lenton, S. Lienert, Z. Liu, D. Lombardozzi, G. Marland, N. Metzl, D.R. Munro, J.E.M.S. Nabel, S.-I. Nakaoka, Y. Niwa, K. O'Brien, T. Ono, P. I. Palmer, D. Pierrot, B. Poulter, L. Resplandy, E. Robertson, C. Rödenbeck, J. Schwinger, R. Séférian, I. Skjelvan, A.J.P. Smith, A.J. Sutton, T. Tanhua, P. Tans, H. Tian, B. Tilbrook, G. van der Werf, N. Vuichard, A. P. Walker, R. Wanninkhof, A. J. Watson, D. Willis, A. J. Wiltshire, W. Yuan, X. Yue, S. Zaehle, Earth Syst. Sci. Data 2020, 12, 3269-3340.

[5] S. Hamels, E. Himpe, J. Laverge, M. Delghust, K.V. den Brande, A. Janssens, J. Albrechta, Renew. Sustain. Energy 2021, 146, 111182.

[6] A. Fujishima, K. Honda, Nature 1972, 238, 37-38.

[7] Q. Wang, K. Domen, Chem. Rev. 2020, 120, 919-985.

[8] X. Li, J. Yu, M. Jaroniec, X. Chen, Chem. Rev. 2019, 119, 3962-4179.

[9] G. Férey, C. Mellot-Draznieks, C. Serre, F. Millange, J. Dutour, S. Surblé, I. Margiolaki, Science 2005, 23, 2040-2042.

[10] H. Furukawa, K. E. Cordova, M. O'Keeffe, O. M. Yaghi, Science 2013, 341, 1230444.

[11] S. Kitagawa, R. Kitaura, S.-I. Noro, Angew. Chem. Int. Ed. 2004, 43, 2334-2375.

[12] A. Dhakshinamoorthy, A. M. Asiri, H. García, Angew. Chem. Int. Ed. 2016, 55, 5414-5445.

[13] A. Dhakshinamoorthy, Z. Li, H. Garcia, Chem. Soc. Rev. 2018, 47, 8134-8172.

[14] X. Chen, X. Peng, L. Jiang, X. Yuan, H. Yub, H. Wang, J. Zhang, Q. Qi Xia, Chem. Eng. J. 2020, 395, 125080.

[15] Y. Yan, C. Li, Y. Wu, J. Gao, Q. Zhang, J. Mater. Chem. A 2020, 8, 15245-15270.

[16] J. Zhu, P.-Z. Li, W. Guo, Y. Zhao, R. Zou, Coord. Chem. Rev. 2018, 359, 80-101.

[17] J. Wang, A. S. Cherevan, C. Hannecart, S. Naghdi, S. P. Nandan, T. Gupta, D. Edera, Appl. Catal. B 2021, 283, 119626.

[18] M. Cabrero-Antonino, J. Albero, C. García-Vallés, M. Álvaro, S. Navalón, H. García, Chem. Eur. J. 2020, 26, 15682 - 15689.

[19] M. A. Nasalevich, R. Becker, E. V. Ramos-Fernandez, S. Castellanos, S. L. Veber, M. V. Fedin, F. Kapteijn, J. N. H. Reek, J. I. van der Vlugt, J. Gascon, Energy Environ. Sci. 2015, 8, 364-375. 
[20] M. A. Nasalevich, C. H. Hendon, J. G. Santaclara, K. Svane, B. van der Linden, S. L. Veber, M. Fedin, A. J. Houtepen, M. A. van der Veen, F. Kapteijn, A. Walsh, J. Gascon, Sci. Rep. 2016, 6, 23676.

[21] S. Remiro-Buenamañana, M. Cabrero-Antonino, M. Martínez-Guanter, M. Álvaro, S. Navalón, H. García, Appl. Catal. B 2019, 677-684.

[20] S. Wang, M. Cabrero-Antonino, S. Navalón, C.-c. Chen-chen Cao, A. Tissot, I. Dovgaliuk, J. Marrot, C. Martineau-Corcos, L. Yu, H. Wang, W. Shepard, H. García, C. Serre, Chem 2020, 6, 3409-3427.

[23] M. Younas, L. L. Loong Kong, M. J. K. Bashir, H. Nadeem, A. Shehzad, S. Sethupathi, Energ. Fuels 2016, 30, 8815-8831.

[21] M. A. Moreira, J. C. Santos, A. F. P. Ferreira, J. M. Loureiro, F. Ragon, P. Horcajada, P. G. Yot, C. Serre, A. E. Rodrigues, Microporous Mesoporous Mater. 2012, 158, 229-234.

[22] M. A. Nasalevich, M. G. Goesten, T. J. Savenije, F. Kapteijn, J. Gascon, Chem. Commun. 2013, 49, 10575--10577.

[23] Z. Xiao, X. Jiang, B. Li, X. Liu, X. Huang, Y. Zhang, Q. Ren, J. Luo, Z. Qin, J. Hu, Nanoscale 2015, 7, 11962-11970.

[24] M. A. Moreira, J. C. Santos, A. F. P. Ferreira, J.M Loureiro, F. Ragon, P. Horcajada, P.G. Yot, C. Serre, A.E. Rodrigues, Microporous Mesoporous Mater. 2012, 158, 229-234.

[25] M. A. Nasalevich, M. G. Goesten, T. J. Savenije, F. Kapteijn, J. Gascon, Chem. Commun. 2013, 49, 10575--10577.

[26] Z. Xiao, X. Jiang, B. Li, X. Liu, X. Huang, Y. Zhang, Q. Ren, J. Luo, Z. Qin, J. Hu, Nanoscale 2015, 7, 11962-11970.

[27] T. P. L. Giang, T. N. M. Tran, X. T. Le, Nanotechnoly 2012, 3, 015008.

[28] D. J. Morgan, Surf. Interface. Anal. 2015, 47, 1072-1079.

[29] K. Wenderich, G. Mul, Chem. Rev. 2016, 116, 14587-14619.

[30] S. Navalón, M. Álvaro, A. Dhakshinamoorthy, H. García, Molecules 2019, 24, 3050.

[31] S. Navalón, A. Dhakshinamoorthy, M. Álvaro, H. García, Chem. Mater. 2020, 32, 4116-4143.

[32] A. Santiago-Portillo, M. Cabrero-Antonino, M. Álvaro, S. Navalón, H. García, Chem. Eur. J. 2019, 25, 9280-9286.

[33] J. Albero, Y. Peng, H.García, ACS Catal. 2020, 10, 5734-5749.

[34] S. Bordiga, C. Lamberti, F. Bonino, A. Travertd, F. Thibault-Starzyk, Chem. Soc. Rev. 2015 44, 7262-7341.

[35] E. López-Maya, N. M. Padial, J. Castells-Gil, C. R. R. Ganivet, A. R. Gaspar, F. G. Cirujano, N. Almora-Barrios, S. Tatay, S. Navalon, C. Martí Gastaldo, Selective Chem. Int. Ed. 2021.

[36] A. Adeyemo, G. Hunter, P.K. Dutta, Sensor Actuat. B-Chem. 2011, 152, 307-315.

(37) M. Cabrero-Antonino, S. Remiro-Buenamañana, M. Souto, A. A. García-Valdivia, D. Choquesillo-Lazarte, S. Navalón, A. Rodríguez-Diéguez, G. Mínguez-Espallargas, H. García, Chem. Commun. 2019, 55, 10932-10935.

(38) D. Mateo, A. Santiago-Portillo, J. Albero, S. Navalon, M. Alvaro, H. García, Angew. Chem. Int. Ed. 2019, 17843-17848. 
Chapter 7. Toward solar-driven photocatalytic $\mathrm{CO}_{2}$ methanation under continuous flow operation using benchmark MIL-125(Ti)- $\mathrm{NH}_{2}$ supported ruthenium nanoparticles

(39) J.-D Xiao, Q. Shang, Y. Xiong, Q. Zhang, Y. Luo, S.-H. Yu, H.-L. Jiang, Angew. Chem. Int. Ed. 2016, 128, 9535-9539.

[40] D. Mateo, J. L. Cerrillo, S. Durini, J. Gascon, Chem. Soc. Rev. 2021, 50, 21732210.

(41) Q.Xiao, Z. Liu, F. Wang, S. Sarina, H. Zhu, Appl. Catal. B 2017, 209, 69-79.

(42) P. Christopher, H. L.Xin, A. Marimuthu, S. Linic, Nat. Mater. 2012, 11, 1044-1050. 


\subsection{Supporting information}

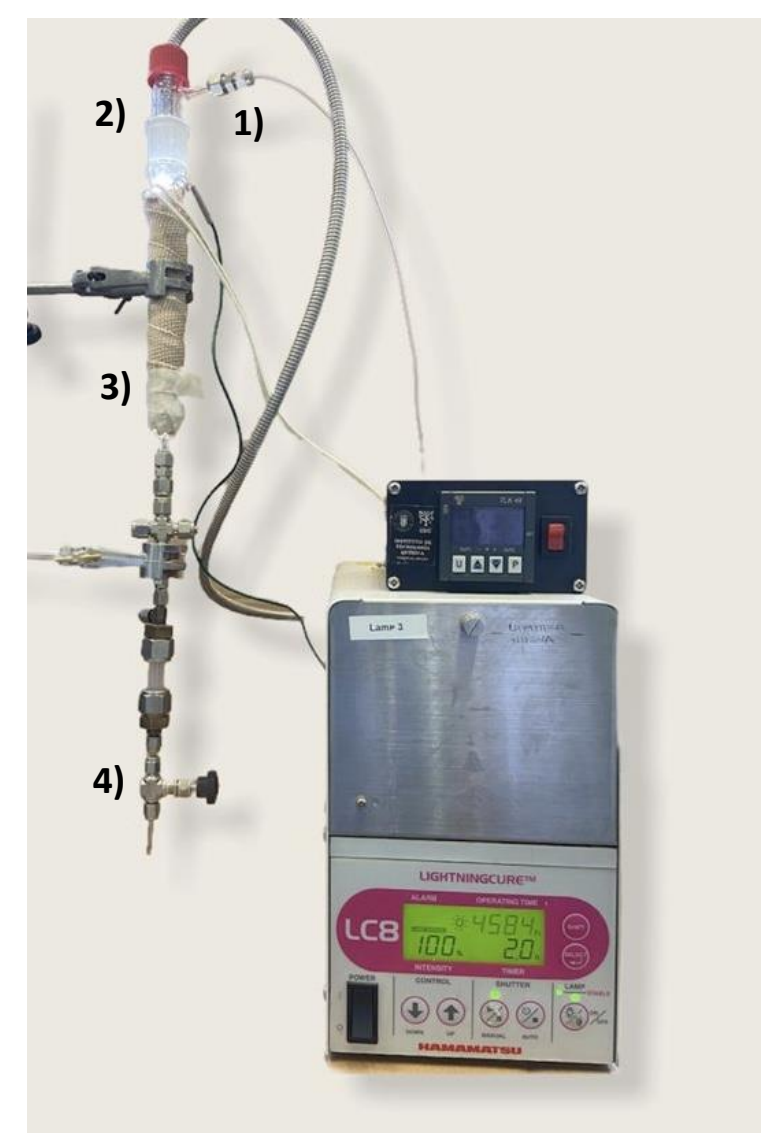

Figure S1. Continuous flow operation photoreactor employed in this study. Legend: Gas entrance (1), optical fiber (2), catalyst bed (3), gas exit (4). 
a)

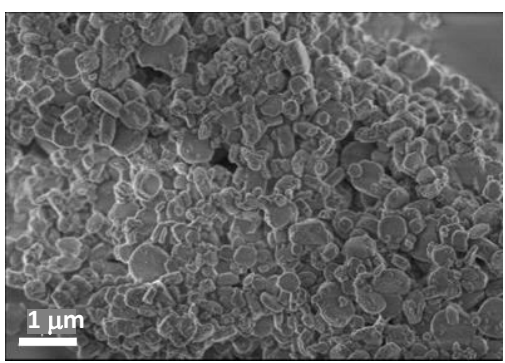

b)

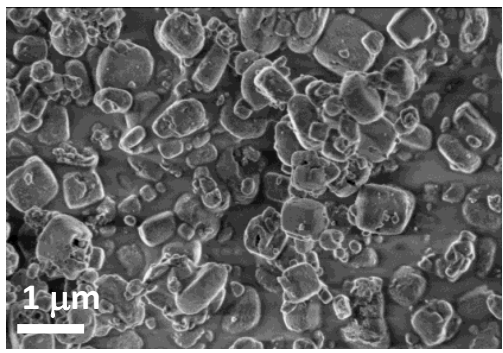

c)

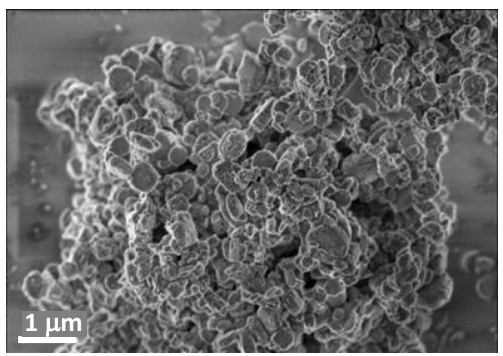

d)

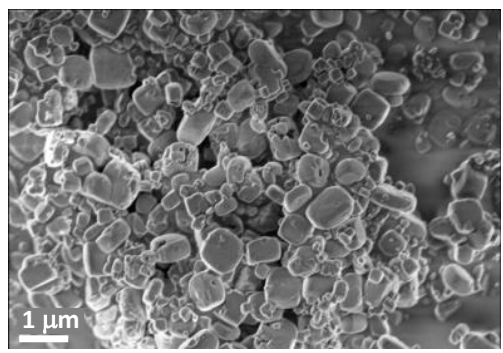

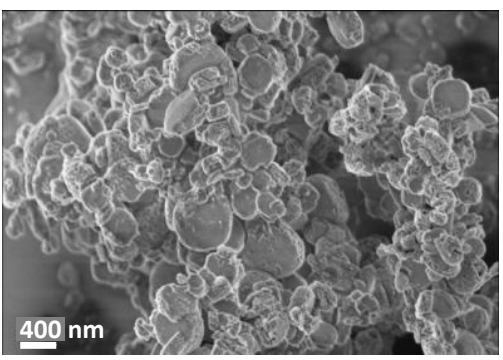
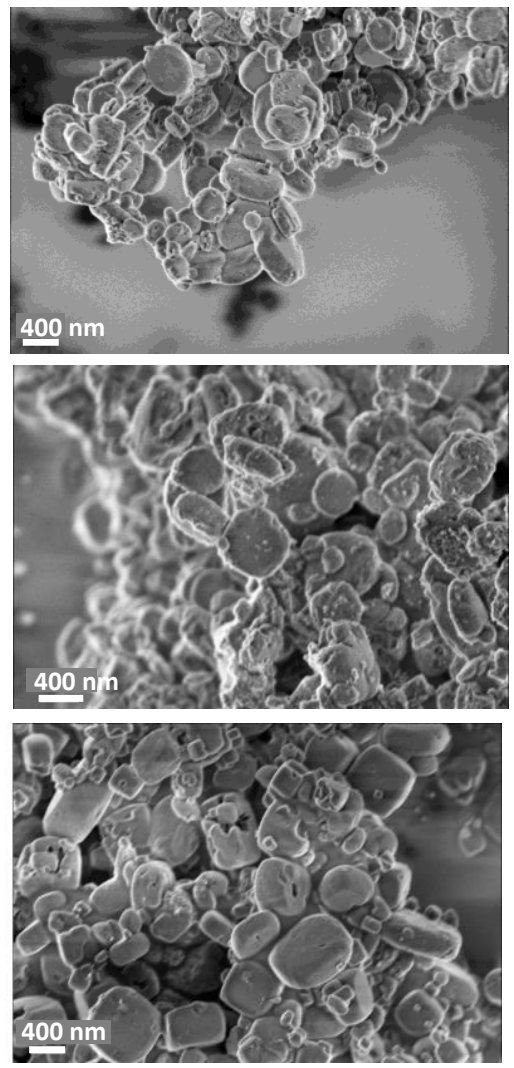

Figure S2. Representative HRSEM images of $\mathrm{RuO}_{x}(1 \mathrm{wt} \%) / \mathrm{MIL}-125(\mathrm{Ti})-\mathrm{NH}_{2} \quad$ (a),

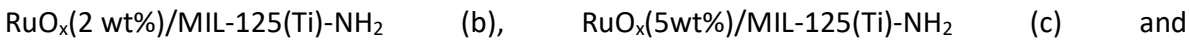
$\mathrm{RuO}_{x}(10 \mathrm{wt} \%) / \mathrm{MIL}-125(\mathrm{Ti})-\mathrm{NH}_{2}(\mathrm{~d})$. 
Chapter 7. Toward solar-driven photocatalytic $\mathrm{CO}_{2}$ methanation under continuous flow operation using benchmark MIL-125(Ti)- $\mathrm{NH}_{2}$ supported ruthenium nanoparticles
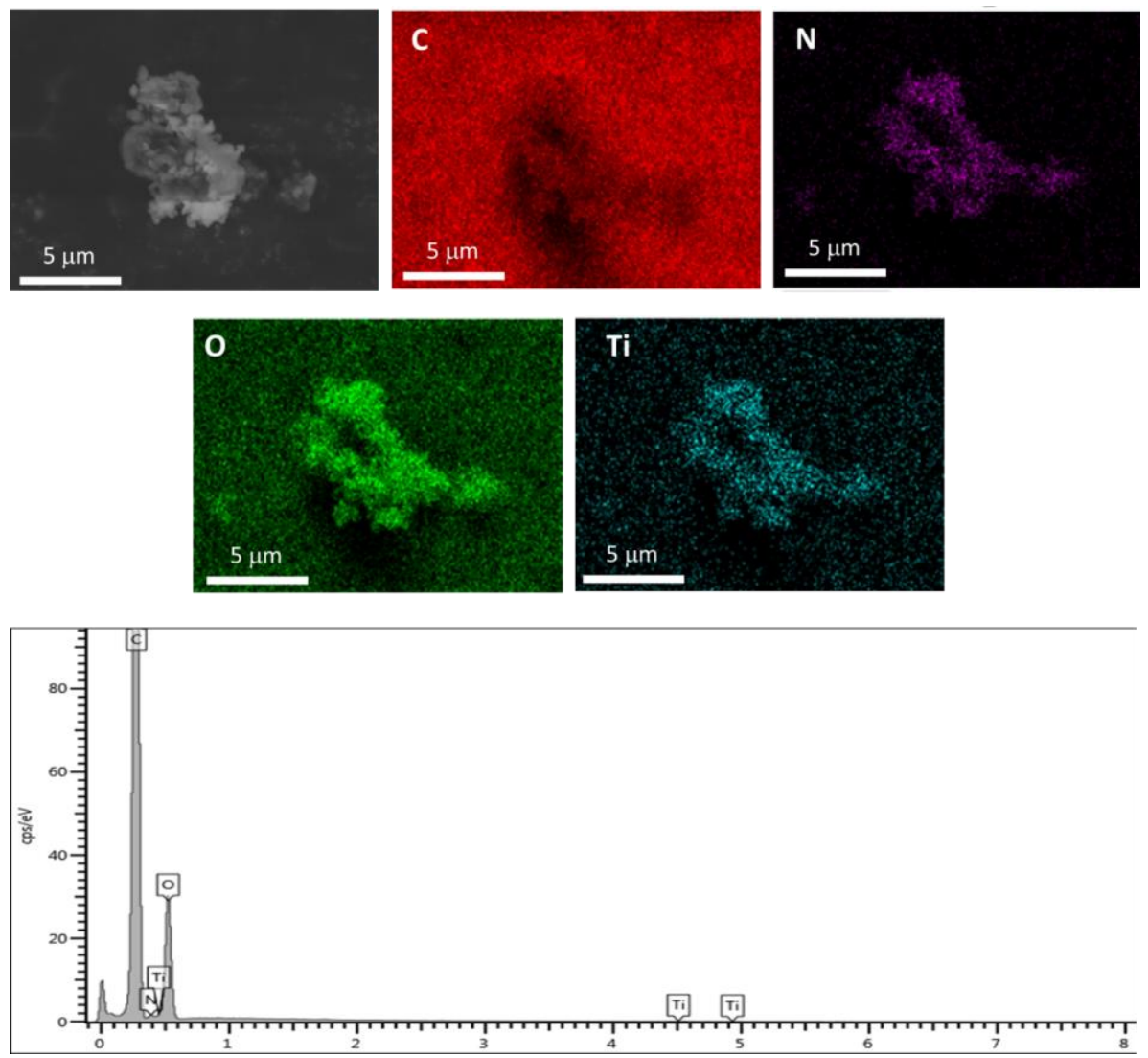

Figure S3. SEM image, EDX mapping and elemental analysis of MIL-125(Ti)- $\mathrm{NH}_{2}$. 
Chapter 7. Toward solar-driven photocatalytic $\mathrm{CO}_{2}$ methanation under continuous flow operation using benchmark MIL-125(Ti)- $\mathrm{NH}_{2}$ supported ruthenium nanoparticles
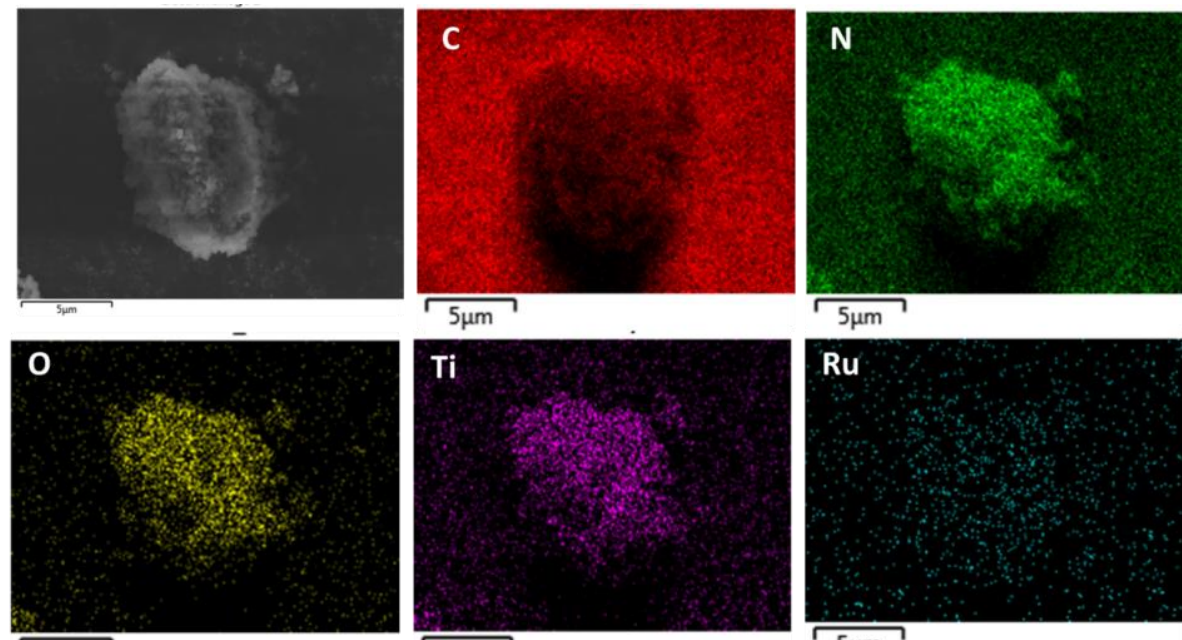

$\longdiv { 5 \mu \mathrm { m } }$

$5 \mu \mathrm{m}$

$5 \mu \mathrm{m}$

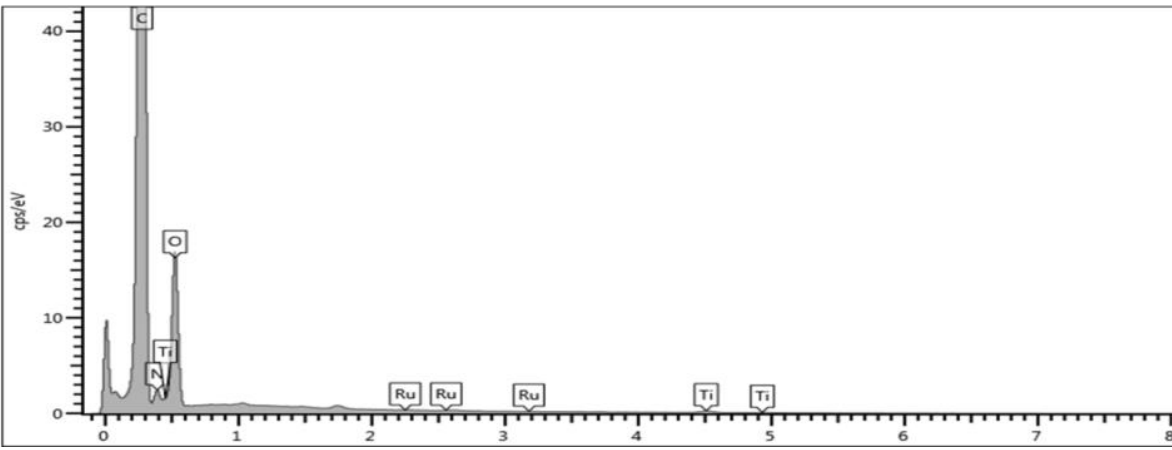

Figure S4. SEM image, EDX mapping and elemental analysis of $\mathrm{RuO}_{x}(1 \mathrm{wt} \%) @ M I L-125(\mathrm{Ti})-\mathrm{NH}_{2}$. 
Chapter 7. Toward solar-driven photocatalytic $\mathrm{CO}_{2}$ methanation under continuous flow operation using benchmark MIL-125(Ti)- $\mathrm{NH}_{2}$ supported ruthenium nanoparticles
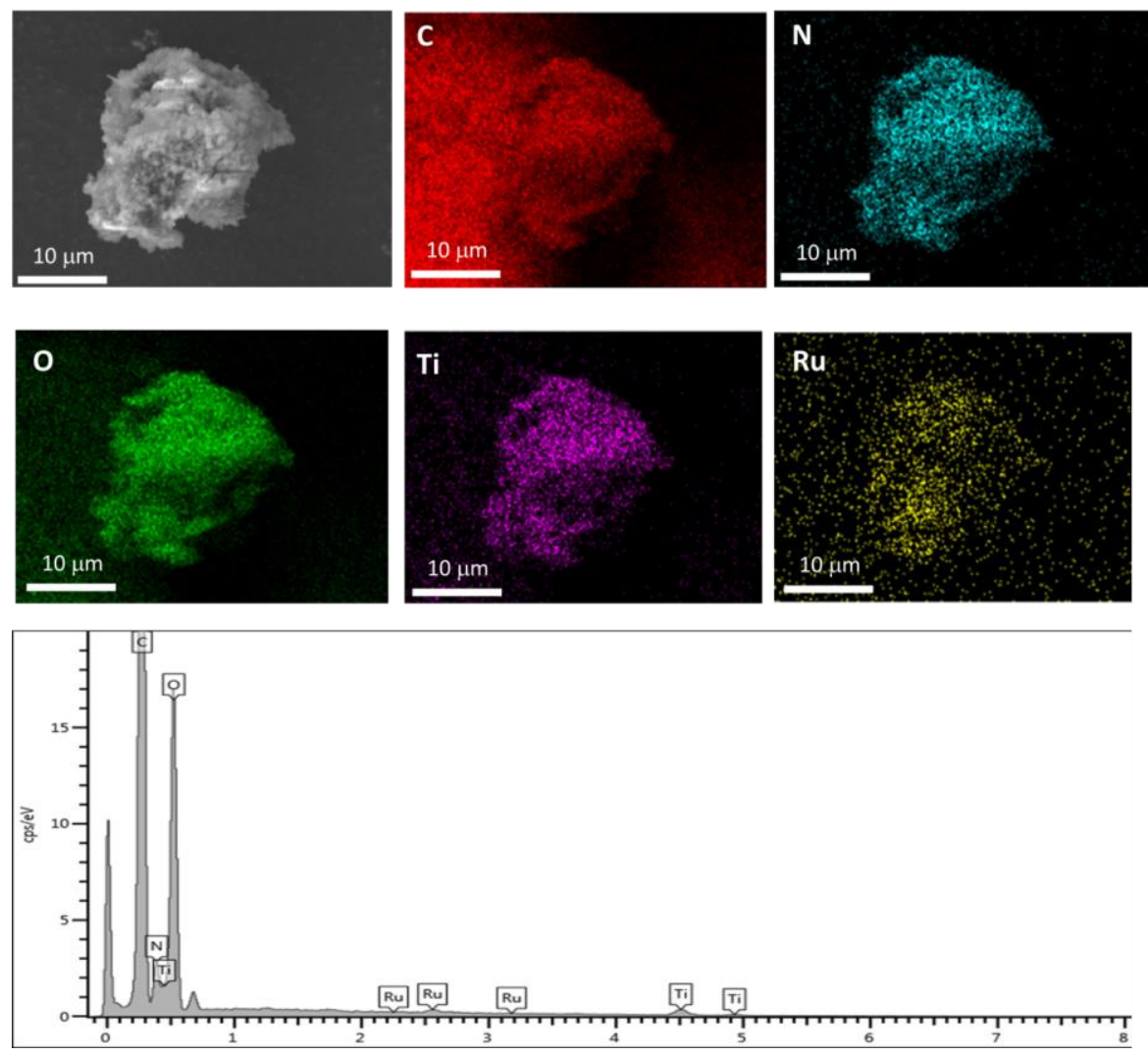

Figure S5. SEM image, EDX mapping and elemental analysis of $\mathrm{RuO}_{x}(2 \mathrm{wt} \%) @ M I L-125(\mathrm{Ti})-\mathrm{NH}_{2}$. 
Chapter 7. Toward solar-driven photocatalytic $\mathrm{CO}_{2}$ methanation under continuous flow operation using benchmark MIL-125(Ti)- $\mathrm{NH}_{2}$ supported ruthenium nanoparticles
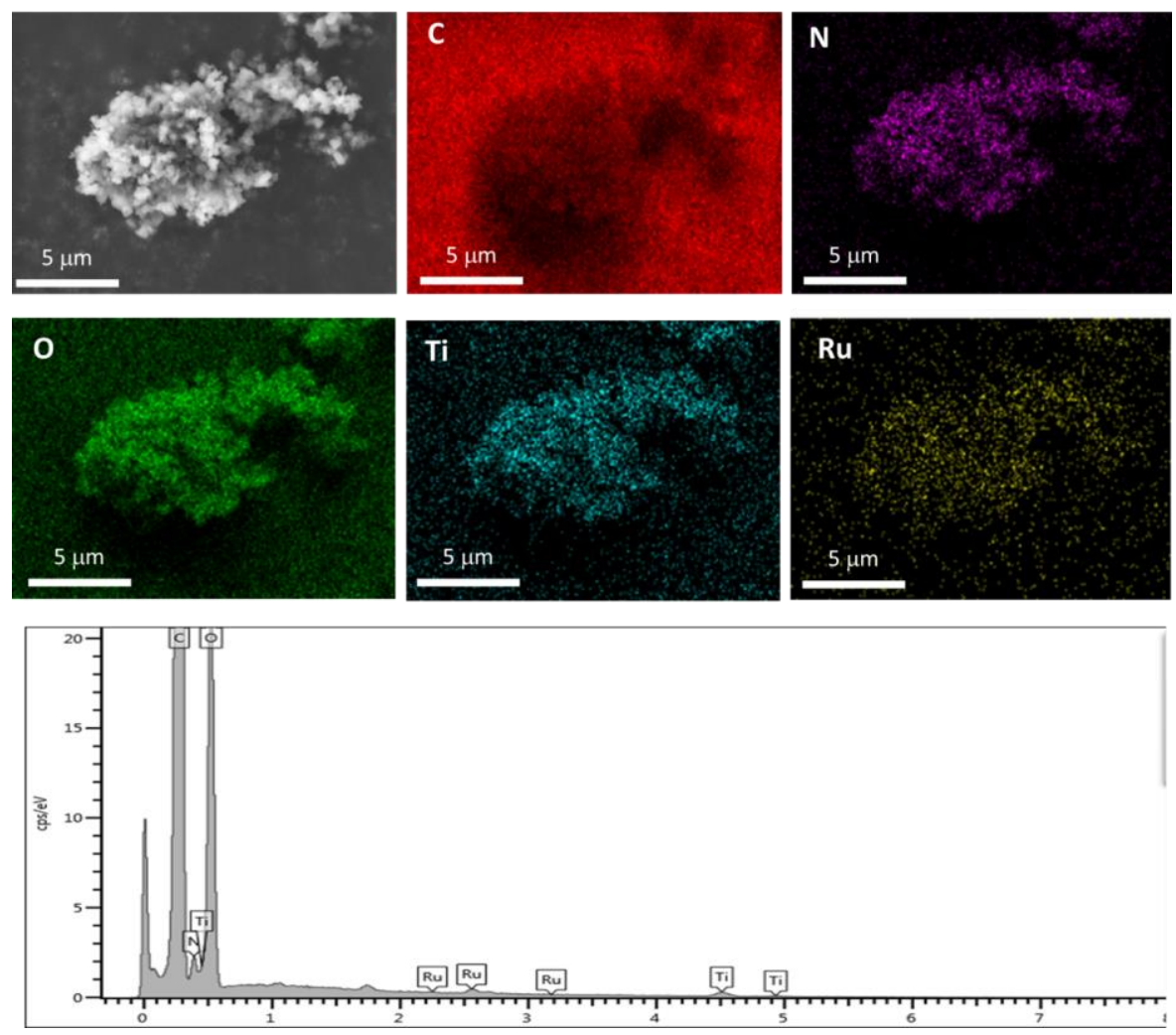

Figure S6. SEM image, EDX mapping and elemental analysis of $\mathrm{RuO}_{x}(5 \mathrm{wt} \%) @ \mathrm{MIL}-125(\mathrm{Ti})-\mathrm{NH}_{2}$ 
Chapter 7. Toward solar-driven photocatalytic $\mathrm{CO}_{2}$ methanation under continuous flow operation using benchmark MIL-125(Ti)- $\mathrm{NH}_{2}$ supported ruthenium nanoparticles
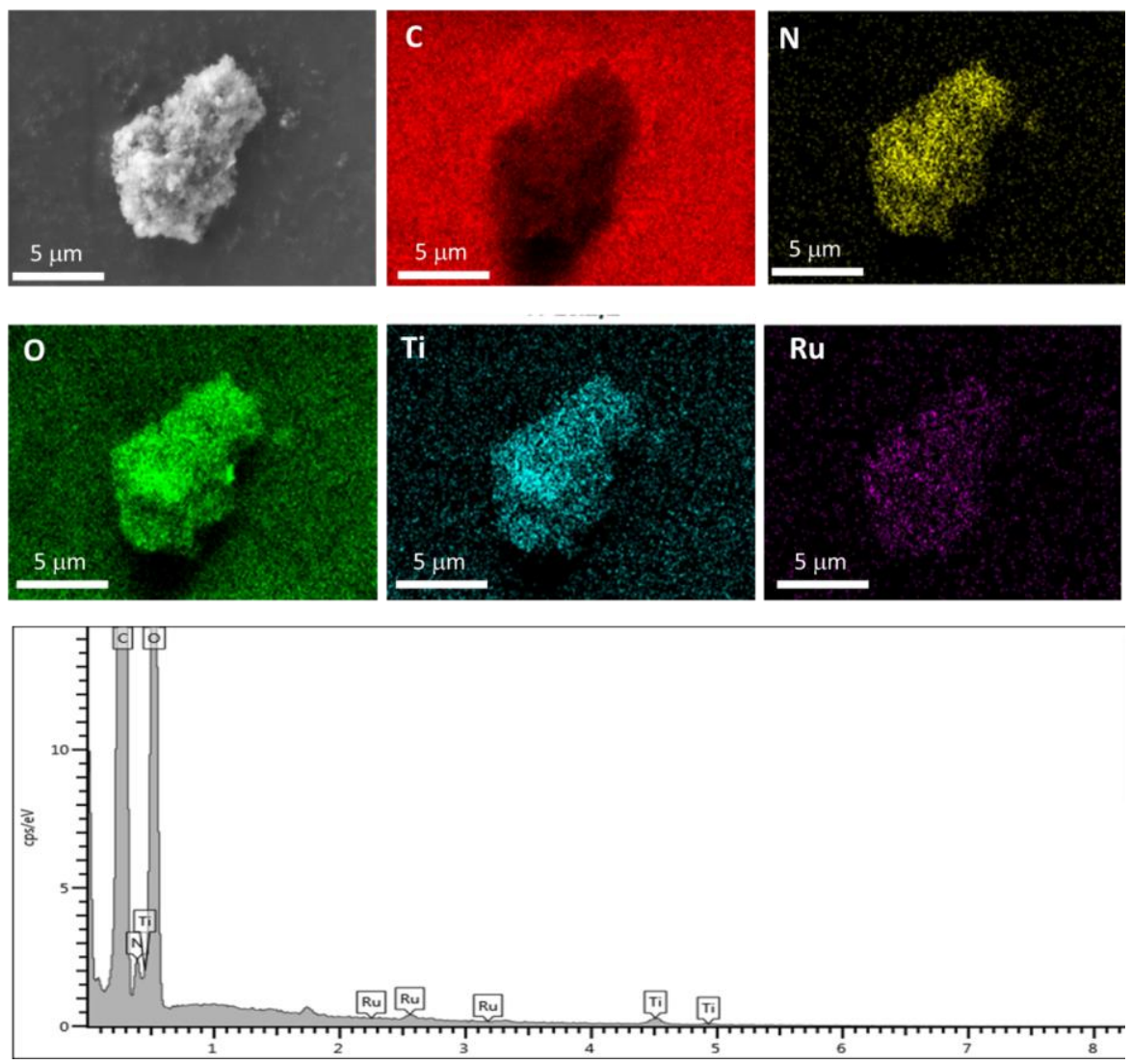

Figure S7. SEM image, EDX mapping and elemental analysis of $\mathrm{RuO}_{\mathrm{x}}(10 \mathrm{wt} \%) @ \mathrm{MIL}-125(\mathrm{Ti})-\mathrm{NH}_{2}$. 


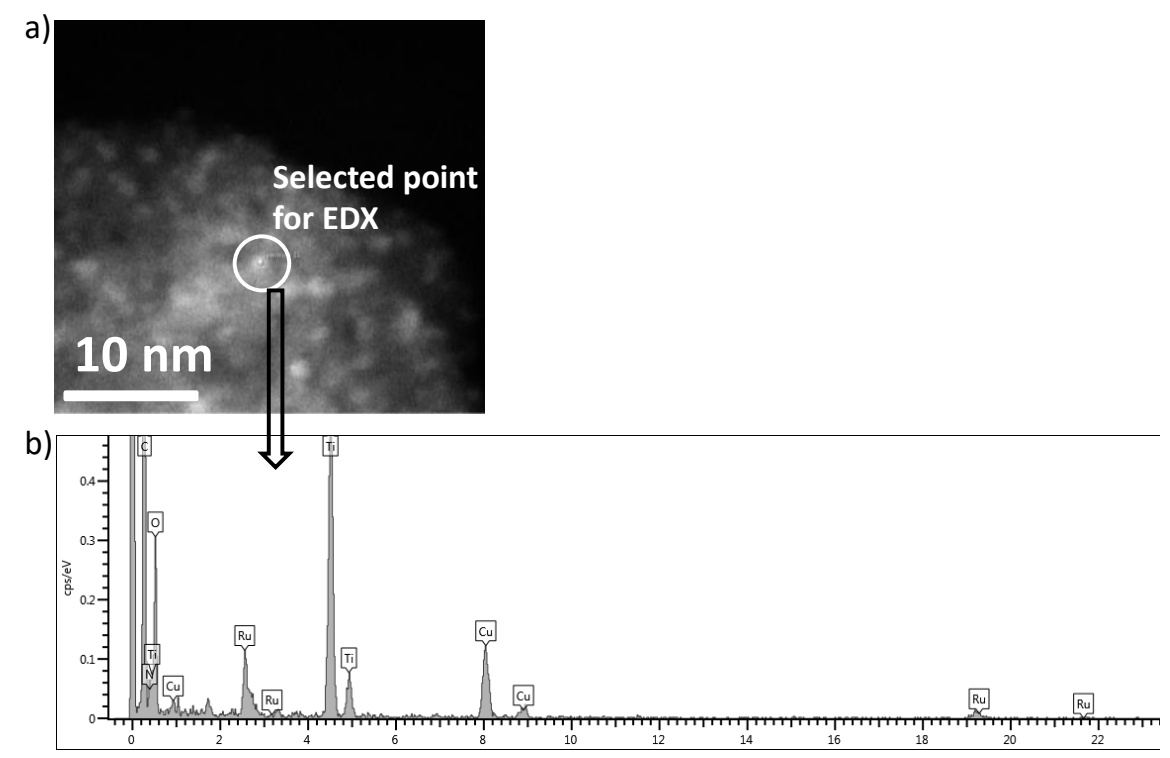

Figure S8. Representative TEM image of $\mathrm{RuO}_{x}(1 \mathrm{wt} \%) @ \mathrm{MIL}-125(\mathrm{Ti})-\mathrm{NH}_{2}(\mathrm{a})$ and EDX spectrum of selected point from panel (a).

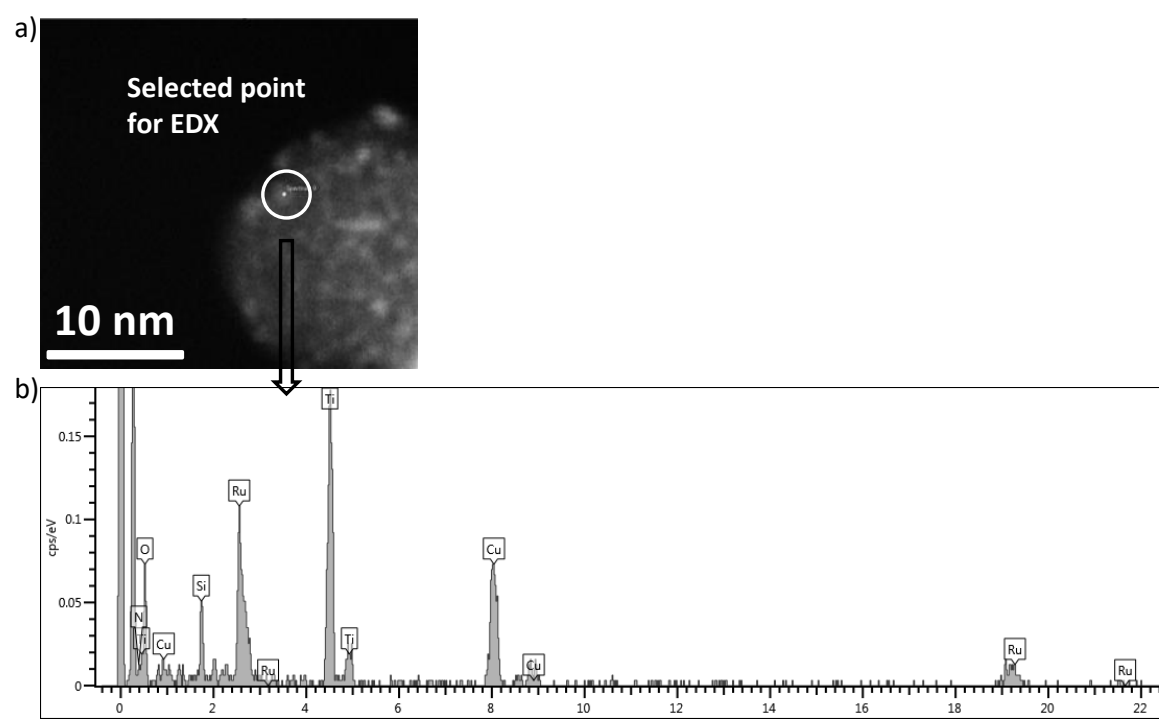

Figure S9. Representative TEM image of $\mathrm{RuO}_{x}(2 \mathrm{wt} \%) @ \mathrm{MIL}-125(\mathrm{Ti})-\mathrm{NH}_{2}(\mathrm{a})$ and EDX spectrum of selected point from panel (a). 


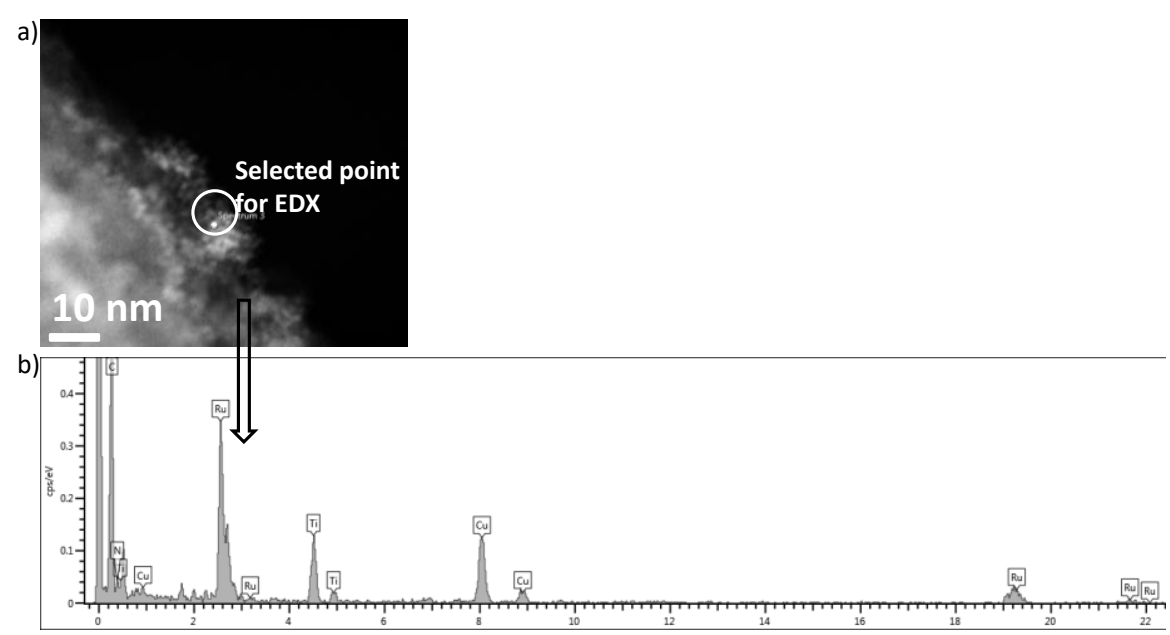

Figure S10. Representative TEM image of $\mathrm{RuO}_{x}\left(5\right.$ wt\%)@MIL-125(Ti)- $\mathrm{NH}_{2}$ (a) and EDX spectrum of selected point from panel (a).

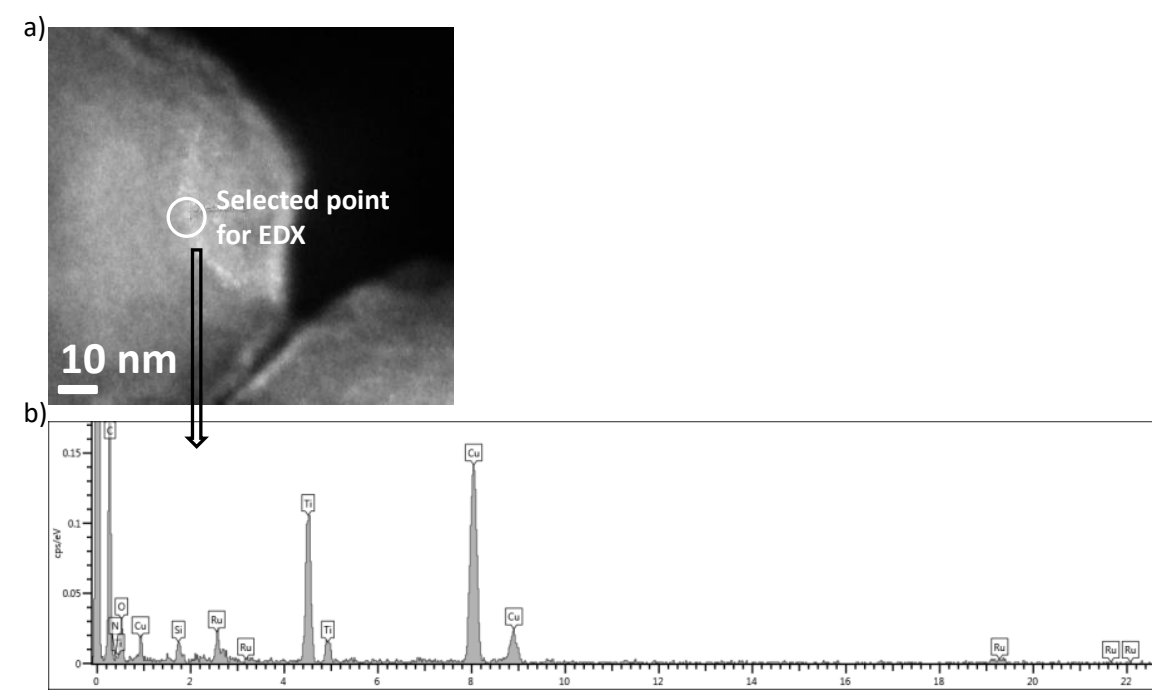

Figure S11. Representative TEM image of $\mathrm{RuO}_{x}(10 \mathrm{wt} \%) @ \mathrm{MIL}-125(\mathrm{Ti})-\mathrm{NH}_{2}$ (a) and EDX spectrum of selected point from panel (a). 
a)

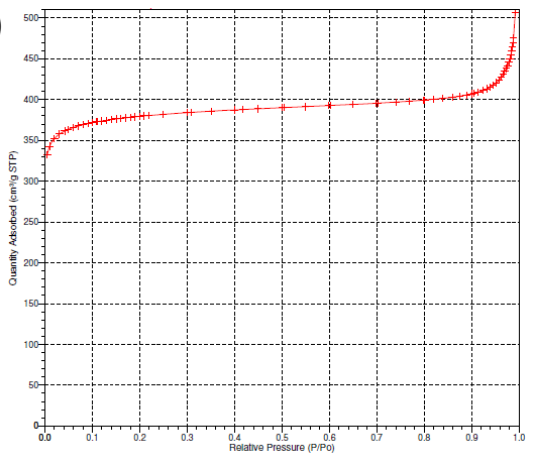

c)

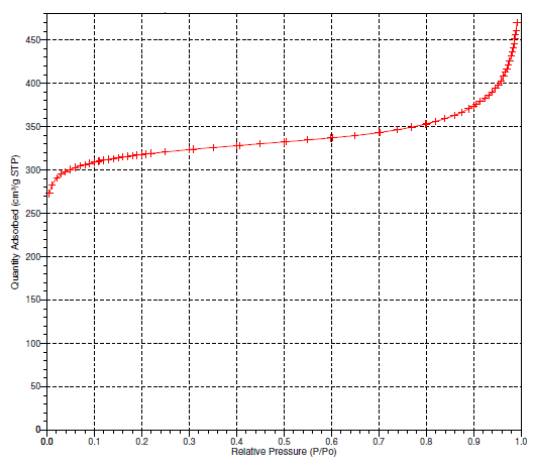

e)

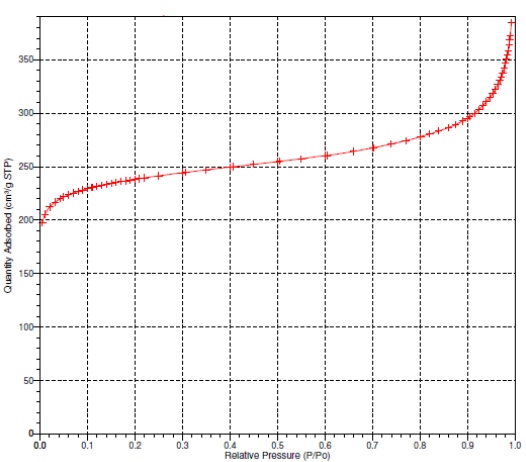

b)

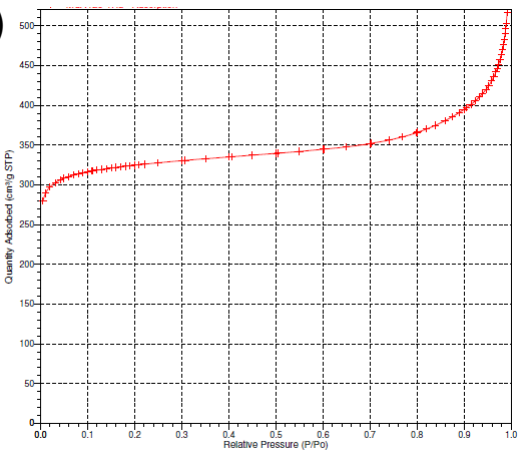

d)

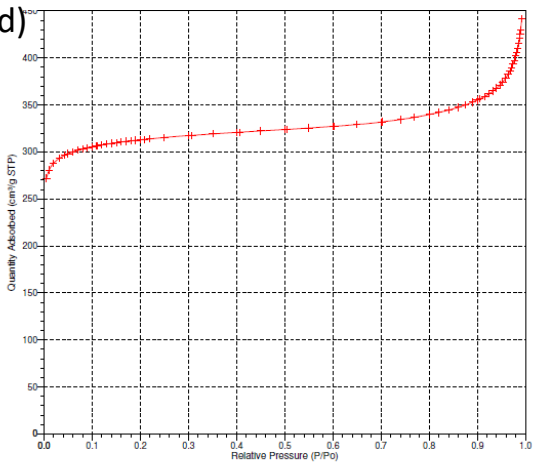

Figure S12. Isothermal nitrogen adsorption curves of MIL-125(Ti)- $\mathrm{NH}_{2}$ (a),

$\mathrm{RuO}_{x}(1 \mathrm{wt} \%) / \mathrm{MIL}-125(\mathrm{Ti})-\mathrm{NH}_{2}$

(b),

$\mathrm{RuO}_{\mathrm{x}}(2 \mathrm{wt} \%) / \mathrm{MIL}-125(\mathrm{Ti})-\mathrm{NH}_{2}$

(c),

$\mathrm{RuO}_{x}(5 \mathrm{wt} \%) / \mathrm{MIL}-125(\mathrm{Ti})-\mathrm{NH}_{2}$ (d) and $\mathrm{RuO}_{x}(10 \mathrm{wt} \%) / \mathrm{MIL}-125(\mathrm{Ti})-\mathrm{NH}_{2}$ (e). 


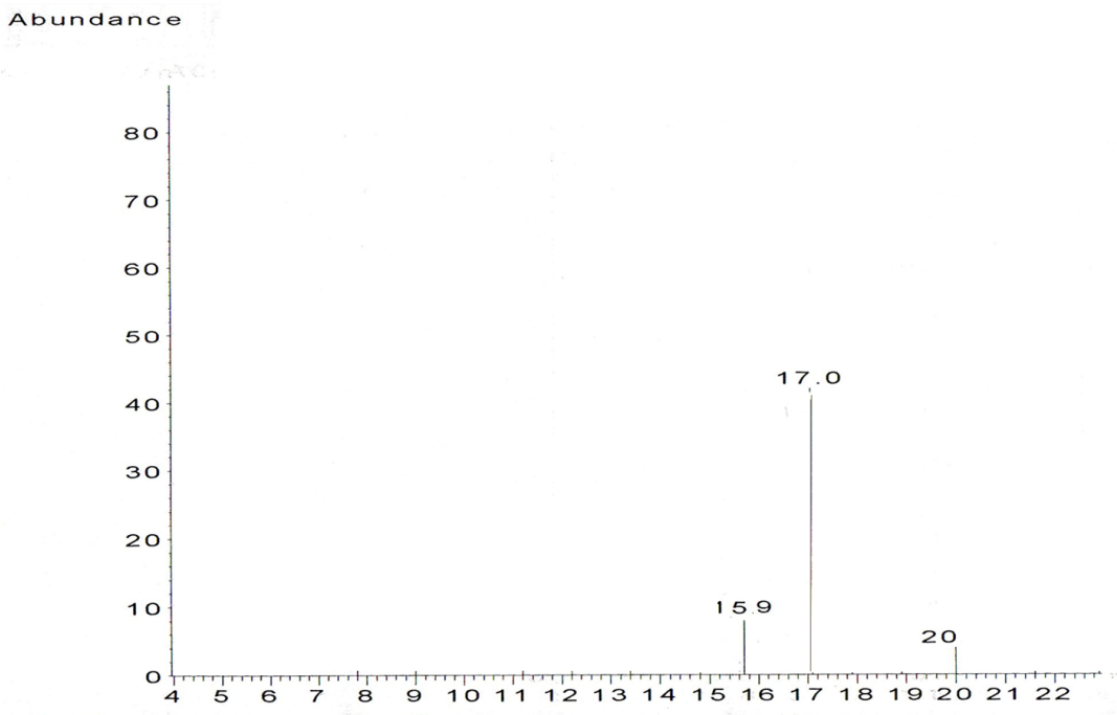

m/z-->

Figure S13. Mass spectrum of the headspace after the photocatalytic $\mathrm{CO}_{2}$ methanation using $\mathrm{RuO}_{\mathrm{x}}(10 \mathrm{wt} \%) @ \mathrm{MIL}-125(\mathrm{Ti})-\mathrm{NH}_{2}$. Reaction conditions: Photocatalyst $(15 \mathrm{mg}), \mathrm{P}_{\mathrm{H} 2}=1.05 \mathrm{bar}$, $\mathrm{P}_{\mathrm{CO} 2}=0.25$ bar, reaction temperature $\left(200^{\circ} \mathrm{C}\right)$.

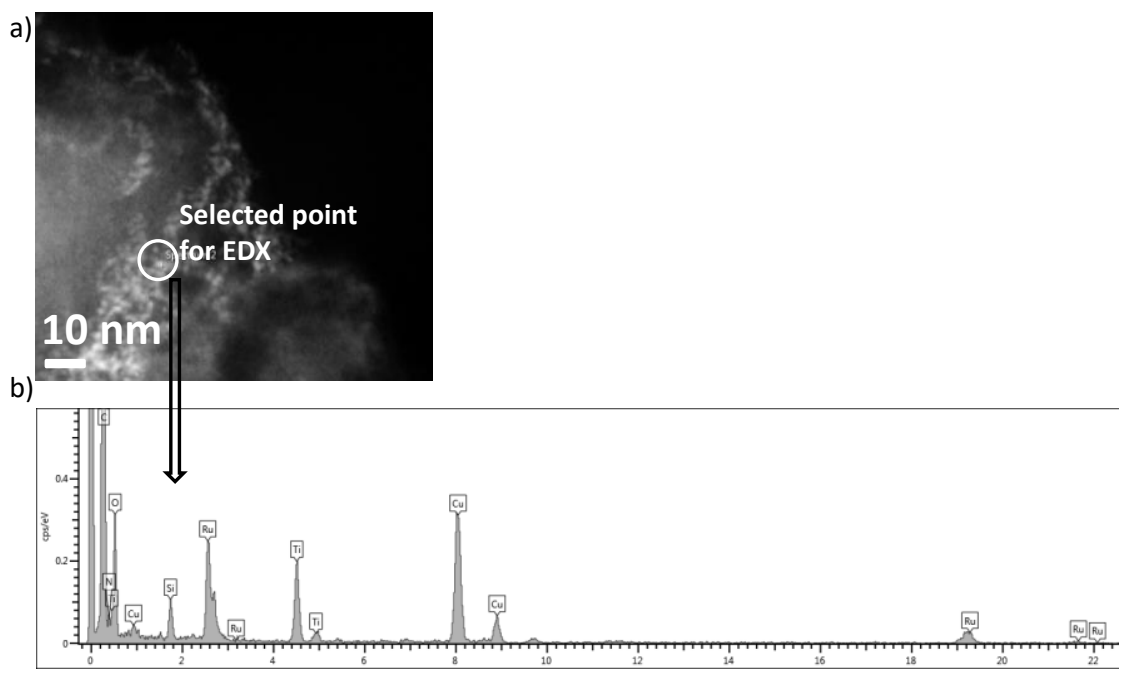

Figure S14. Representative TEM image of seven-times used RuOx(10 wt\%)@MIL-125(Ti)-NH under batch operation (a) and EDX spectrum of selected point from panel (a). 
Chapter 7. Toward solar-driven photocatalytic $\mathrm{CO}_{2}$ methanation under continuous flow operation using benchmark MIL-125(Ti)- $\mathrm{NH}_{2}$ supported ruthenium nanoparticles

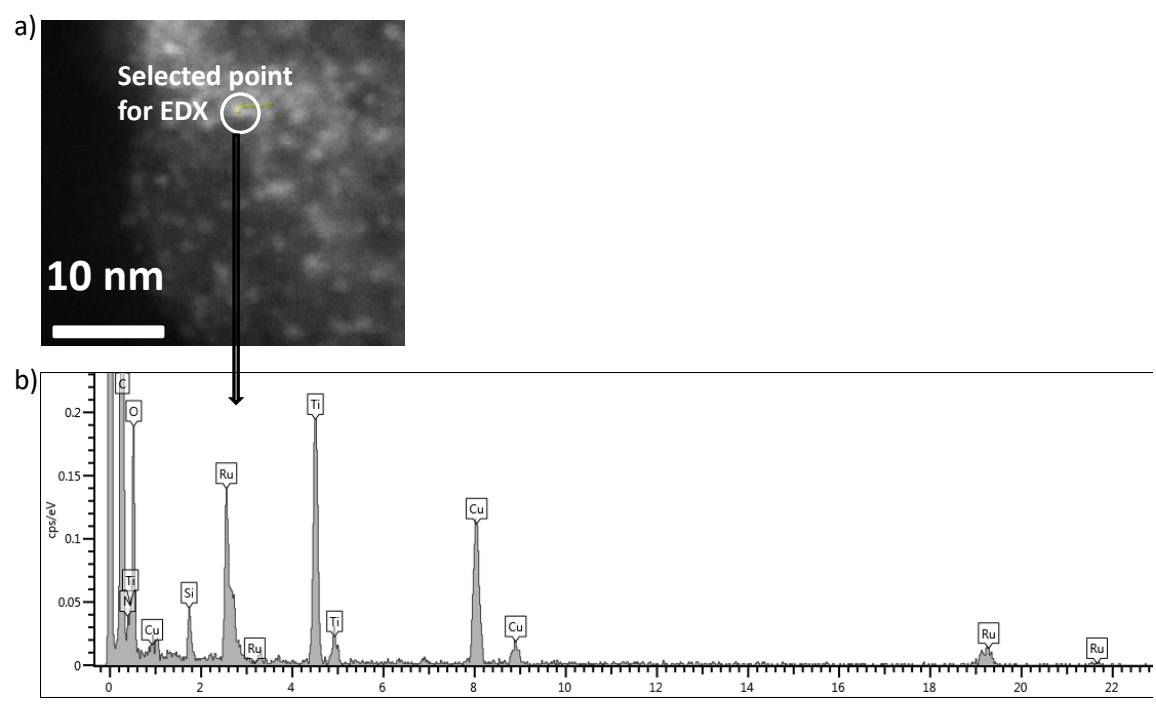

Figure S15. Representative TEM image of used $\mathrm{RuO}_{\mathrm{x}}(10 \mathrm{wt} \%) @ \mathrm{MIL}-125(\mathrm{Ti})-\mathrm{NH}_{2}$ under continuous flow for $154 \mathrm{~h} \mathrm{(a)} \mathrm{and} \mathrm{EDX} \mathrm{spectrum} \mathrm{of} \mathrm{selected} \mathrm{point} \mathrm{from} \mathrm{panel} \mathrm{(a).}$ 

Chapter 8

Conclusions 

In view of the results of the present Thesis it can be concluded that MOFs are potential heterogeneous photocatalysts for the production of solar fuels from $\mathrm{H}_{2} \mathrm{O}$ and $\mathrm{CO}_{2}$. More specifically the conclusions of each chapter are the following.

The titanium-based MOF MIL-125(Ti)- $\mathrm{NH}_{2}$ can be used as photocatalyst for the overall water splitting into $\mathrm{H}_{2}$ and $\mathrm{O}_{2}$. The presence of $\mathrm{Pt}, \mathrm{RuO}_{x}$ or $\mathrm{CoO}_{x}$ nanoparticles as co-catalysts within the MOF cavities increases the catalytic activity of the MOF. The simultaneous combination of $\mathrm{Pt}$ and $\mathrm{RuO}_{x} \mathrm{NPs}$ as co-catalysts in the MIL-125(Ti)- $\mathrm{NH}_{2}$ results in the most active photocatalyst reaching a maximum $\mathrm{H}_{2}$ and $\mathrm{O}_{2}$ production of 218 and $85 \mu \mathrm{mol} / \mathrm{g}$.photocatalyst at $24 \mathrm{~h}$, respectively, under

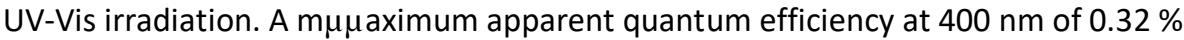
has been achieved using the Pt/RuOx@MIL-125(Ti)- $\mathrm{NH}_{2}$ photocatalyst. The $\mathrm{Pt} / \mathrm{RuO}_{x} @ \mathrm{MIL}-125(\mathrm{Ti})-\mathrm{NH}_{2}$ is active under natural sunlight irradiation achieving a $\mathrm{H}_{2}$ and $\mathrm{O}_{2}$ productions of about 28 and $14 \mu \mathrm{mol} \mathrm{g} \mathrm{g}^{-1}$ in $10 \mathrm{~h}$.

An optimized oxygen plasma treatment generates structural defects on the MIL-125(Ti)- $\mathrm{NH}_{2}$ photocatalyst and enhances its photocatalystic activity for the overall water splitting. The main main physico-chemical changes associated to the oxygen plasma treatment of $\mathrm{MIL}-125(\mathrm{Ti})-\mathrm{NH}_{2}$ are related with a partial decarboxylation and increase of $\mathrm{Ti}-\mathrm{OH}$ population. The oxygen plasma treatment of MIL-125(Ti)- $\mathrm{NH}_{2}$ also tunes the energy levels of the photocatalyst in terms of band gap, HOCO and LUCO in such a way that can be employed to maximice its photocatalytic activity. The optimized plasma treated MIL-125(Ti)- $\mathrm{NH}_{2}$ retains its crystallinity and photoactivity after four consecutive uses.

For the first time it is reported that a MOF termed as MOF(Zn)-1 $\left(\mathrm{Zn}_{3}(\text { btca })_{2}(\mathrm{OH})_{2}\right]\left(\mathrm{H}_{2}\right.$ btca $=1,2,3$-benzotriazole-5-carboxylic acid) can be employed as heterogeneous photocatalyst for the $\mathrm{CO}_{2}$ methanation under mild conditions $\left(\mathrm{CH}_{4}\right.$ production of $30 \mu \mathrm{molg} \cdot$ catalyst $^{-1}$ after $24 \mathrm{~h}$ at $215^{\circ} \mathrm{C}$ under UV-vis irradiation) in the absence of metal nanoparticles or sacrificial agents. The deposition of small $\mathrm{Cu}_{2} \mathrm{O}$ 
nanoparticles into the $\operatorname{MOF}(\mathrm{Zn})-1$ results in an increase of the photocatalytic activity up to $45 \mu \mathrm{mol}$ gcat $^{-1}$ after 24 hours under UV-Vis irradiation at $215^{\circ} \mathrm{C}$.

For the first time it is reported the preparation of a Ti-MOF (MIP-208, MIP) stands for the Materials of the Institute of Porous Materials from Paris) based on isophthalic acid that combines the use of preformed $\mathrm{Ti}^{8}$ oxoclusters and in situ acetylation of the 5-aminoisophthalic acid. The pristine MIP-208(Ti) solid is an active photocatalyst for the $\mathrm{CO}_{2}$ methanation achieving a $\mathrm{CH}_{4}$ production of $45 \mu \mathrm{mol} \mathrm{g-}{ }^{-1}$ at $200{ }^{\circ} \mathrm{C}$ after $22 \mathrm{~h}$. The presence of $\mathrm{RuO}_{\mathrm{x}} \mathrm{NPs}(1.4 \pm 0.14 \mathrm{~nm} ; 0.76 \mathrm{wt} \%)$ further increases the photocatalytic activity achieving a $\mathrm{CH}_{4}$ production of about 800 and $700 \mu \mathrm{mol} \mathrm{g}{ }^{-1}$ at $200{ }^{\circ} \mathrm{C}$ after $22 \mathrm{~h}$ under UV-Vis or simulated sunlight irradiation, respectively. The photocatalyst maintains its initial photoactivity and main structural properties after 7 consecutive uses $(\sim 154 \mathrm{~h})$ at $200^{\circ} \mathrm{C}$ under UV-Vis irradiation. Based on several photocatalytic experiments, spectroscopic evidences and photocurrent measurements it was proposed that the $\mathrm{CO}_{2}$ methanation using the $\mathrm{RuO}_{\mathrm{x}} @ \mathrm{MIP}-208$ occurs via photoinduced charge separation mechanism.

An optimized material based on ruthenium nanoparticles (10 wt\%; $1.48 \mathrm{~nm} \pm 0.53 \mathrm{~nm}$ ) loaded on to MIL-125(Ti)- $\mathrm{NH}_{2}$ as benchmark MOF can be employed as active and benchmark photocatalyst towards solar-driven $\mathrm{CO}_{2}$ methanation. The optimized catalyst exhibits a superior activity $\left(18.5 \mathrm{mmol} \mathrm{g}^{-1}\right.$ at 22 h) and reusability ( 7 cycles for $154 \mathrm{~h}$ ) for the selective $\mathrm{CO}_{2}$ methanation under batch conditions and under simulated sunlight irradiation. The photocatalyst can be also used under continous flow operation for $\mathrm{CO}_{2}$ methanation under visible ligh irraidaiton $(\lambda>450 \mathrm{~nm})$ at $200{ }^{\circ} \mathrm{C}$. Based on the photocatalytic results, selective quenching experiments, photocurrent and fluorescence spectroscopy measurements a photoinduced electron-hole pair mechanism is proposed. 
Chapter 9

Abstract of the Thesis 



\subsection{Abstract}

The present doctoral thesis studied the use of MOFs as photocatalysts to produce solar fuels. MOF-based photocatalysts were used for overall water splitting and $\mathrm{CO}_{2}$ reduction in the absence of sacrificial agents or organic solvents. MIL-125(Ti)- $\mathrm{NH}_{2}$ can be used as photocatalyst for overall water splitting under both UV-Vis or natural sunlight irradiation. The activity of this material can be enhanced using Pt and $\mathrm{RuO}_{x}$ NPs as co-catalysts. Also, the photocatalytic activity of pristine MIL-125(Ti)- $\mathrm{NH}_{2}$ can be enhanced by oxygen-plasma treatment, which introduces structural defects and produces an optimized material for overall water splitting.

This thesis has shown for the first time the possibility of using MOFs as photocatalysts for $\mathrm{CO}_{2}$ methanation. More specifically, a $\mathrm{Zn}$ and Ti MOF materials, $\operatorname{MOF}(\mathrm{Zn})-1$ and MIP-208 respectively, can be used as photocatalysts to promote $\mathrm{CO}_{2}$ methanation under mild reaction conditions. The photocatalytic activity of these MOFs can be enhanced in the presence of small $\mathrm{Cu}_{2} \mathrm{O}$ NPs, and, especially, $\mathrm{RuO}_{x} \mathrm{NPs}$ in their structure. RuO $\mathrm{NPs}$ supported on MIL-125(Ti)- $\mathrm{NH}_{2}$ can be envisioned as a benchmark photocatalyst for solar-driven $\mathrm{CO}_{2}$ methanation in continuous-flow operations. 


\subsection{Resumen}

La presente tesis doctoral se ha basado en el estudio del uso de MOFs como fotocatalizadores para la producción de combustibles solares. Específicamente, los fotocatalizadores basados en MOF se han utilizado para la reacción de descomposición del agua y la reducción de $\mathrm{CO}_{2}$ en ausencia de agentes de sacrificio o disolventes orgánicos. MIL-125(Ti)- $\mathrm{NH}_{2}$ se puede utilizar como fotocatalizador para la reacción de descomposición del agua en presencia de UV-Vis o irradiación natural de la luz solar. La actividad de este material se puede potenciar mediante el uso de Pt y NPs de $\mathrm{RuO}_{\mathrm{x}}$ como co-catalizadores. Además, la actividad fotocatalítica de MIL-125(Ti)- $\mathrm{NH}_{2}$ se puede mejorar mediante un tratamiento de plasma de oxígeno que introduce defectos estructurales dando lugar a un material optimizado para catalizar la reacción de descomposición del agua.

La presente tesis ha mostrado por primera vez la posibilidad de utilizar MOFs como fotocatalizadores para la metanación de $\mathrm{CO}_{2}$. En particular, un Zn-MOF y un Ti-MOF, MOF(Zn)-1 y MIP-208 respectivamente, se pueden utilizar como fotocatalizadores para promover la metanación de $\mathrm{CO}_{2}$ en condiciones de reacción suaves. Además, la actividad fotocatalítica de estos MOFs se incrementa en presencia de pequeñas NPs de $\mathrm{Cu}_{2} \mathrm{O}$ y, especialmente, por NPs de $\mathrm{RuO}_{x}$ en la estructura de estos materiales. Es de destacar que el material compuesto por NPs de $\mathrm{RuO}_{\mathrm{x}}$ soportadas en MIL-125(Ti)- $\mathrm{NH}_{2}$ puede considerarse un fotocatalizador de referencia para la metanación de $\mathrm{CO}_{2}$ mediada por energía solar y en flujo continuo. 


\subsection{Resum}

La present tesi doctoral s'ha basat en l'estudi de l'ús de MOFs com a fotocatalitzadors per a la producció de combustibles solars. Específicament, els fotocatalitzadors basats en MOF s'han utilitzat per a la reacció de descomposició de l'aigua i la reducció de $\mathrm{CO}_{2}$ en absència d'agents de sacrifici o dissolvents orgànics. MIL-125(Ti)- $\mathrm{NH}_{2}$ es pot utilitzar com fotocatalitzador per a la reacció de descomposició de I'aigua sota UV-Vis o irradiació natural de la llum solar i la seua activitat pot ser augmentada mitjançant l'ús de Pt i NPs de $\mathrm{RuO}_{\mathrm{x}}$ com co-catalitzadors. A més, l'activitat fotocatalítica de MIL-125(Ti)- $\mathrm{NH}_{2}$ es pot millorar mitjançant un tractament de plasma d'oxigen que introdueix defectes estructurals resultant en un material optimitzat per a la reacció de descomposició de l'aigua.

La present tesi ha mostrat per primera vegada la possibilitat d'utilitzar MOFs com fotocatalizador per a la metanació de $\mathrm{CO}_{2}$. En particular, un $\mathrm{Zn}-\mathrm{MOF}$ y un Ti-MOF, MOF(Zn)-1 y MIP-208 respectivament, es poden utilitzar com fotocatalitzadors per a promoure la metanació de $\mathrm{CO}_{2}$ en condicions de reacció suaus. A més, l'activitat fotocatalítica d'aquests MOFs pot ser realçada per la presència de xicotetes NPs de $\mathrm{Cu}_{2} \mathrm{O}$ i, especialment, per les $N P s$ de $\mathrm{RuO}_{x}$ en l'estructura d'aquestos materials. És de destacar que el material composat per NPs de $\mathrm{RuO}_{x}$ suportades en MIL-125(Ti)- $\mathrm{NH}_{2}$ es pot considerar un fotocatalitzador de referència per a la metanació de $\mathrm{CO}_{2}$ amb energia solar i en flux continu. 



\section{Annex I}

Research articles and conferences 



\section{Publications related with the Thesis report}

1) Influence of co-catalysts on the photocatalytic activity of MIL 125(Ti)- $\mathrm{NH}_{2}$ in the overall water splitting.

Sonia Remiro-Buenamañana, Maria Cabrero-Antonino, Marcos Martínez-Guanter, Mercedes Álvaro, Sergio Navalón, Hermenegildo García.

Appl. Catal. B 2019, 254, 677-684

2) Plasma-induced defects enhance the visible-light photocatalytic activity of MIL-125(Ti)-NH for overall water splitting

María Cabrero-Antonino, Josep Albero, Cristina García-Vallés, Mercedes Álvaro, Sergio Navalón, Hermenegildo García.

Chem. Eur. J. 2020, 26, 1-9

3) Design of cost-efficient and photocatalytically active Zn-based MOFs decorated with $\mathrm{Cu}_{2} \mathrm{O}$ nanoparticles for $\mathrm{CO}_{2}$ methanation

Maria Cabrero-Antonino, Sonia Remiro-Buenamañana, Manuel Souto, Antonio A. García-Valdivia, Duane Choquesillo-Lazarte, Sergio Navalón, Antonio Rodríguez-Diéguez, Guillermo Mínguez Espallargas, Hermenegildo García

Chem. Commun. 2019, 55, 10932

4) A Robust Titanium Isophthalate Metal-Organic Framework for Visible-Light Photocatalytic $\mathrm{CO}_{2}$ Methanation

Sujing Wang, Maria Cabrero-Antonino, Sergio Navalón, Chen-chen Cao, Antoine Tissot, lurii Dovgaliuk, Jérôme Marrot, Charlotte Martineau-Corcos, Liang Yu, Hao Wang, William Shepard, Hermenegildo García and Christian Serre.

Chem. 2020, 6, 1-19 
5) Toward solar-driven photocatalytic $\mathrm{CO}_{2}$ methanation under continuous flow operation using benchmark MIL-125(Ti)-NH supported ruthenium nanoparticles María Cabrero-Antonino, Belén Ferrer, Herme G. Baldoví, Sergio Navalón.

Submited 


\section{Other publications}

1) Enhancing visible-light photocatalytic activity for overall water splitting in UiO-66 by controlling metal node composition

Arianna Melillo, María Cabrero-Antonino, Sergio Navalón, Mercedes Álvaro, Belén Ferrer, Hermenegildo García.

App. Catal. B 2020, 278, 119345

Abstract: The photocatalytic activity of a series of five UiO-66 (M: Zr, Zr/Ti, $\mathrm{Zr} / \mathrm{Ce}, \mathrm{Zr} / \mathrm{Ce} / \mathrm{Ti}, \mathrm{Ce}$ ) materials for overall water splitting with generation of hydrogen and oxygen has been herein measured. The most efficient photocatalyst for the overall water splitting is the trimetallic MOF UiO-66(Zr/Ce/Ti) which achieves 230 $\mu \mathrm{mol} \cdot \mathrm{g}^{-1}$ of $\mathrm{H}^{2}$ and $110 \mu \mathrm{mol} \cdot \mathrm{g}^{-1}$ of $\mathrm{O}_{2}$, upon UV light irradiation, and $210 \mu \mathrm{mol} \cdot \mathrm{g}^{-1}$ of $\mathrm{H}_{2}$ and $70 \mu \mathrm{mol} \cdot \mathrm{g}^{-1}$ of $\mathrm{O}_{2}$, under visible light irradiation. These productivity data indicate that a considerable percentage of its photocatalytic activity derives from the visible region of the spectrum $(\lambda>450 \mathrm{~nm})$. The photocatalytic activity of trimetallic UiO-66(Zr/Ce/Ti) was maintained upon reuse. Kinetics of the charge separated state monitored by transient absorption spectroscopy shows similar deactivation profiles for the five UiO-66 samples, suggesting that it is the charge separation efficiency the main factor responsible for the differences in the photocatalytic activity. The use of methanol as sacrificial agent during the photocatalytic experiments indicated that the high photocatalytic efficiency for overall water splitting in UiO-66(Zr/Ce/Ti) derives from the favorable kinetics of oxygen evolution. These results show the potential of multi metallic metal-organic frameworks as solar photocatalysts by tuning light absorption towards the visible region. 


\section{2) Nickel phosphonate MOF as efficient water splitting photocatalyst}

Pablo Salcedo-Abraira, Sérgio M. F. Vilela, Artem A. Babaryk, María Cabrero-Antonino, Pedro Gregorio, Fabrice Salles, Sergio Navalón, Hermenegildo García, Patricia Horcajada.

Nano Res. 2021, 14, 450-457

Abstract: A novel microporous two-dimensional (2D) Ni-based phosphonate metal-organic framework (MOF; denoted as IEF-13) has been successfully synthesized by a simple and green hydrothermal method and fully characterized using a combination of experimental and computational techniques. Structure resolution by single-crystal X-ray diffraction reveals that IEF-13 crystallizes in the triclinic space group $\mathrm{Pì}$ having bi-octahedra nickel nodes and a photo/electroactive tritopic phosphonate ligand. Remarkably, this material exhibits coordinatively unsaturated nickel(II) sites, free $-\mathrm{PO}_{3} \mathrm{H}_{2}$ and $-\mathrm{PO}_{3} \mathrm{H}$ acidic groups, a $\mathrm{CO}_{2}$ accessible microporosity, and an exceptional thermal and chemical stability. Further, its in-deep optoelectronic characterization evidences a photoresponse suitable for photocatalysis. In this sense, the photocatalytic activity for challenging $\mathrm{H}_{2}$ generation and overall water splitting in absence of any co-catalyst using UV-Vis irradiation and simulated sunlight has been evaluated, constituting the first report for a phosphonate MOF photocatalyst. IEF-13 is able to produce up to $2,200 \mu \mathrm{mol}$ of $\mathrm{H}_{2}$ per gram using methanol as sacrificial agent, exhibiting stability, maintaining its crystal structure and allowing its recycling. Even more, $170 \mu \mathrm{mol}$ of $\mathrm{H}_{2}$ per gram were produced using IEF-13 as photocatalyst in the absence of any co-catalyst for the overall water splitting, being this reaction limited by the $\mathrm{O}_{2}$ reduction. The present work opens new avenues for further optimization of the photocatalytic activity in this type of multifunctional materials. 


\section{3) A Semiconducting $\mathrm{Bi}_{2} \mathrm{O}_{2}\left(\mathrm{C}_{4} \mathrm{O}_{4}\right)$ Coordination Polymer Showing a Photoelectric Response}

Artem A. Babaryk, Oscar R. Contreras Almengor, María Cabrero-Antonino, Sergio Navalon, Hermenegildo García, Patricia Horcajada

Inorg. Chem. 2020, 59, 3406-3416

Abstract: Inorganic semiconductors are extensively considered to be among the most promising materials to convert solar light into electricity or chemical energy owing to their efficiency in the separation of photoinduced electron/hole. Bismuth oxides, and, in particular, those built up of $\left[\mathrm{Bi}_{2} \mathrm{O}_{2}\right]^{2+}$ layers, show an efficient charge separation and, thus, high photocatalytic activities. To explore a possible synergetic effect of bismuth metallic nodes combined with the electron-rich linker squarate, $\mathrm{Bi}_{2} \mathrm{O}_{2}\left(\mathrm{C}_{4} \mathrm{O}_{4}\right)$ or IEF-3 (an IMDEA Energy framework) was hydrothermally prepared and adequately characterized. As determined from the $\mathrm{X}$-ray structure, $\left[\mathrm{Bi}_{2} \mathrm{O}_{2}\right]^{2+}$ layers are interconnected by squarate ligands, having a pronounced effect of the $6 s^{2}$ lone pair on the bismuth local environment. IEF3 shows high thermal and chemical robustness at industrially relevant model aggressive media. A large panel of physicochemical methods were applied to recognize IEF-3 as an UV-absorbing n-type semiconductor, showing a photocurrent response comparable to that of $\alpha-\mathrm{Bi}_{2} \mathrm{O}_{3}$, offering further possibilities for tuning its electrochemical properties by modifying the ligand. In this way, the well-known compositional and structural versatility of coordination polymers may be applied in the future to fine-tune metal-organic semiconductor systems. 


\section{4) Nitro functionalized chromium terephthalate metal-organic frameworks multifunctional solid acid for the synthesis of benzimidazoles}

Cristina Vallés-García, María Cabrero-Antonino, Sergio Navalón, Mercedes Álvaro, Amarajothi Dhakshinamoorthy and Hermenegildo García.

J. Colloid Interface Sci. J. 2020, 560, 885-893

Abstract: In the present work, nitro functionalized chromium terephthalate [MIL-101(Cr)-NO $\mathrm{NO}_{2}$ ] metal-organic framework is prepared and characterized by powder X-ray diffraction (XRD), elemental analysis, infrared spectroscopy (IR), X-ray photoelectron spectroscopy (XPS), scanning electron microscopy (SEM) and Brunauer-Emmett-Teller (BET) surface area. The inherent Lewis acidity of MIL-101(Cr)- $\mathrm{NO}_{2}$ is confirmed by FT-IR spectroscopy using $\mathrm{CD}_{3} \mathrm{CN}$ as a probe molecule. The performance of MIL-101(Cr)- $\mathrm{NO}_{2}$ as bifunctional catalyst (acid and redox) promoting the synthesis of wide range of benzimidazoles has been examined by catalyzed condensation on acid sites and subsequent oxidative dehydrogenation. The catalytic activity of MIL-101(Cr)- $\mathrm{NO}_{2}$ is found to be superior than analogues catalysts like MIL-101(Cr)-SO ${ }_{3} \mathrm{H}, \mathrm{MIL}-101(\mathrm{Cr})-\mathrm{NH}_{2}$, UiO-66(Zr), UiO-66(Zr)-NO2, MIL-100(Fe) and $\mathrm{Cu}_{3}(\mathrm{BTC})_{2}$ (BTC: 1,3,5-benzenetricarboxylate) under identical reaction conditions. The structural stability of $\mathrm{MIL}-101(\mathrm{Cr})-\mathrm{NO}_{2}$ is supported by leaching analysis andreusabilitytests. MIL-101(Cr)-NO $\mathrm{NO}_{2}$ solid is used five times without decay in its activity. Comparison of the fres hand five times used MIL-101(Cr)-NO solids by powder XRD, SEM and elemental analysis indicate identical crystallinity, morphology and the absence of chromium leaching, respectively. 


\section{5) Tuning the Microenvironment of Gold Nanoparticles Encapsulated within} MIL-101(Cr) for the Selective Oxidation of Alcohols with $\mathrm{O}_{2}$ : Influence of the Amino Terephthalate Linker

Andrea Santiago-Portillo, Maria Cabrero-Antonino, Mercedes Alvaro, Sergio Navalón, Hermenegildo García.

Chem. Eur. J. 2019, 25,9280-9286

Abstract: This manuscript reports a comparative study of the catalytic performance of gold nanoparticles (NPs) encapsulated within MIL-101(Cr) with or without amino groups in the terephthalate linker. The purpose is to show how the amino groups can influence the microenvironment and catalytic stability of incorporated gold nanoparticles. The first influence of the presence of this substituent is the smaller particle size of Au NPs hosted in MIL-101(Cr)-NH $2.45 \pm 0.19 \mathrm{~nm})$ compared with the parent MIL-101(Cr)-H (3.02 $\pm 0.39 \mathrm{~nm})$. Both materials are highly active to promote the aerobic alcohol oxidation and exhibit a wide substrate scope. Although both catalysts can achieve turnover numbers as high as 106 for the solvent-free aerobic oxidation of benzyl alcohol, Au@MIL-101(Cr)-NH $\mathrm{NH}_{2}$ exhibits higher turnover frequency values (12000 $\left.\mathrm{h}^{-1}\right)$ than Au@MIL-101(Cr)-H (6800 h-1). Au@MIL-101(Cr)-NH2 also exhibits higher catalytic stability, being recyclable for 20 times with coincident temporal conversion profiles, in comparison with some decay observed in the parent Au@MIL-101(Cr)-H. Characterization by transmission electron microscopy of the 20 times used samples shows a very minor particle size increase in the case of Au@MIL-101(Cr)-NH2 $(2.97 \pm 0.27$ m) in comparison with the Au@MIL-101(Cr)-H analog $(5.32 \pm 0.72 \mathrm{~nm})$. The data presented show the potential of better control of the microenvironment to improve the performance of encapsulated $\mathrm{Au}$ nanoparticles. 
6) A novel porous Ti-squarate as efficient photocatalyst in the overall water splitting reaction under simulated sunlight irradiation

Pablo Salcedo-Abraira, Artem A. Babaryk, Eva Montero-Lanzuela, Oscar R. Contreras-Almengor, María Cabrero-Antonio, Fabrice Salles, Tom Willhammar, Erik Svensson Grape, Andrew Kentaro, Sara Bals, Sergio Navalón, Erik Elkäim, Hermenegildo García, Patricia Horcajada.

Submited

Abstract: A new porous titanium(IV) metal-organic framework (MOF), denoted as IEF-11, based on the squarate linker having a never reported titanium secondary building unit has been successfully synthesized and fully characterized. IEF-11 not only exhibits a permanent porosity, but also an outstanding chemical stability. Further, as a consequence of the combination of the photoactive $\mathrm{Ti}(\mathrm{IV})$ and the electroactive squarate, IEF-11 presents relevant optoelectronic properties, applied here to the photocatalytic overall water splitting reaction. Remarkably, IEF-11 photocatalyst is able to produce record $\mathrm{H}_{2}$ amounts for MOF-based materials under simulated sunlight (up to $672 \mu \mathrm{mol} \cdot \mathrm{g}_{\text {catalyst }}{ }^{-1}$ in $22 \mathrm{~h}$ ) without any activity loss during at least 10 days. 


\section{Participation in conferences}

1) Participation: Oral presentation

Title: Influence of Co-Catalysts on the Photocatalytic Activity of MIL-125(Ti)-NH $\mathrm{NH}_{2}$ in the Overall Water Splitting

Congress: World Congress on Chemistry

Authors: Maria Cabrero Antonino, Arianna Melillo, Cristina Valles García, Mercedes Álvaro, Hermenegildo García, Sergio Navalón.

Place and date: Valencia, 24-25 October 2019.

2) Participation: Flash communication

Congress: XVI symposium of young researchers of the real Spanish society of chemistry, RSEQ - Sigma Aldrich (Merck)

Title: Tuning the Microenvironment of Gold Nanoparticles Encapsulated within MIL-101(Cr) for the Selective Oxidation of Alcohols with $\mathrm{O}_{2}$ : Influence of the Amino Terephthalate Linker

Authors: Maria Cabrero Antonino, Andrea Santiago Portillo, Mercedes Álvaro, Sergio Navalón and Hermenegildo García

Place and date: Valencia, 4-7 de November 2019.

3) Participation: Oral presentation

Congress: World Congress on Chemistry

Title: MIL-101(Cr) promotes the efficient aerobic oxidative desulfuration of dibenzothiophenes using $\mathrm{O}_{2}$ as oxidant

Authors: Cristina Vallés García, Maria Cabrero Antonino, Arianna Melillo, Andrea Santiago Portillo, Mercedes Álvaro, Sergio Navalón and Hermenegildo García Place and date: Valencia, 24-25 October 2019. 
4) Participation: Oral presentation

Congress: World Congress on Chemistry

Title: UIO-67 Ruthenium (II) Tris(2'-2'-bipyridyl) as photoredox catalyst.

Authors: Arianna Melillo, Cristina Valles García, Maria Cabrero Antonino, Andrea Santiago Portillo, Mercedes Álvaro, Hermenegildo García, Belén Ferrer.

Place and date: Valencia, 24-25 October 2019.

5) Participation: Poster

Congress: XVI symposium of young researchers of the real Spanish society of chemistry, RSEQ - Sigma Aldrich (Merck)

Title: MOFs as heterogeneous catalyst for aerobic oxidative desulfuration of dibenzothiophenes

Authors: Cristina Vallés García, Maria Cabrero Antonino, Arianna Melillo, Andrea Santiago Portillo, Mercedes Álvaro, Sergio Navalón and Hermenegildo García Place and date: Valencia, 4-7 de November 2019.

6) Participation: Flash communication

Congress: XVI symposium of young researchers of the real Spanish society of chemistry, RSEQ - Sigma Aldrich (Merck)

Title: Tuning the Microenvironment of Gold Nanoparticles Encapsulated within MIL-101(Cr) for the Selective Oxidation of Alcohols with $\mathrm{O}_{2}$ : Influence of the Amino Terephthalate Linker

Authors: Arianna Melillo, Cristina Valles García, Maria Cabrero Antonino, Andrea Santiago Portillo, Mercedes Álvaro, Hermenegildo García, Belén Ferrer.

Place and date: Valencia, 4-7 de November 2019. 
7) Participation: Oral presentation

Congress: European Material Research Society via European Materials Research Society

Title: Influence of Co-Catalysts on the Photocatalytic Activity of MIL-125(Ti)- $\mathrm{NH}_{2}$ in the Overall Water Splitting

Authors: Eva Montero Lanzuela, Maria Cabrero Antonino, Herme G. Baldoví and Sergio Navalón

Place and date: Online, September 2021.

8) Participation: Poster

Congress: International Solar Fuels Conference 2021

Title: Tuning the Microenvironment of Gold Nanoparticles Encapsulated within MIL-101(Cr) for the Selective Oxidation of Alcohols with $\mathrm{O}_{2}$ : Influence of the Amino Terephthalate Linker

Authors: Eva Montero Lanzuela, Maria Cabrero Antonino, Josep Albero, Cristina Vallés García, Herme G. Baldoví and Sergio Navalón

Place and date: Online, September 2021. 

